\title{
Personalizing obstetric care
}

Citation for published version (APA):

Meertens, LJE. (2018). Personalizing obstetric care: prediction and prevention of adverse pregnancy outcomes. [Doctoral Thesis, Maastricht University]. Maastricht University. https://doi.org/10.26481/dis.20180831lm

Document status and date:

Published: 01/01/2018

DOI:

10.26481/dis.20180831/m

Document Version:

Publisher's PDF, also known as Version of record

\section{Please check the document version of this publication:}

- A submitted manuscript is the version of the article upon submission and before peer-review. There can be important differences between the submitted version and the official published version of record.

People interested in the research are advised to contact the author for the final version of the publication, or visit the DOI to the publisher's website.

- The final author version and the galley proof are versions of the publication after peer review.

- The final published version features the final layout of the paper including the volume, issue and page numbers.

Link to publication

\footnotetext{
General rights rights.

- You may freely distribute the URL identifying the publication in the public portal. please follow below link for the End User Agreement:

www.umlib.nl/taverne-license

Take down policy

If you believe that this document breaches copyright please contact us at:

repository@maastrichtuniversity.nl

providing details and we will investigate your claim.
}

Copyright and moral rights for the publications made accessible in the public portal are retained by the authors and/or other copyright owners and it is a condition of accessing publications that users recognise and abide by the legal requirements associated with these

- Users may download and print one copy of any publication from the public portal for the purpose of private study or research.

- You may not further distribute the material or use it for any profit-making activity or commercial gain

If the publication is distributed under the terms of Article $25 \mathrm{fa}$ of the Dutch Copyright Act, indicated by the "Taverne" license above, 


\section{PERSONALIZING OBSTETRIC CARE}

Prediction and prevention of adverse pregnancy outcomes 
The research described in this thesis was funded by the Netherlands Organization for Health Research and Development (ZonMw, research programme Pregnancy and Childbirth, project no. 209020007) and Dutch Foundation 'Gezond Geboren'.

The research presented in this thesis was conducted within the Care and Public Health Research Institute (CAPHRI) at the Department of Epidemiology, Maastricht University, the Netherlands, and the Department of Obstetrics and Gynaecology, Maastricht University Medical Centre, Maastricht, the Netherlands.

ISBN: 978-94-9301-419-0

Cover: Canon The Creative Hub, CBS 12970

Layout: Tiny Wouters - Lenssen

Printed by: Gildeprint Drukkerijen, Enschede

(C) Copyright Linda J.E. Meertens, Maastricht 2018

All rights reserved. No part of this thesis may be reproduced or transmitted in any form or by any means, electronic or mechanical, including photocopying, recording or any information storage or retrieval system, without prior permission in writing from the author, or when appropriate, from the publishers of the publications. 


\title{
PERSONALIZING OBSTETRIC CARE \\ Prediction and prevention of adverse pregnancy outcomes
}

\author{
PROEFSCHRIFT \\ ter verkrijging van de graad van doctor aan de Universiteit Maastricht, \\ op gezag van de Rector Magnificus, Prof. dr. Rianne M. Letschert \\ volgens het besluit van het College van Decanen, \\ in het openbaar te verdedigen op vrijdag 31 augustus 2018 om 10.00 uur \\ door
} Linda Jacqueline Elisabeth Meertens 


\section{Promotor}

Prof. dr. M.H. Prins

\section{Copromotores}

Dr. L.J.M. Smits

Dr. H.C.J. Scheepers

\section{Beoordelingscommissie}

Prof. dr. S.P.J. Kremers (voorzitter)

Prof. dr. J.L.H. Evers

Dr. H. Groen (Rijksuniversiteit Groningen)

Prof. dr. S.G. Oei (Máxima Medisch Centrum/Technische Universiteit Eindhoven)

Dr. C.T.M.C.N. Thijs 


\section{Contents}

$\begin{array}{lll}\text { Chapter } 1 & \text { General introduction } & 7\end{array}$

$\begin{array}{lll}\text { Part I External validation and clinical usefulness of early } & 19\end{array}$ obstetric prediction models

Chapter 2 External validation study of first trimester obstetric prediction models (Expect Study I): research protocol and population characteristics

Chapter 3 External validation and clinical usefulness of early prediction models for the risk of pre-eclampsia: a prospective cohort study

Chapter 4 External validation and clinical utility of first trimester prediction 99 models for gestational diabetes mellitus: a prospective cohort study

Chapter 5 First-trimester prediction models for small- and large-forgestational-age infants: external validation and clinical usefulness

Chapter 6 Prediction models for the risk of spontaneous preterm birth based on maternal characteristics: a systematic review and independent external validation

Part II Calcium intake during pregnancy

Chapter $7 \quad$ Calcium intake from diet and supplement use during early 235 pregnancy: the Expect Study I

Chapter 8 Should women be advised to use calcium supplements during 251 pregnancy? A decision analysis

Chapter 9 General discussion

Addendum

Summary

Nederlandstalige samenvatting

Valorisation

Dankwoord 



\section{CHAPTER 1}

General introduction 


\section{Preface}

By the turn of the last century, perinatal mortality, especially fetal mortality, was substantially higher in the Netherlands than in other European countries ${ }^{1,2}$. Five years later the situation had improved, but still the Netherlands, with its much-praised health care system, showed above-average perinatal mortality rates ${ }^{3}$. Perinatal mortality is considered an important quality indicator of obstetric care $e^{4,5}$. In 2008, a steering committee established by the Minister of Health Care published recommendations to optimize obstetric care, which resulted in a ZonMw research programme Pregnancy and Childbirth ${ }^{6}$. One of the four main priorities of the programme was improvement of risk selection during early pregnancy ${ }^{7}$.

In the Netherlands, $85 \%$ of the perinatal deaths go together with asphyxia (Apgar score $<7$ after 5 minutes), preterm birth (PTB) ( $<37$ weeks of gestation), congenital anomalies, and small-for-gestational-age (SGA) $\left(<10^{\text {th }}\right.$ percentile), also called BIG $4 . A$ BIG 4 condition occurs in $16,3 \%$ of all pregnancies ${ }^{8}$. Pre-eclampsia (PE), a hypertensive pregnancy disorder, is associated with SGA and PTB, while gestational diabetes mellitus (GDM) increases the risk for infants born large-for-gestational-age (LGA) $)^{9,10}$. Infants born LGA are at increased risk for asphyxia and birth injuries ${ }^{11}$.

Early identification of women at increased risk of developing adverse outcomes during pregnancy is important considering the short- and long-term health consequences for both mother and child. Women at increased risk may benefit from interventions that aim to lower the chance of developing pregnancy complications or their adverse effects. This thesis focuses on improving personalised obstetric care in both early risk assessment (part I) and intervention strategies (part II).

\section{Part I - External validation and clinical usefulness of early obstetric prediction models}

\section{Risk selection}

Risk selection or risk stratification, i.e. judgment of the probability that an individual will develop a particular outcome, is a continuous process during obstetric care. Risk stratification differs to a large extent among countries. In the Netherlands, primary care midwives work autonomously and monitor the pregnancy of women who are considered to be at low risk to develop pregnancy complications. Pregnant women at high risk are assigned to an obstetrician in second or tertiary care. This unique system emphasizes the importance for early identification of women with a high probability to develop pregnancy complications ${ }^{12}$. Around $85 \%$ of pregnant women start antenatal care with a primary midwife and $\sim 55 \%$ of these women are referred to secondary or tertiary care during pregnancy or labour ${ }^{13}$. The obstetric indication list is an official national guideline to judge the risk and need for referral ${ }^{14}$. A drawback of this guideline is that it is not an individual risk assessment tool, nor does it describe what the content of primary and secondary/tertiary care should be. Moreover, current risk management typically involves reaction to maternal and fetal problems 
when they already exist or are imminent, and contributes little to early detection or prevention.

Early estimation of patient-specific risks for the development of pregnancy complications might improve pregnancy outcomes by changing prenatal care from a series of routine visits to more personalised obstetric care tailored to women's specific needs ${ }^{15}$. Certain published guidelines provide a list of well-established risk factors to assess the probability that a woman will develop a certain pregnancy complication such as PE or GDM ${ }^{13,16-20}$. However, a limitation of these guidelines is that each risk factor is taken into account independently, without taking into account the strength of the different risk factors in relation to the relevant outcome. Furthermore, the variables are often treated categorical (i.e. body mass index $\geq 35$ $\mathrm{kg} / \mathrm{m}^{2}$ ) leading to loss of information that can be obtained using continuous data information $^{21}$. Prognostic prediction models may be more accurate in identifying women at high risk for developing pregnancy complications as multiple risk factors are combined in an algorithm, taking into account the risk dependent weight of each risk factor and possible interrelations ${ }^{22}$.

\section{Prediction models}

Multivariable prognostic prediction models estimate the risk of developing a certain outcome $^{23}$. Prediction modelling research is a multi-step approach, starting with model development including internal validation, followed by external validation, and, lastly, assessment of the impact in clinical practice ${ }^{24}$.

Several first trimester prediction models addressing important obstetric outcomes including PE, GDM, spontaneous PTB, and delivering an infant SGA or LGA have been published $^{25}$. These models rely on several types of predictors such as maternal characteristics, routine antenatal tests (i.e. blood pressure), or more specialized tests including ultrasound imaging (i.e. uterine artery Doppler and cervix length measurement) or biomarkers ${ }^{25}$. Although some specialized measurements have been reported to improve predictive performance, a drawback is that most of these measurements provide additional costs, might be inconvenient for pregnant women, and are not routinely performed or readily available in general antenatal settings ${ }^{23,26,27}$. The latter is a particular important aspect when applying a prediction model in the unique Dutch obstetric setting. While the reported performance of a number of non-invasive prediction models is promising, external validation studies are scarce and impact studies even more ${ }^{25}$.

External validation, which is the evaluation of the generalizability of the model in populations other than used for model development, is crucial before implementing a model in clinical practice ${ }^{28,29}$. Prediction models usually perform less well in other populations than the one in which they were developed, even after internal validation procedures $^{30}$. Moreover, currently published models have been developed in different countries among various types of populations and settings. Evaluation of the predictive performance of all available prediction models in one independent Dutch 
cohort allows for a fair comparison of the potential clinical value in Dutch obstetric care $^{31}$.

If one or more prediction models adequately perform after external validation, possibly after adaptation of the model, it is however not self-evident that the model will be useful in clinical practice ${ }^{30,32}$. Effective follow-up management strategies should be available for women who are identified 'at risk', that either prevent the development of problems or limit the adverse effects of any existing condition. Besides prevention of adverse outcomes in high-risk women, the use of prediction models can also lead to a more efficient use of resources and refraining from unnecessary testing and interventions in low-risk women. Furthermore, the prediction model should be practical, not too costly, and acceptable for end-users. Impact studies are necessary to determine whether the application of a prediction model in a clinical care setting actually leads to the intended improvements ${ }^{30}$.

\section{Expect Study}

In order to improve risk stratification during early pregnancy to set a base for the development of personalized obstetric care, the Expect Study was designed. Personalized obstetric care ultimately might lead to a reduction of maternal and perinatal morbidity and mortality. The Expect Study aimed to evaluate the predictive performance of first trimester prognostic prediction models, consisting exclusively of non-invasive predictors, for the risk of PE, GDM, spontaneous PTB, and delivering an infant SGA or LGA among Dutch pregnant women (Expect Study I, completed) ${ }^{33}$. Furthermore, the impact of the application of adequately performing prediction models in association with risk-tailored care as compared to care-as-usual in Dutch obstetric care is currently being determined in a follow-up study, which is not part of this thesis (Expect Study II, on-going) ${ }^{34}$. Tailored care paths were developed by members of the Limburg Obstetric Consortium (midwives, obstetricians, and deputies of maternity care centres of the south-eastern part of the Netherlands) concurrently with the Expect Study I.

\section{Part II - Calcium intake during pregnancy}

A number of management strategies have shown to be effective in the prevention of adverse pregnancy outcomes ${ }^{35-41}$. One of the interventions that can be used is calcium supplementation during pregnancy. Studies demonstrated that calcium supplementation reduces the risk of developing hypertensive pregnancy disorders, especially in high-risk women or women with a low calcium intake ${ }^{35}$. The question is whether advising calcium supplementation during pregnancy is (cost-)effective in Dutch pregnant women and, if so, which strategy provides most benefit. This depends, besides the efficacy of the intervention, on several other factors such as current calcium intake, outcome incidence, uptake of the intervention, costs of the intervention, and costs related to the outcome. 


\section{Calcium intake}

Calcium is an essential mineral for the human body, necessary for several physiological functions and a critical component of bones and teeth ${ }^{42}$. Intestinal absorption of calcium occurs through both an active transcellular route controlled by calcitriol (vitamin D) and a paracellular passive transport ${ }^{43}$. During pregnancy, the development of the fetal skeleton increases the demand for calcium. The increased requirement for calcium is facilitated by an increased maternal intestinal absorption of calcium ${ }^{44,45}$. However, adequate calcium intake by the mother remains crucial. Insufficient calcium intake is associated with impaired fetal development and increases the risk of developing a hypertensive pregnancy disorder ${ }^{46}$.

The recommended calcium intake for pregnant women varies between countries from 900 to $1200 \mathrm{mg} / \mathrm{day}^{42,47}$. The Dutch Health Council recommends calcium intake to be $1000 \mathrm{mg} /$ day for adults, irrespective of pregnancy status ${ }^{48}$. The main dietary sources of calcium are dairy products. Other food sources rich in calcium include legumes, leafy greens, fish with soft bones (i.e. sardines and canned salmon), almonds, and calcium fortified food products. Consumption of hard water also contributes to calcium intake ${ }^{47}$.

Calcium intakes differ between countries and populations due to food habits and access to food. Dietary calcium intake during pregnancy has been mainly assessed among populations in developing countries ${ }^{49}$. A WHO survey showed that $89 \%$ of nulliparous women in developing countries had an inadequate dietary calcium intake (median $310 \mathrm{mg} /$ day), with lowest values in African and Asian populations ${ }^{49}$. However, also in countries with sufficient availability and affordability of calcium-rich foods the actual calcium intake often does not meet the recommendation ${ }^{49}$. In a cohort of Dutch pregnant women (Generation R Study), the mean dietary calcium intake was $1108 \mathrm{mg} /$ day with a standard deviation of $311 \mathrm{mg}$. This indicates that more than onethird of the women had a dietary intake below the recommended $1000 \mathrm{mg} / \mathrm{day}^{50}$. No data were published on additional calcium intake by supplement use.

The contribution of calcium-containing supplements to total calcium intake is low ${ }^{51,52}$. The Dutch National Food Consumption Survey 2007-2010 demonstrated that approximately $50 \%$ of non-pregnant women in the reproductive age did not meet the recommenced calcium intake by diet alone, and only $4-8 \%$ of these women used calcium supplements ${ }^{52}$. To date, published studies evaluating total daily calcium intake from both diet and supplement use during pregnancy are limited and, to our knowledge, not available for a Dutch pregnant population ${ }^{53-56}$.

\section{Calcium in the prevention of pre-eclampsia}

The protective effect of adequate calcium intake against hypertensive disorders during pregnancy is well established ${ }^{57-60}$. A meta-analysis of 13 randomized controlled trials comprising 15,730 pregnant women showed an overall reduction of $55 \%$ in the risk of developing PE among women receiving calcium supplements (>1000 mg/day) from the second half of pregnancy to delivery as compared to women receiving 
placebo supplements ${ }^{35}$. The protective effect was more pronounced among women with a low dietary calcium intake (mean intake $<900 \mathrm{mg} /$ day) and among women with an increased risk of hypertensive pregnancy disorders. Although the underlying mechanisms remain to be determined, calcium supplementation might reduce the release of parathyroid hormone and thereby intracellular calcium leading to a reduction of vascular smooth muscle contractility ${ }^{35,57}$. In addition, available evidence indicates that calcium supplementation might lower the resistance in uterine and umbilical arteries, and reduces the activation of endothelial cells ${ }^{61,62}$.

Although these data indicate the benefit of calcium supplementation during pregnancy, in addition to a minimal risk for side effects ${ }^{35,63}$, and relative low costs (1000 mg elemental calcium per day costs only about $€ 50$ per pregnancy $)^{64,65}$, this approach is still not part of antenatal care in most countries.

The WHO recommends calcium supplementation during pregnancy in populations with low dietary calcium intake, particularly among those at higher risk of developing a hypertensive pregnancy disorder ${ }^{66}$. Notably, also in populations with sufficient availability and affordability of calcium-rich foods, calcium supplementation among pregnant women is expected to have major public health implications. The effect on public health is, however, also dependent on the size of the target population, the incidence of $\mathrm{PE}$, the percentage of women already taking calcium supplements, and uptake of the intervention. The financial impact is dependent on costs of calcium supplementation and savings due to prevented cases of PE. Decision analysis, combining evidence from efficacy studies with factors previously mentioned, could provide insight into whether an efficacious intervention is attractive for implementation $^{67}$. A study of Meads et al. (2008) considered the clinical and financial impact of calcium supplementation in the prevention of $P E$ for a pregnant population in the United Kingdom ${ }^{68}$. This study showed that calcium supplementation is a costeffective option in the prevention of PE. Noteworthy, in this study several assumptions were made that might have biased the outcome. For example, the use of calcium supplementation in current care was not included and a $100 \%$ uptake of the intervention was assumed.

\section{Aims and outline of this thesis}

The studies in the first part of this thesis were aimed to externally validate existing first trimester obstetric prediction models published in the literature for Dutch population, and to evaluate the clinical potential of the best performing models (Expect Study I). The clinical utility of prediction models is dependent on availability of an effective follow-up management. One available treatment strategy is adequate calcium intake in the prevention of PE. The main purposes of the studies in the second part were to estimate the current calcium intake of Dutch pregnant women and to study the (cost-)effectiveness of different calcium supplementation strategies in the prevention of PE. 


\section{Part I - External validation and clinical usefulness of early obstetric prediction models}

Chapter 2 describes the study protocol of the Expect Study I. Moreover, this chapter describes the results of the pilot study on feasibility and acceptability of the recruitment process and comprehensibility of the study questionnaire of Expect Study I.

Chapter 3, 4, 5 and 6 present the results of the independent validation studies of all published first trimester prediction models, containing exclusively non-invasive predictors, for the risk of PE (chapter 3), GDM (chapter 4), delivering an infant SGA or LGA (chapter 5), and spontaneous PTB (chapter 6) in Dutch pregnant women. Furthermore, the studies elaborate on the clinical potential of the best performing models.

\section{Part II - Calcium intake during pregnancy}

Chapter 7 describes the results of a study estimating total daily calcium intake from both food and supplement use during early pregnancy in Dutch women.

Chapter 8 reports a decision analysis on the expected impact of advising calcium supplementation (1000 mg/day) to either all Dutch pregnant women or selected subgroups (low calcium intake, or high risk of developing PE) on the number of cases of PE prevented and the related health care costs.

The final chapter, chapter 9, contains a general discussion of the main findings of the studies, their implications and limitations, and recommendations for further research. 


\section{References}

1. Buitendijk, S., Zeitlin, J., Cuttini, M., Langhoff-Roos, J., and Bottu, J., Indicators of fetal and infant health outcomes. Eur J Obstet Gynecol Reprod Biol, 2003. 111 Suppl 1: p. S66-77.

2. Zeitlin, J., Wildman, K., Breart, G., Alexander, S., Barros, H., Blondel, B., et al., PERISTAT: indicators for monitoring and evaluating perinatal health in Europe. Eur J Public Health, 2003. 13(3 Suppl): p. 29-37.

3. EURO-PERISTAT project, with SCPE EUROCAT, EURONEOSTAT. European Perinatal Health Report 2008. Available from: http://www.europeristat.co.

4. Zeitlin, J., Wildman, K., Breart, G., Alexander, S., Barros, H., Blondel, B., et al., Selecting an indicator set for monitoring and evaluating perinatal health in Europe: criteria, methods and results from the PERISTAT project. Eur J Obstet Gynecol Reprod Biol, 2003. 111 Suppl 1: p. S5-S14.

5. Richardus, J.H., Graafmans, W.C., Verloove-Vanhorick, S.P., Mackenbach, J.P., EuroNatal International Audit, P., and EuroNatal Working, G., Differences in perinatal mortality and suboptimal care between 10 European regions: results of an international audit. BJOG, 2003. 110(2): p. 97-105.

6. Stuurgroep zwangerschap en geboorte. Een goed begin. Veilige zorg rond zwangerschap en geboorte. December 2009. Available from: http://www.rijksoverheid.nl/documenten/kamerstukken/ 2009/12/30/een-goed-begin-veilige-zorg-rond-zwangerschap-en-geboorte.

7. ZonMw. Programmatekst Zwangerschap en Geboorte. Den Haag: 2011. Available from: http://www.zonmw.nl/nl/onderzoek-resultaten/preventie/programmas/programmadetail/zwangerschap-en-geboorte/publicaties/.

8. Bonsel, G., Birnie, E., Denktas, S., Poeran, J., and Steegers, E., Lijnen in de perinatale sterfte, Signalementstudie Zwangerschap en Geboorte 2010. 2010, Rotterdam: Erasmus MC.

9. Mol, B.W., Roberts, C.T., Thangaratinam, S., Magee, L.A., de Groot, C.J., and Hofmeyr, G.J., Preeclampsia. Lancet, 2016. 387(10022): p. 999-1011.

10. Koning, S.H., Hoogenberg, K., Lutgers, H.L., and Van den Berg, P.P., Gestational Diabetes Mellitus:current knowledge and unmet needs. J Diabetes, 2016. 8(6): p. 770-81.

11. Araujo Junior, E., Peixoto, A.B., Zamarian, A.C., Elito Junior, J., and Tonni, G., Macrosomia. Best Pract Res Clin Obstet Gynaecol, 2016. 38: p. 83-96.

12. Visser, G.H.A., Obstetric care in the Netherlands: relic or example? J Obstet Gynaecol Can, 2012. 34(10): p. 971-975.

13. Perined, Perinatale Zorg in Nederland 2015. Utrecht: Perined, 2016.

14. Commissie Verloskunde van het Collegevoorzorgverzekeringen. Verloskundig Vandemecum Verloskundige indicatielijst (VIL). 2003.

15. Nicolaides, K.H., Turning the pyramid of prenatal care. Fetal Diagn Ther, 2011. 29(3): p. 183-96.

16. Kumar, A., Agarwal, K., Devi, S.G., Gupta, R.K., and Batra, S., Hypocalcemia in pregnant women. Biol Trace Elem Res, 2010. 136(1): p. 26-32.

17. National Institute for Health and Clinical Excellence. Diabetes in pregnancy: management from preconception to the postnatal period. Guideline NG3. 2015; Available from: http://nice.org.uk/ guidance/ng3.

18. LeFevre, M.L., Low-dose aspirin use for the prevention of morbidity and mortality from preeclampsia: U.S. Preventive Services Task Force recommendation statement. Ann Intern Med, 2014. 161(11): p. 819-26.

19. Nederlandse Vereniging voor Obstetrie en Gynaecologie. Richtlijn Diabetes mellitus en zwangerschap (2.0). 2010; Available from: http://www.nvog-documenten.nl/richtlijn/doc/index.php?type= save\&richtlijn_id=863.

20. Sistema Nazionale per le Linee Guida dell'Istituto Superiore di Sanità (SNLG-ISS). Linea guida Gravidanza fisiologica. 2011; Available from: http://www.snlg-iss.it/cms/files/LG_Gravidanza.pdf.

21. Altman, D.G. and Royston, P., The cost of dichotomising continuous variables. BMJ, 2006. 332(7549): p. 1080.

22. Steyerberg, E.W., Vickers, A.J., Cook, N.R., Gerds, T., Gonen, M., Obuchowski, N., et al., Assessing the performance of prediction models: a framework for traditional and novel measures. Epidemiology, 2010. 21(1): p. 128-38.

23. Steyerberg, E.W., Moons, K.G., van der Windt, D.A., Hayden, J.A., Perel, P., Schroter, S., et al., Prognosis Research Strategy (PROGRESS) 3: prognostic model research. PLoS Med, 2013. 10(2): p. e1001381. 
24. Steyerberg, E.W. and Vergouwe, Y., Towards better clinical prediction models: seven steps for development and an ABCD for validation. Eur Heart J, 2014. 35(29): p. 1925-31.

25. Kleinrouweler, C.E., Cheong-See, F.M., Collins, G.S., Kwee, A., Thangaratinam, S., Khan, K.S., et al., Prognostic models in obstetrics: available, but far from applicable. Am J Obstet Gynecol, 2016. 214(1): p. 79-90.e36.

26. Al-Rubaie, Z., Askie, L.M., Ray, J.G., Hudson, H.M., and Lord, S.J., The performance of risk prediction models for pre-eclampsia using routinely collected maternal characteristics and comparison with models that include specialised tests and with clinical guideline decision rules: a systematic review. BJOG, 2016. 123(9): p. 1441-52.

27. Henderson, J.T., Thompson, J.H., Burda, B.U., and Cantor, A., Preeclampsia screening: Evidence report and systematic review for the us preventive services task force. JAMA, 2017. 317(16): p. 1668-1683.

28. Justice, A.C., Covinsky, K.E., and Berlin, J.A., Assessing the generalizability of prognostic information. Ann Intern Med, 1999. 130(6): p. 515-24.

29. Altman, D.G., Vergouwe, Y., Royston, P., and Moons, K.G., Prognosis and prognostic research: validating a prognostic model. BMJ, 2009. 338: p. b605.

30. Moons, K.G., Kengne, A.P., Grobbee, D.E., Royston, P., Vergouwe, Y., Altman, D.G., et al., Risk prediction models: II. External validation, model updating, and impact assessment. Heart, 2012. 98(9): p. 691-8.

31. Collins, G.S. and Moons, K.G., Comparing risk prediction models. BMJ, 2012. 344: p. e3186.

32. Moons, K.G., Altman, D.G., Vergouwe, Y., and Royston, P., Prognosis and prognostic research: application and impact of prognostic models in clinical practice. BMJ, 2009. 338: p. b606.

33. Meertens, L.J.E., Scheepers, H.C.J., De Vries, R.G., Dirksen, C.D., Korstjens, I., Mulder, A.L., et al., External Validation Study of First Trimester Obstetric Prediction Models (Expect Study I): Research Protocol and Population Characteristics. JMIR Res Protoc, 2017. 6(10): p. e203.

34. Van Montfort, P., Willemse, J.P., Dirksen, C.D., van Dooren, I.M., Meertens, L.J., Spaanderman, M.E., et al., Implementation and Effects of Risk-Dependent Obstetric Care in the Netherlands (Expect Study II): Protocol for an Impact Study. JMIR Res Protoc, 2018. 7(5): p. e10066.

35. Hofmeyr, G.J., Lawrie, T.A., Atallah, A.N., Duley, L., and Torloni, M.R., Calcium supplementation during pregnancy for preventing hypertensive disorders and related problems. Cochrane Database Syst Rev, 2014(6): p. CD001059.

36. Alfirevic, Z., Stampalija, T., and Medley, N., Cervical stitch (cerclage) for preventing preterm birth in singleton pregnancy. Cochrane Database Syst Rev, 2017. 6: p. CD008991.

37. Dodd, J.M., Jones, L., Flenady, V., Cincotta, R., and Crowther, C.A., Prenatal administration of progesterone for preventing preterm birth in women considered to be at risk of preterm birth. Cochrane Database Syst Rev, 2013(7): p. CD004947.

38. Poolsup, N., Suksomboon, N., and Amin, M., Effect of treatment of gestational diabetes mellitus: a systematic review and meta-analysis. PLoS One, 2014. 9(3): p. e92485.

39. Roberge, S., Nicolaides, K., Demers, S., Hyett, J., Chaillet, N., and Bujold, E., The role of aspirin dose on the prevention of preeclampsia and fetal growth restriction: systematic review and meta-analysis. Am J Obstet Gynecol, 2017. 216(2): p. 110-120 e6.

40. Romero, R., Conde-Agudelo, A., Da Fonseca, E., O'Brien, J.M., Cetingoz, E., Creasy, G.W., et al., Vaginal progesterone for preventing preterm birth and adverse perinatal outcomes in singleton gestations with a short cervix: a meta-analysis of individual patient data. Am J Obstet Gynecol, 2018. 218(2): p. 161-180.

41. Zheng, L., Dong, J., Dai, Y., Zhang, Y., Shi, L., Wei, M., et al., Cervical pessaries for the prevention of preterm birth: a systematic review and meta-analysis. J Matern Fetal Neonatal Med, 2017: p. 1-10.

42. IOM (Institute of Medicine), Dietary Reference Intakes for Calcium and Vitamin D. Washington, DC: The National Academies Press. 2011.

43. Bronner, F., Recent developments in intestinal calcium absorption. Nutr Rev, 2009. 67(2): p. 109-13.

44. Cross, N.A., Hillman, L.S., Allen, S.H., Krause, G.F., and Vieira, N.E., Calcium homeostasis and bone metabolism during pregnancy, lactation, and postweaning: a longitudinal study. Am J Clin Nutr, 1995. 61(3): p. 514-23.

45. Ritchie, L.D., Fung, E.B., Halloran, B.P., Turnlund, J.R., Van Loan, M.D., Cann, C.E., et al., A longitudinal study of calcium homeostasis during human pregnancy and lactation and after resumption of menses. Am J Clin Nutr, 1998. 67(4): p. 693-701. 
46. Hacker, A.N., Fung, E.B., and King, J.C., Role of calcium during pregnancy: maternal and fetal needs. Nutr Rev, 2012. 70(7): p. 397-409.

47. EFSA NDA Panel (EFSA Panel on Dietetic Products, N.a.A., Scientific Opinion on Dietary Reference Values for calcium EFSA Journal, 2015. 13(5): p. 4101, 82 pp.

48. Health Council of the Netherlands. Dietary reference intakes: calcium, vitamin D, thiamin, riboflavin, niacin, pantothenic acid, and biotin. The Hague: Health Council of the Netherlands, 2000; publication no. 2000/12. ISBN 90-5549-323-6.

49. Merialdi, M., Mathai, M., Ngoc, N., Purwar, M., Campodonico, L., Abdel-Aleem, H., et al., World Health Organization systematic review of the literature and multinational nutritional survey of calcium intake during pregnancy. Fetal Matern Med Rev, 2005. 16(02): p. 97-121.

50. Heppe, D.H., Medina-Gomez, C., Hofman, A., Franco, O.H., Rivadeneira, F., and Jaddoe, V.W., Maternal first-trimester diet and childhood bone mass: the Generation R Study. Am J Clin Nutr, 2013. 98(1): p. 224-32.

51. Bailey, R.L., Dodd, K.W., Goldman, J.A., Gahche, J.J., Dwyer, J.T., Moshfegh, A.J., et al., Estimation of total usual calcium and vitamin D intakes in the United States. J Nutr, 2010. 140(4): p. 817-22.

52. Van Rossum, C., Fransen, H., Verkaik-Kloosterman, J., Buurma-Rethans, E., and Ocké, M. Dutch National Food Consumption Survey 2007-2010: Diet of children and adults aged 7 to 69 years. RIVM report 350050006. RIVM report 350050006 2011; Available from: http://www.rivm.nl/bibliotheek/ rapporten/350050006.pdf.

53. Cormick, G., Zhang, N.N., Andrade, S.P., Quiroga, M.J., Di Marco, I., Porta, A., et al., Gaps between calcium recommendations to prevent pre-eclampsia and current intakes in one hospital in Argentina. BMC Res Notes, 2014. 7: p. 920.

54. Dubois, L., Diasparra, M., Bedard, B., Colapinto, C.K., Fontaine-Bisson, B., Morisset, A.S., et al., Adequacy of nutritional intake from food and supplements in a cohort of pregnant women in Quebec, Canada: the 3D Cohort Study (Design, Develop, Discover). Am J Clin Nutr, 2017. 106(2): p. 541-548.

55. Jia, H.X., Han, J.H., Li, H.Z., Liang, D., Deng, T.T., and Chang, S.Y., Mineral Intake in Urban Pregnant Women from Base Diet, Fortified Foods, and Food Supplements: Focus on Calcium, Iron, and Zinc. Biomed Environ Sci, 2016. 29(12): p. 898-901.

56. Morisset, A.S., Weiler, H.A., Dubois, L., Ashley-Martin, J., Shapiro, G.D., Dodds, L., et al., Rankings of iron, vitamin $D$, and calcium intakes in relation to maternal characteristics of pregnant Canadian women. Appl Physiol Nutr Metab, 2016. 41(7): p. 749-57.

57. Belizan, J.M., Villar, J., and Repke, J., The relationship between calcium intake and pregnancy-induced hypertension: up-to-date evidence. Am J Obstet Gynecol, 1988. 158(4): p. 898-902.

58. Hamlin, R.H., The prevention of eclampsia and pre-eclampsia. Lancet, 1952. 1(6698): p. 64-8.

59. Repke, J.T. and Villar, J., Pregnancy-induced hypertension and low birth weight: the role of calcium. Am J Clin Nutr, 1991. 54(1 Suppl): p. 237S-241S.

60. Villar, J., Belizan, J.M., and Fischer, P.J., Epidemiologic observations on the relationship between calcium intake and eclampsia. Int J Gynaecol Obstet, 1983. 21(4): p. 271-8.

61. Carroli, G., Merialdi, M., Wojdyla, D., Abalos, E., Campodonico, L., Yao, S.E., et al., Effects of calcium supplementation on uteroplacental and fetoplacental blood flow in low-calcium-intake mothers: a randomized controlled trial. Am J Obstet Gynecol, 2010. 202(1): p. 45 e1-9.

62. Chen, Q., Tong, M., Wu, M., Stone, P.R., Snowise, S., and Chamley, L.W., Calcium supplementation prevents endothelial cell activation: possible relevance to preeclampsia. J Hypertens, 2013. 31(9): p. 1828-36.

63. Heaney, R.P., Kopecky, S., Maki, K.C., Hathcock, J., Mackay, D., and Wallace, T.C., A review of calcium supplements and cardiovascular disease risk. Adv Nutr, 2012. 3(6): p. 763-71.

64. BMJ Group and the Royal Pharmaceutical Society of Great Britain. British National Formulary. Calcium Carbonate. 2016 [cited February 19, 2016]; Available from: http://www.medicinescomplete.com/mc/bnf/current/PHP93602-calciumcarbonate.htm?q=calcichew\&t=search\&ss=text\&p=7 - _hit.

65. Zorginstituut Nederland. Medicijnkosten. Calciumcarbonaat. 2016 [cited February 19, 2016]; Available from: http://www.medicijnkosten.nl.

66. WHO, Guideline: Calcium supplementation in pregnant women. World Health Organization: Geneva. 2013. 
67. Aleem, I.S., Schemitsch, E.H., and Hanson, B.P., What is a clinical decision analysis study? Indian J Orthop, 2008. 42(2): p. 137-9.

68. Meads, C.A., Cnossen, J.S., Meher, S., Juarez-Garcia, A., ter Riet, G., Duley, L., et al., Methods of prediction and prevention of pre-eclampsia: systematic reviews of accuracy and effectiveness literature with economic modelling. Health Technol Assess, 2008. 12(6): p. iii-iv, 1-270. 
PART I

External validation and clinical usefulness

of early obstetric prediction models 


\section{CHAPTER 2}

External validation study of first trimester obstetric prediction models (Expect Study I):

research protocol and population characteristics

Linda J.E. Meertens, Hubertina C.J. Scheepers, Raymond G. de Vries, Carmen D. Dirksen, Irene Korstjens, Antonius L.M. Mulder, Marianne J. Nieuwenhuijze, Jan G. Nijhuis, Marc E.A. Spaanderman, and Luc J.M. Smits

JMIR Research Protocols, 2017 Oct; 6(10): e203. 


\section{Abstract}

\section{Background}

A number of first-trimester prediction models addressing important obstetric outcomes have been published. However, most models have not been externally validated. External validation is essential before implementing a prediction model in clinical practice.

\section{Objective}

The objective of this paper is to describe the design of a study to externally validate existing first trimester obstetric prediction models, based upon maternal characteristics and standard measurements (eg, blood pressure), for the risk of preeclampsia (PE), gestational diabetes mellitus (GDM), spontaneous preterm birth (PTB), small-for-gestational-age (SGA) infants, and large-for-gestational-age (LGA) infants among Dutch pregnant women (Expect Study I). The results of a pilot study on the feasibility and acceptability of the recruitment process and the comprehensibility of the Pregnancy Questionnaire 1 are also reported.

\section{Methods}

A multicenter prospective cohort study was performed in the Netherlands between July 1, 2013 and December 31, 2015. First trimester obstetric prediction models were systematically selected from the literature. Predictor variables were measured by the web-based Pregnancy Questionnaire 1 and pregnancy outcomes were established using the Postpartum Questionnaire 1 and medical records. Information about maternal health-related quality of life, costs, and satisfaction with Dutch obstetric care was collected from a subsample of women. A pilot study was carried out before the official start of inclusion. External validity of the models will be evaluated by assessing discrimination and calibration.

\section{Results}

Based on the pilot study, minor improvements were made to the recruitment process and online Pregnancy Questionnaire 1. The validation cohort consists of 2614 women. Data analysis of the external validation study is in progress.

\section{Conclusions}

This study will offer insight into the generalizability of existing, non-invasive first trimester prediction models for various obstetric outcomes in a Dutch obstetric population. An impact study for the evaluation of the best obstetric prediction models in the Dutch setting with respect to their effect on clinical outcomes, costs, and quality of life-Expect Study II-is being planned. 


\section{Introduction}

Perinatal mortality is an important quality indicator of perinatal care. The main causes of perinatal mortality are asphyxia, preterm birth (PTB), and born small-forgestational-age (SGA) $)^{1,2}$. Pre-eclampsia (PE) is commonly related to SGA and induced preterm birth $^{3}$. Another concern is the rising incidence of gestational diabetes mellitus (GDM), leading to large-for-gestational-age (LGA) infants ${ }^{4}$. Children born LGA are at increased risk of asphyxia and birth injuries ${ }^{5}$. Early identification of pregnancies at risk of these complications is important considering the substantial short- and long-term consequences for the health of mother and child. Women at high risk could benefit from further testing, increased surveillance, and preventive interventions.

A number of first trimester prediction models have been published addressing important obstetric outcomes including PE, GDM, spontaneous PTB, and infants born SGA or $\mathrm{LGA}^{6}$. These risk models are based on maternal characteristics, routine antenatal tests (eg, blood pressure), and sometimes include more complex predictors like specialized tests (eg, uterine artery Doppler and cervix length measurements) or biomarkers. Although some complex factors have been reported to improve discrimination, a drawback is that most of these tests provide additional costs, are not readily available in general antenatal settings, and are possibly inconvenient for pregnant women ${ }^{7}$.

While the reported performance of most non-invasive prediction models is promising ${ }^{7}$, few models have been externally validated in independent cohorts $^{8-16}$. Evaluating the model's performance in another population than the one used for model development is crucial before applying a model in daily practice to guide patient care ${ }^{17,18}$.

This paper describes the design of a study aimed to externally validate existing first trimester obstetric prediction models, based upon maternal characteristics and standard measurements (i.e. blood pressure), for the risk of PE, GDM, spontaneous PTB, SGA infants, and LGA infants among Dutch pregnant women (Expect Study I). Results of a pilot study on the feasibility and acceptability of the recruitment process and the comprehensibility of the Pregnancy Questionnaire 1 are also reported. Adequately performing models will be considered for use in clinical practice. We are planning an impact study-Expect Study II-to evaluate the application of adequately performing models (in association with tailored care paths) as compared with care-asusual in Dutch obstetric care.

The specific objectives of the Expect Study I are (1) to identify published first trimester obstetric prediction models, based solely upon maternal characteristics and standard measurements (i.e. blood pressure), for the outcomes PE, GDM, spontaneous PTB, SGA infants, and LGA infants, (2) to evaluate prospectively the predictive performance of these first trimester obstetric prediction models in a Dutch cohort of pregnant women, (3) to update, if necessary, the best performing models to the validation cohort, and (4) to measure maternal health-related quality of life, costs, and 
satisfaction aspects of current Dutch obstetric care for use as care-as-usual comparison to the intended Expect Study II.

\section{Methods}

\section{Selection of prediction models}

Systematic searches were performed in PubMed to identify all published first trimester obstetric prediction models using "prediction model" and its synonyms as search terms combined with relevant outcome terms and MeSH terms. The search terms were restricted to title and abstract fields (tiab). The detailed search strategies are available in Supplementary File S2.1. Articles written in languages other than English, German, French, or Dutch were excluded. Citation lists of relevant articles were checked to select additional articles. The search was first performed in April 2013 , before finalizing the study questionnaires, and will be updated before the start of each validation analysis per outcome. The first author screened all citations, and together with the last author, assessed the eligibility of the full text articles. In cases of disagreement, a third reviewer was used.

Prediction models were eligible for consideration if the following criteria were met: (1) the article presented the development of a prediction model or an update of a previously developed model, (2) the model contained multiple predictors, (3) predictors were routinely collected in Dutch obstetric care (maternal characteristics or blood pressure), (4) predictors were available and/or measured before 16 weeks and 0 days of gestation, (5) the model was based on weighted risk predictors, and (6) outcome of the model was PE, GDM, spontaneous PTB, SGA infants, or LGA infants. Authors of the original studies were contacted if the model intercept, regression coefficients, or definitions of predictors were not available.

\section{Study design and population}

A multicentre prospective cohort study was performed among women living in the south-eastern part of the Netherlands (province of Limburg). Six hospitals and 36 midwifery practices recruited pregnant women less than 16 weeks pregnant and aged 18 years or older between July 1, 2013 and January 1, 2015. Follow-up took place until December 31, 2015. Pregnancies ending in a miscarriage, termination before 24 weeks of gestation, and women lost-to-follow-up were excluded.

The Medical Ethics Committee (MEC) of the Maastricht University Medical Centre evaluated the study protocol and declared that the study did not fall within the scope of the Dutch Medical Research Involving Human Subjects Act (WMO) (MEC 13-4-053). An independent physician was available for consultation by (eligible) participants.

\section{Recruitment}

Eligible pregnant women visiting their midwife (approximately $85 \%$ ) or obstetrician (approximately 15\%) in the first trimester of pregnancy received verbal and written 
information about Expect Study ${ }^{19}$. They were also asked whether they were willing to receive further information by email or telephone. If so, contact details were entered into an online system by their caregiver and used to send an automated information email about the study. Pregnant women were asked to complete a web-based questionnaire before 16 weeks of gestation (Pregnancy Questionnaire 1) and 6 weeks after the due date (Postpartum Questionnaire 1). During the visit, blood pressure and heart rate were routinely measured and the results were given in writing to the women on the information leaflet in order to self-report in Pregnancy Questionnaire $1^{20,21}$.

Study questionnaires could be accessed through the Expect Study website by use of a personal login code contained in the written information and information email ${ }^{22}$. Women agreeing to participate gave online informed consent and answered the eligibility criteria before the start of Pregnancy Questionnaire 1. Paper-and-pencil questionnaires were available upon request. Three reminders were sent by email during 3-day intervals if Pregnancy Questionnaire 1 was not accessed or incomplete. Women who completed Pregnancy Questionnaire 1 were invited 6 weeks after the due date to complete Postpartum Questionnaire 1. Three email reminders were sent during 6-day intervals, and in case of non-response, a paper-and-pencil version of Postpartum Questionnaire 1 was sent (provided that the postal address was available). In Pregnancy Questionnaire 1, women were invited to fill out, on an optional basis, 3 additional questionnaires about costs, quality of life, and satisfaction of current obstetric care around 24 and 34 weeks of gestation (Pregnancy Questionnaire 2 and 3), and 6 weeks after the due date together with Postpartum Questionnaire 1 (Postpartum Questionnaire 2). Again, automatic reminders were sent out in case of non-response. Pregnancy status was asked at the beginning of Pregnancy Questionnaire 2 and 3. Women who reported a miscarriage or termination were referred to the end of the questionnaire and not invited for further questionnaires. Women not responding to Pregnancy Questionnaire 2 received no further invitations for the additional questionnaires, only for Postpartum Questionnaire 1. Women not responding to Pregnancy Questionnaire 3 were invited; however, for Postpartum Questionnaire 2. Medical records and discharge letters were requested from care providers.

A pilot study was carried out in the region of Maastricht before the official start of inclusion (March 25, 2013 to May 10, 2013) to assess the feasibility and acceptability of the recruitment process and the comprehensibility of Pregnancy Questionnaire 1. Evaluation questions about the recruitment process and form, content, and clarity of the questions were added to Pregnancy Questionnaire 1. If permission was given, participants were also approached by telephone.

\section{Data collection}

Inclusion, follow-up, and data collection of participants were managed by use of a logistic application specifically developed for Expect Study I. Questionnaires were 
developed by the research team and where possible, validated questionnaires were included.

Pregnancy Questionnaire 1 contained questions about the following topics: sociodemographic characteristics, anthropometric data, medical conditions, obstetric history, lifestyle, medication, vitamin and mineral supplements, fruit intake, dietary intake of vitamin D and calcium (selection questions from the Dutch National Food Frequency Questionnaire tool ${ }^{23}$ ), sun exposure, family history of medical conditions and obstetric outcomes, mental health (Edinburgh Depression Scale ${ }^{24,25}$ ), health status (EQ-5D-3L and cognitive dimension ${ }^{26,27}$ ), current pregnancy, and blood pressure and heart rate measurements.

The following aspects were collected in Postpartum Questionnaire 1: pregnancy outcome, pregnancy complications, labor and delivery, and neonatal outcomes. We also added several questions about the biological father.

The additional questionnaires-Pregnancy Questionnaire 2 and 3 and Postpartum Questionnaire 2-assessed maternal health status (EQ-5D-3L and cognitive dimension ${ }^{26,27}$ ), state anxiety (State-Trait Anxiety Inventory ${ }^{28}$ ), patient satisfaction, and costs of current obstetric care. Satisfaction was assessed antepartum (Pregnancy Questionnaire 2 and 3) by means of the Patient Satisfaction Questionnaire Short Form (PSQ-18 ${ }^{29}$ ) and postpartum (Postpartum Questionnaire 2 or delivered at Pregnancy Questionnaire 2 or 3 ) by the Pregnancy and Childbirth Questionnaire $\left(\mathrm{PCQ}^{30}\right)$. To evaluate the costs of current obstetric care, all midwifery, hospital, and other care institution costs associated with care for pregnant women and their newborns from the beginning of pregnancy up to around 6 weeks after the due date were requested. In Pregnancy Questionnaire 3 and Postpartum Questionnaire 2, the date of the last completed additional questionnaire was indicated so that participants could see what period was to be covered.

Data from the medical records and letters of discharge were extracted and entered into a predesigned datasheet using Microsoft Access. All records were verified by a second researcher.

An overview of the items collected in the study questionnaires and data extracted from medical records and discharge letters is provided in Supplementary File S2.2.

\section{Outcome measures}

Primary study outcomes were maternal and perinatal adverse outcomes predicted by the selected prediction models. The maternal outcomes were PE and GDM. PE was defined as pregnancy induced hypertension (PIH) accompanied by proteinuria (at least $300 \mathrm{mg}$ protein in a 24 hour urine collection) $)^{31}$. PIH was defined as systolic blood pressure of at least $140 \mathrm{mmHg}$ and/or diastolic blood pressure of at least $90 \mathrm{mmHg}$ (Korotkoff V) after 20 weeks gestation, measured twice in a previously normotensive woman $^{31,32}$. GDM was defined as a diagnosis of hyperglycemia during pregnancy, in a woman without pre-existing diabetes mellitus. The Dutch national guideline, in line with the World Health Organization guideline on Diagnosis and Classification of 
Diabetes Mellitus, defined hyperglycemia as the presence of either a fasting plasma glucose of $7.0 \mathrm{mmol} / \mathrm{l}$ or greater or 2-hour plasma glucose of $7.8 \mathrm{mmol} / \mathrm{l}$ or greater following a $75 \mathrm{~g}$ oral glucose tolerance test ${ }^{33,34}$. Perinatal outcomes included spontaneous PTB, SGA infants, and LGA infants. Spontaneous PTB is a delivery before 37 weeks of gestation started by primary contractions or spontaneous rupture of membranes. SGA and LGA were defined as an infant with a birth weight below the 10th percentile or above the 90th percentile, respectively, corrected for gestational age, ethnicity, gender, and parity ${ }^{35}$.

The following secondary outcomes associated with the primary outcomes and important determinants of child morbidity and mortality were also measured: perinatal death (stillbirth or death within 7 days after birth, after 22 weeks of gestation), asphyxia (Apgar score of less than 7 after 5 minutes), admission to a neonatal intensive care unit (within 28 days after birth), SGA infants below the 2.3 percentile, PTB before 32 weeks of gestation, severe PE (delivery before the 34th completed week), instrumental delivery, cesarean section, and referral from midwife to obstetrician during delivery.

\section{Sample size}

No generally accepted rules are available for the calculation of required sample sizes for external validation studies of prediction models. We followed the rule of thumb by Vergouwe et al. (2005), which states that at least 100 events and 100 non-events are necessary in order to be able to detect relevant differences between model performance in the derivation set and the validation set $^{36}$. Assuming that each primary outcome would affect $4 \%$ or more of the pregnancies, we needed to collect data from about 2500 women. We aimed to recruit 2750 women, allowing for $10 \%$ loss to-follow-up.

\section{Statistical analysis}

Data analysis of the external validation study is in progress. Missing values will be handled by imputation, as analysis of only complete cases can lead to biased results ${ }^{37}$. Predictive performance of each prediction model will be evaluated by assessing discrimination and calibration ${ }^{38,39}$. Discrimination is the ability to distinguish between individuals who will develop the outcome from those who will not and will be assessed by calculating the c-index (area under the receiver operating characteristic curve [AUROC]). Calibration is the degree of agreement between predicted and observed probabilities. We will evaluate whether models may benefit from recalibration. Based on their final calibration and discriminative power, models will be ranked with respect to their predictive performance. The statistical analysis will be described in detail in the validation articles. 


\section{Results}

\section{Pilot study}

A total of 6 midwifery practices and 1 university hospital invited 95 pregnant women to participate. In total, 25 (26\%, 25/95) women gave informed consent, of whom 21 (84\%, 21/25) completed Pregnancy Questionnaire 1 fully and $4(16 \%, 4 / 25)$ only partially because of technical problems. Of the participants, 70 (74\%, 70/95) invited women who did not wish to fill out Pregnancy Questionnaire 1 could have return a non-participation form, but only 1 form was returned indicating that the woman "did not want to invest time in research". The participants were positive about the recruitment process and only minor revisions were needed in the content of Pregnancy Questionnaire 1 . In reaction to the low response rate, we made improvements to the recruitment process by asking contact details of informed pregnant women to send reminders about the study by email or telephone. Furthermore, a leaflet was designed to make the written information more concise and attractive, and we distributed information through social media and posters for promotion. Lastly, half of the pilot study participants declared that an incentive would increase their motivation to participate, and that they preferred higher probability of receiving a low-cost reward in comparison to a lower chance of getting an expensive incentive. On the basis of this information, low-to-medium cost incentives were invoked in the recruitment procedure (lottery of 27 gift cards and 2 photo shoots).

\section{Validation cohort}

The flowchart for enrolment and data collection of the validation cohort is shown in Figure 2.1. A total of 2794 women accessed the study website and gave online informed consent. Pregnancy Questionnaire 1 and Postpartum Questionnaire 1 were filled out by 2762 (98.85\%, 2762/2794) and 2178 (78.86\%, 2178/2762) women, respectively. Medical records were retrieved for 2598 (94.06\%, 2598/2762) women. A completed Postpartum Questionnaire 1 or medical record was available for 2614 (94.64\%, 2614/2762) women (validation cohort). General baseline characteristics and the primary outcomes of the validation cohort are shown in Table 2.1.

Of the women included in the validation cohort, 1548 (59.22\%, 1548/2614) gave permission to be invited for the additional questionnaires. Pregnancy Questionnaire 2 was filled out by 891 (57.56\%, 891/1548) women. Of the women who started the first additional Pregnancy Questionnaire 2 and were still pregnant, 795 (89.5\%, 795/888) women filled out Pregnancy Questionnaire 3. Postpartum Questionnaire 2 was filled out by 744 (83.5\%, 744/891) women. 


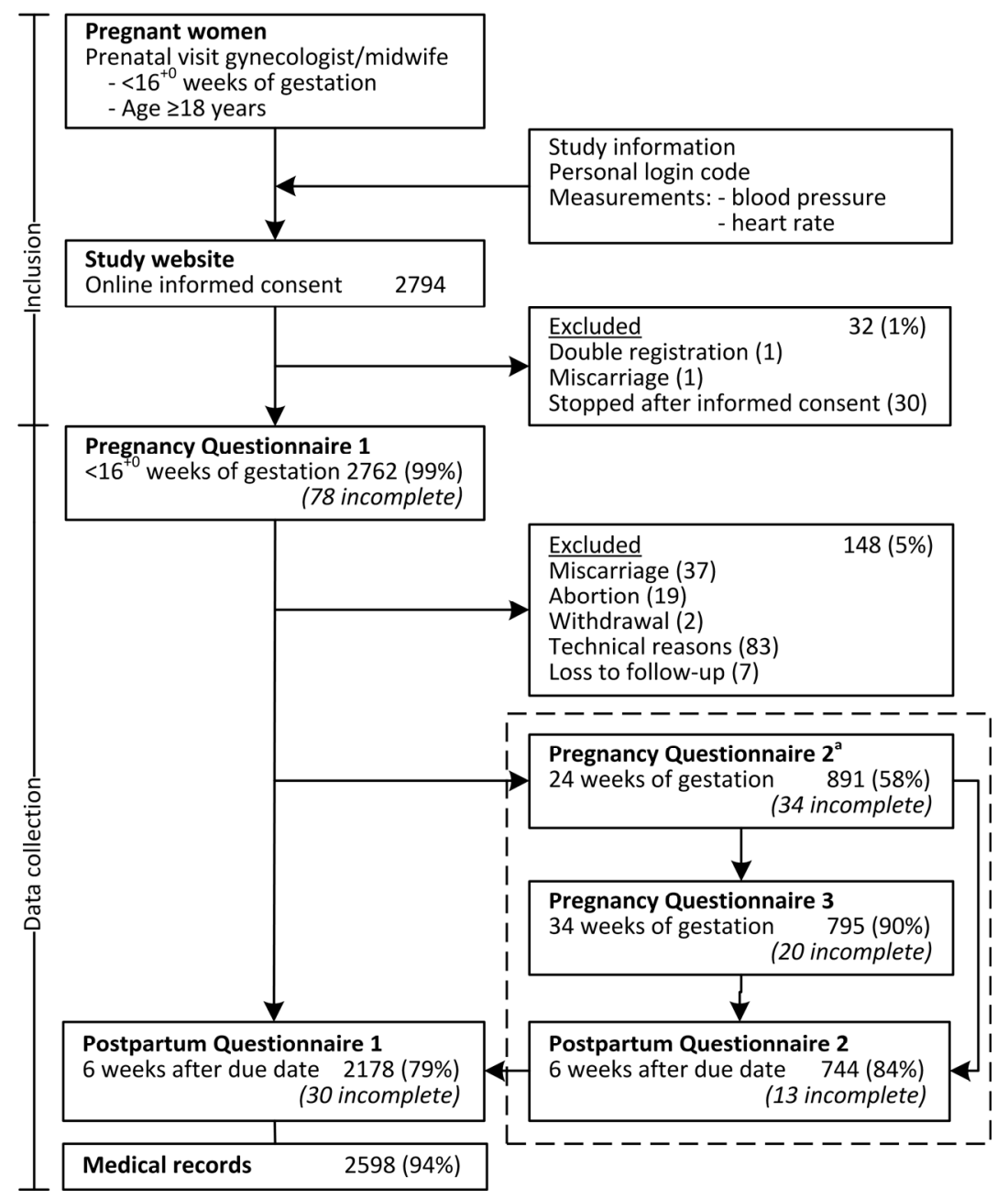

Figure 2.1 Inclusion and data collection of Expect Study I. The components in the dotted box represent the additional questionnaires. A total of 1548 participants gave permission to receive additional questionnaires (a) 
Table 2.1 Baseline characteristics and primary outcomes validation cohort (Expect Study I)

\begin{tabular}{|c|c|}
\hline Baseline characteristics $<16$ weeks of gestation & $\begin{array}{c}\text { Observed validation } \\
\text { cohort }(n=2614)\end{array}$ \\
\hline Age, years $^{\mathrm{a}}$ & $30.2(3.9)$ \\
\hline \multicolumn{2}{|l|}{ Ethnicity } \\
\hline Caucasian & $96.9 \%$ \\
\hline African-Caribbean & $0.1 \%$ \\
\hline Asian & $0.8 \%$ \\
\hline Hispanic & $0.4 \%$ \\
\hline Mixed & $1.8 \%$ \\
\hline Tertiary education & $54.3 \%$ \\
\hline Body mass index, $\mathrm{kg} / \mathrm{m}^{2 a}$ & $24.2(4.3)$ \\
\hline$<18.5$ & $3.3 \%$ \\
\hline $18.5-24.9$ & $63.7 \%$ \\
\hline $25-29.9$ & $22.4 \%$ \\
\hline $30-39.9$ & $10.1 \%$ \\
\hline$\geq 40$ & $0.3 \%$ \\
\hline \multicolumn{2}{|l|}{ Medical history } \\
\hline Chronic hypertension & $1.1 \%$ \\
\hline Diabetes Mellitus & $0.4 \%$ \\
\hline Renal disease & $0.2 \%$ \\
\hline \multicolumn{2}{|l|}{ Smoking during pregnancy } \\
\hline Ever & $12.2 \%$ \\
\hline Current & $6.0 \%$ \\
\hline \multicolumn{2}{|l|}{ Alcohol consumption during pregnancy } \\
\hline Ever & $18.3 \%$ \\
\hline Current & $0.3 \%$ \\
\hline Nulliparous & $50.7 \%$ \\
\hline \multicolumn{2}{|l|}{ Conception } \\
\hline Spontaneous & $93.3 \%$ \\
\hline Ovulation induction & $3.6 \%$ \\
\hline IVF/ICSI & $3.1 \%$ \\
\hline \multicolumn{2}{|l|}{ Obstetric history } \\
\hline Prior pre-eclampsia & $2.8 \%$ \\
\hline Prior gestational diabetes mellitus & $0.6 \%$ \\
\hline Prior preterm birth $<37$ weeks of gestation & $5.4 \%$ \\
\hline Prior birthweight $<10^{\text {th }}$ percentile & $4.1 \%$ \\
\hline Prior birthweight $>90^{\text {th }}$ percentile & $6.5 \%$ \\
\hline \multicolumn{2}{|l|}{ Primary outcomes } \\
\hline Pre-eclampsia & $2.9 \%$ \\
\hline Gestational diabetes mellitus & $2.8 \%$ \\
\hline Spontaneous PTB $<37$ weeks of gestation & $4.9 \%$ \\
\hline Birthweight $<10^{\text {th }}$ percentile & $7.9 \%$ \\
\hline Birthweight $>90^{\text {th }}$ percentile & $8.6 \%$ \\
\hline
\end{tabular}

${ }^{a}$ Continuous variables displayed as mean \pm standard deviation (SD). ICSI, intracytoplasmic sperm injection; IVF, in vitro fertilization

\section{Discussion}

Here, we describe the protocol of a study that aims to assess the predictive performance of multiple first trimester obstetric prediction models within an 
independent Dutch population. In this way, prediction models with similar outcomes can be compared and best performing models can be selected ${ }^{40}$.

In the evaluation of a prediction model, external validation is an essential step. Generally, the predictive performance of the model decreases in the validation dataset due to model over-fitting in the development cohort ${ }^{18,41}$. Existing independent external validation studies of non-invasive, first trimester obstetric prediction models for GDM showed stable discriminative performances, with the highest AUROCs for the models by Nanda et al. (AUROC 0.79) and Van Leeuwen et al. (AUROC 0.76-0.77) ${ }^{13-16}$. For the outcomes early and late PE, only a few models based upon maternal characteristics and blood pressure have been externally validated and AUROCs declined to around $0.70^{8-12}$. A limitation is that the numbers of events in these validation studies were (extremely) low, especially for early PE. No independent external validation studies of non-invasive prediction models for overall $\mathrm{PE}$, spontaneous PTB, SGA infants, and LGA infants have been published.

The main strength of our study is the prospective cohort design, which enables optimal measurement of predictors and outcomes ${ }^{42}$. Recruitment by multiple centers improves the likelihood of obtaining a representative sample of the obstetric population, which is especially important in the obstetric care system in the Netherlands in which most pregnant women start antenatal care with a midwife. Web-based questionnaires were used as a data collection tool, which is efficient in a population with high access to the Internet, as it improves data quality and less missing data due to the incorporation of validation checks. Moreover, it is also more user-friendly in comparison to paper-pencil forms as non-relevant follow-up questions could be hidden, speeding up completion ${ }^{43}$.

If one or more prediction models turns out to be externally valid, eventually after model updating, it is not self-evident that the model will be useful in clinical practice. The prediction models can only lead to improved outcomes for mother and child if they can guide healthcare professionals and individuals in their decision making regarding further management that are tailored to individual risk profiles, including additional testing, preventive interventions, lifestyle changes, monitoring, or treatment ${ }^{42}$.

Statistical performance measures are important aspects of a prediction model, but they do not indicate its clinical usefulness. Even if the statistical performance is less good, the model may predict better compared to usual practice, and vice versa ${ }^{44-46}$. We plan to evaluate the clinical utility of the validated models by decision analysis. Decision analysis provides insight whether the model is better than usual care by combining test characteristics with evidence on consequences of the outcome, effects and burden of the further management, and $\operatorname{costs}^{18}$. In case a model is worth considering for implementation in clinical practice, it is necessary to determine the most optimal threshold value for risk classification. Finally, we will assess the effects of applying prediction models with tailored care paths on decision-making and health outcomes in Dutch obstetric care, as compared with care-as-usual (Expect Study II). 


\section{Supplementary materials}

Supplementary File S2.1 Search strategies first-trimester obstetric prediction models

Supplementary File S2.2 Data collection study questionnaires and medical records 


\section{References}

1. Bonsel, G., Birnie, E., Denktas, S., Poeran, J., and Steegers, E., Lijnen in de perinatale sterfte, Signalementstudie Zwangerschap en Geboorte 2010. 2010, Rotterdam: Erasmus MC.

2. Van der Kooy, J., Poeran, J., de Graaf, J.P., Birnie, E., Denktass, S., Steegers, E.A., et al., Planned home compared with planned hospital births in the Netherlands: intrapartum and early neonatal death in low-risk pregnancies. Obstet Gynecol, 2011. 118(5): p. 1037-46.

3. Mol, B.W., Roberts, C.T., Thangaratinam, S., Magee, L.A., de Groot, C.J., and Hofmeyr, G.J., Preeclampsia. Lancet, 2016. 387(10022): p. 999-1011.

4. Koning, S.H., Hoogenberg, K., Lutgers, H.L., and Van den Berg, P.P., Gestational Diabetes Mellitus:current knowledge and unmet needs. J Diabetes, 2016. 8(6): p. 770-81.

5. Araujo Junior, E., Peixoto, A.B., Zamarian, A.C., Elito Junior, J., and Tonni, G., Macrosomia. Best Pract Res Clin Obstet Gynaecol, 2016. 38: p. 83-96.

6. Kleinrouweler, C.E., Cheong-See, F.M., Collins, G.S., Kwee, A., Thangaratinam, S., Khan, K.S., et al., Prognostic models in obstetrics: available, but far from applicable. Am J Obstet Gynecol, 2016. 214(1): p. 79-90.e36.

7. Al-Rubaie, Z., Askie, L.M., Ray, J.G., Hudson, H.M., and Lord, S.J., The performance of risk prediction models for pre-eclampsia using routinely collected maternal characteristics and comparison with models that include specialised tests and with clinical guideline decision rules: a systematic review. BJOG, 2016. 123(9): p. 1441-52.

8. Herraiz, I., Arbues, J., Camano, I., Gomez-Montes, E., Graneras, A., and Galindo, A., Application of a first-trimester prediction model for pre-eclampsia based on uterine arteries and maternal history in high-risk pregnancies. Prenat Diagn, 2009. 29(12): p. 1123-9.

9. Farina, A., Rapacchia, G., Freni Sterrantino, A., Pula, G., Morano, D., and Rizzo, N., Prospective evaluation of ultrasound and biochemical-based multivariable models for the prediction of late preeclampsia. Prenat Diagn, 2011. 31(12): p. 1147-52.

10. Park, F.J., Leung, C.H., Poon, L.C., Williams, P.F., Rothwell, S.J., and Hyett, J.A., Clinical evaluation of a first trimester algorithm predicting the risk of hypertensive disease of pregnancy. Aust $\mathrm{N} Z \mathrm{~J}$ Obstet Gynaecol, 2013. 53(6): p. 532-9.

11. Skrastad, R.B., Hov, G.G., Blaas, H.G., Romundstad, P.R., and Salvesen, K.A., Risk assessment for preeclampsia in nulliparous women at 11-13 weeks gestational age: prospective evaluation of two algorithms. BJOG, 2015. 122(13): p. 1781-8.

12. E Holanda Moura, S.B., Park, F., Murthi, P., Martins, W.P., Kane, S.C., Williams, P., et al., TNF-R1 as a first trimester marker for prediction of pre-eclampsia. J Matern Fetal Neonatal Med, 2016. 29(6): p. 897-903.

13. Van Leeuwen, M., Opmeer, B.C., Zweers, E.J., van Ballegooie, E., ter Brugge, H.G., de Valk, H.W., et al., External validation of a clinical scoring system for the risk of gestational diabetes mellitus. Diabetes Res Clin Pract, 2009. 85(1): p. 96-101.

14. Theriault, S., Forest, J.C., Masse, J., and Giguere, Y., Validation of early risk-prediction models for gestational diabetes based on clinical characteristics. Diabetes Res Clin Pract, 2014. 103(3): p. 419-25.

15. Syngelaki, A., Pastides, A., Kotecha, R., Wright, A., Akolekar, R., and Nicolaides, K.H., First-Trimester Screening for Gestational Diabetes Mellitus Based on Maternal Characteristics and History. Fetal Diagn Ther, 2015. 38(1): p. 14-21.

16. Lamain-de Ruiter, M., Kwee, A., Naaktgeboren, C.A., de Groot, I., Evers, I.M., Groenendaal, F., et al., External validation of prognostic models to predict risk of gestational diabetes mellitus in one Dutch cohort: prospective multicentre cohort study. BMJ, 2016. 354: p. i4338.

17. Justice, A.C., Covinsky, K.E., and Berlin, J.A., Assessing the generalizability of prognostic information. Ann Intern Med, 1999. 130(6): p. 515-24.

18. Steyerberg, E., Clinical prediction models: a practical approach to development, validation, and updating. 2008: Springer Science \& Business Media.

19. Perined, Perinatale Zorg in Nederland 2014. Utrecht: Perined, 2015.

20. Nederlandse Vereniging voor Obstetrie en Gynaecologie. Addendum bij multidisciplinaire richtlijn Hypertensieve aandoeningen in de zwangerschap uit 2011. 2014; Available from: http://www.nvogdocumenten.nl/uploaded/docs/Addendum Hypertensieve aandoeningen uitgangsvragen bloeddruk meten en significante proteinurie bij rl hypertensieve aandoeningen 2014 (2).pdf. 
21. Koninklijke Nederlandse Organisatie van Verloskundigen. Standaard Hypertensieve aandoeningen tijdens de zwangerschap, bevalling en kraamperiode. 2011; Available from: http://www.knov.nl/fms/file/knov.nl/knov_downloads/393/file/KNOV_Standaard_Hypertensie_versi e2012.pdf?download_category=richtlijnen-praktijkkaarten.

22. Expect Studie. Wetenschappelijk onderzoek bij zwangere vrouwen in de provincie Limburg. Available from: http://www.zwangerinlimburg.nl/.

23. Molag, M.L., de Vries, J.H., Duif, N., Ocke, M.C., Dagnelie, P.C., Goldbohm, R.A., et al., Selecting informative food items for compiling food-frequency questionnaires: comparison of procedures. $\mathrm{Br} \mathrm{J}$ Nutr, 2010. 104(3): p. 446-56.

24. Bergink, V., Kooistra, L., Lambregtse-van den Berg, M.P., Wijnen, H., Bunevicius, R., van Baar, A., et al., Validation of the Edinburgh Depression Scale during pregnancy. J Psychosom Res, 2011. 70(4): p. 3859.

25. Bunevicius, A., Kusminskas, L., Pop, V.J., Pedersen, C.A., and Bunevicius, R., Screening for antenatal depression with the Edinburgh Depression Scale. J Psychosom Obstet Gynaecol, 2009. 30(4): p. 23843.

26. EuroQol Group, EuroQol--a new facility for the measurement of health-related quality of life. Health Policy, 1990. 16(3): p. 199-208.

27. Krabbe, P.F., Stouthard, M.E., Essink-Bot, M.L., and Bonsel, G.J., The effect of adding a cognitive dimension to the EuroQol multiattribute health-status classification system. J Clin Epidemiol, 1999. 52(4): p. 293-301.

28. Ploeg, H.M., Defares, P.B., and Spielberger, C.D., Handleiding bij de Zelf-Beoordelings Vragenlijst ZBV: een nederlandstalige bewerking van de Spielberger State- Trait Anxiety Inventory STAI-DY. 1980: Swets \& Zeitlinger.

29. Marshall, G.N. and Hays, R.D. The patient satisfaction questionnaire short-form (PSQ-18). 1994; Available from: http://www.rand.org/pubs/papers/P7865.html.

30. Truijens, S.E., Pommer, A.M., van Runnard Heimel, P.J., Verhoeven, C.J., Oei, S.G., and Pop, V.J., Development of the Pregnancy and Childbirth Questionnaire (PCQ): evaluating quality of care as perceived by women who recently gave birth. Eur J Obstet Gynecol Reprod Biol, 2014. 174: p. 35-40.

31. Nederlandse Vereniging voor Obstetrie en Gynaecologie. Richtlijn Hypertensieve aandoeningen in de zwangerschap. 2005; Available from: http://nvog-documenten.nl/uploaded/docs/Hypertensieve aandoeningen in de zwangerschap.pdf.

32. Brown, M.A., Hague, W.M., Higgins, J., Lowe, S., McCowan, L., Oats, J., et al., The detection, investigation and management of hypertension in pregnancy: full consensus statement. Aust $\mathrm{N} \mathrm{Z} \mathrm{J}$ Obstet Gynaecol, 2000. 40(2): p. 139-55.

33. WHO, Definition, diagnosis and classification of diabetes mellitus and its complications. Report of a WHO consultation. Part 1: Diagnosis and classification of diabetes mellitus. Geneva, World Health Organization, 1999.

34. Nederlandse Vereniging voor Obstetrie en Gynaecologie. Richtlijn Diabetes Mellitus en Zwangerschap (2.0). 2010; Available from: http://nvog-documenten.nl/richtlijn/doc/index.php?type= save\&richtlijn_id=863.

35. Visser, G.H., Eilers, P.H., Elferink-Stinkens, P.M., Merkus, H.M., and Wit, J.M., New Dutch reference curves for birthweight by gestational age. Early Hum Dev, 2009. 85(12): p. 737-44.

36. Vergouwe, Y., Steyerberg, E.W., Eijkemans, M.J., and Habbema, J.D., Substantial effective sample sizes were required for external validation studies of predictive logistic regression models. J Clin Epidemiol, 2005. 58(5): p. 475-83.

37. Van der Heijden, G.J., Donders, A.R., Stijnen, T., and Moons, K.G., Imputation of missing values is superior to complete case analysis and the missing-indicator method in multivariable diagnostic research: a clinical example. J Clin Epidemiol, 2006. 59(10): p. 1102-9.

38. Steyerberg, E.W. and Vergouwe, Y., Towards better clinical prediction models: seven steps for development and an ABCD for validation. Eur Heart J, 2014. 35(29): p. 1925-31.

39. Debray, T.P., Vergouwe, Y., Koffijberg, H., Nieboer, D., Steyerberg, E.W., and Moons, K.G., A new framework to enhance the interpretation of external validation studies of clinical prediction models. J Clin Epidemiol, 2015. 68(3): p. 279-89.

40. Collins, G.S. and Moons, K.G., Comparing risk prediction models. BMJ, 2012. 344: p. e3186. 
41. Moons, K.G., Kengne, A.P., Grobbee, D.E., Royston, P., Vergouwe, Y., Altman, D.G., et al., Risk prediction models: II. External validation, model updating, and impact assessment. Heart, 2012. 98(9): p. 691-8.

42. Moons, K.G., Royston, P., Vergouwe, Y., Grobbee, D.E., and Altman, D.G., Prognosis and prognostic research: what, why, and how? BMJ, 2009. 338: p. b375.

43. Van Gelder, M.M., Bretveld, R.W., and Roeleveld, N., Web-based questionnaires: the future in epidemiology? Am J Epidemiol, 2010: p. kwq291.

44. Altman, D.G. and Royston, P., What do we mean by validating a prognostic model? Statistics in Medicine, 2000. 19(4): p. 453-473.

45. Moons, K.G., Altman, D.G., Vergouwe, Y., and Royston, P., Prognosis and prognostic research: application and impact of prognostic models in clinical practice. BMJ, 2009. 338: p. b606.

46. Altman, D.G., Vergouwe, Y., Royston, P., and Moons, K.G., Prognosis and prognostic research: validating a prognostic model. BMJ, 2009. 338: p. b605. 
Supplementary File S2.1 - Search strategies first-trimester obstetric prediction models

\section{Pre-eclampsia}

("predictive model"[tiab] OR "predictive models"[tiab] OR prediction[tiab] OR "risk calculator"[tiab] OR "risk calculators"[tiab] OR "risk model"[tiab] OR "risk models"[tiab] OR "risk score"[tiab] OR algorithm*[tiab] OR "risk assessment"[tiab] OR nomogram[tiab] OR "prognostic model"[tiab] OR "prognostic models"[tiab] OR "scoring system"[tiab] OR "scoring systems"[tiab] OR "screening model"[tiab] OR "screening models"[tiab] OR "decision rule"[tiab] OR "decision rules"[tiab]) AND (preeclamp*[tiab] OR pre-eclamp*[tiab] OR "Pre-Eclampsia"[Mesh])

\section{Gestational diabetes mellitus}

("predictive model"[tiab] OR "predictive models"[tiab] OR prediction[tiab] OR "risk calculator"[tiab] OR "risk calculators"[tiab] OR "risk model"[tiab] OR "risk models"[tiab] OR "risk score"[tiab] OR algorithm*[tiab] OR "risk assessment"[tiab] OR nomogram[tiab] OR "prognostic model"[tiab] OR "prognostic models"[tiab] OR "scoring system"[tiab] OR "scoring systems"[tiab] OR "screening model"[tiab] OR "screening models"[tiab] OR "decision rule"[tiab] OR "decision rules"[tiab]) AND ("gestational diabetes"[tiab] OR "pregnancy induced diabetes"[tiab] OR "pregnancyinduced diabetes"[tiab] OR "Diabetes, Gestational"[Mesh])

\section{Spontaneous preterm birth}

("predictive model"[tiab] OR "predictive models"[tiab] OR prediction[tiab] OR "risk calculator"[tiab] OR "risk calculators"[tiab] OR "risk model"[tiab] OR "risk models"[tiab] OR "risk score"[tiab] OR algorithm*[tiab] OR "risk assessment"[tiab] OR nomogram[tiab] OR "prognostic model"[tiab] OR "prognostic models"[tiab] OR "scoring system"[tiab] OR "scoring systems"[tiab] OR "screening model"[tiab] OR "screening models"[tiab] OR "decision rule"[tiab] OR "decision rules"[tiab]) AND ("preterm labour"[tiab] OR "premature labour"[tiab] OR "premature labor"[tiab] OR "premature delivery"[tiab] OR "premature deliveries"[tiab] OR "premature parturition"[tiab] OR "premature birth"[tiab] OR "preterm labor"[tiab] OR "preterm birth"[tiab] OR "preterm delivery"[tiab] OR "preterm deliveries"[tiab] OR "preterm parturition"[tiab] OR "Premature Birth"[Mesh]) 


\section{Small-for-gestational-age}

("predictive model"[tiab] OR "predictive models"[tiab] OR prediction[tiab] OR "risk calculator"[tiab] OR "risk calculators"[tiab] OR "risk model"[tiab] OR "risk models"[tiab] OR "risk score"[tiab] OR algorithm*[tiab] OR "risk assessment"[tiab] OR nomogram[tiab] OR "prognostic model"[tiab] OR "prognostic models"[tiab] OR "scoring system"[tiab] OR "scoring systems"[tiab] OR "screening model"[tiab] OR "screening models"[tiab] OR "decision rule"[tiab] OR "decision rules"[tiab]) AND ("low birthweight"[tiab] OR "low birth weight"[tiab] OR "small for gestational"[tiab] OR "small for gestation"[tiab] OR "small-for-gestational"[tiab] OR "small-forgestation"[tiab] OR "intrauterine growth restriction"[tiab] OR "intra-uterine growth restriction"[tiab] OR "intrauterine growth retardation"[tiab] OR "intra-uterine growth retardation"[tiab] OR "Infant, Small for Gestational Age"[Mesh])

\section{Large-for-gestational-age}

("predictive model"[tiab] OR "predictive models"[tiab] OR prediction[tiab] OR "risk calculator"[tiab] OR "risk calculators"[tiab] OR "risk model"[tiab] OR "risk models"[tiab] OR "risk score"[tiab] OR algorithm*[tiab] OR "risk assessment"[tiab] OR nomogram[tiab] OR "prognostic model"[tiab] OR "prognostic models"[tiab] OR "scoring system"[tiab] OR "scoring systems"[tiab] OR "screening model"[tiab] OR "screening models"[tiab] OR "decision rule"[tiab] OR "decision rules"[tiab]) AND (macrosomi*[tiab] OR "large for gestational"[tiab] OR "large-for-gestational"[tiab] OR "high birthweight"[tiab] OR "high birth weight"[tiab] OR "large for gestation"[tiab] OR "large-for-gestation"[tiab] OR "Fetal Macrosomia"[Mesh]) 


\section{Supplementary File S2.2 - Data collection study questionnaires and medical records}

Supplementary Table S2.1 Aspects covered by Pregnancy Questionnaire 1

\begin{tabular}{|c|c|c|}
\hline Domain & Item & Sub-items \\
\hline \multirow[t]{8}{*}{ Sociodemographic characteristics } & Ethnicity & Country of birth \\
\hline & & Country of birth biological parents \\
\hline & & Ethnic origin \\
\hline & Highest level of education & \\
\hline & Work & \\
\hline & Volunteer work and informal & \\
\hline & care & \\
\hline & Living situation & \\
\hline \multirow[t]{2}{*}{ Anthropometric data } & Height & \\
\hline & Pre-pregnancy weight & \\
\hline \multirow[t]{12}{*}{ Medical conditions } & Chronic hypertension & \\
\hline & Cardiovascular disease & Type \\
\hline & Diabetes mellitus & Type \\
\hline & Thromboembolism & \\
\hline & Thyroid disease & Hypothyroidism \\
\hline & & Hyperthyroidism \\
\hline & Kidney disease & Type \\
\hline & Autoimmune diseases & Systemic lupus erythematosus \\
\hline & & Antiphospholipid syndrome \\
\hline & Lung diseases & Type \\
\hline & Gynaecologic history & Uterus anomaly \\
\hline & & Cervical surgery \\
\hline \multirow[t]{23}{*}{ Obstetric history } & Parity & \\
\hline & Miscarriage & Date \\
\hline & & Gestational age \\
\hline & Termination & Date \\
\hline & & Gestational age \\
\hline & & Indication \\
\hline & Ectopic pregnancy & Date \\
\hline & & Gestational age \\
\hline & Multiple birth & \\
\hline & Pregnancy outcomes & Pre-eclampsia \\
\hline & & HELLP syndrome \\
\hline & & Gestational diabetes mellitus \\
\hline & & Preterm birth \\
\hline & & Placental abruption \\
\hline & & Other \\
\hline & & Management \\
\hline & Labour and delivery & Mode of delivery \\
\hline & & Hospital/home delivery \\
\hline & Neonatal outcomes & Gender \\
\hline & & Birth weight \\
\hline & & Fetal mortality (antenatal, \\
\hline & & intrapartum) \\
\hline & & Neonatal mortality \\
\hline
\end{tabular}


Supplementary Table S2.1 (continued) Aspects covered by Pregnancy Questionnaire 1

\begin{tabular}{|c|c|c|}
\hline Domain & Item & Sub-items \\
\hline \multirow[t]{7}{*}{ Lifestyle } & Smoking & Status \\
\hline & & Quantity \\
\hline & Alcohol & Status \\
\hline & & Quantity \\
\hline & Drugs & Status \\
\hline & & Type(s) \\
\hline & & Frequency \\
\hline \multirow[t]{3}{*}{ Medication } & Name & Dose \\
\hline & & Frequency \\
\hline & & Duration \\
\hline \multirow[t]{6}{*}{ Vitamin and mineral supplements } & Folic acid & Brand name \\
\hline & Prenatal vitamins & Duration \\
\hline & General multivitamins & Dose \\
\hline & Vitamin D & Frequency \\
\hline & Calcium & \\
\hline & Iron & \\
\hline \multirow[t]{15}{*}{ Dietary intake } & Fruit intake & \\
\hline & Selected items from Food & Frequency + average daily amount \\
\hline & Frequency Questionnaire tool: & \\
\hline & Milk and buttermilk & \\
\hline & Yoghurt and fromage frais & \\
\hline & Yoghurt drinks and other dairy & \\
\hline & beverages & \\
\hline & Chocolate milk & \\
\hline & Custard and pudding & \\
\hline & Dutch cheese & \\
\hline & Non-Dutch cheese and cream & \\
\hline & $\begin{array}{l}\text { cheese } \\
\text { Cheese spread }\end{array}$ & \\
\hline & $\begin{array}{l}\text { Cneese spread } \\
\text { Bread spread }\end{array}$ & \\
\hline & Cooking fat & \\
\hline & Fish & \\
\hline \multirow[t]{6}{*}{ Sun exposure } & Skin type & \\
\hline & Sun exposure & Week days \\
\hline & & Weekend \\
\hline & & Skin exposure \\
\hline & & Sunscreen use \\
\hline & Solarium & \\
\hline \multirow{3}{*}{$\begin{array}{l}\text { Family history medical conditions } \\
\text { (grandparents, parents and } \\
\text { siblings) }\end{array}$} & Hypertension & \\
\hline & Heart disease & \\
\hline & Diabetes mellitus & Type \\
\hline \multirow[t]{8}{*}{ Family history obstetric outcomes } & Adverse obstetric outcomes & Pre-eclampsia \\
\hline & (mother and sister(s)) & HELLP syndrome \\
\hline & & Gestational diabetes mellitus \\
\hline & & Preterm birth \\
\hline & & Low birth weight infant \\
\hline & & High birth weight infant \\
\hline & Women's birth weight & \\
\hline & Women's gestation at delivery & \\
\hline
\end{tabular}


Supplementary Table S2.1 (continued) Aspects covered by Pregnancy Questionnaire 1

\begin{tabular}{lll}
\hline Domain & Item & Sub-items \\
\hline Mental health & Mental disorder & Type \\
& Edinburgh Depression Scale & Treatment \\
Health status & EuroQol-5D-3L & Mobility \\
& & Self-care \\
& & Usual activities \\
& & Pain/discomfort \\
Current pregnancy & Cognitive dimension & Anxiety/depression \\
& Evaluation overall health status & Visual analogue scale \\
& Due date & \\
& Conception & Method of conception \\
& & Time to conception \\
& Caregiver (primary & \\
& care/secondary care) & \\
Blood pressure measurement & Multiple pregnancy & Duration \\
Heart rate measurement & Vaginal bleeding & Quantity \\
& pressure & Measurement \\
& Heart rate & Date of measurement \\
& & Measurement \\
& & Date of measurement \\
\hline
\end{tabular}


Supplementary Table S2.2 Aspects covered by Postpartum Questionnaire 1

\begin{tabular}{|c|c|c|}
\hline Domain & Item & Sub-items \\
\hline \multirow[t]{5}{*}{ Pregnancy outcome } & Miscarriage & Gestational age \\
\hline & Termination & Gestational age \\
\hline & & Indication \\
\hline & Ectopic pregnancy & Gestational age \\
\hline & Delivery & \\
\hline \multirow[t]{13}{*}{ Pregnancy complications } & Pregnancy induced hypertension & Gestational age \\
\hline & & Treatment \\
\hline & Pre-eclampsia & Gestational age \\
\hline & & Treatment \\
\hline & & HELLP syndrome \\
\hline & Gestational diabetes mellitus & Gestational age \\
\hline & & Treatment \\
\hline & Threatened preterm labour & $\begin{array}{l}\text { Preterm premature rupture of } \\
\text { membranes }\end{array}$ \\
\hline & & Admission \\
\hline & & Treatment \\
\hline & Growth deviations & Small-for-gestational-age infant \\
\hline & & Low-for-gestational-age infant \\
\hline & & Gestational age \\
\hline \multirow[t]{6}{*}{ Labour and delivery } & Date & \\
\hline & Gestational age & \\
\hline & Hospital/home birth & \\
\hline & Primary/secondary/tertiary care & Referral (indication) \\
\hline & Mode of delivery & \\
\hline & Assisted birth & \\
\hline \multirow[t]{13}{*}{ Neonatal outcomes } & Multiple birth & \\
\hline & Gender & \\
\hline & Birth weight & \\
\hline & Mortality & Antenatal \\
\hline & & Intrapartum \\
\hline & & Postpartum within 24 hours \\
\hline & & Postpartum $\geq 24$ hours \\
\hline & Admission & Indication \\
\hline & & Duration \\
\hline & & Neonatal intensive care unit \\
\hline & Congenital anomalies & \\
\hline & Child's growth & Weight \\
\hline & & Date measurement \\
\hline \multirow[t]{8}{*}{ Biological father } & Ethnicity & Country of birth \\
\hline & & Country of birth biological \\
\hline & & parents \\
\hline & & Ethnic origin \\
\hline & Anthropometric data & Length \\
\hline & & Weight \\
\hline & Father's birth weight & \\
\hline & Father's gestation at delivery & \\
\hline
\end{tabular}


Supplementary Table S2.3 Aspects covered by Pregnancy Questionnaire 2, 3 and Postpartum Questionnaire 2

\begin{tabular}{|c|c|c|}
\hline Domain & Item & Sub-items \\
\hline \multirow{7}{*}{$\begin{array}{l}\text { Pregnancy status } \\
\text { (pregnancy questionnaire } 2 \text { and } \\
\text { 3) }\end{array}$} & Pregnant & Gestational age \\
\hline & Miscarriage & Gestational age \\
\hline & Termination & Gestational age \\
\hline & & Indication \\
\hline & Ectopic pregnancy & Gestational age \\
\hline & Gave birth & Date \\
\hline & & $\begin{array}{l}\text { Referral to postpartum questionnaire } 1 \\
\text { and } 2\end{array}$ \\
\hline \multirow[t]{7}{*}{ Maternal health status } & EuroQol-5D-3L & Mobility \\
\hline & & Self-care \\
\hline & & Usual activities \\
\hline & & Pain/discomfort \\
\hline & & Anxiety/depression \\
\hline & Cognitive dimension & \\
\hline & Evaluation overall health status & Visual analogue scale \\
\hline \multirow[t]{17}{*}{ Patient satisfaction } & Patient Satisfaction & 18-items capturing the most important \\
\hline & $\begin{array}{l}\text { Questionnaire Short Form } \\
\text { (PSQ-18) }\end{array}$ & $\begin{array}{l}\text { characteristics of services and providers } \\
\text { that might influence patient } \\
\text { satisfaction with care (pregnancy } \\
\text { questionnaire } 2 \text { and } 3 \text { ). }\end{array}$ \\
\hline & $\begin{array}{l}\text { Pregnancy and Childbirth } \\
\text { Questionnaire (PCQ) }\end{array}$ & $\begin{array}{l}\text { Quality of care during pregnancy and } \\
\text { delivery as perceived by woman who } \\
\text { recently gave birth (postpartum } \\
\text { questionnaire 2). }\end{array}$ \\
\hline & Primary/secondary care & Referral \\
\hline & & Information \\
\hline & & Collaboration \\
\hline & $\begin{array}{l}\text { Appointments (pregnancy } \\
\text { questionnaire } 2 \text { and } 3 \text { ) }\end{array}$ & \\
\hline & Information (pregnancy & Health \\
\hline & questionnaire 2 and 3 ) & Medical examination(s) \\
\hline & & Treatment(s) \\
\hline & $\begin{array}{l}\text { Intended place of birth } \\
\text { (postpartum questionnaire 2) }\end{array}$ & \\
\hline & Overall grade care during & \\
\hline & pregnancy (pregnancy & \\
\hline & questionnaire 2 and 3 ) & \\
\hline & Overall grade care during & \\
\hline & labour and delivery & \\
\hline & (postpartum questionnaire 2) & \\
\hline \multirow[t]{3}{*}{ Anxiety } & State anxiety of the State-Trait & 20-items \\
\hline & $\begin{array}{l}\text { Anxiety Inventory (pregnancy } \\
\text { questionnaire 2) }\end{array}$ & \\
\hline & Concerns & \\
\hline
\end{tabular}


Supplementary Table S2.3 (continued) Aspects covered by Pregnancy Questionnaire 2, 3 and Postpartum Questionnaire 2

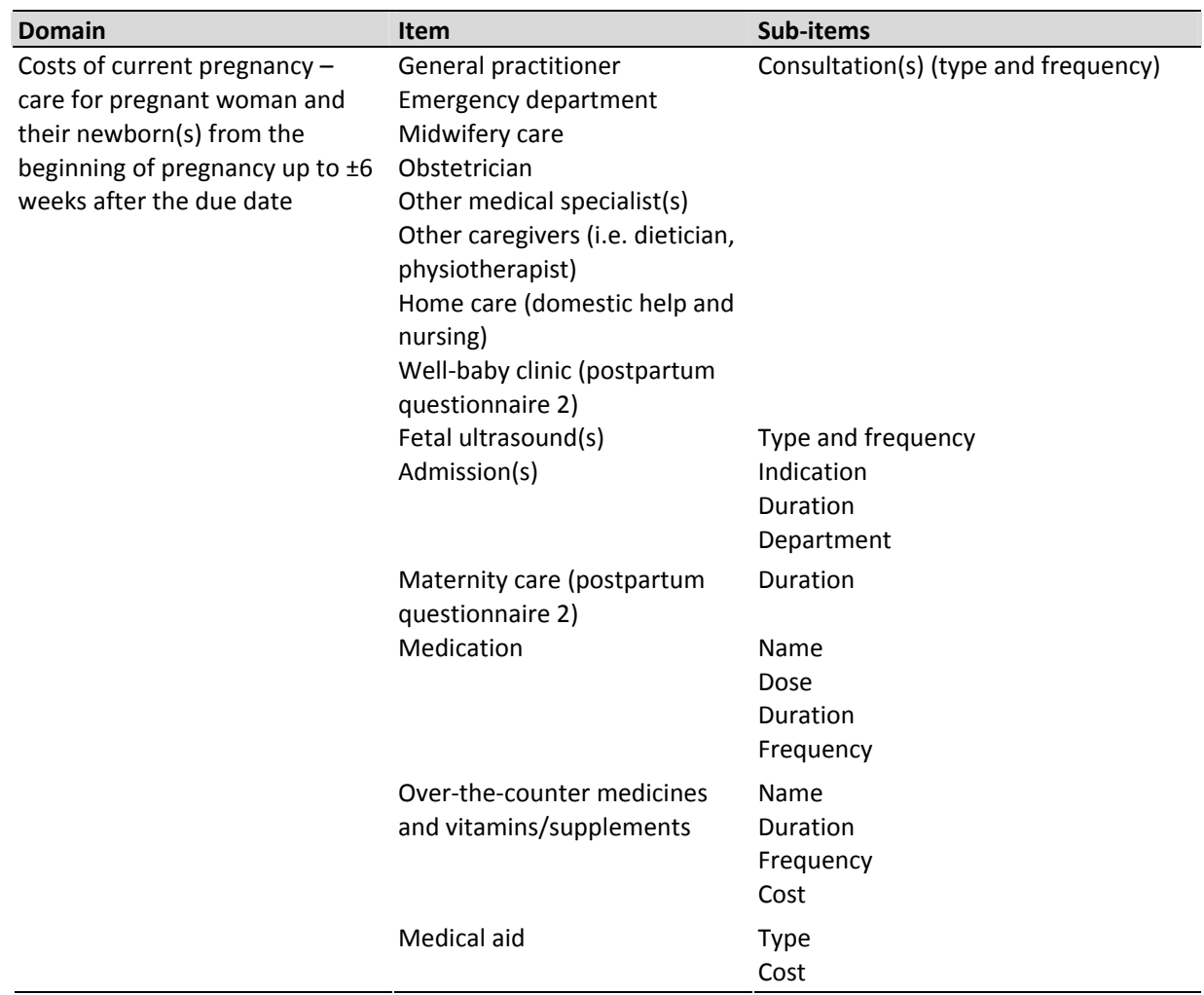


Supplementary Table S2.4 Data extracted from medical records and letters of discharge

\begin{tabular}{|c|c|c|}
\hline Domain & Item & Sub-items \\
\hline \multirow[t]{2}{*}{ Obstetric history } & Gravidity & \\
\hline & Parity & \\
\hline \multirow[t]{3}{*}{ Caregiver } & Primary/secondary/tertiary care & \\
\hline & Referral & Date \\
\hline & & Indication \\
\hline \multirow[t]{13}{*}{ Current pregnancy } & Due date & \\
\hline & Pregnancy outcome & Miscarriage \\
\hline & & Termination \\
\hline & & Ectopic pregnancy \\
\hline & & Gave birth \\
\hline & Method of conception & \\
\hline & $\begin{array}{l}\text { Medical indication secondary } \\
\text { care/tertiary care }\end{array}$ & \\
\hline & Admission & Date \\
\hline & & Indication \\
\hline & Highest diastolic blood pressure & \\
\hline & Proteinuria & \\
\hline & Complication (letter of discharge) & Hypertensive disorder \\
\hline & & Gestational diabetes mellitus \\
\hline \multirow[t]{9}{*}{ Labour and delivery } & Onset of labour & \\
\hline & Mode of delivery & \\
\hline & Assisted birth & \\
\hline & Hospital/home delivery & \\
\hline & Pain medication & \\
\hline & Birth placenta & \\
\hline & Amount of blood loss & \\
\hline & Admission & Indication \\
\hline & & Duration \\
\hline \multirow[t]{10}{*}{ Neonatal outcomes } & Gestational age & \\
\hline & Gender & \\
\hline & Birth weight & \\
\hline & Apgar score 1,5 , and 10 minutes & \\
\hline & pH umbilical cord & Arterial \\
\hline & & Venous \\
\hline & Congenital anomalies & \\
\hline & Paediatric consultation & \\
\hline & Admission & Department \\
\hline & Mortality & Date \\
\hline
\end{tabular}




\section{CHAPTER 3}

External validation and clinical usefulness of first

trimester prediction models for the risk of

pre-eclampsia: a prospective cohort study

Linda J.E. Meertens, Hubertina C.J. Scheepers, Sander M.J. van Kuijk, Robert Aardenburg, Ivo M.A. van Dooren, Josje Langenveld, Annemieke M. van Wijck, Iris M. Zwaan,

Marc E.A. Spaanderman, and Luc J.M. Smits

Fetal Diagnosis and Therapy, 2018 


\section{Abstract}

\section{Introduction}

This study assessed the external validity of all published first trimester prediction models for the risk of pre-eclampsia (PE) based on routinely collected maternal predictors. Moreover, the potential utility of the best-performing models in clinical practice was evaluated.

\section{Methods}

Ten prediction models were systematically selected from the literature. We performed a multicenter prospective cohort study in the Netherlands between July 1 , 2013 and December 31, 2015. Eligible pregnant women completed a web-based questionnaire before 16 weeks' gestation. The outcome PE was established using postpartum questionnaires and medical records. Predictive performance of each model was assessed by means of discrimination (c-statistic) and a calibration plot. Clinical usefulness was evaluated by means of decision curve analysis and by calculating the potential impact at different risk thresholds.

\section{Results}

The validation cohort contained 2614 women of whom 76 developed PE (2.9\%). Five models showed moderate discriminative performance with c-statistics ranging from 0.73 to 0.77 . Adequate calibration was obtained after refitting. The best models were clinically useful over a small range of predicted probabilities.

\section{Discussion}

Five of the ten included first trimester prediction models for PE showed moderate predictive performance. The best models may provide more benefit compared to risk selection as used in current guidelines. 


\section{Introduction}

Pre-eclampsia (PE) is still a leading cause of maternal and neonatal morbidity and mortality worldwide. Although management of PE has improved, the only available curative treatment is delivery of the placenta. Further reduction of the burden of disease may be achieved through prevention ${ }^{1,2}$.

Calcium supplementation and low dose aspirin are well-researched interventions that reduce the risk of developing $\mathrm{PE}$. A daily intake of at least 1 gram of calcium lowers the risk of PE in women with a low dietary calcium intake and women at increased risk of hypertensive disorders ${ }^{3}$. Low dose aspirin safely reduces the occurrence of PE by $10-43 \%$ among high-risk women, and also reduces related adverse outcomes (i.e. preterm birth, small-for-gestational-age $)^{4-10}$. A recent meta-analysis, including the large Aspirin for Evidence-Based Preeclampsia Prevention (ASPRE) trial, demonstrated that aspirin mainly reduces the risk of preterm preeclampsia with a reported risk reduction of $38-67 \%{ }^{11,12}$.

Efficiency of preventive strategies may improve if they are specifically aimed at women that are most likely to benefit from them. Prediction models may help identifying women at increased risk of PE early on in pregnancy, a crucial period at which preventive interventions are most effective.

A considerable number of first trimester prediction models for PE have been published, containing predictors ranging from maternal risk factors, blood pressure measurement, to more specialized tests such as uterine artery Doppler ultrasound and biomarkers (i.e. pregnancy-associated plasma protein-A, placental growth factor). Although specialized tests have been reported to improve predictive performance, a drawback is that these tests are not routinely performed or readily available in general antenatal settings, and generate substantial additional costs ${ }^{13,14}$.

Only a minority of the models have been validated in independent populations ${ }^{14}$. Prediction models usually perform less well in populations other than the ones in which they were developed ${ }^{15}$. External validation of models is necessary in order to gain insight into their robustness across populations and domains ${ }^{15,16}$.

In this paper we report the results of an independent validation study of all published first trimester prediction models based on routinely collected maternal characteristics for the risk of PE, in a cohort of 2614 Dutch pregnant women. Next to this, we evaluated clinical usefulness of the best performing models by means of decision curve analysis and by estimating clinical impact at different risk thresholds and different management scenarios, and compared it with the performance of current international recommendations.

\section{Methods}

\section{Selection prediction models}

We searched PubMed to identify first trimester prediction models for development of PE. The search was first performed in April 2013, before finalizing study 
questionnaires, and then updated until April 2017. The search strategy retrieved 1361 citations (see Supplementary File S3.1). LM screened all citations and, together with LS, assessed eligibility of full text articles. In case of disagreement, a third reviewer (HS) was available.

Fifty articles described prediction models fulfilling the eligibility criteria, which were: 1) article presented the development of a prediction model or an update of a previously developed model, 2) endpoint of the model was the risk of developing PE, 3) model contained multiple predictors, 4) model was based on weighted risk predictors, 5) predictors were routinely collected in Dutch obstetric practice (maternal characteristics, anthropometric measures, or blood pressure measurements), and 6) predictors were available before $16^{+0}$ weeks of gestation. Citation lists of relevant articles were checked and yielded nine additional eligible articles. LM contacted authors if the model intercept, estimates or definition of predictors were not provided in the article. If regression coefficients were nevertheless not obtained, the model was excluded from the validation analyses. We excluded 36 articles for the following reasons: algorithm not available $(n=19)$, model already published in another article $(n=17)$. The 23 included articles described 33 prediction models, 10 of which were aimed at predicting overall PE, 12 models at early PE, 6 models at late PE, 2 models at severe $\mathrm{PE}$, and 4 models at predicting gestational age at delivery with $\mathrm{PE}$. We only validated the models predicting any $P E$ as the number of women with early onset $P E$ (i.e. delivery $<34$ weeks of gestational age) was too low in our validation cohort $(n=5)$. None of the models were used in daily care during the study period.

The characteristics of included models are summarized in Table 3.1 (see Supplementary Table S3.1 for a comprehensive overview) ${ }^{17-26}$. The models were published between 2005 and 2015 in United Kingdom, Iran, Canada, and Australia by 6 different research groups. Three models were developed for nulliparous women $^{18,21,23}$. References of excluded studies are described in Supplementary File S3.1. 
Table 3.1 Characteristics included prediction models for external validation

\begin{tabular}{|c|c|c|c|c|c|c|}
\hline $\begin{array}{l}\text { Study, first } \\
\text { author (year) }\end{array}$ & Country & $\begin{array}{l}\text { Study } \\
\text { design }\end{array}$ & $\begin{array}{l}\text { No. cases } \\
\text { PE/total } \\
\text { (\%) }\end{array}$ & Predictors & $\begin{array}{l}\text { Internally } \\
\text { validated }\end{array}$ & $\begin{array}{l}\text { Other external } \\
\text { validation } \\
\text { studies, AUROC } \\
\text { (CI) }\end{array}$ \\
\hline $\begin{array}{l}\text { Macdonald- } \\
\text { Wallis et al. } \\
\text { (2015) }\end{array}$ & UK & $\begin{array}{l}\text { Prospective } \\
\text { cohort }\end{array}$ & $\begin{array}{l}317 / 12996 \\
(2.4 \%)\end{array}$ & $\begin{array}{l}\text { Age, BMI, CH, DM, } \\
\text { ethnicity, height, MAP, } \\
\text { parity, prior GDM, prior } \\
\text { PIH, smoking }\end{array}$ & No & $\begin{array}{l}\text { UK: } 0.79 \\
(0.73-0.85)^{17}\end{array}$ \\
\hline $\begin{array}{l}\text { Kenny et al. } \\
(2014)\end{array}$ & $\begin{array}{l}\text { SCOPE } \\
\text { study }\end{array}$ & $\begin{array}{l}\text { Prospective } \\
\text { cohort }\end{array}$ & $\begin{array}{l}196 / 3747 \\
(4.9 \%)\end{array}$ & $\begin{array}{l}\text { BMI, fam history } P E \text {, fruit } \\
\text { intake, MAP }\end{array}$ & Yes & - \\
\hline $\begin{array}{l}\text { Direkvand- } \\
\text { Moghadam et } \\
\text { al. (2013) }\end{array}$ & Iran & Cohort & $\begin{array}{l}58 / 610 \\
(9.5 \%)\end{array}$ & $\begin{array}{l}\mathrm{CH} \text {, prior infertility, prior } \\
\mathrm{PE}\end{array}$ & No & - \\
\hline $\begin{array}{l}\text { Syngelaki et al. } \\
\text { (2011) }\end{array}$ & UK & $\begin{array}{l}\text { Prospective } \\
\text { cohort }\end{array}$ & $\begin{array}{l}N R / 41577 \\
\text { (NR) }\end{array}$ & $\begin{array}{l}\text { Age, } \mathrm{BMI}, \mathrm{CH}, \mathrm{DM} \text {, } \\
\text { ethnicity, fam history } \mathrm{PE} \text {, } \\
\text { method conception, } \\
\text { parity, prior PE, smoking }\end{array}$ & No & - \\
\hline $\begin{array}{l}\text { North et al. } \\
\text { (2011) }\end{array}$ & $\begin{array}{l}\text { SCOPE } \\
\text { study }\end{array}$ & $\begin{array}{l}\text { Prospective } \\
\text { cohort }\end{array}$ & $\begin{array}{l}186 / 3529 \\
(5.3 \%)\end{array}$ & $\begin{array}{l}\text { Age, alcohol, BMI, fam } \\
\text { history CHD, fam history } \\
\text { PE, fruit intake, MAP, } \\
\text { single miscarriage, } \\
\text { smoking, time to } \\
\text { conceive, vaginal } \\
\text { bleeding, woman's birth } \\
\text { weight }\end{array}$ & Yes & - \\
\hline $\begin{array}{l}\text { Seed et al. } \\
(2011)\end{array}$ & UK & RCT & $\begin{array}{l}190 / 1121 \\
(17 \%)\end{array}$ & $\begin{array}{l}\mathrm{CH}, \mathrm{DBP} \text {, ethnicity, folic } \\
\text { acid supplementation, } \\
\text { prior PE, SBP }\end{array}$ & Yes & - \\
\hline $\begin{array}{l}\text { Audibert et al. } \\
\text { (2010) }\end{array}$ & Canada & $\begin{array}{l}\text { Prospective } \\
\text { cohort }\end{array}$ & $\begin{array}{l}40 / 893 \\
(6.2 \%)\end{array}$ & $\begin{array}{l}\text { BMI, pre-existing medical } \\
\text { condition }\end{array}$ & No & - \\
\hline $\begin{array}{l}\text { Poon et al. } \\
\text { (2008) BJOG }\end{array}$ & UK & $\begin{array}{l}\text { Prospective } \\
\text { cohort }\end{array}$ & $\begin{array}{l}51 / 2486 \\
(2.0 \%)\end{array}$ & $\begin{array}{l}\text { Age, } \mathrm{BMI} \text {, ethnicity, fam } \\
\text { history } \mathrm{PE} \text {, parity, prior } \mathrm{PE}\end{array}$ & No & - \\
\hline $\begin{array}{l}\text { Poon et al. } \\
(2008) \\
\text { Hypertension }\end{array}$ & UK & $\begin{array}{l}\text { Prospective } \\
\text { cohort }\end{array}$ & $\begin{array}{l}104 / 5193 \\
(2.3 \%)\end{array}$ & $\begin{array}{l}\mathrm{BMI} \text {, ethnicity, fam history } \\
\mathrm{PE} \text {, parity, prior } \mathrm{PE}, \mathrm{MAP}\end{array}$ & No & $\begin{array}{l}\text { UK: } 0.71(0.64- \\
0.78)^{40}\end{array}$ \\
\hline $\begin{array}{l}\text { Plasencia et al. } \\
\text { (2007) }\end{array}$ & UK & $\begin{array}{l}\text { Prospective } \\
\text { cohort }\end{array}$ & $\begin{array}{l}107 / 6015 \\
(1.8 \%)\end{array}$ & $\begin{array}{l}\mathrm{BMI} \text {, ethnicity, fam history } \\
\mathrm{PE} \text {, parity, prior } \mathrm{PE}\end{array}$ & No & $\begin{array}{l}\text { Italy: } 0.72(0.62- \\
0.82)^{41} \\
\text { Spain: early PE } \\
0.74(0.60-0.89) \text {, } \\
\text { late PE } 0.65 \\
(0.49-0.80)^{42}\end{array}$ \\
\hline
\end{tabular}

AUROC, area under the receiver operating characteristic curve; $\mathrm{BMI}$, body mass index; $\mathrm{CH}$, chronic hypertension; CHD, coronary heart disease; $\mathrm{Cl}$, confidence interval; $\mathrm{DBP}$, diastolic blood pressure; DM, diabetes mellitus; GDM, gestational diabetes mellitus; MAP, mean arterial pressure; NR, not reported; PE, pre-eclampsia; PIH, pregnancy-induced hypertension; RCT, randomized controlled trial; SBP, systolic blood pressure; SCOPE study, multicenter study Australia, New Zealand, and UK; UK, United Kingdom

\section{Validation cohort}

We performed a multicenter prospective cohort study (Expect Study I) in the southeastern part of the Netherlands (province of Limburg) ${ }^{27}$. Pregnant women less than 16 
weeks of pregnancy and aged 18 years or older were recruited between July 1, 2013 and January 1, 2015 in 36 midwifery practices (primary care) and 6 hospitals (secondary and tertiary care). Follow-up took place until December 31, 2015. We excluded pregnancies that terminated before 24 weeks of gestation or for which the outcome was not available. Eligible pregnant women were asked to complete a webbased questionnaire before 16 weeks of gestation (pregnancy questionnaire) and at 6 weeks after the due date (postpartum questionnaire). The web-based questionnaires could be accessed through the study website by use of a personal login code provided with the study information. Paper-and-pencil questionnaires were made available upon request. Automatic reminders were sent out in case of incompleteness or nonresponse. Medical records and letters of discharge about the pregnancy and birth were requested from caregivers.

The Medical Ethical Committee of the Maastricht University Medical Center evaluated the study protocol and declared that no ethical approval was necessary (MEC 13-4-053). All participating women gave informed consent through the Internet.

\section{Assessment of predictors}

Predictors were assessed by means of the pregnancy questionnaire. Systolic and diastolic blood pressure $(\mathrm{mmHg})$ and heart rate (beats per minute) were measured before 16 weeks of gestation by the gynaecologist or midwife. The results of these measurements were subsequently self-reported in the pregnancy questionnaire. The predictors were defined as described in the original articles. For the predictor woman's birth weight, a proxy variable was made as we measured this variable in categories instead of as a continuous variable. Since no measurements were available for crown-rump length (CRL) at blood pressure measurement, we made a proxy variable based on gestational age ${ }^{28}$. A detailed description about definition and assessment of the predictors is provided in Supplementary Table S3.2.

\section{Assessment of pre-eclampsia}

The Dutch national guideline defines PE as systolic blood pressure $\geq 140 \mathrm{mmHg}$ and/or diastolic blood pressure $\geq 90 \mathrm{mmHg}$ (Korotkoff $\mathrm{V}$ ) after 20 weeks gestation, measured twice in a previously normotensive woman, accompanied by proteinuria (at least 300 $\mathrm{mg}$ protein in a 24 hour urine collection $)^{29,30}$. The outcome was obtained from a combination of the medical record and postpartum questionnaire. We checked whether the medical record stated a diagnosis of PE or a combination of the field codes proteinuria and highest diastolic blood pressure measurement $\geq 90 \mathrm{mmHg}$. Women were asked to report any occurrence of PE in the postpartum questionnaire. PE was defined as present when the diagnosis was confirmed by both sources. In the absence of the postpartum questionnaire $(n=435)$, the medical record was used as a gold standard and vice versa $(n=16)$. In case of a discrepancy between the pregnancy questionnaire and medical record, we contacted the obstetric caregiver for final decision. 


\section{Statistical analysis}

There is no generally accepted rule for the required sample size for external validation studies of prediction models. Vergouwe et al. state that at least 100 events and 100 non-events are necessary in order to be able to detect relevant differences between model performance in the derivation set and the validation $\operatorname{set}^{31}$. Expecting that around $4 \%$ of the pregnancies would be affected by PE and accounting for incomplete records (10\%), recruitment of 2750 women was necessary.

Baseline characteristics were analysed in the validation cohort and presented as means \pm standard deviation for continuous variables and an absolute value with percentage for categorical variables. We imputed the missing values using stochastic regression imputation using predictive mean matching as the imputation model ${ }^{32}$. We evaluated the relatedness of the predictors and outcome between the validation cohort and the included original cohorts (case-mix).

For each subject in our validation cohort, we computed probabilities of developing PE on the basis of all included models. The algorithms of the included models are presented in Supplementary Table S3.3. Predictive performance of the models was assessed by means of discrimination and calibration. Discrimination is the models' ability to distinguish between women who will develop PE and those who will not. We quantified discrimination by calculating the c-statistic (area under the receiver operating characteristic curve, or AUROC) with 95\%-confidence interval (CI). Calibration is the degree of agreement between the predicted probabilities and observed outcomes and was examined by constructing calibration plots. Perfect predictions should be on the $45^{\circ}$ line with an intercept of 0 (calibration-in-the-large) and a slope of $1^{33}$. Calibration-in-the-large compares the mean predicted risk with the observed proportion of PE cases, and indicates whether predictions are systematically too low or too high ${ }^{33}$. Calibration slope refers to the average strength of the predictor effects $^{15}$. At validation, the slope is often smaller than one, reflecting overfitting of the model (low predictions too low and high predictions too high) ${ }^{33}$. We divided the women into 10 groups of roughly equal size with similar predicted risk. In case of miscalibration we recalibrated the prediction model by adjusting the intercept and slope using the linear predictor as the only covariate ${ }^{15}$. This recalibration method has no effect on the discriminative performance of the model as the spread and ranking of the predictions remain the same.

We used the validation cohort with our own defined eligibility criteria for the analyses of each model. However, the original models were developed in different pregnant populations with their own in- and exclusion criteria. We additionally assessed the discriminative performance for each original study according to their specific eligibility criteria. Furthermore, a subgroup analysis was performed among nulliparous women, as previous PE was a strong predictor in most models.

Lastly, we determined the potential impact of the (recalibrated) models in clinical practice. Decision curve analysis was carried out for the best performing models as it provides a first impression of the clinical usefulness of the models. Decision curve 
analysis assesses net benefit (net proportion of true positives) of the models over a range of threshold probabilities compared to the scenarios of classifying all and no women as high risk of developing $\mathrm{PE}^{34}$. For the model with the highest net benefit, we evaluated the potential clinical impact of the model at different risk thresholds and different management strategies. We calculated incidence reduction of PE and number needed to prevent one case of PE using theoretical preventive interventions with relative risk reductions of $10 \%, 20 \%$, and $40 \%$. We also compared the model performance to current guidelines, the NICE and ACOG criteria ${ }^{35-37}$. As the ACOG criteria do not specifically define the number of moderate risk factors to identify women at high risk for $\mathrm{PE}$, we defined $\geq 2$ moderate risk factors as high risk ${ }^{36}$. Low socioeconomic status was defined as education below the level of tertiary education. All statistical analyses were conducted with IBM SPSS statistics version 23 (SPSS, Chicago, IL) and R version 3.2.3, packages rms, pROC, and DecisionCurve.

\section{Results}

\section{Validation cohort}

We included a total of 2614 women in the validation cohort (Figure 3.1). Table 3.2 shows the characteristics of the validation cohort in the observed data. For most predictors the percentage of missing data was less than one. However, woman's own birth weight, systolic blood pressure, and diastolic blood pressure were missing in $12.2 \%, 9.9 \%$, and $10.3 \%$ of women, respectively. An overview of the number of missing values per predictor, and the characteristics of both the complete cases and the validation cohort after imputation is provided in Supplementary Table S3.4. The pregnancy was complicated by PE in 76 women (2.9\%).

We also described the characteristics of the development samples and compared these to the current validation sample (see Supplementary Table S3.5). The occurrence of the outcome was considerably higher in the development cohorts of Direkvand-Moghadam et al. and Seed et al.. The case-mix of Direkvand-Moghadam et al., Seed et al., and North et al. substantially differed. In contrast to most development cohorts, our validation cohort had a low incidence of non-Caucasian ethnicity. Kenny et al. and Audibert et al. reported no predictor characteristics, and Syngelaki et al. did not describe the number of cases. 


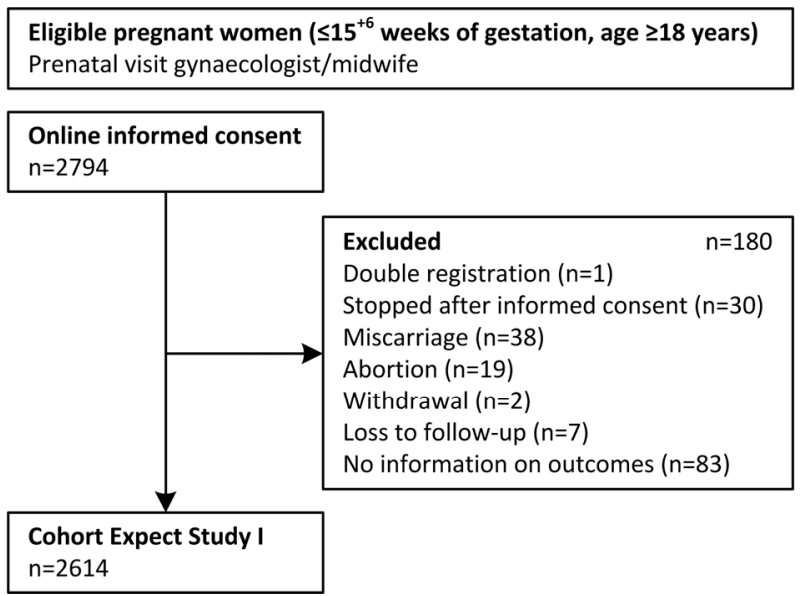

Figure 3.1 Flowchart of the validation cohort

Table 3.2 Baseline characteristics of the validation cohort (Expect Study I)

\begin{tabular}{|c|c|c|c|c|}
\hline \multirow[t]{2}{*}{ Characteristics } & \multirow{2}{*}{$\begin{array}{c}\text { Missing } \\
\text { values, } \\
\text { n (\%) }\end{array}$} & \multicolumn{3}{|c|}{ Observed validation cohort (Expect Study I) ${ }^{\mathrm{a}}$} \\
\hline & & Overall ( $n=2614)$ & $\begin{array}{c}\text { Pre-eclampsia } \\
\quad(n=76)\end{array}$ & $\begin{array}{c}\text { No Pre-eclampsia } \\
\qquad(n=2538)\end{array}$ \\
\hline Age, years & $0(0.0)$ & $30.2(3.9)$ & $29.2(4.1)$ & $30.2(3.9)$ \\
\hline Ethnicity & $0(0.0)$ & & & \\
\hline Caucasian & & $2533(96.9)$ & $73(96.1)$ & 2460 (96.9) \\
\hline Afro-Caribbean & & $3(0.1)$ & $0(0.0)$ & $3(0.1)$ \\
\hline Indian, Pakistani or Bangladeshi & & $4(0.2)$ & $0(0.0)$ & $4(0.2)$ \\
\hline East Asian & & $4(0.2)$ & $0(0.0)$ & $4(0.2)$ \\
\hline Other Asian & & $12(0.4)$ & $1(1.3)$ & $11(0.4)$ \\
\hline Hispanic & & $11(0.4)$ & $1(1.3)$ & $10(0.4)$ \\
\hline Mixed & & $47(1.8)$ & $1(1.3)$ & $46(1.8)$ \\
\hline Tertiary education & $3(0.1)$ & $1420(54.3)$ & $35(46.1)$ & $1385(54.6)$ \\
\hline Height, cm & $3(0.1)$ & $168.8(6.4)$ & $168.7(6.2)$ & $168.8(6.4)$ \\
\hline Weight, kg & $5(0.2)$ & $68.9(13.0)$ & $70.4(12.8)$ & $68.8(13.0)$ \\
\hline Body mass index, $\mathrm{kg} / \mathrm{m}^{2}$ & $5(0.2)$ & $24.2(4.3)$ & $24.7(3.9)$ & $24.1(4.3)$ \\
\hline \multicolumn{5}{|l|}{ Smoking } \\
\hline Ever <16 weeks' gestation & $1(0.0)$ & $318(12.2)$ & $8(10.5)$ & $310(12.2)$ \\
\hline $\begin{array}{l}\text { Current (at completion } \\
\text { questionnaire) }\end{array}$ & $1(0.0)$ & $157(6.0)$ & $2(2.6)$ & $155(6.1)$ \\
\hline Number cigarettes/day & $1(0.0)$ & $6.8(3.9)$ & $11(5.7)$ & $6.8(3.9)$ \\
\hline Alcohol consumption & $3(0.1)$ & 479 (18.3) & $10(13.2)$ & 469 (18.5) \\
\hline \multicolumn{5}{|l|}{ ever $<16$ weeks' gestation } \\
\hline Diabetes mellitus & $0(0.0)$ & $11(0.4)$ & $1(1.3)$ & $10(0.4)$ \\
\hline Type 1 & & $9(0.3)$ & $1(1.3)$ & $8(0.3)$ \\
\hline Type 2 & & $1(0.0)$ & $0(0.0)$ & $1(0.0)$ \\
\hline Other & & $1(0.0)$ & $0(0.0)$ & $1(0.0)$ \\
\hline History of chronic hypertension & $0(0.0)$ & $28(1.1)$ & $2(2.6)$ & $26(1.0)$ \\
\hline Chronic renal disease & $0(0.0)$ & $5(0.2)$ & $0(0.0)$ & $5(0.2)$ \\
\hline Systemic Lupus Erythematosus & $0(0.0)$ & $3(0.1)$ & $0(0.0)$ & $3(0.1)$ \\
\hline Antiphospholipid syndrome & $0(0.0)$ & $0(0.0)$ & $0(0.0)$ & $0(0.0)$ \\
\hline
\end{tabular}


Table 3.2 (continued) Baseline characteristics of the validation cohort (Expect Study I)

\begin{tabular}{|c|c|c|c|c|}
\hline \multirow[t]{2}{*}{ Characteristics } & \multirow{2}{*}{$\begin{array}{l}\text { Missing } \\
\text { values, } \\
\text { n (\%) }\end{array}$} & \multicolumn{3}{|c|}{ Observed validation cohort (Expect Study I) ${ }^{a}$} \\
\hline & & $\begin{array}{l}\text { Overall } \\
(n=2614)\end{array}$ & $\begin{array}{l}\text { Pre-eclampsia } \\
\qquad(n=76)\end{array}$ & $\begin{array}{c}\text { No Pre-eclampsia } \\
(n=2538)\end{array}$ \\
\hline Hyperthyroid & $0(0.0)$ & $11(0.4)$ & $0(0.0)$ & $11(0.4)$ \\
\hline High fruit intake $\geq 3 /$ day & $1(0.0)$ & $67(2.6)$ & $0(0.0)$ & $67(2.6)$ \\
\hline $\begin{array}{l}\text { Family history of coronary heart } \\
\text { disease (father) }\end{array}$ & $1(0.0)$ & $439(16.8)$ & $11(14.5)$ & $428(16.9)$ \\
\hline \multicolumn{5}{|l|}{ Family history pre-eclampsia } \\
\hline Mother & $2(0.1)$ & $91(3.5)$ & $5(6.6)$ & $86(3.4)$ \\
\hline Sister & $4(0.2)$ & $41(1.6)$ & $1(1.3)$ & $40(1.6)$ \\
\hline Mother or sister & $6(0.2)$ & $130(5.0)$ & $6(7.9)$ & $124(4.9)$ \\
\hline Woman's birth weight, g & $319(12.2)$ & $3174.1(475.6)$ & $3062.5(556.3)$ & $3177.3(472.8)$ \\
\hline Parity & $0(0.0)$ & & & \\
\hline Nulliparous & & $1326(50.7)$ & $66(86.8)$ & $1260(49.6)$ \\
\hline Primiparous & & $1026(39.3)$ & $10(13.2)$ & $1016(40.0)$ \\
\hline Multiparous & & $262(10.0)$ & $0(0.0)$ & $262(10.4)$ \\
\hline Time to conceive $\geq 12$ months & $9(0.3)$ & $357(13.7)$ & $22(28.9)$ & $335(13.2)$ \\
\hline Conception & $0(0.0)$ & & & \\
\hline Spontaneous & & $2440(93.3)$ & $63(82.9)$ & 2377 (93.7) \\
\hline Ovulation induction & & $93(3.6)$ & $4(5.3)$ & $89(3.5)$ \\
\hline IVF/ICSI & & $81(3.1)$ & $9(11.8)$ & $72(2.8)$ \\
\hline $\begin{array}{l}\text { Previous single miscarriage } \leq 10 \\
\text { weeks' gestation, same father }\end{array}$ & $0(0.0)$ & $395(15.1)$ & $7(9.2)$ & $388(15.3)$ \\
\hline $\begin{array}{l}\text { Folic acid supplementation at } \\
\text { completion questionnaire }\end{array}$ & $3(0.1)$ & $2226(85.2)$ & $71(93.4)$ & 2155 (84.9) \\
\hline Vaginal bleeding $\geq 5$ days & $0(0.0)$ & $102(3.9)$ & $3(3.9)$ & 99 (3.9) \\
\hline $\begin{array}{l}\text { History of pregnancy induced } \\
\text { hypertension }\end{array}$ & $18(0.7)$ & $115(4.4)$ & $3(3.9)$ & $112(4.4)$ \\
\hline History of pre-eclampsia & $18(0.7)$ & $72(2.8)$ & $5(6.6)$ & $67(2.6)$ \\
\hline $\begin{array}{l}\text { History of gestational diabetes } \\
\text { mellitus }\end{array}$ & $19(0.7)$ & $15(0.6)$ & $0(0.0)$ & $15(0.6)$ \\
\hline Systolic blood pressure, $\mathrm{mmHg}$ & $260(9.9)$ & $114.4(12.5)$ & $116.9(13.7)$ & $114.4(12.4)$ \\
\hline Diastolic blood pressure, $\mathrm{mmHg}$ & $270(10.3)$ & $67.6(8.5)$ & $69.7(8.5)$ & $67.6(8.5)$ \\
\hline Mean arterial pressure, $\mathrm{mmHg}$ & $270(10.3)$ & $83.2(8.8)$ & $85.4(9.3)$ & $83.2(8.8)$ \\
\hline Crown-rump length, $\mathrm{mm}$ & $270(10.3)$ & $33.8(23.5)$ & $30.4(21.1)$ & $33.9(23.6)$ \\
\hline
\end{tabular}

${ }^{a}$ Original data (not imputed) presented as mean (SD) or absolute number (\%). ICSI, intracytoplasmic sperm injection; IVF, in vitro fertilisation

\section{Predictive performances}

The discriminative performance of the models is presented in Table 3.3. The AUROC decreased in five out of ten models to below or equal to 0.60 . The model of Syngelaki et al. showed the best discriminative ability (AUROC 0.77). The models of MacDonaldWallis et al. and Kenny et al. stayed most stable after external validation ( 0.04 decline in AUROC). The receiver operating characteristic (ROC) curves are available in Supplementary Figure S3.1A-B. The discriminative performances did not change much when validating the models in the cohort according to their own eligibility criteria. 
Table 3.3 Discrimination of selected prediction models for pre-eclampsia

\begin{tabular}{|c|c|c|c|}
\hline Study, first author (year) & $\begin{array}{l}\text { AUROC }(95 \% \mathrm{CI}) \\
\text { Original publication }\end{array}$ & $\begin{array}{l}\text { AUROC }(95 \% \mathrm{Cl}) \\
\text { Validation cohort } \\
\quad(n=2614)\end{array}$ & $\begin{array}{c}\text { AUROC }(95 \% \mathrm{Cl}) \\
\text { Validation cohort } \\
\text { Definition original } \\
\text { publication }\end{array}$ \\
\hline $\begin{array}{l}\text { MacDonald-Wallis et al. } \\
\text { (2015) }\end{array}$ & $\begin{array}{c}0.77(0.75-0.80) \\
\text { External validation: } \\
0.79(0.73-0.85)\end{array}$ & $0.73(0.68-0.77)$ & $0.73(0.68-0.77)$ \\
\hline Kenny et al. (2014) & $\begin{array}{c}0.73(0.69-0.76) \\
\text { Internal validation: } \\
0.64(0.59-0.69)\end{array}$ & $0.60(0.54-0.67)$ & $0.60(0.53-0.66)$ \\
\hline $\begin{array}{l}\text { Direkvand-Moghadam et } \\
\text { al. (2013) }\end{array}$ & $0.67(N R)$ & $0.56(0.50-0.62)$ & $0.56(0.50-0.62)$ \\
\hline Syngelaki et al. (2011) & NR & $0.77(0.72-0.81)$ & $0.77(0.72-0.81)$ \\
\hline North et al. (2011) & $\begin{array}{c}0.76(\mathrm{NR}) \\
\text { Internal validation: } \\
0.71(\mathrm{NR})\end{array}$ & $0.58(0.51-0.64)$ & $0.56(0.48-0.63)$ \\
\hline Seed et al. (2011) & $\begin{array}{c}0.70(\mathrm{NR}) \\
\text { Internal validation: } \\
0.66(\mathrm{NR})\end{array}$ & $0.52(0.46-0.59)$ & $0.56(0.38-0.74)$ \\
\hline Audibert et al. (2010) & $0.75(0.67-0.83)$ & $0.56(0.49-0.62)$ & $0.57(0.50-0.64)$ \\
\hline Poon et al. (2008) BJOG & $0.85(0.84-0.87)$ & $0.74(0.69-0.78)$ & $0.75(0.70-0.79)$ \\
\hline Poon et al. (2008) & A priori risk $(A)$ : & A priori risk $(A)$ : & A priori risk $(A)$ : \\
\hline Hypertension & $0.80(N R)$ & $0.74(0.70-0.79)$ & $0.75(0.70-0.79)$ \\
\hline & $\begin{array}{c}\text { A priori risk + MAP (B): } \\
0.85(\mathrm{NR})\end{array}$ & $\begin{array}{c}\text { A priori risk + MAP (B): } \\
0.63(0.57-0.69)\end{array}$ & $\begin{array}{c}\text { A priori risk + MAP (B): } \\
0.63(0.57-0.70)\end{array}$ \\
\hline Plasencia et al. (2007) & $0.806(0.80-0.82)$ & $0.74(0.70-0.78)$ & $0.75(0.71-0.79)$ \\
\hline
\end{tabular}

AUROC, area under the receiver operating characteristic curve; NR, not reported; MAP, mean arterial pressure

Calibration plots of the models are provided in Figure 3.2A-B. The distribution of the predicted probabilities was closely clustered around the mean for most models. Models consistently overestimated the risk of $\mathrm{PE}$, except for the model of Poon et al. (BJOG), Poon et al. (A) (Hypertension), and Plasencia et al.. All models were overfitted (i.e. the calibration slope <1). The model of Poon et al. (A) (Hypertension) was best calibrated to our population (slope 0.92). The model of Syngelaki et al. had a slope of 1.1. Recalibration of the models showed closer fitting to the ideal calibration line (Figure 3.3A-B).

Secondary analysis, in which the models were only applied to nulliparous women $(n=1326)$, showed that the discriminative performance decreased considerably for all models with AUROC ranging from 0.51 to 0.61 (see Supplementary Figure S3.2A-B). The models specifically developed for nulliparous women (Kenny et al., North et al., and Audibert et al.) did not perform better than the other models. The calibration plots are available in Supplementary Figure S3.3A-B. The model of Syngelaki et al. had a slope of 0.59 . 

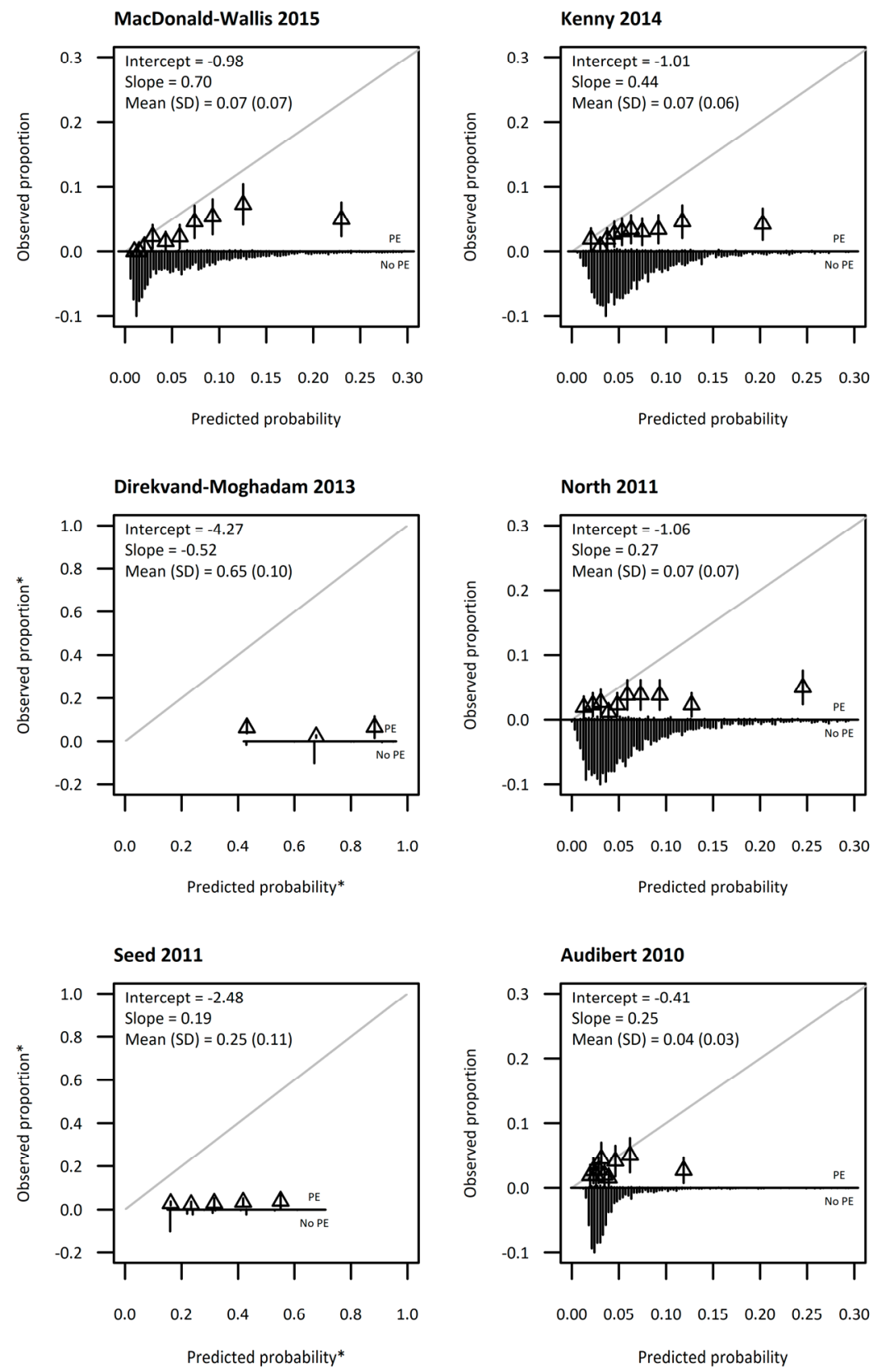

Figure 3.2A Calibration plots of externally validated first trimester prediction models for pre-eclampsia. The grey line is the reference line with intercept $=0$ and slope $=1$ (perfect calibration). Triangles correspond to grouped predicted risks with $95 \%$ confidence intervals (vertical lines). *Different limits $\mathrm{x}$ - and $\mathrm{y}$-axis 

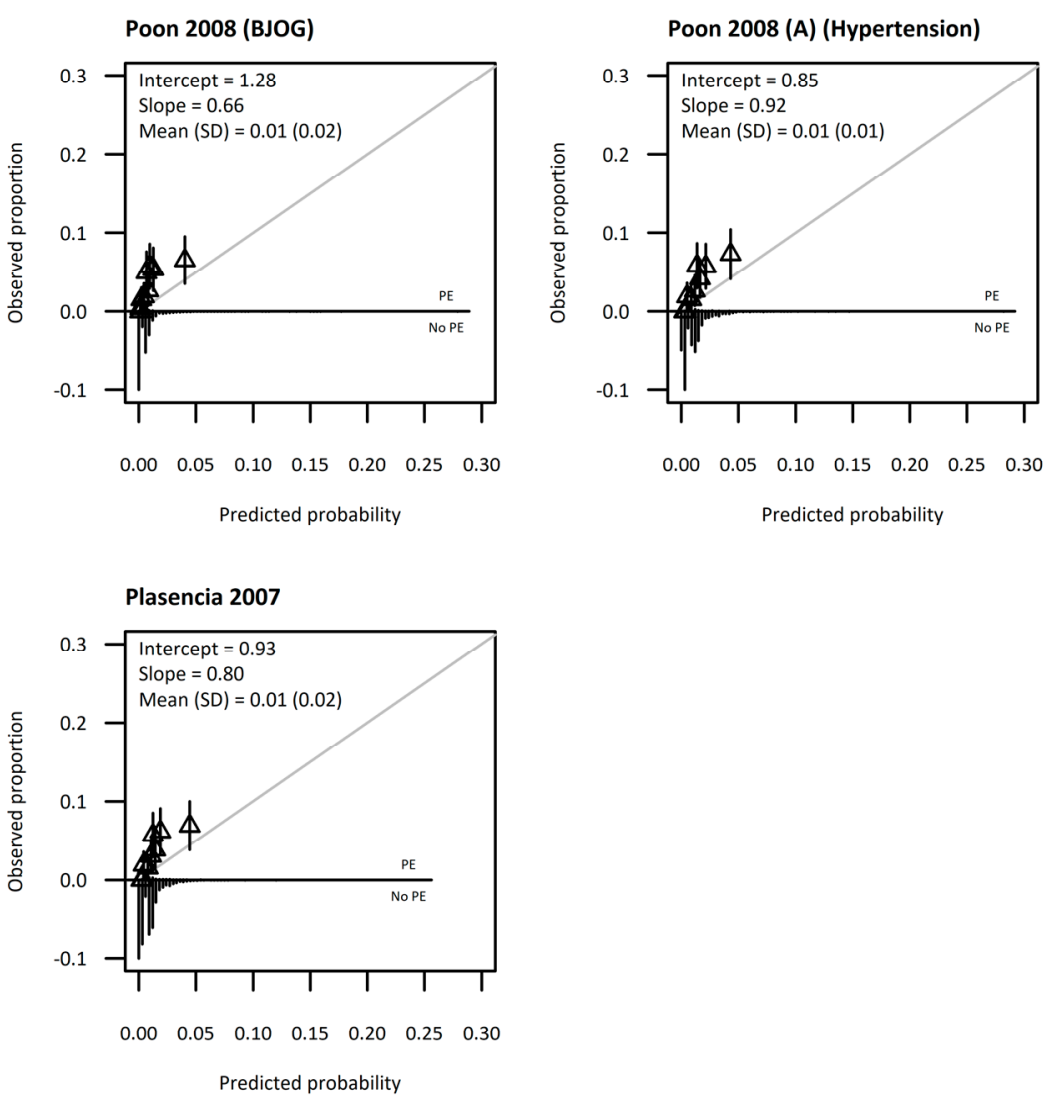

Figure 3.2B Calibration plots of externally validated first trimester prediction models for pre-eclampsia. The grey line is the reference line with intercept $=0$ and slope $=1$ (perfect calibration). Triangles correspond to grouped predicted risks with $95 \%$ confidence intervals (vertical lines). *Different limits $x$ - and y-axis

\section{Clinical usefulness}

Figure 3.4 shows the net benefit of the five best performing models over a range of risk thresholds. The models were clinically useful, compared with classifying all or no women as high-risk, over a small range of probability thresholds (MacDonald-Wallis et al. 0.50-5.07\%, Syngelaki et al. 0.52\%-5.98\%, Poon et al. (BJOG) 0.52-6.08\%, Poon et al. (A) (Hypertension) 0.52-6.44\%, Plasencia et al. 0.68-6.31\%). Although the curves differed only slightly, the model of Syngelaki et al. had the highest net benefit for almost the complete range of clinical useful threshold probabilities. 


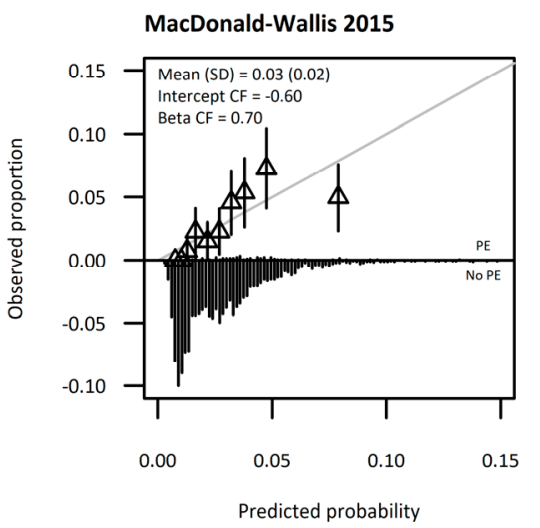

Direkvand-Moghadam 2013

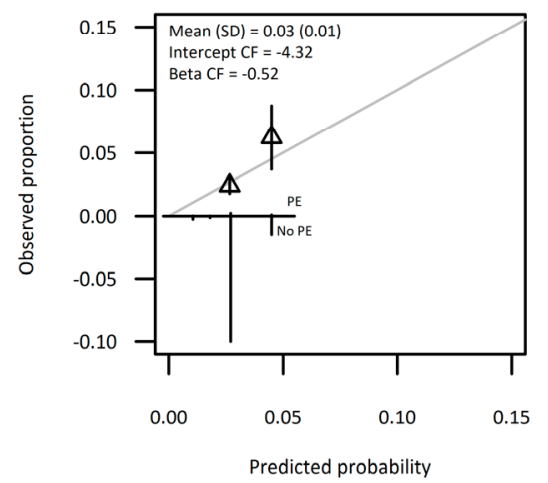

North 2011

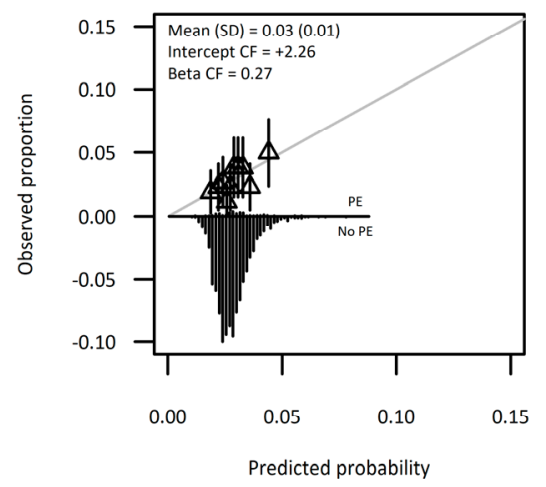

Kenny 2014

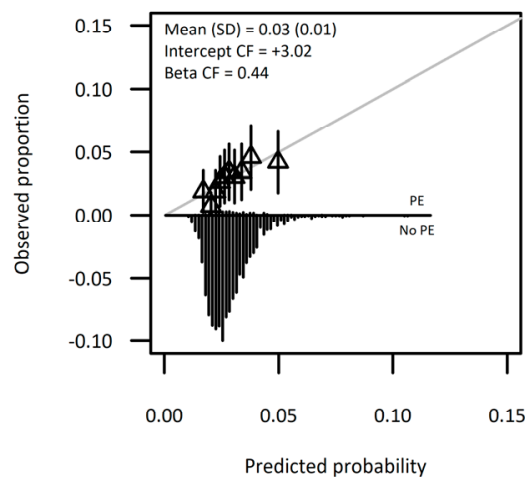

Syngelaki 2011

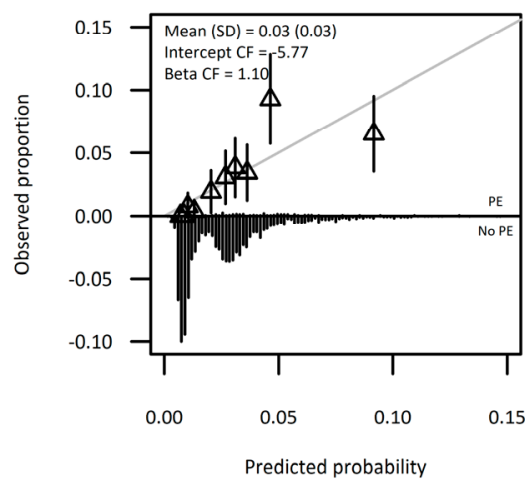

Seed 2011

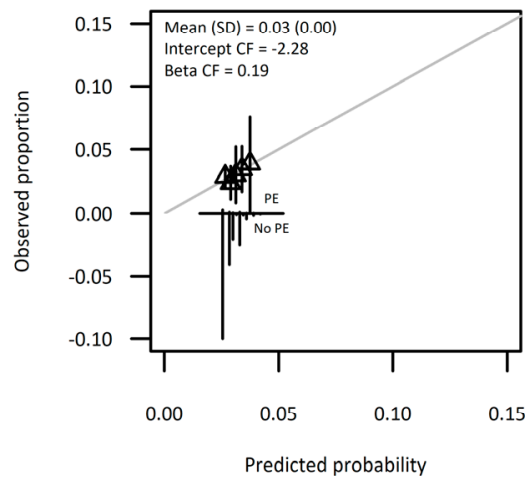

Figure 3.3A Calibration plots of recalibrated first trimester prediction models for pre-eclampsia. The grey line is the reference line with intercept $=0$ and slope $=1$ (perfect calibration). Triangles correspond to grouped predicted risks with 95\% confidence intervals (vertical lines). CF = correction factor 

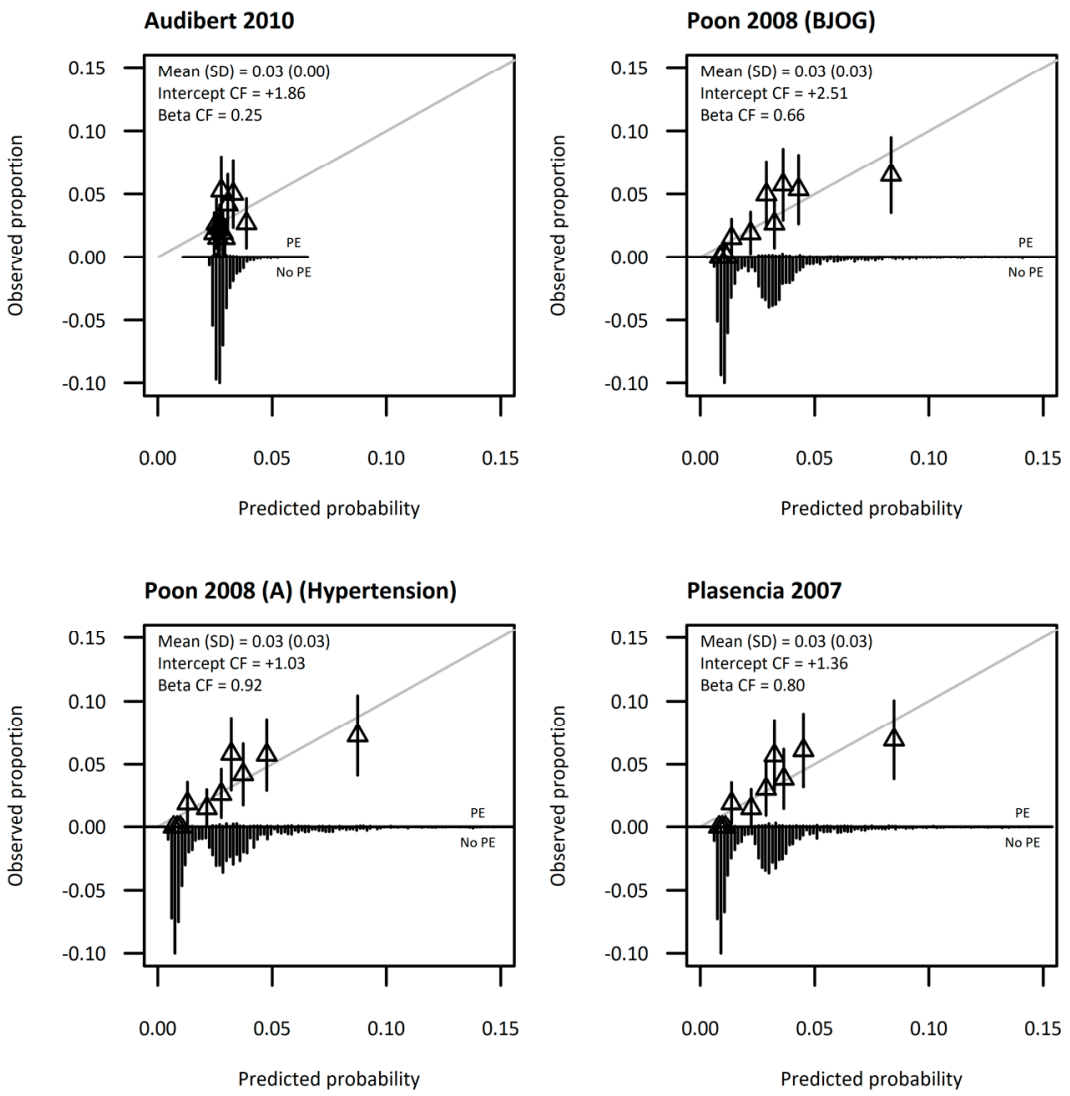

Figure 3.3B Calibration plots of recalibrated first trimester prediction models for pre-eclampsia. The grey line is the reference line with intercept $=0$ and slope $=1$ (perfect calibration). Triangles correspond to grouped predicted risks with $95 \%$ confidence intervals (vertical lines). CF = correction factor

The prognostic measures of the model of Syngelaki et al. and the potential effect of the interventions on PE incidence reduction for six different risk thresholds are presented in Table 3.4. A low risk threshold ensures that almost no cases will be missed (high sensitivity), but many women will be treated unnecessarily. Conversely, a high specificity leads to a low proportion of false positives. However, the effect of the intervention will be smaller since more women prone to develop PE will be considered as low risk. The number needed to prevent one case of PE is dependent on the efficacy of the intervention, but less so of risk threshold. 


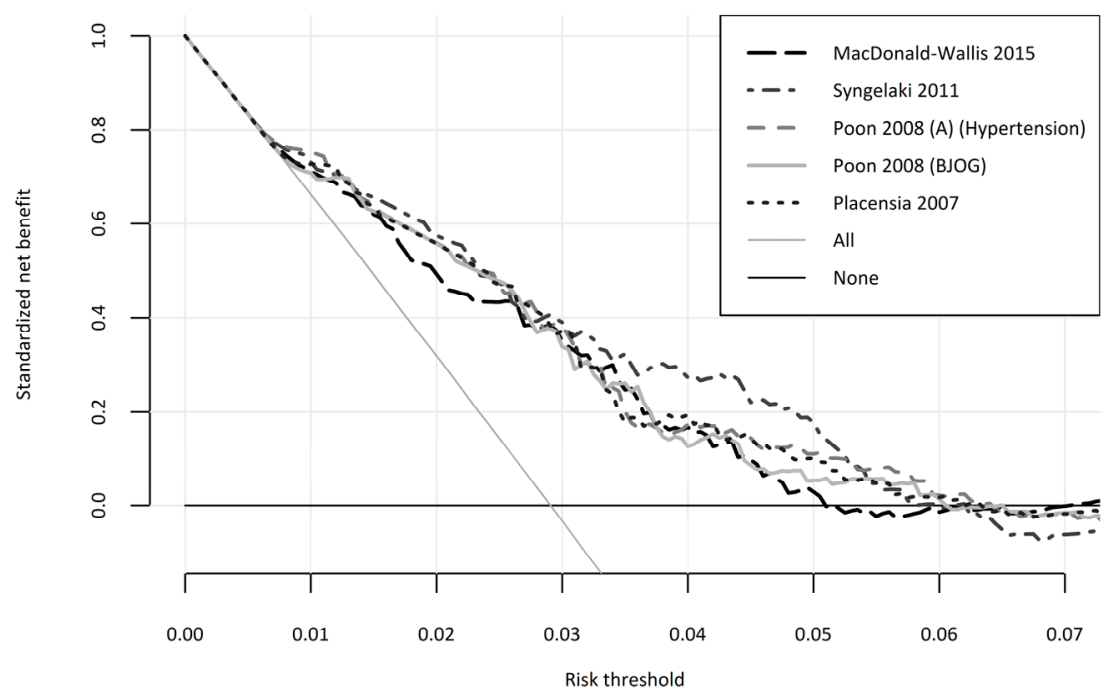

Figure 3.4 Decision curve analysis of the five best performing models for pre-eclampsia. The solid grey line is the net benefit when considering all women as high risk and the horizontal black line when considering no women at high risk

Table 3.4 Predictive performance measures of recalibrated model Syngelaki et al. and effect of an intervention on pre-eclampsia incidence for different risk thresholds

\begin{tabular}{|c|c|c|c|c|c|c|c|c|}
\hline \multirow[t]{2}{*}{$\begin{array}{l}\text { Risk } \\
\text { threshold }{ }^{\mathrm{a}}, \\
\%\end{array}$} & \multirow[t]{2}{*}{$\begin{array}{l}\text { High risk, } \\
\%(n / n)\end{array}$} & \multirow[t]{2}{*}{$\begin{array}{c}\text { Sensitivity, } \\
\%(n / n)\end{array}$} & \multirow[t]{2}{*}{$\begin{array}{c}\text { Specificity, } \\
\%(n / n)\end{array}$} & \multirow[t]{2}{*}{$\begin{array}{c}\text { PPV, } \\
\%(n / n)\end{array}$} & \multirow[t]{2}{*}{$\begin{array}{c}\text { NPV, } \\
\%(n / n)\end{array}$} & \multicolumn{3}{|c|}{$\begin{array}{c}\text { PE incidence } \\
\text { reduction, \% } \\
(\mathrm{NNP}, \mathrm{n}) \\
\text { Effect intervention }^{\mathrm{b}} \text { : }\end{array}$} \\
\hline & & & & & & RR 0.9 & RR 0.8 & RR 0.6 \\
\hline 1.0 & $\begin{array}{c}76.2 \\
(1993 / 2614)\end{array}$ & $\begin{array}{c}98.7 \\
(75 / 76)\end{array}$ & $\begin{array}{c}24.4 \\
(620 / 2538)\end{array}$ & $\begin{array}{c}3.8 \\
(75 / 1993)\end{array}$ & $\begin{array}{c}99.8 \\
(620 / 621)\end{array}$ & $\begin{array}{c}9.9 \\
\text { (NNP } \\
266)\end{array}$ & $\begin{array}{c}19.7 \\
\text { (NNP } \\
133)\end{array}$ & $\begin{array}{c}39.5 \\
\text { (NNP } \\
66)\end{array}$ \\
\hline 2.0 & $\begin{array}{c}55.8 \\
(1459 / 2614)\end{array}$ & $\begin{array}{c}94.7 \\
(72 / 76)\end{array}$ & $\begin{array}{c}45.4 \\
(1151 / 2538)\end{array}$ & $\begin{array}{c}4.9 \\
(72 / 1459)\end{array}$ & $\begin{array}{c}99.7 \\
(1151 / 1155)\end{array}$ & $\begin{array}{c}9.5 \\
\text { (NNP } \\
203)\end{array}$ & $\begin{array}{l}18.9 \\
\text { (NNP } \\
101)\end{array}$ & $\begin{array}{c}37.9 \\
\text { (NNP } \\
51 \text { ) }\end{array}$ \\
\hline 3.0 & $\begin{array}{c}37.3 \\
(974 / 2614)\end{array}$ & $\begin{array}{c}76.3 \\
(58 / 76)\end{array}$ & $\begin{array}{c}63.9 \\
(1622 / 2538)\end{array}$ & $\begin{array}{c}6.0 \\
(58 / 974)\end{array}$ & $\begin{array}{c}98.9 \\
(1622 / 1640)\end{array}$ & $\begin{array}{c}7.6 \\
\text { (NNP } \\
168)\end{array}$ & $\begin{array}{c}15.3 \\
(\mathrm{NNP} \\
84)\end{array}$ & $\begin{array}{c}30.5 \\
\text { (NNP } \\
42 \text { ) }\end{array}$ \\
\hline 4.0 & $\begin{array}{c}20.2 \\
(528 / 2614)\end{array}$ & $\begin{array}{c}53.9 \\
(41 / 76)\end{array}$ & $\begin{array}{c}80.8 \\
(2051 / 2538)\end{array}$ & $\begin{array}{c}7.8 \\
(41 / 528)\end{array}$ & $\begin{array}{c}98.3 \\
(2051 / 2086)\end{array}$ & $\begin{array}{c}5.4 \\
\text { (NNP } \\
129)\end{array}$ & $\begin{array}{c}10.8 \\
(\mathrm{NNP} \\
64)\end{array}$ & $\begin{array}{c}21.6 \\
\text { (NNP } \\
32 \text { ) }\end{array}$ \\
\hline 5.0 & $\begin{array}{c}12.4 \\
(323 / 2614)\end{array}$ & $\begin{array}{c}38.2 \\
(29 / 76)\end{array}$ & $\begin{array}{c}88.4 \\
(2244 / 2538)\end{array}$ & $\begin{array}{c}9.0 \\
(29 / 323)\end{array}$ & $\begin{array}{c}97.9 \\
(2244 / 2291)\end{array}$ & $\begin{array}{c}3.8 \\
(N N P \\
111)\end{array}$ & $\begin{array}{c}7.6 \\
(\mathrm{NNP} \\
56)\end{array}$ & $\begin{array}{c}15.3 \\
\text { (NNP } \\
28)\end{array}$ \\
\hline 6.0 & $\begin{array}{c}8.6 \\
(224 / 2614)\end{array}$ & $\begin{array}{c}17.1 \\
(13 / 76)\end{array}$ & $\begin{array}{c}91.7 \\
(2327 / 2538)\end{array}$ & $\begin{array}{c}5.8 \\
(13 / 224)\end{array}$ & $\begin{array}{c}97.4 \\
(2327 / 2390)\end{array}$ & $\begin{array}{c}1.7 \\
(N N P \\
172)\end{array}$ & $\begin{array}{c}3.4 \\
(N N P \\
86)\end{array}$ & $\begin{array}{c}6.8 \\
\text { (NNP } \\
43)\end{array}$ \\
\hline
\end{tabular}

${ }^{a}$ Predicted risk at or above this level was considered as high risk. ' Intervention to all high-risk women. NNP, number needed to prevent; NPV, negative predictive value; PE, pre-eclampsia; PPV, positive predictive value; $R R$, risk reduction 
We compared the model of Syngelaki et al. with current guidelines. When applying the NICE criteria to our population, $8.5 \%$ of the women were considered as high risk with a sensitivity of $23.7 \%$ and a specificity of $91.9 \%$. The ACOG criteria indicated $43.6 \%$ of our women as high-risk with a sensitivity of $68.4 \%$ and specificity of $57.1 \%$. The model of Syngelaki et al. had a specificity of $90.1 \%$ and $70.1 \%$ at a sensitivity of $23.7 \%$ and $68.4 \%$, respectively.

\section{Discussion}

\section{Main findings}

We assessed the generalizability of ten first trimester prediction models based on routinely collected maternal characteristics for the risk of PE in a Dutch population. Five models (MacDonald-Wallis et al., Syngelaki et al., Poon et al. (BJOG), Poon et al. (A) (Hypertension), Plasencia et al.) showed moderate discriminative performance (AUROCs ranged from 0.73-0.77). The model of Poon et al. (A) (Hypertension) showed the best calibration. This model underestimated the risk of developing PE over the entire range, but showed the best fit of predictor effects (slope 0.92). Refitting of the models improved calibration.

\section{Interpretation}

Validation is an important step in predictive modelling since the predictive performance is usually too optimistic in development samples ${ }^{38}$. Internal validation was only performed for three of the included models (Kenny et al., North et al. and Seed et al.). The model of Kenny et al. stayed most stable in our external validation cohort. External validation studies of prediction models for PE are scarce ${ }^{13,14,39,40}$. None have simultaneously considered all first trimester prediction models based on routinely collected maternal characteristics for the risk of PE. MacDonald-Wallis et al. estimated the external validity of their own developed model using another cohort from the same country ${ }^{17}$. Independent external validation was only performed for the model of Plasencia et al. and Poon et al. (Hypertension) ${ }^{40-42}$. These external validation studies, particularly those validating the model of Plasencia et al. ${ }^{41,42}$, were hampered by a (very) low number of cases.

Our results confirm the importance of performing an external validation study. The predictive performance decreased for all included models. A previous pregnancy complicated by PE is a strong risk factor and the risk for multiparous women with no previous PE reduces substantially for a subsequent pregnancy ${ }^{43-45}$. The subanalysis among nulliparous women showed that the performance decreased considerably, even for the models specifically developed for nulliparous women. This shows the difficulty of predicting PE among low risk nulliparous women based on exclusively routinely collected maternal characteristics. Although there appears scope for further improvement of the models, for now predictive performance of models based on only routinely collected maternal predictors measured up to 16 weeks of gestation is 
unlikely to improve sufficiently by adding other predictors as most studies already took into account the well-described maternal risk factors. Very strong risk factors such as antiphospholipid syndrome and chronic hypertension are absent in most models ${ }^{45}$. This is probably due to the low prevalence of some of these factors in the general pregnant population. Another possible factor is that pregnant women with essential hypertension may already receive high-risk treatment, reducing PE risk. Most prediction models are developed to assess the risk in a low-risk population. In case of the presence of very strong risk factors women should also be considered as high risk.

\section{Implications}

Performance parameters are important characteristics of a prediction model but do not equal the usefulness of the model in clinical practice ${ }^{38}$. Moreover, a prediction model can only lead to benefit if there is an effective follow-up strategy. Decision curve analysis indicated that the five best performing models were clinically useful compared to treating all women or none at all as high-risk over a small range of probability thresholds. No model had a considerably higher net benefit than others. Based on predictive performance, mainly among nulliparous women, we prefer the model of Syngelaki et al.. Containing a wide range of known risk factors for PE (ethnicity, BMI, age, pre-existing chronic hypertension, pre-existing diabetes mellitus, smoking status, conception method, family history of PE, previous PE, and parity), this model also has good face value for the end user.

Decision curve analysis gives only a first impression of clinical usefulness. Determining the best risk threshold is a subsequent challenge that has had surprisingly little attention in prediction literature. A prediction tool should correctly identify individuals at high risk of developing disease, while avoiding unnecessary interventions for individuals at low risk. There is a trade-off between sensitivity and specificity. In the case of PE, a high sensitivity is preferred due to the high burden of disease. The best performing models still had a considerably large number of false positives at a high sensitivity. The choice of a cut-off is therefore also dependent on the available intervention. Beside the efficiency of the intervention in reducing PE, tolerance, side effects, and costs are as well important aspects to consider. The current available preventive interventions low dose aspirin and calcium supplementation are safe, have no major side effects, not burdensome and relatively inexpensive ${ }^{3-12}$.

Several current guidelines provide a list of risk factors to indicate women at high risk of developing PE. A limitation of some published guidelines is that they can be interpreted differently by caregivers ${ }^{36,46}$. Furthermore, criteria lists do not take into account the strength of the different risk factors in relation to PE. Our best model performed better than the ACOG criteria and slightly the same as the NICE at the same sensitivity.

At the moment, the validated models with an acceptable performance are simple, readily available and cheap to implement. An extensive decision analysis can provide 
insight about the expected impact of the model compared to usual care by combining test characteristics with evidence on consequences of the outcome, effects and burden of the further management, and costs. In case the model is worth considering for use in clinical practice, an empirical impact study can determine whether the model indeed leads to better care. Not only outcomes are important but also a lot of other aspects like applicability of the model, acceptability of the intervention, risk counselling, satisfaction, and real costs.

\section{Strengths and limitations}

The main strengths of our study were the design and data collection. We performed a multicenter prospective study in which nearly all pregnant women less than 16 weeks of gestation were eligible. This design ensures a representative and unselected population to a high degree. The use of online questionnaires, an efficient data collection tool in women of reproductive age, improved our data quality and quantity of missing data due incorporation of validation checks ${ }^{47}$. Our dataset contained less than $1 \%$ missing data for almost all predictors and these were imputed in order to prevent biased results and a loss of statistical precision. Outcome assessment based on both the postpartum questionnaires and medical records has ensured for accurate and most complete available information as possible in a large cohort ${ }^{48}$.

We selected all existing first trimester prediction models based on routinely collected maternal characteristics for the risk of PE. The paper of Syngelaki et al., included on the basis of citation lists, was not selected from our systematic search as the title and abstract did not clearly indicate that it addressed prediction models for a wide range of adverse pregnancy outcomes. Syngelaki's model was also not described in existing systematic reviews about prediction models for $P E^{13,14,39,49}$. A limitation in the selection process is that we had to exclude a substantial proportion of prediction models as the algorithm was not available, even after contacting the authors. Moreover, the dataset was too small to validate algorithms predicting early PE. Another point to be mentioned is that we used our own eligibility criteria for a fair comparison of all models. Analysis of the performance measures of the models according to their specific eligibility criteria however did not show better performance. Furthermore, we had to create a proxy variable for the predictors woman's own birth weight and CRL. These proxy variables could have led to an underestimation of the predictive performance of the model. The variable blood pressure could have been subject to measurement error as this variable was selfreported and measured according to routine clinical practice ${ }^{50}$. Despite availability of standardized protocols for blood pressure measurement, the procedure is often not strictly followed in real practice. A last limitation to be mentioned is the number of cases in our validation cohort. No golden rule is available for the sample size of external validation studies. However, studies suggest that a minimum of 100 events, or preferably more, are needed for accurate and precise model performances ${ }^{31,51}$. The 
study of Collins et al. showed that the precision of the c-statistic and calibration slope did not differ considerably between 75 and 100 cases $^{51}$.

\section{Conclusion}

Five of the ten included first trimester prediction models based on routinely collected maternal characteristics for the risk of PE showed moderate predictive performance after external validation. The models are expected to perform better than current available guidelines in the separation of high- and low-risk pregnancies. Further research should focus on the determination of an acceptable risk threshold and impact of implementation of a chosen model in clinical practice. 


\section{Supplementary materials}

Supplementary File S3.1

Supplementary Table S3.1

Supplementary Table S3.2

Supplementary Table S3.3

Supplementary Table S3.4

Supplementary Table S3.5

Supplementary Figure S3.1A-B

Supplementary Figure S3.2A-B

Supplementary Figure S3.3A-B
Search strategy and references included studies

Comprehensive overview included prediction models for external validation

Definition and assessment of predictors

Model algorithms for prediction of pre-eclampsia as applied in the Expect Study I cohort

Characteristics of pregnancies in the observed and imputed validation cohort

Baseline characteristics original cohorts and validation cohort (case-mix)

ROC curves of externally validated first trimester prediction models for pre-eclampsia. $(A)=$ model $a$ priori risk, $(B)=$ model a priori risk + mean arterial pressure

ROC curves of externally validated first trimester prediction models for pre-eclampsia in nulliparous women. $(A)=$ model a priori risk $(B)=$ model a priori risk + mean arterial pressure

Calibration plots of first trimester prediction models for preeclampsia in nulliparous women. The grey line is the reference line with intercept $=0$ and slope $=1$ (perfect calibration). Triangles correspond to grouped predicted risks with 95\% confidence intervals (vertical lines). *Different limits $x$ - and $y$ axis 


\section{References}

1. Mol, B.W., Roberts, C.T., Thangaratinam, S., Magee, L.A., de Groot, C.J., and Hofmeyr, G.J., Preeclampsia. Lancet, 2016. 387(10022): p. 999-1011.

2. Poon, L.C. and Nicolaides, K.H., Early prediction of preeclampsia. Obstet Gynecol Int, 2014. 2014: p. 297-397.

3. Hofmeyr, G.J., Lawrie, T.A., Atallah, A.N., Duley, L., and Torloni, M.R., Calcium supplementation during pregnancy for preventing hypertensive disorders and related problems. Cochrane Database Syst Rev, 2014(6): p. CD001059.

4. Duley, L., Henderson-Smart, D.J., Meher, S., and King, J.F., Antiplatelet agents for preventing preeclampsia and its complications. Cochrane Database Syst Rev, 2007(2): p. Cd004659.

5. Askie, L.M., Duley, L., Henderson-Smart, D.J., and Stewart, L.A., Antiplatelet agents for prevention of pre-eclampsia: a meta-analysis of individual patient data. Lancet, 2007. 369(9575): p. 1791-8.

6. Bujold, E., Roberge, S., Lacasse, Y., Bureau, M., Audibert, F., Marcoux, S., et al., Prevention of preeclampsia and intrauterine growth restriction with aspirin started in early pregnancy: a metaanalysis. Obstet Gynecol, 2010. 116(2 Pt 1): p. 402-14.

7. Roberge, S., Nicolaides, K.H., Demers, S., Villa, P., and Bujold, E., Prevention of perinatal death and adverse perinatal outcome using low-dose aspirin: a meta-analysis. Ultrasound Obstet Gynecol, 2013. 41(5): p. 491-9.

8. Henderson, J.T., Whitlock, E.P., O'Connor, E., Senger, C.A., Thompson, J.H., and Rowland, M.G., Lowdose aspirin for prevention of morbidity and mortality from preeclampsia: a systematic evidence review for the U.S. Preventive Services Task Force. Ann Intern Med, 2014. 160(10): p. 695-703.

9. Meher, S., Duley, L., Hunter, K., and Askie, L., Antiplatelet therapy before or after 16 weeks' gestation for preventing preeclampsia: an individual participant data meta-analysis. Am J Obstet Gynecol, 2017. 216(2): p. 121-128 e2.

10. Roberge, S., Nicolaides, K., Demers, S., Hyett, J., Chaillet, N., and Bujold, E., The role of aspirin dose on the prevention of preeclampsia and fetal growth restriction: systematic review and meta-analysis. Am J Obstet Gynecol, 2017. 216(2): p. 110-120 e6.

11. Roberge, S., Bujold, E., and Nicolaides, K.H., Aspirin for the prevention of preterm and term preeclampsia: systematic review and metaanalysis. Am J Obstet Gynecol, 2017.

12. Rolnik, D.L., Wright, D., Poon, L.C., O'Gorman, N., Syngelaki, A., de Paco Matallana, C., et al., Aspirin versus Placebo in Pregnancies at High Risk for Preterm Preeclampsia. N Engl J Med, 2017. 377(7): p. 613-622.

13. Al-Rubaie, Z., Askie, L.M., Ray, J.G., Hudson, H.M., and Lord, S.J., The performance of risk prediction models for pre-eclampsia using routinely collected maternal characteristics and comparison with models that include specialised tests and with clinical guideline decision rules: a systematic review. BJOG, 2016. 123(9): p. 1441-52.

14. Henderson, J.T., Thompson, J.H., Burda, B.U., and Cantor, A., Preeclampsia screening: Evidence report and systematic review for the us preventive services task force. JAMA, 2017. 317(16): p. 1668-1683.

15. Steyerberg, E., Clinical prediction models: a practical approach to development, validation, and updating. 2008: Springer Science \& Business Media.

16. Justice, A.C., Covinsky, K.E., and Berlin, J.A., Assessing the generalizability of prognostic information. Ann Intern Med, 1999. 130(6): p. 515-24.

17. Macdonald-Wallis, C., Silverwood, R.J., de Stavola, B.L., Inskip, H., Cooper, C., Godfrey, K.M., et al., Antenatal blood pressure for prediction of pre-eclampsia, preterm birth, and small for gestational age babies: development and validation in two general population cohorts. BMJ, 2015. 351: p. h5948.

18. Kenny, L.C., Black, M.A., Poston, L., Taylor, R., Myers, J.E., Baker, P.N., et al., Early pregnancy prediction of preeclampsia in nulliparous women, combining clinical risk and biomarkers: the Screening for Pregnancy Endpoints (SCOPE) international cohort study. Hypertension, 2014. 64(3): p. 644-52.

19. Direkvand-Moghadam, A., Khosravi, A., and Sayehmiri, K., Predictive factors for preeclampsia in pregnant women: a Receiver Operation Character approach. Arch Med Sci, 2013. 9(4): p. 684-9.

20. Syngelaki, A., Bredaki, F.E., Vaikousi, E., Maiz, N., and Nicolaides, K.H., Body mass index at 11-13 weeks' gestation and pregnancy complications. Fetal Diagn Ther, 2011. 30(4): p. 250-65. 
21. North, R.A., McCowan, L.M., Dekker, G.A., Poston, L., Chan, E.H., Stewart, A.W., et al., Clinical risk prediction for pre-eclampsia in nulliparous women: development of model in international prospective cohort. BMJ, 2011. 342: p. d1875.

22. Seed, P.T., Chappell, L.C., Black, M.A., Poppe, K.K., Hwang, Y.C., Kasabov, N., et al., Prediction of preeclampsia and delivery of small for gestational age babies based on a combination of clinical risk factors in high-risk women. Hypertens Pregnancy, 2011. 30(1): p. 58-73.

23. Audibert, F., Boucoiran, I., An, N., Aleksandrov, N., Delvin, E., Bujold, E., et al., Screening for preeclampsia using first-trimester serum markers and uterine artery Doppler in nulliparous women. Am J Obstet Gynecol, 2010. 203(4): p. 383.e1-8.

24. Poon, L.C., Kametas, N., Bonino, S., Vercellotti, E., and Nicolaides, K.H., Urine albumin concentration and albumin-to-creatinine ratio at $11(+0)$ to $13(+6)$ weeks in the prediction of pre-eclampsia. BJOG, 2008. 115(7): p. 866-73.

25. Poon, L.C., Kametas, N.A., Pandeva, I., Valencia, C., and Nicolaides, K.H., Mean arterial pressure at $11(+0)$ to $13(+6)$ weeks in the prediction of preeclampsia. Hypertension, 2008. 51(4): p. 1027-33.

26. Plasencia, W., Maiz, N., Bonino, S., Kaihura, C., and Nicolaides, K.H., Uterine artery Doppler at $11+0$ to $13+6$ weeks in the prediction of pre-eclampsia. Ultrasound Obstet Gynecol, 2007. 30(5): p. 742-9.

27. Meertens, L.J.E., Scheepers, H.C., De Vries, R.G., Dirksen, C.D., Korstjens, I., Mulder, A.L., et al., External Validation Study of First Trimester Obstetric Prediction Models (Expect Study I): Research Protocol and Population Characteristics. JMIR Res Protoc, 2017. 6(10): p. e203.

28. Robinson, H.P. and Fleming, J.E., A critical evaluation of sonar "crown-rump length" measurements. BJOG, 1975. 82(9): p. 702-10.

29. Brown, M.A., Hague, W.M., Higgins, J., Lowe, S., McCowan, L., Oats, J., et al., The detection, investigation and management of hypertension in pregnancy: full consensus statement. Aust $\mathrm{N} \mathrm{Z} \mathrm{J}$ Obstet Gynaecol, 2000. 40(2): p. 139-55.

30. Nederlandse Vereniging voor Obstetrie en Gynaecologie. Richtlijn Hypertensieve aandoeningen in de zwangerschap. 200514 December 2016]; Available from: http://nvog-documenten.nl/uploaded/ docs/Hypertensieve aandoeningen in de zwangerschap.pdf.

31. Vergouwe, Y., Steyerberg, E.W., Eijkemans, M.J., and Habbema, J.D., Substantial effective sample sizes were required for external validation studies of predictive logistic regression models. J Clin Epidemiol, 2005. 58(5): p. 475-83.

32. Van Buuren, S., Flexible imputation of missing data. 2012: CRC press.

33. Steyerberg, E.W. and Vergouwe, Y., Towards better clinical prediction models: seven steps for development and an ABCD for validation. Eur Heart J, 2014. 35(29): p. 1925-31.

34. Vickers, A.J. and Elkin, E.B., Decision curve analysis: a novel method for evaluating prediction models. Med Decis Making, 2006. 26(6): p. 565-74.

35. National Collaborating Centre for Women's and Children's Health. Hypertension in Pregnancy: The Management of Hypertensive Disorders During Pregnancy [CG107]. National Institute for Health and Clinical Excellence: Guidance. 2010.

36. LeFevre, M.L., Low-dose aspirin use for the prevention of morbidity and mortality from preeclampsia: U.S. Preventive Services Task Force recommendation statement. Ann Intern Med, 2014. 161(11): p. 819-26.

37. American College of Obstetricians and Gynecologists. Practice Advisory on Low-Dose Aspirin and Prevention of Preeclampsia: Updated Recommendations (July 2016). 1 November 2016]; Available from: http://www.acog.org/About-ACOG/News-Room/Practice-Advisories/Practice-Advisory-LowDose-Aspirin-and-Prevention-of-Preeclampsia-Updated-Recommendations.

38. Steyerberg, E.W., Vickers, A.J., Cook, N.R., Gerds, T., Gonen, M., Obuchowski, N., et al., Assessing the performance of prediction models: a framework for traditional and novel measures. Epidemiology, 2010. 21(1): p. 128-38.

39. Kleinrouweler, C.E., Cheong-See, F.M., Collins, G.S., Kwee, A., Thangaratinam, S., Khan, K.S., et al., Prognostic models in obstetrics: available, but far from applicable. Am J Obstet Gynecol, 2016. 214(1): p. $79-90$ e36.

40. Allen, R.E., Zamora, J., Arroyo-Manzano, D., Velauthar, L., Allotey, J., Thangaratinam, S., et al., External validation of preexisting first trimester preeclampsia prediction models. Eur J Obstet Gynecol Reprod Biol, 2017. 217: p. 119-125. 
41. Farina, A., Rapacchia, G., Freni Sterrantino, A., Pula, G., Morano, D., and Rizzo, N., Prospective evaluation of ultrasound and biochemical-based multivariable models for the prediction of late preeclampsia. Prenat Diagn, 2011. 31(12): p. 1147-52.

42. Herraiz, I., Arbues, J., Camano, I., Gomez-Montes, E., Graneras, A., and Galindo, A., Application of a first-trimester prediction model for pre-eclampsia based on uterine arteries and maternal history in high-risk pregnancies. Prenat Diagn, 2009. 29(12): p. 1123-9.

43. Duckitt, K. and Harrington, D., Risk factors for pre-eclampsia at antenatal booking: systematic review of controlled studies. BMJ, 2005. 330(7491): p. 565.

44. Hernandez-Diaz, S., Toh, S., and Cnattingius, S., Risk of pre-eclampsia in first and subsequent pregnancies: prospective cohort study. BMJ, 2009. 338: p. b2255.

45. Bartsch, E., Medcalf, K.E., Park, A.L., and Ray, J.G., Clinical risk factors for pre-eclampsia determined in early pregnancy: systematic review and meta-analysis of large cohort studies. BMJ, 2016. 353: p. i1753.

46. World Health Organization. WHO recommendations for prevention and treatment of pre-eclampsia and eclampsia. Geneva, Switzerland, 2011.

47. Van Gelder, M.M., Bretveld, R.W., and Roeleveld, N., Web-based questionnaires: the future in epidemiology? Am J Epidemiol, 2010. 172(11): p.1292-8.

48. Van Gelder, M., Vorstenbosch, S., Derks, L., Te Winkel, B., van Puijenbroek, E.P., and Roeleveld, N., Web-based questionnaires to assess perinatal outcome proved to be valid. J Clin Epidemiol, 2017. 90: p. 136-143.

49. Brunelli, V.B. and Prefumo, F., Quality of first trimester risk prediction models for pre-eclampsia: a systematic review. BJOG, 2015. 122(7): p. 904-14.

50. Poon, L.C., Zymeri, N.A., Zamprakou, A., Syngelaki, A., and Nicolaides, K.H., Protocol for measurement of mean arterial pressure at 11-13 weeks' gestation. Fetal Diagn Ther, 2012. 31(1): p. 42-8.

51. Collins, G.S., Ogundimu, E.O., and Altman, D.G., Sample size considerations for the external validation of a multivariable prognostic model: a resampling study. Stat Med, 2016. 35(2): p. 214-26. 


\section{Supplementary File S3.1 - Search strategy and references excluded studies}

\section{Search strategy PubMed}

("predictive model"[tiab] OR "predictive models"[tiab] OR prediction[tiab] OR "risk calculator"[tiab] OR "risk calculators"[tiab] OR "risk model"[tiab] OR "risk models"[tiab] OR "risk score"[tiab] OR algorithm*[tiab] OR "risk assessment"[tiab] OR nomogram[tiab] OR "prognostic model"[tiab] OR "prognostic models"[tiab] OR "scoring system"[tiab] OR "scoring systems"[tiab] OR "screening model"[tiab] OR "screening models"[tiab] OR "decision rule"[tiab] OR "decision rules"[tiab]) AND (preeclamp*[tiab] OR pre-eclamp*[tiab] OR "Pre-Eclampsia"[Mesh])

\section{References excluded studies}

\section{Algorithm non-invasive predictors not available}

1. Akolekar, R., Zaragoza, E., Poon, L.C., Pepes, S., and Nicolaides, K.H., Maternal serum placental growth factor at $11+0$ to $13+6$ weeks of gestation in the prediction of pre-eclampsia. Ultrasound Obstet Gynecol, 2008. 32(6): p. 732-9.

2. Onwudiwe, N., Yu, C.K., Poon, L.C., Spiliopoulos, I., and Nicolaides, K.H., Prediction of pre-eclampsia by a combination of maternal history, uterine artery Doppler and mean arterial pressure. Ultrasound Obstet Gynecol, 2008. 32(7): p. 877-83.

3. Poon, L.C., Maiz, N., Valencia, C., Plasencia, W., and Nicolaides, K.H., First-trimester maternal serum pregnancy-associated plasma protein-A and pre-eclampsia. Ultrasound Obstet Gynecol, 2009. 33(1): p. 23-33.

4. Leal, A.M., Poon, L.C., Frisova, V., Veduta, A., and Nicolaides, K.H., First-trimester maternal serum tumor necrosis factor receptor-1 and pre-eclampsia. Ultrasound Obstet Gynecol, 2009. 33(2): p. 13541.

5. Poon, L.C., Nekrasova, E., Anastassopoulos, P., Livanos, P., and Nicolaides, K.H., First-trimester maternal serum matrix metalloproteinase-9 (MMP-9) and adverse pregnancy outcome. Prenat Diagn, 2009. 29(6): p. 553-9.

6. Akolekar, R., Minekawa, R., Veduta, A., Romero, X.C., and Nicolaides, K.H., Maternal plasma inhibin A at 11-13 weeks of gestation in hypertensive disorders of pregnancy. Prenat Diagn, 2009. 29(8): p. 75360.

7. Akolekar, R., Syngelaki, A., Sarquis, R., Zvanca, M., and Nicolaides, K.H., Prediction of early, intermediate and late pre-eclampsia from maternal factors, biophysical and biochemical markers at 11-13 weeks. Prenat Diagn, 2011. 31(1): p. 66-74.

8. Khalil, A., Akolekar, R., Syngelaki, A., Elkhouli, M., and Nicolaides, K.H., Maternal hemodynamics at 1113 weeks' gestation and risk of pre-eclampsia. Ultrasound Obstet Gynecol, 2012. 40(1): p. 28-34.

9. Myatt, L., Clifton, R.G., Roberts, J.M., Spong, C.Y., Hauth, J.C., Varner, M.W., et al., First-trimester prediction of preeclampsia in nulliparous women at low risk. Obstet Gynecol, 2012. 119(6): p. 123442.

10. Parra-Cordero, M., Rodrigo, R., Barja, P., Bosco, C., Rencoret, G., Sepulveda-Martinez, A., et al., Prediction of early and late pre-eclampsia from maternal characteristics, uterine artery Doppler and markers of vasculogenesis during first trimester of pregnancy. Ultrasound Obstet Gynecol, 2013. 41(5): p. 538-44.

11. Goetzinger, K.R., Zhong, Y., Cahill, A.G., Odibo, L., Macones, G.A., and Odibo, A.O., Efficiency of firsttrimester uterine artery Doppler, a-disintegrin and metalloprotease 12, pregnancy-associated plasma protein a, and maternal characteristics in the prediction of preeclampsia. J Ultrasound Med, 2013. 32(9): p. 1593-600.

12. Keikkala, E., Vuorela, P., Laivuori, H., Romppanen, J., Heinonen, S., and Stenman, U.H., First trimester hyperglycosylated human chorionic gonadotrophin in serum - a marker of early-onset preeclampsia. Placenta, 2013. 34(11): p. 1059-65. 
13. Schneuer, F.J., Roberts, C.L., Ashton, A.W., Guilbert, C., Tasevski, V., Morris, J.M., et al., Angiopoietin 1 and 2 serum concentrations in first trimester of pregnancy as biomarkers of adverse pregnancy outcomes. Am J Obstet Gynecol, 2014. 210(4): p. 345.e1-9.

14. Metcalfe, A., Langlois, S., Macfarlane, J., Vallance, H., and Joseph, K.S., Prediction of obstetrical risk using maternal serum markers and clinical risk factors. Prenat Diagn, 2014. 34(2): p. 172-9.

15. Gurgel Alves, J.A., Praciano de Sousa, P.C., Bezerra Maia, E.H.M.S., Kane, S.C., and da Silva Costa, F., First-trimester maternal ophthalmic artery Doppler analysis for prediction of pre-eclampsia. Ultrasound Obstet Gynecol, 2014. 44(4): p. 411-8.

16. Skrastad, R.B., Hov, G.G., Blaas, H.G., Romundstad, P.R., and Salvesen, K.A., A prospective study of screening for hypertensive disorders of pregnancy at 11-13 weeks in a Scandinavian population. Acta Obstet Gynecol Scand, 2014. 93(12): p. 1238-47.

17. Giguere, Y., Masse, J., Theriault, S., Bujold, E., Lafond, J., Rousseau, F., et al., Screening for preeclampsia early in pregnancy: performance of a multivariable model combining clinical characteristics and biochemical markers. BJOG, 2015. 122(3): p. 402-10.

18. Widmer, M., Cuesta, C., Khan, K.S., Conde-Agudelo, A., Carroli, G., Fusey, S., et al., Accuracy of angiogenic biomarkers at 20weeks' gestation in predicting the risk of pre-eclampsia: A WHO multicentre study. Pregnancy Hypertens, 2015. 5(4): p. 330-8.

19. Anderson, U.D., Gram, M., Ranstam, J., Thilaganathan, B., Kerstrom, B., and Hansson, S.R., Fetal hemoglobin, alpha1-microglobulin and hemopexin are potential predictive first trimester biomarkers for preeclampsia. Pregnancy Hypertens, 2016. 6(2): p. 103-9.

\section{Model published in another article}

1. Poon, L.C., Staboulidou, I., Maiz, N., Plasencia, W., and Nicolaides, K.H., Hypertensive disorders in pregnancy: screening by uterine artery Doppler at 11-13 weeks. Ultrasound Obstet Gynecol, 2009. 34(2): p. 142-8.

2. Poon, L.C., Karagiannis, G., Leal, A., Romero, X.C., and Nicolaides, K.H., Hypertensive disorders in pregnancy: screening by uterine artery Doppler imaging and blood pressure at 11-13 weeks. Ultrasound Obstet Gynecol, 2009. 34(5): p. 497-502.

3. Akolekar, R., Syngelaki, A., Beta, J., Kocylowski, R., and Nicolaides, K.H., Maternal serum placental protein 13 at 11-13 weeks of gestation in preeclampsia. Prenat Diagn, 2009. 29(12): p. 1103-8.

4. Poon, L.C., Stratieva, V., Piras, S., Piri, S., and Nicolaides, K.H., Hypertensive disorders in pregnancy: combined screening by uterine artery Doppler, blood pressure and serum PAPP-A at 11-13 weeks. Prenat Diagn, 2010. 30(3): p. 216-23.

5. Foidart, J.M., Munaut, C., Chantraine, F., Akolekar, R., and Nicolaides, K.H., Maternal plasma soluble endoglin at 11-13 weeks' gestation in pre-eclampsia. Ultrasound Obstet Gynecol, 2010. 35(6): p. 6807.

6. Poon, L.C., Akolekar, R., Lachmann, R., Beta, J., and Nicolaides, K.H., Hypertensive disorders in pregnancy: screening by biophysical and biochemical markers at 11-13 weeks. Ultrasound Obstet Gynecol, 2010. 35(6): p. 662-70.

7. Ashoor, G., Maiz, N., Rotas, M., Kametas, N.A., and Nicolaides, K.H., Maternal thyroid function at 11 to 13 weeks of gestation and subsequent development of preeclampsia. Prenat Diagn, 2010. 30(11): p. 1032-8.

8. Direkvand-Moghadam, A., Khosravi, A., and Sayehmiri, K., Predictive factors for preeclampsia in pregnant women: a unvariate and multivariate logistic regression analysis. Acta Biochim Pol, 2012. 59(4): p. 673-7.

9. Akolekar, R., Syngelaki, A., Poon, L., Wright, D., and Nicolaides, K.H., Competing risks model in early screening for preeclampsia by biophysical and biochemical markers. Fetal Diagn Ther, 2013. 33(1): p. 8-15.

10. Crovetto, F., Figueras, F., Triunfo, S., Crispi, F., Rodriguez-Sureda, V., Peguero, A., et al., Added value of angiogenic factors for the prediction of early and late preeclampsia in the first trimester of pregnancy. Fetal Diagn Ther, 2014. 35(4): p. 258-66. 
11. Yliniemi, A., Nurkkala, M.M., Kopman, S., Korpimaki, T., Kouru, H., Ryynanen, M., et al., First trimester placental retinol-binding protein 4 (RBP4) and pregnancy-associated placental protein A (PAPP-A) in the prediction of early-onset severe pre-eclampsia. Metabolism, 2015. 64(4): p. 521-6.

12. Crovetto, F., Figueras, F., Crispi, F., Triunfo, S., Pugia, M., Lasalvia, L., et al., Forms of Circulating Luteinizing Hormone Human Chorionic Gonadotropin Receptor for the Prediction of Early and Late Preeclampsia in the First Trimester of Pregnancy. Fetal Diagn Ther, 2015. 38(2): p. 94-102.

13. Koster, M.P., Vreeken, R.J., Harms, A.C., Dane, A.D., Kuc, S., Schielen, P.C., et al., First-Trimester Serum Acylcarnitine Levels to Predict Preeclampsia: A Metabolomics Approach. Dis Markers, 2015. 2015: p. 857108.

14. Tsiakkas, A., Mendez, O., Wright, A., Wright, D., and Nicolaides, K.H., Maternal serum soluble fms-like tyrosine kinase-1 at $12,22,32$ and 36 weeks' gestation in screening for pre-eclampsia. Ultrasound Obstet Gynecol, 2016. 47(4): p. 478-83.

15. Bredaki, F.E., Mataliotakis, M., Wright, A., Wright, D., and Nicolaides, K.H., Maternal serum alphafetoprotein at 12, 22 and 32 weeks' gestation in screening for pre-eclampsia. Ultrasound Obstet Gynecol, 2016. 47(4): p. 466-71.

16. Wright, D., Krajewska, K., Bogdanova, A., Wright, A., and Nicolaides, K.H., Maternal serum soluble fmslike tyrosine kinase-1 at 22 and 32 weeks in the prediction of pre-eclampsia. Ultrasound Obstet Gynecol, 2016. 47(6): p. 755-61.

17. O'Gorman, N., Wright, D., Syngelaki, A., Akolekar, R., Wright, A., Poon, L.C., et al., Competing risks model in screening for preeclampsia by maternal factors and biomarkers at 11-13 weeks gestation. Am J Obstet Gynecol, 2016. 214(1): p. 103 e1-103 e12.

\section{Early, late, and severe PE}

1. Poon, L.C., Kametas, N.A., Chelemen, T., Leal, A., and Nicolaides, K.H., Maternal risk factors for hypertensive disorders in pregnancy: a multivariate approach. J Hum Hypertens, 2010. 24(2): p. 10410.

2. Poon, L.C., Kametas, N.A., Valencia, C., Chelemen, T., and Nicolaides, K.H., Hypertensive disorders in pregnancy: screening by systolic diastolic and mean arterial pressure at 11-13 weeks. Hypertens Pregnancy, 2011. 30(1): p. 93-107.

3. Scazzocchio, E., Figueras, F., Crispi, F., Meler, E., Masoller, N., Mula, R., et al., Performance of a firsttrimester screening of preeclampsia in a routine care low-risk setting. Am J Obstet Gynecol, 2013. 208(3): p. 203.e1-203.e10.

4. Kuc, S., Koster, M.P., Franx, A., Schielen, P.C., and Visser, G.H., Maternal characteristics, mean arterial pressure and serum markers in early prediction of preeclampsia. PLoS One, 2013. 8(5): p. e63546.

5. Myers, J.E., Kenny, L.C., McCowan, L.M., Chan, E.H., Dekker, G.A., Poston, L., et al., Angiogenic factors combined with clinical risk factors to predict preterm pre-eclampsia in nulliparous women: a predictive test accuracy study. BJOG, 2013. 120(10): p. 1215-23.

6. Baschat, A.A., Magder, L.S., Doyle, L.E., Atlas, R.O., Jenkins, C.B., and Blitzer, M.G., Prediction of preeclampsia utilizing the first trimester screening examination. Am J Obstet Gynecol, 2014. 211(5): p. 514.e1-7.

7. Teixeira, C., Tejera, E., Martins, H., Pereira, A.T., Costa-Pereira, A., and Rebelo, I., First trimester aneuploidy screening program for preeclampsia prediction in a portuguese obstetric population. Obstet Gynecol Int, 2014. 2014: p. 435037.

8. Crovetto, F., Figueras, F., Triunfo, S., Crispi, F., Rodriguez-Sureda, V., Dominguez, C., et al., First trimester screening for early and late preeclampsia based on maternal characteristics, biophysical parameters, and angiogenic factors. Prenat Diagn, 2015. 35(2): p. 183-91.

9. Yliniemi, A., Makikallio, K., Korpimaki, T., Kouru, H., Marttala, J., and Ryynanen, M., Combination of PAPPA, fhCGbeta, AFP, PIGF, sTNFR1, and Maternal Characteristics in Prediction of Early-onset Preeclampsia. Clin Med Insights Reprod Health, 2015. 9: p. 13-20. 


\section{Gestational age at delivery with PE}

1. Wright, D., Akolekar, R., Syngelaki, A., Poon, L.C., and Nicolaides, K.H., A competing risks model in early screening for preeclampsia. Fetal Diagn Ther, 2012. 32(3): p. 171-8.

2. Gallo, D., Poon, L.C., Fernandez, M., Wright, D., and Nicolaides, K.H., Prediction of preeclampsia by mean arterial pressure at 11-13 and 20-24 weeks' gestation. Fetal Diagn Ther, 2014. 36(1): p. 28-37.

3. Wright, D., Syngelaki, A., Akolekar, R., Poon, L.C., and Nicolaides, K.H., Competing risks model in screening for preeclampsia by maternal characteristics and medical history. Am J Obstet Gynecol, 2015. 213(1): p. 62.e1-10.

4. Tayyar, A., Krithinakis, K., Wright, A., Wright, D., and Nicolaides, K.H., Mean arterial pressure at 12, 22, 32 and 36 weeks' gestation in screening for pre-eclampsia. Ultrasound Obstet Gynecol, 2016. 47(5): p. 573-9. 


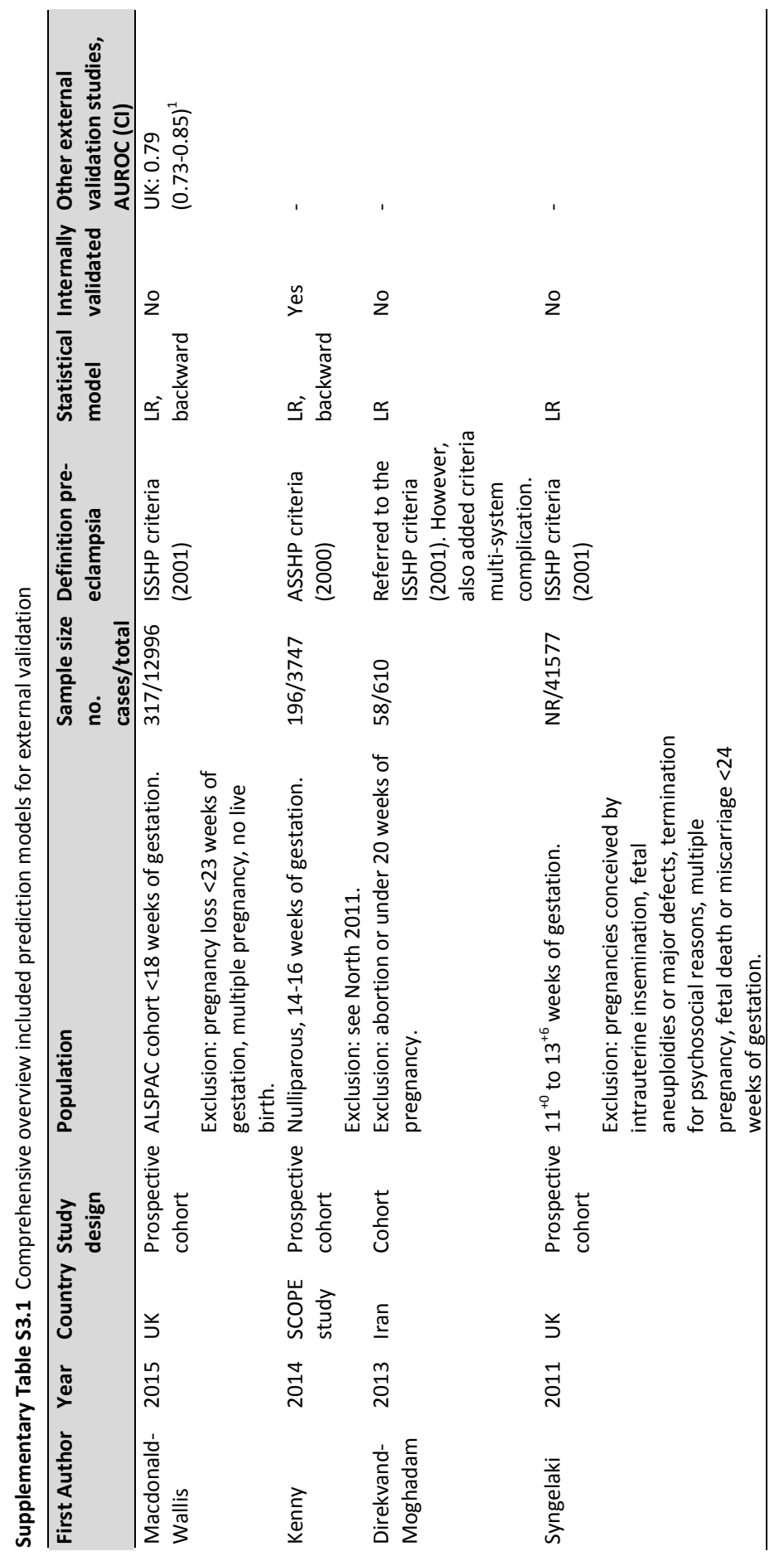




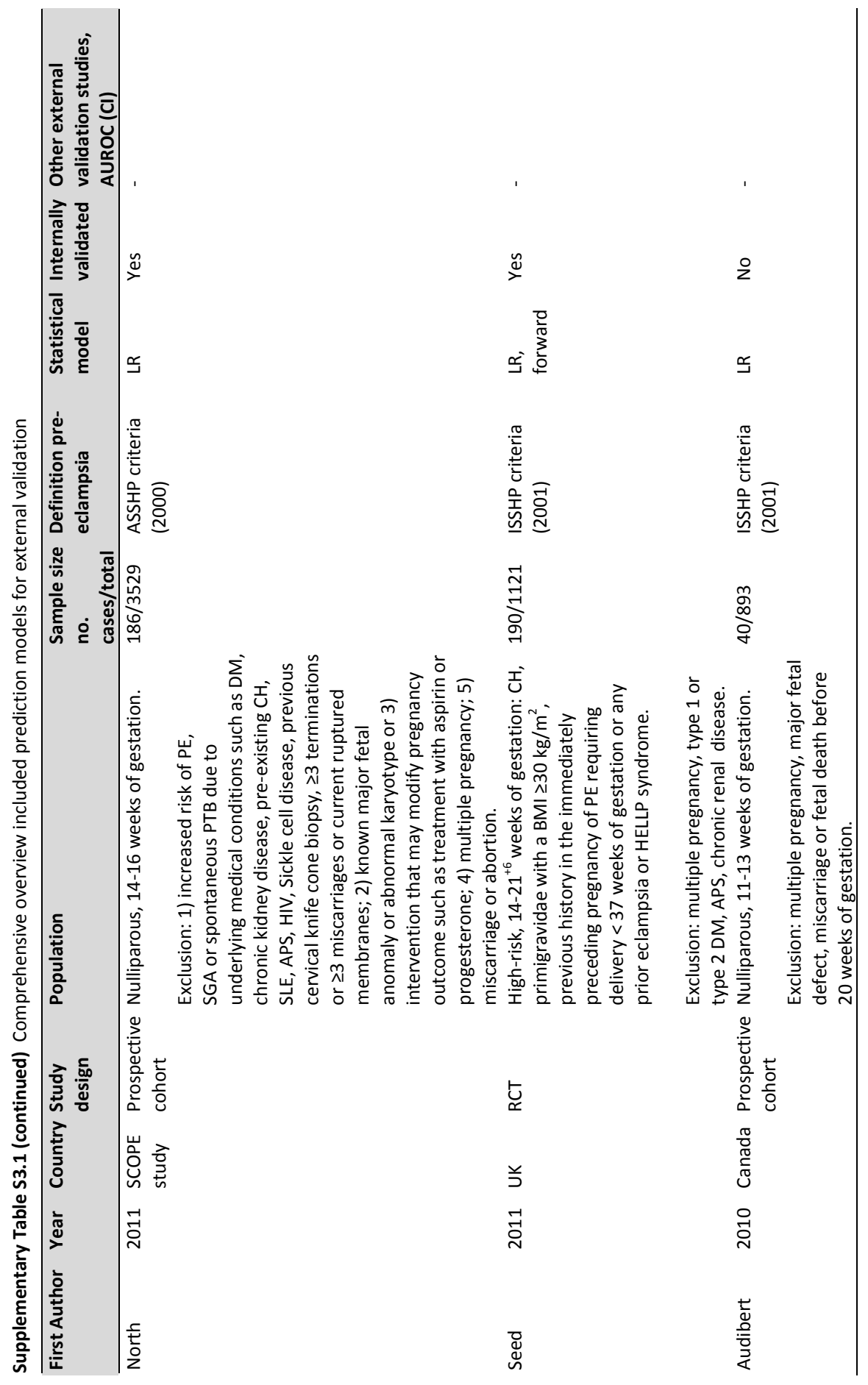




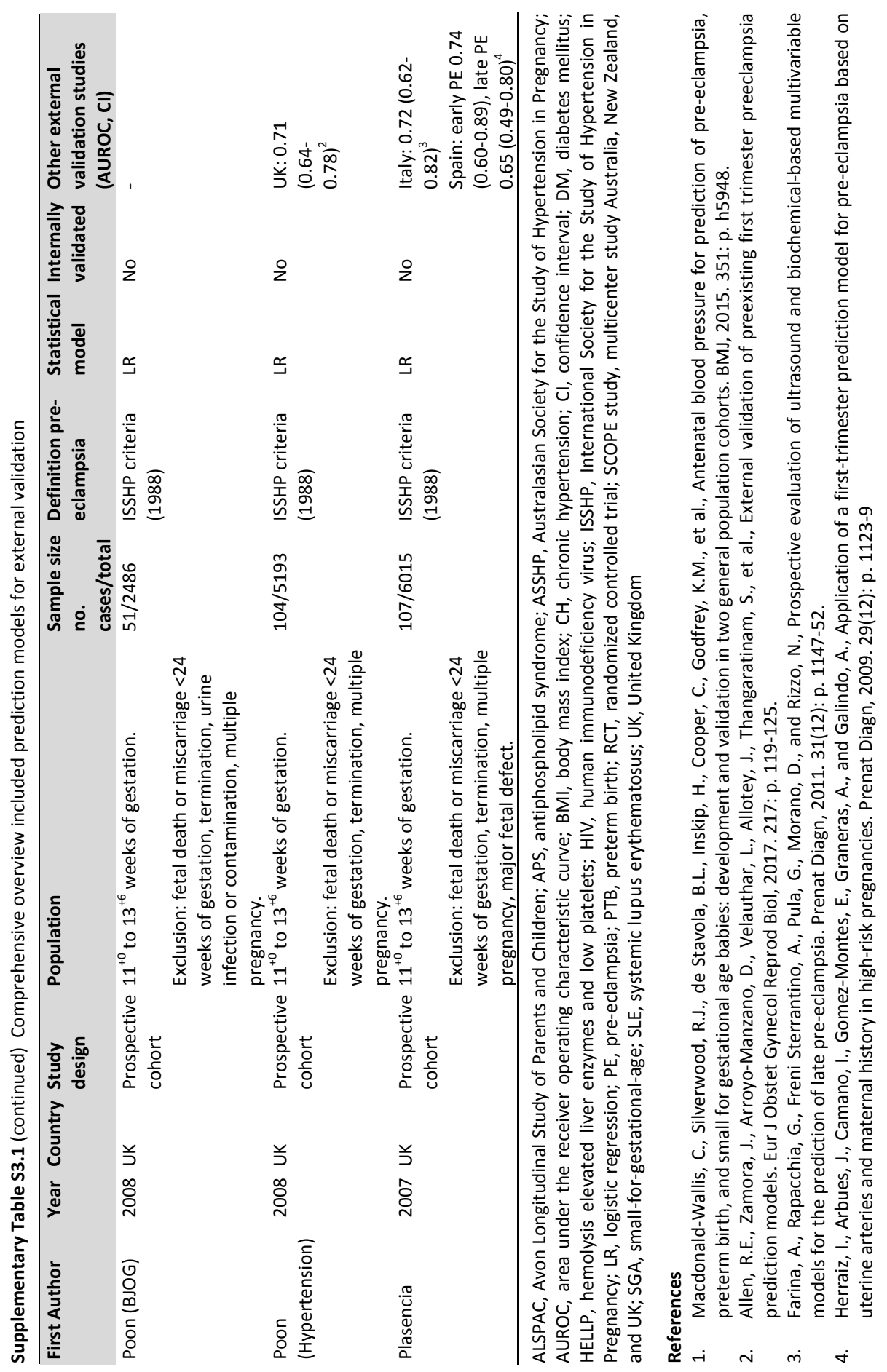




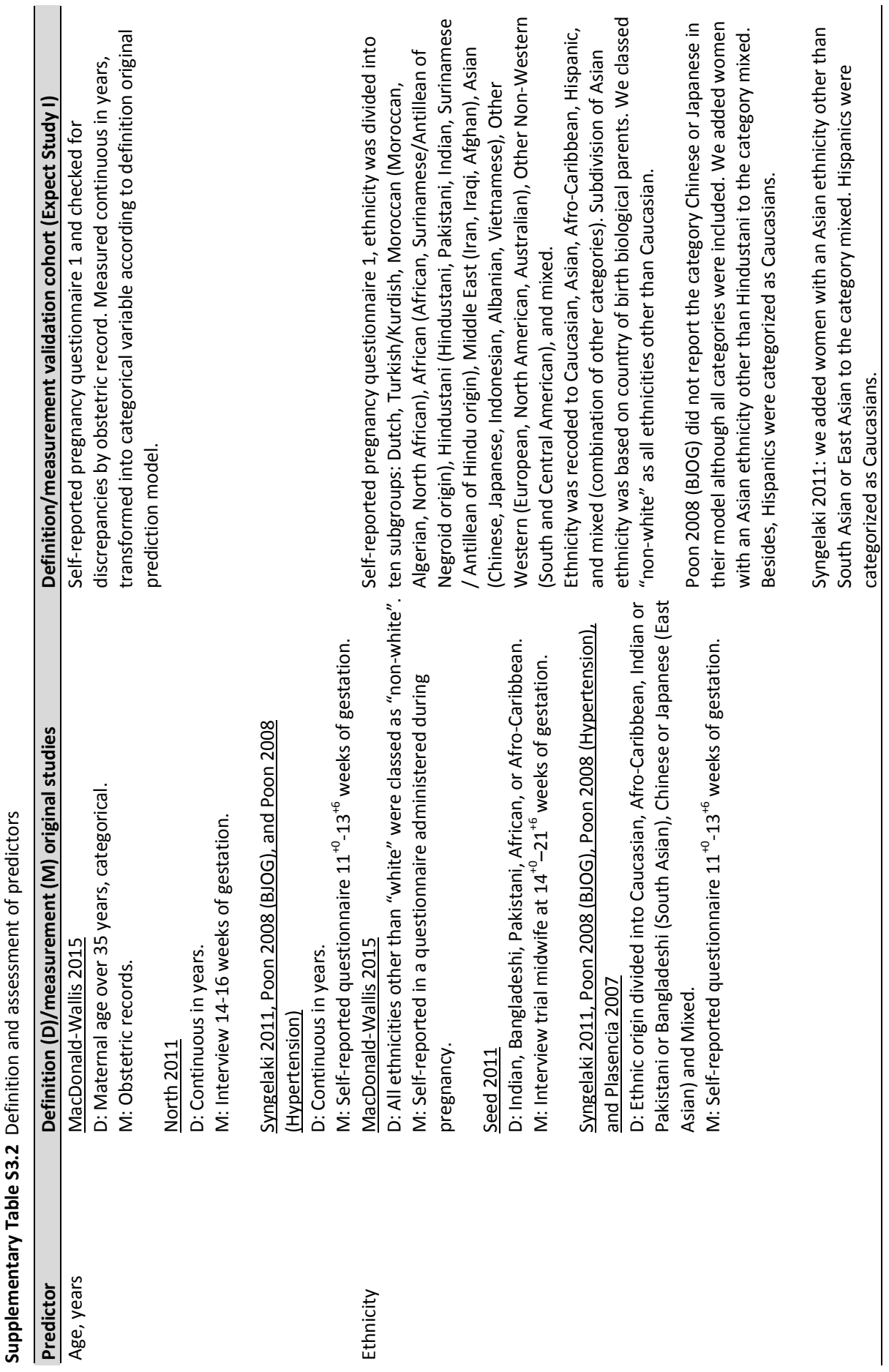




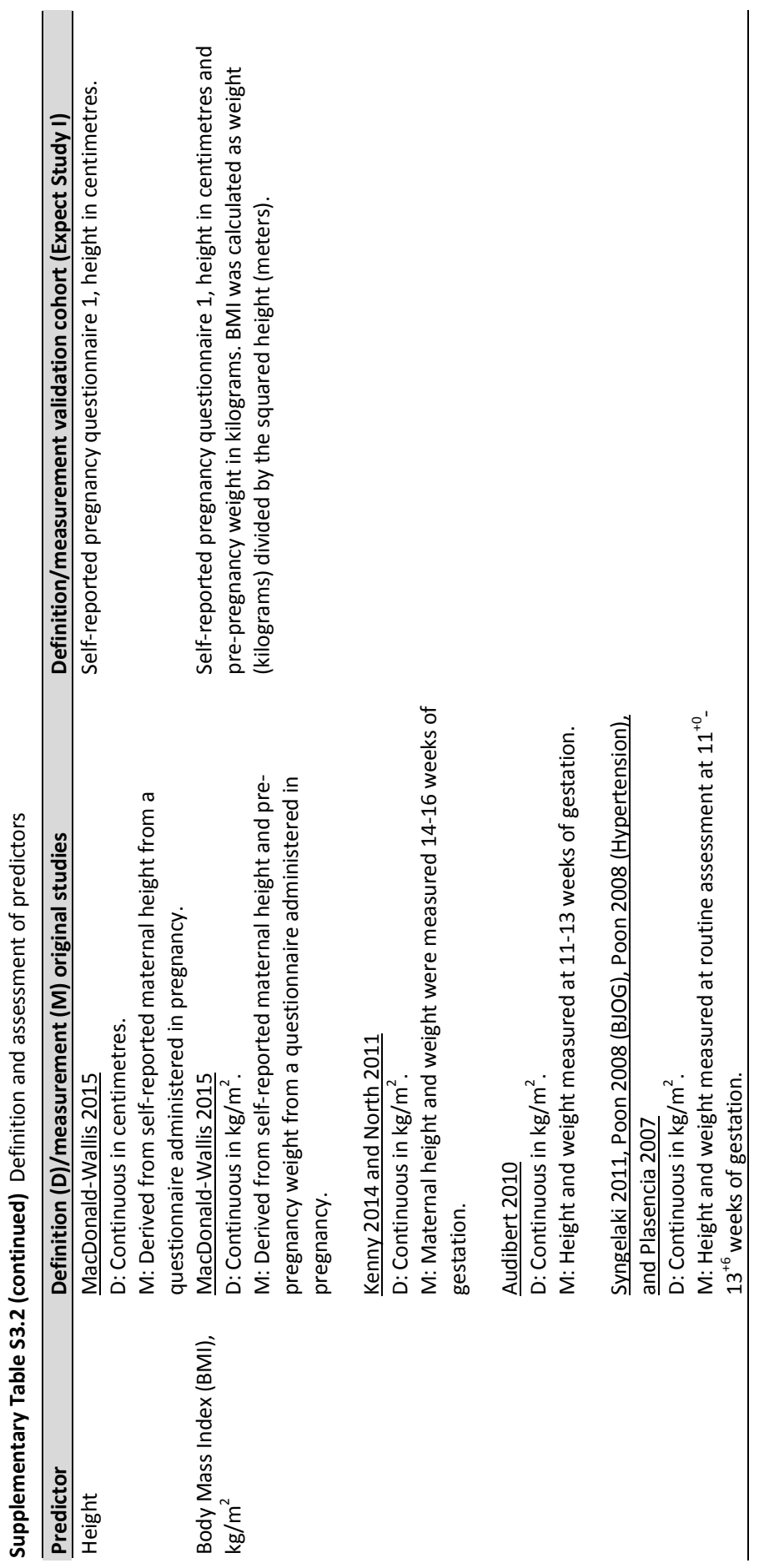




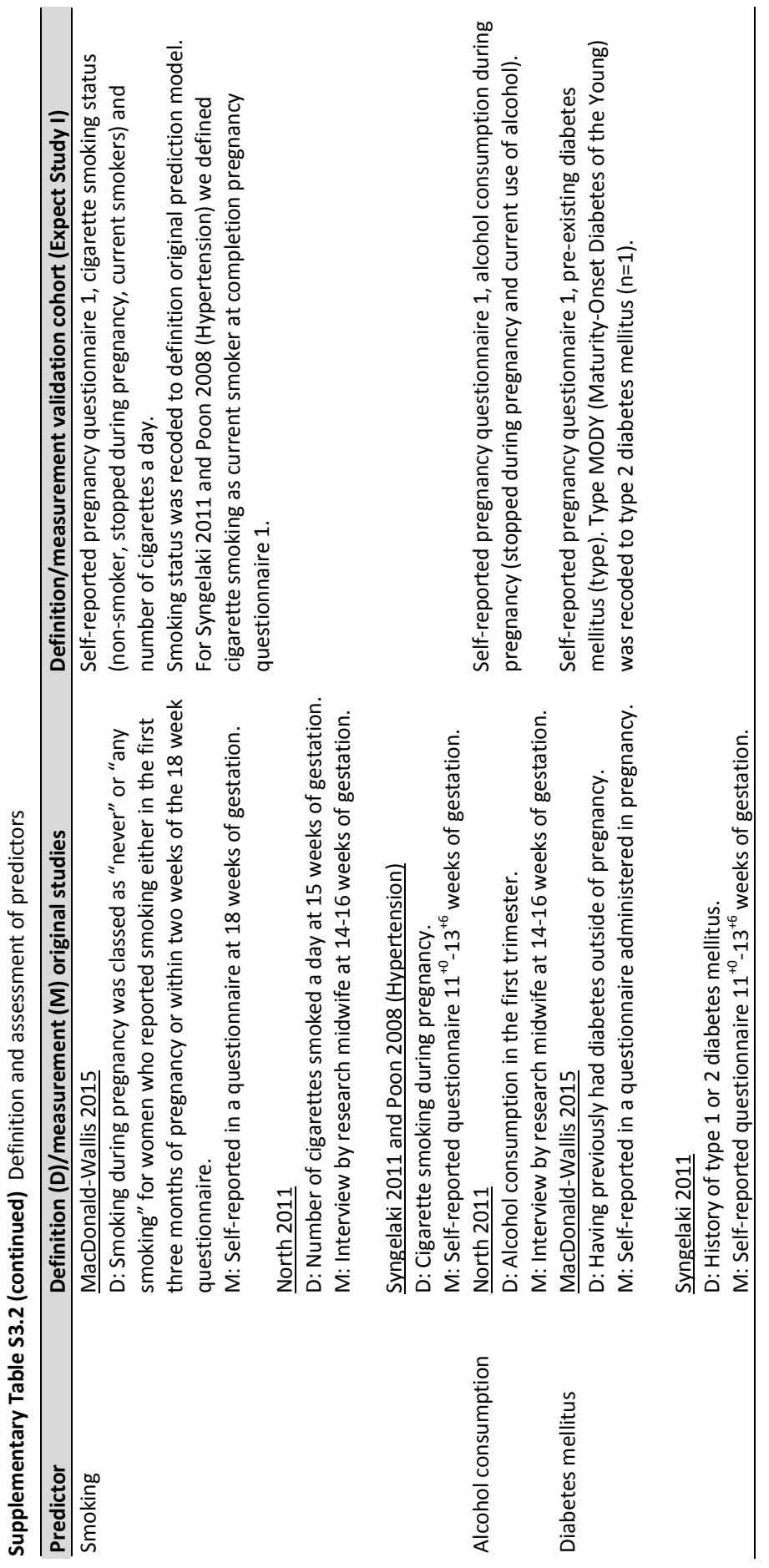



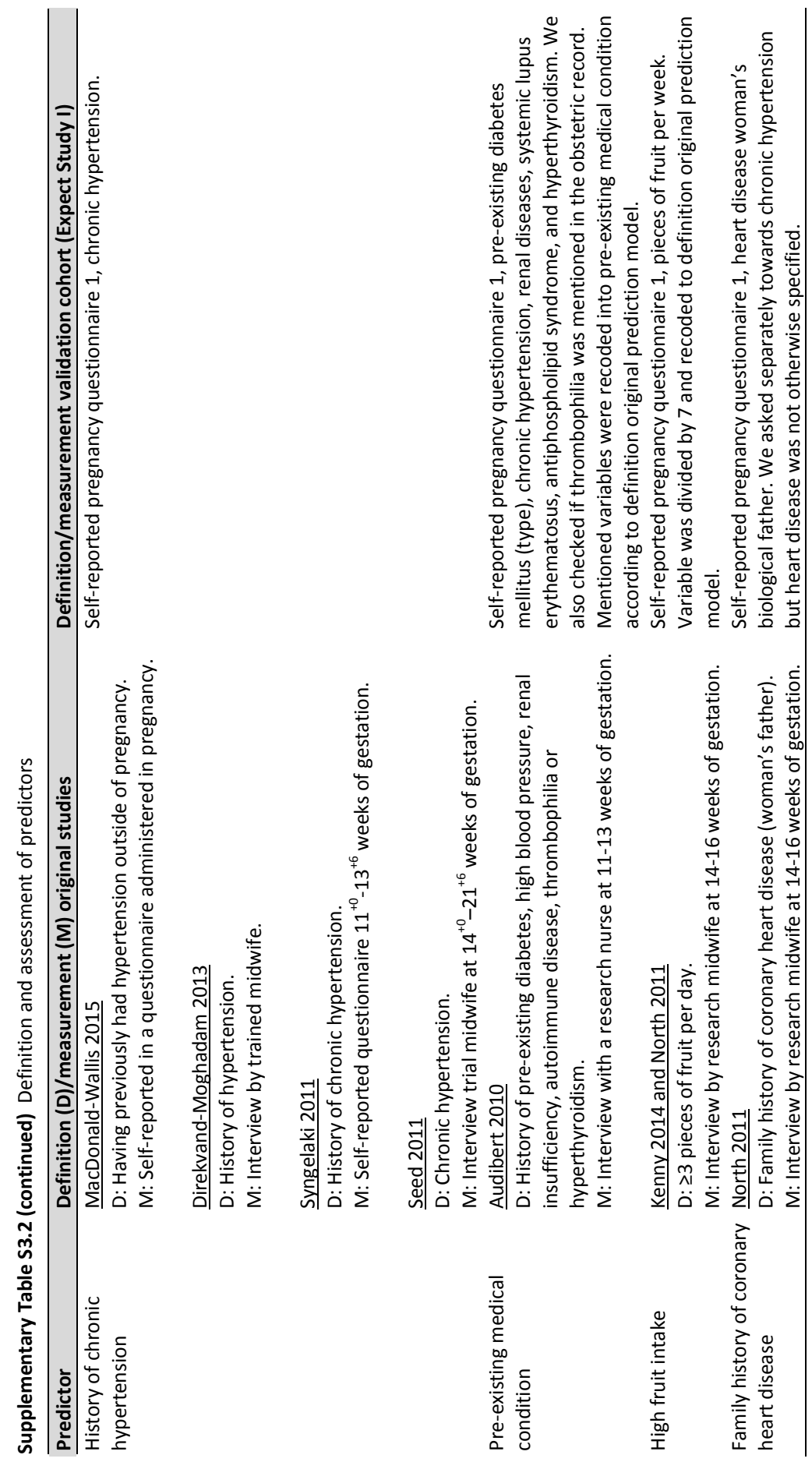


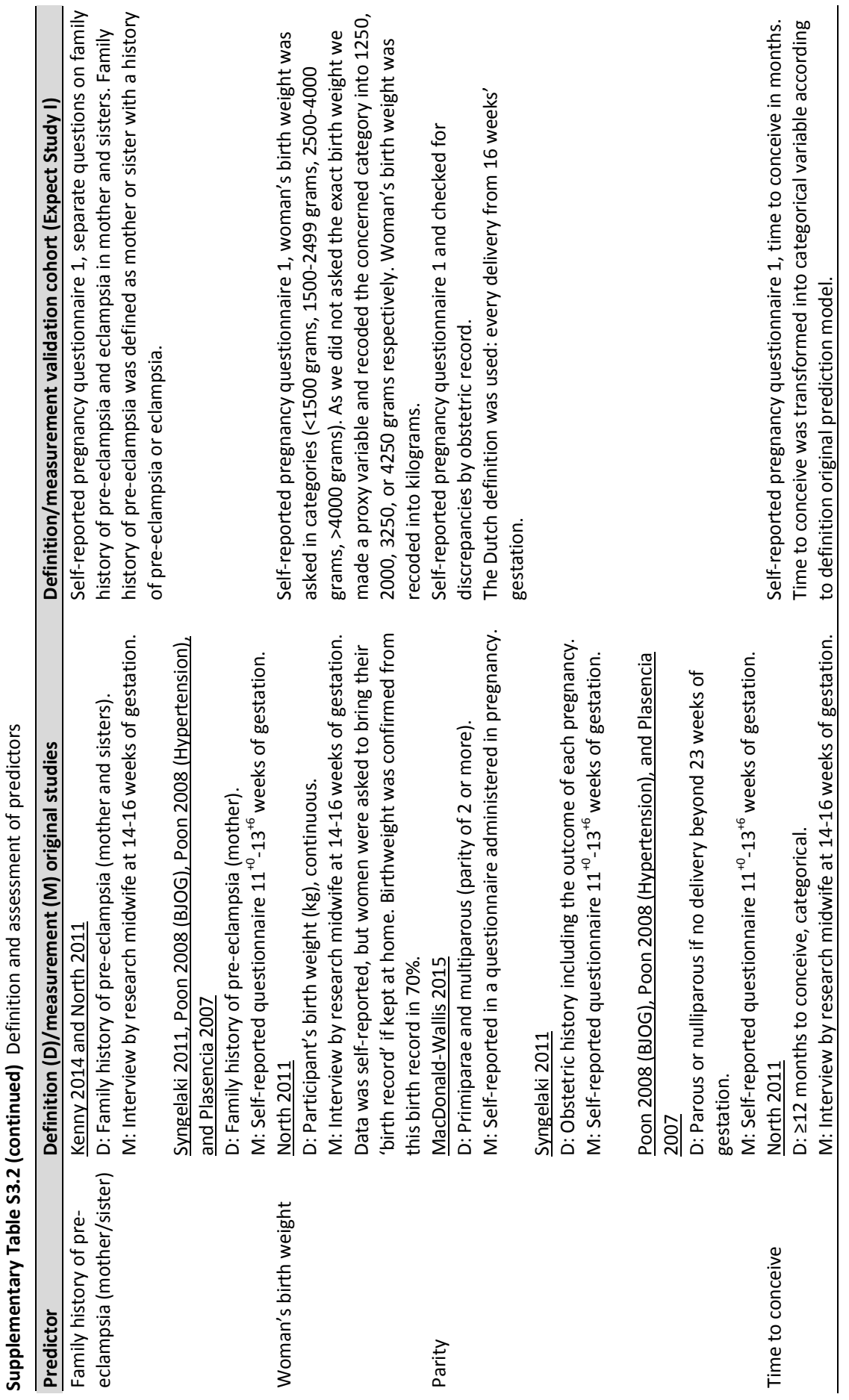




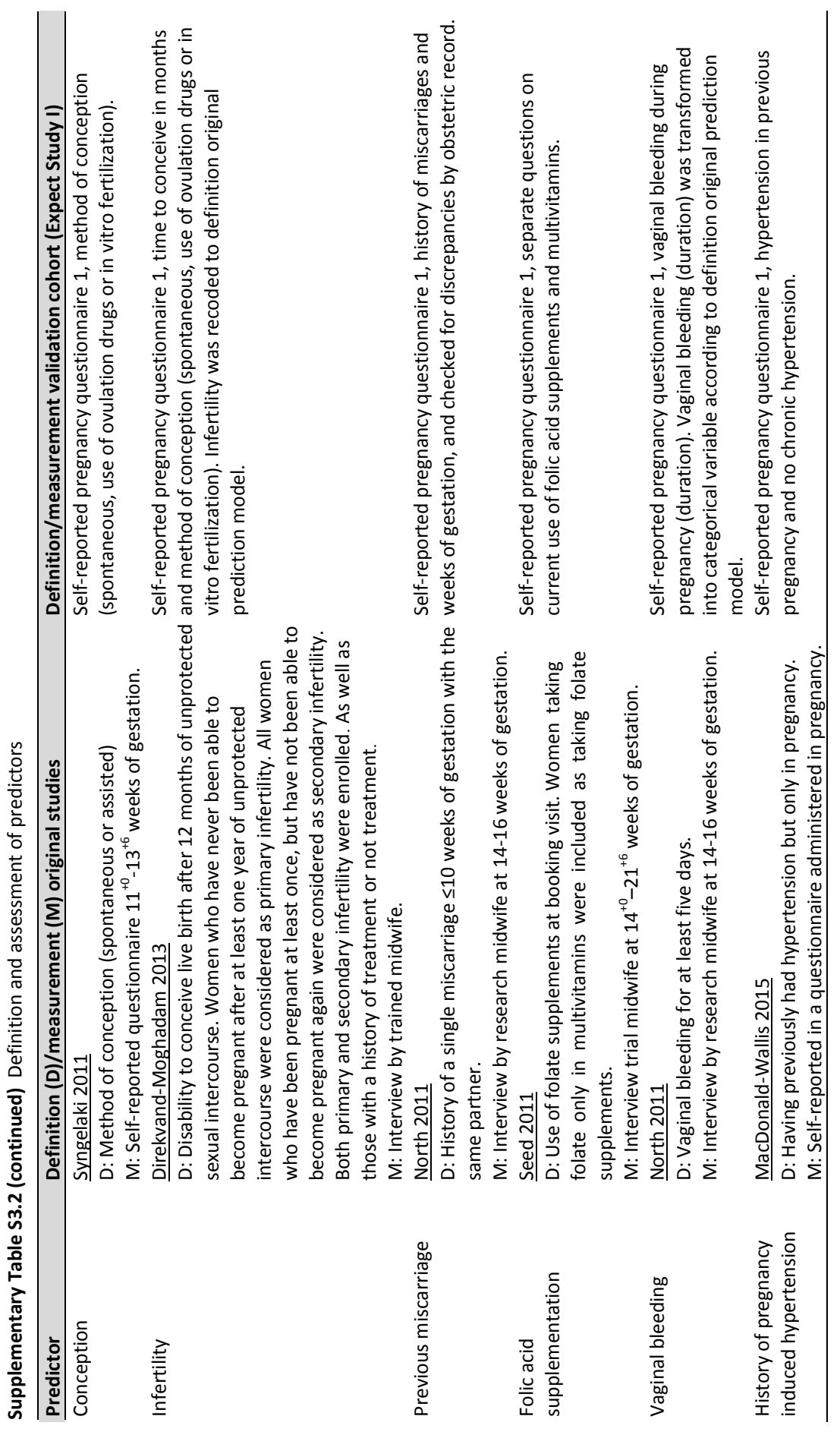



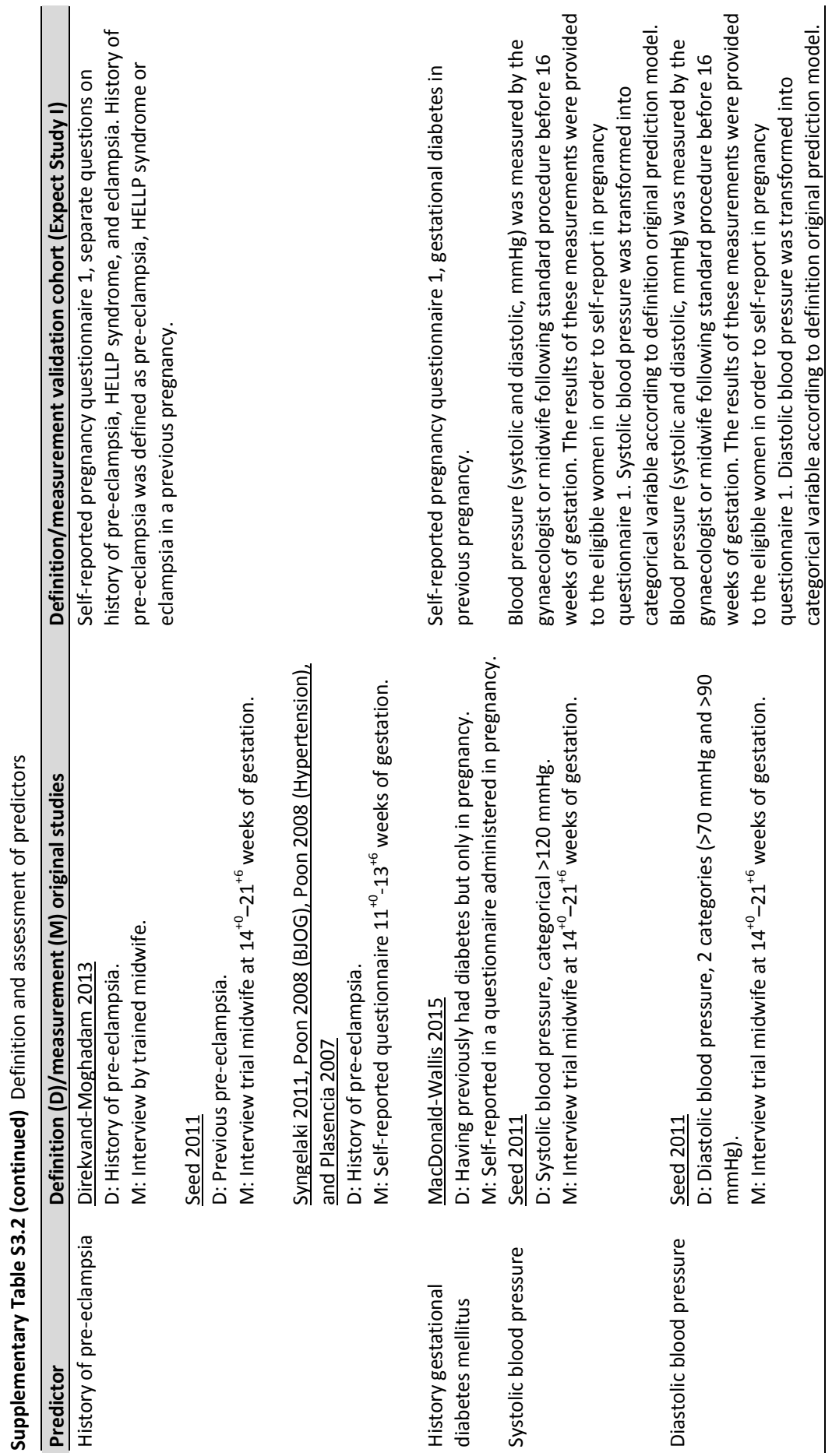

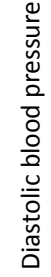




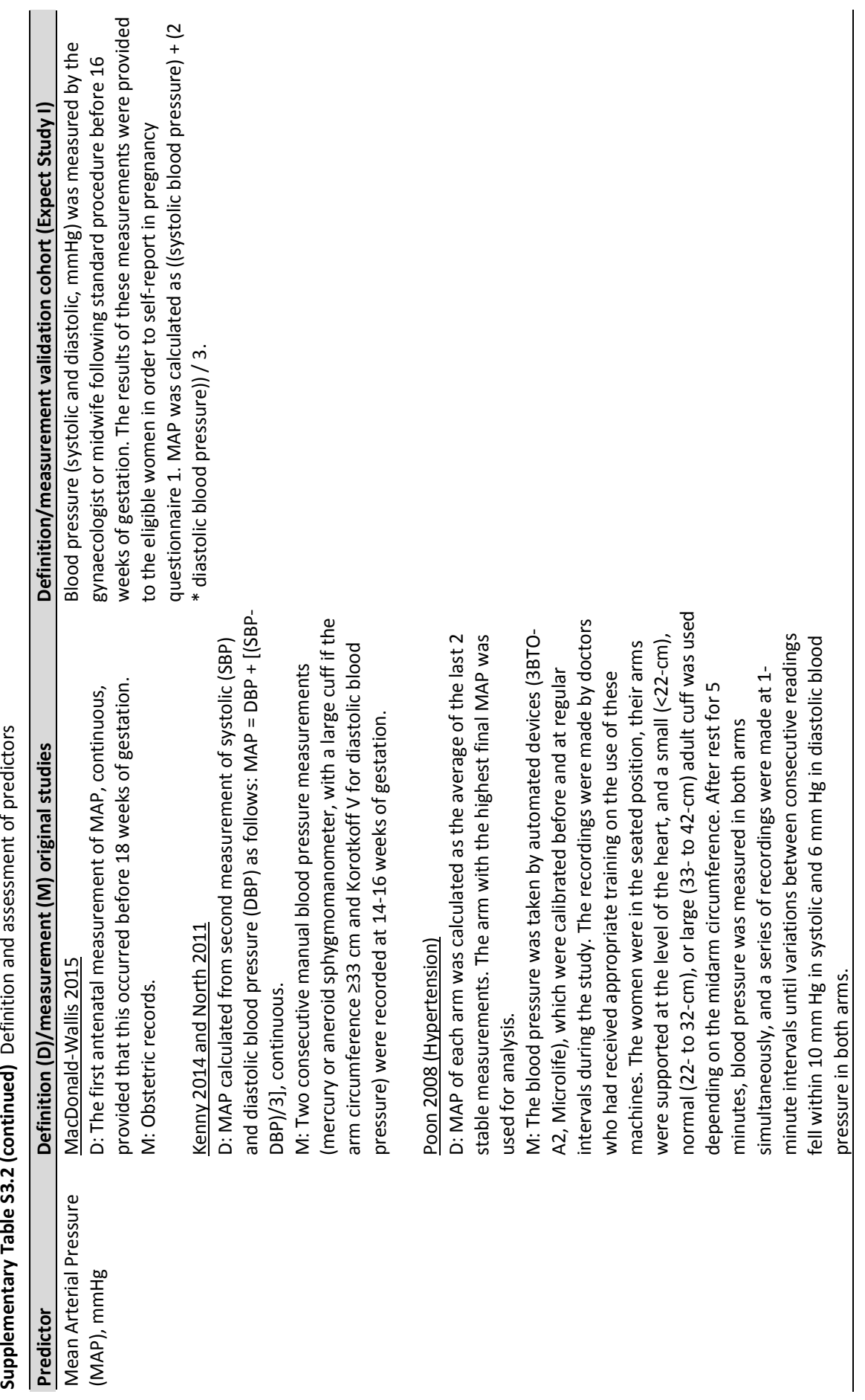




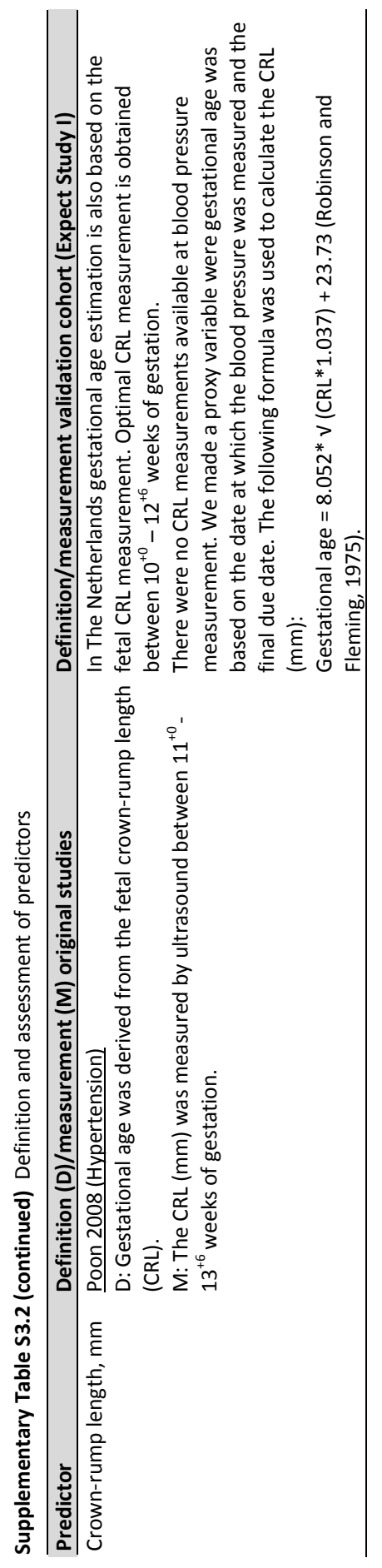




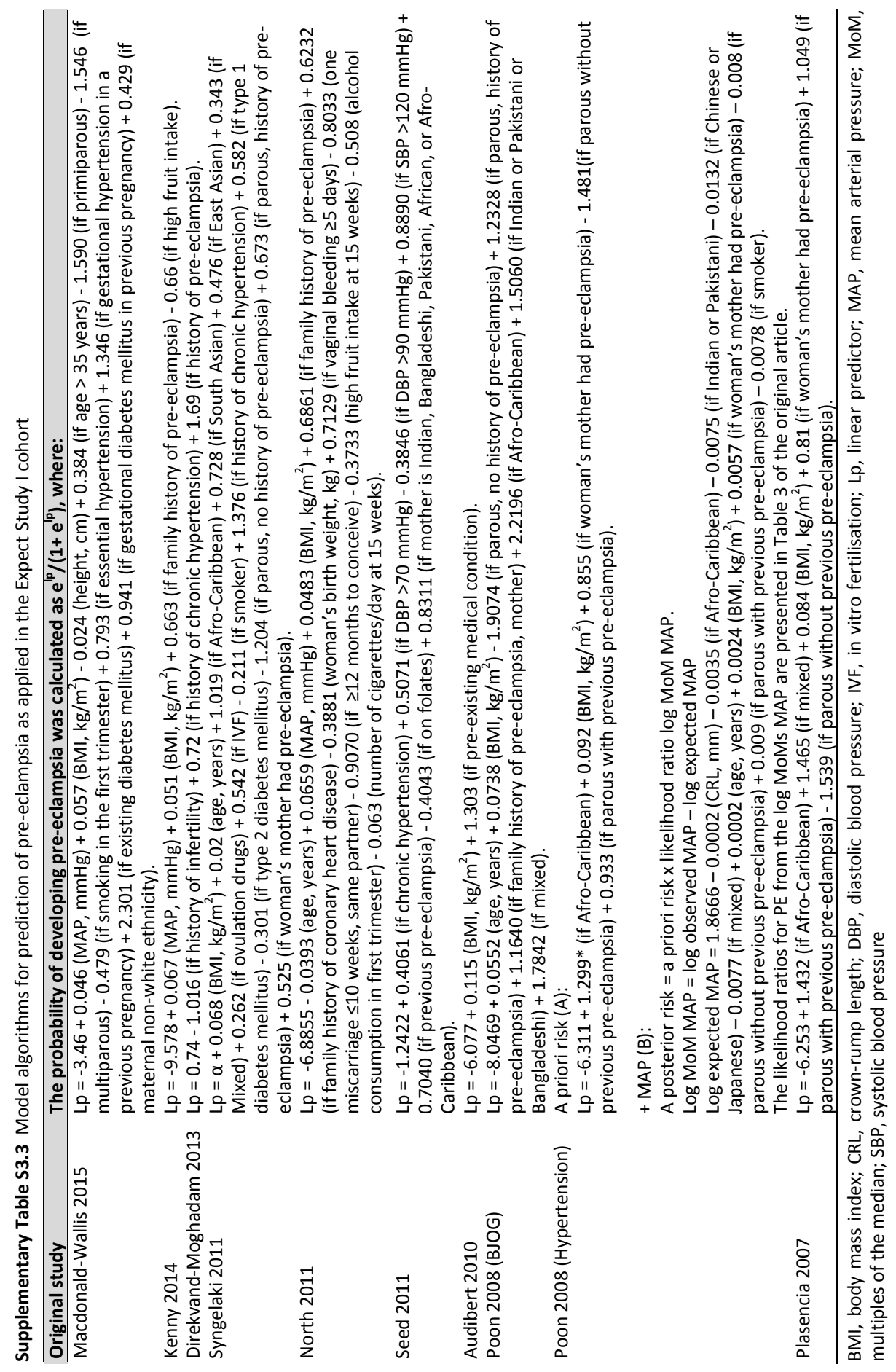


Supplementary Table S3.4 Characteristics of pregnancies in the observed and imputed validation cohort

\begin{tabular}{|c|c|c|c|c|}
\hline Characteristics & $\begin{array}{c}\text { Missing } \\
\text { values, } n(\%) \\
(n=2614)\end{array}$ & $\begin{array}{c}\text { Observed } \\
\text { validation cohort } \\
\text { Complete cases }^{a} \\
\quad(n=2027)\end{array}$ & $\begin{array}{c}\text { Observed } \\
\text { validation cohort } \\
\text { Women with } \\
\text { missing value(s) } \\
(n=587) \\
\end{array}$ & $\begin{array}{l}\text { Imputed } \\
\text { validation cohort } \\
(n=2614)\end{array}$ \\
\hline Age, years & $0(0.0)$ & $30.3(3.9)$ & $29.8(4.1)$ & $30.2(3.9)$ \\
\hline$>35$ years $^{c}$ & & $179(8.8)$ & $47(8.0)$ & $226(8.6)$ \\
\hline Ethnicity & $0(0.0)$ & & & \\
\hline Caucasian & & $1976(97.5)$ & 557 (94.9) & 2533 (96.9) \\
\hline Afro-Caribbean & & $2(0.1)$ & $1(0.2)$ & $3(0.1)$ \\
\hline Indian, Pakistani or & & $1(0.0)$ & $3(0.5)$ & $4(0.2)$ \\
\hline \multicolumn{5}{|l|}{ Bangladeshi (South Asian) } \\
\hline East Asian & & $1(0.0)$ & $3(0.5)$ & $4(0.2)$ \\
\hline Other Asian & & $8(0.4)$ & $4(0.7)$ & $12(0.4)$ \\
\hline Hispanic $^{d}$ & & $8(0.4)$ & $3(0.5)$ & $11(0.4)$ \\
\hline Mixed & & $31(1.5)$ & $16(2.7)$ & $47(1.8)$ \\
\hline Tertiary education $^{\mathrm{d}}$ & $3(0.1)$ & $1178(58.1)$ & $242(41.2)$ & $1420(54.3)$ \\
\hline Height, cm & $3(0.1)$ & $169.0(6.4)$ & $168.2(6.4)$ & $168.8(6.4)$ \\
\hline Weight $^{\mathrm{d}}, \mathrm{kg}$ & $5(0.2)$ & $69.0(13.2)$ & $68.5(12.4)$ & $68.9(13.0)$ \\
\hline Body mass index ${ }^{\mathrm{c}}, \mathrm{kg} / \mathrm{m}^{2}$ & $5(0.2)$ & $24.1(4.3)$ & $24.2(4.3)$ & $24.2(4.3)$ \\
\hline \multicolumn{5}{|l|}{ Smoking } \\
\hline Ever $<16$ weeks' gestation & $1(0.0)$ & $214(10.6)$ & $104(17.7)$ & 319 (12.2) \\
\hline $\begin{array}{l}\text { Current (at completion } \\
\text { questionnaire) }\end{array}$ & $1(0.0)$ & $108(5.3)$ & $49(8.3)$ & $158(6.0)$ \\
\hline Number cigarettes/day & $1(0.0)$ & $6.9(3.9)$ & $6.6(4.0)$ & $6.8(3.9)$ \\
\hline $\begin{array}{l}\text { Alcohol consumption } \\
\text { ever }<16 \text { weeks' gestation }\end{array}$ & $3(0.1)$ & $374(18.5)$ & 105 (17.9) & $480(18.4)$ \\
\hline Diabetes mellitus & $0(0.0)$ & $11(0.5)$ & $0(0.0)$ & $11(0.4)$ \\
\hline Type 1 & & $9(0.4)$ & $0(0.0)$ & $9(0.3)$ \\
\hline Type 2 & & $1(0.0)$ & $0(0.0)$ & $1(0.0)$ \\
\hline Other $^{d}$ & & $1(0.0)$ & $0(0.0)$ & $1(0.0)$ \\
\hline History of chronic hypertension & $0(0.0)$ & $20(1.0)$ & $8(1.4)$ & $28(1.1)$ \\
\hline Chronic renal disease & $0(0.0)$ & $3(0.1)$ & $2(0.3)$ & $5(0.2)$ \\
\hline Systemic lupus erythematosus & $0(0.0)$ & $3(0.1)$ & $0(0.0)$ & $3(0.1)$ \\
\hline Antiphospholipid syndrome & $0(0.0)$ & $0(0.0)$ & $0(0.0)$ & $0(0.0)$ \\
\hline Hyperthyroid & $0(0.0)$ & $10(0.5)$ & $1(0.2)$ & $11(0.4)$ \\
\hline Fruit intake ${ }^{d}$, per day & $1(0.0)$ & $1.3(0.7)$ & $1.2(0.7)$ & $1.3(0.7)$ \\
\hline High $\geq 3 /$ day $^{c}$ & & $52(2.6)$ & $15(2.6)$ & $67(2.6)$ \\
\hline $\begin{array}{l}\text { Family history of coronary } \\
\text { heart disease (father) }\end{array}$ & $1(0.0)$ & $357(17.6)$ & $82(14.0)$ & $439(16.8)$ \\
\hline \multicolumn{5}{|l|}{ Family history pre-eclampsia } \\
\hline Mother & $2(0.1)$ & $73(3.6)$ & $18(3.1)$ & $92(3.5)$ \\
\hline Sister & $4(0.2)$ & $32(1.6)$ & $9(1.5)$ & $41(1.6)$ \\
\hline Mother or sister & $6(0.2)$ & $103(5.1)$ & $27(4.6)$ & $131(5.0)$ \\
\hline Woman's birth weight, g & $319(12.2)$ & 3176.9 (471.5) & $3153.0(505.5)$ & $3169.1(474.6)$ \\
\hline$<1500 g^{d}$ & & $13(0.6)$ & $3(0.5)$ & \\
\hline $1500-2499 g^{d}$ & & $189(9.3)$ & $28(4.8)$ & \\
\hline $2500-4000 \mathrm{~g}^{\mathrm{d}}$ & & $1711(84.4)$ & $222(37.8)$ & \\
\hline$>4000 g^{d}$ & & $114(5.6)$ & $15(2.6)$ & \\
\hline Don't know $^{d}$ & & $0(0.0)$ & $319(54.3)$ & \\
\hline
\end{tabular}


Supplementary Table S3.4 (continued) Characteristics of pregnancies in the observed and imputed validation cohort

\begin{tabular}{|c|c|c|c|c|c|}
\hline \multirow{2}{*}{\multicolumn{2}{|c|}{$\begin{array}{l}\text { Characteristics } \\
\text { Parity }\end{array}$}} & \multirow[t]{2}{*}{$\begin{array}{c}\text { Observed } \\
\text { validation cohort } \\
\text { Complete cases }^{\mathrm{a}} \\
(\mathrm{n}=\mathbf{2 0 2 7 )} \\
0(0.0)\end{array}$} & \multicolumn{2}{|c|}{$\begin{array}{c}\text { Observed } \\
\text { validation cohort } \\
\text { Women with missing } \\
\text { value(s) } \\
(n=587)\end{array}$} & \multirow[t]{2}{*}{$\begin{array}{l}\text { Imputed validation } \\
\text { cohort } \\
(n=2614)\end{array}$} \\
\hline & & & & & \\
\hline Nulliparous & & & $980(48.3)$ & $346(58.9)$ & $1326(50.7)$ \\
\hline Primiparous & & & $830(40.9)$ & $196(33.4)$ & $1026(39.3)$ \\
\hline Multiparous & & & $217(10.8)$ & $45(7.7)$ & $262(10.0)$ \\
\hline Time to conceiv & nonths & $9(0.3)$ & $5.7(8.9)$ & $5.7(8.6)$ & $5.7(8.8)$ \\
\hline$\geq 12$ months $^{c}$ & & & $276(13.6)$ & $81(13.8)$ & $359(13.7)$ \\
\hline Conception & & $0(0.0)$ & & & \\
\hline Spontaneous & & & 1895 & $545(92.8)$ & $2440(93.3)$ \\
\hline Ovulation indu & & & $(93.5)$ & $23(3.9)$ & 93 (3.6) \\
\hline \multicolumn{2}{|l|}{ IVF/ICSI } & & $\begin{array}{l}70(3.5) \\
62(3.1)\end{array}$ & $19(3.2)$ & $81(3.1)$ \\
\hline $\begin{array}{l}\text { Previous single } r \\
\leq 10 \text { weeks' gest }\end{array}$ & \multicolumn{4}{|c|}{$\leq 10$ weeks' gestation, same father } & $395(15.1)$ \\
\hline $\begin{array}{l}\text { Folic acid supple } \\
\text { questionnaire }\end{array}$ & ntation at completion & $3(0.1)$ & $\begin{array}{c}1760 \\
(86.8)\end{array}$ & $466(79.4)$ & $2229(85.3)$ \\
\hline Vaginal bleeding & & $0(0.0)$ & $491(24.2)$ & $147(25.0)$ & $638(24.4)$ \\
\hline Days $^{d}$ & & $0(0.0)$ & $2.7(3.9)$ & $3.3(8.2)$ & $2.8(5.2)$ \\
\hline$\geq 5$ days $^{c}$ & & & $78(3.8)$ & $24(4.1)$ & 102 (3.9) \\
\hline $\begin{array}{l}\text { History of pregn } \\
\text { hypertension }\end{array}$ & $y$ induced & $18(0.7)$ & $98(4.8)$ & $17(2.9)$ & $115(4.4)$ \\
\hline History of pre-e & npsia & $18(0.7)$ & $58(2.9)$ & $14(2.4)$ & $72(2.8)$ \\
\hline History of gesta & al diabetes mellitus & $19(0.7)$ & $15(0.7)$ & $0(0.0)$ & $15(0.6)$ \\
\hline \multicolumn{2}{|l|}{$>120 \mathrm{mmHg}^{\mathrm{c}}$} & 260 (9.9) & $\begin{array}{c}114.5 \\
(12.5) \\
501(24.7)\end{array}$ & $\begin{array}{c}114.1 \\
(12.5) \\
77(13.1)\end{array}$ & $\begin{array}{c}114.5(12.4) \\
647(24.8)\end{array}$ \\
\hline Diastolic blood $\mathrm{p}$ & sure $^{\mathrm{d}}, \mathrm{mmHg}$ & $270(10.3)$ & $67.6(8.5)$ & $68.0(8.6)$ & $67.6(8.5)$ \\
\hline$>70 \mathrm{mmHg}^{\mathrm{c}}$ & & & $579(28.6)$ & $101(17.2)$ & $759(29.0)$ \\
\hline$>90 \mathrm{mmHg}^{\mathrm{c}}$ & & & $16(0.8)$ & $3(0.5)$ & $19(0.7)$ \\
\hline Mean arterial pr & $u_{r e}{ }^{c}, m m H g$ & $270(10.3)$ & $83.2(8.8)$ & $83.4(8.7)$ & $83.3(8.7)$ \\
\hline Crown-rump len & ${ }^{\mathrm{c}}, \mathrm{mm}$ & $270(10.3)$ & $33.9(23.5)$ & $34.3(23.4)$ & $33.8(23.5)$ \\
\hline
\end{tabular}

${ }^{a}$ All predictor values of the included models were complete. ${ }^{b}$ At least one missing value for a predictor of the included models. ${ }^{\mathrm{C}}$ Recoded/calculated on the basis of (imputed) original variables. ${ }^{\mathrm{d}}$ Not a predictor in the included models. ICSI, intracytoplasmic sperm injection; IVF, in vitro fertilisation 


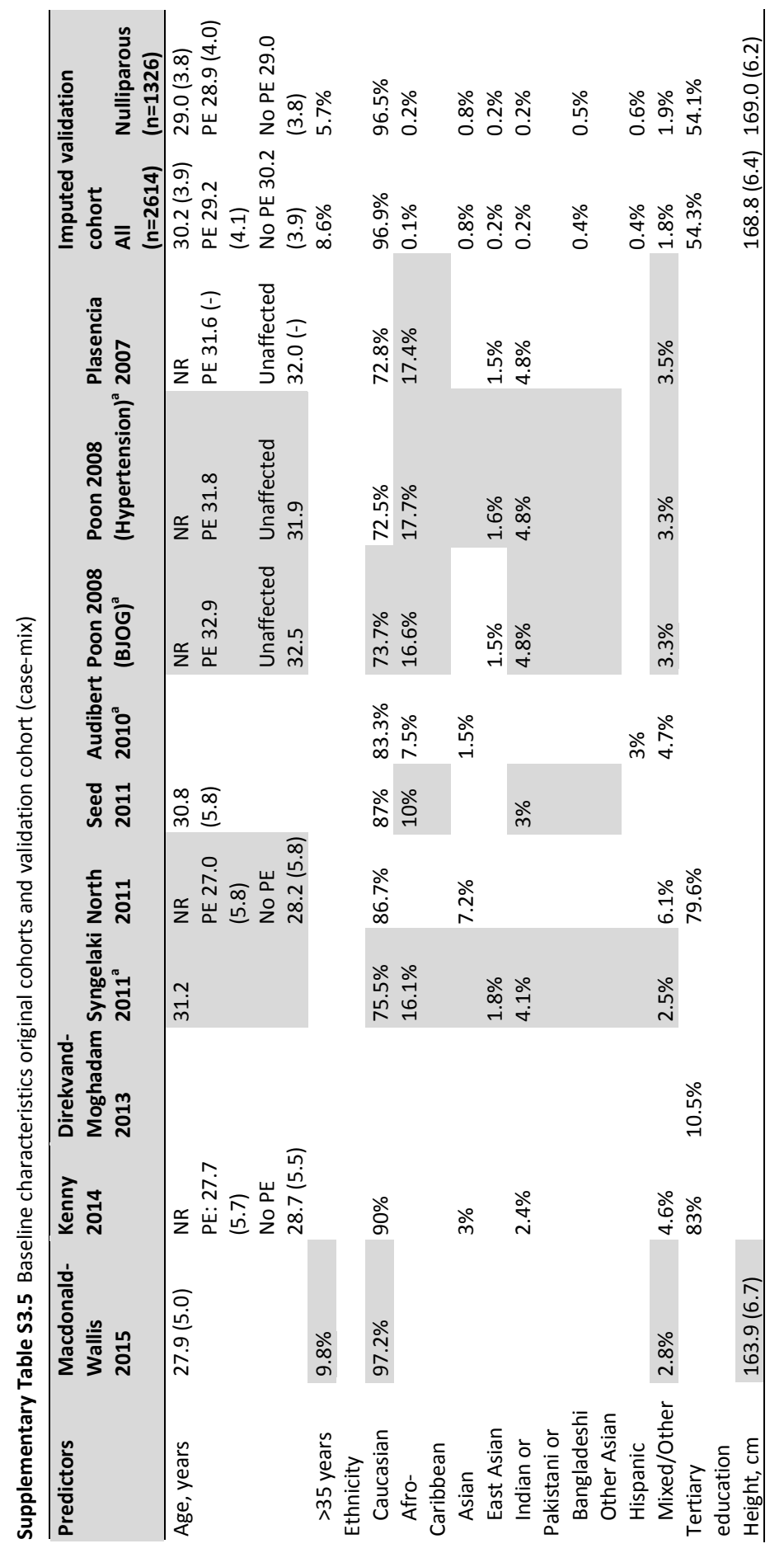




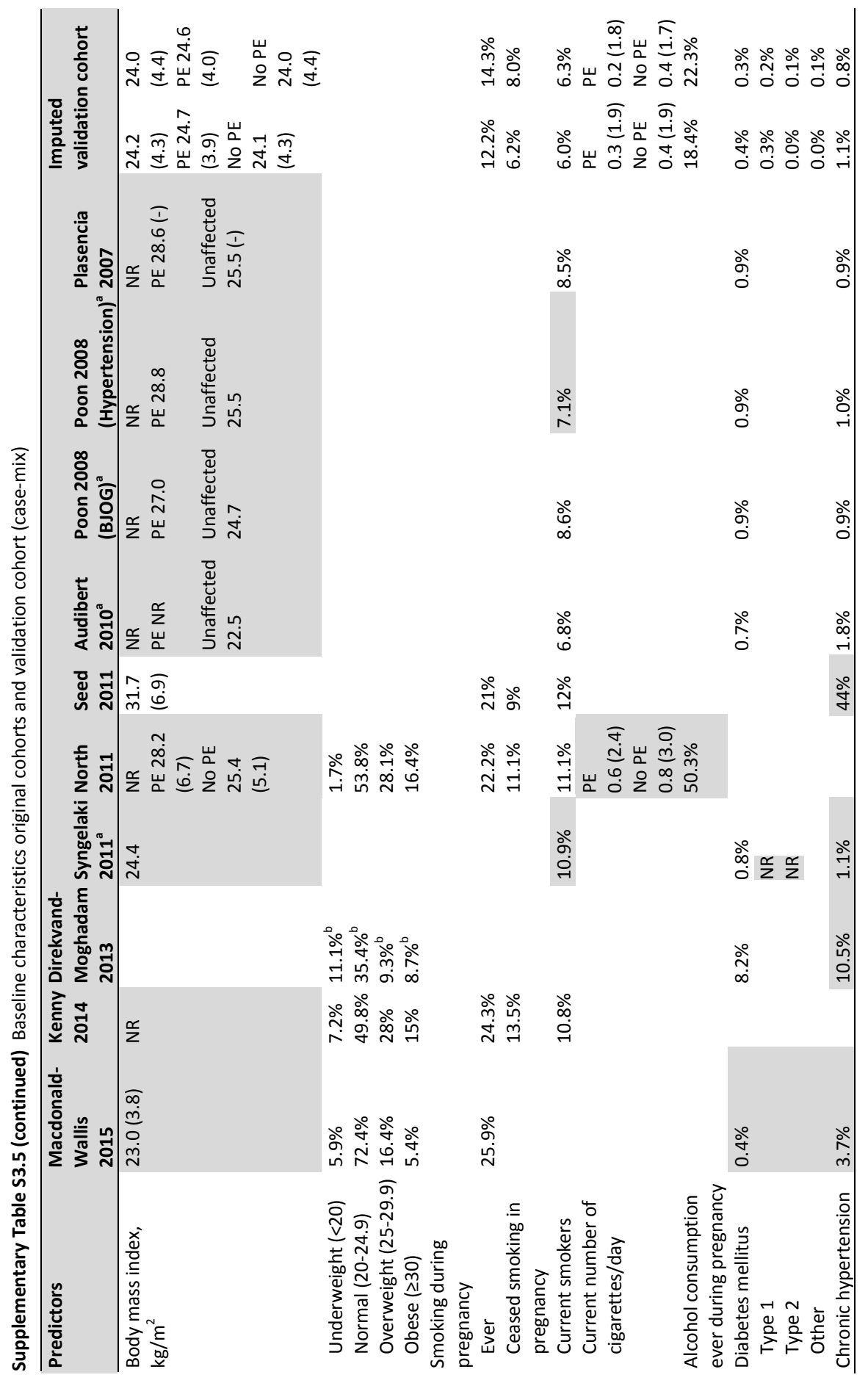




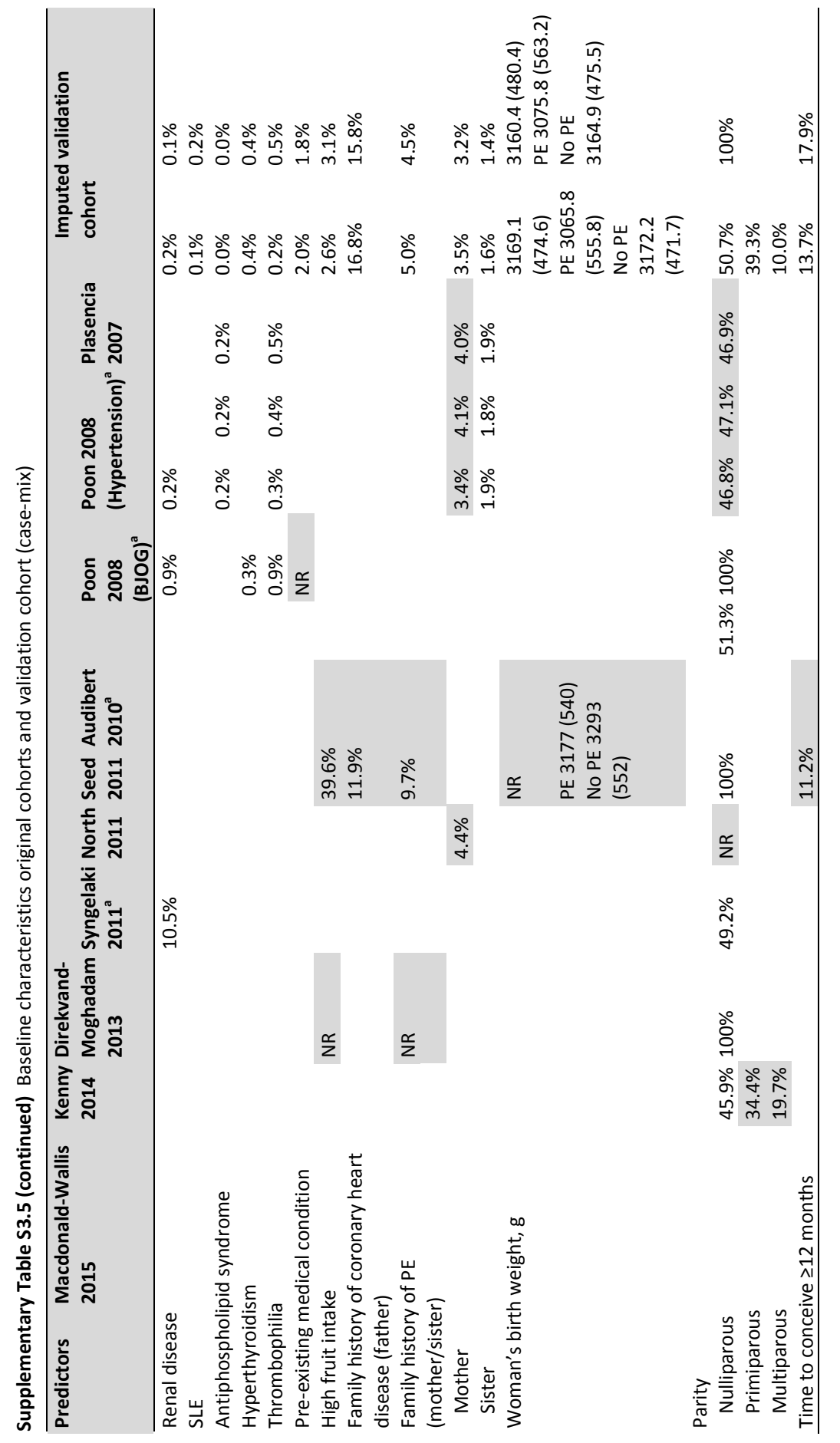




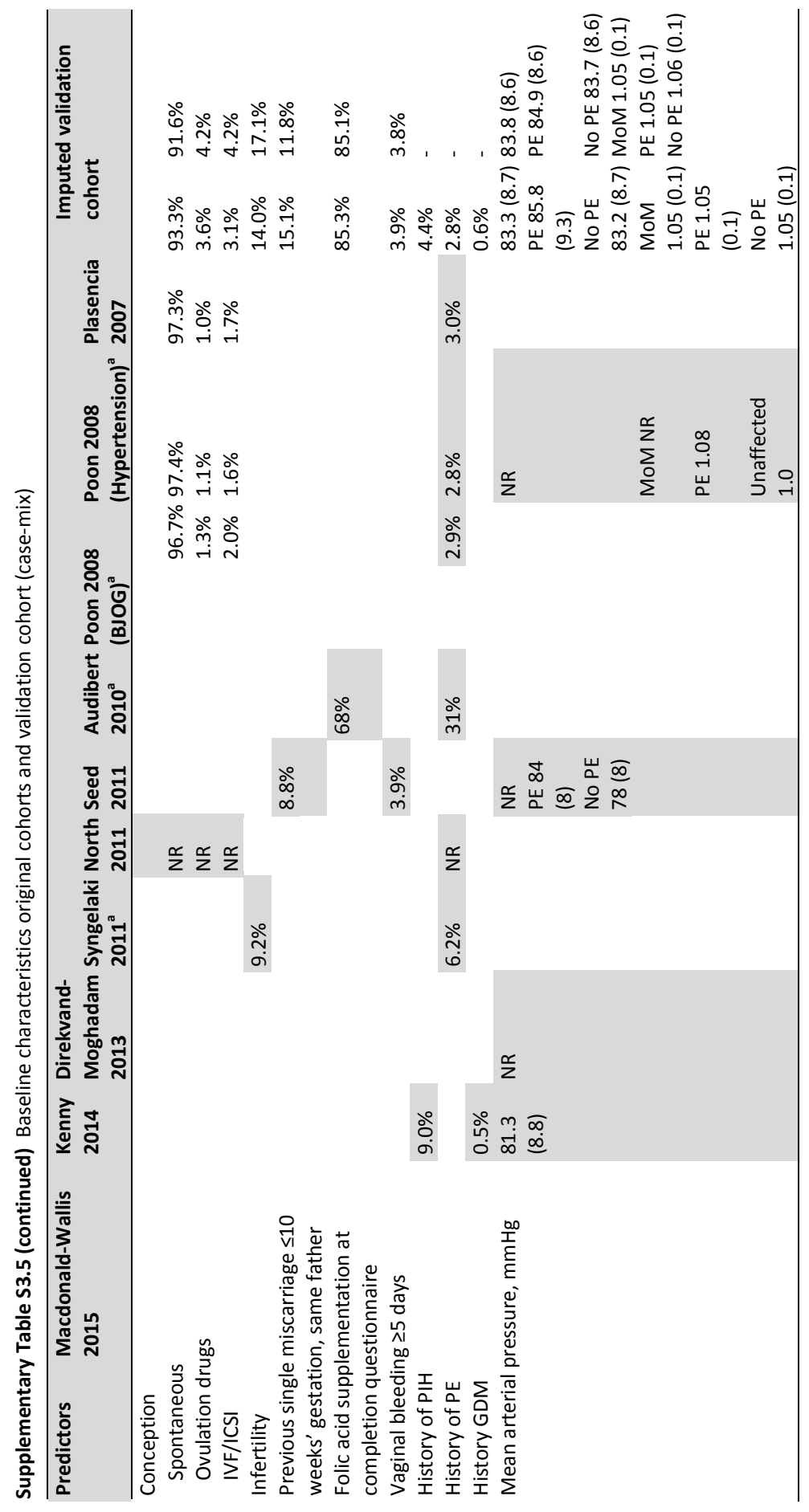




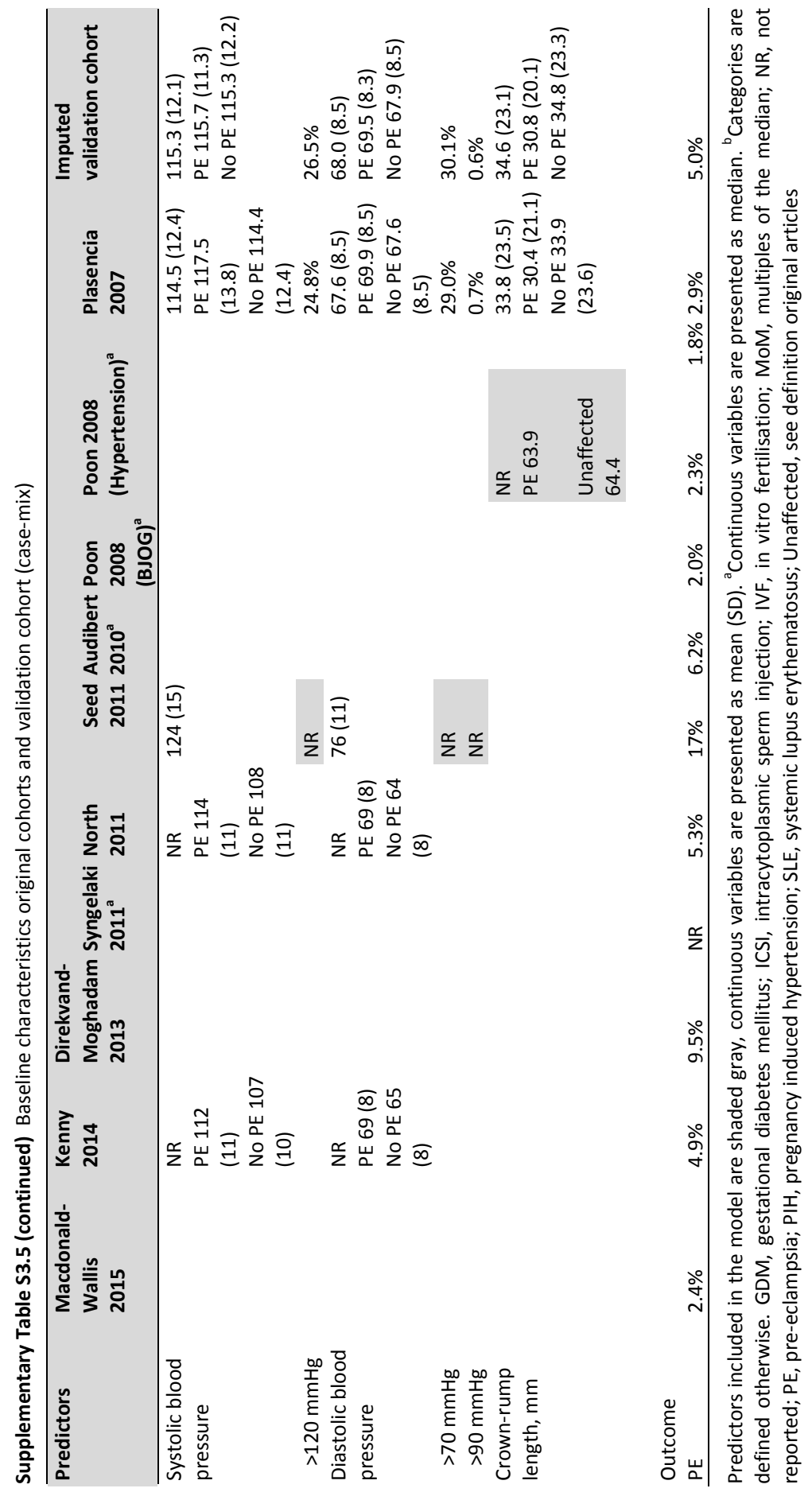



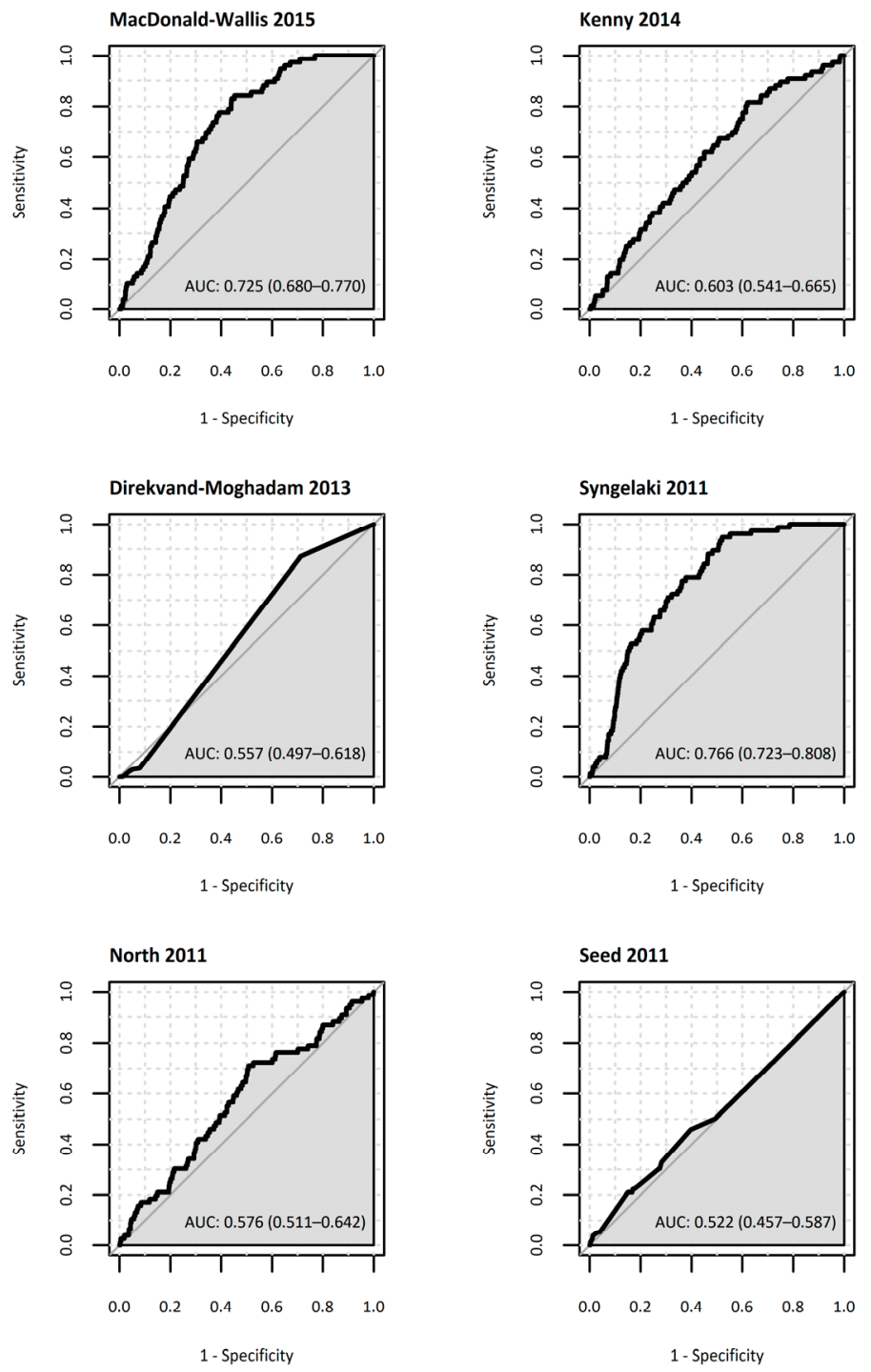

Supplementary Figure S3.1A ROC curves of externally validated first trimester prediction models for preeclampsia. $(A)=$ model a priori risk, $(B)=$ model a priori risk + mean arterial pressure 

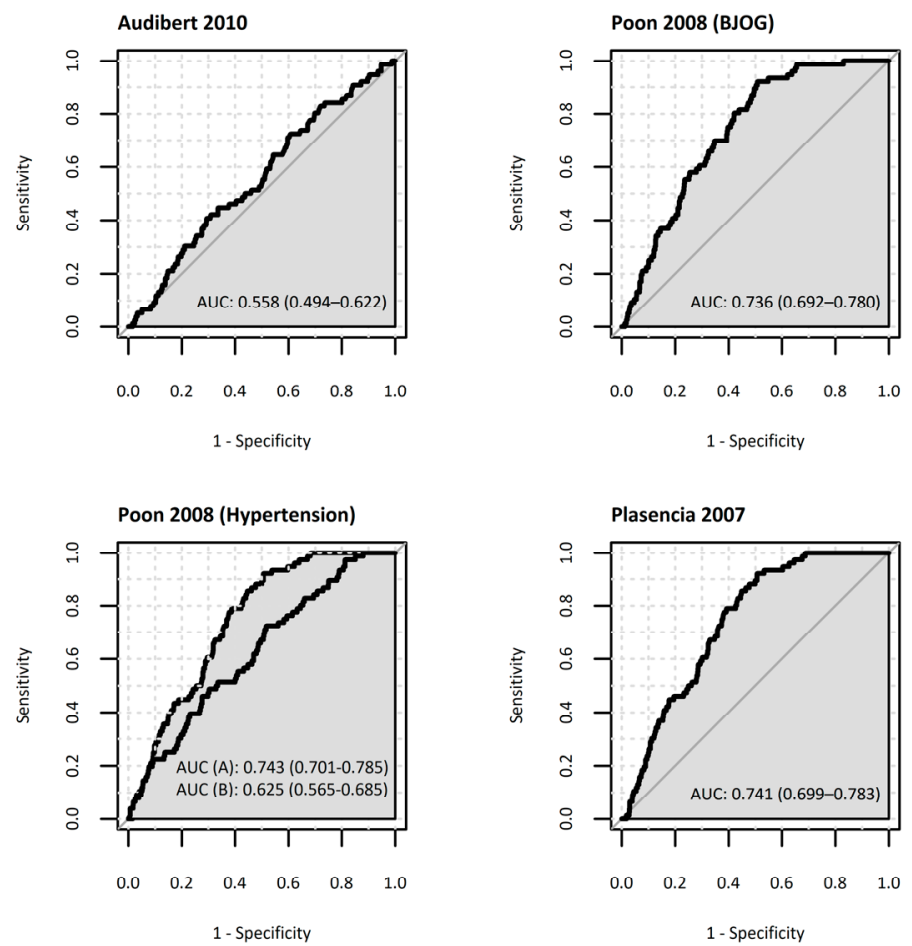

Supplementary Figure S3.1B ROC curves of externally validated first trimester prediction models for preeclampsia. $(A)=$ model a priori risk, $(B)=$ model a priori risk + mean arterial pressure 

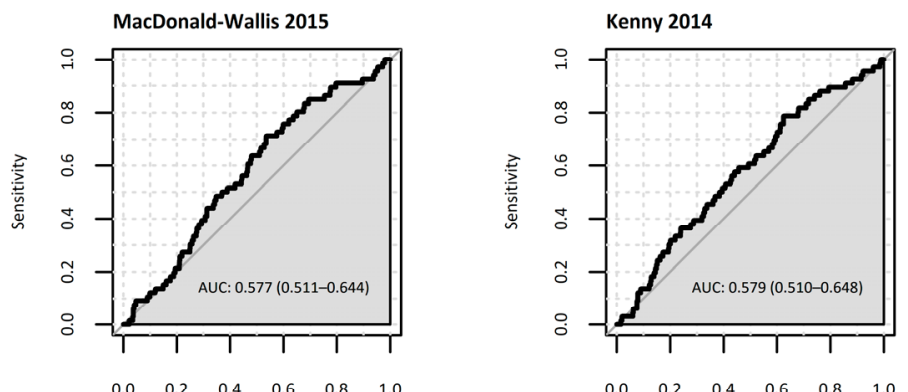

1 - Specificity

1 - Specificity
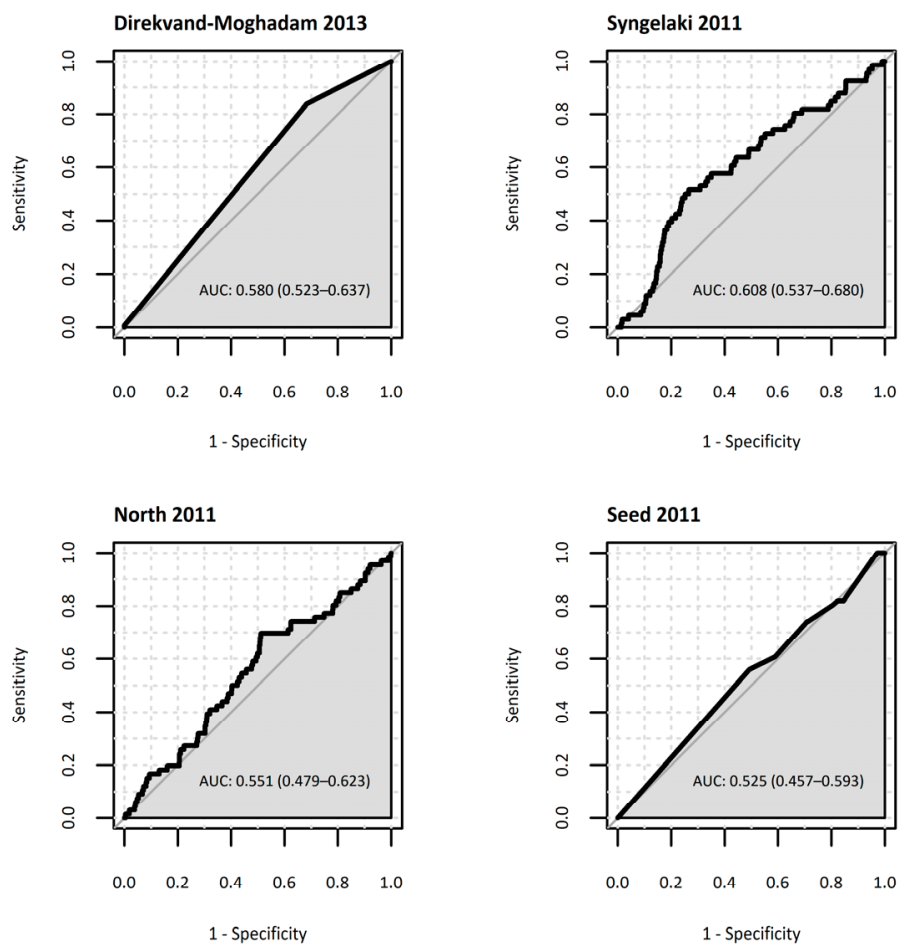

Supplementary Figure S3.2A ROC curves of externally validated first trimester prediction models for preeclampsia in nulliparous women. $(A)=$ model a priori risk, $(B)=$ model a priori risk + mean arterial pressure 

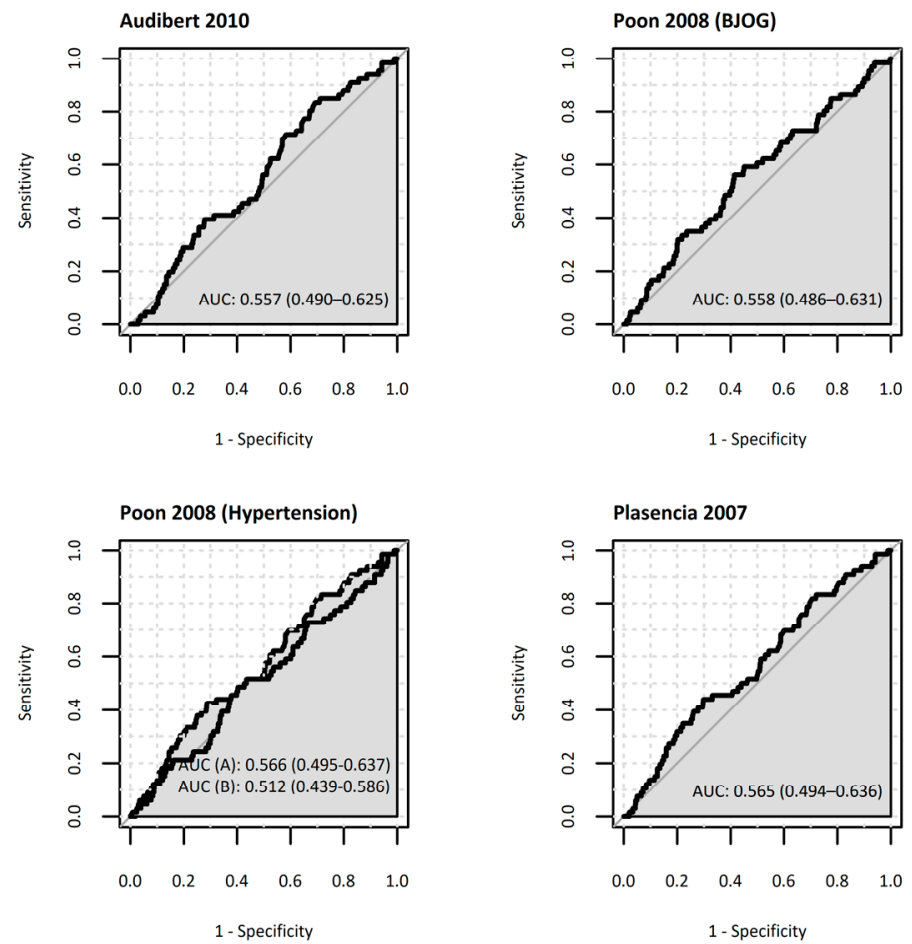

Supplementary Figure S3.2B ROC curves of externally validated first trimester prediction models for preeclampsia in nulliparous women. $(A)=$ model a priori risk, $(B)=$ model a priori risk + mean arterial pressure 


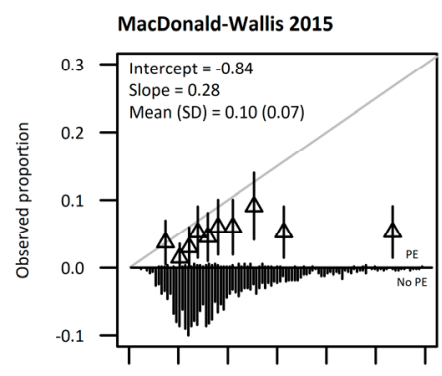

$\begin{array}{lllllll}0.00 & 0.05 & 0.10 & 0.15 & 0.20 & 0.25 & 0.30\end{array}$

Predicted probability

\section{Direkvand-Moghadam 2013}

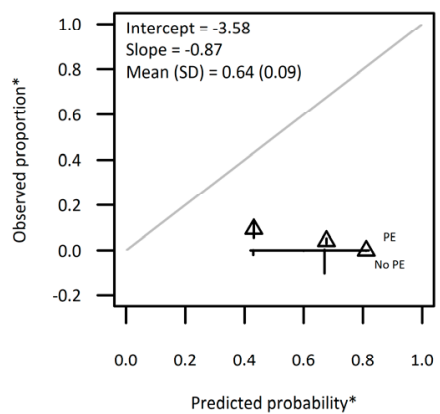

Seed 2011

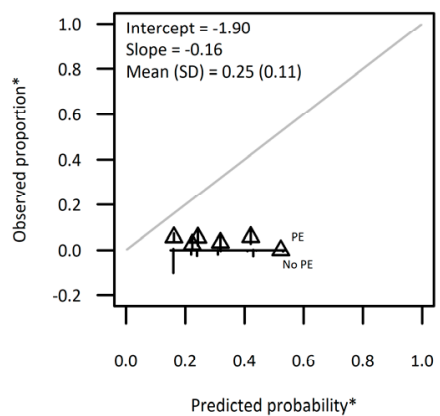

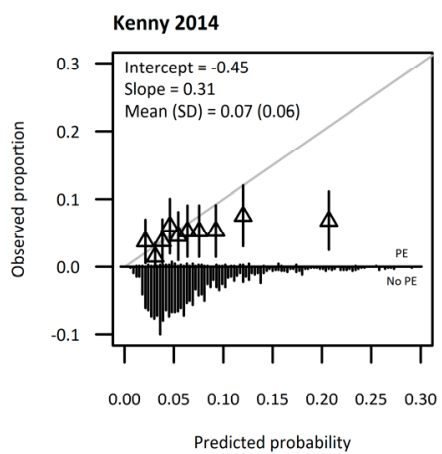

North 2011

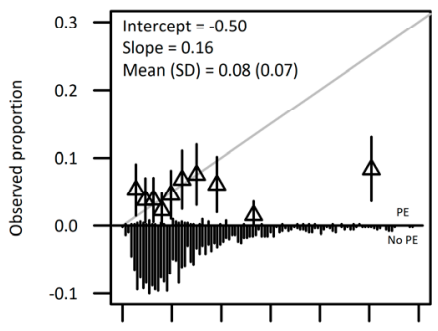

$\begin{array}{lllllll}0.00 & 0.05 & 0.10 & 0.15 & 0.20 & 0.25 & 0.30\end{array}$ Predicted probability

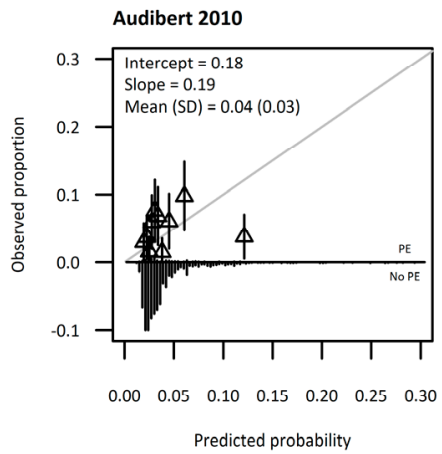

Supplementary Figure S3.3A Calibration plots of first trimester prediction models for preeclampsia in nulliparous women. The grey line is the reference line with intercept $=0$ and slope $=1$ (perfect calibration). Triangles correspond to grouped predicted risks with $95 \%$ confidence intervals (vertical lines). ${ }^{*}$ Different limits $x$ - and $y$-axis 


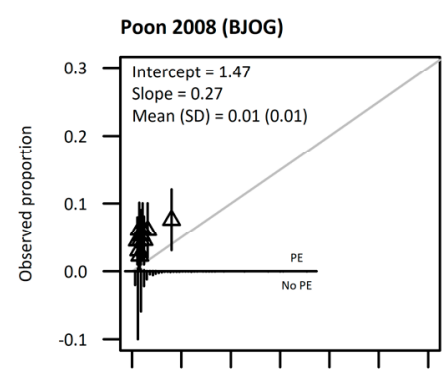

$\begin{array}{lllllll}0.00 & 0.05 & 0.10 & 0.15 & 0.20 & 0.25 & 0.30\end{array}$ Predicted probability

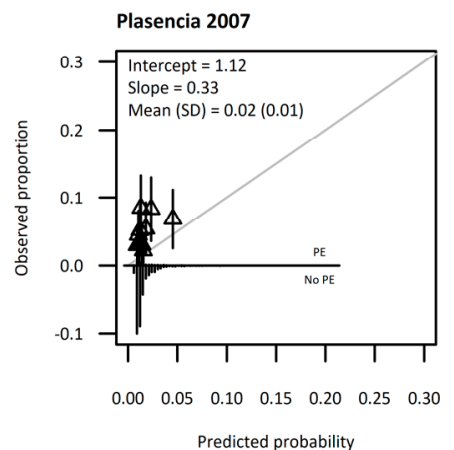

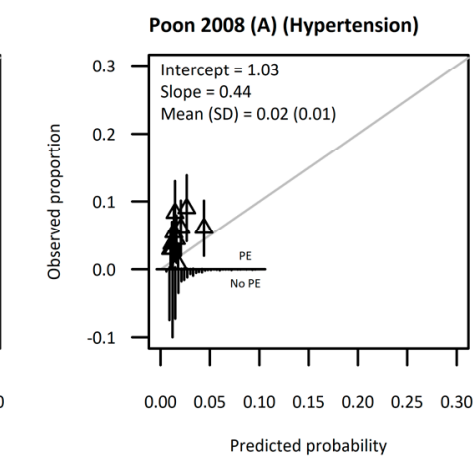




\section{CHAPTER 4}

External validation and clinical utility of first trimester prediction models for gestational diabetes mellitus:

a prospective cohort study

Linda J.E. Meertens, Hubertina C.J. Scheepers, Sander M.J. van Kuijk, Nel Roeleveld, Robert Aardenburg, Ivo M.A. van Dooren, Josje Langenveld, Iris M. Zwaan, Marc E.A. Spaanderman, Marleen M.H.J. van Gelder, and Luc J.M. Smits 


\begin{abstract}
Introduction

We performed an independent validation study of all published first trimester prediction models, containing non-invasive predictors, for the risk of gestational diabetes mellitus (GDM). Furthermore, the clinical potential of the best performing models was evaluated.
\end{abstract}

\title{
Methods
}

Systemically selected prediction models from the literature were validated in a Dutch prospective cohort using data from Expect Study I and PRIDE Study. The predictive performance of the models was evaluated by discrimination and calibration. Clinical utility was assessed using decision curve analysis. Screening performance measures were calculated at different risk thresholds for the best model and compared with current selective screening strategies.

\section{Results}

The validation cohort included 5263 women. GDM was diagnosed in 127 women (2.7\%). The discriminative performance of the 12 included models ranged from 68 to 75\%. Nearly all models overestimated the risk. After recalibration, agreement between the observed outcomes and predicted probabilities improved for most models. Performance measures of the best model were not better at high-risk thresholds compared with current selective screening guidelines.

\section{Discussion}

All 12 included prediction models for GDM showed a moderate predictive performance after external validation. Although the best performing model does not provide more benefit at certain risk thresholds compared with current selective screening strategies, the model is easily applicable in clinical practice and enables personalized selective screening. 


\section{Introduction}

Gestational diabetes mellitus (GDM) is a common condition during pregnancy. The prevalence has been increasing over the last years and varies considerably between countries $(2-25 \%)$ as it depends on the population studied, the screening method employed and diagnostic criteria used ${ }^{1,2}$. GDM is a risk factor for maternal and perinatal complications such as pre-eclampsia, caesarean section, macrosomia, shoulder dystocia, and neonatal hypoglycaemia ${ }^{3,4}$. Long-term consequences, i.e. increased risk of developing type 2 diabetes mellitus (DM) in both mother and offspring, primarily contribute to the global burden of disease $e^{5-8}$.

Early diagnosis of GDM is important as clinical management improves pregnancy outcomes $^{9,10}$. GDM is usually diagnosed by an $\mathrm{OGTT}^{11}$. However, consequences of GDM are often already present at the time of diagnosis (i.e. large-for-gestational-age (LGA) infant) as the disorder is mostly asymptomatic. Therefore, early screening of pregnant women for GDM is essential. Internationally, however, there is no consensus about whether to screen all women for GDM (universal screening) or only women with pre-specified risk factors (selective screening) ${ }^{12}$. Universal screening has a high detection rate, but may also lead to an increased burden for women as well as for health care resources. Although selective screening, as advocated in current guidelines, reduces the number of women to be screened, its drawback is that this method treats each risk factor as an independent screening tool ${ }^{13,14}$. Prediction models may be more accurate in identifying women at high risk for GDM as multiple risk factors are weighed and combined ${ }^{15}$. In addition, they may also constitute a basis for primary prevention of $\mathrm{GDM}^{16}$.

A substantial number of prediction models for the risk of GDM have been developed $^{17}$, but to our knowledge none of these are routinely used in clinical practice. Validation of prediction models in independent populations is a crucial step before implementation in clinical practice ${ }^{15,18}$. Only a few studies externally validated models for GDM, but most validated only up to five models ${ }^{19-23}$. A first comparison of multiple non-invasive early prediction models for the risk of GDM in an independent cohort was published in $2016^{24}$. Most of the prediction models showed acceptable discrimination and calibration.

In this study, we performed a fully independent validation study of all published first trimester prediction models, containing non-invasive predictors, for the risk of GDM in a Dutch prospective cohort study. Contrary to the previous published external validation effort, we evaluated the clinical potential of the best performing models and compared it with the performance of current screening strategies.

\section{Methods}

\section{Selection of prediction models}

We performed a systematic search in Pubmed to identify early prediction models for the risk of GDM. The search was conducted in April 2013 before development of study 
questionnaires and updated until April 13, 2017. The search strategy has been published elsewhere ${ }^{25}$. One author (LM) screened the retrieved titles and, together with LS, assessed eligibility of full papers. A third reviewer (HS) was available in case of disagreement. Citation lists of included articles, as well as systematic reviews and validation studies of prediction models for GDM were checked to identify other relevant articles. We included studies that met the following criteria: 1) presented the development of a prediction model or an update of a previously developed model, 2) endpoint of the model was the risk of developing GDM, 3) model contained multiple predictors, 4) model was based on weighted risk predictors, 5) predictors were routinely collected in Dutch obstetric practice (maternal characteristics, anthropometric measures, or blood pressure measurements), and 6) predictors were available before $16^{+0}$ weeks of gestation. Authors of the original studies were contacted if the model intercept, regression coefficients, or definitions of predictors were not available. When regression estimates could not be obtained or the paper was written in another language than English, German, French, or Dutch, the article was excluded.

\section{Validation cohort}

Two population-based prospective cohorts of pregnant women were used for the validation sample: the Expect Study I and the PRIDE (PRegnancy and Infant DEvelopment) Study. Women with any type of pre-existing DM were excluded from the analysis.

\section{Expect Study I}

We performed a multicentre prospective cohort study with the primary objective to validate published first trimester prediction models for adverse pregnancy outcomes. Six hospitals and 36 midwifery practices in the south-eastern part of the Netherlands recruited pregnant women less than 16 weeks of gestation and aged 18 years or older between July 1, 2013 and January 1, 2015, with follow-up until December 31, 2015. Pregnancies ending in miscarriage, termination before 24 weeks of gestation, or for which no outcome data were available, were excluded. Eligible pregnant women were invited to complete two web-based questionnaires (paper-based upon request), one before 16 weeks of gestation and one at 6 weeks after the due date. Medical records and discharge letters were requested from health care providers. A detailed description of the Expect Study I has been published in full elsewhere ${ }^{25}$.

The Medical Ethical Committee of the Maastricht University Medical Centre declared that no ethical approval was necessary (MEC 13-4-053). Online informed consent was obtained from all participating women.

\section{PRIDE Study}

The PRIDE Study is an ongoing large Dutch prospective cohort study among pregnant women. Full details of the study have been published previously ${ }^{26}$. Inclusion started in 
July 2011 in the region of Nijmegen and gradually expanded to encompass all of the Netherlands in the beginning of 2016. Pregnant women aged 18 years or older were asked to complete web-based questionnaires, or paper-based upon request, at baseline (questionnaire 1; usually 8-12 weeks of gestation), during gestational weeks 17 (questionnaire 2) and 34 (questionnaire 3), and 2 (questionnaire 4) and 6 (questionnaire 5) months after the due date. Permission was asked to obtain medical records.

Women enrolled between July 2011 and May 2016 were included in this study. We excluded pregnant women $\geq 16$ weeks of gestation at completion of the baseline questionnaire, miscarriages, terminations before 24 weeks of gestation, and women with no follow-up data on outcomes (questionnaire 4 or medical record). Medical records were obtained for women who gave permission ( 75\%) and who had an estimated due date before March 1, 2015.

The PRIDE Study was approved by the Committee on Research involving Human Subjects region Arnhem-Nijmegen (CMO 2009/305). Participating women gave informed consent digitally through the Internet.

\section{Predictor variables}

The variables in the included prediction models for GDM were extracted from the web-based questionnaires: pregnancy questionnaire 1 (Expect Study I) and baseline questionnaire (PRIDE Study). In both studies, systolic and diastolic blood pressure was measured according to routine antenatal care and self-reported in the questionnaire. In the Expect Study I, predictor variables were defined according to the original articles. Although the primary goals of the PRIDE Study do not include prediction of pregnancy complications, most predictors were measured similarly. The original articles had different definitions for family history of DM. For comparison and because no distinction was made between the types of DM in the PRIDE Study, we defined two proxy variables for family history of DM: first degree relative with any type of DM and second degree relative with any type of DM. The latter predictor was imputed for PRIDE Study participants as only family history of first degree relatives was assessed. We also redefined the predictor poor obstetric outcome (model Teede et al.) as history of antepartum haemorrhage, shoulder dystocia, and neonatal death was not administered. A detailed description on predictor definition is provided in Supplementary Table S4.1.

\section{Assessment of gestational diabetes mellitus}

GDM was defined as a diagnosis of hyperglycaemia during pregnancy in a woman without pre-existing DM. According to the WHO guideline, the Dutch national guideline defines hyperglycaemia as the presence of either a fasting plasma glucose $\geq 7.0 \mathrm{mmol} / \mathrm{l}$ or 2 -hour plasma glucose $\geq 7.8 \mathrm{mmol} / \mathrm{l}$ following a $75 \mathrm{~g} \mathrm{OGTT}{ }^{13,27}$. Women at high risk of GDM (prior GDM, BMI $>30 \mathrm{~kg} / \mathrm{m}^{2}$ at first trimester, history of birth weight $>95^{\text {th }}$ centile or $>4500$ g, first degree relative with $D M$, history of unexplained 
stillbirth, polycystic ovarium syndrome, and certain non-western ethnic groups) are offered an OGTT between 24 and 28 weeks of gestation (selective screening) or if any signs of GDM are present (LGA infant or polyhydramnios). A random glucose measurement is recommended in the first trimester to screen for pre-existing diabetes.

In both cohorts, the outcome was present in case the postpartum questionnaire or medical record recorded a diagnosis of GDM. For PRIDE Study participants, we also examined questionnaires 2 and 3 for a diagnosis of GDM. In the Expect Study I, we contacted the obstetric care providers in case of discrepancies between the two data sources $(n=29)$. The postpartum questionnaire was used as reference standard to resolve discrepancies in the PRIDE Study $(n=2)$.

\section{Statistical analysis}

There is no explicit rule for the required sample size for studies externally validating prediction models. Vergouwe et al. recommends a minimum of 100 events and 100 non-events ${ }^{28}$.

The characteristics of both cohorts were described as mean \pm SD for continuous variables and an absolute value with percentage for categorical variables. We used stochastic regression imputation with predictive mean matching as the imputation model to substitute missing predictor variables ${ }^{29}$. The comparability between the development cohorts and the validation cohort was evaluated.

We calculated the individual probabilities of developing GDM for all subjects using the original prediction model algorithms (Supplementary Table S4.2). The predictive performance of each model was quantified by measures of discrimination and calibration. We determined discrimination by the area under the receiver operating characteristic curve (AUROC) with $95 \% \mathrm{Cl}$. Discrimination is the ability of the model to correctly separate women who develop GDM from those who will not. Calibration, the agreement between the predicted probabilities of the model and the observed outcomes, was assessed graphically by calibration plots and by calculation of calibration-in-the-large and the calibration slope. Calibration-in-the-large indicates whether predictions are systematically too high or too low ${ }^{30}$. The slope measures the average strength of the predictor effects ${ }^{31}$. The calibration plot should ideally follow the $45^{\circ}$ line with an intercept of 0 (calibration-in-the-large) and a slope of $1^{30}$. A prediction model is often overfitted (low probabilities too low and high probabilities too high), resulting in a slope $<1$ after validation ${ }^{30}$. The women were ordered with respect to their predicted probability and subsequently divided into 10 groups of roughly equal size. We recalibrated the prediction models - adjustment intercept and slope - using the linear predictor as the only covariate ${ }^{31}$. Discriminative performance remained the same as recalibration does not change the ranking order of the predicted probabilities. We performed a subgroup analysis among nulliparous women as prior GDM is a strong predictor. 
For comparability of the models, we used the validation cohort with our in- and exclusion criteria. A sensitivity analysis was performed to assess the predictive performance of each model according to their additionally defined eligibility criteria. We also assessed the performance measures in the Expect Study I and the PRIDE Study separately.

The potential clinical utility was evaluated for the best discriminative models by means of decision curve analysis. Decision curve analysis provides insight into the net benefit (net proportion of true positives) of the models over a range of threshold risks as opposed to designate all or no women as at high risk of developing $\mathrm{GDM}^{32}$. Finally, we composed a table for the model with the highest net benefit comparing sensitivity, specificity, and positive and negative predictive values for different risk thresholds. Model performance was also compared with that of current selective screening guidelines, the National Institute for Health and Clinical Excellence (NICE) criteria and the Dutch national guideline ${ }^{13,14}$. Polycystic ovary syndrome, a risk factor according to the Dutch national guideline, was not included as this predictor was not measured in the Expect Study I cohort.

Statistical analyses were performed with IBM SPSS statistics version 23 (SPSS, Chicago, $\mathrm{IL}$ ) and $\mathrm{R}$ version 3.2.3, packages rms, pROC, and DecisionCurve.

\section{Results}

\section{Selection of prediction models}

The search strategy identified 530 articles. We selected 18 articles that described prediction models fulfilling the eligibility criteria. We excluded seven papers because the algorithm was not available $(n=3)^{33-35}$, or the model was already published in one of the included articles $(n=4)^{36-39}$. Reference cross-checking yielded two additional studies, so 12 articles were included in this validation study ${ }^{22,23,40-49}$. The models were published between 1997 and 2017, and developed in nine different countries. The models used different screening strategies for GDM. Almost all studies $(n=9)$ diagnosed GDM using a 2-hour 75-g OGTT, but the diagnostic criteria varied between studies. A comprehensive overview of the characteristics is available in Supplementary Table S4.3.

\section{Validation cohort}

The validation cohort included 5263 women, 2603 women from the Expect Study I and 2660 women from the PRIDE Study (Figure 4.1). GDM was diagnosed in 127 women (2.4\%), 72 women in the Expect Study I and 55 women in the PRIDE Study. Twenty-nine pregnancies complicated by GDM $(22.8 \%)$ delivered a LGA infant $\left(>90^{\text {th }}\right.$ percentile). The overall prevalence of a LGA infant in the validation cohort was 9.6\%. Population characteristics are presented in Table 4.1. The imputed validation cohort was generally similar when compared to the observed cohort. An overview of 
the characteristics of the complete cases and the imputed validation cohort is provided in Supplementary Table S4.4.

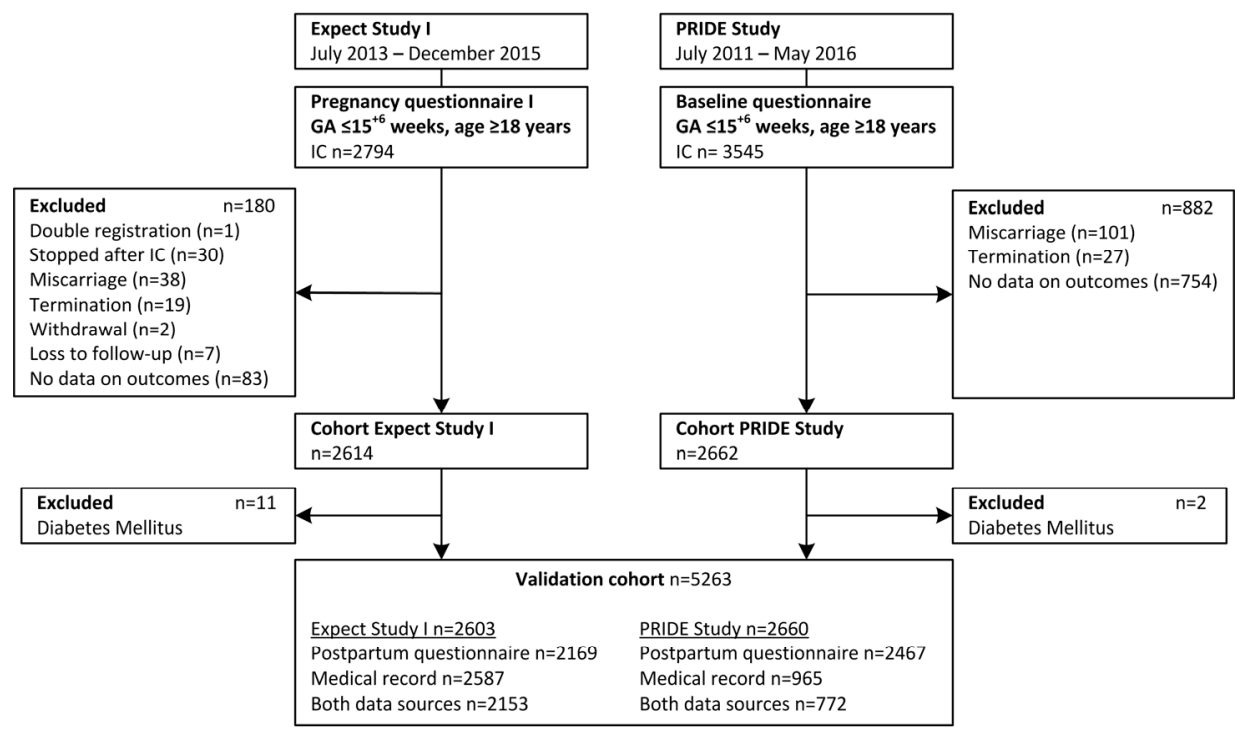

Figure 4.1 Flowchart of women included in the validation cohort (GA, gestational age; IC, informed consent)

We also evaluated the relatedness between the original cohorts and the validation sample (Supplementary Table S4.5A-B). The patient characteristics of Sweeting et al., Gabbay-Benziv et al., Eleftheriades et al., Tran et al., Teede et al., Shirazian et al., and Phaloprakarn et al. differed considerably from the validation cohort and the prevalence of GDM was substantially higher in these original cohorts. Women in our validation cohort were, in contrast to almost all original cohorts, nearly all of Caucasian origin. Van Leeuwen et al. did not describe population characteristics while Syngelaki et al. did not present all predictor characteristics and the number of cases of GDM. 
Table 4.1 Baseline characteristics of the validation cohort

\begin{tabular}{|c|c|c|c|c|c|c|c|}
\hline \multirow[t]{2}{*}{ Characteristics } & \multirow{2}{*}{$\begin{array}{l}\text { Missing } \\
\text { values, } \\
\text { n (\%) }\end{array}$} & \multirow{2}{*}{$\begin{array}{c}\text { Expect } \\
\text { Study I } \\
(n=2603)\end{array}$} & \multirow{2}{*}{$\begin{array}{l}\text { Missing } \\
\text { values, } \\
\text { n (\%) }\end{array}$} & \multirow{2}{*}{$\begin{array}{c}\text { PRIDE } \\
\text { Study } \\
(\mathrm{n}=2660)\end{array}$} & \multicolumn{3}{|c|}{ Observed validation cohort ${ }^{a}$} \\
\hline & & & & & $\begin{array}{c}\text { Overall } \\
(n=5263)\end{array}$ & $\begin{array}{c}\text { GDM } \\
(n=127)\end{array}$ & $\begin{array}{l}\text { No GDM } \\
(n=5136)\end{array}$ \\
\hline Age, years & $0(0.0)$ & $30.2(3.9)$ & $0(0.0)$ & $30.6(3.7)$ & $30.4(3.8)$ & $31.1(4.1)$ & $30.4(3.8)$ \\
\hline Ethnicity & $0(0.0)$ & & $36(1.4)$ & & & & \\
\hline Caucasian & & $2522(96.9)$ & & $2611(98.2)$ & $5133(97.5)$ & 123 (96.9) & $5010(97.5)$ \\
\hline Afro-Caribbean & & $3(0.1)$ & & $1(0.0)$ & $4(0.1)$ & $0(0.0)$ & $4(0.1)$ \\
\hline Asian & & $20(0.8)$ & & $6(0.2)$ & $26(0.5)$ & $3(2.4)$ & $23(0.4)$ \\
\hline Hispanic & & $11(0.4)$ & & $2(0.1)$ & $13(0.2)$ & $0(0.0)$ & $13(0.3)$ \\
\hline Mixed & & $47(1.8)$ & & $4(0.2)$ & $51(1.0)$ & $0(0.0)$ & $51(1.0)$ \\
\hline Tertiary education & $3(0.1)$ & $1415(54.4)$ & $38(1.4)$ & $2017(75.8)$ & $3432(65.2)$ & $65(51.2)$ & $3367(65.6)$ \\
\hline Height, $\mathrm{cm}$ & $3(0.1)$ & $168.8(6.4)$ & $17(0.6)$ & $171.1(6.3)$ & $170.0(6.4)$ & $168.8(6.7)$ & $170.0(6.4)$ \\
\hline Weight, kg & $5(0.2)$ & $68.9(13.0)$ & $19(0.7)$ & $68.6(11.8)$ & $68.7(12.4)$ & $78.8(16.3)$ & $68.5(12.2)$ \\
\hline $\begin{array}{l}\text { Body mass index, } \\
\mathrm{kg} / \mathrm{m}^{2}\end{array}$ & $5(0.2)$ & $24.1(4.3)$ & $25(0.9)$ & $23.4(3.8)$ & $23.8(4.1)$ & $27.7(6.0)$ & $23.7(3.9)$ \\
\hline $\begin{array}{l}\text { Smoking during } \\
\text { pregnancy }\end{array}$ & $1(0.0)$ & $156(6.0)$ & $31(1.2)$ & $48(1.8)$ & 204 (3.9) & $5(3.9)$ & $199(3.9)$ \\
\hline $\begin{array}{l}\text { History of chronic } \\
\text { hypertension } \\
\text { Family history of } \\
\text { diabetes mellitus }\end{array}$ & $0(0.0)$ & $28(1.1)$ & $17(0.6)$ & $2(0.1)$ & $30(0.6)$ & $0(0.0)$ & $30(0.6)$ \\
\hline First degree & $1(0.0)$ & 378 (14.5) & $13(0.5)$ & $292(11.0)$ & 670 (12.7) & 39 (30.7) & $631(12.3)$ \\
\hline Second degree & $1(0.0)$ & $855(32.8)$ & NM & NM & 855 (16.2) & $31(24.4)$ & $824(16.0)$ \\
\hline Nulliparous & $0(0.0)$ & $1322(50.8)$ & $0(0.0)$ & $1445(54.3)$ & 2767 (52.6) & 71 (55.9) & $2696(52.5)$ \\
\hline Conception & $0(0.0)$ & & $15(0.6)$ & & & & \\
\hline Spontaneous & & $2429(93.3)$ & & 2501 (94.0) & 4930 (93.7) & $110(86.6)$ & $4820(93.8)$ \\
\hline Ovulation & & $93(3.6)$ & & 79 (3.0) & $172(3.3)$ & $9(7.1)$ & $163(3.2)$ \\
\hline induction & & & & & & & \\
\hline IVF/ICSI & & $81(3.1)$ & & $65(2.4)$ & $146(2.8)$ & $6(4.7)$ & $140(2.7)$ \\
\hline $\begin{array}{l}\text { History recurrent } \\
\text { miscarriages }(\geq 2)\end{array}$ & $0(0.0)$ & $151(5.8)$ & $0(0.0)$ & $124(4.7)$ & $275(5.2)$ & $8(6.3)$ & $267(5.2)$ \\
\hline $\begin{array}{l}\text { History of GDM } \\
\text { History of } \\
\text { macrosomia }\end{array}$ & $19(0.7)$ & $14(0.5)$ & $3(0.1)$ & $11(0.4)$ & $25(0.5)$ & $12(9.4)$ & $13(0.3)$ \\
\hline$>90^{\text {th }}$ percentile & $52(2.0)$ & $166(6.4)$ & 44 (1.7) & $218(8.2)$ & $384(7.3)$ & $21(16.5)$ & $363(7.1)$ \\
\hline$>4000 \mathrm{~g}$ & $42(1.6)$ & $145(5.6)$ & $61(2.3)$ & $182(6.8)$ & $327(6.2)$ & 15 (11.8) & $312(6.1)$ \\
\hline $\begin{array}{l}\text { Systolic blood } \\
\text { pressure, mmHg }\end{array}$ & $260(10.0)$ & $114(13)$ & $948(35.6)$ & $114(12)$ & $114(12)$ & $117(12)$ & $114(12)$ \\
\hline $\begin{array}{l}\text { Diastolic blood } \\
\text { pressure, } \mathrm{mmHg}\end{array}$ & $270(10.4)$ & $68(9)$ & 954 (35.9) & 67 (9) & $68(9)$ & $71(9)$ & $67(9)$ \\
\hline
\end{tabular}

${ }^{a}$ Original data (not imputed) presented as mean (SD) or absolute number (\%). GDM, gestational diabetes mellitus; ICSI, intracytoplasmic sperm injection; IVF, in vitro fertilisation; NM, not measured

\section{Predictive performance}

Table 4.2 presents the discriminative performance of the included models. Although the AUROC decreased for almost all models compared with the original cohorts, discriminative ability remained satisfactory for all models with AUROCs ranging from 0.68 to 0.75 . The AUROC of the model of Naylor et al. remained the same and an improvement was observed for the models of Tran et al., according to the WHO 1999 
criteria, and Teede et al.. The models of Nanda et al. and Syngelaki et al. yielded the highest discriminative performance (AUROC $0.75,95 \% \mathrm{Cl} 0.70-0.80$ for both models). Application of the models in nulliparous women showed only slight decreases of the AUROCs, except for the model of Gabbay-Benziv et al. (0.05 decline). Sensitivity analyses showed that the models performed similarly in the Expect Study I and the PRIDE Study. Assessment of the discriminative performance of each model according to their own population eligibility criteria did not change the AUROC materially (results not shown). The ROC curves of the models in the overall cohort are available in Supplementary Figure S4.1A-B.

Table 4.2 Discriminative performance of included prediction models for GDM

\begin{tabular}{|c|c|c|c|c|c|}
\hline $\begin{array}{l}\text { Study, author } \\
\text { (year) }\end{array}$ & $\begin{array}{c}\text { AUROC }(95 \% \mathrm{Cl}) \\
\text { Original publication }\end{array}$ & $\begin{array}{l}\text { AUROC }(95 \% \mathrm{CI}) \\
\text { Validation } \\
\text { cohort } \\
(n=5263)\end{array}$ & $\begin{array}{l}\text { AUROC }(95 \% \mathrm{CI}) \\
\text { Validation } \\
\text { cohort, } \\
\text { nulliparous } \\
\text { women } \\
(\mathrm{n}=2767)\end{array}$ & $\begin{array}{c}\text { AUROC }(95 \% \mathrm{CI}) \\
\text { Expect Study I } \\
(n=2603)\end{array}$ & $\begin{array}{c}\text { AUROC }(95 \% \mathrm{CI}) \\
\text { PRIDE Study } \\
(n=2660)\end{array}$ \\
\hline $\begin{array}{l}\text { Sweeting } \\
(2017)\end{array}$ & $0.88(0.85-0.92)$ & $0.72(0.67-0.77)$ & $0.69(0.62-0.76)$ & $0.71(0.65-0.78)$ & $0.71(0.63-0.79)$ \\
\hline $\begin{array}{l}\text { Syngelaki } \\
\text { (2015) }\end{array}$ & $\begin{array}{c}\text { Internal validation: } \\
0.82(0.82-0.83)\end{array}$ & $0.68(0.62-0.74)$ & $0.64(0.56-0.72)$ & $0.70(0.62-0.77)$ & $0.66(0.56-0.75)$ \\
\hline $\begin{array}{l}\text { Eleftheriades } \\
(2014)\end{array}$ & $0.73(0.65-0.81)$ & $0.68(0.63-0.73)$ & $0.68(0.60-0.75)$ & $0.67(0.60-0.74)$ & $0.69(0.61-0.77)$ \\
\hline $\begin{array}{l}\text { Gabbay-Benziv } \\
\text { (2014) }\end{array}$ & $0.82(0.77-0.87)$ & $0.72(0.67-0.77)$ & $0.67(0.59-0.75)$ & $0.70(0.64-0.77)$ & $0.73(0.65-0.81)$ \\
\hline Tran (2013) & $\begin{array}{c}\text { ADA } \\
0.71(0.68-0.75) \\
\text { ADIPS } \\
0.64(0.62-0.67) \\
\text { IADPSG } \\
0.65(0.62-0.67) \\
\text { WHO } \\
0.63(0.60-0.65)\end{array}$ & $0.70(0.64-0.75)$ & $0.69(0.62-0.77)$ & $0.68(0.61-0.75)$ & $0.71(0.63-0.79)$ \\
\hline $\begin{array}{l}\text { Syngelaki } \\
(2011)\end{array}$ & NR & $0.75(0.70-0.80)$ & $0.72(0.65-0.80)$ & $0.76(0.69-0.82)$ & $0.73(0.66-0.81)$ \\
\hline $\begin{array}{l}\text { Teede } \\
(2011)\end{array}$ & $\begin{array}{l}\text { Internal validation: } \\
0.70\end{array}$ & $0.73(0.68-0.78)$ & $0.71(0.63-0.78)$ & $0.71(0.64-0.78)$ & $0.75(0.67-0.82)$ \\
\hline $\begin{array}{l}\text { Nanda } \\
(2011)\end{array}$ & $0.79(0.76-0.82)$ & $0.75(0.70-0.80)$ & $0.71(0.64-0.79)$ & $0.75(0.68-0.82)$ & $0.75(0.67-0.82)$ \\
\hline $\begin{array}{l}\text { Van Leeuwen } \\
(2010)\end{array}$ & $0.77(0.69-0.85)$ & $0.74(0.70-0.79)$ & $0.71(0.64-0.78)$ & $0.75(0.68-0.81)$ & $0.74(0.66-0.81)$ \\
\hline $\begin{array}{l}\text { Shirazian } \\
(2009)\end{array}$ & NR & $0.71(0.66-0.76)$ & $0.71(0.65-0.78)$ & $0.70(0.64-0.77)$ & $0.71(0.63-0.78)$ \\
\hline $\begin{array}{l}\text { Phaloprakarn } \\
\text { (2009) }\end{array}$ & $\begin{array}{c}0.77(0.75-0.79) \\
\text { Internal validation: } \\
0.75(0.73-0.78)\end{array}$ & $0.74(0.69-0.79)$ & $0.73(0.66-0.80)$ & $0.74(0.67-0.80)$ & $0.73(0.66-0.81)$ \\
\hline $\begin{array}{l}\text { Naylor } \\
\text { (1997) }\end{array}$ & $\begin{array}{c}0.68(\mathrm{NR}) \\
\text { Internal validation: } \\
\text { NR }\end{array}$ & $0.68(0.63-0.73)$ & $0.67(0.60-0.74)$ & $0.67(0.60-0.73)$ & $0.69(0.62-0.77)$ \\
\hline
\end{tabular}

ADA, American Diabetes Association; ADIPS, Australasian Diabetes in Pregnancy Society; AUROC, area under the receiver operating characteristic curve; $\mathrm{Cl}$, confidence interval; IADPSG, International Association of the Diabetes and Pregnancy Study Groups; NR, not reported 
Calibration plots for the original models that provided a complete prediction algorithm are presented in Figure 4.2A-B. Models tended to overestimate the risk of GDM (intercept $<0$, triangles under ideal calibration line), except the model of Nanda et al.. The models by Sweeting et al. and Syngelaki et al. were overfitted (calibration slope $<1$ ). The models of Gabbay-Benziv et al. and Nanda et al. were calibrated the best. After adjustment for differences in the baseline risk of GDM and refitting of the regression coefficients with a constant factor, most models showed better calibration (Supplementary Figure S4.2A-B). The models of Sweeting et al., Syngelaki et al., Eleftheriades et al., Gabbay-Benziv et al., Tran et al., Syngelaki et al., Nanda et al., and Phaloprakarn et al. over- and underestimated the probability of GDM throughout the risk spectrum. The model of Van Leeuwen et al. showed closest fit to the ideal calibration line.

\section{Clinical usefulness}

Figure 4.3 shows the decision curve analysis of the four best performing models. These models had a positive net benefit compared with classifying all or no women as at high risk for GDM for a risk threshold ranging between 1 and 55\%.

Sensitivity, specificity, and positive and negative predictive values were estimated at different clinically useful risk thresholds for the recalibrated model of Nanda et al. (Table 4.3). At a low risk threshold (i.e. $2 \%$ ), we observed a high sensitivity and a high negative predictive value, suggesting a strong ability to rule out GDM in women who are indicated as low risk. At this high sensitivity, however, a lot of women will be unnecessarily indicated as having a high risk (high false positive rate). A risk threshold above $5 \%$ leads to a drastically low sensitivity, so a large proportion of women that will develop GDM would be incorrectly classified as having a low risk.

We compared the model of Nanda et al. with current selective screening guidelines (NICE, Dutch national guideline). The NICE criteria classified $21 \%$ of the women as at high risk in the validation cohort with a sensitivity of $62 \%$ and a specificity of $80 \%$. When applying the Dutch national guideline criteria to the validation cohort, $23 \%$ of the women were considered to be at high risk for developing GDM with a sensitivity of $65 \%$ and a specificity of $78 \%$. 


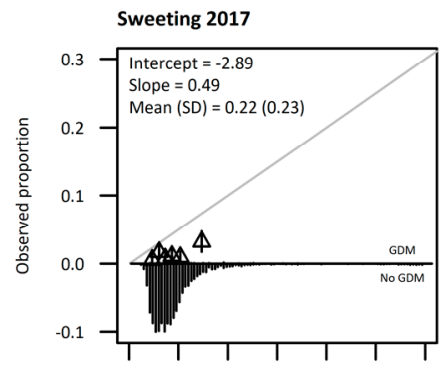

$\begin{array}{lllllll}0.00 & 0.05 & 0.10 & 0.15 & 0.20 & 0.25 & 0.30\end{array}$ Predicted probability

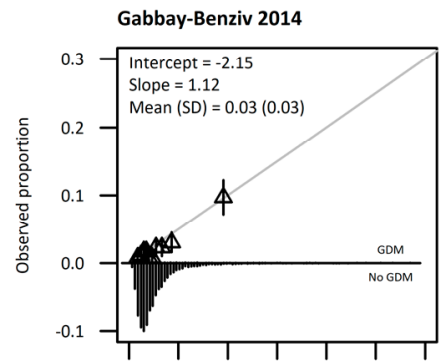

$\begin{array}{lllllll}0.00 & 0.05 & 0.10 & 0.15 & 0.20 & 0.25 & 0.30\end{array}$ Predicted probability

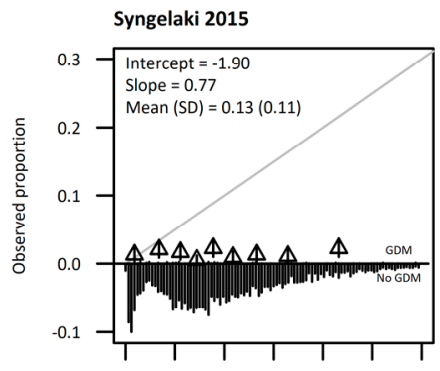

$\begin{array}{lllllll}0.00 & 0.05 & 0.10 & 0.15 & 0.20 & 0.25 & 0.30\end{array}$ Predicted probability

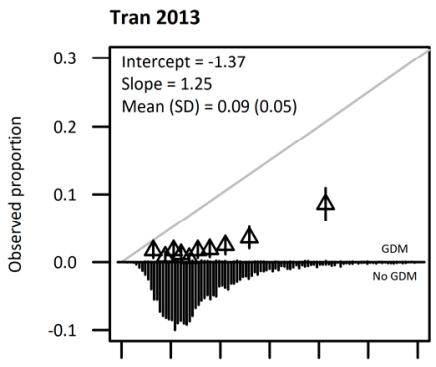

$\begin{array}{lllllll}0.00 & 0.05 & 0.10 & 0.15 & 0.20 & 0.25 & 0.30\end{array}$ Predicted probability

Figure 4.2A Calibration plots of externally validated first trimester prediction models for gestational diabetes mellitus (GDM). The grey line is the reference line with intercept $=0$ and slope $=1$ (perfect calibration). Triangles correspond to grouped predicted risks with $95 \% \mathrm{Cl}$ (vertical lines) 

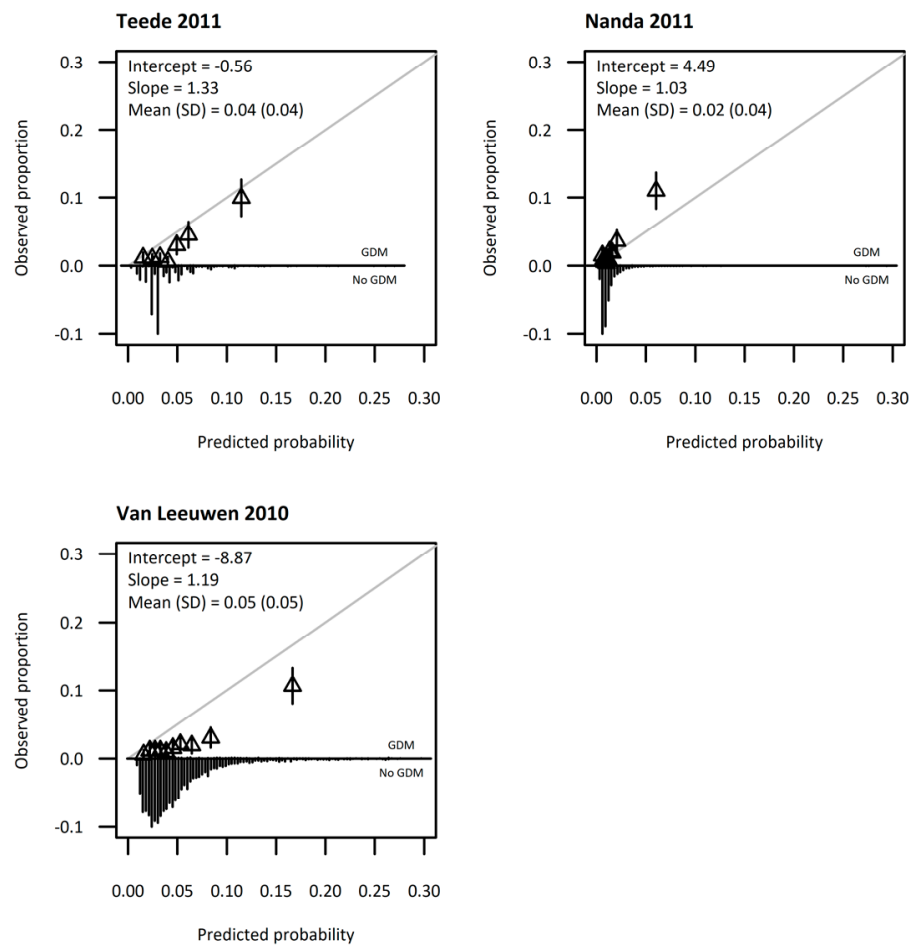

Figure 4.2B Calibration plots of externally validated first trimester prediction models for gestational diabetes mellitus (GDM). The grey line is the reference line with intercept $=0$ and slope $=1$ (perfect calibration). Triangles correspond to grouped predicted risks with $95 \% \mathrm{Cl}$ (vertical lines)

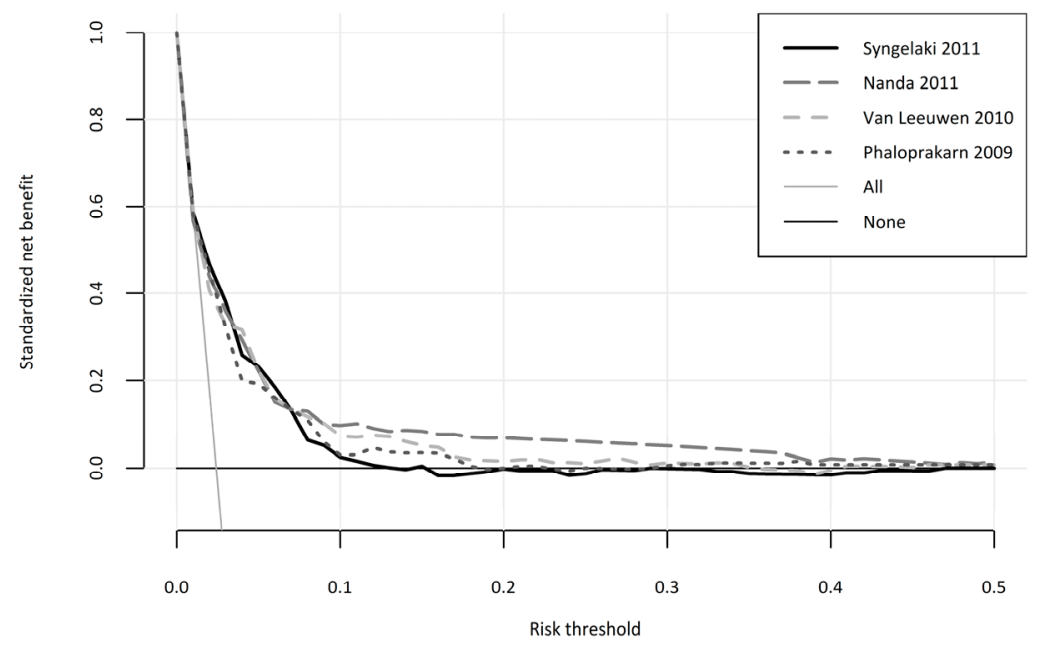

Figure 4.3 Decision curve analysis of four best performing models for the risk of gestational diabetes mellitus. The solid grey line is the net benefit when considering all women as at high risk and the horizontal black line when considering no women at high risk 
Table 4.3 Sensitivities, specificities and predictive values at different risk thresholds for the recalibrated model of Nanda et al.

\begin{tabular}{lccccc}
\hline $\begin{array}{l}\text { Risk threshold } \\
\%\end{array}$ & $\begin{array}{c}\text { High risk, } \% \\
(\mathbf{n} / \mathbf{n})\end{array}$ & $\begin{array}{c}\text { Sensitivity, } \\
(\mathbf{n} / \mathbf{n})\end{array}$ & $\begin{array}{c}\text { Specificity, } \\
\%(\mathbf{n} / \mathbf{n})\end{array}$ & $\begin{array}{c}\text { PPV, } \\
\%(\mathbf{n} / \mathbf{n})\end{array}$ & $\begin{array}{c}\text { NPV, } \\
\%(\mathbf{n} / \mathbf{n})\end{array}$ \\
\hline 1 & 90.5 & 93.7 & 9.6 & 2.5 & 98.4 \\
& $(4764 / 5263)$ & $(119 / 127)$ & $(491 / 5136)$ & $(119 / 4764)$ & $(491 / 499)$ \\
2 & 35.6 & 72.4 & 65.3 & 4.9 & 99.0 \\
3 & $(1873 / 5263)$ & $(92 / 127)$ & $(3355 / 5136)$ & $(92 / 1873)$ & $(3355 / 3390)$ \\
& 16.3 & 55.1 & 84.6 & 8.1 & 98.7 \\
4 & $(860 / 5263)$ & $(70 / 127)$ & $(4346 / 5136)$ & $(70 / 860)$ & $(4346 / 4403)$ \\
& 9.1 & 43.3 & 91.7 & 11.4 & 98.5 \\
5 & $(481 / 5263)$ & $(55 / 127)$ & $(4710 / 5136)$ & $(55 / 481)$ & $(4710 / 4782)$ \\
& 5.4 & 32.3 & 95.3 & 14.5 & 98.3 \\
10 & $(282 / 5263)$ & $(41 / 127)$ & $(4895 / 5136)$ & $(41 / 282)$ & $(4895 / 4981)$ \\
& 1.1 & 13.4 & 99.2 & 28.8 & 97.9 \\
20 & $(59 / 5263)$ & $(17 / 127)$ & $(5094 / 5136)$ & $(17 / 59)$ & $(5094 / 5204)$ \\
& 0.5 & 9.4 & 99.7 & 48.0 & 97.8 \\
40 & $(25 / 5263)$ & $(12 / 127)$ & $(5123 / 5136)$ & $(12 / 25)$ & $(5123 / 5238)$ \\
& 0.4 & 7.9 & 99.8 & 47.6 & 97.8 \\
& $(22 / 5263)$ & $(10 / 127)$ & $(5125 / 5136)$ & $(10 / 22)$ & $(5125 / 5242)$ \\
\hline
\end{tabular}

${ }^{\mathrm{a}}$ Predicted risk at or above this level was considered as high risk. NPV, negative predictive value; PPV, positive predictive value

\section{Discussion}

\section{Principal findings}

We validated 12 non-invasive first trimester prediction models for the risk of GDM in a Dutch prospective cohort. All models had a moderate discriminative performance with an AUROC around 70\%. The best discriminating models were those of Syngelaki et al. and Nanda et al. with an AUROC of $75 \%$. Nearly all models overestimated the risk of developing GDM in our cohort. Recalibration led to better agreement between actual risks and predicted probabilities for most models.

\section{Previous research}

External validation is important as prediction models generally give a too optimistic picture of predictive performance in the development sample ${ }^{31}$. The discriminative performance decreased for all models, except for the model of Tran et al., Teede et al., and Naylor et al.. Predictors in the included models were routinely recorded risk factors, such as age, BMI, ethnicity, family history of DM, prior macrosomia, and prior $\mathrm{GDM}^{16}$. A history of GDM is strongly associated with the risk of GDM, however, the discriminative performance of most models stayed stable in the subgroup analysis including only nulliparous women.

Previous external validation studies that validated only a few models yielded similar results for the models of Nanda et al., Teede et al., Van Leeuwen et al., and Naylor et al. ${ }^{19,21-23}$. Only a study by Lovati et al., a case-control study in a tertiary care clinic, showed a lower AUROC (0.60) for the model of Teede et al. $^{20}$. Moreover, the research group of Sweeting et al., also using a case-control study design, presented a lower 
performance for the model of Van Leeuwen et al. (AUROC 0.64) and a higher discriminative ability for the model of Syngelaki et al. (AUROC 0.87$)^{23}$. These discrepancies might be due to differences in the population characteristics. The only published study that also performed a comprehensive external validation of multiple prediction models showed slightly higher discriminative performances compared to our results ${ }^{24}$. We validated three additional models based on maternal characteristics.

Multiple external validation of a prediction model adds to the robustness of model performance $^{31}$. Two of our best performing models, Nanda et al. and Van Leeuwen et al., showed similar performances in several independent populations. The other comprehensive external validation study was performed among a Dutch population as well, but from another geographic area. This strengthens the generalizability of the models to the general Dutch population and even to antenatal populations in other high-income countries. In the end, only an impact study can determine whether the model contributes to improved personalized care as this depends on several other aspects, such as participant and care givers' behaviour and management, risk counselling, and related costs ${ }^{50}$.

\section{Implications}

Early risk stratification for GDM may benefit from the use of prediction models in contrast to current strategies. In case of screening, the proportion of women with identified GDM increases with the number of women offered an OGTT irrespective of the screening strategy used ${ }^{51}$. Universal screening leads to $100 \%$ detection, but the majority of women have to undergo an OGTT that may lead to unnecessarily increased burden on individual women and health care resources. Current selective screening strategies are based on a list of risk factors and have a fixed sensitivity and specificity. Our study indicated that the best prediction model had a similar sensitivity and specificity of around $65 \%$ and $80 \%$, respectively, compared to selective screening strategies $^{13,14}$. However, an advantage of prediction models is that a particular tradeoff between sensitivity and specificity can be chosen. Determination of an acceptable risk threshold is a critical and challenging aspect of clinical usefulness. The choice for a specific risk threshold depends on several factors, such as consequences of the outcome, the effect of treatment of GDM, burden of OGTT, and related costs. Shortand long-term consequences of GDM are well known and treatment (dietary intervention and pharmacological therapy) is proven to be effective ${ }^{3-10}$. However, robust evidence is lacking on reduction of more serious maternal and perinatal complications as well as on the long-term benefit of treatment, such as reduced incidence of type $2 \mathrm{DM}^{9,10}$. Moreover, no evidence is available regarding the effects of the different screening methods on health outcomes ${ }^{51}$. Most benefit would be obtained if GDM could be prevented. Despite emerging promising studies of preventive interventions, such as lifestyle interventions, no hard evidence is available $^{16}$. The few studies available have methodological shortcomings such as heterogeneity of the interventions and small sample size ${ }^{12,16}$. 


\section{Strengths and limitations}

The main strengths of our study are the large sample size, sufficient number of cases and the multicentre prospective cohort design. We combined two cohorts from different geographic areas. The design of the studies should have ensured an as representative and unselected population as possible. However, women of Caucasian origin were overrepresented in both cohorts and the PRIDE Study comprised a large proportion of women with a high educational level. Subgroup analysis showed no differences in model performance between the two cohorts, demonstrating consistency of the results in different populations. High data quality and low quantity of missing data were achieved by the use of web-based questionnaires ${ }^{52}$. Nevertheless, blood pressure measurements had a substantial amount of missing values as a result of self-report ${ }^{53}$. The predictor blood pressure was, however, only necessary for one included prediction model. Next, we had to generate proxy variables for family history of DM. Although a positive family history of second degree relatives was imputed completely for the PRIDE Study cohort, no differences in the predictive performance of the models containing this predictor were observed between both cohorts. Another limitation to be mentioned is that the OGTT was only performed as screening tool in women at high risk for GDM according to the Dutch national guideline ${ }^{13}$. Nevertheless, diagnosis of GDM was based on reviewing of medical records and the postpartum questionnaire allowing us to detect all cases of GDM, including late diagnosis of GDM. In our study, $65 \%$ of the women with a diagnosis of GDM fulfilled the Dutch criteria of screening indicating that $35 \%$ of our cases were detected outside of selective screening. Still, cases of GDM may have been missed in asymptomatic women. However, the study of Van Leeuwen et al., who performed universal screening with the same diagnostic criteria in a Dutch pregnant population, showed a similar prevalence of $\mathrm{GDM}^{46}$. Lastly, predictive performance measures may have been affected as the outcome GDM was defined differently across studies, as well as the screening strategies used. A comparison of multiple prediction models provides sincere verification of the predictive performances in a particular population at specific screening and diagnostic criteria used.

\section{Conclusion}

Twelve non-invasive early prediction models for the risk of developing GDM showed a moderate predictive performance after external validation. Four models (Syngelaki et al., Nanda et al., Van Leeuwen et al., Phaloprakarn et al.) had an AUROC of at least $74 \%$, of which the model of Van Leeuwen et al. was best recalibrated. Although the best performing models do not provide more benefit at certain risk thresholds compared with current selective screening strategies, the prediction models are easily applicable in clinical practice and enable personalized selective screening at an acceptable and clinically useful risk threshold. Further research on the effects and most optimal method of screening for GDM is recommended. 


\section{Supplementary materials}

Supplementary Table S4.1

Supplementary Table S4.2

Supplementary Table S4.3

Supplementary Table S4.4

Supplementary Table S4.5A-B

Supplementary Figure S4.1A-B

Supplementary Figure S4.2A-B
Definition and assessment of predictors

Model algorithms for prediction of gestational diabetes mellitus

Characteristics included prediction models for external validation

Characteristics of pregnancies in the observed and imputed validation cohort

Baseline characteristics original cohorts and validation cohort (case-mix)

ROC curves of externally validated first trimester prediction models for gestational diabetes mellitus Calibration plots of recalibrated first trimester prediction models for gestational diabetes mellitus (GDM). The grey line is the reference line with intercept $=0$ and slope $=1$ (perfect calibration). Triangles correspond to grouped predicted risks with $95 \% \mathrm{Cl}$ (vertical lines). CF = correction factor 


\section{References}

1. Poston, L., Caleyachetty, R., Cnattingius, S., Corvalan, C., Uauy, R., Herring, S., et al., Preconceptional and maternal obesity: epidemiology and health consequences. Lancet Diabetes Endocrinol, 2016. 4(12): p. 1025-1036.

2. Zhu, Y. and Zhang, C., Prevalence of Gestational Diabetes and Risk of Progression to Type 2 Diabetes: a Global Perspective. Current Diabetes Reports, 2016. 16(1): p. 7.

3. Metzger, B.E., Lowe, L.P., Dyer, A.R., Trimble, E.R., Chaovarindr, U., Coustan, D.R., et al., Hyperglycemia and adverse pregnancy outcomes. N Engl J Med, 2008. 358(19): p. 1991-2002.

4. Wendland, E.M., Torloni, M.R., Falavigna, M., Trujillo, J., Dode, M.A., Campos, M.A., et al., Gestational diabetes and pregnancy outcomes--a systematic review of the World Health Organization (WHO) and the International Association of Diabetes in Pregnancy Study Groups (IADPSG) diagnostic criteria. BMC Pregnancy Childbirth, 2012. 12: p. 23.

5. Hillier, T.A., Pedula, K.L., Schmidt, M.M., Mullen, J.A., Charles, M.A., and Pettitt, D.J., Childhood obesity and metabolic imprinting: the ongoing effects of maternal hyperglycemia. Diabetes Care, 2007. 30(9): p. 2287-92.

6. Bellamy, L., Casas, J.P., Hingorani, A.D., and Williams, D., Type 2 diabetes mellitus after gestational diabetes: a systematic review and meta-analysis. Lancet, 2009. 373(9677): p. 1773-9.

7. Xu, Y., Shen, S., Sun, L., Yang, H., Jin, B., and Cao, X., Metabolic syndrome risk after gestational diabetes: a systematic review and meta-analysis. PLoS One, 2014. 9(1): p. e87863.

8. Danyliv, A., Gillespie, P., O'Neill, C., Noctor, E., O'Dea, A., Tierney, M., et al., Short- and long-term effects of gestational diabetes mellitus on healthcare cost: a cross-sectional comparative study in the ATLANTIC DIP cohort. Diabet Med, 2015. 32(4): p. 467-76.

9. Hartling, L., Dryden, D.M., Guthrie, A., Muise, M., Vandermeer, B., and Donovan, L., Benefits and harms of treating gestational diabetes mellitus: a systematic review and meta-analysis for the U.S. Preventive Services Task Force and the National Institutes of Health Office of Medical Applications of Research. Ann Intern Med, 2013. 159(2): p. 123-9.

10. Poolsup, N., Suksomboon, N., and Amin, M., Effect of treatment of gestational diabetes mellitus: a systematic review and meta-analysis. PLoS One, 2014. 9(3): p. e92485.

11. Donovan, L., Hartling, L., Muise, M., Guthrie, A., Vandermeer, B., and Dryden, D.M., Screening tests for gestational diabetes: a systematic review for the U.S. Preventive Services Task Force. Ann Intern Med, 2013. 159(2): p. 115-22.

12. Chiefari, E., Arcidiacono, B., Foti, D., and Brunetti, A., Gestational diabetes mellitus: an updated overview. J Endocrinol Invest, 2017. 40 (9): p. 899-909.

13. Nederlandse Vereniging voor Obstetrie en Gynaecologie. Richtlijn Diabetes mellitus en zwangerschap (2.0). 2010; Available from: http://www.nvog-documenten.nl/richtlijn/doc/index.php?type= save\&richtlijn_id=863.

14. National Institute for Health and Clinical Excellence. Diabetes in pregnancy: management from preconception to the postnatal period. Guideline NG3. 2015; Available from: http://nice.org.uk/guidance/ng3.

15. Steyerberg, E.W., Vickers, A.J., Cook, N.R., Gerds, T., Gonen, M., Obuchowski, N., et al., Assessing the performance of prediction models: a framework for traditional and novel measures. Epidemiology, 2010. 21(1): p. 128-38.

16. Kennelly, M.A. and McAuliffe, F.M., Prediction and prevention of Gestational Diabetes: an update of recent literature. Eur J Obstet Gynecol Reprod Biol, 2016. 202: p. 92-8.

17. Lamain - de Ruiter, M., Kwee, A., Naaktgeboren, C.A., Franx, A., Moons, K.G.M., and Koster, M.P.H., Prediction models for the risk of gestational diabetes: a systematic review. Diagnostic and Prognostic Research, 2017. 1(1): p. 3.

18. Justice, A.C., Covinsky, K.E., and Berlin, J.A., Assessing the generalizability of prognostic information. Ann Intern Med, 1999. 130(6): p. 515-24.

19. van Leeuwen, M., Opmeer, B.C., Zweers, E.J., van Ballegooie, E., ter Brugge, H.G., de Valk, H.W., et al., External validation of a clinical scoring system for the risk of gestational diabetes mellitus. Diabetes Res Clin Pract, 2009. 85(1): p. 96-101.

20. Lovati, E., Beneventi, F., Simonetta, M., Laneri, M., Quarleri, L., Scudeller, L., et al., Gestational diabetes mellitus: including serum pregnancy-associated plasma protein-A testing in the clinical 
management of primiparous women? A case-control study. Diabetes Res Clin Pract, 2013. 100(3): p. 340-7.

21. Theriault, S., Forest, J.C., Masse, J., and Giguere, Y., Validation of early risk-prediction models for gestational diabetes based on clinical characteristics. Diabetes Res Clin Pract, 2014. 103(3): p. 419-25.

22. Syngelaki, A., Pastides, A., Kotecha, R., Wright, A., Akolekar, R., and Nicolaides, K.H., First-Trimester Screening for Gestational Diabetes Mellitus Based on Maternal Characteristics and History. Fetal Diagn Ther, 2015. 38(1): p. 14-21.

23. Sweeting, A.N., Appelblom, H., Ross, G.P., Wong, J., Kouru, H., Williams, P.F., et al., First trimester prediction of gestational diabetes mellitus: A clinical model based on maternal demographic parameters. Diabetes Res Clin Pract, 2017. 127: p. 44-50.

24. Lamain-de Ruiter, M., Kwee, A., Naaktgeboren, C.A., de Groot, I., Evers, I.M., Groenendaal, F., et al., External validation of prognostic models to predict risk of gestational diabetes mellitus in one Dutch cohort: prospective multicentre cohort study. BMJ, 2016. 354: p. i4338.

25. Meertens, L.J.E., Scheepers, H.C., De Vries, R.G., Dirksen, C.D., Korstjens, I., Mulder, A.L., et al., External Validation Study of First Trimester Obstetric Prediction Models (Expect Study I): Research Protocol and Population Characteristics. JMIR Res Protoc, 2017. 6(10): p. e203.

26. van Gelder, M.M., Bretveld, R.W., Roukema, J., Steenhoek, M., van Drongelen, J., Spaanderman, M.E., et al., Rationale and design of the PRegnancy and Infant DEvelopment (PRIDE) Study. Paediatr Perinat Epidemiol, 2013. 27(1): p. 34-43.

27. WHO, Definition, diagnosis and classification of diabetes mellitus and its complications. Report of a WHO consultation. Part 1: Diagnosis and classification of diabetes mellitus. Geneva, World Health Organization, 1999.

28. Vergouwe, Y., Steyerberg, E.W., Eijkemans, M.J., and Habbema, J.D., Substantial effective sample sizes were required for external validation studies of predictive logistic regression models. J Clin Epidemiol., 2005. 58(5): p. 475-83.

29. Van Buuren, S., Flexible imputation of missing data. 2012: CRC press.

30. Steyerberg, E.W. and Vergouwe, Y., Towards better clinical prediction models: seven steps for development and an ABCD for validation. Eur Heart J, 2014. 35(29): p. 1925-31.

31. Steyerberg, E., Clinical prediction models: a practical approach to development, validation, and updating. 2008: Springer Science \& Business Media.

32. Vickers, A.J. and Elkin, E.B., Decision curve analysis: a novel method for evaluating prediction models. Med Decis Making, 2006. 26(6): p. 565-74.

33. Lu, L., Koulman, A., Petry, C.J., Jenkins, B., Matthews, L., Hughes, I.A., et al., An Unbiased Lipidomics Approach Identifies Early Second Trimester Lipids Predictive of Maternal Glycemic Traits and Gestational Diabetes Mellitus. Diabetes Care, 2016. 39(12): p. 2232-2239.

34. Theriault, S., Giguere, Y., Masse, J., Girouard, J., and Forest, J.C., Early prediction of gestational diabetes: a practical model combining clinical and biochemical markers. Clin Chem Lab Med, 2016. 54(3): p. 509-18.

35. Savvidou, M., Nelson, S.M., Makgoba, M., Messow, C.M., Sattar, N., and Nicolaides, K., First-trimester prediction of gestational diabetes mellitus: examining the potential of combining maternal characteristics and laboratory measures. Diabetes, 2010. 59(12): p. 3017-22.

36. Syngelaki, A., Visser, G.H., Krithinakis, K., Wright, A., and Nicolaides, K.H., First trimester screening for gestational diabetes mellitus by maternal factors and markers of inflammation. Metabolism, 2016. 65(3): p. 131-7.

37. Hassiakos, D., Eleftheriades, M., Papastefanou, I., Lambrinoudaki, I., Kappou, D., Lavranos, D., et al., Increased Maternal Serum Interleukin-6 Concentrations at 11 to 14 Weeks of Gestation in Low Risk Pregnancies Complicated with Gestational Diabetes Mellitus: Development of a Prediction Model. Horm Metab Res, 2016. 48(1): p. 35-41.

38. Papastefanou, I., Eleftheriades, M., Kappou, D., Lambrinoudaki, I., Lavranos, D., Pervanidou, P., et al., Maternal serum osteocalcin at 11-14 weeks of gestation in gestational diabetes mellitus. Eur J Clin Invest, 2015. 45(10): p. 1025-31.

39. Ferreira, A.F., Rezende, J.C., Vaikousi, E., Akolekar, R., and Nicolaides, K.H., Maternal serum visfatin at 11-13 weeks of gestation in gestational diabetes mellitus. Clin Chem, 2011. 57(4): p. 609-13. 
40. Eleftheriades, M., Papastefanou, I., Lambrinoudaki, I., Kappou, D., Lavranos, D., Akalestos, A., et al., Elevated placental growth factor concentrations at 11-14 weeks of gestation to predict gestational diabetes mellitus. Metabolism, 2014. 63(11): p. 1419-25.

41. Gabbay-Benziv, R., Doyle, L.E., Blitzer, M., and Baschat, A.A., First trimester prediction of maternal glycemic status. J Perinat Med, 2015. 43(3): p. 283-9.

42. Tran, T.S., Hirst, J.E., Do, M.A., Morris, J.M., and Jeffery, H.E., Early prediction of gestational diabetes mellitus in Vietnam: clinical impact of currently recommended diagnostic criteria. Diabetes Care, 2013. 36(3): p. 618-24.

43. Syngelaki, A., Bredaki, F.E., Vaikousi, E., Maiz, N., and Nicolaides, K.H., Body mass index at 11-13 weeks' gestation and pregnancy complications. Fetal Diagn Ther, 2011. 30(4): p. 250-65.

44. Teede, H.J., Harrison, C.L., Teh, W.T., Paul, E., and Allan, C.A., Gestational diabetes: development of an early risk prediction tool to facilitate opportunities for prevention. Aust N Z J Obstet Gynaecol, 2011. 51(6): p. 499-504.

45. Nanda, S., Savvidou, M., Syngelaki, A., Akolekar, R., and Nicolaides, K.H., Prediction of gestational diabetes mellitus by maternal factors and biomarkers at 11 to 13 weeks. Prenat Diagn, 2011. 31(2): p. 135-41.

46. Van Leeuwen, M., Opmeer, B.C., Zweers, E.J., van Ballegooie, E., ter Brugge, H.G., de Valk, H.W., et al., Estimating the risk of gestational diabetes mellitus: a clinical prediction model based on patient characteristics and medical history. BJOG, 2010. 117(1): p. 69-75.

47. Shirazian, N., Emdadi, R., Mahboubi, M., Motevallian, A., Fazel-Sarjuei, Z., Sedighpour, N., et al., Screening for gestational diabetes: usefulness of clinical risk factors. Arch Gynecol Obstet, 2009. 280(6): p. 933-7.

48. Phaloprakarn, C., Tangjitgamol, S., and Manusirivithaya, S., A risk score for selective screening for gestational diabetes mellitus. Eur J Obstet Gynecol Reprod Biol, 2009. 145(1): p. 71-5.

49. Naylor, C.D., Sermer, M., Chen, E., and Farine, D., Selective screening for gestational diabetes mellitus. Toronto Trihospital Gestational Diabetes Project Investigators. N Engl J Med, 1997. 337(22): p. 1591-6.

50. Hendriksen, J.M., Geersing, G.J., Moons, K.G., and de Groot, J.A., Diagnostic and prognostic prediction models. J Thromb Haemost, 2013. 11 Suppl 1: p. 129-41.

51. Farrar, D., Simmonds, M., Bryant, M., Lawlor, D.A., Dunne, F., Tuffnell, D., et al., Risk factor screening to identify women requiring oral glucose tolerance testing to diagnose gestational diabetes: A systematic review and meta-analysis and analysis of two pregnancy cohorts. PLoS One, 2017. 12(4): p. e0175288.

52. Van Gelder, M.M., Bretveld, R.W., and Roeleveld, N., Web-based questionnaires: the future in epidemiology? Am J Epidemiol, 2010. 172(11): p.1292-8.

53. Van Gelder, M.M. and Schouten, N.P., Using Web-Based Questionnaires and Obstetric Records to Assess General Health Characteristics Among Pregnant Women: A Validation Study. J Med Internet Res, 2015. 17(6): p. e149. 


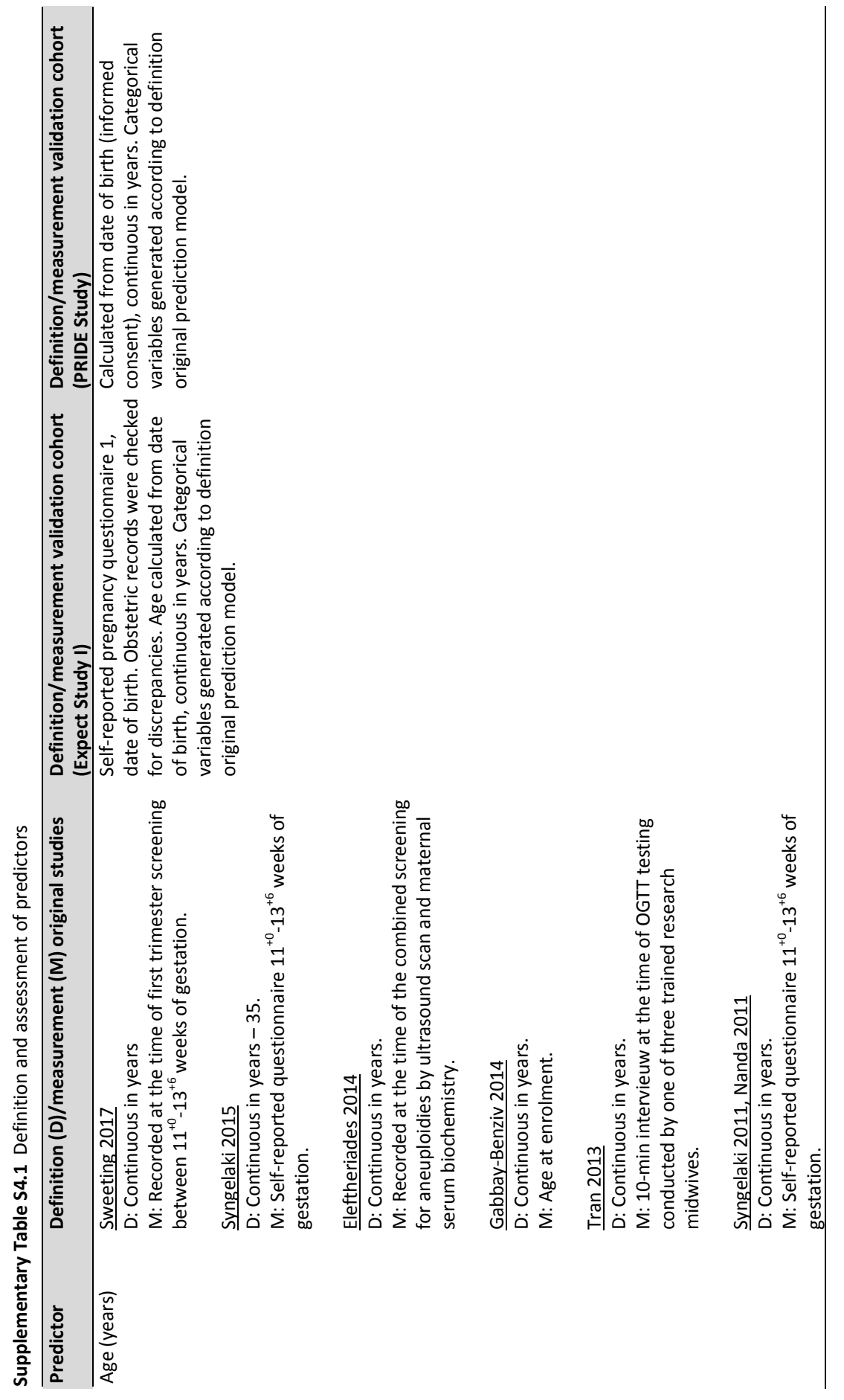



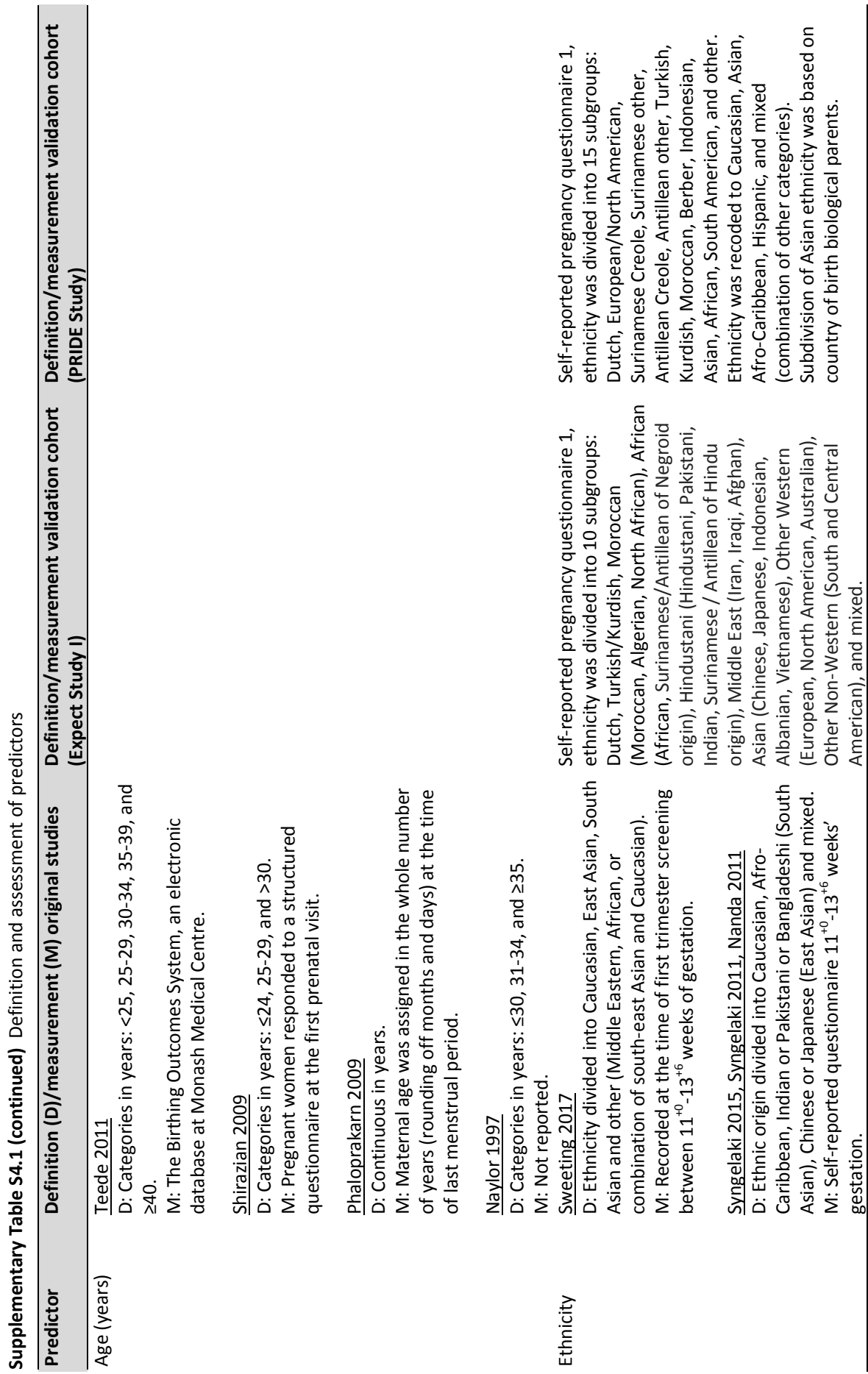

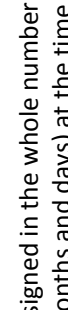

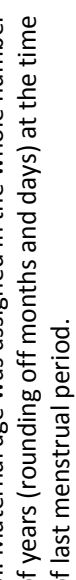

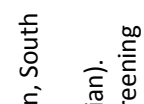
雪

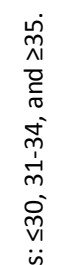

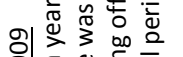

范

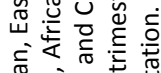

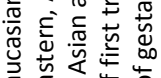

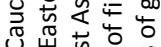

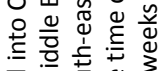

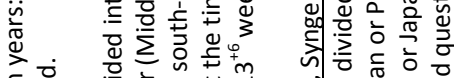

\ष्ठ

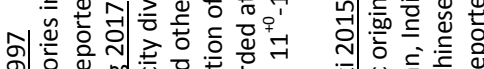

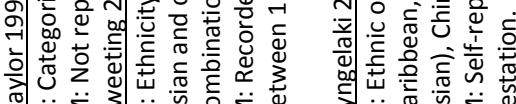

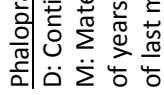

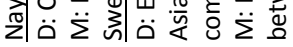

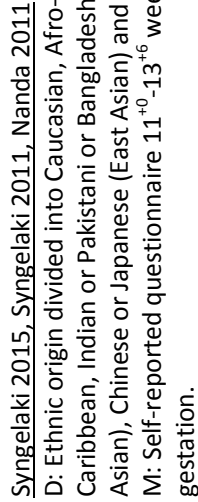

: 


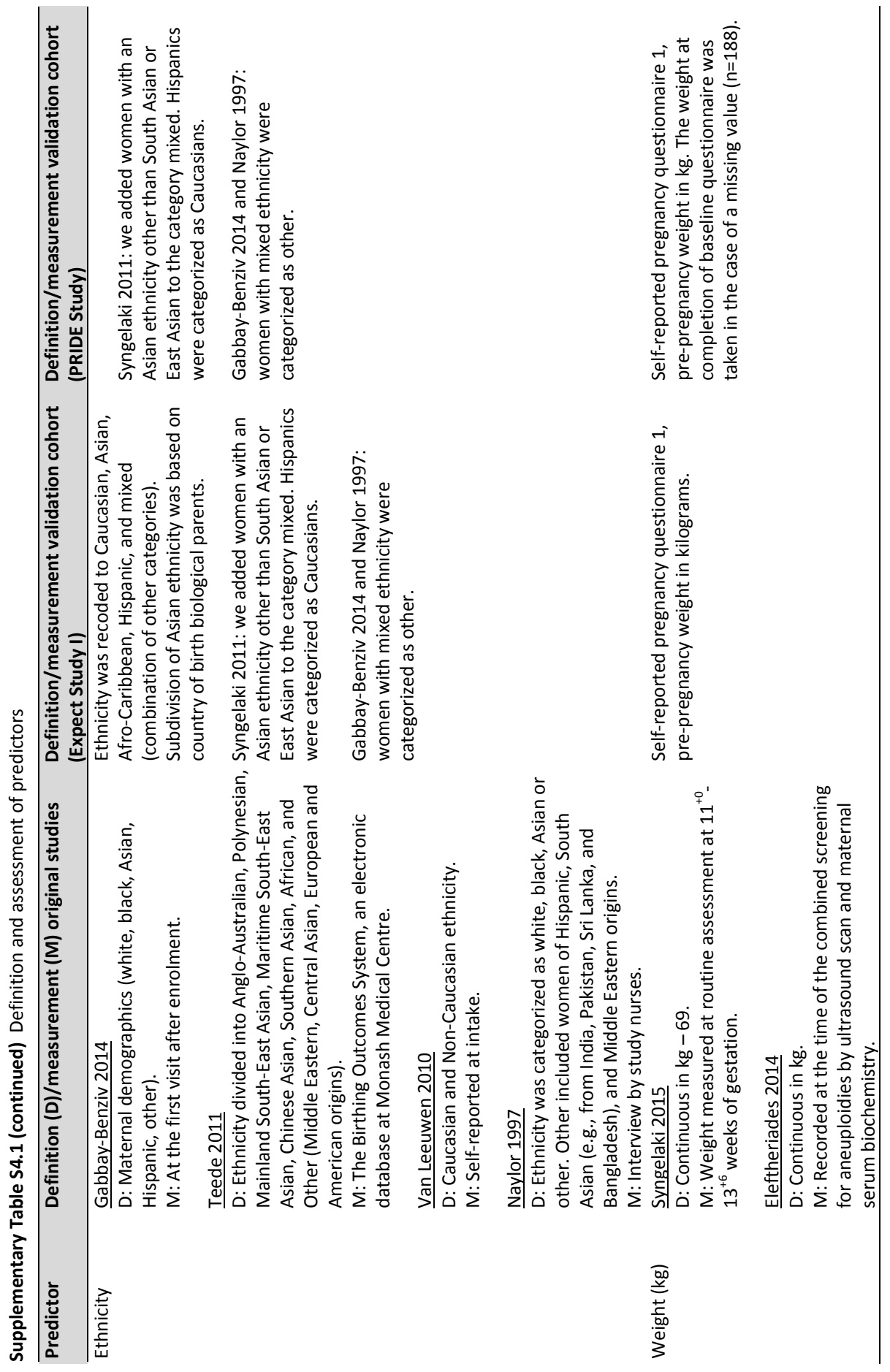




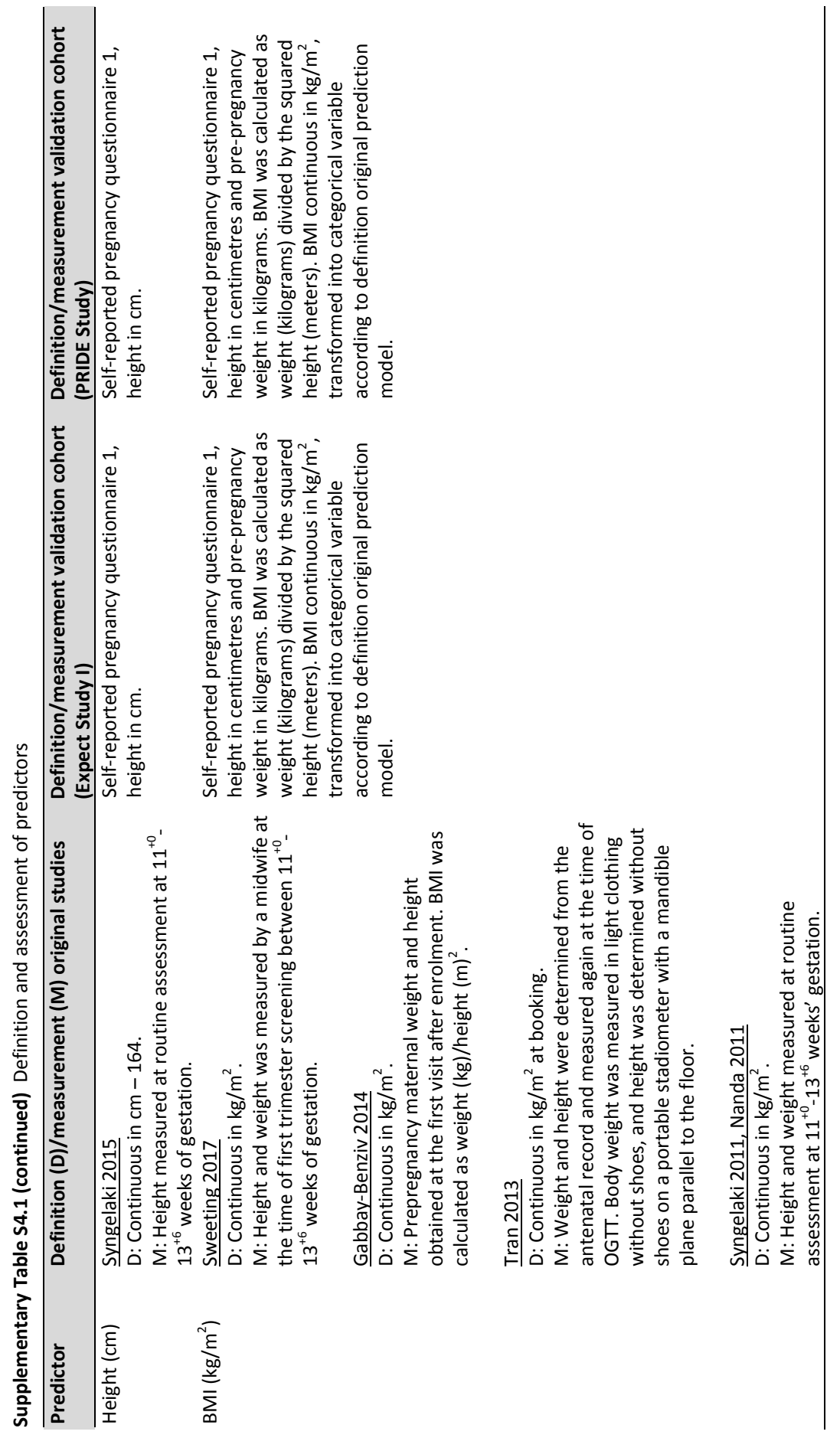




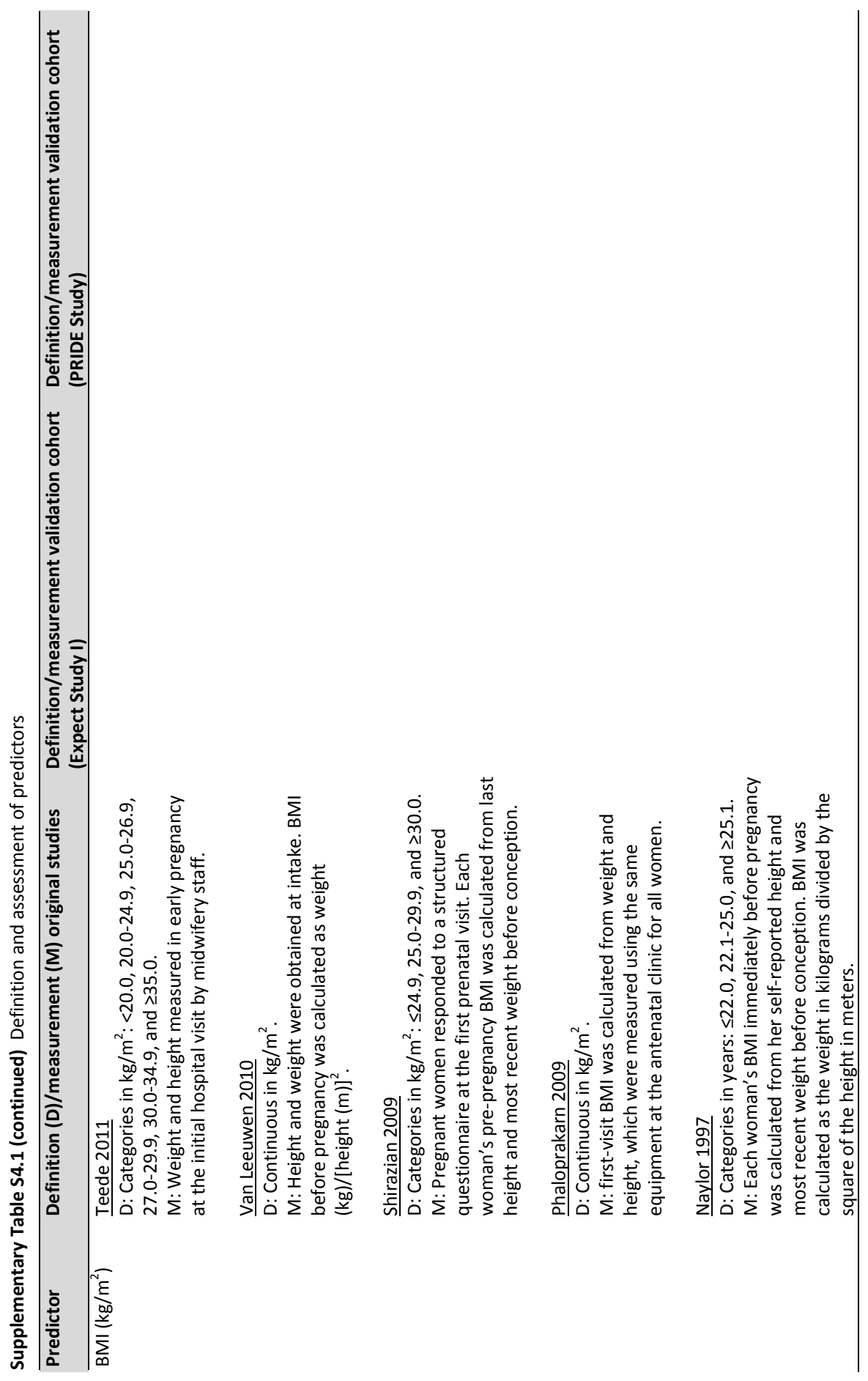




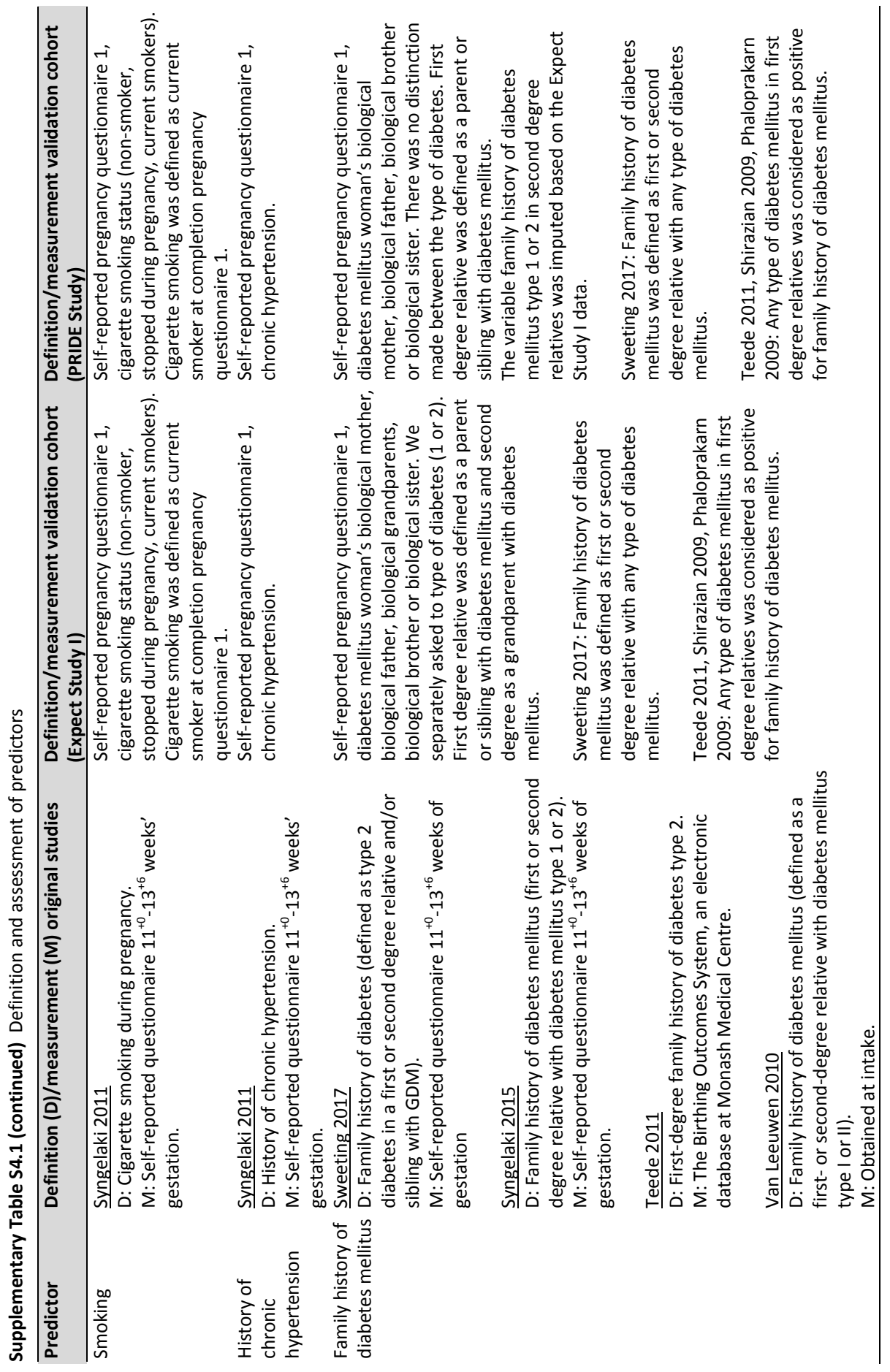



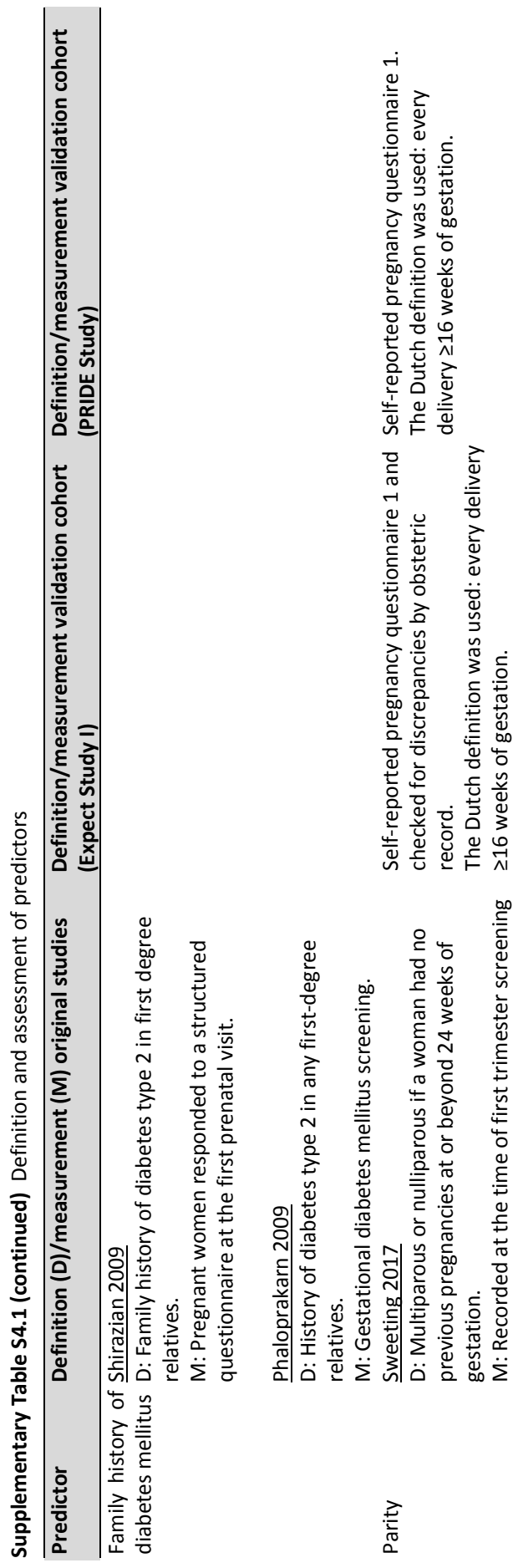

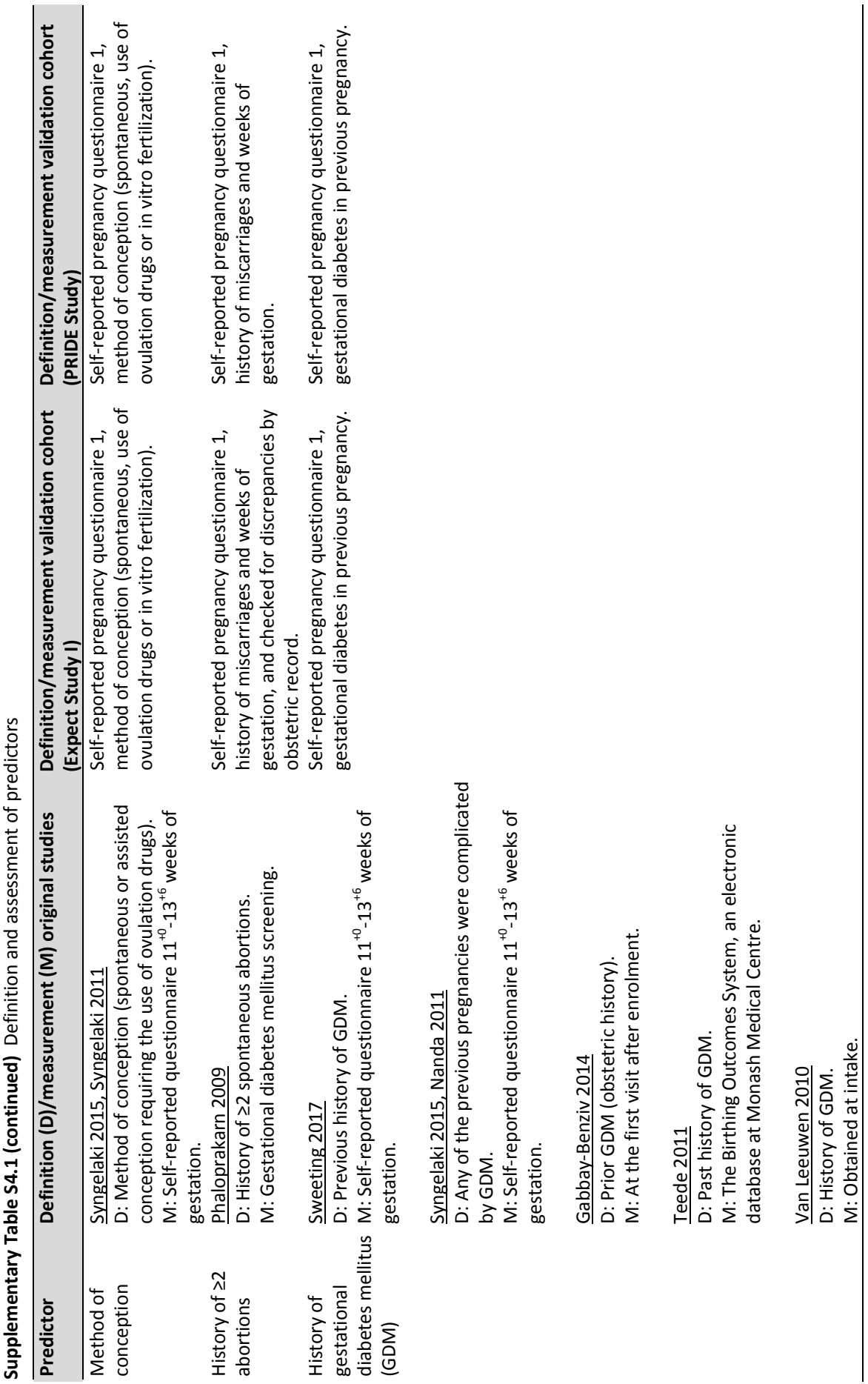

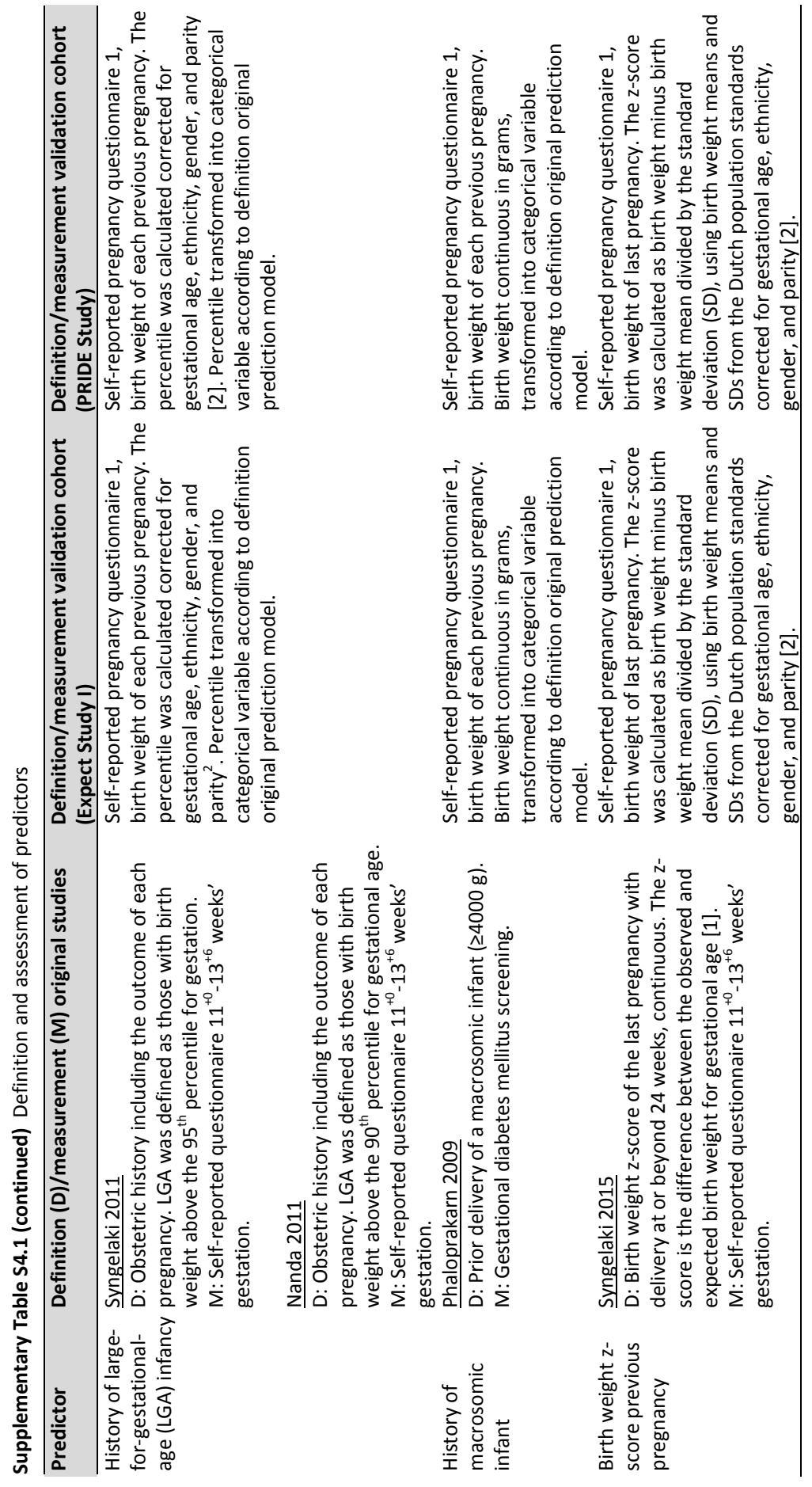


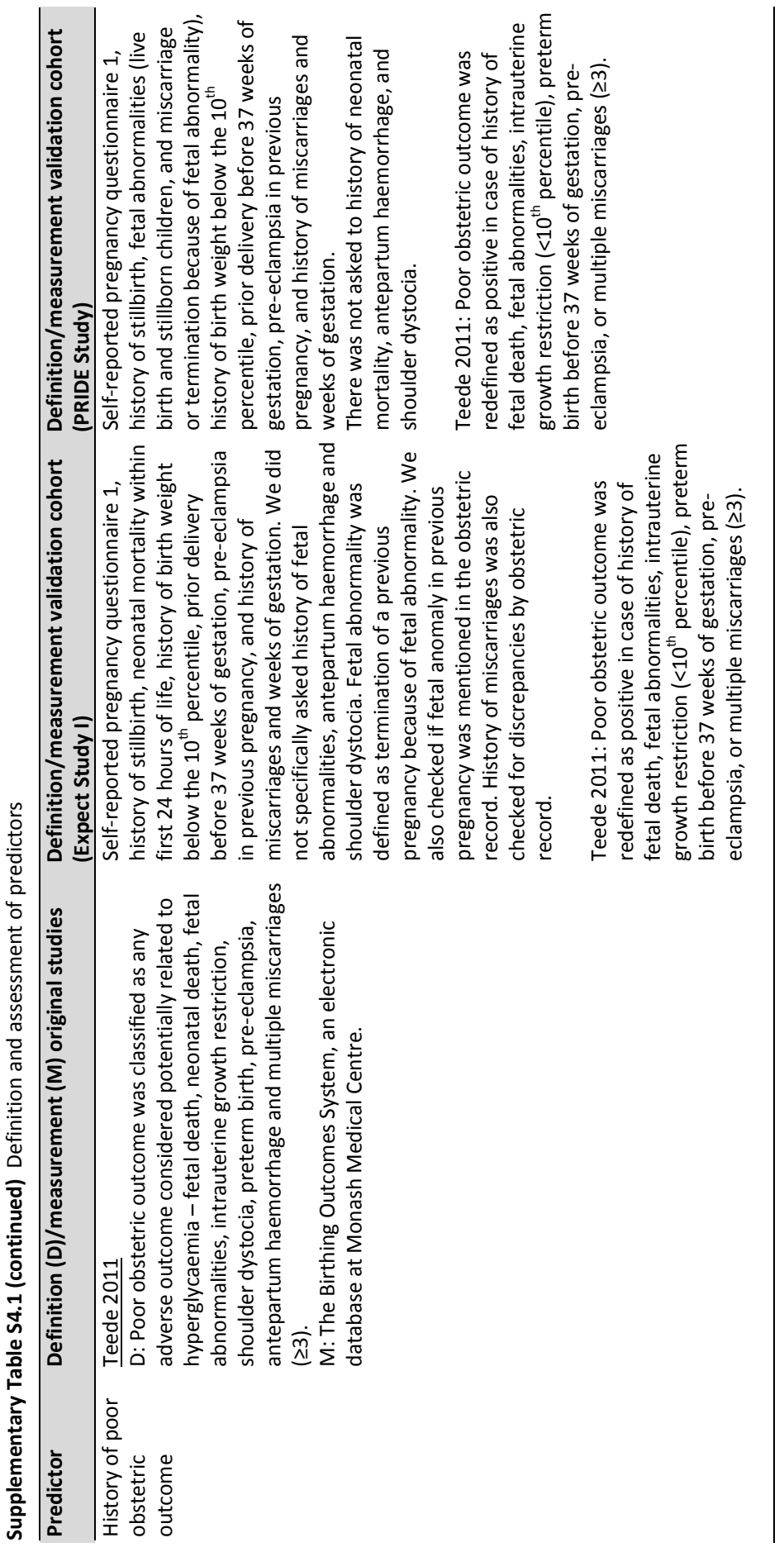




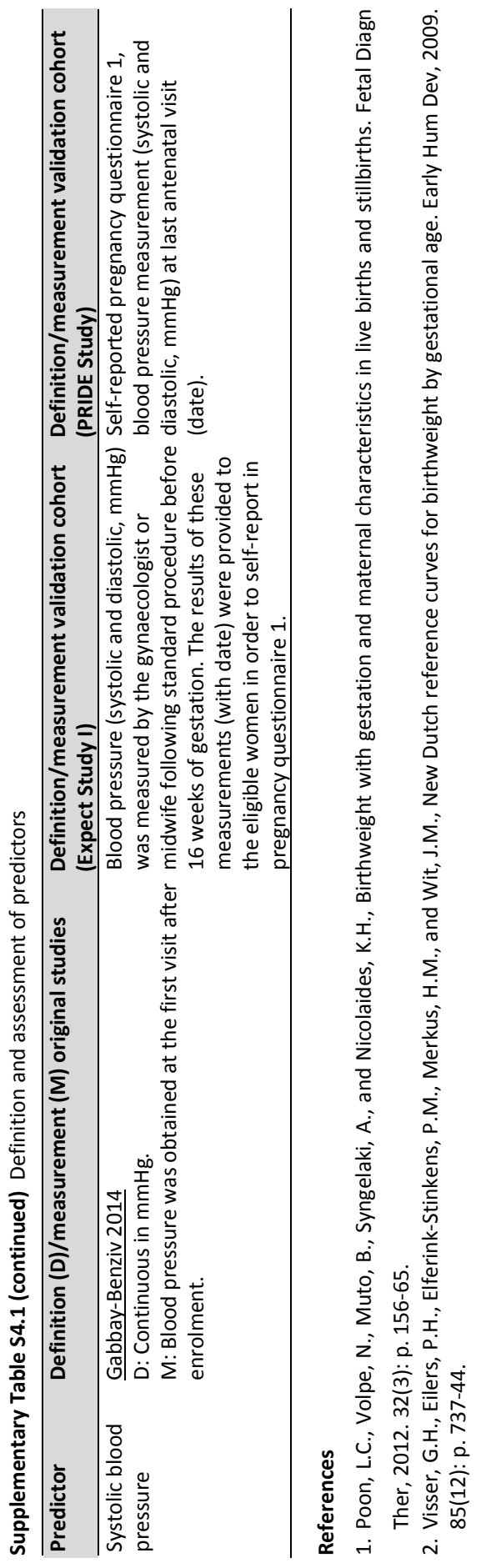




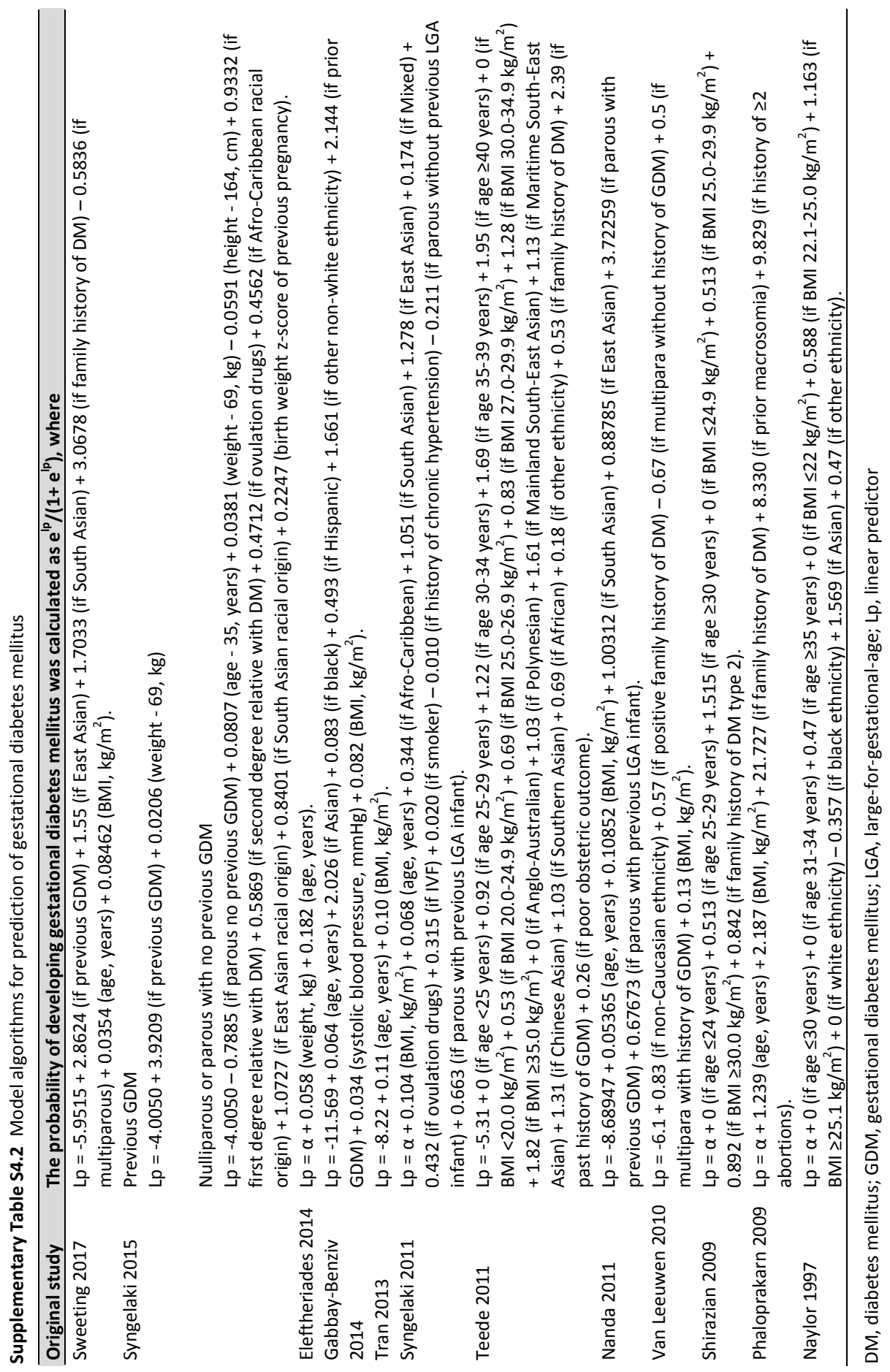




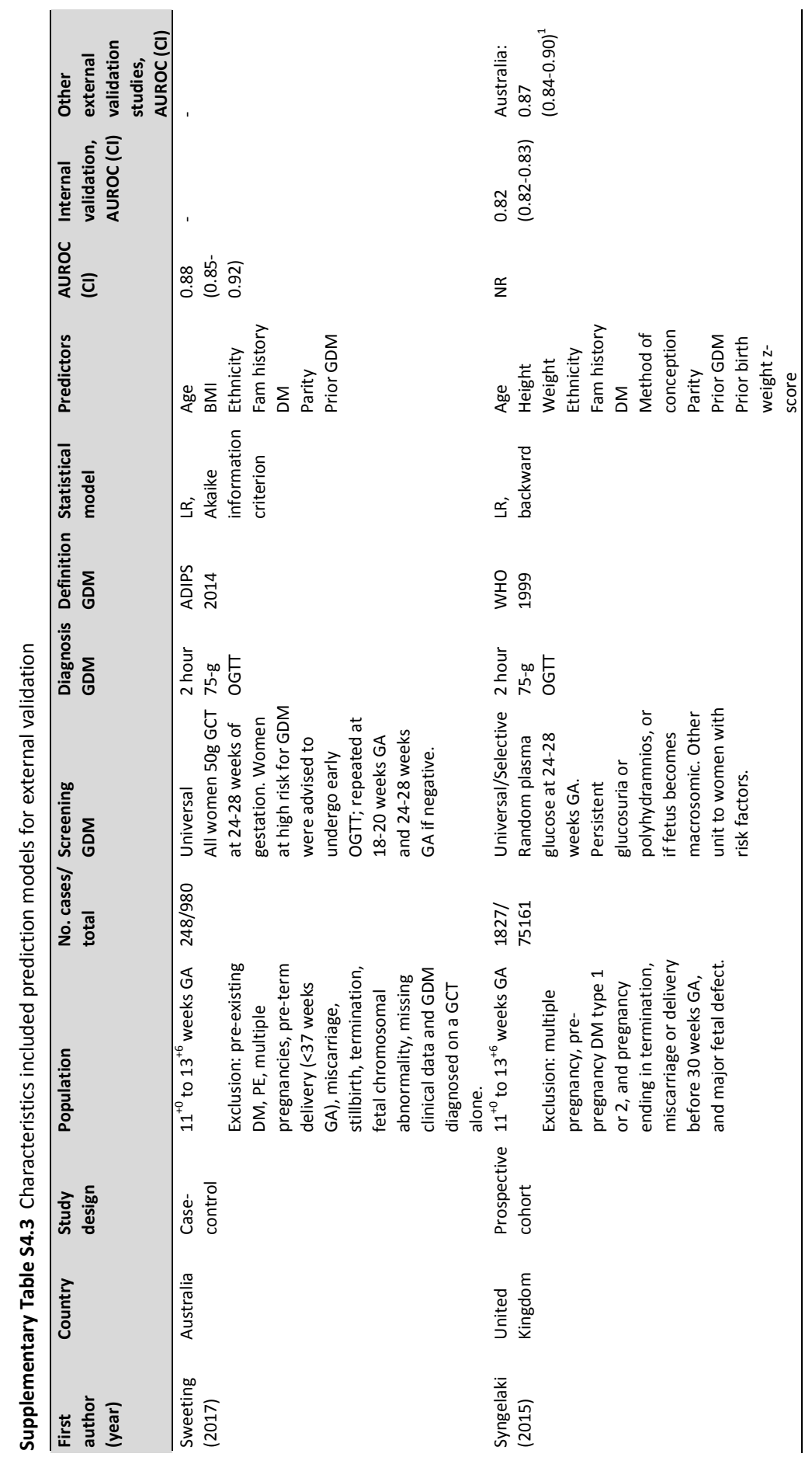




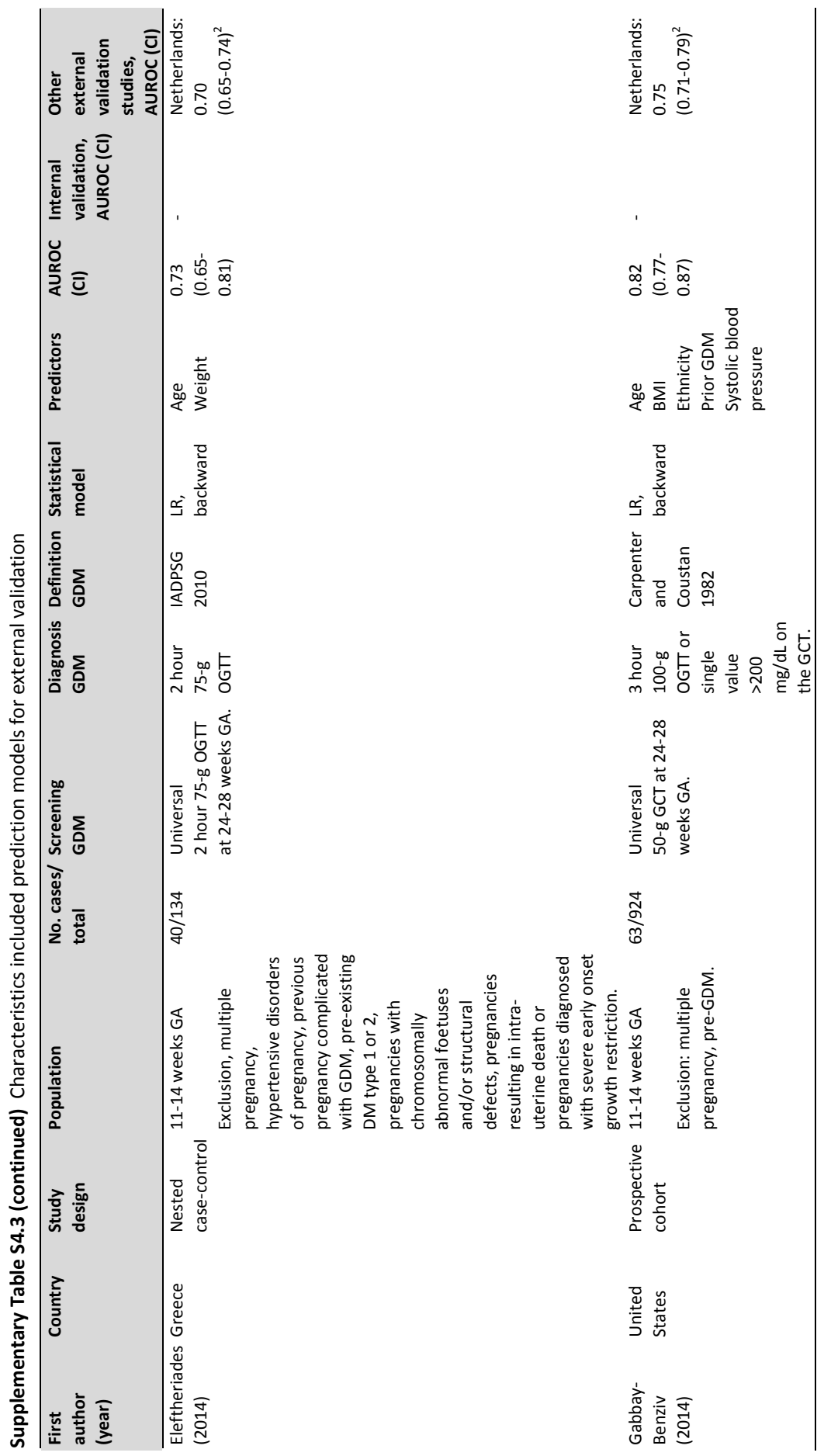




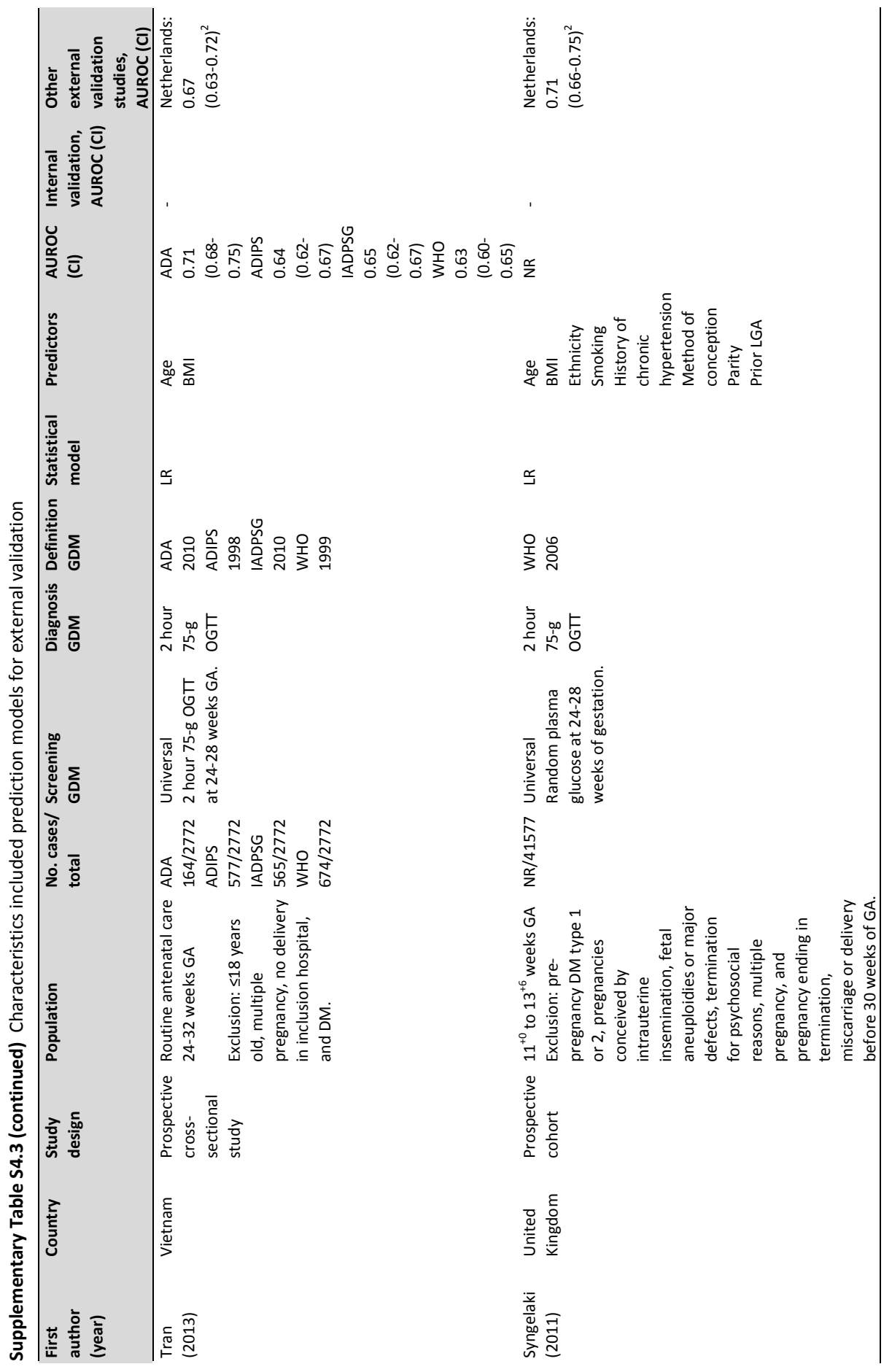




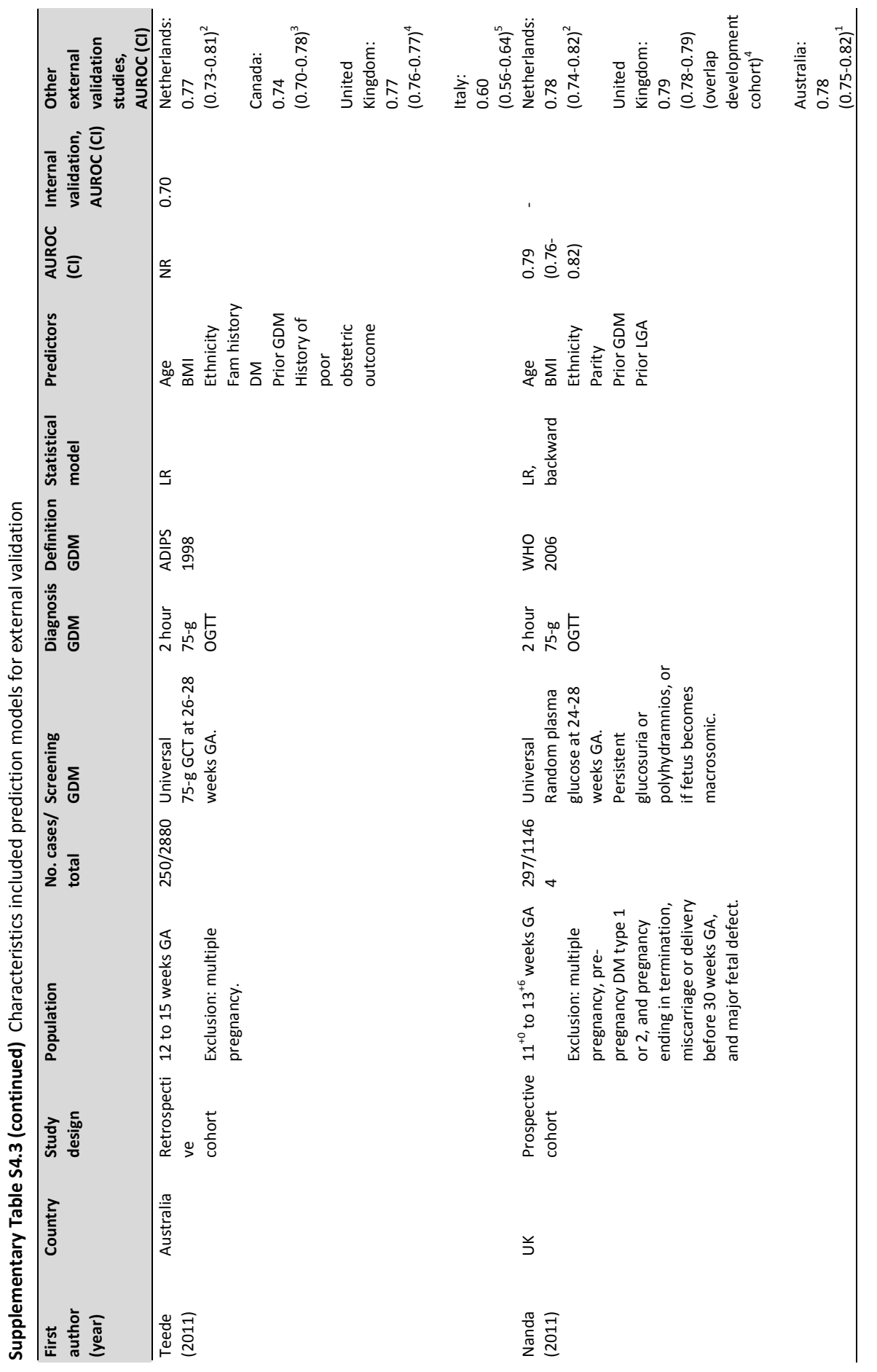




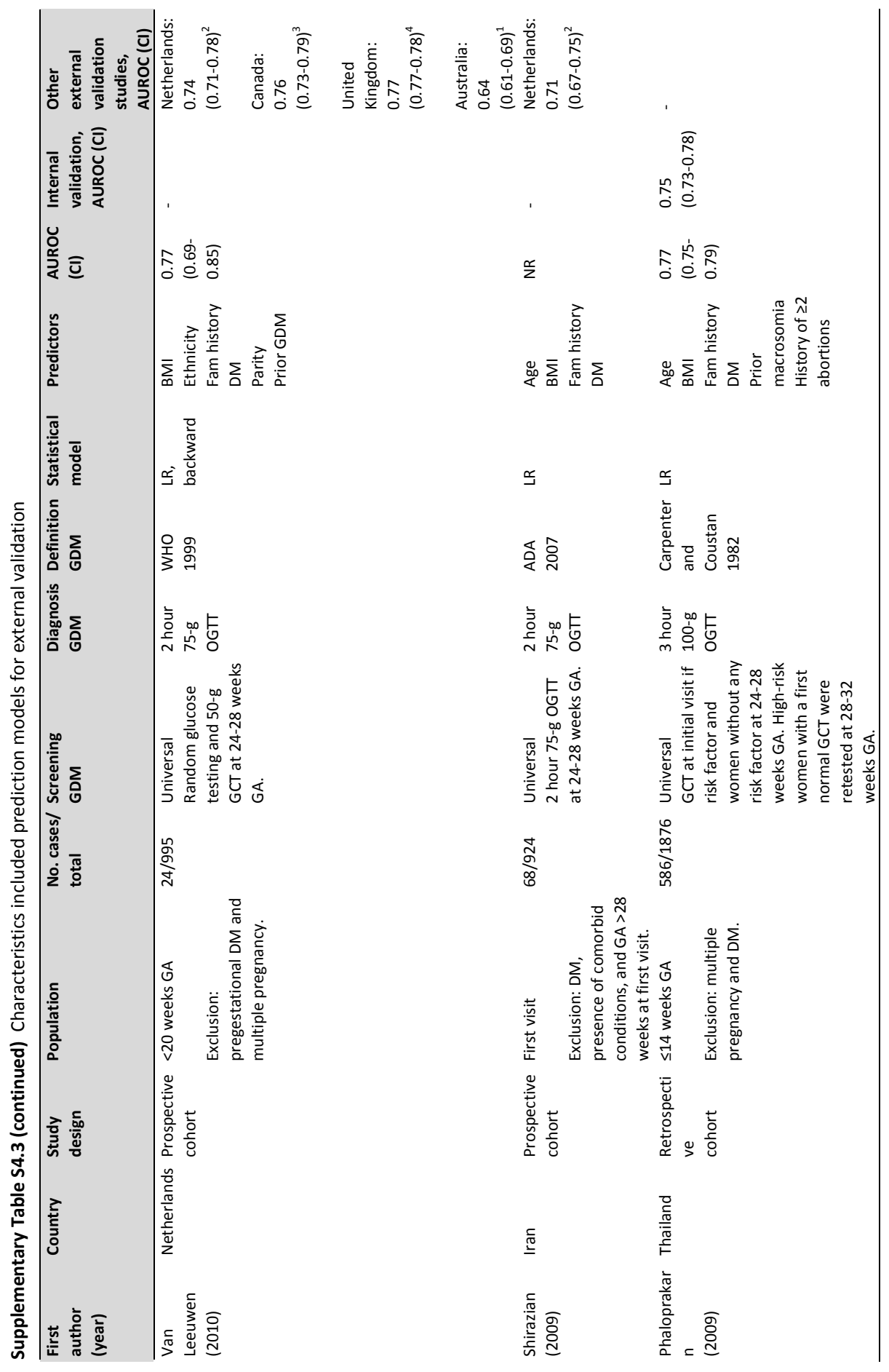




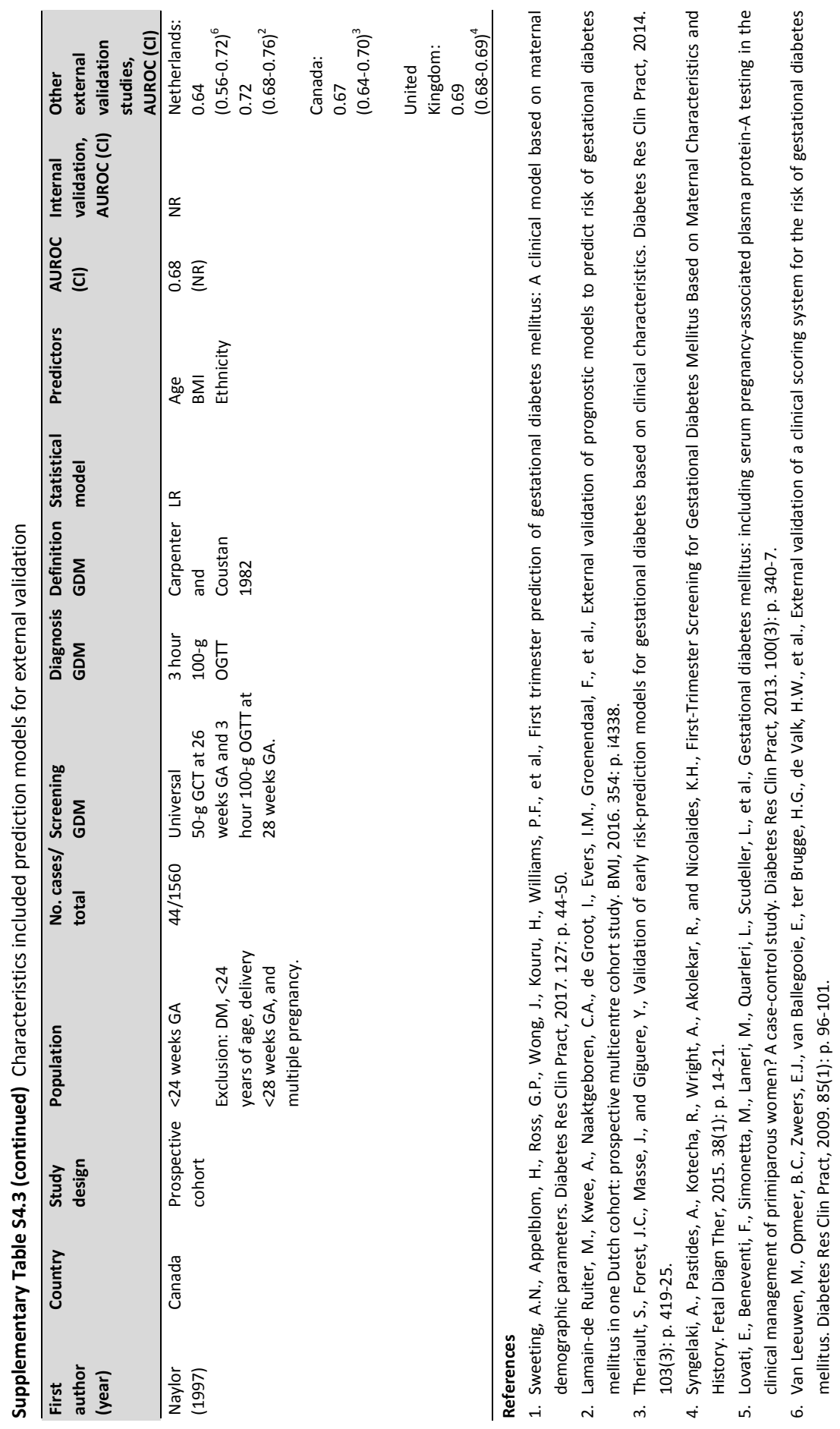


Supplementary Table S4.4 Characteristics of pregnancies in the observed and imputed validation cohort

\begin{tabular}{|c|c|c|c|c|}
\hline Characteristics & $\begin{array}{c}\text { Missing values, } \\
n(\%) \\
(n=5263)\end{array}$ & $\begin{array}{c}\text { Observed } \\
\text { validation cohort } \\
\text { Complete cases }^{a} \\
\quad(n=3927)\end{array}$ & $\begin{array}{l}\text { Observed } \\
\text { validation } \\
\text { cohort } \\
\text { Women with } \\
\text { missing value(s) } \\
(n=1336)\end{array}$ & $\begin{array}{l}\text { Imputed } \\
\text { validation } \\
\text { cohort } \\
(n=5263)\end{array}$ \\
\hline Age, years & $0(0.0)$ & $30.4(3.8)$ & $30.5(3.9)$ & $30.4(3.8)$ \\
\hline Ethnicity & $36(0.7)$ & & & \\
\hline Caucasian & & $3858(98.2)$ & $1275(95.4)$ & $5169(98.2)$ \\
\hline Afro-Caribbean & & $3(0.1)$ & $1(0.1)$ & $4(0.1)$ \\
\hline Indian, Pakistani or & & $3(0.1)$ & $1(0.1)$ & $4(0.1)$ \\
\hline \multicolumn{5}{|l|}{ Bangladeshi (South Asian) } \\
\hline East Asian & & $4(0.1)$ & $3(0.2)$ & $7(0.1)$ \\
\hline Other Asian & & $10(0.3)$ & $5(0.4)$ & $15(0.3)$ \\
\hline Hispanic & & $10(0.3)$ & $3(0.2)$ & $13(0.2)$ \\
\hline Mixed & & $39(1.0)$ & $12(97.3)$ & $51(1.0)$ \\
\hline Tertiary education $^{c}$ & $3(0.1)$ & $2577(65.6)$ & $855(64.0)$ & $3448(65.5)$ \\
\hline Height, cm & $20(0.4)$ & $169.9(6.4)$ & $170.3(6.6)$ & $170.0(6.4)$ \\
\hline Weight, kg & $24(0.5)$ & $68.8(12.4)$ & $68.6(12.4)$ & $68.7(12.4)$ \\
\hline Body mass index ${ }^{\mathrm{d}}, \mathrm{kg} / \mathrm{m}^{2}$ & $30(0.6)$ & $23.8(4.0)$ & $23.7(4.1)$ & $23.8(4.1)$ \\
\hline Smoking during pregnancy & $32(0.6)$ & $152(3.9)$ & $52(3.9)$ & 205 (3.9) \\
\hline History of chronic hypertension & $17(0.3)$ & $25(0.6)$ & $5(0.4)$ & $30(0.6)$ \\
\hline \multicolumn{5}{|l|}{ Family history of diabetes mellitus } \\
\hline First degree & $14(0.3)$ & $512(13.0)$ & $158(11.8)$ & $670(12.7)$ \\
\hline \multirow[t]{2}{*}{ Second degree } & $1(0.0)$ & $747 / 2289(32.6)$ & $108 / 314(34.4)$ & $1671(31.7)$ \\
\hline & NM PRIDE Study & NM PRIDE Study & NM PRIDE Study & \\
\hline Nulliparous & $0(0.0)$ & $2055(52.3)$ & $712(53.3)$ & $2767(52.6)$ \\
\hline Conception & $15(0.3)$ & & & \\
\hline Spontaneous & & $3677(93.6)$ & $1253(93.8)$ & 4943 (93.9) \\
\hline Ovulation induction & & $131(3.3)$ & $41(3.1)$ & $173(3.3)$ \\
\hline IVF/ICSI & & $119(3.0)$ & $27(2.0)$ & $147(2.8)$ \\
\hline History recurrent miscarriages $(\geq 2)$ & $0(0.0)$ & $204(5.2)$ & $71(5.3)$ & $275(5.2)$ \\
\hline $\begin{array}{l}\text { History of gestational diabetes } \\
\text { mellitus }\end{array}$ & $22(0.4)$ & $21(0.5)$ & $4(0.3)$ & $25(0.5)$ \\
\hline \multicolumn{5}{|l|}{ History of macrosomia } \\
\hline$>90^{\text {th }}$ percentile & $96(1.8)$ & $292(7.4)$ & 92 (6.9) & $385(7.3)$ \\
\hline$>95^{\text {th }}$ percentile & $96(1.8)$ & $159(4.0)$ & $47(3.5)$ & 207 (3.9) \\
\hline$\geq 4000 \mathrm{~g}$ & $103(2.0)$ & $257(6.5)$ & $87(6.5)$ & $344(6.5)$ \\
\hline$>4000 \mathrm{~g}$ & $103(2.0)$ & $243(6.2)$ & $84(6.3)$ & $327(6.2)$ \\
\hline $\begin{array}{l}\text { Birth weight z-score of previous } \\
\text { pregnancy }\end{array}$ & $95(1.8)$ & $0.2(1.0)$ & $0.3(1.0)$ & $0.2(1.0)$ \\
\hline History of poor obstetric outcome & $67(1.3)$ & $433(11.0)$ & $166(12.4)$ & $600(11.4)$ \\
\hline Systolic blood pressure, $\mathrm{mmHg}$ & $1208(23.0)$ & $114.4(12.2)$ & $113.0(11.8)$ & $114.5(12.1)$ \\
\hline Diastolic blood pressure ${ }^{c}, \mathrm{mmHg}$ & $1224(23.3)$ & $67.5(8.7)$ & $67.4(9.3)$ & $67.6(8.6)$ \\
\hline
\end{tabular}

${ }^{a}$ All predictor values of the included models were complete; ${ }^{b}$ At least one missing value for a predictor of the included models; ' Not a predictor in the included models; ${ }^{d}$ Recoded/calculated on the basis of (imputed) original variables. Data presented as mean (SD) or absolute number (\%). ICSI, intracytoplasmic sperm injection; IVF, in vitro fertilisation; NM, not measured 


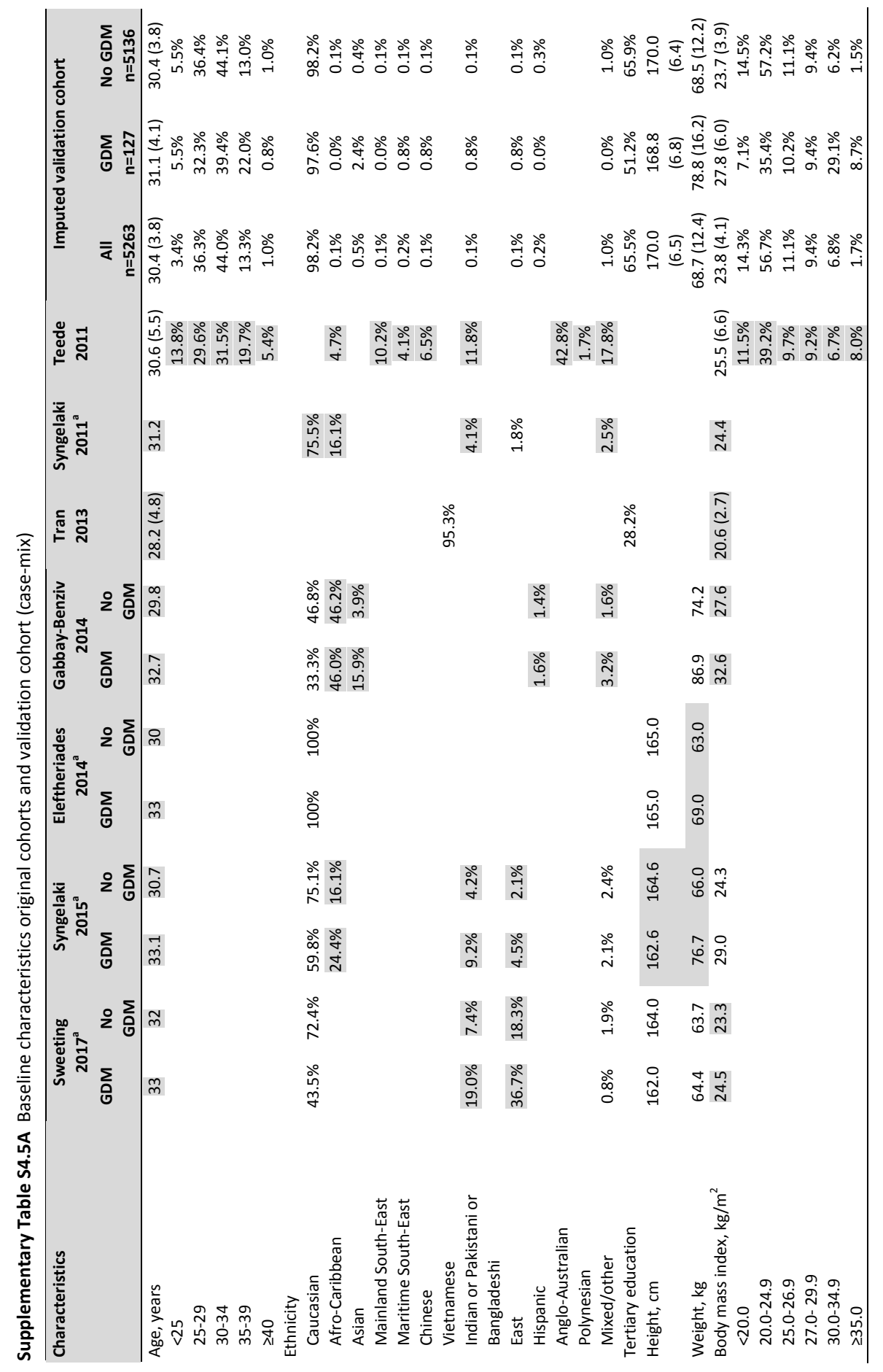




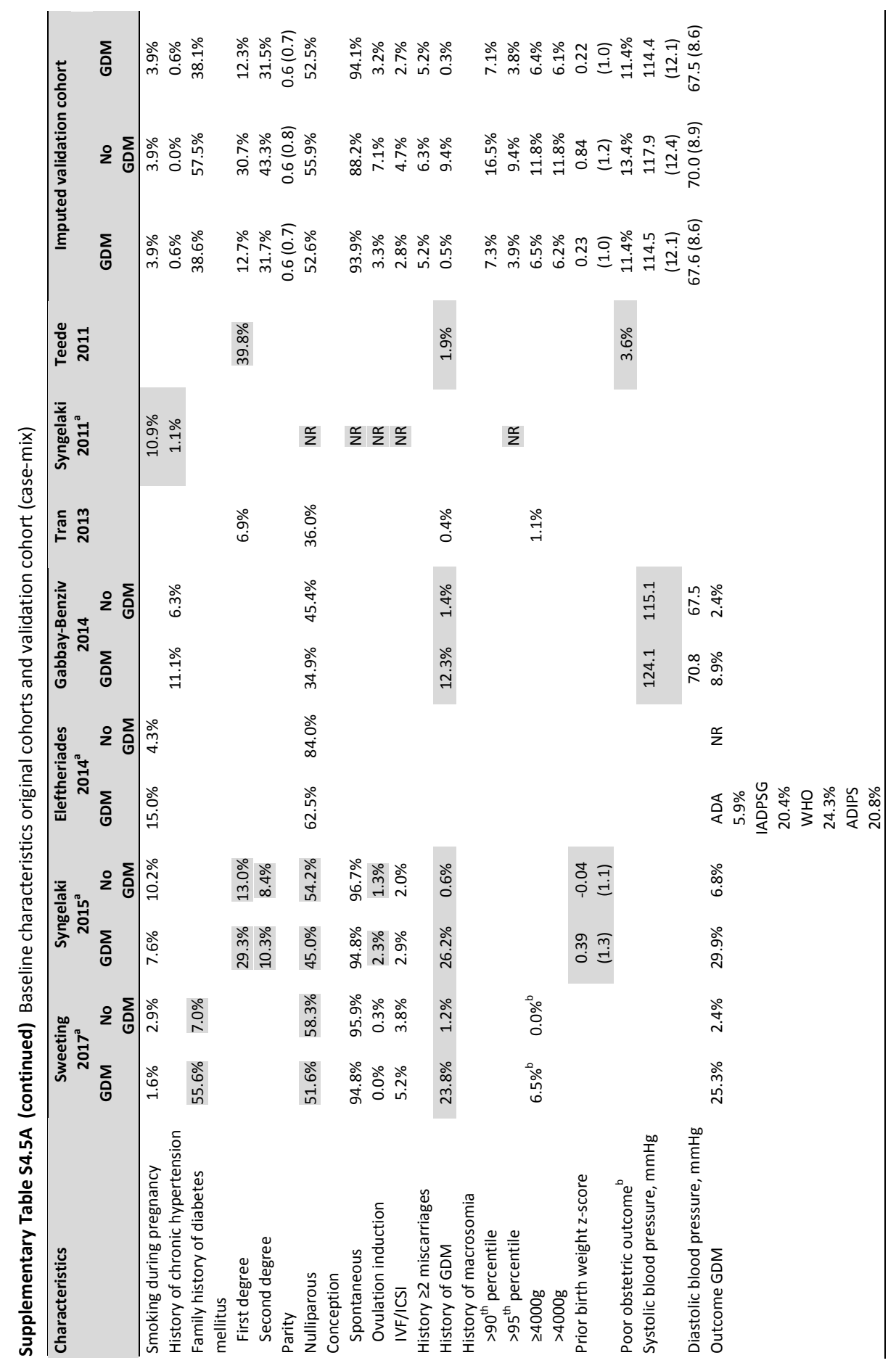




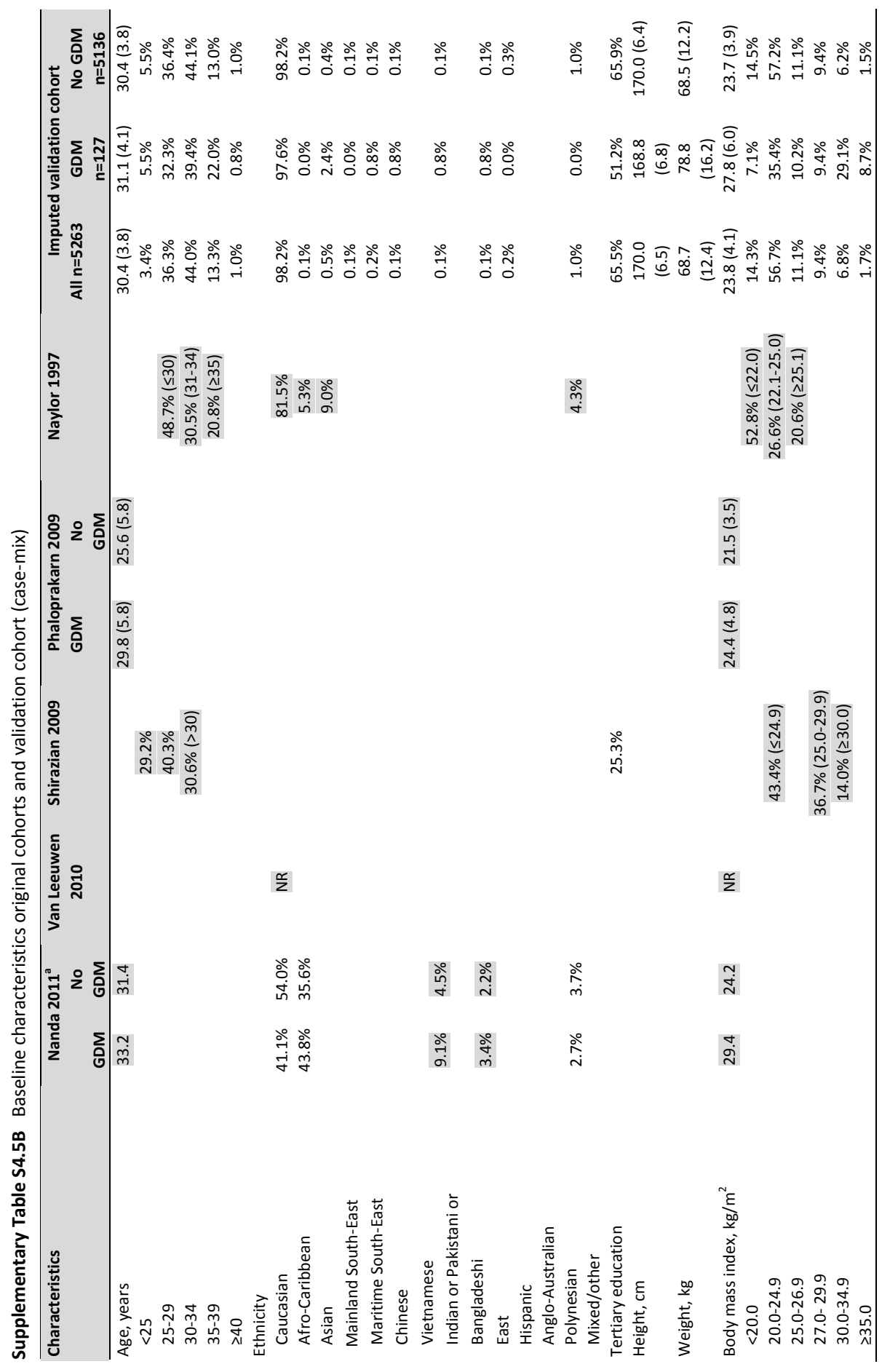




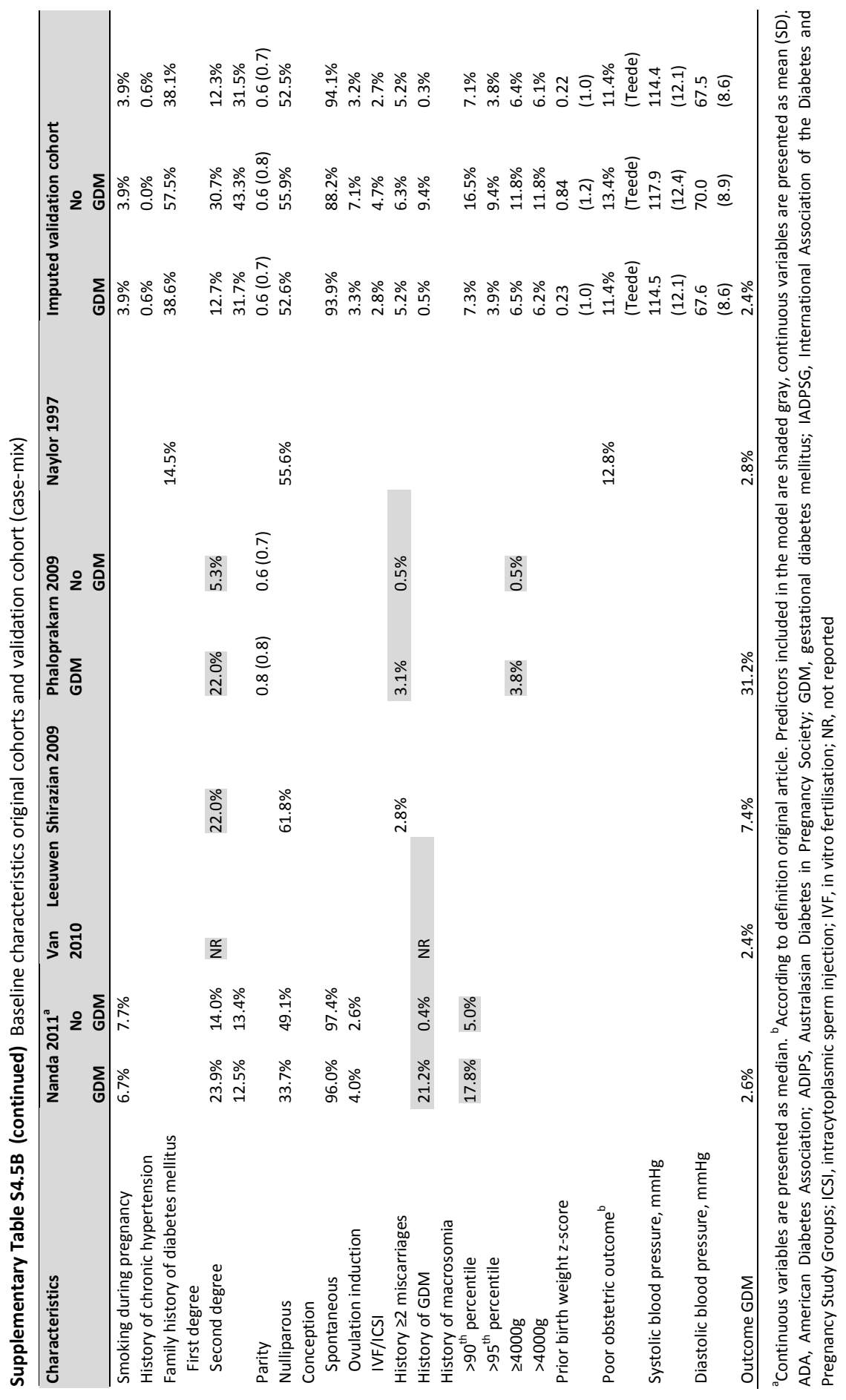




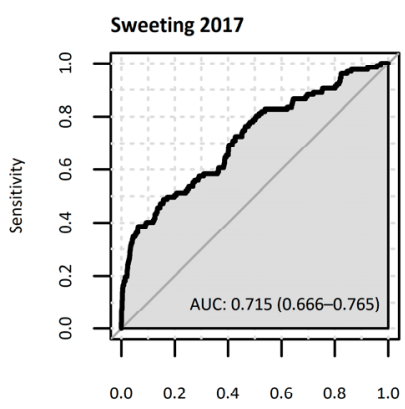

1 - Specificity
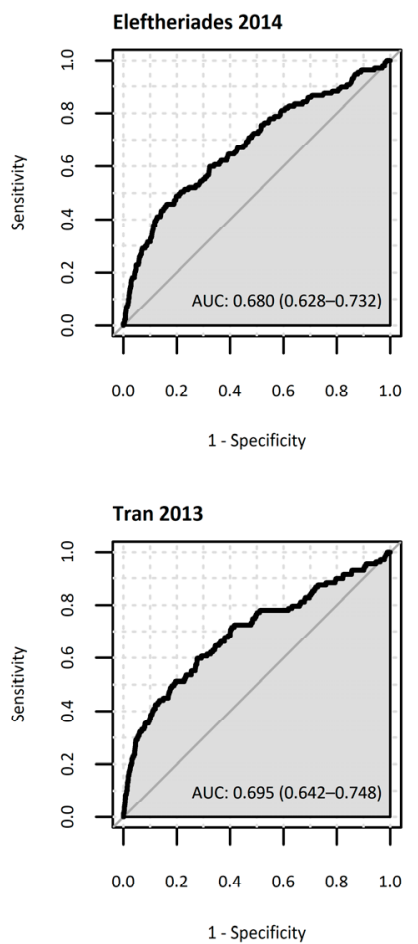
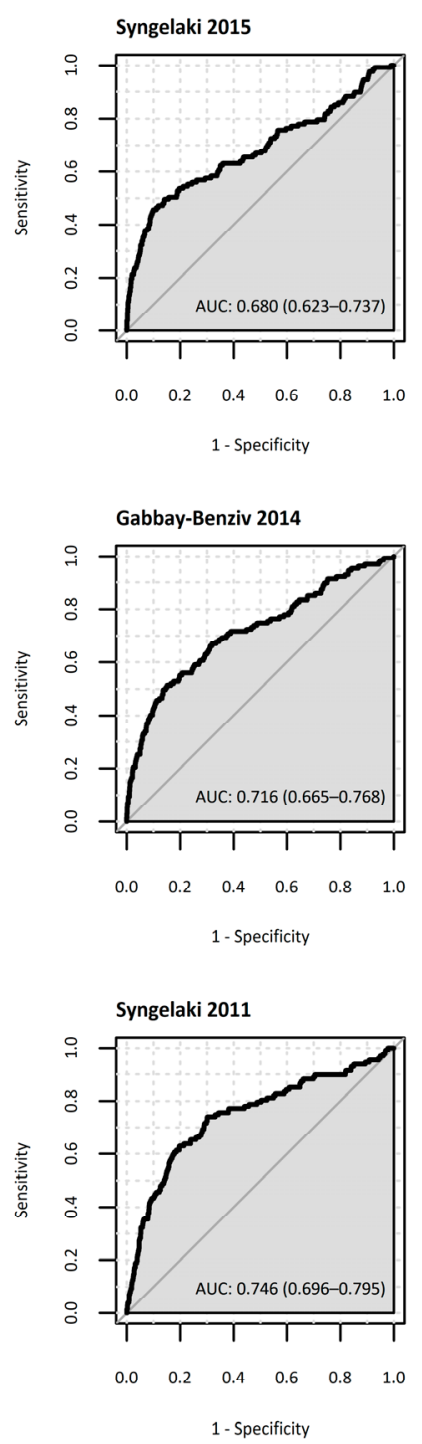

Supplementary Figure S4.1A ROC curves of externally validated first trimester prediction models for gestational diabetes mellitus 

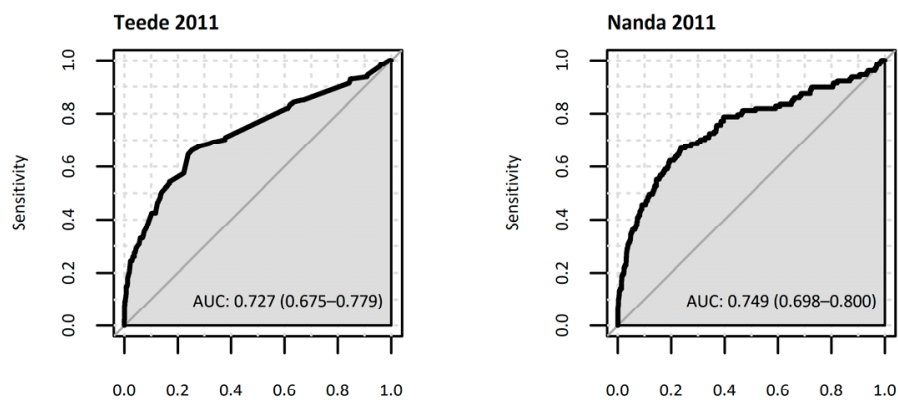

1 - Specificity

1 - Specificity
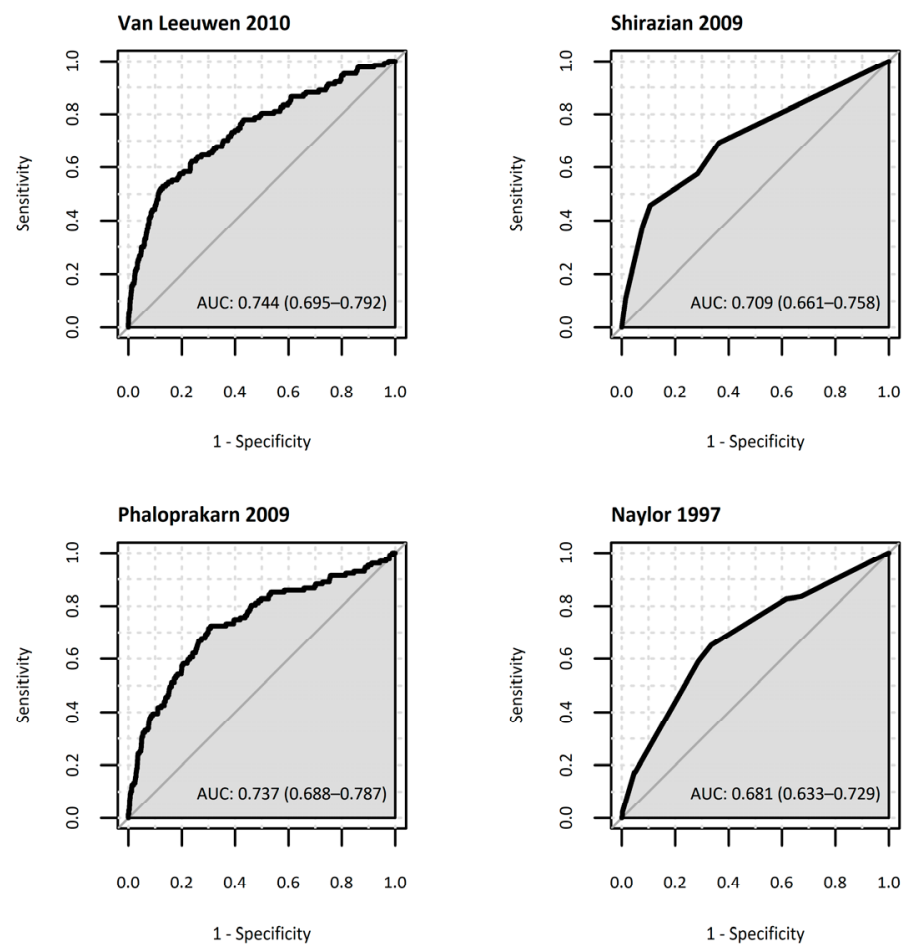

Supplementary Figure S4.1B ROC curves of externally validated first trimester prediction models for gestational diabetes mellitus 

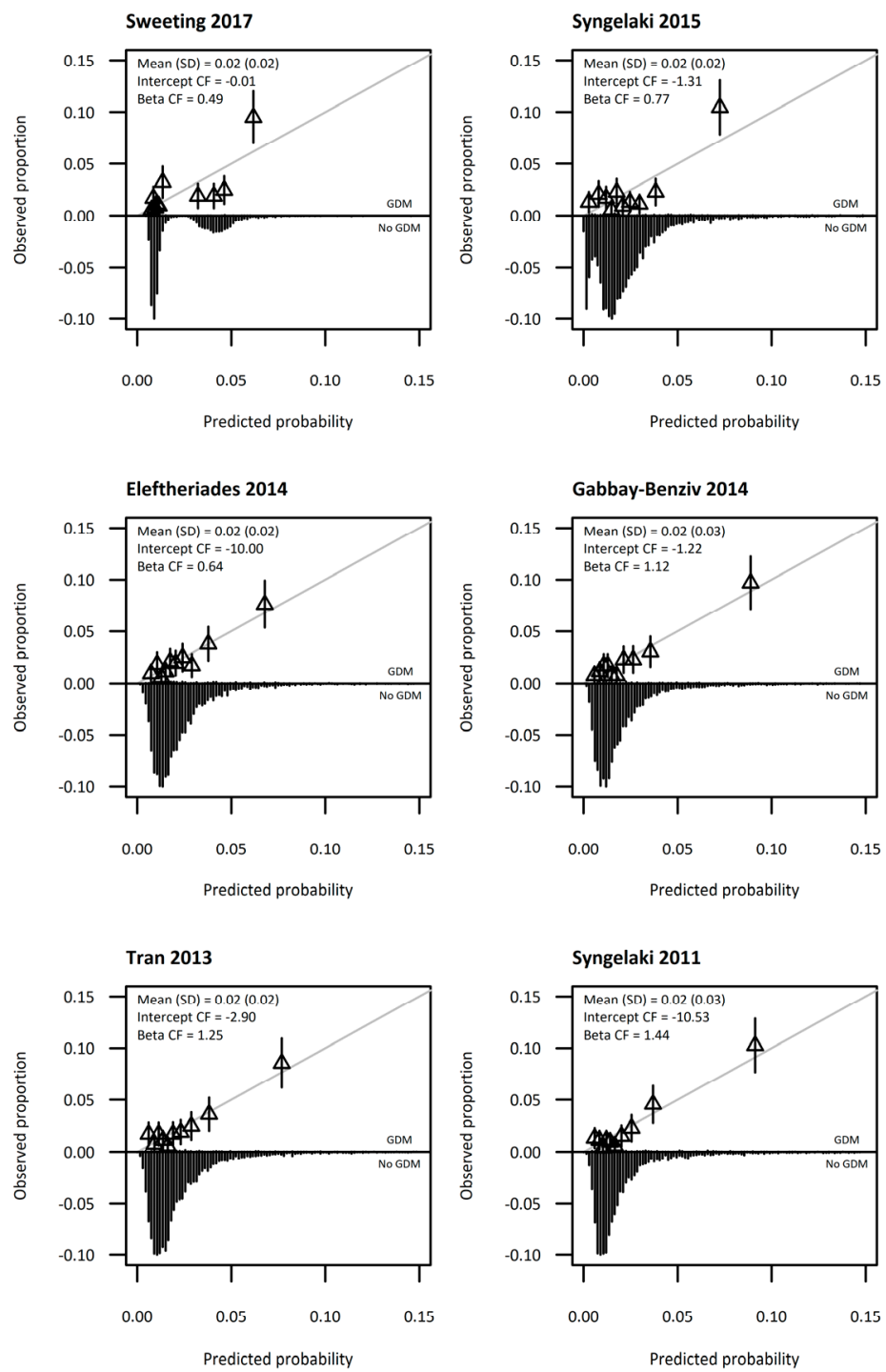

Supplementary Figure S4.2A Calibration plots of recalibrated first trimester prediction models for gestational diabetes mellitus (GDM). The grey line is the reference line with intercept $=0$ and slope $=1$ (perfect calibration). Triangles correspond to grouped predicted risks with $95 \% \mathrm{Cl}$ (vertical lines). CF = correction factor 

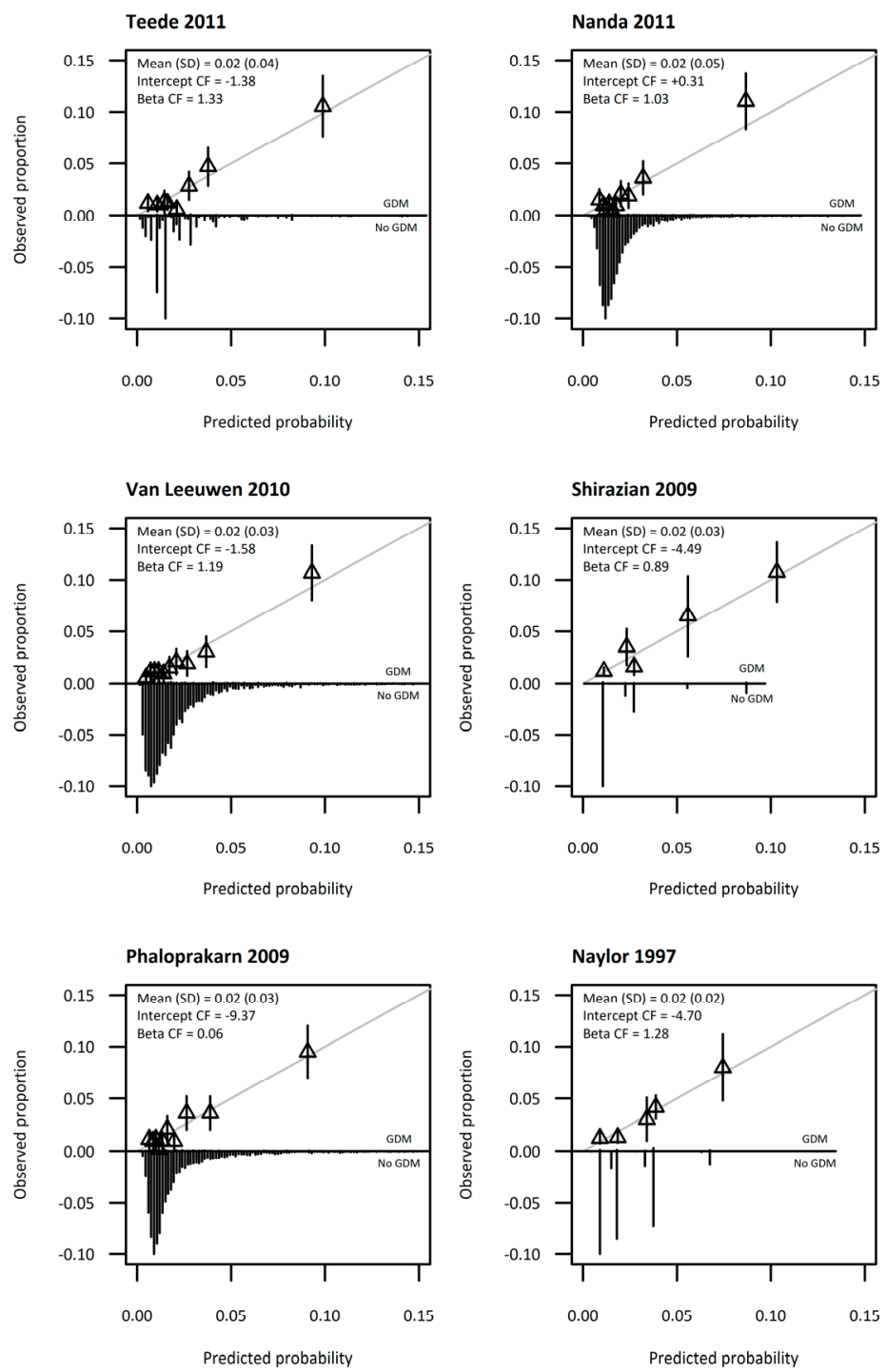

Supplementary Figure S4.2B Calibration plots of recalibrated first trimester prediction models for gestational diabetes mellitus (GDM). The grey line is the reference line with intercept $=0$ and slope $=1$ (perfect calibration). Triangles correspond to grouped predicted risks with $95 \% \mathrm{Cl}$ (vertical lines). CF = correction factor 


\section{CHAPTER 5}

First-trimester prediction models for small- and largefor-gestational-age infants: external validation and clinical usefulness

Linda J.E. Meertens, Luc J.M. Smits, Sander M.J. van Kuijk, Robert Aardenburg, Ivo M.A. van Dooren, Josje Langenveld, Iris M. Zwaan, Marc E.A. Spaanderman, and Hubertina C.J. Scheepers 


\begin{abstract}

\section{Introduction}

Children born small-for-gestational-age (SGA) or large-for-gestational-age (LGA) have increased morbidity and mortality in early infancy and childhood. Timely risk estimation could allow for individual-based care to prevent adverse outcomes. Several promising prediction models have been developed, but none of them have been independently validated in another population. We externally validated all published prediction models based on non-invasive predictors, for the risk of SGA and LGA. Furthermore, we evaluated the clinical potential of the best performing models.
\end{abstract}

\title{
Methods
}

Published prediction models were systematically selected from the literature and validated in a multicentre prospective Dutch cohort study performed between July 1 , 2013 and December 31, 2015. Information on predictors was obtained before 16 weeks of gestation by use of a web-based questionnaire. Birth weight centiles were corrected for gestational age, parity, fetal sex, and ethnicity. Discrimination (cstatistic) and calibration were assessed to evaluate the predictive performance for each model. Clinical utility of the best performing models was evaluated by use of decision curve analysis and by calculating prognostic measures at different risk thresholds.

\section{Results}

The validation cohort consisted of 2582 infants, including 203 SGA $<10^{\text {th }}$ percentile and 224 LGA $>90^{\text {th }}$ percentile. The c-statistics of the six included models for SGA ranged from 0.52 to 0.64 and for the six included models for LGA from 0.60 to 0.69 . All models yielded higher c-statistics for more severe cases of SGA $\left(<5^{\text {th }}\right.$ percentile) and LGA $\left(>95^{\text {th }}\right.$ percentile). Initial calibration showed poor to moderate agreement between predicted probabilities and observed outcomes, but improved substantially after recalibration. The models, particularly for SGA, showed limited overall benefit compared to classifying all or no women as high risk.

\section{Discussion}

The clinical relevance of the models is limited because of their moderate predictive performance and because the definitions of LGA and SGA do not exclude constitutionally larger or smaller infants. As most clinically relevant fetal growth deviations are 'vascular' or 'metabolic' related, models predicting hypertensive disorders and gestational diabetes are likely to be more specific. 


\section{Introduction}

Fetal growth deviations are associated with short- and long-term health consequences for both mother and child. Delivering an infant that is large-for-gestational-age (LGA) is associated with trauma to the birth canal, induction of labour, instrumental vaginal delivery, caesarean section, shoulder dystocia, and perinatal asphyxia ${ }^{1-5}$. Infants born small-for-gestational-age (SGA) are at increased risk of perinatal asphyxia, respiratory distress, intubation at term, sepsis, and mortality ${ }^{4,6-9}$. Long-term risks of infants born SGA or LGA are development of obesity, hypertension, cardiovascular complications and diabetes later in life ${ }^{10-18}$.

Fetal growth is determined by a complex interplay of genetic factors, uterine conditions, environmental factors, fetal syndromes, hormones, pregnancy complications, and maternal characteristics ${ }^{17,19-21}$. Risk factors for LGA are a high pregestational body-mass-index (BMI), pre-existing diabetes mellitus, previous LGA, gestational diabetes mellitus, and a high BMI of the father ${ }^{2,22-24}$. Smoking, short maternal height, chronic hypertension, nulliparity, placental pathology, and intrauterine infections are associated with an increased risk of SGA ${ }^{17,25,26}$. A number of these risk factors are modifiable, others are not.

Early and correct identification of women at risk would enable personalized follow-up management, which could help avoid adverse perinatal outcomes. Prediction modelling combines risk factors into a single model that takes into account the risk dependent weight of each factor and possible interrelations ${ }^{27}$. Several prediction models based on maternal characteristics, biomarkers, and biophysical tests have been developed for the risk of SGA or LGA, showing promising discriminative performance in separating fetal growth deviations from normal growth. Biomarkers and biophysical tests may improve the accuracy of the model beyond using only maternal characteristics. Published studies show, however, only a limited contribution of these factors to a higher discriminative performance ${ }^{28-45}$. Moreover, most of these more complex predictors are relative expensive, not readily available in general antenatal settings, and possibly inconvenient for pregnant women ${ }^{46}$. To our knowledge, no external validation studies of prediction models for SGA or LGA have been published so far. External validation is a crucial step before implementing a model in clinical practice by evaluating the performance in data that were not used to develop the model on ${ }^{47}$.

In this study, an overview of all published prediction models for the risk of SGA or LGA based on maternal characteristics and standard antenatal measurements (i.e. blood pressure) is provided. We validated the selected models in an independent Dutch prospective cohort consisting of 2582 pregnant women. Furthermore, we evaluated the clinical potential of the best performing models. 


\section{Methods}

\section{Selection of prediction models}

We systematically searched PubMed to select all published early prediction models for the risk of SGA or LGA. The search strategies have been published elsewhere ${ }^{48}$. The searches were performed in April 2013, before development of the study questionnaires, and updated until June 22, 2017. The first author screened all retrieved citations and, together with the last author, assessed eligibility of the full text articles. A third reviewer (HS) was available in case of no consensus. Studies were eligible if they met the following criteria: (1) the article presented the development of a prediction model or an update of a previously developed model, (2) the model contained multiple predictors, (3) predictors were routinely collected in Dutch obstetric care (maternal characteristics or blood pressure), (4) predictors were available and/or measured before $16^{+0}$ weeks of gestation, (5) the model was based on weighted risk predictors, and (6) the outcome of the model was SGA or LGA. Citation lists of included articles and relevant (systematic) reviews were checked to identify additional articles. Authors of the original studies were contacted in case the model intercept, regression coefficients, or definition of predictor variable(s) were not published. Models for which regression coefficients could not be obtained and articles written in any language other than English, German, French, or Dutch were excluded.

\section{Validation cohort}

We performed a multicenter prospective cohort study in the south-eastern part of the Netherlands (Expect Study I). The primary objective of this study was to validate published first trimester prediction models for several adverse pregnancy outcomes. Six hospitals and 36 midwifery practices recruited pregnant women $<16$ weeks of gestation and $\geq 18$ years old between July 1, 2013 and January 1, 2015 with follow-up until December 31, 2015. Eligible pregnant women were invited to complete two webbased questionnaires, or paper-based upon request, one before 16 weeks of gestation (pregnancy questionnaire) and one 6 weeks after the due date (postpartum questionnaire). Medical records and discharge letters were requested from health care providers. Pregnancies ending in a miscarriage ( $<16$ weeks of gestation) or termination before 24 weeks of gestation and women lost-to-follow-up were excluded. For this study, we also excluded multiple pregnancies and women who delivered between $16^{+} 0$ and $25^{+0}$ weeks of gestation, as the customized birth weight curves are only available from 25 weeks onwards ${ }^{49}$. A detailed description of the Expect Study I has been published in full elsewhere ${ }^{48}$.

The Medical Ethical Committee of the Maastricht University Medical Centre declared that no ethical approval was necessary (MEC 13-4-053). All participating women gave online informed consent. 


\section{Assessment of predictors and outcomes}

The predictors in the included prediction models were assessed by means of the pregnancy questionnaire. Blood pressure was measured according to routine antenatal care and self-reported in the pregnancy questionnaire. We used the same definitions as published in the original articles (Supplementary Table S5.1 and S5.2).

The outcomes SGA and LGA were defined as an infant with a birth weight $<10^{\text {th }}$ percentile or $>90^{\text {th }}$ percentile, respectively, corrected for gestational age, ethnicity, gender, and parity ${ }^{49}$. Secondly, we also evaluated the performance of the models for SGA and LGA using the cutoff values $<5^{\text {th }}$ percentile and $>95^{\text {th }}$ percentile, respectively. Birth weight was obtained from the medical record. Data from the postpartum questionnaire was used in case of missing birth weight $(n=1)$ or the complete medical record $(n=16)$.

\section{Statistical analysis}

There is no generally accepted rule for the required sample size for external validation of prediction models. We followed Vergouwe et al., which recommends a minimum of 100 events and 100 non-events ${ }^{50}$.

The baseline characteristics of the validation cohort were described as mean \pm standard deviation (SD) for continuous variables and an absolute value with percentage for categorical variables. Missing predictor variables were imputed by means of stochastic regression imputation with predictive mean matching as the imputation mode ${ }^{51}$. We also evaluated the similarity of the validation cohort to the derivation cohorts.

We computed the individual probabilities for the risk of SGA or LGA using the original prediction algorithms (Supplementary Table S5.3 and S5.4). The predictive performance of each model was assessed by means of discrimination and calibration. Discriminative performance, the model's ability to distinguish between women who will have the outcome and those who will not, was quantified as the area under the receiver operating characteristic curve (AUROC) with $95 \%$ confidence interval $(\mathrm{CI})^{47}$. A subgroup analysis was performed for nulliparous women, as a history of SGA or LGA is a strong predictor for recurrent SGA or LGA, respectively. Calibration is a measure of the agreement between the predicted probabilities of the model and the actual outcomes ${ }^{47}$. We assessed calibration graphically by calibration plots in which women were divided into groups of equal size (up to 10) with similar predicted risks, and computed calibration-in-the-large and the calibration slope. Calibration-in-the-large (intercept) indicates whether predictions are systematically too low (intercept $>0$ | slope $=1$ ) or too high (intercept $<0 \mid$ slope=1) by comparing the mean predicted risk with the observed proportion of cases ${ }^{47}$. The slope refers to the average strength of the predictor effects (overfitting $<1$, underfitting $>1$ ). Calibration plots that indicate perfect agreement have an intercept of 0 and a slope of $1\left(45^{\circ} \text { line }\right)^{47}$. We recalibrated the models by adjusting the intercept and slope using the linear predictor as the only 
covariate. This recalibration method has no influence on the discriminative performance ${ }^{52}$.

Lastly, we evaluated the clinical potential of the best performing models by means of decision curve analysis. Decision curve analysis provides insight into the net benefit of the prediction model over a range of risk thresholds compared to the scenarios that all ('treat all') or no ('treat none') women are at high risk for the outcome ${ }^{53}$. The net benefit of a model can be clinically interpreted as the net increase in the proportion of appropriately treated patients or as the net decrease in the proportion of patients treated unnecessarily ${ }^{54}$. Next, we calculated sensitivity, specificity, and positive and negative predictive values at certain risk thresholds for the models with the highest overall net benefit.

Statistical analyses were performed with $\mathrm{R}$ version 3.4.1 (packages mice, rms, pROC, and rmda).

\section{Results}

\section{Selection of prediction models}

The search strategies identified 1522 and 334 articles for SGA and LGA, respectively. Fifteen articles fulfilled the eligibility criteria for the outcome SGA. Cross-checking of citation lists yielded 3 additional articles. We excluded 10 articles for the following reasons: algorithm not available $(n=8)^{34,37-39,42,44,45,55}$, predictors not applicable in high income country $(n=1)^{56}$, and model already published in another included article $(n=1)^{33}$. The 8 eligible articles described 9 prediction models aimed at predicting any SGA $(n=6)^{28,32,43,57-59}$, preterm SGA $(n=2)^{60,61}$, and late SGA $(n=1)^{60}$. For the outcome LGA, we selected 9 eligible articles all describing a prediction model for any $\operatorname{LGA}^{30,31,36,38-41,58,62}$. No additional articles were found by reference cross-checking. Three articles were excluded as the algorithm was not available ${ }^{38,39,62}$.

We only validated the models predicting the risk of any SGA or any LGA as the number of preterm SGA was too low in our validation cohort ( $n=6<37$ weeks of gestation). None of the models were used in antenatal care during the study period.

The characteristics of the included models for SGA $(n=6)^{28,32,43,57-59}$ or LGA $(n=6)^{30,31,36,40,41,58}$ are summarized in Table 5.1 and 5.2, respectively. The models for SGA were published by 5 different research groups from United Kingdom, Canada and Spain between 2011 and 2017. Four models originally defined SGA as an infant with a birth weight $<10^{\text {th }}$ percentile and two models used a cut-off value $<5^{\text {th }}$ percentile. Three different research groups from United Kingdom and Spain published models predicting the risk of LGA between 2011 and 2016. Four models defined LGA as a birth weight $>95^{\text {th }}$ percentile and two models $>90^{\text {th }}$ percentile. 


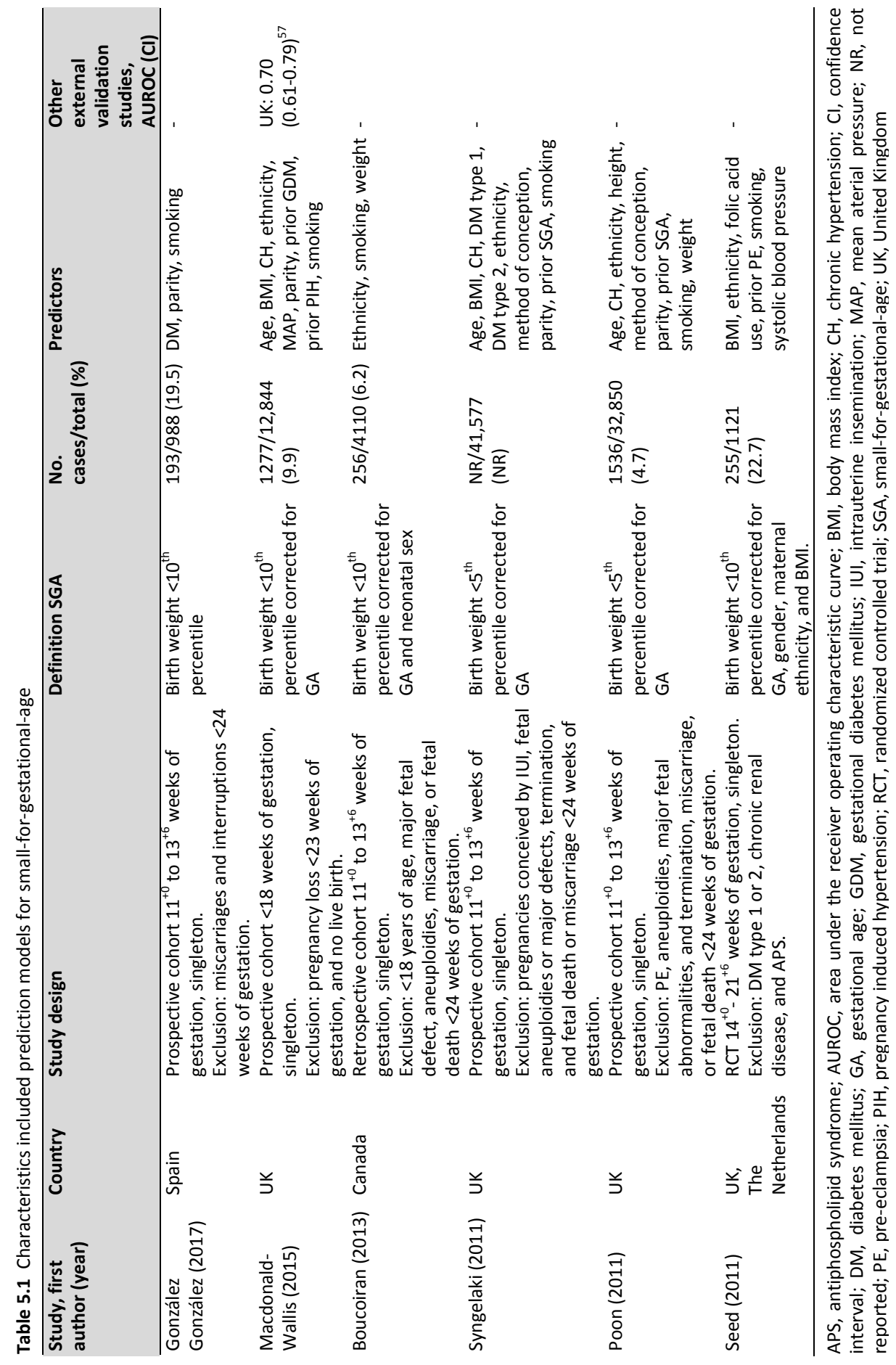




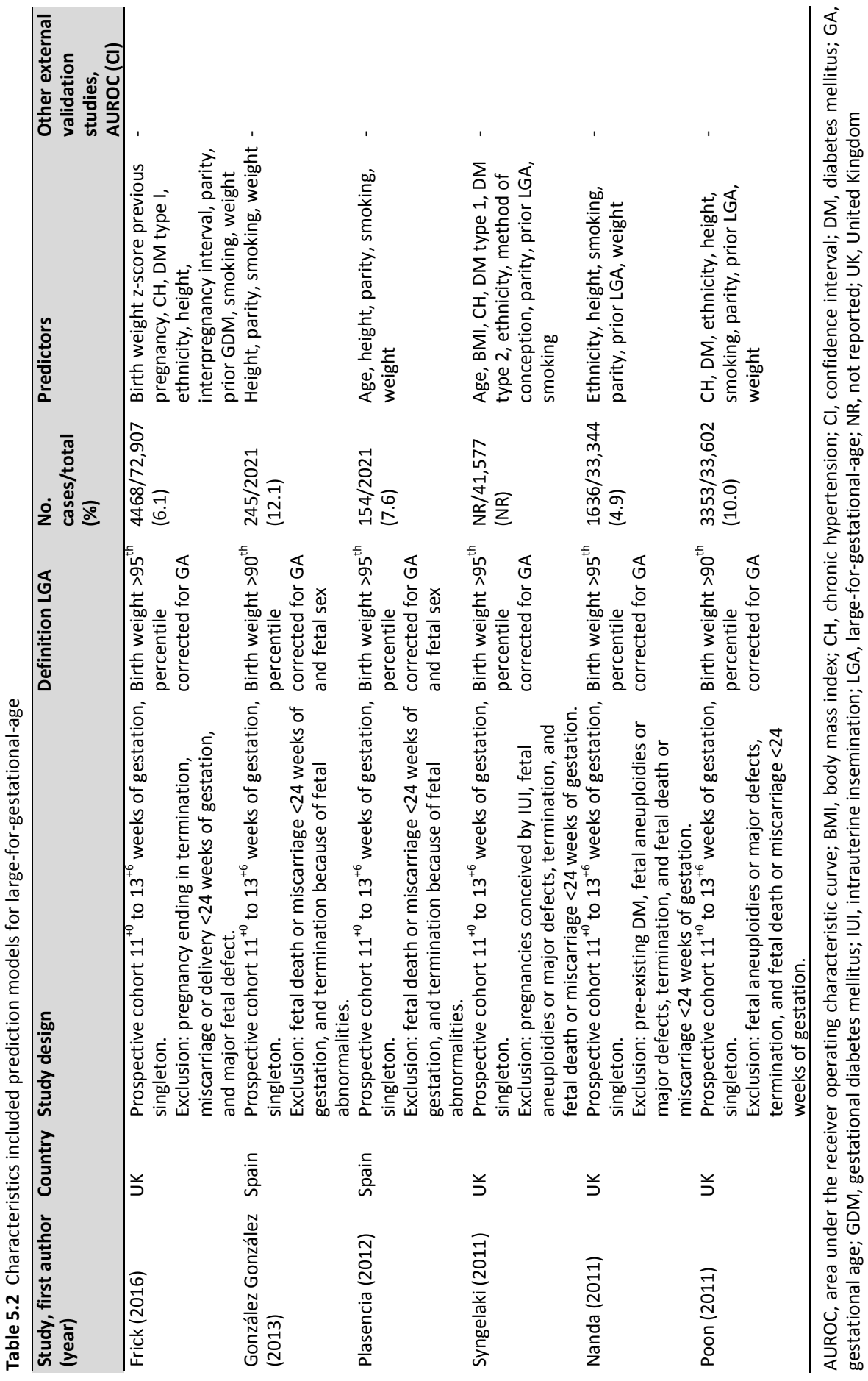




\section{Validation cohort}

We included 2582 women in the validation cohort (Figure 5.1). The outcome SGA $<10^{\text {th }}$ percentile was present in 203 women $(7.9 \%)$. Six SGA infants were born prematurely ( $<37$ weeks of gestation) (3.0\%) and 14 SGA infants were born to mothers whose pregnancy was complicated by a hypertensive pregnancy disorder (6.9\%). Of the 224 infants who were LGA $>90^{\text {th }}$ percentile $(8.7 \%), 20$ were born to mothers with gestational diabetes mellitus (8.9\%). Table 5.3 shows the characteristics of the overall cohort and for SGA, non-SGA, LGA, and non-LGA groups in the observed data. The characteristics of the imputed validation cohort were generally comparable with those of the observed data (Supplementary Table S5.5). We also compared the characteristics of the validation cohort with the derivation cohorts (Supplementary Table S5.6 and S5.7). In contrast to most derivation cohorts, our validation cohort had a low prevalence of non-Caucasian ethnicity and smoking during pregnancy. Average height and weight of the women was higher compared to all other development cohorts, but the mean BMI was similar. The occurrence of the outcome SGA was considerably higher in the derivation cohorts of Seed et al. (high-risk women) and González González et al.. The prevalence of LGA was comparable between the development cohorts and our validation cohort. Compared to all other derivation cohorts, nulliparous women in our cohort delivered proportionally more often a LGA infant than no LGA infant. Syngelaki et al. neither reported any predictor characteristics nor the number of SGA and LGA.

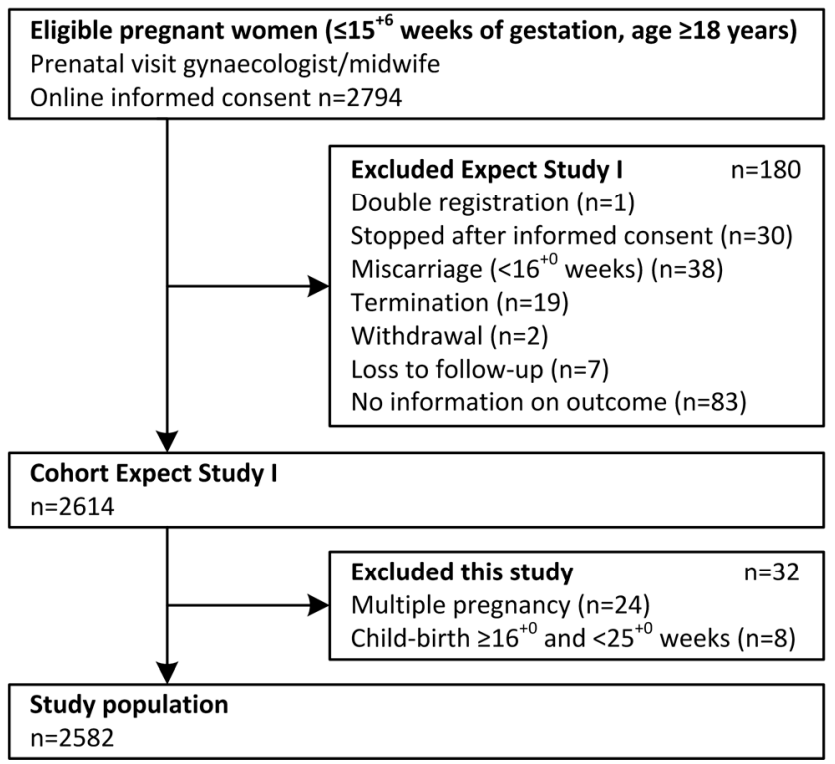

Figure 5.1 Flowchart validation cohort fetal growth deviations 


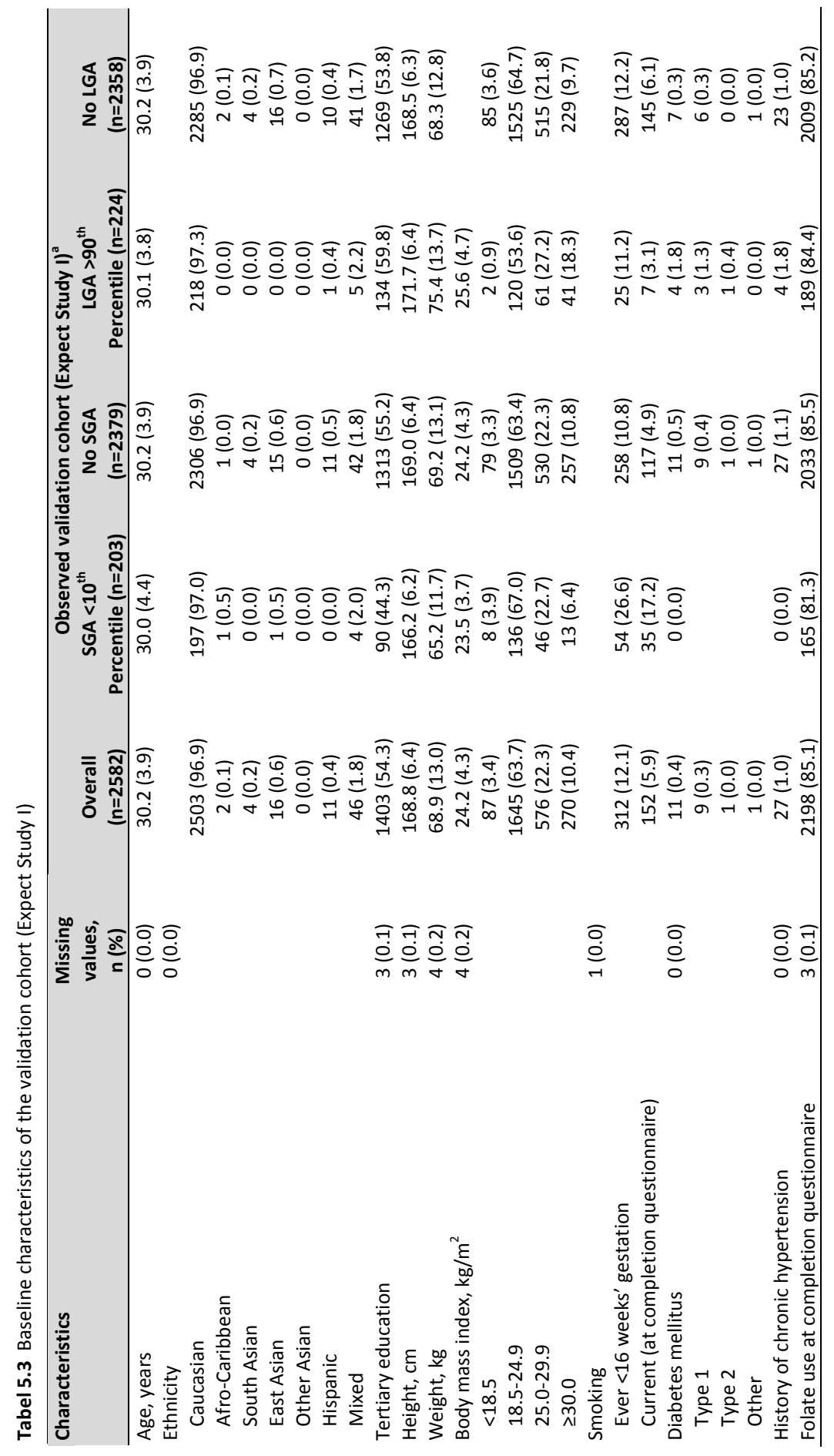




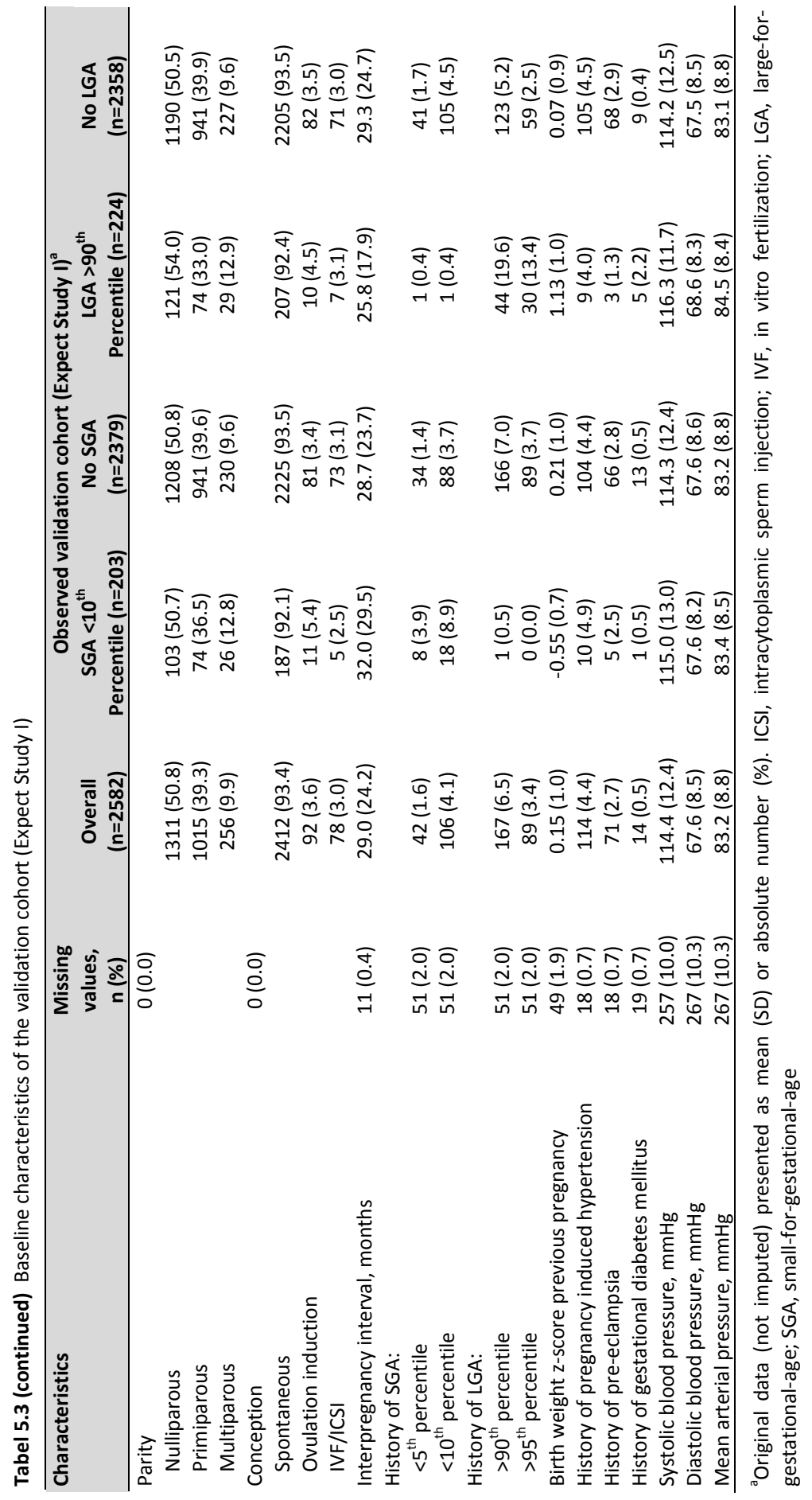




\section{Predictive performances}

Table 5.4 shows the AUROCs for prediction of SGA. The discriminative performance decreased considerably for all models compared with the development cohorts, but most for the models with the highest AUC. The model of Boucoiran et al. retained the highest AUROC $(0.64, \mathrm{Cl} 95 \%$ 0.60-0.68). All models demonstrated a higher ability to predict the risk of SGA $<5^{\text {th }}$ percentile as compared to SGA $<10^{\text {th }}$ percentile, with AUROCs of up to 0.67. Subgroup analysis showed no difference in discriminative ability of the models between nulliparous and multiparous women. The ROC curves are displayed in Supplementary Figure S5.1. The three models for which the full algorithm was provided, showed poor calibration (Figure 5.2). Recalibration of all models led to better agreement between predicted and observed risks for most models (Supplementary Figure S5.2). The model of MacDonald-Wallis et al. showed closest fit to the perfect calibration line. The predicted risks were closely clustered around the overall risk for all models.

The discriminative performances of the prediction models for LGA are presented in Table 5.5. Although the AUROCs also decreased for all models after external validation, three models showed moderate discriminative ability (AUROCs 0.68-0.69). The model of Frick et al. showed the highest discriminative performance with AUROC of 0.69 and 0.74 for LGA $>90^{\text {th }}$ percentile and $>95^{\text {th }}$ percentile, respectively. All models showed a higher discriminative ability for LGA $>95^{\text {th }}$ percentile compared to LGA $>90^{\text {th }}$ percentile. In contrast to the outcome SGA, most models for LGA were also originally developed to predict the $5 \%$ most extreme birth weight deviations ( $>95^{\text {th }}$ percentile). Supplementary Figure S5.3 presents the ROC curves. Subgroup analysis showed better discriminative performance among multiparous women, with highest AUROC $(0.80)$ for the model of Frick et al.. Performance among nulliparous women was slightly lower than in the total group (AUROC up to 0.67). The three fully available algorithms for LGA showed better calibration as compared with models for SGA (Figure 5.3). All models overestimated the probabilities on average (intercept $<0$ ) and showed overfitting of the predictor effects (slope $<1$, low predictions too low and high predictions too high). Recalibration of all models considerably improved the agreement between predicted probabilities and observed outcomes for almost all models (Supplementary Figure S5.4). 

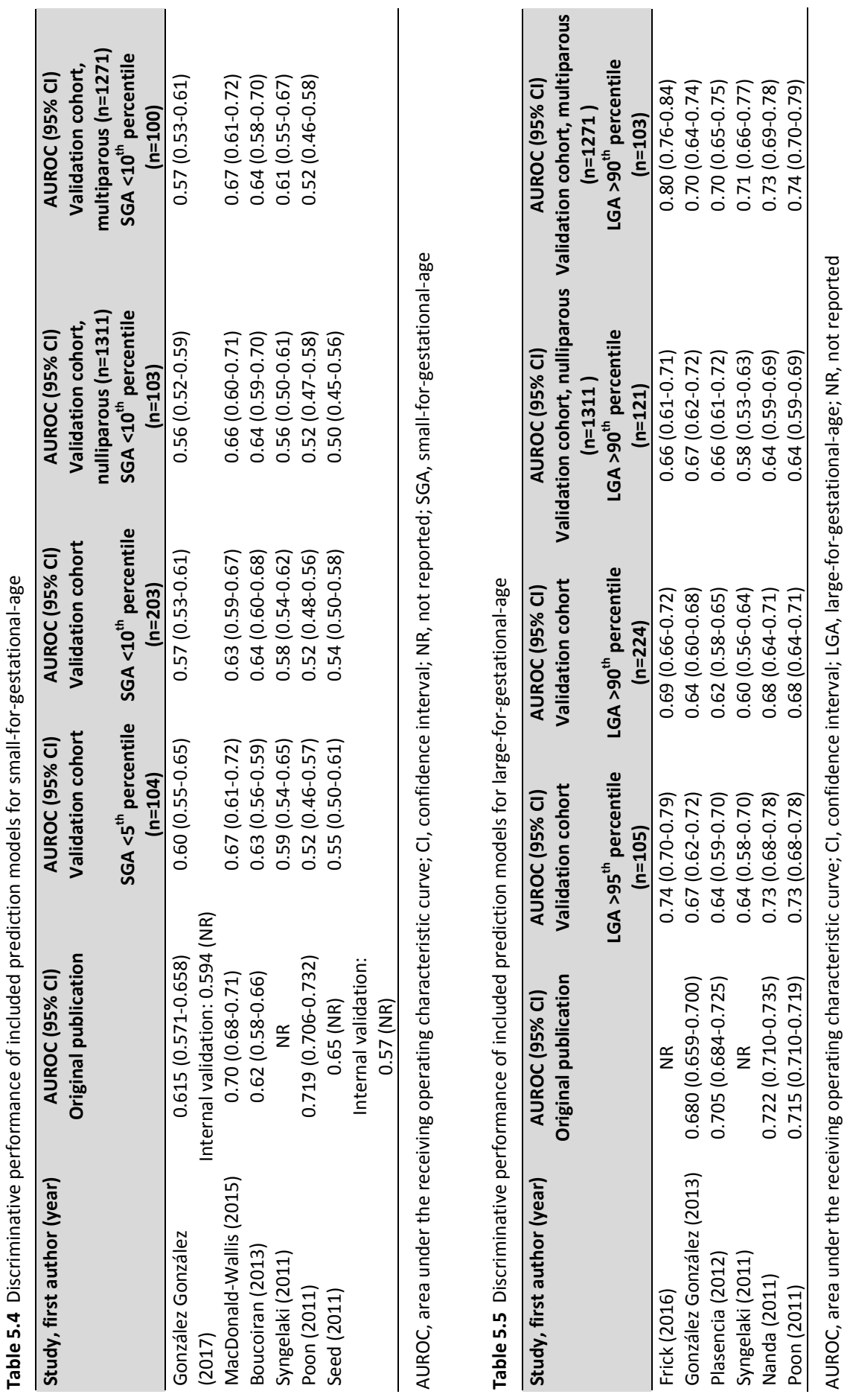

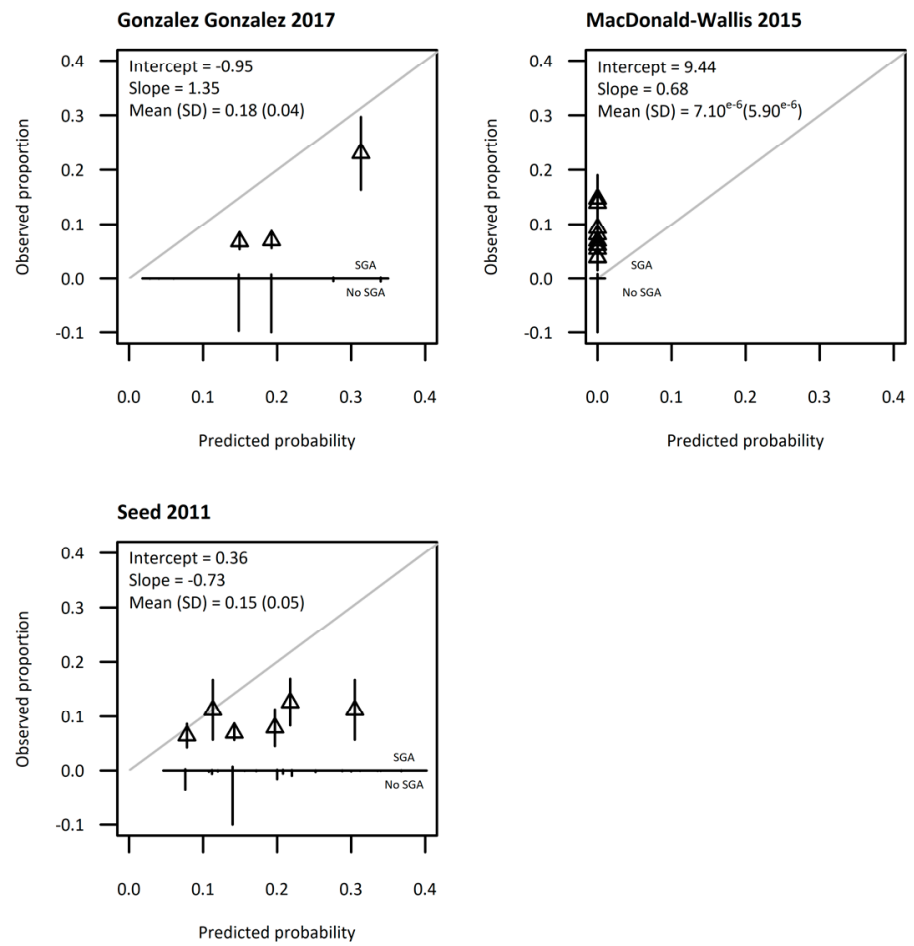

Figure 5.2. Calibration plots of externally validated first trimester prediction models for small-forgestational-age $<10^{\text {th }}$ percentile. The grey line is the reference line with intercept $=0$ and slope $=1$ (perfect calibration). Triangles correspond to grouped predicted risks with $95 \%$ confidence intervals (vertical lines)

\section{Clinical usefulness}

Decision curve analysis of the two best performing models for SGA revealed a positive net benefit compared to classifying all or no women as at high risk for SGA for a risk threshold between 4-22\% (Figure 5.4). However, the overall net benefit was low as also demonstrated in Table 5.6. Choosing a cut-off leading to high sensitivity leads to a large proportion of women unnecessarily indicated as high risk. A higher risk threshold ensures a high specificity but only a small proportion of cases will be detected.

Figure 5.5 shows the net benefit of the three best discriminative models for the risk of LGA. The models were beneficial compared with classifying all or no women as high risk over a threshold range from 1-40\%. The three curves differed only slightly. Table 5.7 presents the performance measures at different risk thresholds. 

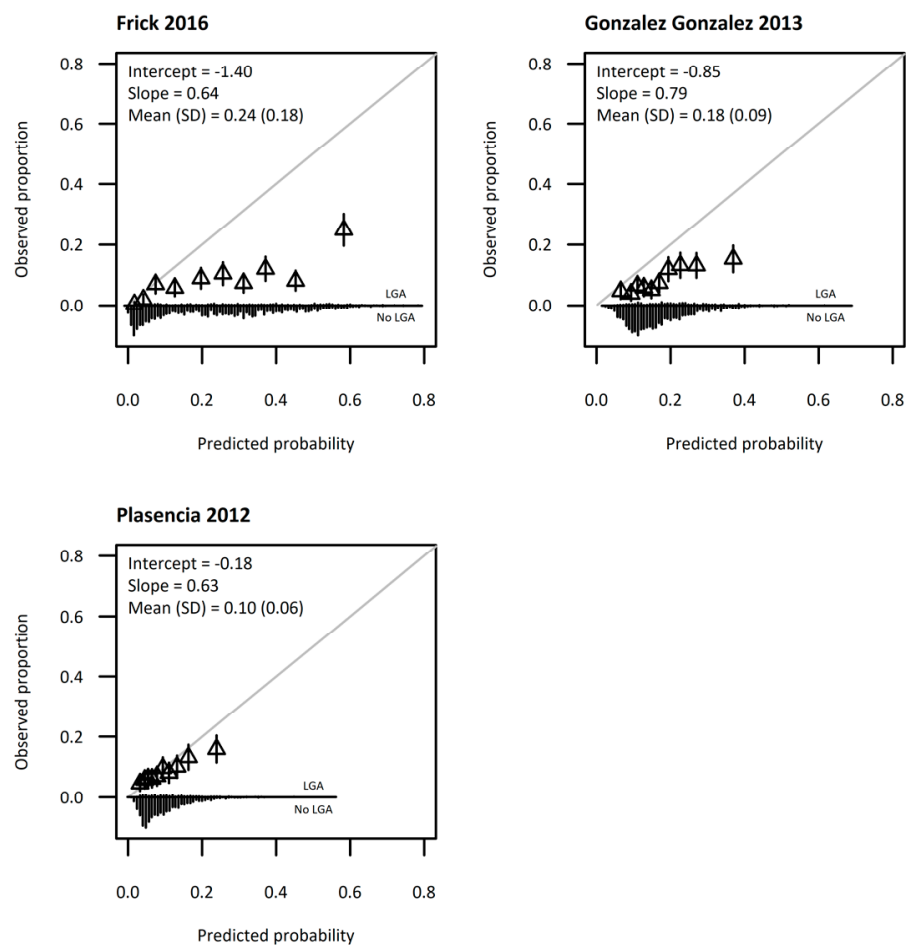

Figure 5.3 Calibration plots of externally validated first trimester prediction models for large-forgestational-age $>90^{\text {th }}$ percentile. The grey line is the reference line with intercept $=0$ and slope $=1$ (perfect calibration). Triangles correspond to grouped predicted risks with $95 \%$ confidence intervals (vertical lines)

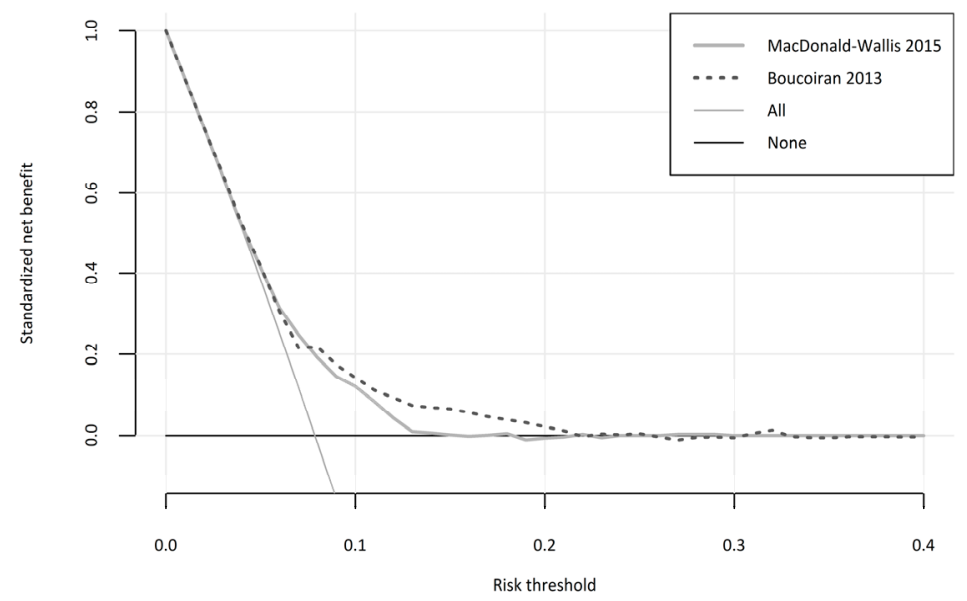

Figure 5.4 Decision curve analysis of 2 best performing models for the risk of small-for-gestational-age $<10^{\text {th }}$ percentile. The solid grey line is the net benefit when considering all women as at high risk and the horizontal black line when considering no women at high risk 
Table 5.6 Performance measures at different risk thresholds for recalibrated model Boucoiran et al. predicting the risk of small-for-gestational-age

\begin{tabular}{lccccc}
\hline $\begin{array}{l}\text { Risk threshold } \\
\%\end{array}$ & $\begin{array}{c}\text { High risk, } \% \\
(\mathbf{n} / \mathbf{n})\end{array}$ & $\begin{array}{c}\text { Sensitivity, } \\
(\mathbf{n} / \mathbf{n})\end{array}$ & $\begin{array}{c}\text { Specificity, \% } \\
(\mathbf{n} / \mathbf{n})\end{array}$ & $\begin{array}{c}\text { PPV, \% } \\
(\mathbf{n} / \mathbf{n})\end{array}$ & $\begin{array}{c}\mathbf{N P V}, \% \\
(\mathbf{n} / \mathbf{n})\end{array}$ \\
\hline 2 & 99.6 & 100 & 0.46 & 7.9 & 100 \\
& $(2571 / 2582)$ & $(203 / 203)$ & $(11 / 2379)$ & $(203 / 2571)$ & $(11 / 11)$ \\
4 & 92.1 & 97.0 & 8.4 & 8.3 & 97.1 \\
& $(2377 / 2582)$ & $(197 / 203)$ & $(199 / 2379)$ & $(197 / 2377)$ & $(199 / 205)$ \\
6 & 70.1 & 82.3 & 30.9 & 9.2 & 95.3 \\
& $(1811 / 2582)$ & $(167 / 203)$ & $(735 / 2379)$ & $(167 / 1811)$ & $(735 / 771)$ \\
8 & 32.1 & 52.7 & 69.7 & 12.9 & 94.5 \\
& $(829 / 2582)$ & $(107 / 203)$ & $(1657 / 2379)$ & $(107 / 829)$ & $(1657 / 1753)$ \\
10 & 9.7 & 25.1 & 91.6 & 20.4 & 93.5 \\
& $(250 / 2582)$ & $(51 / 203)$ & $(2180 / 2379)$ & $(51 / 250)$ & $(2180 / 2332)$ \\
12 & 5.9 & 17.2 & 95.0 & 22.9 & 93.1 \\
& $(153 / 2582)$ & $(35 / 203)$ & $(2261 / 2379)$ & $(35 / 153)$ & $(2261 / 2429)$ \\
& 5.5 & 15.8 & 95.3 & 22.4 & 93.0 \\
& $(143 / 2582)$ & $(32 / 203)$ & $(2268 / 2379)$ & $(32 / 143)$ & $(2268 / 2439)$ \\
\hline
\end{tabular}

${ }^{a}$ Predicted risk at or above this level was considered as high risk. NPV, negative predictive value; PPV, positive predictive value

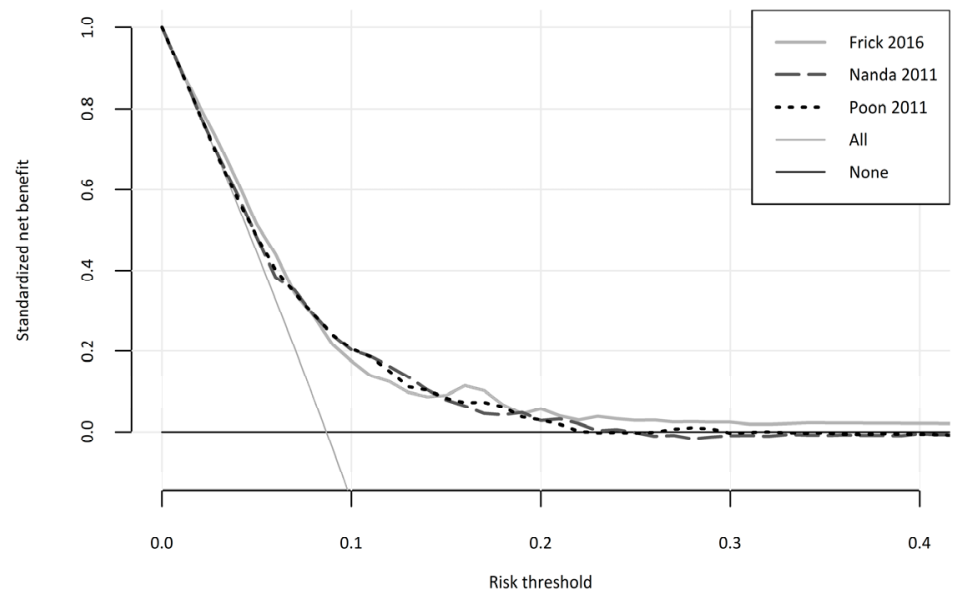

Figure 5.5 Decision curve analysis of 3 best performing models for the risk of large-for-gestational-age $>90^{\text {th }}$ percentile. The solid grey line is the net benefit when considering all women as at high risk and the horizontal black line when considering no women at high risk 
Table 5.7 Performance measures at different risk thresholds for recalibrated model Frick et al. predicting the risk of large-for-gestational-age

\begin{tabular}{lccccc}
\hline $\begin{array}{l}\text { Risk threshold } \\
\%\end{array}$ & $\begin{array}{c}\text { High risk, } \% \\
(\mathbf{n} / \mathbf{n})\end{array}$ & $\begin{array}{c}\text { Sensitivity, } \% \\
(\mathbf{n} / \mathbf{n})\end{array}$ & $\begin{array}{c}\text { Specificity, } \% \\
(\mathbf{n} / \mathbf{n})\end{array}$ & $\begin{array}{c}\text { PPV, \% } \\
(\mathbf{n} / \mathbf{n})\end{array}$ & $\begin{array}{c}\text { NPV, \% } \\
(\mathbf{n} / \mathbf{n})\end{array}$ \\
\hline 1 & 98.5 & 100 & 1.7 & 8.8 & 100 \\
& $(2541 / 2582)$ & $(224 / 224)$ & $(41 / 2358)$ & $(224 / 2541)$ & $(41 / 41)$ \\
2 & 89.7 & 99.6 & 11.3 & 9.6 & 99.6 \\
& $(2424 / 2582)$ & $(223 / 224)$ & $(266 / 2358)$ & $(223 / 2424)$ & $(266 / 267)$ \\
4 & 72.7 & 92.9 & 29.2 & 11.1 & 97.7 \\
& $(1877 / 2582)$ & $(208 / 224)$ & $(689 / 2358)$ & $(208 / 1877)$ & $(689 / 705)$ \\
& 50.7 & 73.2 & 51.4 & 12.5 & 95.3 \\
10 & $(1309 / 2582)$ & $(164 / 224)$ & $(1213 / 2358)$ & $(154 / 1309)$ & $(1213 / 1273)$ \\
& 37.8 & 59.4 & 64.2 & 13.6 & 94.3 \\
14 & $(976 / 2582)$ & $(133 / 224)$ & $(1515 / 2358)$ & $(133 / 976)$ & $(1515 / 1606)$ \\
& 17.0 & 34.8 & 84.7 & 17.8 & 93.2 \\
18 & $(438 / 2582)$ & $(78 / 224)$ & $(1998 / 2358)$ & $(78 / 438)$ & $(1998 / 2144)$ \\
& 5.7 & 17.4 & 95.4 & 26.4 & 92.4 \\
20 & $(148 / 2582)$ & $(39 / 224)$ & $(2249 / 2358)$ & $(39 / 148)$ & $(2249 / 2434)$ \\
& 2.7 & 10.7 & 98.1 & 34.8 & 92.0 \\
& $(69 / 2582)$ & $(24 / 224)$ & $(2313 / 2358)$ & $(24 / 69)$ & $(2313 / 2513)$ \\
\hline
\end{tabular}

${ }^{a}$ Predicted risk at or above this level was considered as high risk. NPV, negative predictive value; PPV, positive predictive value

\section{Discussion}

\section{Principal findings}

Six early non-invasive prediction models for the risk of SGA as well as six models for the outcome LGA were selected from the literature, some of which showed promising original discriminative performance (AUROC up to 0.72 ). We validated these models in an independent prospective cohort of 2582 women. The discriminative performance decreased for all models, especially those predicting SGA. All models showed better discriminative ability for predicting the more severe cases of SGA and LGA, which are also associated with a higher risk of adverse outcomes ${ }^{30,63}$. Calibration was poor for the prediction models for SGA. The models predicting the risk of LGA all overestimated the risk in our population. Recalibration provided better agreement of predicted with actual risks for most models.

\section{Previous studies}

Validation of promising prediction models is essential as the predictive performance is usually lower in other populations, even when a similar population as the one in which the model was developed is being used ${ }^{47}$. Only two of the selected models were internally validated and their performance stayed fairly stable after external validation $^{32,59}$. MacDonald-Wallis et al. validated their developed model in another cohort from the same country ${ }^{57}$. To our knowledge, no independent or other external validation studies have been published on prediction models for SGA or LGA. 
Validating prediction models in an independent population provides insight into the generalizability, an essential element before clinical application can be considered ${ }^{46}$.

\section{Clinical implications}

Predictive performance measures of a prediction model do not coincide with usefulness of the model in clinical practice. Decision curve analysis and prognostic measures at different risk thresholds give a first impression of clinical utility. However, clinical utility is also dependent on the possibility to detect a subgroup of infants that are actually at risk for adverse outcomes and the availability of an effective follow-up management, to prevent either the development of fetal growth deviations (primary) or related adverse effects (secondary).

The heterogeneous aetiology of fetal growth deviations makes prediction difficult ${ }^{24,64}$. Infants who are constitutionally smaller or larger for gestational age are less related to adverse outcomes and also less likely to benefit from interventions ${ }^{64,65}$. A subset of possible clinically relevant SGA and LGA frequently has a 'metabolic' (i.e. high body mass index, gestational diabetes mellitus; GDM) or 'vascular' (i.e. hypertensive disorder) origin. The predictors in the included models for SGA and LGA considerably overlap with those of models predicting hypertensive pregnancy disorder and GDM, respectively ${ }^{66,67}$. Although most SGA and LGA infants are born to mothers without a hypertensive pregnancy disorder or GDM, respectively, the conditions share common pathophysiological aspects ${ }^{24,64}$.

Regarding primary prevention strategies, recent meta-analyses demonstrated that aspirin modestly reduces the risk for delivering an infant SGA in women at high risk, with most benefit when starting before 16 weeks of gestation and using a dose $\geq 100$ $\mathrm{mg}$ (risk ratio $0.56-0.76)^{68,69}$. Patient selection of those at increased risk was primarily based on an increased risk of developing a hypertensive pregnancy disorder rather than delivering an infant $\mathrm{SGA}^{70}$. Currently, there are no effective interventions for the primary prevention of LGA available, except for the treatment of women with GDM that indirectly lowers the risk of LGA, such as $\operatorname{diet}^{24}$. All taken together, application of current available prediction models for the risk of SGA or LGA in settings in which models for identification of 'vascular' (pre-eclampsia) and 'metabolic' (GDM) related complications are applied, are not likely to result in additional benefit regarding overlap of predictors and preventive interventions.

Identification of women at risk may also allow for secondary prevention of adverse effects related to SGA and LGA. Antenatal detection of infants born SGA and delivery at the appropriate time may reduce the risk of severe morbidity and mortality ${ }^{71-74}$. Induction of labour at or near term for pregnancies suspected to deliver an infant LGA results in a lower mean birth weight, and fewer birth fractures and shoulder dystocia $^{75,76}$. In most clinical settings, ultrasound fetal biometry is the current method for the prediction of birth weight. Based on the decision curve analysis, the use of prediction models to select women for ultrasound fetal biometry will probably not be more beneficial compared to providing it to all women. Moreover, in case ultrasound 
fetal biometry should be restricted to high-risk women, it is again clinically relevant that the model selects the pathological fetal growth deviations. Another important aspect is that even infants who do not meet the criteria for SGA or LGA can have a pathological growth pattern, such as asymmetrical growth or a declining or accelerated growth pattern ${ }^{65}$. These pathological growth patterns are also likely related to 'vascular' and 'metabolic' complicated pregnancies, and serial ultrasound fetal biometry is needed for detection. In conclusion, models that would predict pathological fetal growth deviations would be more likely to improve clinical outcomes than models predicting SGA or LGA.

\section{Strengths and limitations}

We externally validated all published non-invasive prediction models in an independent population. The multicentre prospective study design, with no strict inclusion criteria, ensured for a sample as heterogeneous as possible. Our data contained a low quantity of missing data ( $<1 \%$ for most predictors) and out of range values, as we incorporated validation checks in the web-based questionnaires. Missing data were handled by use of imputation in order to prevent biased results. Nevertheless, blood pressure measurement had a substantial amount of missing data (10\%) most likely due to self-report of the measurements in the web-based questionnaire. Only 2 models contained a predictor based on blood pressure measurement. Another limitation to be mentioned is that we had to exclude women who delivered at $16^{+0}-24^{+6}$ weeks of gestation $(n=8)$, as the Dutch population-based reference curves for birth weight centiles are available from 25 weeks of gestational age onwards ${ }^{49}$. Lastly, we had to exclude 2 prediction models in the selection process, as we did not dispose of routine blood parameters (random glucose, rhesus group) and ultrasound measurements (crown-rump length) ${ }^{35,77}$.

\section{Conclusion}

The prediction models for SGA showed poor to moderate predictive performance after external validation. The algorithms for LGA performed slightly better with a discriminative performance up to 0.67. All models performed better for the more severe cases of fetal growth deviations, with highest AUROC of 0.74 for a model predicting LGA $>95^{\text {th }}$ percentile. The models, especially for SGA, showed a limited overall benefit compared to classifying all or no women as high risk.

Clinical relevance of prediction models for SGA and LGA can be questioned both due to moderate predictive performance as the heterogeneous aetiology of fetal growth deviations. It is important to distinguish between constitutionally and pathologically fetal growth deviations to improve clinical outcomes. Not much additional clinical benefit is expected of current prediction models for SGA and LGA over models that predict pre-eclampsia and GDM due overlap of predictors and available treatment strategies. 


\section{Supplementary materials}

Supplementary Table S5.1

Supplementary Table S5.2

Supplementary Table S5.3

Supplementary Table S5.4

Supplementary Table S5.5

Supplementary Table S5.6

Supplementary Table S5.7

Supplementary Figure S5.1

Supplementary Figure S5.2

Supplementary Figure S5.3

Supplementary Figure S5.4
Definition and assessment predictors included prediction models for small-for-gestational-age

Definition and assessment predictors included prediction models for large-for-gestational-age

Model algorithms for predicting the risk of small-forgestational-age

Model algorithms for predicting the risk of large-forgestational-age

Characteristics of observed and imputed validation cohort

Baseline characteristics original cohorts and validation cohort for small-for-gestational-age

Baseline characteristics original cohorts and validation cohort for large-for-gestational-age

ROC curves of externally validated first trimester prediction models for small-for-gestational-age $<5^{\text {th }}$ percentile and $<10^{\text {th }}$ percentile

Calibration plots of recalibrated first trimester prediction models for small-for-gestational-age $<10^{\text {th }}$ percentile. The grey line is the reference line with intercept $=0$ and slope $=1$ (perfect calibration). Triangles correspond to grouped predicted risks with 95\% confidence intervals (vertical lines). CF = correction factor

ROC curves of externally validated first trimester prediction models for large-for-gestational-age $>90^{\text {th }}$ percentile and $>95^{\text {th }}$ percentile

Calibration plots of recalibrated first trimester prediction models for large-for-gestational-age $>90^{\text {th }}$ percentile. The grey line is the reference line with intercept $=0$ and slope $=1$ (perfect calibration). Triangles correspond to grouped predicted risks with 95\% confidence intervals (vertical lines). $\mathrm{CF}=$ correction factor 


\section{References}

1. Bjorstad, A.R., Irgens-Hansen, K., Daltveit, A.K., and Irgens, L.M., Macrosomia: mode of delivery and pregnancy outcome. Acta Obstet Gynecol Scand, 2010. 89(5): p. 664-9.

2. Jolly, M.C., Sebire, N.J., Harris, J.P., Regan, L., and Robinson, S., Risk factors for macrosomia and its clinical consequences: a study of 350,311 pregnancies. Eur J Obstet Gynecol Reprod Biol, 2003. 111(1): p. 9-14.

3. Weissmann-Brenner, A., Simchen, M.J., Zilberberg, E., Kalter, A., Weisz, B., Achiron, R., et al., Maternal and neonatal outcomes of large for gestational age pregnancies. Acta Obstet Gynecol Scand, 2012. 91(7): p. 844-9.

4. Chavkin, U., Wainstock, T., Sheiner, E., Sergienko, R., and Walfisch, A., Perinatal outcome of pregnancies complicated with extreme birth weights at term. J Matern Fetal Neonatal Med, 2017: p. 1-5.

5. Mendez-Figueroa, H., Truong, V.T.T., Pedroza, C., and Chauhan, S.P., Large for Gestational Age Infants and Adverse Outcomes among Uncomplicated Pregnancies at Term. Am J Perinatol, 2017. 34(7): p. 655-662.

6. Garite, T.J., Clark, R., and Thorp, J.A., Intrauterine growth restriction increases morbidity and mortality among premature neonates. Am J Obstet Gynecol, 2004. 191(2): p. 481-7.

7. Grisaru-Granovsky, S., Reichman, B., Lerner-Geva, L., Boyko, V., Hammerman, C., Samueloff, A., et al., Mortality and morbidity in preterm small-for-gestational-age infants: a population-based study. Am J Obstet Gynecol, 2012. 206(2): p. 150 e1-7.

8. McIntire, D.D., Bloom, S.L., Casey, B.M., and Leveno, K.J., Birth weight in relation to morbidity and mortality among newborn infants. N Engl J Med, 1999. 340(16): p. 1234-8.

9. Mendez-Figueroa, H., Truong, V.T., Pedroza, C., and Chauhan, S.P., Morbidity and Mortality in Smallfor-Gestational-Age Infants: A Secondary Analysis of Nine MFMU Network Studies. Am J Perinatol, 2017. 34(4): p. 323-332.

10. Barker, D.J., Osmond, C., Forsen, T.J., Kajantie, E., and Eriksson, J.G., Maternal and social origins of hypertension. Hypertension, 2007. 50(3): p. 565-71.

11. Boney, C.M., Verma, A., Tucker, R., and Vohr, B.R., Metabolic syndrome in childhood: association with birth weight, maternal obesity, and gestational diabetes mellitus. Pediatrics, 2005. 115(3): p. e290-6.

12. Crispi, F., Miranda, J., and Gratacos, E., Long-term cardiovascular consequences of fetal growth restriction: biology, clinical implications, and opportunities for prevention of adult disease. Am J Obstet Gynecol, 2018. 218(2S): p. S869-S879.

13. Eriksson, J.G., Forsen, T., Tuomilehto, J., Jaddoe, V.W., Osmond, C., and Barker, D.J., Effects of size at birth and childhood growth on the insulin resistance syndrome in elderly individuals. Diabetologia, 2002. 45(3): p. 342-8.

14. Harder, T., Rodekamp, E., Schellong, K., Dudenhausen, J.W., and Plagemann, A., Birth weight and subsequent risk of type 2 diabetes: a meta-analysis. Am J Epidemiol, 2007. 165(8): p. 849-57.

15. Hermann, G.M., Dallas, L.M., Haskell, S.E., and Roghair, R.D., Neonatal macrosomia is an independent risk factor for adult metabolic syndrome. Neonatology, 2010. 98(3): p. 238-44.

16. Newsome, C.A., Shiell, A.W., Fall, C.H., Phillips, D.I., Shier, R., and Law, C.M., Is birth weight related to later glucose and insulin metabolism?--A systematic review. Diabet Med, 2003. 20(5): p. 339-48.

17. Ornoy, A., Prenatal origin of obesity and their complications: Gestational diabetes, maternal overweight and the paradoxical effects of fetal growth restriction and macrosomia. Reprod Toxicol, 2011. 32(2): p. 205-12.

18. Rogers, I. and Group, E.-B.S., The influence of birthweight and intrauterine environment on adiposity and fat distribution in later life. Int J Obes Relat Metab Disord, 2003. 27(7): p. 755-77.

19. Johnston, L.B., Clark, A.J., and Savage, M.O., Genetic factors contributing to birth weight. Arch Dis Child Fetal Neonatal Ed, 2002. 86(1): p. F2-3.

20. Spencer, N. and Logan, S., Social influences on birth weight. Arch Dis Child Fetal Neonatal Ed, 2002. 86(1): p. F6-7.

21. Stephenson, T. and Symonds, M.E., Maternal nutrition as a determinant of birth weight. Arch Dis Child Fetal Neonatal Ed, 2002. 86(1): p. F4-6. 
22. He, X.J., Qin, F.Y., Hu, C.L., Zhu, M., Tian, C.Q., and Li, L., Is gestational diabetes mellitus an independent risk factor for macrosomia: a meta-analysis? Arch Gynecol Obstet, 2015. 291(4): p. 72935.

23. Dai, R.X., He, X.J., and Hu, C.L., Maternal pre-pregnancy obesity and the risk of macrosomia: a metaanalysis. Arch Gynecol Obstet, 2018. 297(1): p. 139-145.

24. Araujo Junior, E., Peixoto, A.B., Zamarian, A.C., Elito Junior, J., and Tonni, G., Macrosomia. Best Pract Res Clin Obstet Gynaecol, 2017. 38: p. 83-96.

25. Anderson, N.H., Sadler, L.C., Stewart, A.W., Fyfe, E.M., and McCowan, L.M., Independent risk factors for infants who are small for gestational age by customised birthweight centiles in a multi-ethnic New Zealand population. Aust N Z J Obstet Gynaecol, 2013. 53(2): p. 136-42.

26. McCowan, L.M., Roberts, C.T., Dekker, G.A., Taylor, R.S., Chan, E.H., Kenny, L.C., et al., Risk factors for small-for-gestational-age infants by customised birthweight centiles: data from an international prospective cohort study. BJOG, 2010. 117(13): p. 1599-607.

27. Steyerberg, E.W., Vickers, A.J., Cook, N.R., Gerds, T., Gonen, M., Obuchowski, N., et al., Assessing the performance of prediction models: a framework for traditional and novel measures. Epidemiology, 2010. 21(1): p. 128-38.

28. Boucoiran, I., Djemli, A., Taillefer, C., Rypens, F., Delvin, E., and Audibert, F., First-trimester prediction of birth weight. Am J Perinatol, 2013. 30(8): p. 665-72.

29. Crovetto, F., Triunfo, S., Crispi, F., Rodriguez-Sureda, V., Dominguez, C., Figueras, F., et al., Differential performance of first-trimester screening in predicting small-for-gestational-age neonate or fetal growth restriction. Ultrasound Obstet Gynecol, 2017. 49(3): p. 349-356.

30. Frick, A.P., Syngelaki, A., Zheng, M., Poon, L.C., and Nicolaides, K.H., Prediction of large-forgestational-age neonates: screening by maternal factors and biomarkers in the three trimesters of pregnancy. Ultrasound Obstet Gynecol, 2016. 47(3): p. 332-9.

31. Gonzalez Gonzalez, N.L., Plasencia, W., Gonzalez Davila, E., Padron, E., di Renzo, G.C., and Bartha, J.L., First and second trimester screening for large for gestational age infants. J Matern Fetal Neonatal Med, 2013. 26(16): p. 1635-40.

32. Gonzalez-Gonzalez, N.L., Gonzalez-Davila, E., Gonzalez Marrero, L., Padron, E., Conde, J.R., and Plasencia, W., Value of placental volume and vascular flow indices as predictors of intrauterine growth retardation. Eur J Obstet Gynecol Reprod Biol, 2017. 212: p. 13-19.

33. Karagiannis, G., Akolekar, R., Sarquis, R., Wright, D., and Nicolaides, K.H., Prediction of small-forgestation neonates from biophysical and biochemical markers at 11-13 weeks. Fetal Diagn Ther, 2011. 29(2): p. 148-54.

34. Leal, A.M., Poon, L.C., Frisova, V., Veduta, A., and Nicolaides, K.H., First-trimester maternal serum tumor necrosis factor receptor-1 and pre-eclampsia. Ultrasound Obstet Gynecol, 2009. 33(2): p. 13541.

35. McCowan, L.M., Thompson, J.M., Taylor, R.S., Baker, P.N., North, R.A., Poston, L., et al., Prediction of Small for Gestational Age Infants in Healthy Nulliparous Women Using Clinical and Ultrasound Risk Factors Combined with Early Pregnancy Biomarkers. PLoS One, 2017. 12(1): p. e0169311.

36. Nanda, S., Akolekar, R., Sarquis, R., Mosconi, A.P., and Nicolaides, K.H., Maternal serum adiponectin at 11 to 13 weeks of gestation in the prediction of macrosomia. Prenat Diagn, 2011. 31(5): p. 479-83.

37. Onwudiwe, N., Yu, C.K., Poon, L.C., Spiliopoulos, I., and Nicolaides, K.H., Prediction of pre-eclampsia by a combination of maternal history, uterine artery Doppler and mean arterial pressure. Ultrasound Obstet Gynecol, 2008. 32(7): p. 877-83.

38. Papastefanou, I., Souka, A.P., Pilalis, A., Eleftheriades, M., Michalitsi, V., and Kassanos, D., First trimester prediction of small- and large-for-gestation neonates by an integrated model incorporating ultrasound parameters, biochemical indices and maternal characteristics. Acta Obstet Gynecol Scand, 2012. 91(1): p. 104-11.

39. Plasencia, W., Akolekar, R., Dagklis, T., Veduta, A., and Nicolaides, K.H., Placental volume at 11-13 weeks' gestation in the prediction of birth weight percentile. Fetal Diagn Ther, 2011. 30(1): p. 23-8.

40. Plasencia, W., Gonzalez Davila, E., Tetilla, V., Padron Perez, E., Garcia Hernandez, J.A., and Gonzalez Gonzalez, N.L., First-trimester screening for large-for-gestational-age infants. Ultrasound Obstet Gynecol, 2012. 39(4): p. 389-95.

41. Poon, L.C., Karagiannis, G., Stratieva, V., Syngelaki, A., and Nicolaides, K.H., First-trimester prediction of macrosomia. Fetal Diagn Ther, 2011. 29(2): p. 139-47. 
42. Poon, L.C., Chelemen, T., Granvillano, O., Pandeva, I., and Nicolaides, K.H., First-trimester maternal serum a disintegrin and metalloprotease 12 (ADAM12) and adverse pregnancy outcome. Obstet Gynecol, 2008. 112(5): p. 1082-90.

43. Poon, L.C., Karagiannis, G., Staboulidou, I., Shafiei, A., and Nicolaides, K.H., Reference range of birth weight with gestation and first-trimester prediction of small-for-gestation neonates. Prenat Diagn, 2011. 31(1): p. 58-65.

44. Poon, L.C., Zaragoza, E., Akolekar, R., Anagnostopoulos, E., and Nicolaides, K.H., Maternal serum placental growth factor (PIGF) in small for gestational age pregnancy at $11(+0)$ to $13(+6)$ weeks of gestation. Prenat Diagn, 2008. 28(12): p. 1110-5.

45. Schneuer, F.J., Roberts, C.L., Ashton, A.W., Guilbert, C., Tasevski, V., Morris, J.M., et al., Angiopoietin 1 and 2 serum concentrations in first trimester of pregnancy as biomarkers of adverse pregnancy outcomes. Am J Obstet Gynecol, 2014. 210(4): p. 345 e1-345 e9.

46. Steyerberg, E.W., Moons, K.G., van der Windt, D.A., Hayden, J.A., Perel, P., Schroter, S., et al., Prognosis Research Strategy (PROGRESS) 3: prognostic model research. PLoS Med, 2013. 10(2): p. e1001381.

47. Steyerberg, E.W. and Vergouwe, Y., Towards better clinical prediction models: seven steps for development and an ABCD for validation. Eur Heart J, 2014. 35(29): p. 1925-31.

48. Meertens, L.J.E., Scheepers, H.C., De Vries, R.G., Dirksen, C.D., Korstjens, I., Mulder, A.L., et al., External Validation Study of First Trimester Obstetric Prediction Models (Expect Study I): Research Protocol and Population Characteristics. JMIR Res Protoc, 2017. 6(10): p. e203.

49. Visser, G.H., Eilers, P.H., Elferink-Stinkens, P.M., Merkus, H.M., and Wit, J.M., New Dutch reference curves for birthweight by gestational age. Early Hum Dev, 2009. 85(12): p. 737-44.

50. Vergouwe, Y., Steyerberg, E.W., Eijkemans, M.J., and Habbema, J.D., Substantial effective sample sizes were required for external validation studies of predictive logistic regression models. J Clin Epidemiol., 2005. 58(5): p. 475-83.

51. Van Buuren, S., Flexible imputation of missing data. 2012: CRC press.

52. Steyerberg, E., Clinical prediction models: a practical approach to development, validation, and updating. 2008: Springer Science \& Business Media.

53. Vickers, A.J. and Elkin, E.B., Decision curve analysis: a novel method for evaluating prediction models. Med Decis Making, 2006. 26(6): p. 565-74.

54. Steyerberg, E.W. and Vickers, A.J., Decision curve analysis: a discussion. Med Decis Making, 2008. 28(1): p. 146-9.

55. Schwartz, N., Pessel, C., Coletta, J., Krieger, A.M., and Timor-Tritsch, I.E., Early biometric lag in the prediction of small for gestational age neonates and preeclampsia. J Ultrasound Med, 2011. 30(1): p. 55-60.

56. de Caunes, F., Alexander, G.R., Berchel, C., Guengant, J.P., and Papiernik, E., Anamnestic pregnancy risk assessment. Int J Gynaecol Obstet, 1990. 33(3): p. 221-7.

57. Macdonald-Wallis, C., Silverwood, R.J., de Stavola, B.L., Inskip, H., Cooper, C., Godfrey, K.M., et al., Antenatal blood pressure for prediction of pre-eclampsia, preterm birth, and small for gestational age babies: development and validation in two general population cohorts. BMJ, 2015. 351: p. h5948.

58. Syngelaki, A., Bredaki, F.E., Vaikousi, E., Maiz, N., and Nicolaides, K.H., Body mass index at 11-13 weeks' gestation and pregnancy complications. Fetal Diagn Ther, 2011. 30(4): p. 250-65.

59. Seed, P.T., Chappell, L.C., Black, M.A., Poppe, K.K., Hwang, Y.C., Kasabov, N., et al., Prediction of preeclampsia and delivery of small for gestational age babies based on a combination of clinical risk factors in high-risk women. Hypertens Pregnancy, 2011. 30(1): p. 58-73.

60. Crovetto, F., Crispi, F., Scazzocchio, E., Mercade, I., Meler, E., Figueras, F., et al., First-trimester screening for early and late small-for-gestational-age neonates using maternal serum biochemistry, blood pressure and uterine artery Doppler. Ultrasound Obstet Gynecol, 2014. 43(1): p. 34-40.

61. Poon, L.C., Syngelaki, A., Akolekar, R., Lai, J., and Nicolaides, K.H., Combined screening for preeclampsia and small for gestational age at 11-13 weeks. Fetal Diagn Ther, 2013. 33(1): p. 16-27.

62. Berntorp, K., Anderberg, E., Claesson, R., Ignell, C., and Kallen, K., The relative importance of maternal body mass index and glucose levels for prediction of large-for-gestational-age births. BMC Pregnancy Childbirth, 2015. 15: p. 280. 
63. Mlynarczyk, M., Chauhan, S.P., Baydoun, H.A., Wilkes, C.M., Earhart, K.R., Zhao, Y., et al., The clinical significance of an estimated fetal weight below the 10th percentile: a comparison of outcomes of $<5$ th vs 5th-9th percentile. Am J Obstet Gynecol, 2017. 217(2): p. 198 e1-198 e11.

64. Nardozza, L.M., Caetano, A.C., Zamarian, A.C., Mazzola, J.B., Silva, C.P., Marcal, V.M., et al., Fetal growth restriction: current knowledge. Arch Gynecol Obstet, 2017. 295(5): p. 1061-1077.

65. Mayer, C. and Joseph, K.S., Fetal growth: a review of terms, concepts and issues relevant to obstetrics. Ultrasound Obstet Gynecol, 2013. 41(2): p. 136-45.

66. Al-Rubaie, Z., Askie, L.M., Ray, J.G., Hudson, H.M., and Lord, S.J., The performance of risk prediction models for pre-eclampsia using routinely collected maternal characteristics and comparison with models that include specialised tests and with clinical guideline decision rules: a systematic review. BJOG, 2016. 123(9): p. 1441-52.

67. Lamain - de Ruiter, M., Kwee, A., Naaktgeboren, C.A., Franx, A., Moons, K.G.M., and Koster, M.P.H., Prediction models for the risk of gestational diabetes: a systematic review. Diag Progn Res, 2017. 1(3).

68. Meher, S., Duley, L., Hunter, K., and Askie, L., Antiplatelet therapy before or after 16 weeks' gestation for preventing preeclampsia: an individual participant data meta-analysis. Am J Obstet Gynecol, 2017. 216(2): p. 121-128 e2.

69. Roberge, S., Nicolaides, K., Demers, S., Hyett, J., Chaillet, N., and Bujold, E., The role of aspirin dose on the prevention of preeclampsia and fetal growth restriction: systematic review and meta-analysis. Am J Obstet Gynecol, 2017. 216(2): p. 110-120 e6.

70. Groom, K.M. and David, A.L., The role of aspirin, heparin, and other interventions in the prevention and treatment of fetal growth restriction. Am J Obstet Gynecol, 2018. 218(2S): p. S829-S840.

71. Audette, M.C. and Kingdom, J.C., Screening for fetal growth restriction and placental insufficiency. Semin Fetal Neonatal Med, 2018. 23(2): p. 119-125.

72. Lindqvist, P.G. and Molin, J., Does antenatal identification of small-for-gestational age fetuses significantly improve their outcome? Ultrasound Obstet Gynecol, 2005. 25(3): p. 258-64.

73. Bond, D.M., Gordon, A., Hyett, J., de Vries, B., Carberry, A.E., and Morris, J., Planned early delivery versus expectant management of the term suspected compromised baby for improving outcomes. Cochrane Database Syst Rev, 2015(11): p. CD009433.

74. Gardosi, J., Madurasinghe, V., Williams, M., Malik, A., and Francis, A., Maternal and fetal risk factors for stillbirth: population based study. BMJ, 2013. 346: p. f108.

75. Boulvain, M., Irion, O., Dowswell, T., and Thornton, J.G., Induction of labour at or near term for suspected fetal macrosomia. Cochrane Database Syst Rev, 2016(5): p. CD000938.

76. Magro-Malosso, E.R., Saccone, G., Chen, M., Navathe, R., Di Tommaso, M., and Berghella, V., Induction of labour for suspected macrosomia at term in non-diabetic women: a systematic review and meta-analysis of randomized controlled trials. BJOG, 2017. 124(3): p. 414-421.

77. Plasencia, W., Maiz, N., Bonino, S., Kaihura, C., and Nicolaides, K.H., Uterine artery Doppler at $11+0$ to $13+6$ weeks in the prediction of pre-eclampsia. Ultrasound Obstet Gynecol, 2007. 30(5): p. 742-9. 
Supplementary Table S5.1 Definition and assessment predictors included prediction models for small-forgestational-age

\begin{tabular}{|c|c|c|}
\hline Predictor & $\begin{array}{l}\text { Definition (D)/measurement (M) } \\
\text { original studies }\end{array}$ & $\begin{array}{l}\text { Definition/measurement validation } \\
\text { cohort (Expect Study I) }\end{array}$ \\
\hline Age & $\begin{array}{l}\text { MacDonald-Wallis } 2015 \\
\text { D: Maternal age over } 35 \text { years, } \\
\text { categorical. } \\
\text { M: Obstetric records. } \\
\text { Syngelaki } 2011 \text {, Poon } 2011 \\
\text { D: Continuous in years. } \\
\text { M: Self-reported questionnaire } 11^{+0} \text { - } \\
13^{+6} \text { weeks of gestation. }\end{array}$ & $\begin{array}{l}\text { Self-reported pregnancy questionnaire } \\
1 \text { and checked for discrepancies by } \\
\text { obstetric record. Measured continuous } \\
\text { in years, transformed into categorical } \\
\text { variable according to definition original } \\
\text { prediction model. }\end{array}$ \\
\hline $\begin{array}{l}\text { Blood pressure } \\
\text { measurement }\end{array}$ & $\begin{array}{l}\text { MacDonald-Wallis } 2015 \\
\text { D: The first antenatal measurement of } \\
\text { MAP, continuous, provided that this } \\
\text { occurred before } 18 \text { weeks of gestation. } \\
\text { M: Obstetric records. } \\
\text { Seed } 2011 \\
\text { D: Systolic blood pressure, categorical } \\
>105 \mathrm{mmHg} \text { and }>130 \mathrm{mmHg} \text {. } \\
\text { M: Interview trial midwife at } 14^{+0}-21^{+6} \\
\text { weeks of gestation. }\end{array}$ & $\begin{array}{l}\text { Blood pressure (systolic and diastolic, } \\
\mathrm{mmHg} \text { ) was measured by the } \\
\text { gynaecologist or midwife following } \\
\text { standard procedure before } 16 \text { weeks of } \\
\text { gestation. The results of these } \\
\text { measurements were provided to the } \\
\text { eligible women in order to self-report } \\
\text { in pregnancy questionnaire } 1 \text {. Systolic } \\
\text { blood pressure was transformed into } \\
\text { categorical variable according to } \\
\text { definition original prediction model. } \\
\text { MAP was calculated as ((systolic blood } \\
\text { pressure) }+(2 * \text { diastolic blood } \\
\text { pressure)) } / 3 \text {. }\end{array}$ \\
\hline \multirow[t]{3}{*}{ Body mass index } & $\begin{array}{l}\text { MacDonald-Wallis } 2015 \\
\text { D: Four categories: underweight } \\
\left(<18.5 \mathrm{~kg} / \mathrm{m}^{2}\right) \text {, normal weight }(18.5- \\
\left.24.9 \mathrm{~kg} / \mathrm{m}^{2}\right) \text {, overweight }(25-29.9 \\
\left.\mathrm{kg} / \mathrm{m}^{2}\right) \text { and obese }\left(\geq 30 \mathrm{~kg} / \mathrm{m}^{2}\right) . \\
\text { M: Derived from self-reported } \\
\text { maternal height and pre-pregnancy } \\
\text { weight from a questionnaire } \\
\text { administered in pregnancy. }\end{array}$ & $\begin{array}{l}\text { Self-reported pregnancy questionnaire } \\
1 \text {, height in centimetres and pre- } \\
\text { pregnancy weight in kilograms. Body } \\
\text { mass index was calculated as weight } \\
\text { (kilograms) divided by the squared } \\
\text { height (meters). Categorical variables } \\
\text { generated according to definition } \\
\text { original prediction model. }\end{array}$ \\
\hline & $\begin{array}{l}\text { Syngelaki } 2011 \\
\mathrm{D}: \text { Continuous in } \mathrm{kg} / \mathrm{m}^{2} \text {. } \\
\mathrm{M} \text { : Height and weight measured at } \\
\text { routine assessment at } 11^{+0}-13^{+6} \text { weeks } \\
\text { of gestation. }\end{array}$ & \\
\hline & $\begin{array}{l}\text { Seed } 2011 \\
\text { D: Body mass index category }>35 \\
\mathrm{~kg} / \mathrm{m}^{2} \text {. } \\
\mathrm{M}: \text { Measured at interview trial midwife } \\
\text { at } 14^{+0}-21^{+6} \text { weeks of gestation. }\end{array}$ & \\
\hline
\end{tabular}


Supplementary Table S5.1 (continued) Definition and assessment predictors included prediction models for small-for-gestational-age

\begin{tabular}{|c|c|c|}
\hline Predictor & $\begin{array}{l}\text { Definition (D)/measurement (M) } \\
\text { original studies }\end{array}$ & $\begin{array}{l}\text { Definition/measurement validation } \\
\text { cohort (Expect Study I) }\end{array}$ \\
\hline Chronic hypertension & $\begin{array}{l}\text { MacDonald-Wallis } 2015 \\
\text { D: Having previously had hypertension } \\
\text { outside of pregnancy. } \\
\text { M: Self-reported in a questionnaire } \\
\text { administered in pregnancy. }\end{array}$ & $\begin{array}{l}\text { Self-reported pregnancy questionnaire } \\
1 \text {, chronic hypertension. }\end{array}$ \\
\hline
\end{tabular}

Syngelaki 2011, Poon 2011

D: History of chronic hypertension. $\mathrm{M}$ : Self-reported questionnaire $11^{+0}$ $13^{+6}$ weeks of gestation.

Diabetes Mellitus González González 2017

Self-reported pregnancy questionnaire D: Pre-gestational diabetes mellitus. 1 , pre-existing diabetes mellitus (type). M: Recorded prior to ultrasound at $11+$ 0 to $13+6$ weeks of pregnancy.

Syngelaki 2011

D: History of type 1 or 2 diabetes mellitus.

M: Self-reported questionnaire $11^{+0}$ $13^{+6}$ weeks of gestation.

Ethnicity MacDonald-Wallis 2015

D: All ethnicities other than 'white' were classed as 'non-white'. $M$ : Self-reported in a questionnaire administered during pregnancy.

\section{Boucoiran 2013}

D: Afro-Caribbean origin.

M: Prenatal database.

Self-reported pregnancy questionnaire 1, ethnicity was divided into ten subgroups: Dutch, Turkish/Kurdish, Moroccan (Moroccan, Algerian, North African), African (African, Surinamese/Antillean of Negroid origin), Hindustani (Hindustani, Pakistani, Indian, Surinamese / Antillean of Hindu origin), Middle East

Poon 2011, Syngelaki 2011 (Iran, Iraqi, Afghan), Asian (Chinese, Japanese, Indonesian, Albanian, D: Racial origin (Caucasian, AfroVietnamese), Other Western Caribbean, South Asian, East Asian, and (European, North American, mixed). M: Self-reported questionnaire $11^{+0}$ $13^{+6}$ weeks of gestation.

Australian), Other Non-Western (South and Central American), and mixed. Ethnicity was recoded to Caucasian, Asian, Afro-Caribbean, Hispanic, and

$\underline{\text { Seed } 2011}$

D: Indian, Bangladeshi, Pakistani, African, or Afro-Caribbean. $\mathrm{M}$ : Interview trial midwife at $14^{+0}-21^{+6}$ mixed (combination of other categories). Subdivision of Asian ethnicity was based on country of birth weeks of gestation.

MacDonald-Wallis 2015: We classed 'non-white' as all ethnicities other than Caucasian.

Poon 2011: We added women with an Asian ethnicity other than South Asian or East Asian to the category mixed. Hispanics were categorized as Caucasians. 
Supplementary Table S5.1 (continued) Definition and assessment predictors included prediction models for small-for-gestational-age

\begin{tabular}{|c|c|c|}
\hline Predictor & $\begin{array}{l}\text { Definition (D)/measurement (M) } \\
\text { original studies }\end{array}$ & $\begin{array}{l}\text { Definition/measurement validation } \\
\text { cohort (Expect Study I) }\end{array}$ \\
\hline Folic acid use & $\begin{array}{l}\text { Seed } 2011 \\
\text { D: Use of folate supplements at } \\
\text { booking visit. Women taking folate } \\
\text { only in multivitamins were included as } \\
\text { taking folate supplements. } \\
\text { M: Interview trial midwife at } 14^{+0}-21^{+6} \\
\text { weeks of gestation. }\end{array}$ & $\begin{array}{l}\text { Self-reported pregnancy questionnaire } \\
1 \text {, separate questions on current use of } \\
\text { folic acid supplements and } \\
\text { multivitamins. }\end{array}$ \\
\hline Height & $\begin{array}{l}\text { MacDonald-Wallis } 2015 \\
\text { D: Continuous in centimetres. } \\
\text { M: Derived from self-reported } \\
\text { maternal height from a questionnaire } \\
\text { administered in pregnancy. } \\
\text { Poon } 2011 \\
\text { D: Continuous in centimetres. } \\
\text { M: Height measured at routine } \\
\text { assessment at } 11^{+0}-13^{+6} \text { weeks of } \\
\text { gestation. }\end{array}$ & $\begin{array}{l}\text { Self-reported pregnancy questionnaire } \\
1 \text {, height in centimetres. }\end{array}$ \\
\hline $\begin{array}{l}\text { History of gestational } \\
\text { diabetes mellitus }\end{array}$ & $\begin{array}{l}\text { MacDonald-Wallis } 2015 \\
\text { D: Having previously had diabetes but } \\
\text { only in pregnancy. } \\
\text { M: Self-reported in a questionnaire } \\
\text { administered in pregnancy. }\end{array}$ & $\begin{array}{l}\text { Self-reported pregnancy questionnaire } \\
1 \text {, gestational diabetes in previous } \\
\text { pregnancy. }\end{array}$ \\
\hline History of pre-eclampsia & $\begin{array}{l}\frac{\text { Seed } 2011}{\text { D: Previous pre-eclampsia. }} \\
\text { M: Interview trial midwife at } 14^{+0}-21^{+6} \\
\text { weeks of gestation. }\end{array}$ & $\begin{array}{l}\text { Self-reported pregnancy questionnaire } \\
1 \text {, separate questions on history of pre- } \\
\text { eclampsia, HELLP syndrome, and } \\
\text { eclampsia. History of pre-eclampsia } \\
\text { was defined as pre-eclampsia, HELLP } \\
\text { syndrome or eclampsia in a previous } \\
\text { pregnancy. }\end{array}$ \\
\hline $\begin{array}{l}\text { History of pregnancy } \\
\text { induced hypertension }\end{array}$ & $\begin{array}{l}\text { MacDonald-Wallis } 2015 \\
\text { D: Having previously had hypertension } \\
\text { but only in pregnancy. } \\
\text { M: Self-reported in a questionnaire } \\
\text { administered in pregnancy. }\end{array}$ & $\begin{array}{l}\text { Self-reported pregnancy questionnaire } \\
1 \text {, hypertension in previous pregnancy, } \\
\text { no chronic hypertension. }\end{array}$ \\
\hline $\begin{array}{l}\text { History of small-for- } \\
\text { gestational-age }\end{array}$ & $\begin{array}{l}\text { Syngelaki } 2011 \text {, Poon } 2011 \\
\text { D: Previous history of small-for- } \\
\text { gestational-age }\left(<5^{\text {th }} \text { percentile). }\right. \\
\text { M: Self-reported questionnaire } 11^{+0}- \\
13^{+6} \text { weeks of gestation. }\end{array}$ & $\begin{array}{l}\text { Self-reported pregnancy questionnaire } \\
1 \text {, birth weight of each previous } \\
\text { pregnancy. The percentile was } \\
\text { calculated corrected for gestational } \\
\text { age, ethnicity, gender, and parity [1]. } \\
\text { Percentile transformed into categorical } \\
\text { variable according to definition original } \\
\text { prediction model. }\end{array}$ \\
\hline
\end{tabular}


Supplementary Table S5.1 (continued) Definition and assessment predictors included prediction models for small-for-gestational-age

\begin{tabular}{|c|c|c|}
\hline Predictor & $\begin{array}{l}\text { Definition (D)/measurement (M) } \\
\text { original studies }\end{array}$ & $\begin{array}{l}\text { Definition/measurement validation } \\
\text { cohort (Expect Study I) }\end{array}$ \\
\hline Method of conception & $\begin{array}{l}\frac{\text { Poon } 2011}{\mathrm{D}: \text { Assisted conception requiring the }} \\
\text { use of ovulation drugs. } \\
\mathrm{M}: \text { Self-reported questionnaire } 11^{+0}- \\
13^{+6} \text { weeks of gestation. } \\
\text { Syngelaki } 2011 \\
\text { D: Method of conception (spontaneous } \\
\text { or assisted). } \\
\mathrm{M}: \text { Self-reported questionnaire } 11^{+0}- \\
13^{+6} \text { weeks of gestation. }\end{array}$ & $\begin{array}{l}\text { Self-reported pregnancy questionnaire } \\
1 \text {, method of conception (spontaneous, } \\
\text { use of ovulation drugs or in vitro } \\
\text { fertilization). }\end{array}$ \\
\hline Parity & $\begin{array}{l}\frac{\text { González González } 2017}{\text { D: Parous or nulliparous if no previous }} \\
\text { conception or pregnancy progressing } \\
\text { beyond } 23 \text { weeks. } \\
\text { M: Recorded prior to ultrasound at } 11+ \\
0 \text { to } 13+6 \text { weeks of pregnancy. } \\
\text { MacDonald-Wallis } 2015 \\
\text { D: Primiparae and multiparous (parity } \\
\text { of } 2 \text { or more). } \\
\text { M: Self-reported in a questionnaire } \\
\text { administered in pregnancy. }\end{array}$ & $\begin{array}{l}\text { Self-reported pregnancy questionnaire } \\
1 \text { and checked for discrepancies by } \\
\text { obstetric record. } \\
\text { The Dutch definition was used: every } \\
\text { delivery from } 16 \text { weeks of gestation. }\end{array}$ \\
\hline Smoking & $\begin{array}{l}\text { González González } 2017 \\
\text { D: Smoking status during pregnancy. } \\
\text { M: Recorded prior to ultrasound at } 11+ \\
0 \text { to } 13+6 \text { weeks of pregnancy. } \\
\text { MacDonald-Wallis } 2015 \\
\text { D: Smoking during pregnancy was } \\
\text { classed as 'never' or 'any smoking' for } \\
\text { women who reported smoking either in } \\
\text { the first three months of pregnancy or } \\
\text { within two weeks of the } 18 \text { week } \\
\text { questionnaire. } \\
\text { M: Self-reported in a questionnaire at } \\
18 \text { weeks of gestation. } \\
\text { Boucoiran } 2013 \\
\text { D: Smoking status. } \\
\text { M: Prenatal database. } \\
\text { Syngelaki } 2011, \text { Poon } 2011 \\
\text { D: Cigarette smoking during pregnancy. } \\
\text { M: Self-reported questionnaire } 11^{+0}- \\
13^{+6} \text { weeks of gestation. } \\
\text { Seed } 2011 \\
\text { D: Smoking at recruitment. } \\
\text { M: Interview trial midwife at } 14^{+0}-21^{+6} \\
\text { weeks of gestation. }\end{array}$ & $\begin{array}{l}\text { Self-reported pregnancy questionnaire } \\
1 \text {, cigarette smoking status (non- } \\
\text { smoker, stopped during pregnancy, } \\
\text { current smokers) and number of } \\
\text { cigarettes a day. } \\
\text { Smoking status was recoded to } \\
\text { definition original prediction model. } \\
\text { González González 2017, Boucoiran } \\
\text { 2013, Syngelaki 2011, Poon 2011: We } \\
\text { defined cigarette smoking as current } \\
\text { smoker at completion pregnancy } \\
\text { questionnaire } 1 .\end{array}$ \\
\hline
\end{tabular}


Supplementary Table S5.1 (continued) Definition and assessment predictors included prediction models for small-for-gestational-age

\begin{tabular}{lll}
\hline Predictor & $\begin{array}{l}\text { Definition (D)/measurement (M) } \\
\text { original studies }\end{array}$ & $\begin{array}{l}\text { Definition/measurement validation } \\
\text { cohort (Expect Study I) }\end{array}$ \\
\hline Weight & Boucoiran 2013 & $\begin{array}{l}\text { Self-reported pregnancy questionnaire } \\
1, \text { pre-pregnancy weight in kilograms. }\end{array}$ \\
\hline $\begin{array}{l}\text { D: Weight (kg). } \\
\text { M: Prenatal database. }\end{array}$ & \\
& $\begin{array}{l}\text { Poon } 2011 \\
\text { D: Continuous in kg. } \\
\text { M: Height measured at routine } \\
\text { assessment at } 11^{+0}-13^{+6} \text { weeks of } \\
\text { gestation. }\end{array}$ \\
\hline
\end{tabular}

HELLP, hemolysis, elevated liver enzymes and low platelets; MAP, mean arterial pressure

Supplementary Table S5.2 Definition and assessment predictors included prediction models for large-forgestational-age

\begin{tabular}{|c|c|c|}
\hline Predictor & $\begin{array}{l}\text { Definition (D)/measurement (M) } \\
\text { original studies }\end{array}$ & $\begin{array}{l}\text { Definition/measurement validation } \\
\text { cohort (Expect Study I) }\end{array}$ \\
\hline Age & $\begin{array}{l}\text { Plasencia } 2012 \\
\text { D: Maternal age in years. } \\
\text { M: Recorded prior to ultrasound at } 11+ \\
0 \text { to } 13+6 \text { weeks of pregnancy. } \\
\text { Syngelaki } 2011 \\
\text { D: Continuous in years. } \\
\text { M: Self-reported questionnaire } 11^{+0}- \\
13^{+6} \text { weeks of gestation. }\end{array}$ & $\begin{array}{l}\text { Self-reported pregnancy questionnaire } \\
1 \text { and checked for discrepancies by } \\
\text { obstetric record. Measured continuous } \\
\text { in years. }\end{array}$ \\
\hline Birth weight z-score & $\begin{array}{l}\text { Frick } 2016 \\
\text { D: Neonatal birth weight z-score } \\
\text { (corrected for gestational age at } \\
\text { delivery of previous pregnancy [1]. } \\
\text { M: Self-reported questionnaire } 11^{+0} \text { - } \\
13^{+6} \text { weeks of gestation. }\end{array}$ & $\begin{array}{l}\text { Self-reported pregnancy questionnaire } \\
1 \text {, birth weight of last pregnancy. The z- } \\
\text { score was calculated as birth weight } \\
\text { minus birth weight mean divided by the } \\
\text { standard deviation (SD), using birth } \\
\text { weight means and SDs from the Dutch } \\
\text { population standards corrected for } \\
\text { gestational age, ethnicity, gender, and } \\
\text { parity [1]. }\end{array}$ \\
\hline Body mass index & $\begin{array}{l}\text { Syngelaki } 2011 \\
\text { D: Continuous in } \mathrm{kg} / \mathrm{m}^{2} . \\
\text { M: Height and weight measured at } \\
\text { routine assessment at } 11^{+0}-13^{+6} \text { weeks } \\
\text { of gestation. }\end{array}$ & $\begin{array}{l}\text { Self-reported pregnancy questionnaire } \\
1 \text {, height in centimetres and pre- } \\
\text { pregnancy weight in kilograms. Body } \\
\text { mass index was calculated as weight } \\
\text { (kilograms) divided by the squared } \\
\text { height (meters). Categorical variables } \\
\text { generated according to definition } \\
\text { original prediction model. }\end{array}$ \\
\hline Chronic hypertension & $\begin{array}{l}\text { Frick } 2016 \text {, Syngelaki } 2011 \text {, Poon } 2011 \\
\text { D: History of chronic hypertension. } \\
\text { M: Self-reported questionnaire } 11^{+0}- \\
13^{+6} \text { weeks of gestation. }\end{array}$ & $\begin{array}{l}\text { Self-reported pregnancy questionnaire } \\
1 \text {, chronic hypertension. }\end{array}$ \\
\hline
\end{tabular}


Supplementary Table S5.2 (continued) Definition and assessment predictors included prediction models for large-for-gestational-age

\begin{tabular}{|c|c|c|}
\hline Predictor & $\begin{array}{l}\text { Definition (D)/measurement (M) } \\
\text { original studies }\end{array}$ & $\begin{array}{l}\text { Definition/measurement validation } \\
\text { cohort (Expect Study I) }\end{array}$ \\
\hline Diabetes mellitus & $\begin{array}{l}\text { Frick } 2016 \\
\text { D: History of type } 1 \text { diabetes mellitus. } \\
\text { M: Self-reported questionnaire } 11^{+0}- \\
13^{+6} \text { weeks of gestation. } \\
\text { Syngelaki } 2011 \text {, Poon } 2011 \\
\text { D: History of type } 1 \text { or } 2 \text { diabetes } \\
\text { mellitus. } \\
\text { M: Self-reported questionnaire } 11^{+0} \text { - } \\
13^{+6} \text { weeks of gestation. }\end{array}$ & $\begin{array}{l}\text { Self-reported pregnancy questionnaire } \\
1 \text {, pre-existing diabetes mellitus (type). }\end{array}$ \\
\hline Ethnicity & $\begin{array}{l}\text { Frick 2016, Syngelaki 2011, Nanda } \\
2011, \text { Poon } 2011 \\
\text { D: Racial origin (Caucasian, Afro- } \\
\text { Caribbean, South Asian, East Asian, and } \\
\text { mixed). } \\
\text { M: Self-reported questionnaire } 11^{+0}- \\
13^{+6} \text { weeks of gestation. }\end{array}$ & $\begin{array}{l}\text { Self-reported pregnancy questionnaire } \\
\text { 1, ethnicity was divided into ten } \\
\text { subgroups: Dutch, Turkish/Kurdish, } \\
\text { Moroccan (Moroccan, Algerian, North } \\
\text { African), African (African, } \\
\text { Surinamese/Antillean of Negroid } \\
\text { origin), Hindustani (Hindustani, } \\
\text { Pakistani, Indian, Surinamese / } \\
\text { Antillean of Hindu origin), Middle East } \\
\text { (Iran, Iraqi, Afghan), Asian (Chinese, } \\
\text { Japanese, Indonesian, Albanian, } \\
\text { Vietnamese), Other Western } \\
\text { (European, North American, } \\
\text { Australian), Other Non-Western (South } \\
\text { and Central American), and mixed. } \\
\text { Ethnicity was recoded to Caucasian, } \\
\text { Asian, Afro-Caribbean, Hispanic, and } \\
\text { mixed (combination of other } \\
\text { categories). Subdivision of Asian } \\
\text { ethnicity was based on country of birth } \\
\text { biological parents. We added women } \\
\text { with an Asian ethnicity other than } \\
\text { South Asian or East Asian to the } \\
\text { category mixed. Hispanics were } \\
\text { categorized as Caucasians. }\end{array}$ \\
\hline & & $\begin{array}{l}\text { Poon 2011: did not report the category } \\
\text { East Asian in their model although all } \\
\text { categories were included. We added } \\
\text { women with an Asian ethnicity other } \\
\text { than South Asian to the category } \\
\text { mixed. }\end{array}$ \\
\hline
\end{tabular}


Supplementary Table S5.2 (continued) Definition and assessment predictors included prediction models for large-for-gestational-age

\begin{tabular}{|c|c|c|}
\hline Predictor & $\begin{array}{l}\text { Definition (D)/measurement (M) } \\
\text { original studies }\end{array}$ & $\begin{array}{l}\text { Definition/measurement validation } \\
\text { cohort (Expect Study I) }\end{array}$ \\
\hline Height & $\begin{array}{l}\text { Frick 2016, Nanda } 2011, \text { Poon } 2011 \\
\text { D: Continuous in centimetres. } \\
\text { M: Height measured at routine } \\
\text { assessment at } 11^{+0}-13^{+6} \text { weeks of } \\
\text { gestation. } \\
\text { González González } 2013 \\
\text { D: Continuous in centimetres. } \\
\text { M: Recorded prior to ultrasound at } 11+ \\
0 \text { to } 13+6 \text { weeks of pregnancy. } \\
\text { Plasencia } 2012 \\
\text { D: Height in meters. } \\
\text { M: Recorded prior to ultrasound at } 11+ \\
0 \text { to } 13+6 \text { weeks of pregnancy. }\end{array}$ & $\begin{array}{l}\text { Self-reported pregnancy questionnaire } \\
1 \text {, height in centimetres. }\end{array}$ \\
\hline $\begin{array}{l}\text { History of gestational } \\
\text { diabetes mellitus }\end{array}$ & $\begin{array}{l}\text { Frick } 2016 \\
\text { D: Previous pregnancy with gestational } \\
\text { diabetes mellitus. } \\
\text { M: Self-reported questionnaire } 11^{+0} \text { - } \\
13^{+6} \text { weeks of gestation. }\end{array}$ & $\begin{array}{l}\text { Self-reported pregnancy questionnaire } \\
1 \text {, gestational diabetes in previous } \\
\text { pregnancy. }\end{array}$ \\
\hline $\begin{array}{l}\text { History of large-for- } \\
\text { gestational-age (LGA) }\end{array}$ & $\begin{array}{l}\text { Syngelaki } 2011, \text { Nanda } 2011 \\
\text { D: Obstetric history including the } \\
\text { outcome of each pregnancy. LGA was } \\
\text { defined as those with birth weight } \\
\text { above the } 95^{\text {th }} \text { percentile for gestation. } \\
\text { M: Self-reported questionnaire } 11^{+0}- \\
13^{+6} \text { weeks' gestation. } \\
\text { Poon } 2011 \\
\text { D: Obstetric history including the } \\
\text { outcome of each pregnancy. LGA was } \\
\text { defined as those with birth weight } \\
\text { above the } 90^{\text {th }} \text { percentile for gestation. } \\
\text { M: Self-reported questionnaire } 11^{+0}- \\
13^{+6} \text { weeks' gestation. }\end{array}$ & $\begin{array}{l}\text { Self-reported pregnancy questionnaire } \\
1 \text {, birth weight of each previous } \\
\text { pregnancy. The percentile was } \\
\text { calculated corrected for gestational } \\
\text { age, ethnicity, gender, and parity [1]. } \\
\text { Percentile transformed into categorical } \\
\text { variable according to definition original } \\
\text { prediction model. }\end{array}$ \\
\hline Interpregnancy interval & $\begin{array}{l}\text { Frick } 2016 \\
\text { D: Time interval between the last } \\
\text { delivery and conception of the current } \\
\text { pregnancy in years. } \\
\mathrm{M} \text { : Self-reported questionnaire } 11^{+0} \text { - } \\
13^{+6} \text { weeks of gestation. }\end{array}$ & $\begin{array}{l}\text { Self-reported pregnancy questionnaire } \\
1, \text { interval between date last delivery } \\
\text { and date of conception of the current } \\
\text { pregnancy. }\end{array}$ \\
\hline Method of conception & $\begin{array}{l}\text { Syngelaki } 2011 \\
\text { D: Method of conception (spontaneous } \\
\text { or assisted). } \\
\text { M: Self-reported questionnaire } 11^{+0} \text { - } \\
13^{+6} \text { weeks of gestation. }\end{array}$ & $\begin{array}{l}\text { Self-reported pregnancy questionnaire } \\
1 \text {, method of conception (spontaneous, } \\
\text { use of ovulation drugs or in vitro } \\
\text { fertilization). }\end{array}$ \\
\hline
\end{tabular}


Supplementary Table S5.2 (continued) Definition and assessment predictors included prediction models for large-for-gestational-age

\begin{tabular}{|c|c|c|}
\hline Predictor & $\begin{array}{l}\text { Definition }(\mathrm{D}) / \text { measurement }(\mathrm{M}) \\
\text { original studies }\end{array}$ & $\begin{array}{l}\text { Definition/measurement validation } \\
\text { cohort (Expect Study I) }\end{array}$ \\
\hline Parity & $\begin{array}{l}\frac{\text { Frick } 2016}{\text { D: Parous/nulliparous if no previous }} \\
\text { pregnancies } \geq 24 \text { weeks of gestation. } \\
\text { M: Self-reported questionnaire } 11^{+0}- \\
13^{+6} \text { weeks of gestation. } \\
\text { González González } 2013 \\
\text { D: Nulliparous versus parous. } \\
\text { M: Recorded prior to ultrasound at } 11+ \\
0 \text { to } 13+6 \text { weeks of pregnancy. } \\
\text { Plasencia } 2012 \\
\text { D: Nulliparous versus parous. } \\
\text { M: Recorded prior to ultrasound at } 11+ \\
0 \text { to } 13+6 \text { weeks of pregnancy. }\end{array}$ & $\begin{array}{l}\text { Self-reported pregnancy questionnaire } \\
1 \text { and checked for discrepancies by } \\
\text { obstetric record. } \\
\text { The Dutch definition was used: every } \\
\text { delivery from } 16 \text { weeks of gestation. }\end{array}$ \\
\hline Smoking & $\begin{array}{l}\text { Frick 2016, Syngelaki } 2011, \text { Nanda } \\
\frac{2011, \text { Poon } 2011}{\text { D: Cigarette smoking during pregnancy. }} \\
\text { M: Self-reported questionnaire } 11^{+0}- \\
13^{+6} \text { weeks of gestation. } \\
\text { González González } 2013 \\
\text { D: Cigarette smoker. } \\
\text { M: Recorded prior to ultrasound at } 11+ \\
0 \text { to } 13+6 \text { weeks of pregnancy. } \\
\text { Plasencia } 2012 \\
\text { D: Cigarette smoker. } \\
\text { M: Recorded prior to ultrasound at } 11+ \\
0 \text { to } 13+6 \text { weeks of pregnancy. }\end{array}$ & $\begin{array}{l}\text { Self-reported pregnancy questionnaire } \\
1 \text {, cigarette smoking status (non- } \\
\text { smoker, stopped during pregnancy, } \\
\text { current smokers) and number of } \\
\text { cigarettes a day. } \\
\text { We defined cigarette smoking as } \\
\text { current smoker at completion } \\
\text { pregnancy questionnaire } 1 .\end{array}$ \\
\hline Weight & $\begin{array}{l}\text { Frick } 2016, \text { Nanda } 2011, \text { Poon } 2011 \\
\text { D: Continuous in kg. } \\
\text { M: Height measured at routine } \\
\text { assessment at } 11^{+0}-13^{+6} \text { weeks of } \\
\text { gestation. } \\
\text { González González } 2013 \\
\text { D: Continuous in kg. } \\
\text { M: Recorded prior to ultrasound at } 11+ \\
0 \text { to } 13+6 \text { weeks of pregnancy. } \\
\text { Plasencia } 2012 \\
\text { D: Continuous in kg. } \\
\text { M: Recorded prior to ultrasound at } 11+ \\
0 \text { to } 13+6 \text { weeks of pregnancy. }\end{array}$ & $\begin{array}{l}\text { Self-reported pregnancy questionnaire } \\
1 \text {, pre-pregnancy weight in kilograms. }\end{array}$ \\
\hline
\end{tabular}

\section{References}

1. Visser GH, Eilers PH, Elferink-Stinkens PM, Merkus HM, Wit JM (2009) New Dutch reference curves for birthweight by gestational age. Early Hum Dev 85: 737-744 


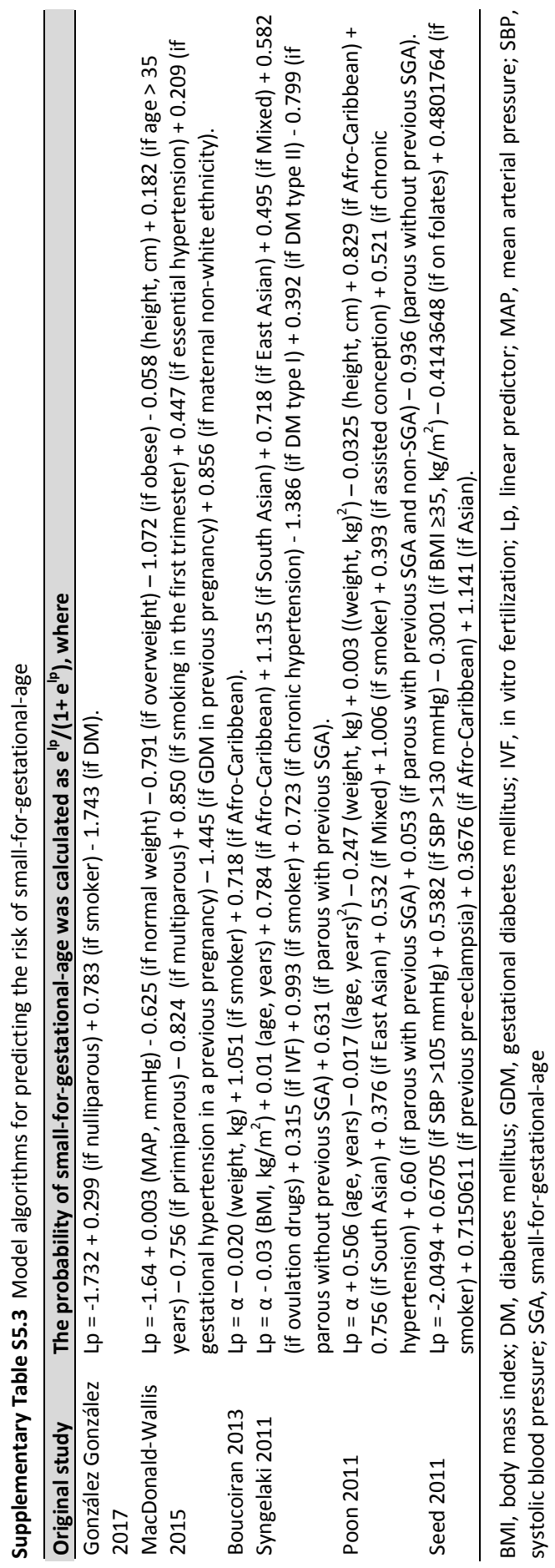




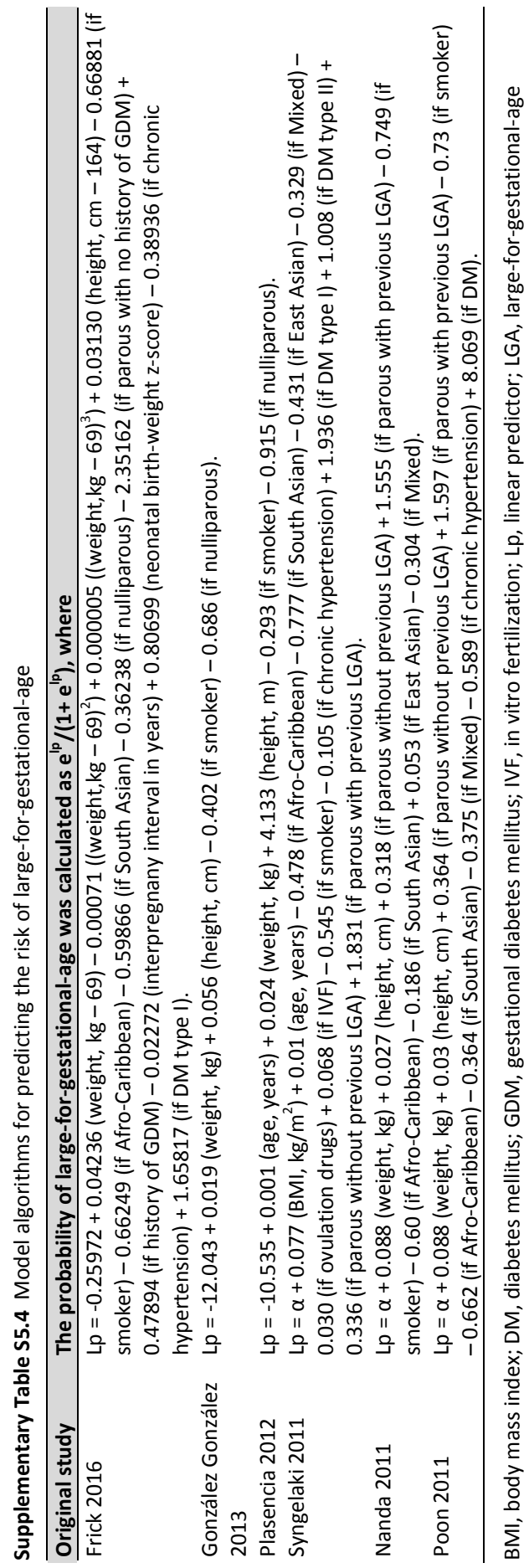


Supplementary Table S5.5 Characteristics of observed and imputed validation cohort

\begin{tabular}{|c|c|c|c|c|}
\hline Characteristics & $\begin{array}{c}\text { Missing } \\
\text { values, } \\
\text { n (\%) }\end{array}$ & $\begin{array}{c}\text { Observed } \\
\text { validation } \\
\text { cohort } \\
\text { Complete }^{\mathrm{a}}(\mathrm{n}=\mathbf{2 2 6 6 )}\end{array}$ & $\begin{array}{c}\text { Observed } \\
\text { validation } \\
\text { cohort } \\
\text { Women with } \\
\text { missing } \\
\text { value(s) } \\
\text { (n=316) }\end{array}$ & $\begin{array}{l}\text { Imputed } \\
\text { validation } \\
\text { cohort } \\
(n=2582)\end{array}$ \\
\hline Age, years & $0(0.0)$ & $30.2(3.9)$ & $30.0(4.1)$ & $30.2(3.9)$ \\
\hline Ethnicity & $0(0.0)$ & & & \\
\hline Caucasian & & 2207 (97.4) & $296(93.7)$ & 2503 (96.9) \\
\hline Afro-Caribbean & & $1(0.0)$ & $1(0.3)$ & $2(0.1)$ \\
\hline South Asian & & $2(0.1)$ & $2(0.6)$ & $4(0.2)$ \\
\hline East Asian & & $10(0.4)$ & $5(1.6)$ & $15(0.6)$ \\
\hline Other Asian & & $1(0.0)$ & $0(0.0)$ & $1(0.0)$ \\
\hline Hispanic & & $10(0.4)$ & $1(0.3)$ & $11(0.4)$ \\
\hline Mixed & & $35(1.5)$ & $11(3.5)$ & $46(1.8)$ \\
\hline Tertiary education* & $3(0.1)$ & $1275(56.3)$ & $128(40.5)$ & $1403(54.3)$ \\
\hline Height, $\mathrm{cm}$ & $3(0.1)$ & $168.9(6.4)$ & $167.8(6.4)$ & $168.8(6.4)$ \\
\hline Weight, kg & $4(0.2)$ & $69.0(13.0)$ & $67.8(12.8)$ & $68.9(13.0)$ \\
\hline Body mass index\#, $\mathrm{kg} / \mathrm{m}^{2}$ & $4(0.2)$ & $24.2(4.3)$ & $24.1(4.3)$ & $24.2(4.3)$ \\
\hline$<18.5$ & & $73(3.2)$ & $14(4.4)$ & $87(3.4)$ \\
\hline $18.5-24.9$ & & $1446(63.8)$ & $199(63.0)$ & $1648(63.8)$ \\
\hline $25.0-29.9$ & & $509(22.5)$ & $67(21.2)$ & $577(22.3)$ \\
\hline$\geq 30.0$ & & $238(10.5)$ & $32(10.1)$ & $270(10.5)$ \\
\hline Smoking & $1(0.0)$ & & & \\
\hline Ever $<16$ weeks' gestation & & $256(11.3)$ & $56(17.7)$ & $313(12.1)$ \\
\hline Current (at completion questionnaire) & & $124(5.5)$ & $28(8.9)$ & $153(5.9)$ \\
\hline Diabetes mellitus & $0(0.0)$ & $11(0.5)$ & $0(0.0)$ & $11(0.4)$ \\
\hline Type 1 & & $9(0.4)$ & & $9(0.3)$ \\
\hline Type 2 & & $1(0.0)$ & & $1(0.0)$ \\
\hline Other & & $1(0.0)$ & & $1(0.0)$ \\
\hline History of chronic hypertension & $0(0.0)$ & $22(1.0)$ & $5(1.6)$ & $27(1.0)$ \\
\hline Folate use at completion questionnaire & $3(0.1)$ & $1955(86.3)$ & $243(76.9)$ & $2201(85.2)$ \\
\hline Parity & $0(0.0)$ & & & \\
\hline Nulliparous & & $1156(51.0)$ & $155(49.1)$ & $1311(50.8)$ \\
\hline Primiparous & & $891(39.3)$ & $124(39.2)$ & 1015 (39.3) \\
\hline Multiparous & & $219(9.7)$ & $37(11.7)$ & $256(9.9)$ \\
\hline Conception & $0(0.0)$ & & & \\
\hline Spontaneous & & $2112(93.2)$ & $300(94.9)$ & $2412(93.4)$ \\
\hline Ovulation induction & & $83(3.7)$ & $9(2.8)$ & $92(3.6)$ \\
\hline IVF/ICSI & & $71(3.1)$ & $7(2.2)$ & $78(3.0)$ \\
\hline Interpregnancy interval, months & $11(0.4)$ & $28.4(23.4)$ & $33.4(29.2)$ & $29.1(24.5)$ \\
\hline \multicolumn{5}{|l|}{ History of SGA: } \\
\hline$<5^{\text {th }}$ percentile & $51(2.0)$ & $38(1.7)$ & $4(1.3)$ & 45 (1.7) \\
\hline$<10^{\text {th }}$ percentile* & $51(2.0)$ & $97(4.3)$ & $9(2.8)$ & $109(4.2)$ \\
\hline \multicolumn{5}{|l|}{ History of LGA: } \\
\hline$>90^{\text {th }}$ percentile & $51(2.0)$ & $156(6.9)$ & $11(3.5)$ & $168(6.5)$ \\
\hline$>95^{\text {th }}$ percentile & $51(2.0)$ & $83(3.7)$ & $6(1.9)$ & $90(3.5)$ \\
\hline Birth weight z-score previous pregnancy & 49 (1.9) & $0.17(1.0)$ & $-0.02(0.9)$ & $0.16(1.0)$ \\
\hline History of pregnancy induced hypertension & $18(0.7)$ & $103(4.5)$ & $11(3.5)$ & $114(4.4)$ \\
\hline History of pre-eclampsia* & $18(0.7)$ & $58(2.6)$ & $13(4.1)$ & $71(2.7)$ \\
\hline History of gestational diabetes mellitus & $19(0.7)$ & $14(0.6)$ & $0(0.0)$ & $14(0.5)$ \\
\hline Systolic blood pressure, $\mathrm{mmHg}$ & $257(10.0)$ & $114.4(12.4)$ & $111.4(11.9)$ & $114.4(12.4)$ \\
\hline Diastolic blood pressure, $\mathrm{mmHg} *$ & $267(10.3)$ & $67.6(8.5)$ & $66.3(9.2)$ & $67.6(8.5)$ \\
\hline Mean arterial pressure\#, mmHg & $267(10.3)$ & $83.2(8.8)$ & $81.6(9.8)$ & $83.2(8.7)$ \\
\hline
\end{tabular}

${ }^{a}$ All predictor values of the included models were complete; ${ }^{b}$ At least one missing value for a predictor of the included models; *Not a predictor in the included models; \#Recoded/calculated on the basis of (imputed) original variable. ICSI, intracytoplasmic sperm injection; IVF, in vitro fertilisation; LGA, large-forgestational-age; SGA, small-for-gestational-age 


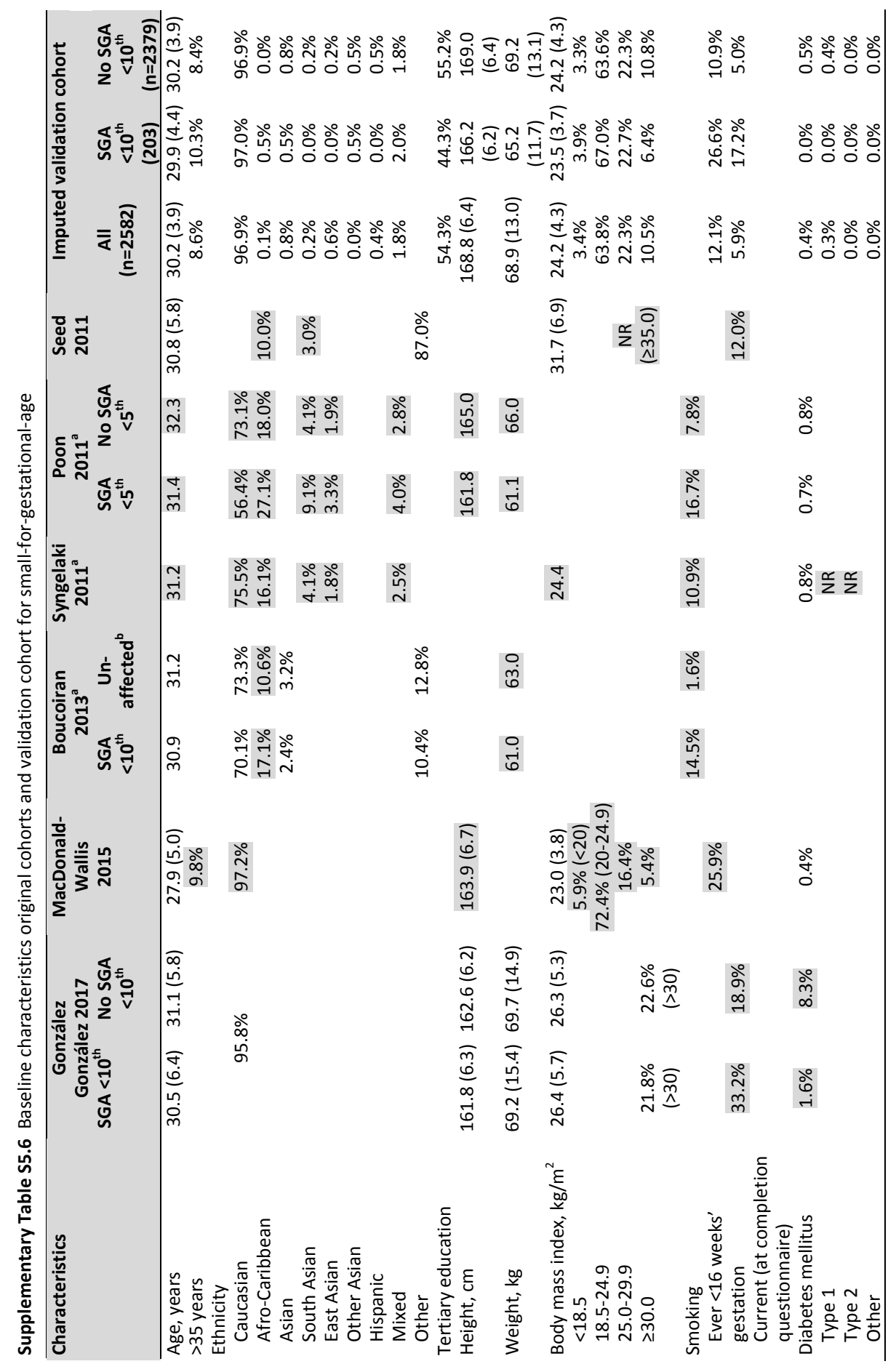




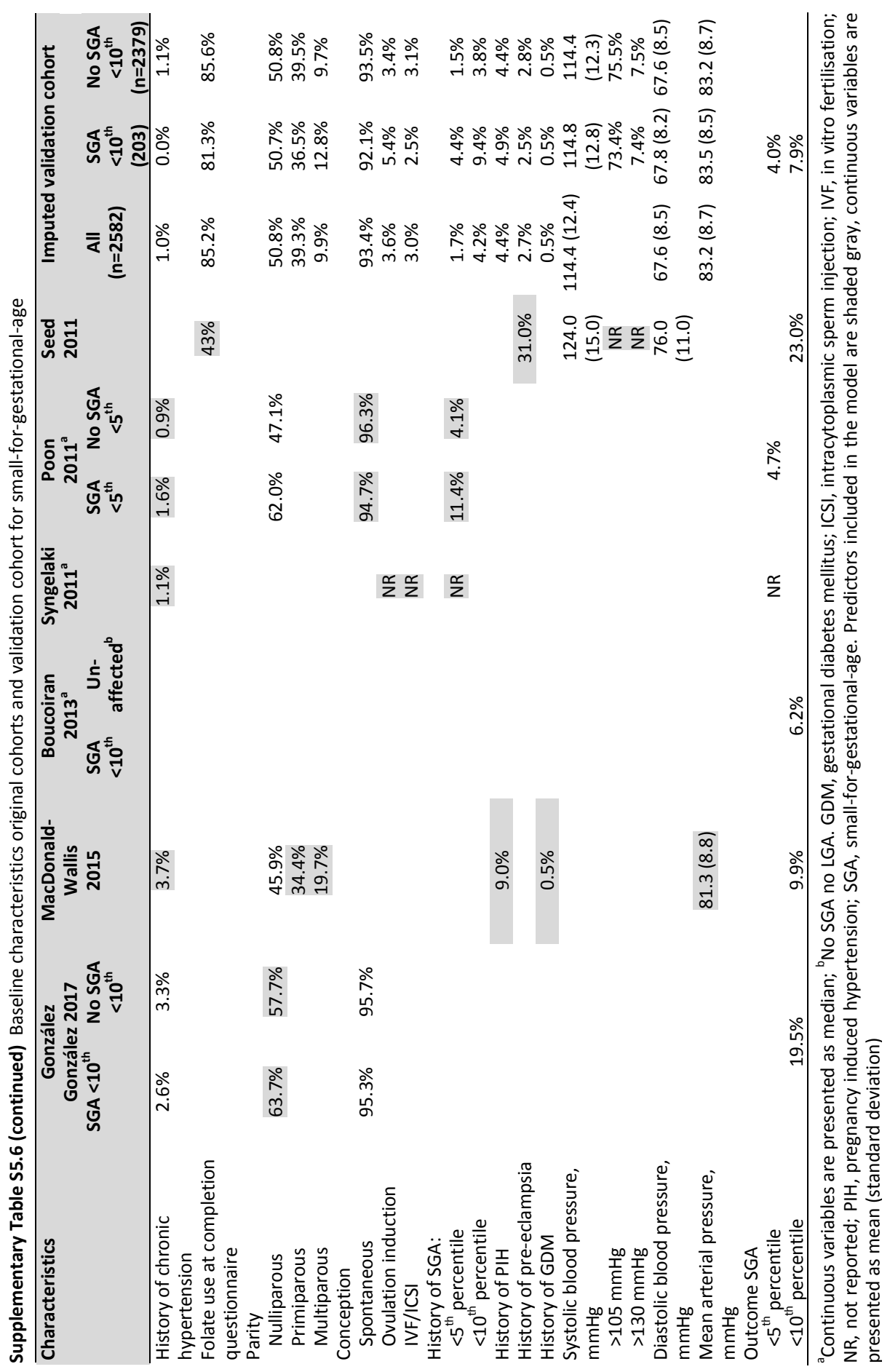




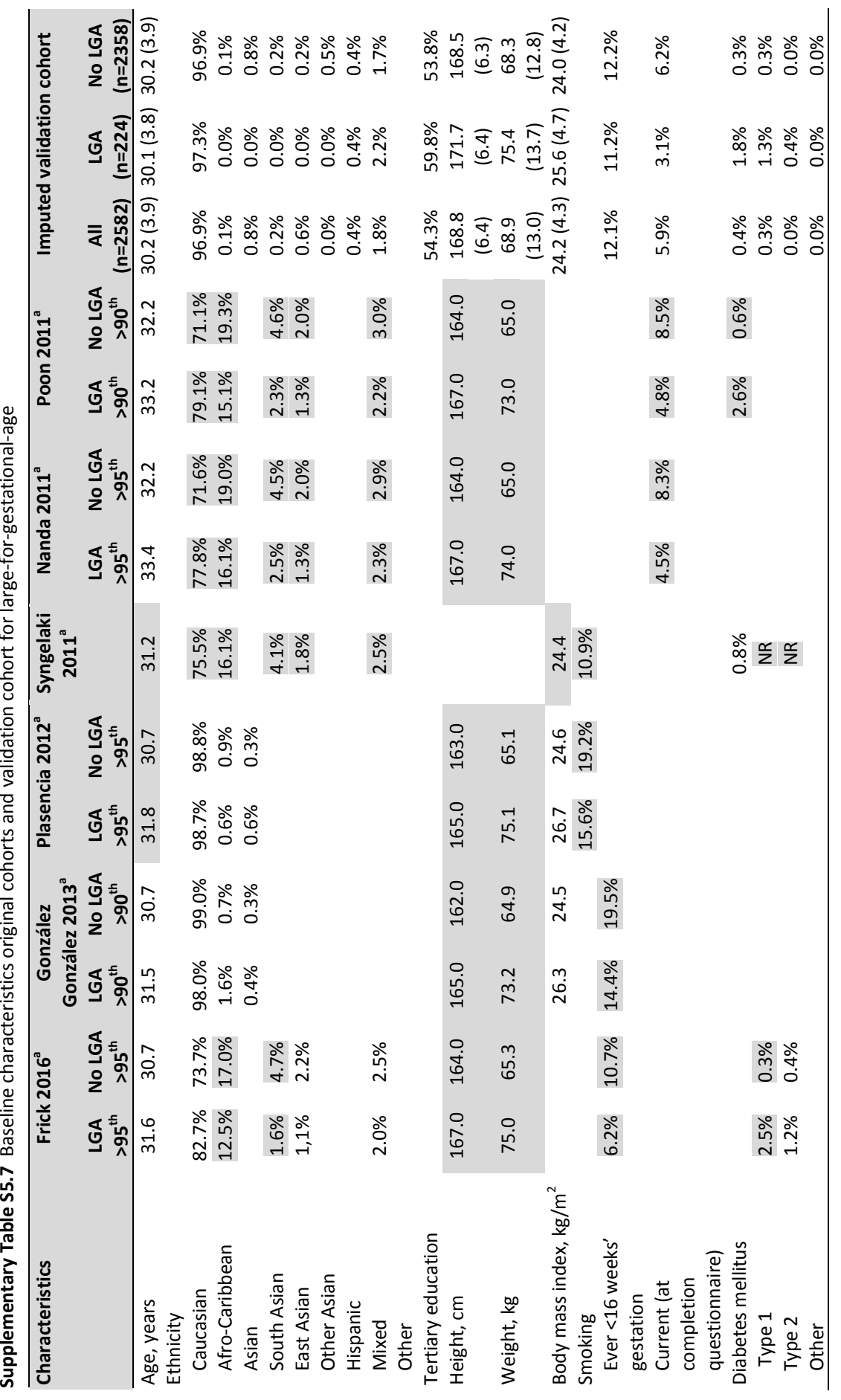




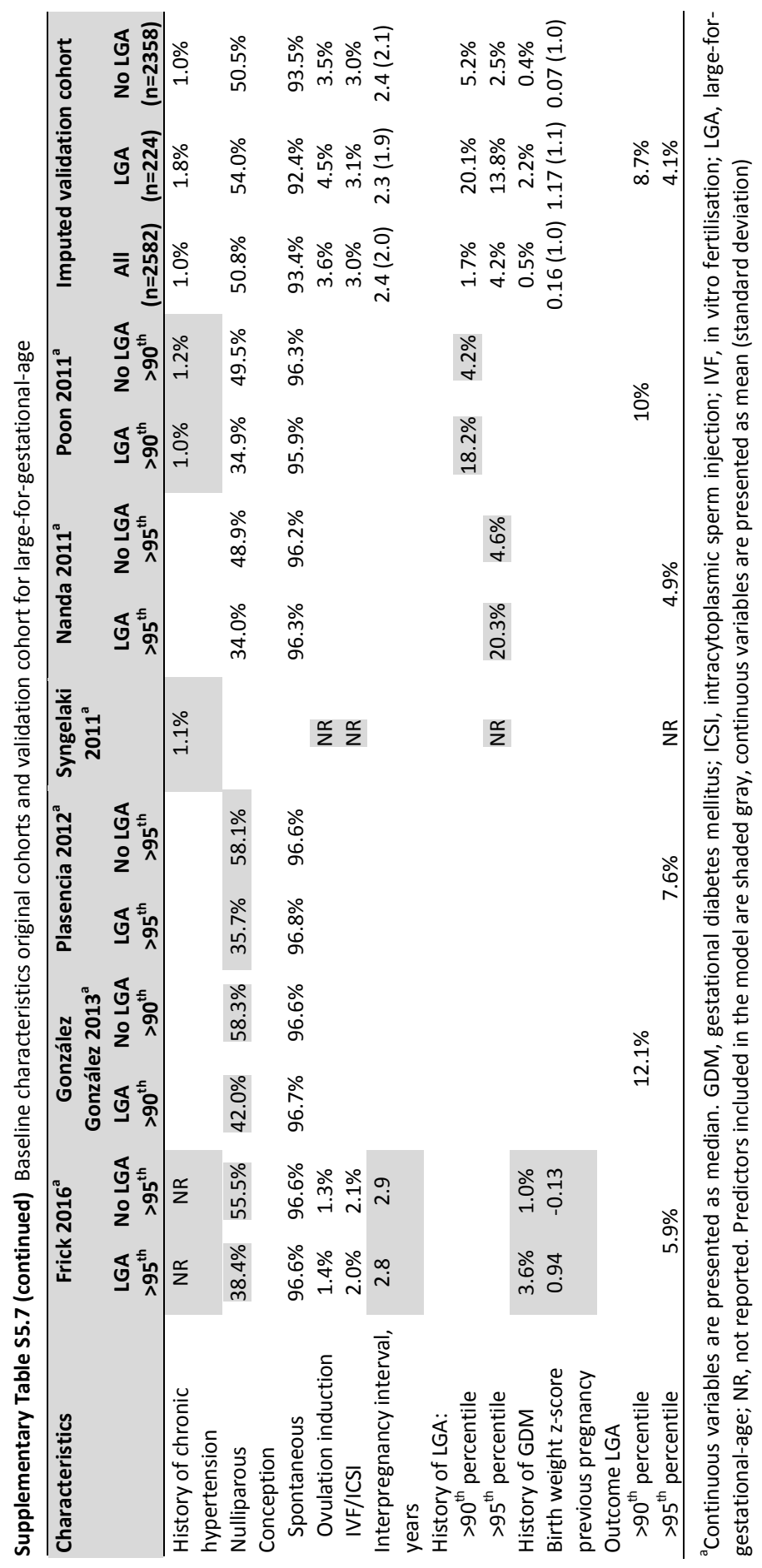




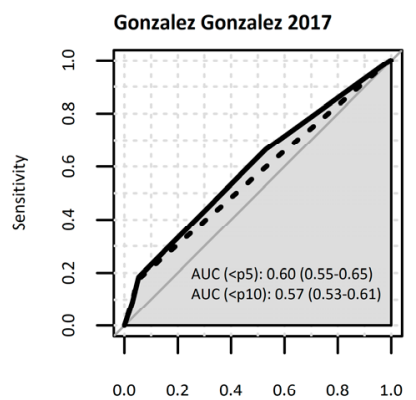

1 - Specificity

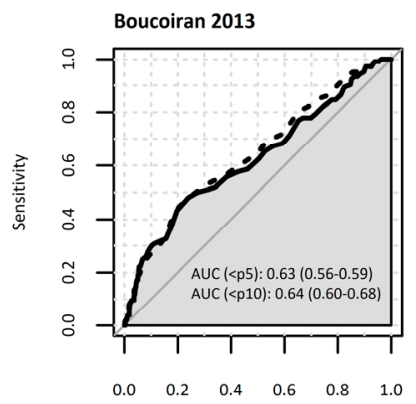

1 - Specificity

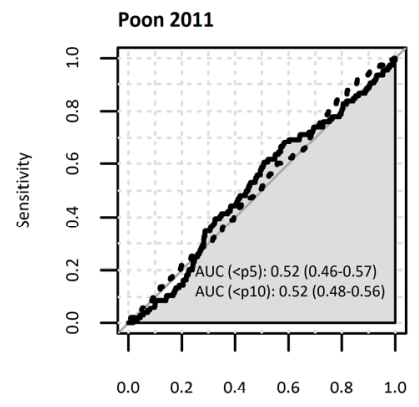

1 - Specificity

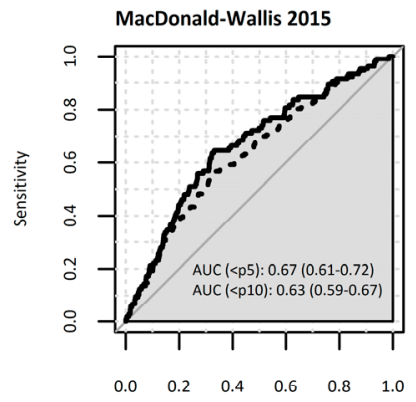

1 - Specificity

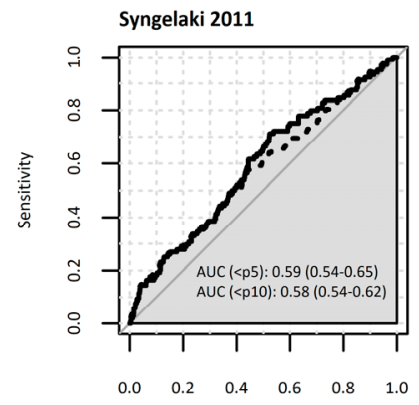

1 - Specificity

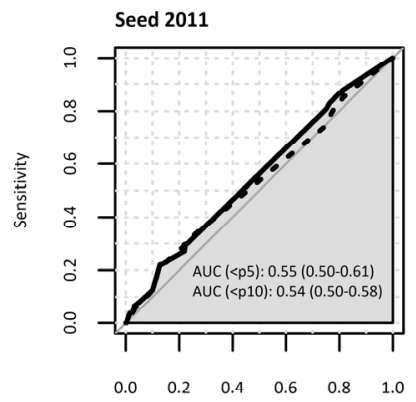

1 - Specificity

Supplementary Figure S5.1 ROC curves of externally validated first trimester prediction models for smallfor-gestational-age $<5^{\text {th }}$ percentile and $<10^{\text {th }}$ percentile 


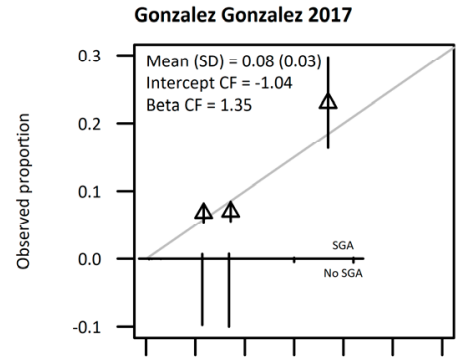

$\begin{array}{lllllll}0.00 & 0.05 & 0.10 & 0.15 & 0.20 & 0.25 & 0.30\end{array}$

Predicted probability

Boucoiran 2013

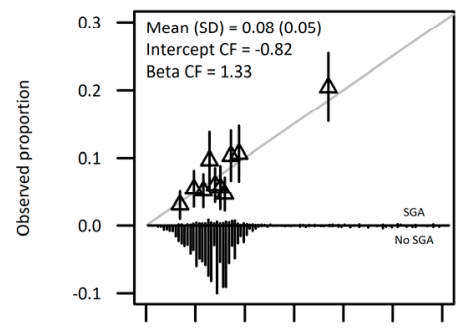

$\begin{array}{lllllll}0.00 & 0.05 & 0.10 & 0.15 & 0.20 & 0.25 & 0.30\end{array}$

Predicted probability

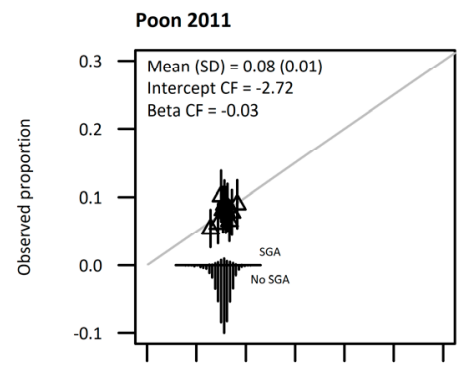

$\begin{array}{lllllll}0.00 & 0.05 & 0.10 & 0.15 & 0.20 & 0.25 & 0.30\end{array}$

Predicted probability

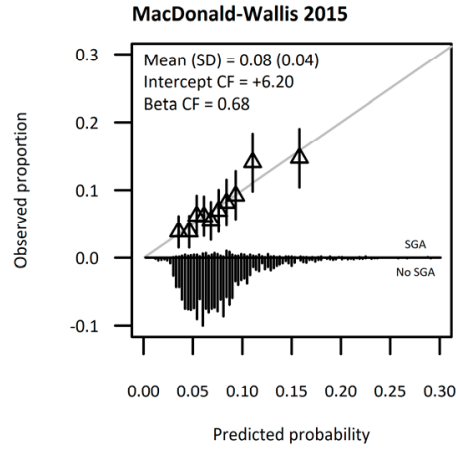

Syngelaki 2011

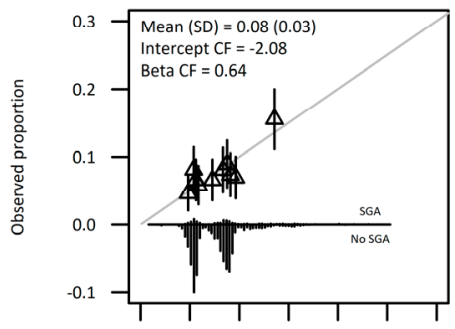

$\begin{array}{lllllll}0.00 & 0.05 & 0.10 & 0.15 & 0.20 & 0.25 & 0.30\end{array}$

Predicted probability

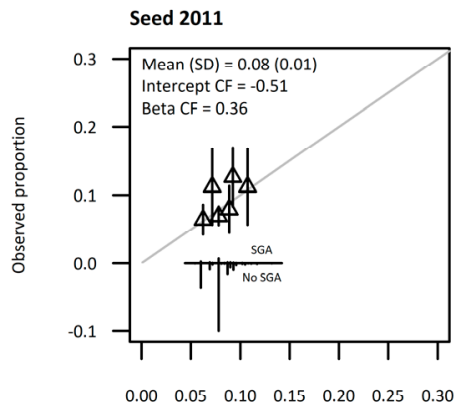

Predicted probability

Supplementary Figure S5.2 ROC curves of externally validated first trimester prediction models for largefor-gestational-age $>90^{\text {th }}$ percentile and $>95^{\text {th }}$ percentile 


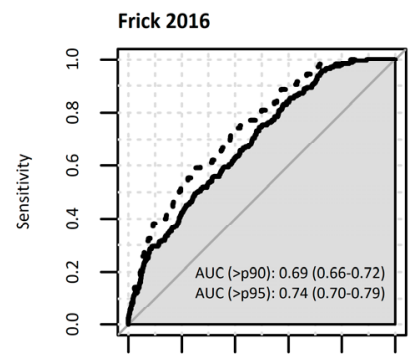

$\begin{array}{llllll}0.0 & 0.2 & 0.4 & 0.6 & 0.8 & 1.0\end{array}$

1 - Specificity
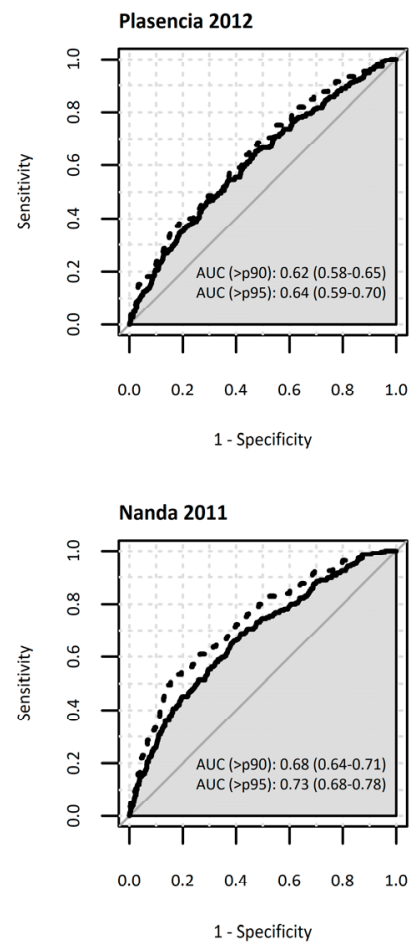

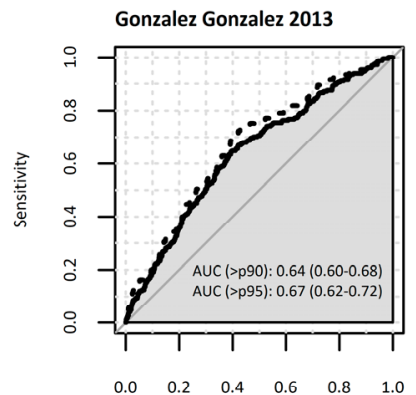

1 - Specificity
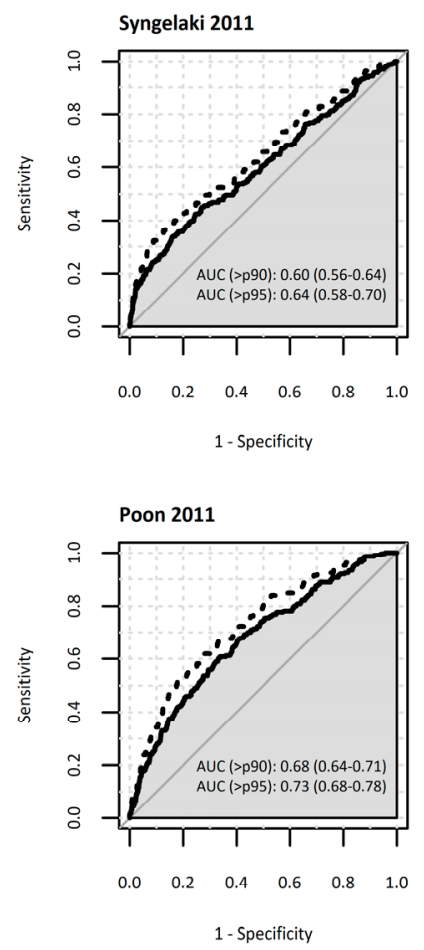

Supplementary Figure S5.3 Calibration plots of recalibrated first trimester prediction models for small-forgestational-age $<10^{\text {th }}$ percentile. The grey line is the reference line with intercept $=0$ and slope $=1$ (perfect calibration). Triangles correspond to grouped predicted risks with $95 \%$ confidence intervals (vertical lines). $\mathrm{CF}=$ correction factor 


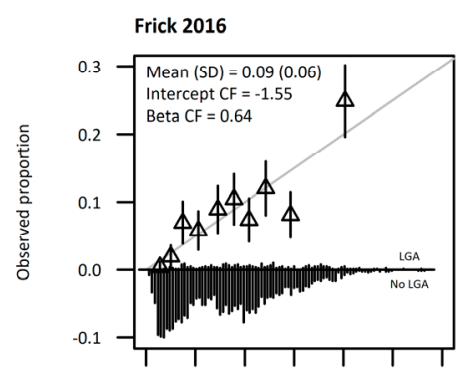

$\begin{array}{lllllll}0.00 & 0.05 & 0.10 & 0.15 & 0.20 & 0.25 & 0.30\end{array}$

Predicted probability

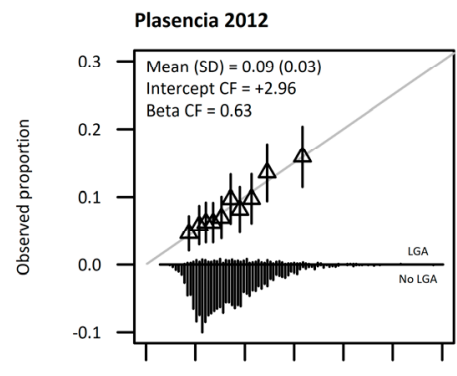

$\begin{array}{lllllll}0.00 & 0.05 & 0.10 & 0.15 & 0.20 & 0.25 & 0.30\end{array}$

Predicted probability

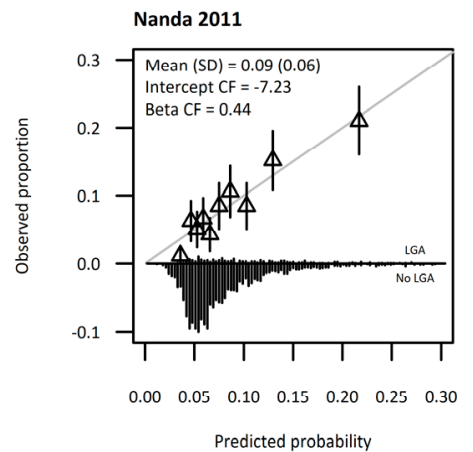

Gonzalez Gonzalez 2013

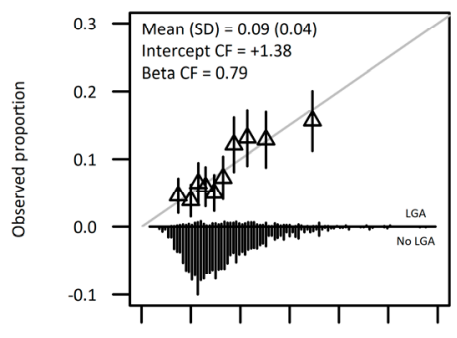

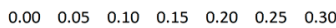

Predicted probability

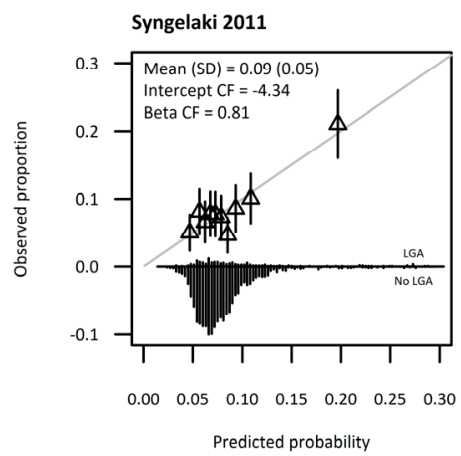

Poon 2011

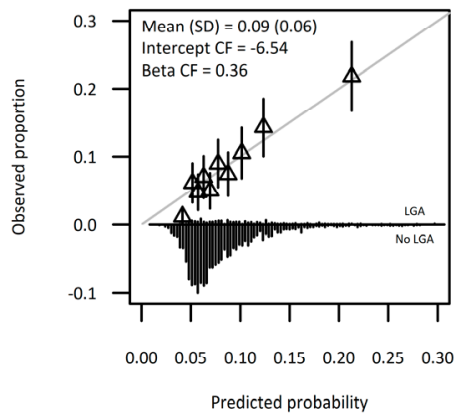

Supplementary Figure S5.4 Calibration plots of recalibrated first trimester prediction models for large-forgestational-age $>90^{\text {th }}$ percentile. The grey line is the reference line with intercept $=0$ and slope $=1$ (perfect calibration). Triangles correspond to grouped predicted risks with $95 \%$ confidence intervals (vertical lines). $\mathrm{CF}=$ correction factor 


\section{CHAPTER 6}

Prediction models for the risk of spontaneous preterm birth based on maternal characteristics: a systematic review and independent external validation

Linda J.E. Meertens*, Pim van Montfort*, Hubertina C.J. Scheepers, Sander M.J. van Kuijk, Robert Aardenburg, Ivo M.A. van Dooren, Josje Langenveld, Iris M. Zwaan, Marc E.A. Spaanderman, and Luc J.M. Smits

* Contributed equally 


\begin{abstract}
Introduction

Prediction models may contribute to personalized risk-based management of women at high risk of spontaneous preterm delivery. Although prediction models are published frequently, often with promising results, external validation generally is lacking. We performed a systematic review of prediction models for the risk of spontaneous preterm birth based on routine clinical parameters. Additionally, we externally validated and evaluated the clinical potential of the models.
\end{abstract}

\title{
Methods
}

Prediction models based on routinely collected maternal parameters obtainable during first 16 weeks of gestation were eligible for selection. Risk of bias was assessed according to the CHARMS guideline. We validated the selected models in a Dutch multicentre prospective cohort study comprising 2614 unselected pregnant women. Information on predictors was obtained by a web-based questionnaire. Predictive performance of the models was quantified by the area under the receiver operating characteristic curve and calibration plots for the outcomes spontaneous preterm birth $<37$ weeks and $<34$ weeks of gestation. Clinical value was evaluated by means of decision curve analysis and calculating classification accuracy for different risk thresholds.

\section{Results}

Four studies describing five prediction models fulfilled the eligibility criteria. Risk of bias assessment revealed a moderate to high risk of bias in three studies. The AUROC of the models ranged from 0.54 to 0.67 and 0.56 to 0.70 for the outcomes spontaneous preterm birth $<37$ weeks and $<34$ weeks of gestation, respectively. A subanalysis showed that the models discriminated poorly (AUROC 0.51 to 0.56 ) for nulliparous women. Although we recalibrated the models, two models retained evidence of overfitting. The decision curve analysis showed low clinical benefit for the best performing models.

\section{Discussion}

This review revealed several reporting and methodological shortcomings of published prediction models for spontaneous preterm birth. Our external validation study indicated that none of the models had the ability to adequately predict spontaneous preterm birth in our population. Further improvement of prediction models, using recent knowledge about both model development and potential risk factors, is necessary in order to provide an added value in personalized risk assessment of spontaneous preterm birth. 


\section{Introduction}

Preterm birth (PTB), usually defined as birth before 37 weeks of gestation, occurs in 5$10 \%$ of singleton pregnancies in Europe ${ }^{1}$. The majority of preterm deliveries, approximately $70 \%$, start spontaneously (sPTB) ${ }^{2}$. As both perinatal mortality and morbidity are inversely related to gestational age, health benefits may be achieved by increased monitoring and preventive interventions resulting in a prolongation of pregnancy $^{3,4}$.

Progesterone treatment has been reported to reduce the risk of SPTB before 34 weeks of gestation in women at high risk ${ }^{5,6}$. Cervical cerclage or application of a pessary may also protect against $\mathrm{SPTB}^{7-9}$. Evidence whether which of the three interventions is most effective is limited ${ }^{7-9}$.

Women with a history of SPTB, cervical surgery or a mid-pregnancy short cervix are considered to be at high risk ${ }^{10}$. Without routine cervical length screening, the majority of nulliparous women are regarded as low risk and thus do not receive any preventive treatment. However, universal cervical length screening in women without a history of SPTB results in relatively high numbers needed to screen (1147 in low-risk nulliparous women) ${ }^{11,12}$. Universal cervical length screening is not performed in Dutch obstetric care. Besides a history of SPTB, other risk factors have been associated with PTB, including socioeconomic status, psychological characteristics, family history, height, weight and smoking ${ }^{13}$. Early risk assessment may be useful in order to identify women at risk who may benefit from effective follow-up management strategies.

In the past, several risk assessment tools for SPTB based on a list of single risk factors were developed showing low accuracy rates ${ }^{14}$. In the last decade, a number of promising prediction models based on multivariable regression analysis for the risk of SPTB have been published ${ }^{15}$. Prediction models may be more accurate in identifying women at high risk as regression allows for a more fine-tuned estimation of the weight of multiple risk factors and possible inter-relations ${ }^{16}$. A review of all existing models assessing their methodological quality is lacking. Moreover, most models have not been externally validated, an essential step before implementation in clinical practice $^{17}$. In this article, we performed a systematic review of all existing models predicting SPTB based on routine clinical parameters obtained in first 16 weeks of pregnancy. We externally validated and compared the selected models in a Dutch multicenter prospective cohort of pregnant women.

\section{Methods}

\section{Search strategy}

This systematic review is reported in accordance with the recently published guidelines for systematic reviews and meta-analyses of prediction model performance $^{18}$. We systematically searched PubMed and EMBASE up to June 26, 2017. Keywords for prediction studies were combined with synonyms for the outcome sPTB appearing in the title, abstract, or MeSH terms. Reference lists of included 
studies and related articles (i.e. reviews) were manually checked to identify additional eligible articles. The detailed search strategy is provided in Supplementary File S6.1.

\section{Selection criteria}

We aimed to identify all published prediction models for the risk of SPTB that are applicable in the first 16 weeks of pregnancy and are based on non-invasive predictors (Supplementary Table S6.1). Studies were eligible if they met the following criteria: (1) the article presented a newly developed prediction model, or a validation or update of a previously developed model in pregnant women, (2) the outcome of the model was the risk of SPTB, (3) the model contained more than one predictor, (4) predictors were available in Dutch obstetric practice (maternal characteristics, anthropometric measures, or blood pressure measurements), 5) predictor values were obtainable during first 16 weeks of pregnancy, and (6) these predictor values were based on regression coefficients. Authors of the original articles were contacted if the model algorithm or definitions of predictors were not available. Studies were excluded in a language other than English, German, French, or Dutch, or if it was a non-original study (for example review). Two researchers (LM, PvM) screened the retrieved titles and abstracts and assessed the eligibility of the full-text papers independently. Discrepancies were resolved by discussion. A third reviewer (LS) was available in case no consensus was reached.

\section{Data extraction and critical appraisal}

The risk of bias of the included studies was assessed using the CHecklist for critical Appraisal and data extraction for systematic Reviews of prediction Modelling Studies $(\text { CHARMS })^{19}$. The following data were extracted for each included study: source of data, participants, outcome(s) to be predicted, candidate predictors, sample size, handling of missing data, model development, model performance, model evaluation, model presentation, and model interpretation. The risk of bias was critically assessed for eight risk domains: source of data, participant selection, predictor assessment, outcome assessment, sample size, attrition, analysis, and presentation of the model. Risk of bias was rated as low if bias was unlikely, moderate if there were no fatal shortcomings and high if essential errors were made. Previously published risk of bias criteria were used and slightly adapted ${ }^{20}$. Data extraction and critical appraisal was performed independently by two reviewers (LM, PvM). Discrepancies were resolved by discussion and a third reviewer (LS) was available in case of no consensus.

\section{Validation cohort}

The included prediction models were externally validated in the Expect Study $I^{21}$. The main purpose of the Expect Study I was to validate published prediction models for several obstetric complications in an independent population. A multicentre prospective cohort study was performed in 36 midwifery practices (primary care) and six hospitals (secondary and tertiary care) in the south-eastern part of the 
Netherlands between July 1, 2013 and January 1, 2015. Follow-up took place until December 31, 2015. All pregnant women up to 16 weeks of gestation and aged 18 years or older were eligible. Eligible pregnant women were asked to complete two web-based questionnaires (a paper version was available upon request), one before 16 weeks of gestation and one six weeks after the estimated due date. The online questionnaires were accessible via the study website using a unique login code provided with the study information. Automatic reminders were sent in case of incompleteness or nonresponse. Medical records and discharge letters were requested from caregivers. Pregnancies ending in a miscarriage or termination before 24 weeks of gestation, and women lost-to-follow-up, were excluded. For this study, we also excluded multiple pregnancies and cases of iatrogenic preterm onset of parturition.

The Medical Ethical Committee of the Maastricht University Medical Centre evaluated the study protocol and declared that no ethical approval was necessary (MEC 13-4053). All participating women gave informed consent through the Internet. The study was registered at the Netherlands Trial Registry on 21 August 2013 (NTR4143, www.trialregister.nl).

\section{Predictor and outcome assessment}

Predictors in the included prediction models were assessed by the pregnancy questionnaire completed before 16 weeks of gestation. We used the same definitions as defined in the original articles (Supplementary Table S6.2).

The primary outcome sPTB was defined as a delivery before 37 weeks of gestation with spontaneous onset of parturition (primary contractions or preterm premature rupture of membranes). Secondly, we defined early SPTB as a spontaneously delivery before 34 weeks of gestation. The outcome was obtained from a combination of the medical record and postpartum questionnaire. Cause of labour onset (i.e. spontaneous or not) was available in both data sources. Duration of pregnancy was also available in both data sources and was moreover calculated based on estimated due date and date of birth. Discrepancies between the two variables and data sources were checked. In the absence of the postpartum questionnaire ( $n=421$ sPTB <37 weeks and $n=424$ SPTB $<34$ weeks), the medical record was used as reference standard and vice versa ( $n=16$ for both sPTB $<37$ weeks and sPTB $<34$ weeks).

\section{Data analysis}

A sample size of 2500 women was expected to provide a minimum of 100 cases and 100 non-cases, assuming a $4.5 \%$ incidence rate of spontaneous preterm birth $<37$ weeks of gestation $^{22}$.

We imputed missing data for predictors using stochastic regression imputation with predictive mean matching as the imputation model ${ }^{23}$. Characteristics of the validation cohort were described as an absolute value with percentage for categorical variables and as mean \pm standard deviation (SD) for continuous variables. We evaluated the 
relatedness of development samples and validation cohort by comparing the distribution of population characteristics.

The original formulas were used to calculate individual predicted probabilities for each model (Supplementary Table S6.3). We assessed the predictive performance of each model by means of discrimination and calibration for the outcomes SPTB $<37$ and $<34$ weeks of gestation, as described in the framework reported by Steyerberg et al. ${ }^{16}$. Discrimination indicates the ability of the model to distinguish between women who will have a SPTB and those who will not. For each model, we computed the area under the receiver operating characteristic curve (AUROC) with 95\%-confidence interval $(\mathrm{CI})$. A subgroup analysis was performed among nulliparous women as a history of SPTB is a strong risk factor for recurrent SPTB. Calibration refers to the agreement between the actual outcome and predicted probabilities by the model. We constructed calibration plots in which women were divided into 10 groups with similar predicted risks, and calculated calibration-in-the-large and the slope. Calibration-in-the-large (intercept), which compares the mean predicted probabilities with mean observed risk, indicates the extent to which predictions are systematically too low or too high. The slope refers to the average strength of predictor effects. Perfect predictions have an intercept of zero and a slope of one ${ }^{17}$. The prediction models were recalibrated by adjusting the intercept and slope using the linear predictor as the only covariate. Discriminative performance (AUROC) of the models is not affected as this recalibration method does not change the ranking of the predicted probabilities ${ }^{24}$. A discriminative performance below 0.70 is generally considered moderate ${ }^{16}$.

Lastly, we performed decision curve analysis to evaluate the potential clinical utility of the models. Decision curve analysis assesses the net benefit (proportion of true positives and false positives) of the prediction models over a range of risk thresholds compared with considering all and no women to be at high risk for sPTB ${ }^{25}$. Sensitivity, specificity, and positive and negative predictive values at certain risk thresholds were calculated for the model with the highest overall net benefit.

Statistical analyses were performed with $\mathrm{R}$ version 3.4.1, packages $\mathrm{rms}$, $\mathrm{pROC}$, and DecisionCurve.

\section{Results}

\section{General characteristics of the studies}

The search identified 2018 unique articles. After title and abstract screening, full text assessment was performed for 47 articles. Four articles fulfilled the eligibility criteria $^{26-29}$. Reference cross-checking provided no additional articles. An overview of the systematic study selection is shown in Supplementary Figure S6.1.

The four included studies were all development studies describing five models predicting the risk for SPTB based on maternal characteristics. The studies were conducted in four different countries and published between 2011 and 2014. Two studies used a prospective cohort design and the other two were based on registry 
data. The number of predictors in the published prediction models varied between 2 and 16. Common predictors were body mass index (BMI), smoking, and previous preterm delivery. The prevalence of SPTB, defined as SPTB $<34$ weeks of gestation by two studies and $<37$ weeks of gestation by the other two studies, ranged from $0.9 \%$ to $1.1 \%$ for SPTB $<34$ weeks of gestation and from $3.7 \%$ to $5.7 \%$ for SPTB $<37$ weeks of gestation. Discriminative performance (AUROC) varied from 0.62 to 0.70 . Only one study performed internal validation by bootstrapping and the study of Sananes et al. performed an external validation of which the results were not reported. The key characteristics of the included studies are shown in Table 6.1.

\section{Risk of bias}

A summary of potential bias per domain is shown in Figure 6.1. Two studies used registry data for model development, which may be less effective for research purposes due to the likelihood of missing data on promising predictors. Moreover, the outcome was extracted at the same time as the predictors which may lead to bias. Nevertheless, sPTB is an objective outcome so assessment may be less biased. The domain participants was rated as liable to a moderate to high risk of bias due to selective reporting of patient characteristics. Para-Cordero et al. used criteria which are not available at the intended moment of prediction. Besides, women may be treated for spontaneous onset of PTB. Only Alleman et al. explicitly reports exclusion of women undergoing cerclage or tocolysis from their study population. ParraCordero et al. merely excluded women with a history of cerclage. Sample size was scored at moderate risk for the model of Parra-Cordero et al. because the overall number of cases was low $(n=31)$ which probably led to the inclusion of only two predictors. The domains attrition and analysis had the highest risk of bias for all included models. All studies either had incomplete data (loss-to-follow-up or missing predictor values), or did not report any information about missing data (Parra-Cordero et al.). 


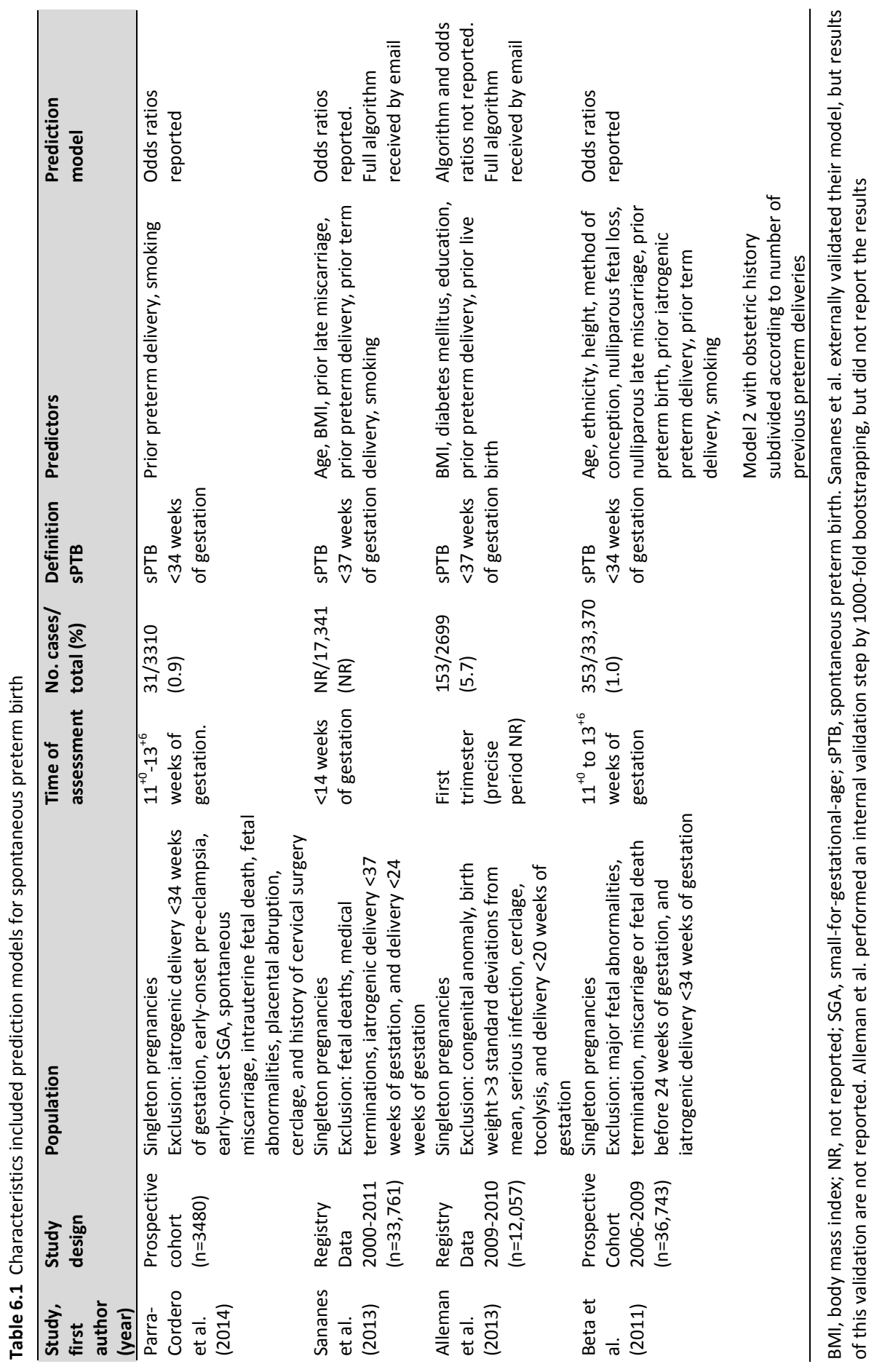


The other three studies were scored as moderate risk because they had a substantial amount of missing data and performed a complete case analysis. Methods of analysis were not reported in enough detail by Parra-Cordero et al.. All studies selected predictors based on statistical significance and only one study performed shrinkage of the regression coefficients. For the models of two studies, only odds ratios were available. As the intercept was unavailable, no initial calibration plots could be drawn. Alleman et al. reported their final model including serum markers. The algorithm consisting only maternal characteristics was provided after contacting the authors. Overall, the study of Beta et al. showed the lowest risk of bias. A detailed description of the data extraction and risk of bias assessment according to the CHARMS checklist is provided in Supplementary Table S6.4 and S6.5.

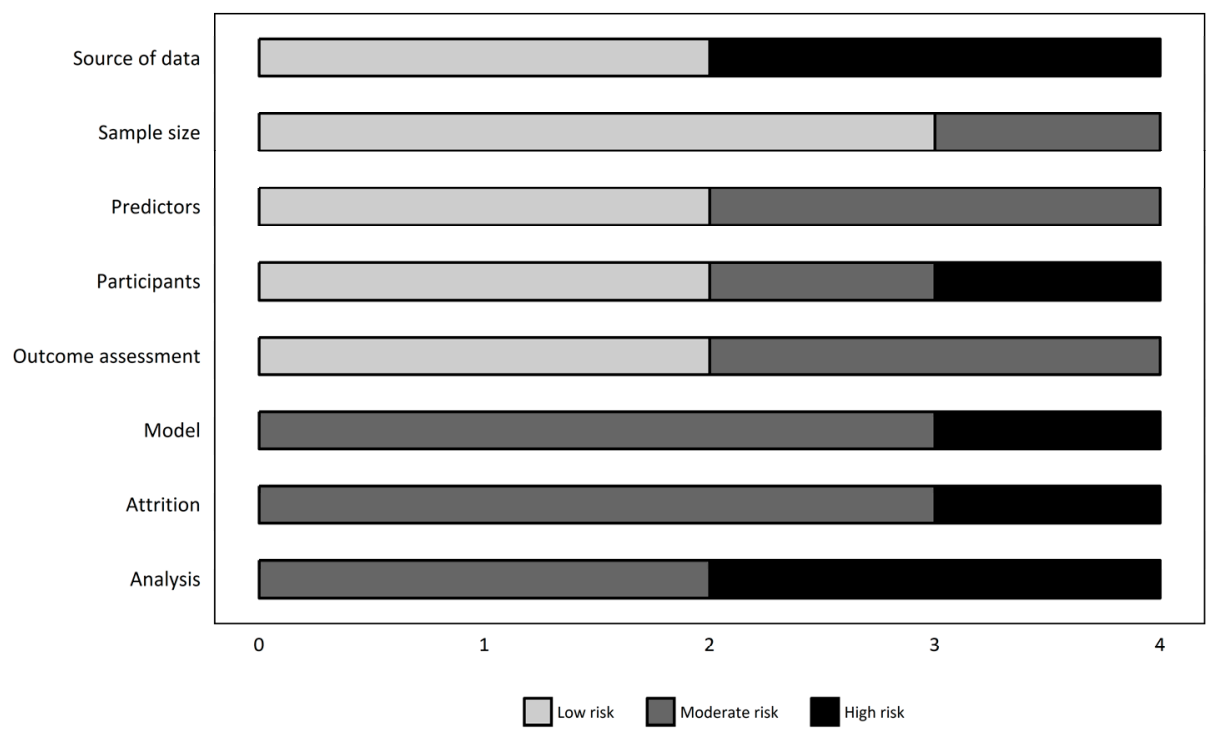

Figure 6.1 Risk of bias assessment of the four included studies according to CHARMS checklist ${ }^{19}$

\section{Validation cohort}

The validation cohort consisted of 2540 women of which $118(4.6 \%)$ had a sPTB <37 weeks of gestation (Figure 6.2). Patient characteristics are shown in Table 6.2. There were $\leq 1.2 \%$ missing values per predictor and the cohort was generally similar after imputation of incomplete predictor variables. Supplementary Table S6.6 provides an overview of complete cases and the imputed validation cohort. The study population for the outcome SPTB $<34$ weeks of gestation comprised 2,576 women, since fewer women were excluded because of an iatrogenic preterm onset of labour, of which 34 women (1.3\%) delivered spontaneously before 34 weeks of gestation. 
The distribution of predictors and predictor effects in the original cohorts and our validation cohort are available in Supplementary Table S6.7. In contrast to the original cohorts, women in our validation cohort were nearly all of Caucasian origin. Almost all population characteristics of Sananes et al. differed considerably compared with the validation cohort. Women in the cohort of Alleman et al. had a higher BMI and higher prevalence of pre-existing diabetes mellitus. The populations of Parra-Cordero et al. and Beta et al. were more comparable, but Parra-Cordero et al. had a higher prevalence of smoking during pregnancy and women in the cohort of Beta et al. were shorter and had a higher prevalence of previous fetal loss. The prevalence of SPTB $<37$ weeks of gestation was higher in Alleman et al. (5.7\%) and lower in the overall population of Sananes et al. (3.7\%) compared with the validation cohort (4.6\%). The outcome SPTB $<34$ weeks of gestation was comparable with our prevalence.

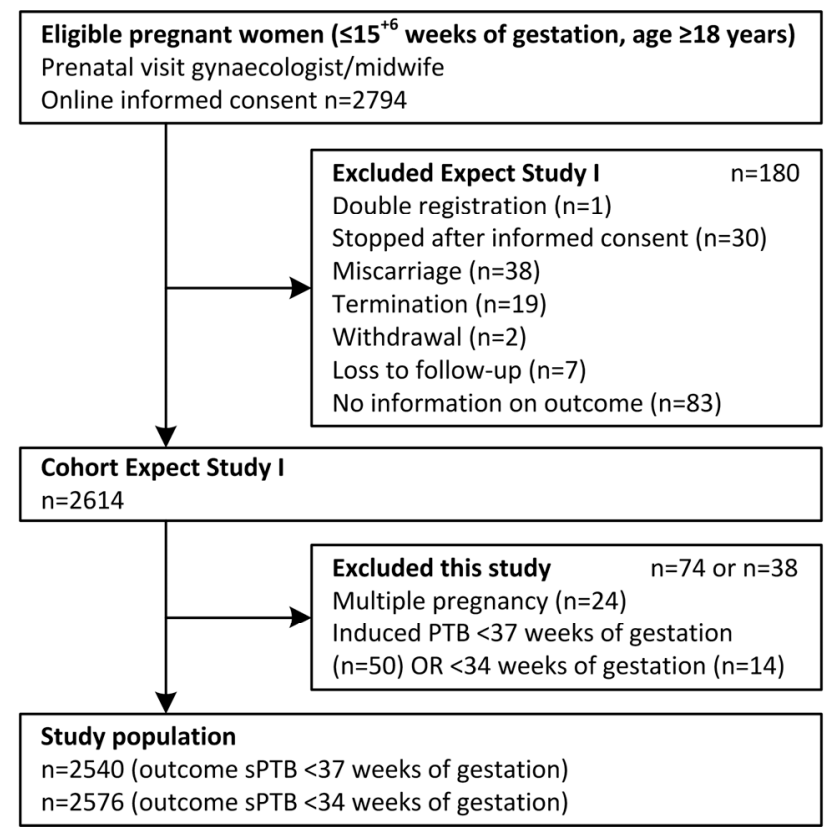

Figure 6.2 Flowchart validation cohort spontaneous preterm birth (sPTB)

\section{Performance of the models}

The discriminative performance of the included models is shown in Table 6.3. For the primary outcome SPTB $<37$ weeks of gestation, the AUROC ranged from 0.54 to 0.67 . The AUROC of the model of Alleman et al. decreased considerably from 0.70 to 0.57 (95\% Cl 0.52-0.62). The model of Sananes et al. had a slightly higher discrimination compared with the original cohort. All models performed better for the outcome SPTB $<34$ weeks of gestation. Model 2 of Beta et al. yielded the highest discriminative performance (AUROC 0.70, 95\% Cl 0.61-0.78). Wide confidence intervals were 
observed due to the low number of cases for SPTB $<34$ weeks of gestation. The subgroup analysis among nulliparous women showed a drastic decrease towards almost no discriminative performance for all models. The ROCs in the overall cohort are presented in Figure 6.3.

Table 6.2 Baseline characteristics of the validation cohort (Expect Study I)

\begin{tabular}{|c|c|c|c|c|}
\hline \multirow[t]{2}{*}{ Characteristics } & \multirow{2}{*}{$\begin{array}{l}\text { Missing } \\
\text { values, } \\
\text { n (\%) }\end{array}$} & \multicolumn{3}{|c|}{ Observed validation cohort (Expect Study I) } \\
\hline & & $\begin{array}{l}\text { Overall } \\
(n=2540)\end{array}$ & $\begin{array}{c}\text { sPTB }<37 \\
\text { weeks } \\
(n=118) \\
\end{array}$ & $\begin{array}{c}\text { No sPTB } \geq 37 \\
\text { weeks } \\
(n=2422)\end{array}$ \\
\hline Age, years & $0(0.0)$ & $30.2(3.9)$ & $30.1(3.8)$ & $30.2(3.9)$ \\
\hline Ethnicity & $0(0.0)$ & & & \\
\hline Caucasian & & $2462(96.9)$ & $115(97.5)$ & 2347 (96.9) \\
\hline Afro-Caribbean & & $3(0.1)$ & $1(0.8)$ & $2(0.1)$ \\
\hline South Asian & & $4(0.2)$ & $0(0.0)$ & $4(0.2)$ \\
\hline East Asian & & $4(0.2)$ & $1(0.8)$ & $3(0.1)$ \\
\hline Other Asian & & $11(0.4)$ & $1(0.8)$ & $10(0.4)$ \\
\hline Hispanic & & $11(0.4)$ & $0(0.0)$ & $11(0.5)$ \\
\hline Mixed & & $45(1.8)$ & $0(0.0)$ & 45 (1.9) \\
\hline Tertiary level of education & $3(0.1)$ & $1380(54.3)$ & $69(58.5)$ & $1311(54.1)$ \\
\hline Height, $\mathrm{cm}$ & $3(0.1)$ & $168.8(6.4)$ & $167.3(6.6)$ & $168.9(6.4)$ \\
\hline Weight, kg & $5(0.2)$ & $68.9(13.0)$ & $65.6(11.5)$ & $69.0(13.0)$ \\
\hline Body mass index, $\mathrm{kg} / \mathrm{m}^{2}$ & $5(0.2)$ & $24.1(4.3)$ & $23.4(3.8)$ & $24.2(4.3)$ \\
\hline Smoking during pregnancy & $1(0.0)$ & $149(5.9)$ & $8(6.8)$ & $141(5.8)$ \\
\hline Diabetes mellitus & $0(0.0)$ & $10(0.4)$ & $1(0.8)$ & $9(0.4)$ \\
\hline Type 1 & & $8(0.3)$ & $1(0.8)$ & $7(0.3)$ \\
\hline Type 2 & & $1(0.0)$ & $0(0.0)$ & $1(0.0)$ \\
\hline Other & & $1(0.0)$ & $0(0.0)$ & $1(0.0)$ \\
\hline History of chronic hypertension & $0(0.0)$ & $24(0.9)$ & $0(0.0)$ & $24(1.0)$ \\
\hline Parity & $0(0.0)$ & & & \\
\hline Nulliparous & & $1284(50.6)$ & $77(65.3)$ & $1207(49.8)$ \\
\hline Primiparous & & $1003(39.5)$ & $35(29.7)$ & $968(40.0)$ \\
\hline Multiparous & & 253 (9.9) & $6(5.0)$ & $247(10.2)$ \\
\hline Conception & $0(0.0)$ & & & \\
\hline Spontaneous & & $2375(93.5)$ & $114(96.6)$ & $2261(93.4)$ \\
\hline Ovulation induction & & $88(3.5)$ & $3(2.5)$ & $85(3.5)$ \\
\hline IVF/ICSI & & $77(3.0)$ & $1(0.8)$ & $76(3.1)$ \\
\hline History of fetal loss $<16$ weeks of gestation & $0(0.0)$ & $702(27.6)$ & $24(20.3)$ & $678(28.0)$ \\
\hline History of recurrent miscarriages $(\geq 3)$ & $0(0.0)$ & 49 (1.9) & $1(0.8)$ & $48(2.0)$ \\
\hline Vaginal bleeding ( $\geq 2$ days) & $0(0.0)$ & $277(10.9)$ & $27(20.3)$ & $250(10.3)$ \\
\hline History of sPTB & $30(1.2)$ & $76(3.0)$ & $16(13.6)$ & $60(2.5)$ \\
\hline $16-23$ weeks of gestation & & $4(0.2)$ & $1(0.8)$ & $3(0.1)$ \\
\hline $24-27$ weeks of gestation & & $7(0.3)$ & $1(0.8)$ & $6(0.2)$ \\
\hline $28-30$ weeks of gestation & & $2(0.1)$ & $2(1.7)$ & $0(0.0)$ \\
\hline $31-33$ weeks of gestation & & $13(0.5)$ & $3(2.5)$ & $10(0.4)$ \\
\hline 34-36 weeks of gestation & & $52(2.0)$ & $9(7.6)$ & $43(1.8)$ \\
\hline $\begin{array}{l}\text { History of iatrogenic preterm delivery } \\
\geq 24 \text { weeks of gestation }\end{array}$ & $29(1.1)$ & $44(1.7)$ & $0(0.0)$ & $44(1.8)$ \\
\hline History of term delivery & $29(1.1)$ & $1130(44.5)$ & $29(24.6)$ & $1101(45.5)$ \\
\hline History of live birth & $18(0.7)$ & $1221(48.1)$ & $40(33.9)$ & $1181(48.8)$ \\
\hline
\end{tabular}

${ }^{a}$ Original data (not imputed) presented as mean (SD) or absolute number (\%). ICSI, intracytoplasmic sperm injection; IVF, in vitro fertilisation; SPTB, spontaneous preterm birth 
Table 6.3 Discrimination of selected prediction models for spontaneous preterm birth

\begin{tabular}{|c|c|c|c|c|c|}
\hline $\begin{array}{l}\text { Study, first } \\
\text { author (year) }\end{array}$ & $\begin{array}{c}\text { AUROC }(95 \% \mathrm{CI}) \\
\text { Original } \\
\text { publication }\end{array}$ & $\begin{array}{l}\text { AUROC }(95 \% \mathrm{CI}) \\
\text { Validation } \\
\text { cohort } \\
\text { sPTB }<37 \text { weeks } \\
(n=2540)\end{array}$ & $\begin{array}{l}\text { AUROC }(95 \% \mathrm{CI}) \\
\text { Validation } \\
\text { cohort } \\
\text { sPTB }<34 \text { weeks } \\
(n=2576)\end{array}$ & $\begin{array}{l}\text { AUROC }(95 \% \mathrm{CI}) \\
\text { Validation } \\
\text { cohort }, \\
\text { nulliparous } \\
\text { sPTB <37 weeks } \\
(n=1284)\end{array}$ & $\begin{array}{l}\text { AUROC }(95 \% \mathrm{CI}) \\
\text { Validation } \\
\text { cohort } \\
\text { nulliparous } \\
\text { sPTB <34 weeks } \\
(n=1305)\end{array}$ \\
\hline $\begin{array}{l}\text { Parra- } \\
\text { Cordero et al. } \\
(2014)\end{array}$ & NR & $0.54(0.50-0.57)$ & $0.56(0.49-0.63)$ & $0.52(0.50-0.54)$ & $0.51(0.46-0.55)$ \\
\hline $\begin{array}{l}\text { Sananes et al. } \\
\text { (2013) }\end{array}$ & $0.618(0.595-0.641)$ & $0.64(0.60-0.68)$ & $0.68(0.59-0.76)$ & $0.53(0.48-0.57)$ & $0.53(0.43-0.63)$ \\
\hline $\begin{array}{l}\text { Alleman et al. } \\
(2013)\end{array}$ & 0.703 (NR) & $0.57(0.52-0.62)$ & $0.61(0.51-0.71)$ & $0.55(0.49-0.60)$ & $0.51(0.39-0.63)$ \\
\hline Beta et al. & Model 1: 0.668 & $0.65(0.60-0.70)$ & $0.68(0.59-0.77)$ & $0.51(0.45-0.57)$ & $0.52(0.39-0.65)$ \\
\hline (2011) & $\begin{array}{l}\text { (0.639-0.698) } \\
\text { Model 2: NR }\end{array}$ & $0.67(0.62-0.72)$ & $0.70(0.61-0.78)$ & $0.54(0.48-0.60)$ & $0.56(0.44-0.68)$ \\
\hline
\end{tabular}

AUROC, area under the receiver operating characteristic curve; $\mathrm{Cl}$, confidence interval; $\mathrm{NR}$, not reported; SPTB, spontaneous preterm birth

Calibration plots of the two models that provided a complete algorithm are provided in Figure 6.4. The model of Alleman et al. underestimated the risk of sPTB and was overfitted (slope <1). Besides the difference in baseline risk, Sananes et al. was fitted well to our population (slope $=1$ ). Recalibration showed closer fitting to the ideal calibration line (Supplementary Figure S6.2 and S6.3). The models of Alleman et al. and Beta et al. retained some overfitting.

The decision curve analysis of the two best performing models is presented in Figure 6.5. The models had a positive net benefit compared with classifying all or no women as high-risk over a small range of probability thresholds (2.5-10\%). However, net benefit remained low throughout this range. This low clinical usefulness is also shown in Table 6.4. Choosing a high sensitivity leads to a large proportion of women that will be indicated unnecessarily as having a high risk of SPTB $<37$ weeks of gestation. Conversely, a higher specificity leads to a minimal amount of true positives. The model performed especially insufficient among nulliparous women. The moderate performance is predominantly determined by a history of sPTB or term delivery. 

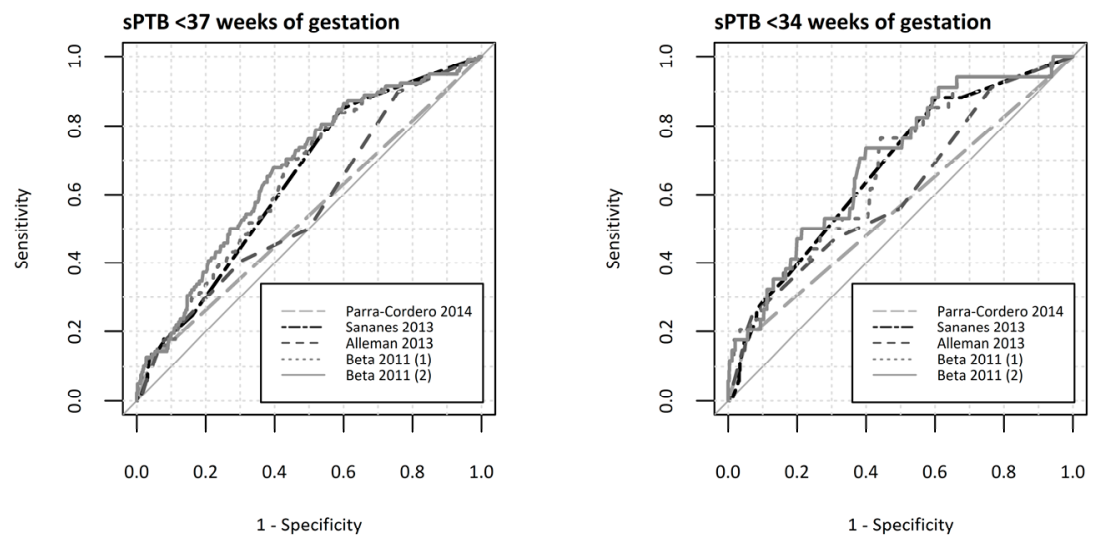

Figure 6.3 ROC curves of externally validated first trimester prediction models for spontaneous preterm birth (sPTB) $<37$ weeks and $<34$ weeks of gestation

SPTB $<37$ weeks of gestation

Sananes 2013

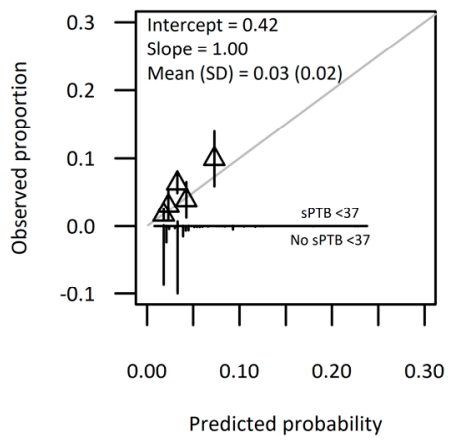

Alleman 2013

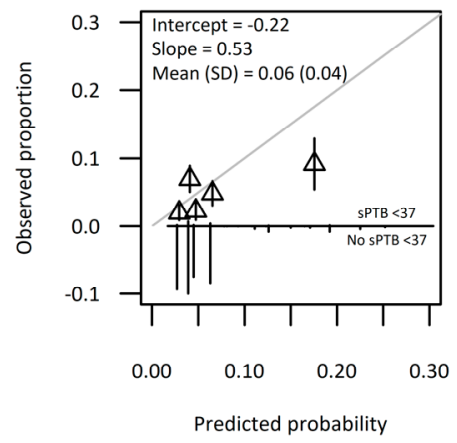

sPTB $<34$ weeks of gestation
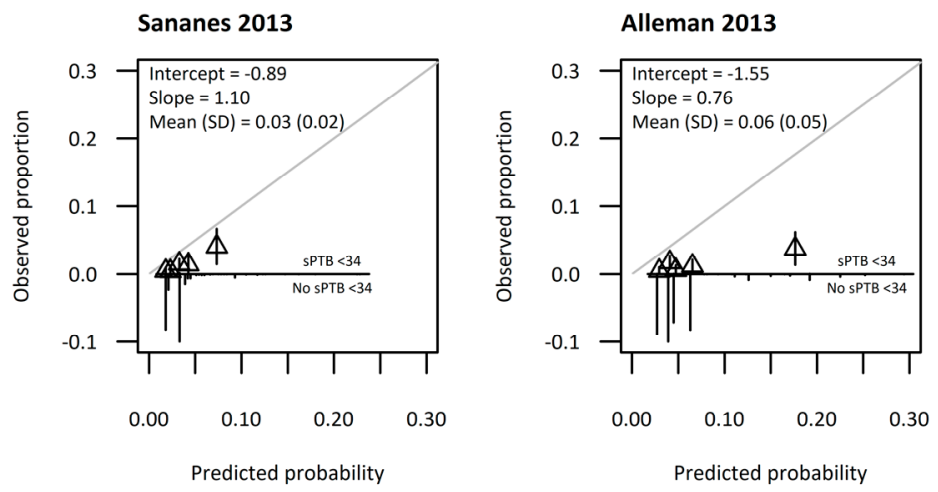

Figure 6.4 Calibration plots of externally validated first trimester prediction models for spontaneous preterm birth (SPTB) <37 weeks and $<34$ weeks of gestation. The grey line is the reference line with intercept $=0$ and slope $=1$ (perfect calibration). Triangles correspond to grouped predicted risks with $95 \%$ confidence intervals (vertical lines) 


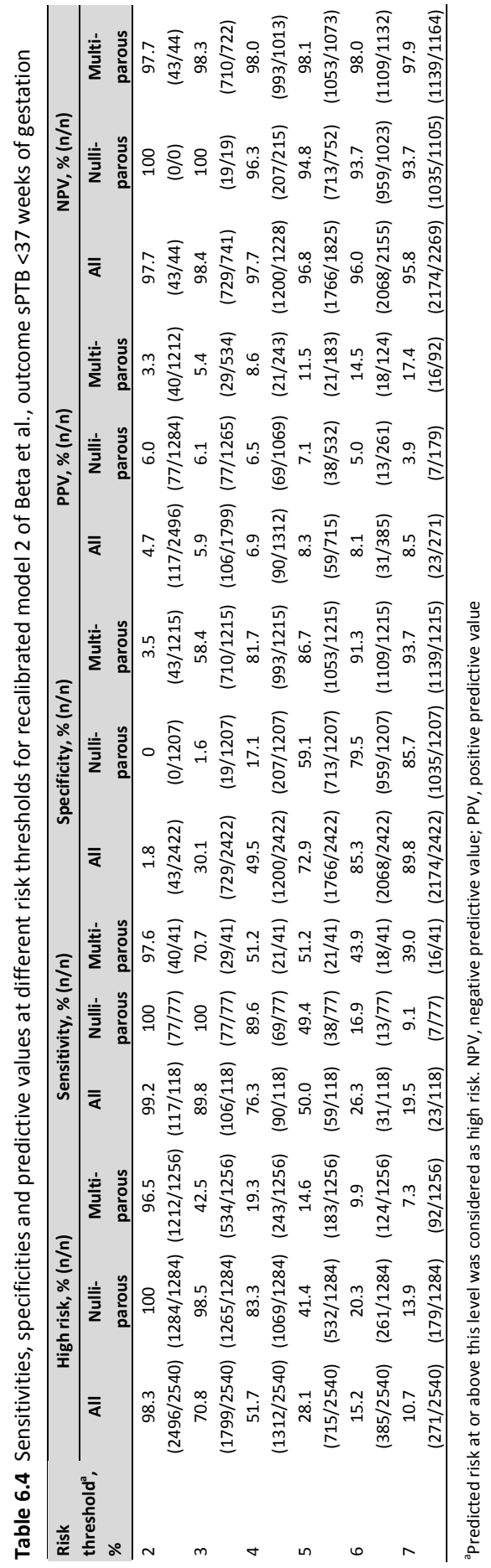




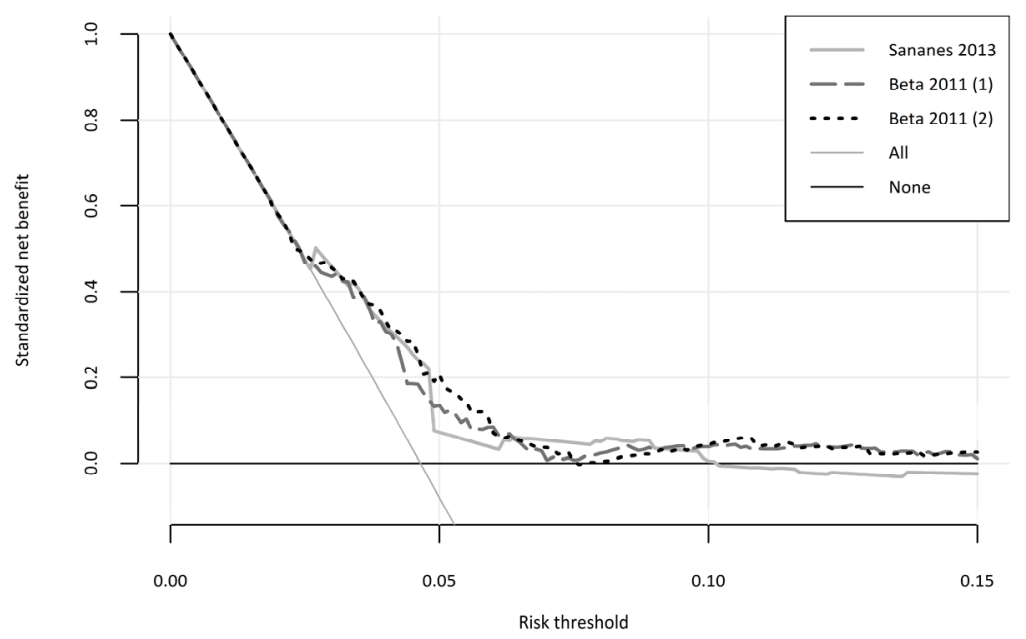

Figure 6.5 Decision curve analysis of three best performing models for the risk of spontaneous preterm birth $<37$ weeks of gestation. Decision curve analysis assesses the net benefit (vertical axis; proportion of true positives and false positives) of the prediction models over a range of risk thresholds compared to considering all (solid grey line) and no women (horizontal solid black line) to be at high risk for sPTB

\section{Discussion}

\section{Main findings}

In this systematic review we provided an overview of the currently available prediction models of SPTB based on routine clinical parameters. We identified four articles describing five models fulfilling the eligibility criteria. Assessment of methodological quality revealed several shortcomings in reporting of models. Furthermore, there is a moderate to high risk of bias in the development of the models according to the CHARMS criteria. External validation resulted in a decreased discriminative ability for all models. Model 2 of Beta et al. had the highest AUROC (sPTB <37 weeks: 0.67 , and SPTB <34 weeks: 0.70 ) after validation. This model was based on age, ethnicity, height, method of conception, nulliparous fetal loss, nulliparous late miscarriage, prior PTB (subcategories), prior iatrogenic PTB, prior term delivery, and smoking. The model of Sananes et al. showed the best calibration (slope of one) for SPTB $<37$ weeks of gestation.

\section{Interpretation}

Our systematic review identified a moderate reporting quality of most studies according to the CHARMS criteria. Reporting shortcomings were also noted in a general systematic review about obstetric prediction models ${ }^{15}$. The recently published transparent reporting of a multivariable prediction model for individual prognosis or 
diagnosis (TRIPOD) statement, may lead to improvements in the reporting quality of future studies ${ }^{30}$.

Risk of bias assessment revealed a moderate to high risk of bias in three out of four studies. The main sources of bias were in the domains of analysis, attrition and modeling. All studies selected predictors on the basis of statistical significance, which leads to a model that fits the data too closely ${ }^{24,31}$. Next, continuous variables were often dichotomized, in example age and BMI in two of our selected models, leading to loss of information ${ }^{32}$. Moreover, only one study, Beta et al., applied the regression shrinkage technique and only Alleman et al. performed an internal validation by bootstrapping. The methodological limitations mentioned could have been one of the reasons why the reported model performance was not achieved in our validation cohort.

Only Sananes et al. mentioned that they validated their model in another population, but the results were not reported. To our knowledge, no other independent external validation study of prediction models for SPTB exists. External validation is recommended to assess the generalizability to other 'related' populations ${ }^{24}$. Our comprehensive independent validation study indicated that all models overestimated performance measures. This illustrates the need for external validation of models before clinical implementation.

Nevertheless, performance measures do not indicate whether a model is clinically useful. Assessment of the clinical utility of the best discriminating model showed a very high false positive rate at acceptable sensitivity rates. These cut-off points result in a major proportion of nulliparous women being unnecessarily considered to be at high risk. Furthermore, for multiparous women the most important predictors are derived from a previous SPTB. In summary, we think that the clinical utility of currently available models is low.

\section{Implications}

This systematic review demonstrates shortcomings in the quality and performance of existing non-invasive prediction models for SPTB. Improvement of non-invasive models is necessary. The currently available prediction models mainly rely on previous PTB as predicting variable. However, models mainly relying upon a prior event as the discriminative factor do not add much clinical value since caregivers are already aware that these women are at high risk. Obstetric care would benefit from valid prediction of SPTB in nulliparous women ${ }^{11}$.

Future research should focus on the variety of published association studies when selecting candidate predictors. Another important well-known risk factor is cervical surgery $^{10,33}$. However, only a minority of women will be identified as high risk by adding this predictor ${ }^{11}$. Other routine clinical parameters that may also contribute to the prediction of SPTB in nulliparous women are: socio-economic status, psychological characteristics, family history, medical history, and smoking status ${ }^{10}$. Predictive performance of a model might improve by taking into account biomarkers or 
ultrasound imaging (i.e. cervical length). A few models based on cervical length measurements and biomarkers such as pregnancy-associated plasma protein A (PAPPA) or alpha-fetoprotein (AFP) have been published ${ }^{29,34,35}$. The reported discriminative performance of these models was only slightly better than the performance of models using maternal characteristics alone. We focused in this review on routine clinical parameters, as these 'specialized' tests are not always routinely performed or readily available in general care, and may generate substantial additional costs ${ }^{36}$. Lastly, different modeling methods can be employed as well. In this review, all selected studies used a multiple logistic regression model. Other methods that can be used are machine learning methods using health records, such as tree-based algorithms or neural networks ${ }^{37,38}$. However, despite all efforts, sPTB may remain a tough outcome to predict due to its heterogeneous and often unknown causes ${ }^{2}$.

Nevertheless, a future model with a moderate performance may still be useful. The tradeoff between the benefit of identifying women at high risk and the false positive rate is important. Using cervical length screening in all women results in the need to screen relatively high numbers of women ${ }^{11}$. A non-invasive model combined with a high sensitivity cut-off point will be able to identify women at very low risk of SPTB who could be excluded from cervical length screening, resulting in the need to screen a smaller number of women. Furthermore, such an approach creates the opportunity to identify women at high risk whom may benefit from preventive interventions such as progesterone treatment ${ }^{3-5}$.

\section{Strengths and limitations}

To our knowledge, this is the first systematic review of studies reporting non-invasive prediction models for the risk of SPTB. We had to exclude several published models as three models contained predictors which are not available in the first 16 weeks of pregnancy, in example fetal gender, since this is crucial for early prediction of SPTB. Moreover, three other models did not provide the algorithm, which is essential for independent external validation.

A strength of our study is that we validated all included prediction models in a large independent multicentre prospective cohort of unselected pregnant women. The data were very complete with a maximum of only $1.2 \%$ of missing values. However, although our cohort contained a sufficient number of cases for sPTB $<37$ weeks of gestation, there were only 34 cases for the secondary outcome sPTB $<34$ weeks of gestation. An inadequate sample size decreases the precision of external validation measures $^{22,39}$.

Our cohort might suffer from treatment bias to a small extent since we did not exclude women who had received treatment such as a cerclage or tocolysis. This may have resulted into the prevention of SPTB and thus an underestimation of model discrimination and calibration ${ }^{40}$. One of the selected studies, Alleman et al., explicitly reported exclusion of women undergoing cerclage or tocolysis from their study population $^{27}$. Parra-Cordero et al. only excluded women with a history of cerclage ${ }^{28}$. 


\section{Conclusion}

This review revealed several reporting and methodological shortcomings of published prediction models for SPTB. Our external validation indicated that none of the models had the ability to adequately predict SPTB in our population. Obstetric care would benefit most from models predicting SPTB accurately among nulliparous women since most of these women are indicated as low risk in current practice. 


\section{Supplementary materials}

Supplementary File S6.1

Supplementary Table S6.1

Supplementary Figure S6.1

Supplementary Table S6.2

Supplementary Table S6.3

Supplementary Table S6.4

Supplementary Table S6.5

Supplementary Table S6.6

Supplementary Table S6.7

Supplementary Figure S6.2

Supplementary Figure S6.3

\section{Search strategy}

Framework of systematic research aim according to the CHARMS checklist ${ }^{19}$

Flowchart study selection

Definition and assessment predictors included prediction models for spontaneous preterm birth

Model algorithms for prediction of spontaneous preterm birth.

Data extraction of included studies according to the CHARMS checklist ${ }^{19}$

Risk of bias assessment according to the CHARMS checklist ${ }^{19}$ and a study of Smit et al. $(2015)^{20}$

Characteristics of pregnancies in the observed and imputed validation cohort

Baseline characteristics original cohorts and validation cohort

Calibration plots of recalibrated first trimester prediction models for spontaneous preterm birth (sPTB) $<37$ weeks of gestation. The grey line is the reference line with intercept $=0$ and slope $=1$ (perfect calibration). Triangles correspond to grouped predicted risks with $95 \%$ confidence intervals (vertical lines). CF, correction factor

Calibration plots of recalibrated first trimester prediction models for spontaneous preterm birth (sPTB) <34 weeks of gestation. The grey line is the reference line with intercept $=0$ and slope $=1$ (perfect calibration). Triangles correspond to grouped predicted risks with $95 \%$ confidence intervals (vertical lines). CF, correction factor 


\section{References}

1. Euro-Peristat Project with SCPE and EUROCAT, European Perinatal Health Report. The Health and care of pregnant women and babies in Europe in 2010. 2013: p. 113.

2. Goldenberg, R.L., Culhane, J.F., lams, J.D., and Romero, R., Epidemiology and causes of preterm birth. Lancet, 2008. 371(9606): p. 75-84.

3. Saigal, S. and Doyle, L.W., An overview of mortality and sequelae of preterm birth from infancy to adulthood. Lancet, 2008. 371(9608): p. 261-9.

4. lams, J.D., Romero, R., Culhane, J.F., and Goldenberg, R.L., Primary, secondary, and tertiary interventions to reduce the morbidity and mortality of preterm birth. Lancet, 2008. 371(9607): p. 164-75.

5. Dodd, J.M., Jones, L., Flenady, V., Cincotta, R., and Crowther, C.A., Prenatal administration of progesterone for preventing preterm birth in women considered to be at risk of preterm birth. Cochrane Database Syst Rev, 2013. 31(7): p. Cd004947.

6. Romero, R., Conde-Agudelo, A., Da Fonseca, E., O'Brien, J.M., Cetingoz, E., Creasy, G.W., et al., Vaginal progesterone for preventing preterm birth and adverse perinatal outcomes in singleton gestations with a short cervix: a meta-analysis of individual patient data. Am J Obstet Gynecol, 2018. 218(2): p. 161-180.

7. Gilner, J. and Biggio, J., Management of Short Cervix during Pregnancy: A Review. Am J Perinatol, 2016. 33(3): p. 245-52.

8. Alfirevic, Z., Stampalija, T., and Medley, N., Cervical stitch (cerclage) for preventing preterm birth in singleton pregnancy. Cochrane Database Syst Rev, 2017. 6: p. Cd008991.

9. Zheng, L., Dong, J., Dai, Y., Zhang, Y., Shi, L., Wei, M., et al., Cervical pessaries for the prevention of preterm birth: a systematic review and meta-analysis. J Matern Fetal Neonatal Med, 2017: p. 1-10.

10. Koullali, B., Oudijk, M.A., Nijman, T.A., Mol, B.W., and Pajkrt, E., Risk assessment and management to prevent preterm birth. Semin Fetal Neonatal Med, 2016. 21(2): p. 80-8.

11. Ven, J., Os, M.A., Kazemier, B.M., Kleinrouweler, E., Verhoeven, C.J., Miranda, E., et al., The capacity of mid-pregnancy cervical length to predict preterm birth in low-risk women: a national cohort study. Acta Obstet Gynecol Scand, 2015. 94(11): p. 1223-1234.

12. Esplin, M.S., Elovitz, M.A., lams, J.D., Parker, C.B., Wapner, R.J., Grobman, W.A., et al., Predictive Accuracy of Serial Transvaginal Cervical Lengths and Quantitative Vaginal Fetal Fibronectin Levels for Spontaneous Preterm Birth Among Nulliparous Women. JAMA, 2017. 317(10): p. 1047-1056.

13. Goffinet, F., Primary predictors of preterm labour. BJOG, 2005. 112(s1): p. 38-47.

14. Honest, H., Bachmann, L.M., Sundaram, R., Gupta, J.K., Kleijnen, J., and Khan, K.S., The accuracy of risk scores in predicting preterm birth--a systematic review. J Obstet Gynaecol, 2004. 24(4): p. 343-59.

15. Kleinrouweler, C.E., Cheong-See, F.M., Collins, G.S., Kwee, A., Thangaratinam, S., Khan, K.S., et al., Prognostic models in obstetrics: available, but far from applicable. Am J Obstet Gynecol, 2016. 214(1): p. 79-90. e36.

16. Steyerberg, E.W., Vickers, A.J., Cook, N.R., Gerds, T., Gonen, M., Obuchowski, N., et al., Assessing the performance of prediction models: a framework for traditional and novel measures. Epidemiology, 2010. 21(1): p. 128-38.

17. Steyerberg, E.W. and Vergouwe, Y., Towards better clinical prediction models: seven steps for development and an ABCD for validation. Eur Heart J, 2014. 35(29): p. 1925-31.

18. Debray, T.P., Damen, J.A., Snell, K.I., Ensor, J., Hooft, L., Reitsma, J.B., et al., A guide to systematic review and meta-analysis of prediction model performance. BMJ, 2017. 356: p. i6460.

19. Moons, K.G., de Groot, J.A., Bouwmeester, W., Vergouwe, Y., Mallett, S., Altman, D.G., et al., Critical appraisal and data extraction for systematic reviews of prediction modelling studies: the CHARMS checklist. PLoS Med, 2014. 11(10): p. e1001744.

20. Smit, H.A., Pinart, M., Anto, J.M., Keil, T., Bousquet, J., Carlsen, K.H., et al., Childhood asthma prediction models: a systematic review. Lancet Respir Med, 2015. 3(12): p. 973-84.

21. Meertens, L.J.E., Scheepers, H.C., De Vries, R.G., Dirksen, C.D., Korstjens, I., Mulder, A.L., et al., External Validation Study of First Trimester Obstetric Prediction Models (Expect Study I): Research Protocol and Population Characteristics. JMIR Res Protoc, 2017. 6(10): p. e203. 
22. Vergouwe, Y., Steyerberg, E.W., Eijkemans, M.J., and Habbema, J.D., Substantial effective sample sizes were required for external validation studies of predictive logistic regression models. J Clin Epidemiol, 2005. 58(5): p. 475-83.

23. Van Buuren, S., Flexible imputation of missing data. 2012: CRC press.

24. Steyerberg, E., Clinical prediction models: a practical approach to development, validation, and updating. 2008: Springer Science \& Business Media.

25. Vickers, A.J. and Elkin, E.B., Decision curve analysis: a novel method for evaluating prediction models. Med Decis Making, 2006. 26(6): p. 565-74.

26. Sananes, N., Meyer, N., Gaudineau, A., Aissi, G., Boudier, E., Fritz, G., et al., Prediction of spontaneous preterm delivery in the first trimester of pregnancy. Eur J Obstet Gynecol Reprod Biol, 2013. 171(1): $p$. 18-22.

27. Alleman, B.W., Smith, A.R., Byers, H.M., Bedell, B., Ryckman, K.K., Murray, J.C., et al., A proposed method to predict preterm birth using clinical data, standard maternal serum screening, and cholesterol. Am J Obstet Gynecol, 2013. 208(6): p. 472. e1-472. e11.

28. Parra-Cordero, M., Sepúlveda-Martínez, A., Rencoret, G., Valdés, E., Pedraza, D., and Muñoz, H., Is there a role for cervical assessment and uterine artery Doppler in the first trimester of pregnancy as a screening test for spontaneous preterm delivery? Ultrasound Obstet Gynecol, 2014. 43(3): p. 291296.

29. Beta, J., Akolekar, R., Ventura, W., Syngelaki, A., and Nicolaides, K.H., Prediction of spontaneous preterm delivery from maternal factors, obstetric history and placental perfusion and function at 1113 weeks. Prenat Diagn, 2011. 31(1): p. 75-83.

30. Collins, G.S., Reitsma, J.B., Altman, D.G., and Moons, K.G., Transparent reporting of a multivariable prediction model for individual prognosis or diagnosis (TRIPOD): the TRIPOD statement. BMC Med, 2015. 13(1): p. 1.

31. Harrell, F., Regression modeling strategies: with applications to linear models, logistic and ordinal regression, and survival analysis. 2015: Springer.

32. Royston, P., Altman, D.G., and Sauerbrei, W., Dichotomizing continuous predictors in multiple regression: a bad idea. Stat Med, 2006. 25(1): p. 127-141.

33. Castanon, A., Landy, R., Brocklehurst, P., Evans, H., Peebles, D., Singh, N., et al., Risk of preterm delivery with increasing depth of excision for cervical intraepithelial neoplasia in England: nested case-control study. BMJ, 2014. 349: p. g6223.

34. van Ravenswaaij, R., Tesselaar-van der Goot, M., de Wolf, S., van Leeuwen-Spruijt, M., Visser, G.H., and Schielen, P.C., First-trimester serum PAPP-A and fbeta-hCG concentrations and other maternal characteristics to establish logistic regression-based predictive rules for adverse pregnancy outcome. Prenat Diagn, 2011. 31(1): p. 50-7.

35. Poon, L.C., Nekrasova, E., Anastassopoulos, P., Livanos, P., and Nicolaides, K.H., First-trimester maternal serum matrix metalloproteinase-9 (MMP-9) and adverse pregnancy outcome. Prenat Diagn, 2009. 29(6): p. 553-9.

36. Steyerberg, E.W., Moons, K.G., van der Windt, D.A., Hayden, J.A., Perel, P., Schroter, S., et al., Prognosis Research Strategy (PROGRESS) 3: prognostic model research. PLoS Med, 2013. 10(2): p. e1001381.

37. Goldstein, B.A., Navar, A.M., and Carter, R.E., Moving beyond regression techniques in cardiovascular risk prediction: applying machine learning to address analytic challenges. Eur Heart J, 2016.

38. Peissig, P.L., Santos Costa, V., Caldwell, M.D., Rottscheit, C., Berg, R.L., Mendonca, E.A., et al., Relational machine learning for electronic health record-driven phenotyping. J Biomed Inform, 2014. 52: p. 260-70.

39. Collins, G.S., Ogundimu, E.O., and Altman, D.G., Sample size considerations for the external validation of a multivariable prognostic model: a resampling study. Stat Med, 2016. 35(2): p. 214-226.

40. Pajouheshnia, R., Peelen, L.M., Moons, K.G., Reitsma, J.B., and Groenwold, R.H., Accounting for treatment use when validating a prognostic model: a simulation study. BMC Med Res Methodol, 2017. 17(1): p. 103. 


\section{Supplementary File S6.1 - Search strategy}

\section{PubMed}

("predictive model"[tiab] OR "predictive models"[tiab] OR prediction[tiab] OR "risk calculator"[tiab] OR "risk calculators"[tiab] OR "risk model"[tiab] OR "risk models"[tiab] OR "risk score"[tiab] OR algorithm*[tiab] OR "risk assessment"[tiab] OR nomogram[tiab] OR "prognostic model"[tiab] OR "prognostic models"[tiab] OR "scoring system"[tiab] OR "scoring systems"[tiab] OR "screening model"[tiab] OR "screening models"[tiab] OR "decision rule"[tiab] OR "decision rules"[tiab]) AND ("preterm labour"[tiab] OR "premature labour"[tiab] OR "premature labor"[tiab] OR "premature delivery"[tiab] OR "premature deliveries"[tiab] OR "premature parturition"[tiab] OR "premature birth"[tiab] OR "preterm labor"[tiab] OR "preterm birth"[tiab] OR "preterm delivery"[tiab] OR "preterm deliveries"[tiab] OR "preterm parturition"[tiab] OR "Premature Birth"[Mesh])

\section{Embase}

1. predictive model.ab,ti.

2. predictive models.ab,ti.

3. prediction.ab,ti.

4. risk calculator.ab,ti.

5. risk calculators.ab,ti.

6. risk model.ab,ti.

7. risk models.ab,ti.

8. risk score.ab,ti.

9. algorithm.ab,ti.

10. risk assessment.ab,ti.

11. nomogram.ab,ti.

12. prognostic model.ab,ti.

13. prognostic models.ab,ti.

14. scoring system.ab,ti.

15. scoring systems.ab,ti.

16. screening model.ab,ti.

17. screening models.ab,ti.

18. decision rule.ab,ti.

19. decision rules.ab,ti.

20. 1 or 2 or 3 or 4 or 5 or 6 or 7 or 8 or 9 or 10 or 11 or 12 or 13 or 14 or 15 or 16 or 17 or 18 or 19

21. preterm labour.ab,ti.

22. preterm labor.ab,ti.

23. premature labour.ab,ti.

24. premature labor.ab,ti.

25. premature delivery.ab,ti. 
26. premature deliveries.ab,ti.

27. premature parturition.ab,ti.

28. premature birth.ab,ti.

29. preterm birth.ab,ti.

30. preterm delivery.ab,ti.

31. preterm deliveries.ab,ti.

32. preterm parturition.ab,ti.

33. 21 or 22 or 23 or 24 or 25 or 26 or 27 or 28 or 29 or 30 or 31 or 32

34. 20 and 33

35. remove duplicates from 34 
Supplementary Table S6.1 Framework of systematic research aim according to the CHARMS checklist ${ }^{19}$

\begin{tabular}{|c|c|}
\hline Item & Systematic review aim \\
\hline Type of prediction model & Prognostic prediction model \\
\hline Intended scope of review & $\begin{array}{l}\text { Reviewing prediction models that may help identifying } \\
\text { women who are at high risk for spontaneous preterm birth to } \\
\text { aid decision-making regarding preventive interventions or } \\
\text { closer monitoring }\end{array}$ \\
\hline Type of prediction modelling studies & Model development studies and model validation studies \\
\hline Target population & Overall pregnant population \\
\hline Outcome to be predicted & Probability of spontaneous preterm birth \\
\hline Time span of prediction & $\begin{array}{l}\text { First trimester prediction for probability of the outcome in } \\
\text { current pregnancy }\end{array}$ \\
\hline Intended moment of using the model & First trimester of pregnancy \\
\hline
\end{tabular}

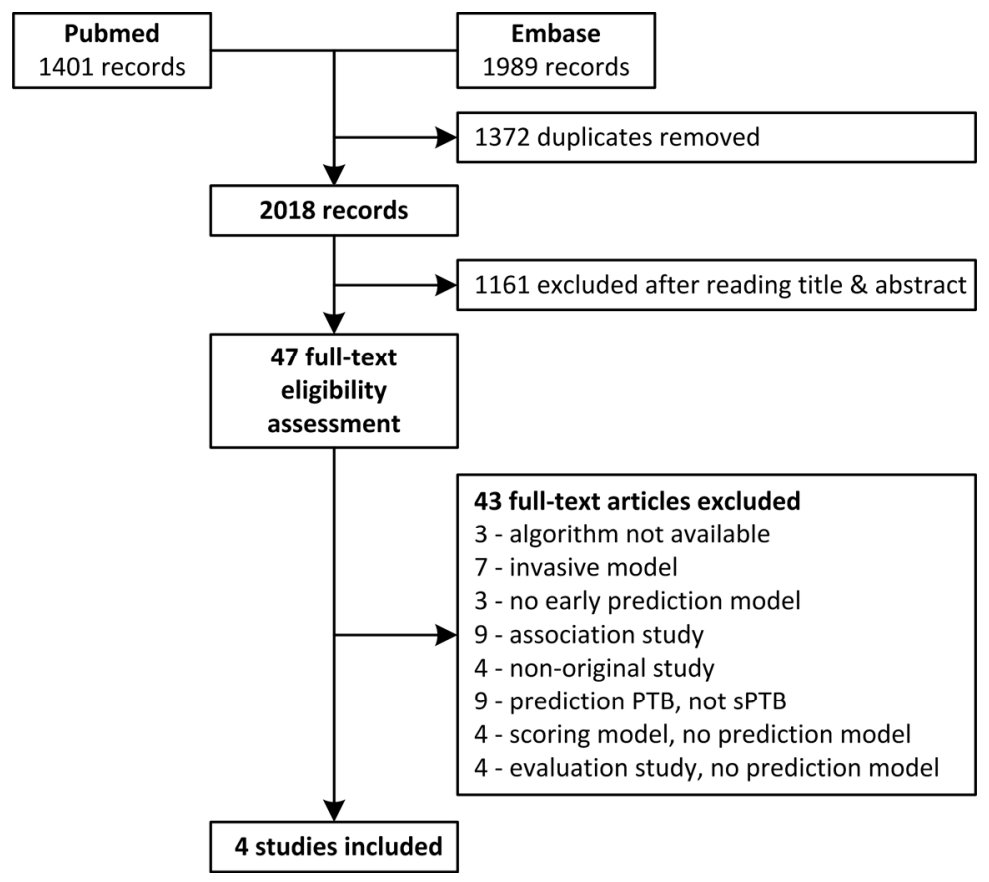

Supplementary Figure S6.1 Flowchart study selection 
Supplementary Table S6.2 Definition and assessment predictors included prediction models for spontaneous preterm birth

\begin{tabular}{|c|c|c|}
\hline Predictor & $\begin{array}{l}\text { Definition (D)/measurement (M) } \\
\text { original studies }\end{array}$ & $\begin{array}{l}\text { Definition/measurement validation } \\
\text { cohort (Expect Study I) }\end{array}$ \\
\hline Age, years & $\begin{array}{l}\frac{\text { Sananes } 2013}{D: \text { Continuous in years, categorized as }} \\
\text { maternal age } \leq 22 \text { or } \geq 35 \text { years. } \\
\text { M: Electronic medical records. } \\
\frac{\text { Beta } 2011}{\text { D: Continuous in years. }} \\
\text { M: Self-reported questionnaire } 11^{+0} \text { - } \\
13^{+6} \text { weeks of gestation. }\end{array}$ & $\begin{array}{l}\text { Self-reported pregnancy questionnaire } \\
1 \text { and checked for discrepancies by } \\
\text { obstetric record. Measured continuous } \\
\text { in years, transformed into categorical } \\
\text { variable according to definition original } \\
\text { prediction model. }\end{array}$ \\
\hline Assisted conception & $\begin{array}{l}\frac{\text { Beta } 2011}{\text { D: Method of conception (spontaneous }} \\
\text { or conceived on ovulation induction } \\
\text { drugs). } \\
\text { M: Self-reported questionnaire } 11^{+0}- \\
13^{+6} \text { weeks of gestation. }\end{array}$ & $\begin{array}{l}\text { Self-reported pregnancy questionnaire } \\
1, \text { method of conception (spontaneous, } \\
\text { use of ovulation drugs or in vitro } \\
\text { fertilization). }\end{array}$ \\
\hline Body mass index, $\mathrm{kg} / \mathrm{m}^{2}$ & $\begin{array}{l}\frac{\text { Sananes } 2013}{\mathrm{D}: \text { Body mass index at the beginning of }} \\
\text { pregnancy, categorized as } \leq 19.5 \mathrm{~kg} / \mathrm{m}^{2} \text {. } \\
\text { M: Electronic medical records. } \\
\frac{\text { Alleman } 2013}{\mathrm{D}: \text { Measured body mass index during }} \\
\text { first trimester. Body mass index was } \\
\text { categorized as }<18.5 \mathrm{~kg} / \mathrm{m}^{2} \text { and }>40 \\
\mathrm{~kg} / \mathrm{m}^{2} \text {. } \\
\mathrm{M}: \text { Medical records. }\end{array}$ & $\begin{array}{l}\text { Self-reported pregnancy questionnaire } \\
1 \text {, height in centimetres and pre- } \\
\text { pregnancy weight in kilograms. BMI } \\
\text { was calculated as weight (kilograms) } \\
\text { divided by the squared height (meters). } \\
\text { Categorical variables generated } \\
\text { according to definition original } \\
\text { prediction model. }\end{array}$ \\
\hline Diabetes mellitus & $\begin{array}{l}\frac{\text { Alleman } 2013}{\text { D: Prepregnancy diabetes. }} \\
\text { M: Neonatal birth certificates. }\end{array}$ & $\begin{array}{l}\text { Self-reported pregnancy questionnaire } \\
1 \text {, pre-existing diabetes mellitus (type). }\end{array}$ \\
\hline Education & $\begin{array}{l}\text { Alleman } 2013 \\
\text { D: Maternal postsecondary degree } \\
\text { defined as an associate's degree or } \\
\text { higher. } \\
\text { M: Neonatal birth certificates. }\end{array}$ & $\begin{array}{l}\text { Self-reported pregnancy questionnaire } \\
1 \text {, highest level of education (primary, } \\
\text { secondary, postsecondary, and tertiary } \\
\text { level of education). We defined } \\
\text { postsecondary degree as a tertiary level } \\
\text { of education. }\end{array}$ \\
\hline
\end{tabular}


Supplementary Table S6.2 (continued) Definition and assessment predictors included prediction models for spontaneous preterm birth

\begin{tabular}{|c|c|c|}
\hline Predictor & $\begin{array}{l}\text { Definition (D)/measurement (M) } \\
\text { original studies }\end{array}$ & $\begin{array}{l}\text { Definition/measurement validation } \\
\text { cohort (Expect Study I) }\end{array}$ \\
\hline Ethnicity & $\begin{array}{l}\text { Beta } 2011 \\
\text { D: Ethnic origin divided into Caucasian, } \\
\text { Afro-Caribbean, Indian or Pakistani or } \\
\text { Bangladeshi (South Asian), Chinese or } \\
\text { Japanese (East Asian) and mixed. } \\
\text { M: Self-reported questionnaire } 11^{+0} \text { - } \\
13^{+6} \text { weeks of gestation. }\end{array}$ & $\begin{array}{l}\text { Self-reported pregnancy questionnaire } \\
\text { 1, ethnicity was divided into ten } \\
\text { subgroups: Dutch, Turkish/Kurdish, } \\
\text { Moroccan (Moroccan, Algerian, North } \\
\text { African), African (African, } \\
\text { Surinamese/Antillean of Negroid } \\
\text { origin), Hindustani (Hindustani, } \\
\text { Pakistani, Indian, Surinamese / } \\
\text { Antillean of Hindu origin), Middle East } \\
\text { (Iran, Iraqi, Afghan), Asian (Chinese, } \\
\text { Japanese, Indonesian, Albanian, } \\
\text { Vietnamese), Other Western } \\
\text { (European, North American, } \\
\text { Australian), Other Non-Western (South } \\
\text { and Central American), and mixed. } \\
\text { Ethnicity was recoded to Caucasian, } \\
\text { Asian, Afro-Caribbean, Hispanic, and } \\
\text { mixed (combination of other } \\
\text { categories). Subdivision of Asian } \\
\text { ethnicity was based on country of birth } \\
\text { biological parents. }\end{array}$ \\
\hline
\end{tabular}

Height, cm

History of fetal loss $<16$ weeks of gestation

History of iatrogenic preterm birth

\section{Beta 2011}

D: Continuous in centimetres.

$\mathrm{M}$ : Height measured at routine assessment at $11^{+0}-13^{+6}$ weeks of gestation.

Beta 2011

D: Previous miscarriage or termination before 16 weeks.

M: Self-reported questionnaire $11^{+0}$ $13^{+6}$ weeks of gestation.

\section{Beta 2011}

D: Parous iatrogenic preterm delivery before 37 weeks.

M: Self-reported questionnaire $11^{+0}$ $13^{+6}$ weeks of gestation.
Beta 2011: we added women with an Asian ethnicity other than South Asian or East Asian to the category mixed. Hispanics were categorized as Caucasians.

Self-reported pregnancy questionnaire 1 , height in centimetres.

Self-reported pregnancy questionnaire 1 , previous pregnancies (miscarriages and terminations $<16$ weeks of gestation). Obstetric records were checked for discrepancies. Self-reported pregnancy questionnaire 1 , previous pregnancies (gestational age at delivery and spontaneous onset labour). Obstetric records were checked for additional information about onset of labour.

We defined history of iatrogenic preterm delivery as a prior iatrogenic preterm birth $\geq 24$ weeks of gestation. 
Supplementary Table S6.2 (continued) Definition and assessment predictors included prediction models for spontaneous preterm birth

\begin{tabular}{|c|c|c|}
\hline Predictor & $\begin{array}{l}\text { Definition (D)/measurement (M) } \\
\text { original studies }\end{array}$ & $\begin{array}{l}\text { Definition/measurement validation } \\
\text { cohort (Expect Study I) }\end{array}$ \\
\hline History of live birth & $\begin{array}{l}\text { Alleman } 2013 \\
\text { D: Previous live birth. } \\
\text { M: Neonatal birth certificates. }\end{array}$ & $\begin{array}{l}\text { Self-reported pregnancy questionnaire } \\
1 \text {, previous pregnancies (live birth). }\end{array}$ \\
\hline History of preterm birth & $\begin{array}{l}\text { Parra-Cordero } 2014 \\
\text { D: Prior preterm delivery }<37 \text { weeks of } \\
\text { gestation. } \\
\text { M: Interview before the ultrasound } \\
\text { scan at } 11^{+0}-13^{+6} \text { weeks of gestation. } \\
\text { Sananes } 2013 \\
\text { D: Previous preterm deliveries } \\
\text { categorized as } 24-27 \text { weeks, } 28-33 \\
\text { weeks, and } 34-36 \text { weeks of gestation. } \\
\text { M: Electronic medical records. } \\
\text { Alleman } 2013 \\
\text { D: Previous preterm birth. } \\
\text { M: Neonatal birth certificates. }\end{array}$ & $\begin{array}{l}\text { Self-reported pregnancy questionnaire } \\
1, \text { previous pregnancies (gestational } \\
\text { age at delivery) and checked for } \\
\text { discrepancies by obstetric record. We } \\
\text { defined preterm birth as a delivery }<37 \\
\text { weeks of gestation. Categorical } \\
\text { variables generated according to } \\
\text { definition original prediction model. }\end{array}$ \\
\hline $\begin{array}{l}\text { History of spontaneous } \\
\text { preterm birth }\end{array}$ & $\begin{array}{l}\frac{\text { Sananes } 2013}{D: \text { History of miscarriage between } 16} \\
\text { and } 24 \text { weeks of gestation. } \\
\text { M: Electronic medical records. } \\
\text { Beta } 2011 \\
\text { D: Previous spontaneous deliveries } \geq 24 \\
\text { weeks of gestation, subdivided into: } 24- \\
27^{+6} \text { weeks, } 28-30^{+6} \text { weeks, } 31-33^{+6} \\
\text { weeks, and } 34-36^{+6} \text { weeks of gestation. } \\
\text { In a second model, the categories were } \\
\text { subdivided according to the number or } \\
\text { previous preterm deliveries: one or at } \\
\text { least two spontaneous deliveries } \\
\text { between } 16-30^{+6} \text { weeks of gestation } \\
\text { with and without additional deliveries } \\
\text { between } 31-36^{+6} \text { weeks or } \geq 37 \text { weeks } \\
\text { of gestation, and spontaneous delivery } \\
\text { between } 31-36^{+6} \text { weeks of gestation } \\
\text { with and without additional deliveries } \\
\geq 37 \text { weeks of gestation. } \\
M: \text { Self-reported questionnaire } 11^{+0}- \\
13^{+6} \text { weeks of gestation. }\end{array}$ & $\begin{array}{l}\text { Self-reported pregnancy questionnaire } \\
\text { 1, previous pregnancies (gestational } \\
\text { age at delivery and spontaneous onset } \\
\text { labour). Obstetric records were } \\
\text { checked for additional information } \\
\text { about onset of labour. Categorical } \\
\text { variables generated according to } \\
\text { definition original prediction model. }\end{array}$ \\
\hline History of term delivery & $\begin{array}{l}\frac{\text { Sananes } 2013}{\mathrm{D}: \text { Term delivery } \geq 37 \text { weeks of }} \\
\text { gestation. } \\
\text { M: Electronic medical records. } \\
\frac{\text { Beta } 2011}{\mathrm{D}: \text { Deliveries at or after } 37 \text { weeks. }} \\
\text { M: Self-reported questionnaire } 11^{+0}- \\
13^{+6} \text { weeks of gestation. }\end{array}$ & $\begin{array}{l}\text { Self-reported pregnancy questionnaire } \\
1 \text {, previous pregnancies (gestational } \\
\text { age at delivery). We defined term } \\
\text { delivery as a delivery } \geq 37 \text { weeks of } \\
\text { gestation. }\end{array}$ \\
\hline
\end{tabular}


Supplementary Table S6.2 (continued) Definition and assessment predictors included prediction models for spontaneous preterm birth

\begin{tabular}{|c|c|c|}
\hline Predictor & $\begin{array}{l}\text { Definition }(D) / \text { measurement }(M) \\
\text { original studies }\end{array}$ & $\begin{array}{l}\text { Definition/measurement validation } \\
\text { cohort (Expect Study I) }\end{array}$ \\
\hline Smoking & $\begin{array}{l}\text { Parra-Cordero } 2014 \\
\text { D: Smoking during pregnancy. } \\
\text { M: Interview before the ultrasound } \\
\text { scan at } 11^{+0}-13^{+6} \text { weeks of gestation. } \\
\text { Sananes } 2013 \\
\text { D: Smoking status during pregnancy. } \\
\text { M: Electronic medical records. } \\
\text { Beta } 2011 \\
\text { D: Cigarette smoker. } \\
\text { M: Self-reported questionnaire } 11^{+0}- \\
13^{+6} \text { weeks of gestation. }\end{array}$ & $\begin{array}{l}\text { Self-reported pregnancy questionnaire } \\
1 \text {, cigarette smoking status (non- } \\
\text { smoker, stopped during pregnancy, } \\
\text { current smokers) and number of } \\
\text { cigarettes a day. } \\
\text { Smoking status was recoded to } \\
\text { definition original prediction model. } \\
\text { We defined cigarette smoking as } \\
\text { current smoker at completion } \\
\text { pregnancy questionnaire } 1 .\end{array}$ \\
\hline
\end{tabular}




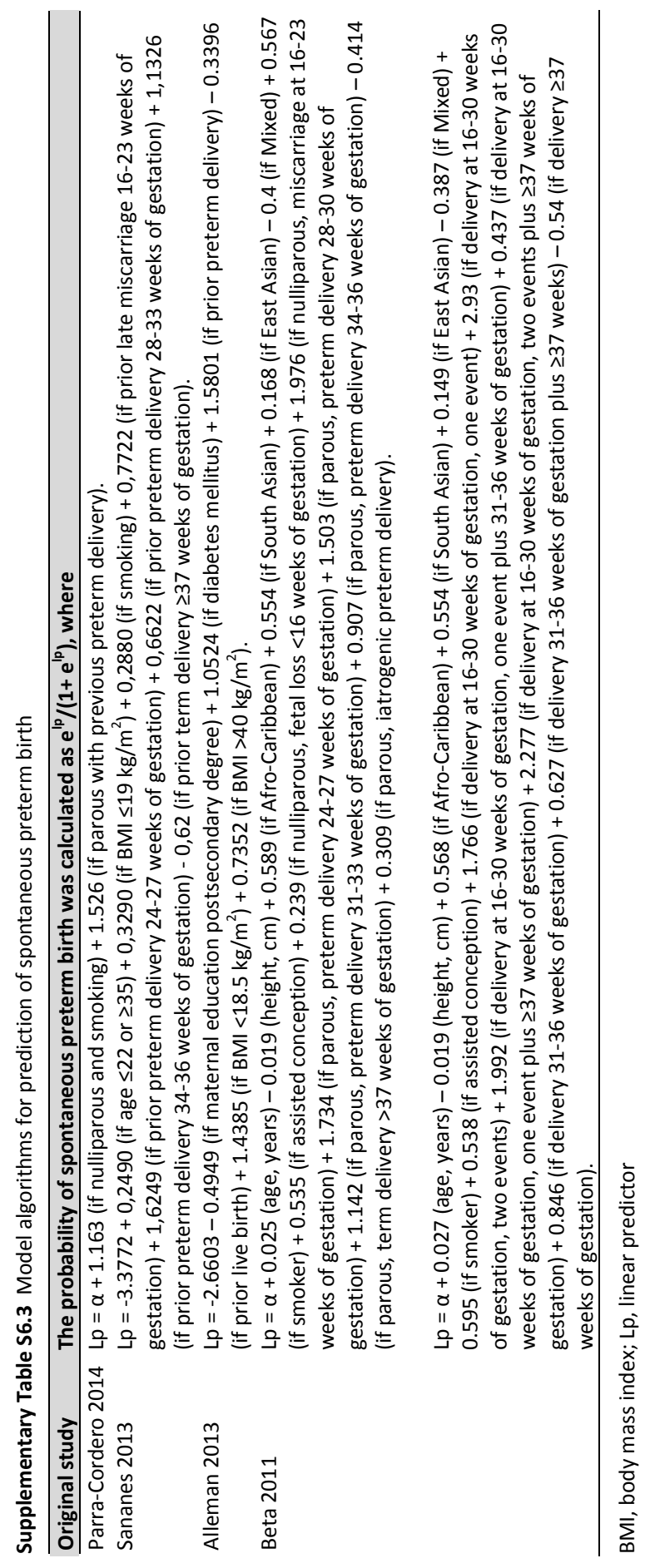




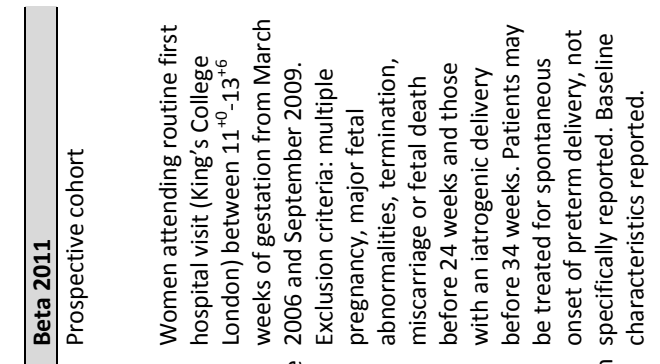

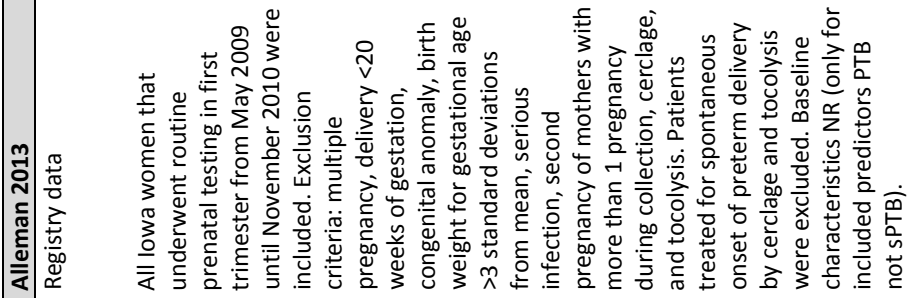

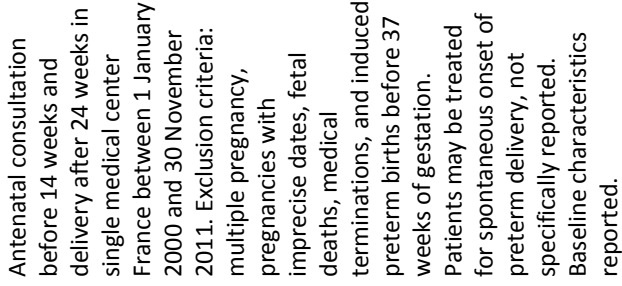

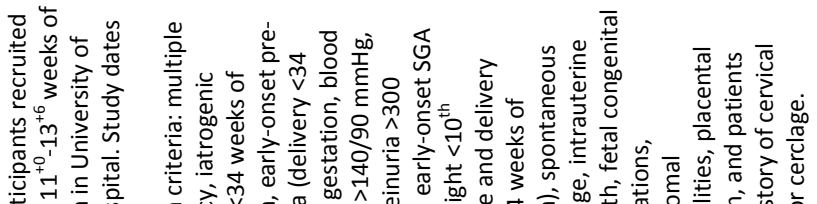

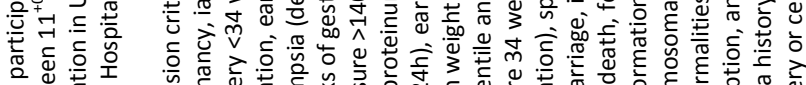

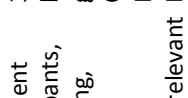

竞: 总

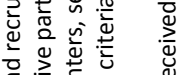

돈

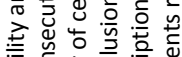

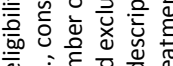

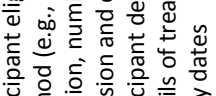

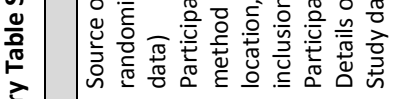

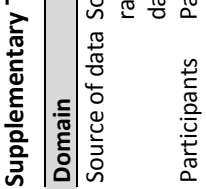

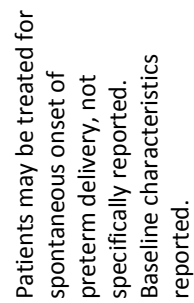




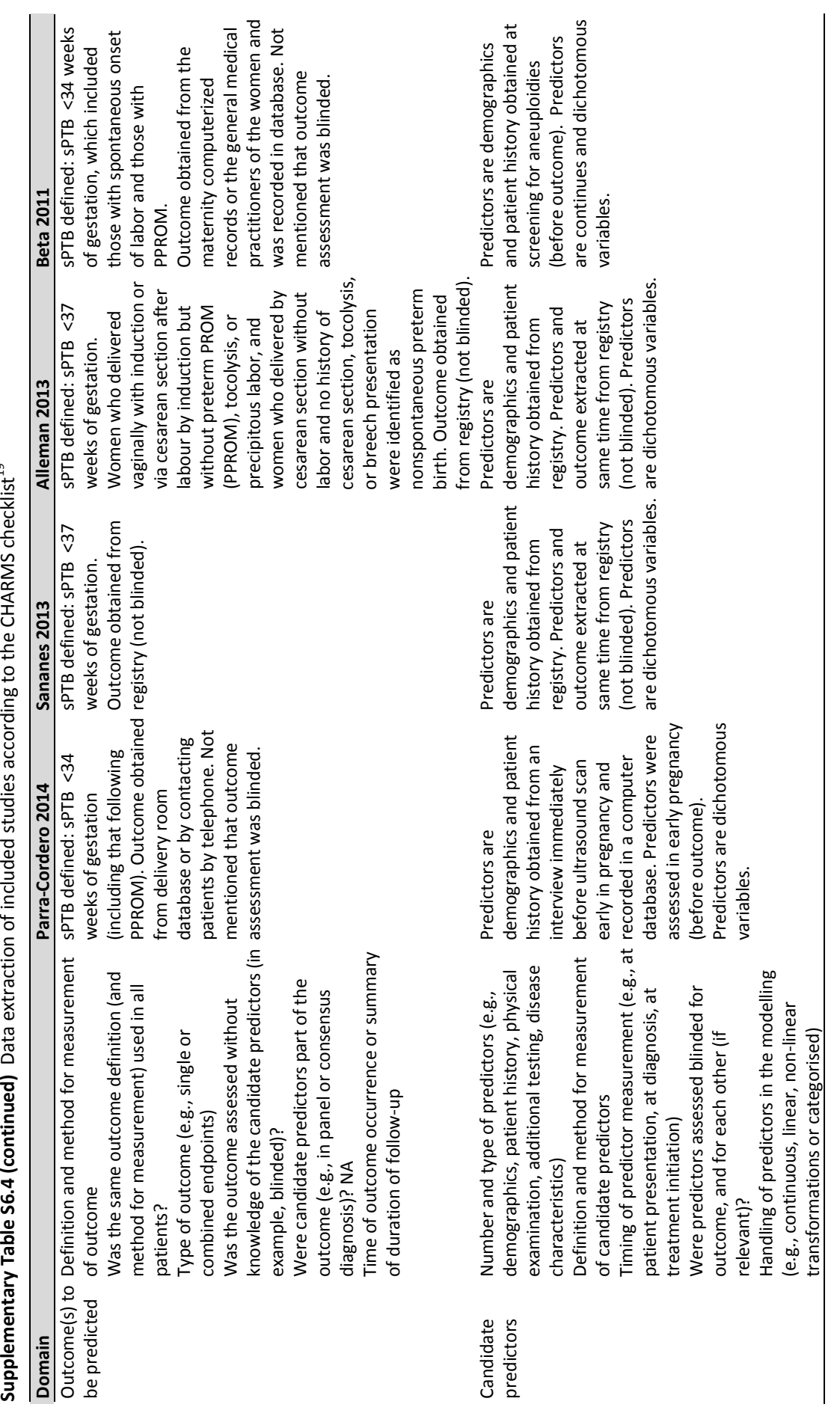




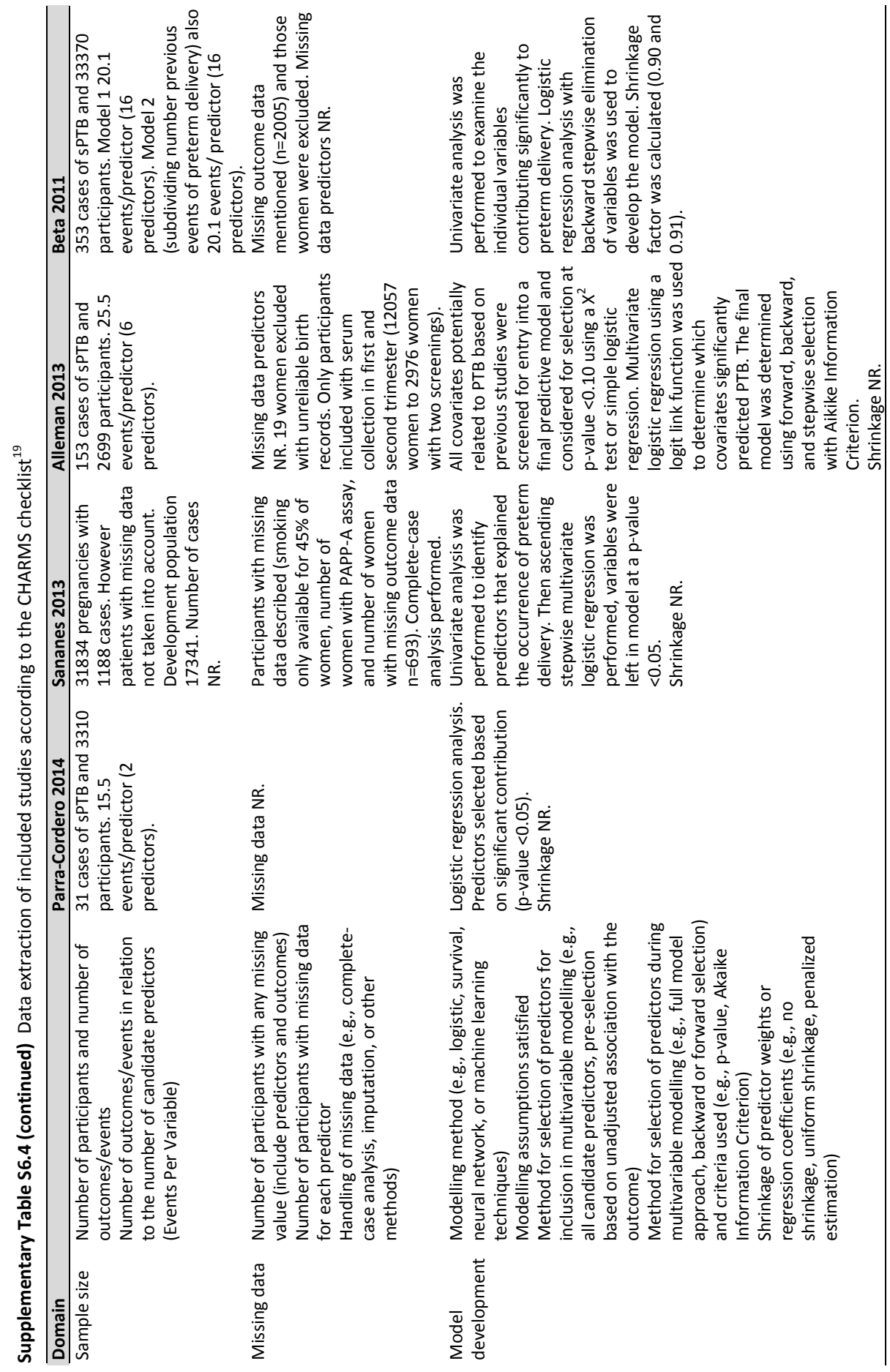




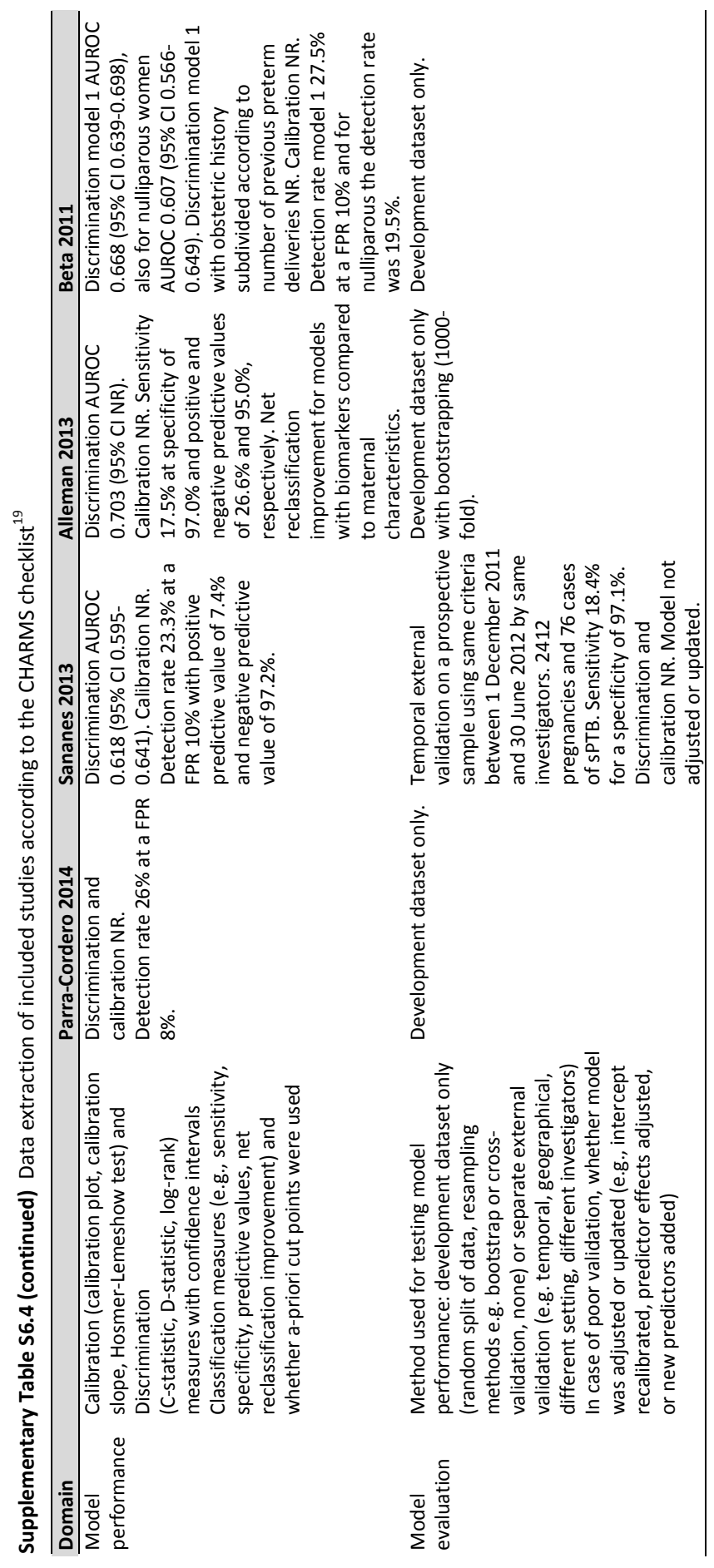




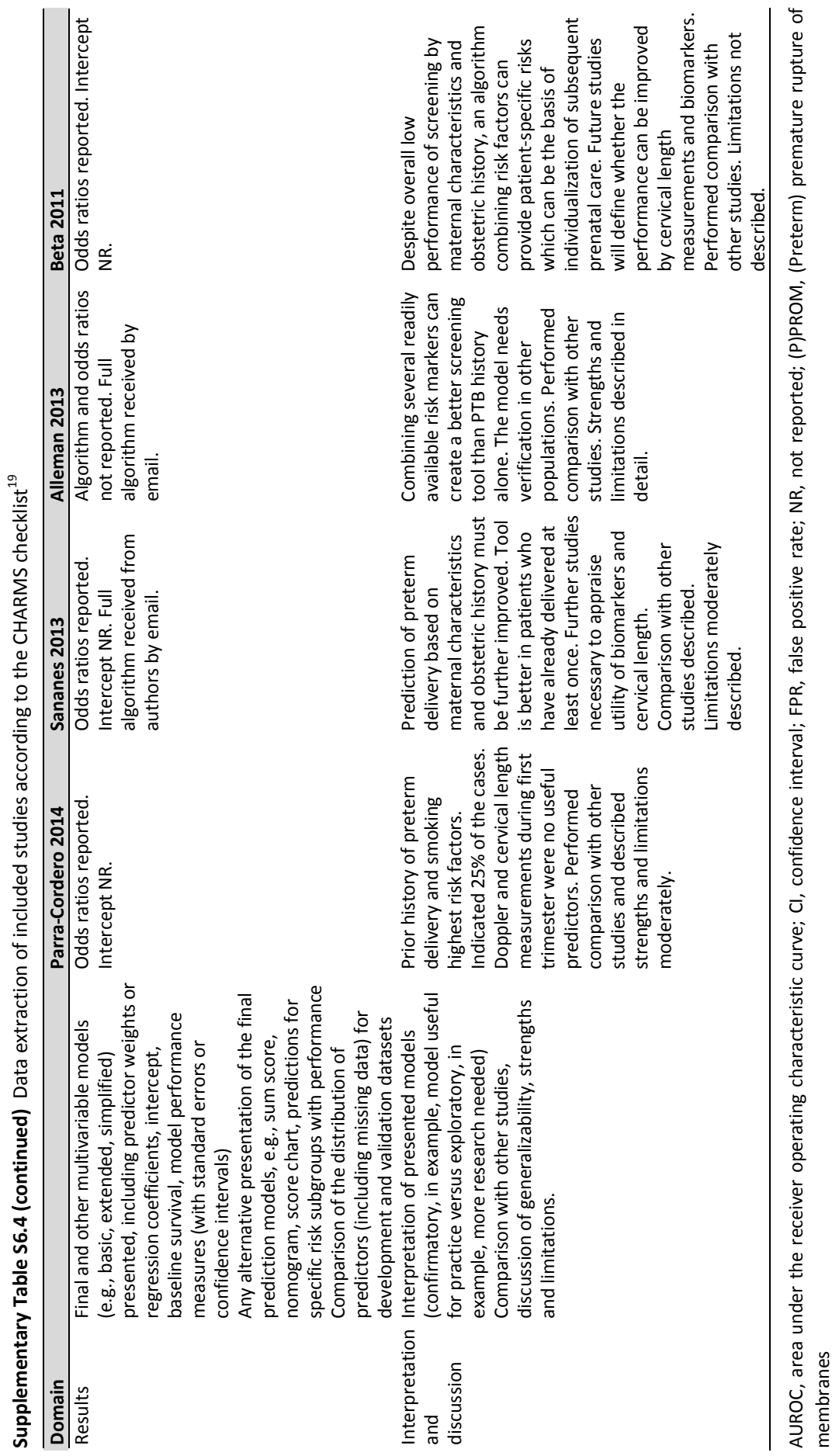




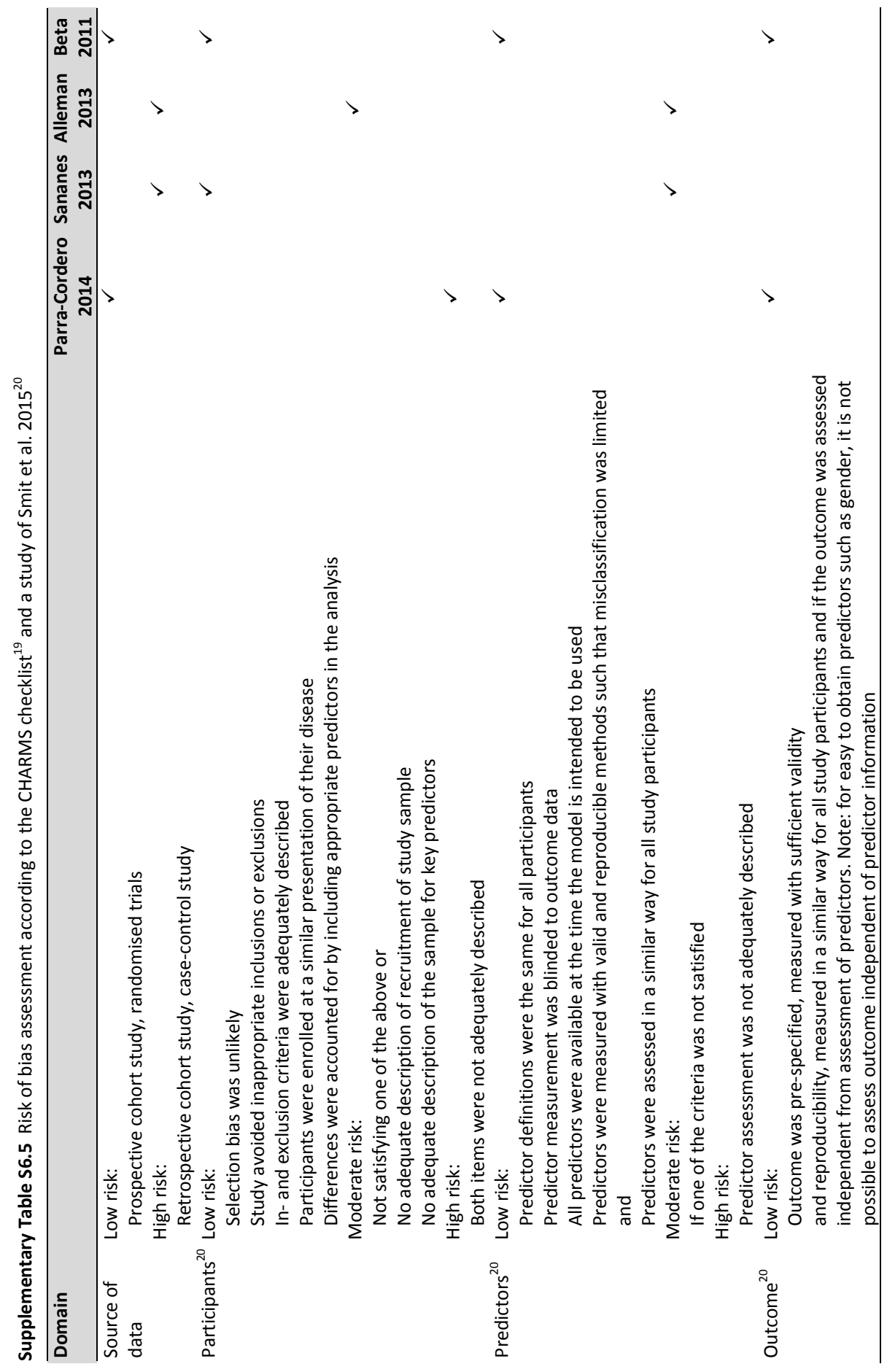




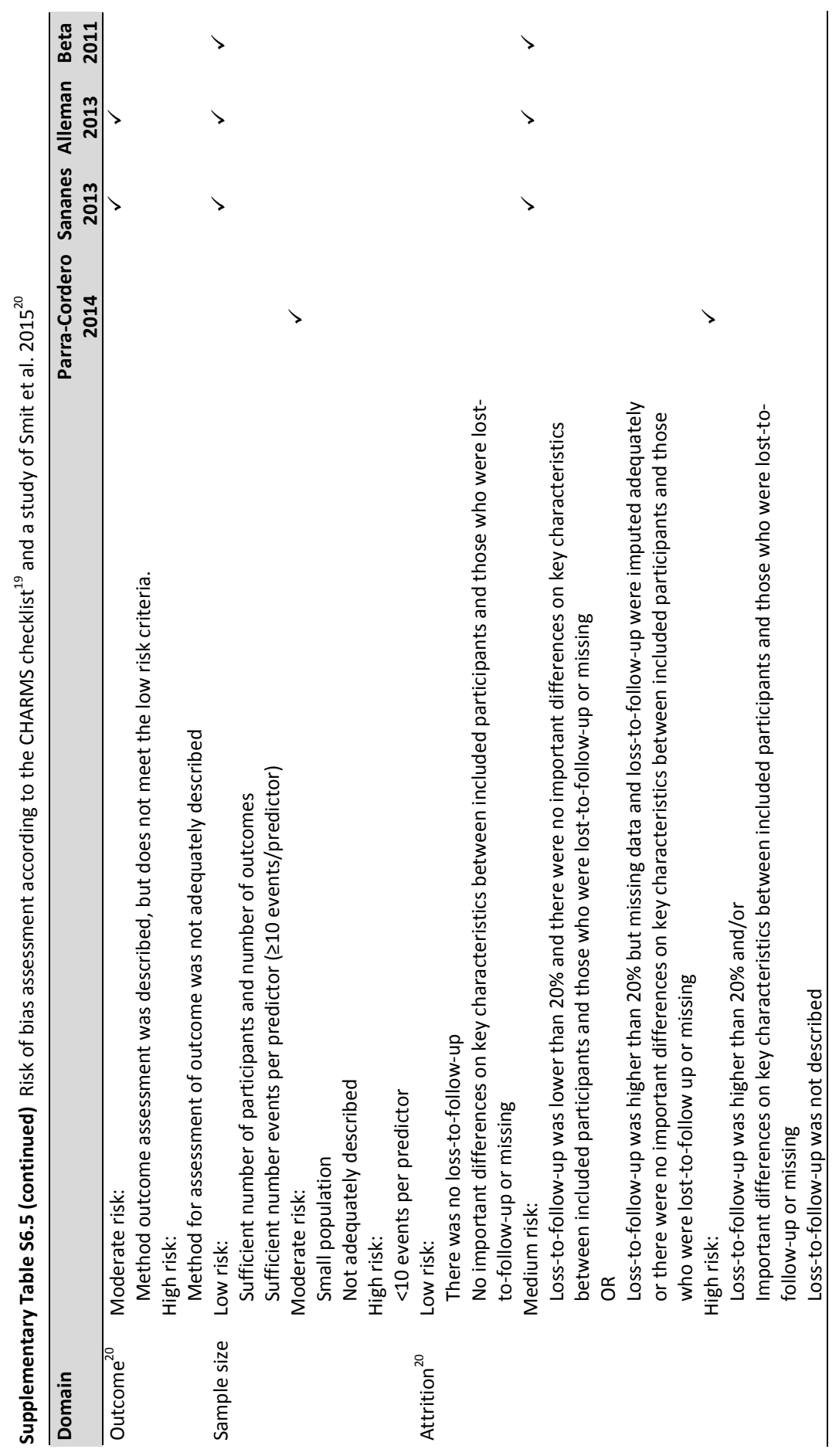


Prediction models for spontaneous preterm birth

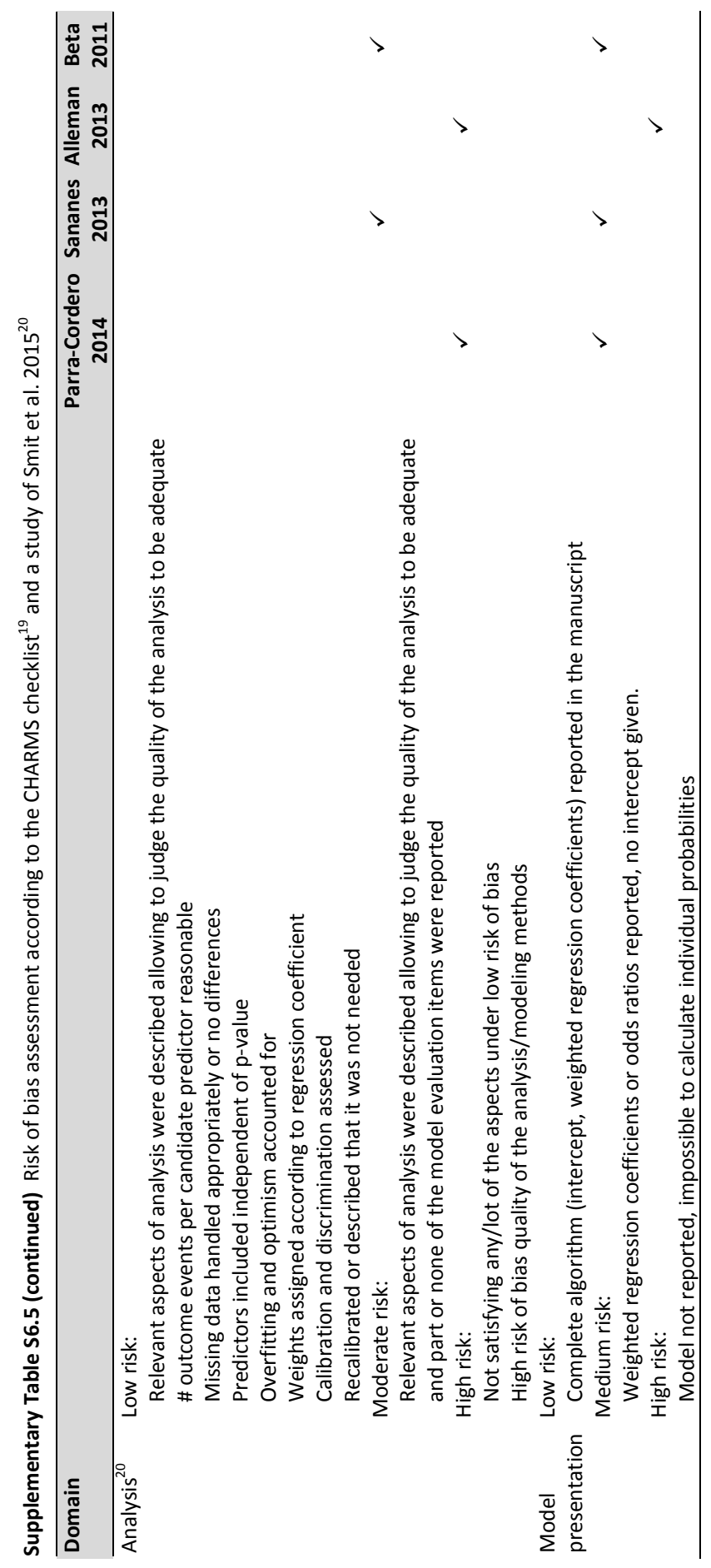


Supplementary Table S6.6 Characteristics of pregnancies in the observed and imputed validation cohort

\begin{tabular}{|c|c|c|c|c|}
\hline Characteristics & $\begin{array}{l}\text { Missing values, } \\
\mathrm{n}(\%)\end{array}$ & $\begin{array}{c}\text { Observed } \\
\text { Validation } \\
\text { cohort } \\
\text { Complete } \\
\text { cases }^{\mathrm{a}}(\mathrm{n}=2502)\end{array}$ & $\begin{array}{c}\text { Observed } \\
\text { Validation } \\
\text { cohort } \\
\text { Women with } \\
\text { missing } \\
\text { value }(s)^{\text {b }}(n=38)\end{array}$ & $\begin{array}{l}\text { Imputed } \\
\text { Validation } \\
\text { cohort } \\
(n=2540)\end{array}$ \\
\hline Age, years & $0(0.0)$ & $30.2(3.9)$ & $30.9(4.0)$ & $30.2(3.9)$ \\
\hline Ethnicity & $0(0.0)$ & & & \\
\hline Caucasian & & $2426(97.0)$ & $36(94.7)$ & 2462 (96.9) \\
\hline Afro-Caribbean & & $3(0.1)$ & $0(0.0)$ & $3(0.1)$ \\
\hline South Asian & & $3(0.1)$ & $1(2.6)$ & $4(0.2)$ \\
\hline East Asian & & $4(0.2)$ & $0(0.0)$ & $4(0.2)$ \\
\hline Other Asian & & $11(0.4)$ & $0(0.0)$ & $11(0.4)$ \\
\hline Hispanic & & $11(0.4)$ & $0(0.0)$ & $11(0.4)$ \\
\hline Mixed & & $44(1.8)$ & $1(2.6)$ & $45(1.8)$ \\
\hline Tertiary level of education & $3(0.1)$ & $1367(54.6)$ & $13(34.2)$ & $1380(54.3)$ \\
\hline Height, $\mathrm{cm}$ & $3(0.1)$ & $168.8(6.4)$ & $167.9(6.7)$ & $168.8(6.4)$ \\
\hline Weight, kg* & $5(0.2)$ & $68.8(13.0)$ & $71.6(12.9)$ & $68.9(13.0)$ \\
\hline Body mass index ${ }^{\#}, \mathrm{~kg} / \mathrm{m}^{2}$ & $5(0.2)$ & $24.1(4.3)$ & $25.3(4.2)$ & $24.1(4.3)$ \\
\hline Smoking during pregnancy & $1(0.0)$ & $145(5.8)$ & $4(10.5)$ & $150(5.9)$ \\
\hline Diabetes mellitus & $0(0.0)$ & $10(0.4)$ & $0(0.0)$ & $10(0.4)$ \\
\hline Type 1 & & $8(0.3)$ & $0(0.0)$ & $8(0.3)$ \\
\hline Type 2 & & $1(0.0)$ & $0(0.0)$ & $1(0.0)$ \\
\hline Other & & $1(0.0)$ & $0(0.0)$ & $1(0.0)$ \\
\hline History of chronic hypertension* & $0(0.0)$ & $23(0.9)$ & $1(2.6)$ & $24(0.9)$ \\
\hline Parity & $0(0.0)$ & & & \\
\hline Nulliparous & & $1280(51.2)$ & $4(10.5)$ & $1284(50.6)$ \\
\hline Primiparous & & $977(39.0)$ & $26(68.4)$ & $1003(39.5)$ \\
\hline Multiparous & & $245(9.8)$ & $8(21.1)$ & $253(9.9)$ \\
\hline Conception & $0(0.0)$ & & & \\
\hline Spontaneous & & $2338(93.4)$ & $37(97.4)$ & $2375(93.5)$ \\
\hline Ovulation induction & & $88(3.5)$ & $0(0.0)$ & $88(3.5)$ \\
\hline IVF/ICSI & & $76(3.0)$ & $1(2.6)$ & $77(3.0)$ \\
\hline $\begin{array}{l}\text { History of fetal loss }<16 \text { weeks of } \\
\text { gestation }\end{array}$ & $0(0.0)$ & $686(27.4)$ & $16(42.1)$ & $702(27.6)$ \\
\hline History of recurrent miscarriages $(\geq 3)^{*}$ & $0(0.0)$ & $46(1.8)$ & $3(7.9)$ & 49 (1.9) \\
\hline Vaginal bleeding ( $\geq 2$ days) ${ }^{*}$ & $0(0.0)$ & $275(11.0)$ & $2(5.3)$ & $277(10.9)$ \\
\hline History of spontaneous preterm & $30(1.2)$ & $75(3.0)$ & $1(2.6)$ & $77(3.0)$ \\
\hline delivery & & $3(0.1)$ & $1(2.6)$ & $4(0.2)$ \\
\hline $16-23$ weeks of gestation & & $7(0.3)$ & $0(0.0)$ & $7(0.3)$ \\
\hline 24-27 weeks of gestation & & $2(0.1)$ & $0(0.0)$ & $2(0.1)$ \\
\hline $28-30$ weeks of gestation & & $13(0.5)$ & $0(0.0)$ & $13(0.5)$ \\
\hline $\begin{array}{l}\text { 31-33 weeks of gestation } \\
34-36 \text { weeks of gestation }\end{array}$ & & $52(2.1)$ & $0(0.0)$ & $53(2.1)$ \\
\hline $\begin{array}{l}\text { History of iatrogenic preterm delivery } \\
\geq 24 \text { weeks of gestation }\end{array}$ & $29(1.1)$ & $43(1.7)$ & $1(2.6)$ & $44(1.7)$ \\
\hline History of term delivery & $29(1.1)$ & $1128(45.1)$ & $2(5.3)$ & 1159 (45.6) \\
\hline History of live birth & $18(0.7)$ & $1206(48.2)$ & $15(39.5)$ & 1239 (48.8) \\
\hline
\end{tabular}

${ }^{a}$ All predictor values of the included models were complete; ${ }^{b}$ At least one missing value for a predictor of the included models; *Not a predictor in the included models; \#Recoded/calculated on the basis of (imputed) original variables. ICSI, intracytoplasmic sperm injection; IVF, in vitro fertilisation 


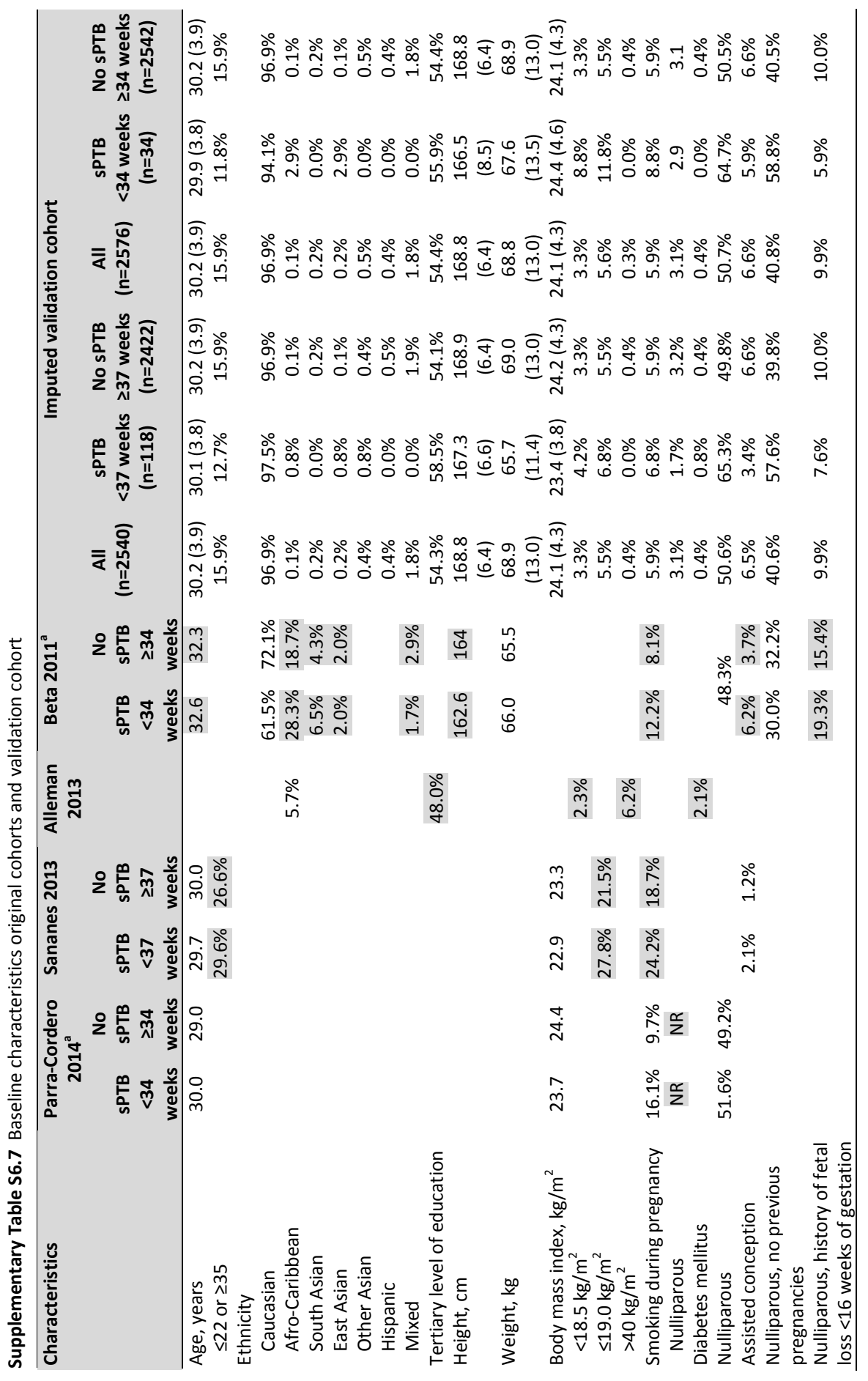




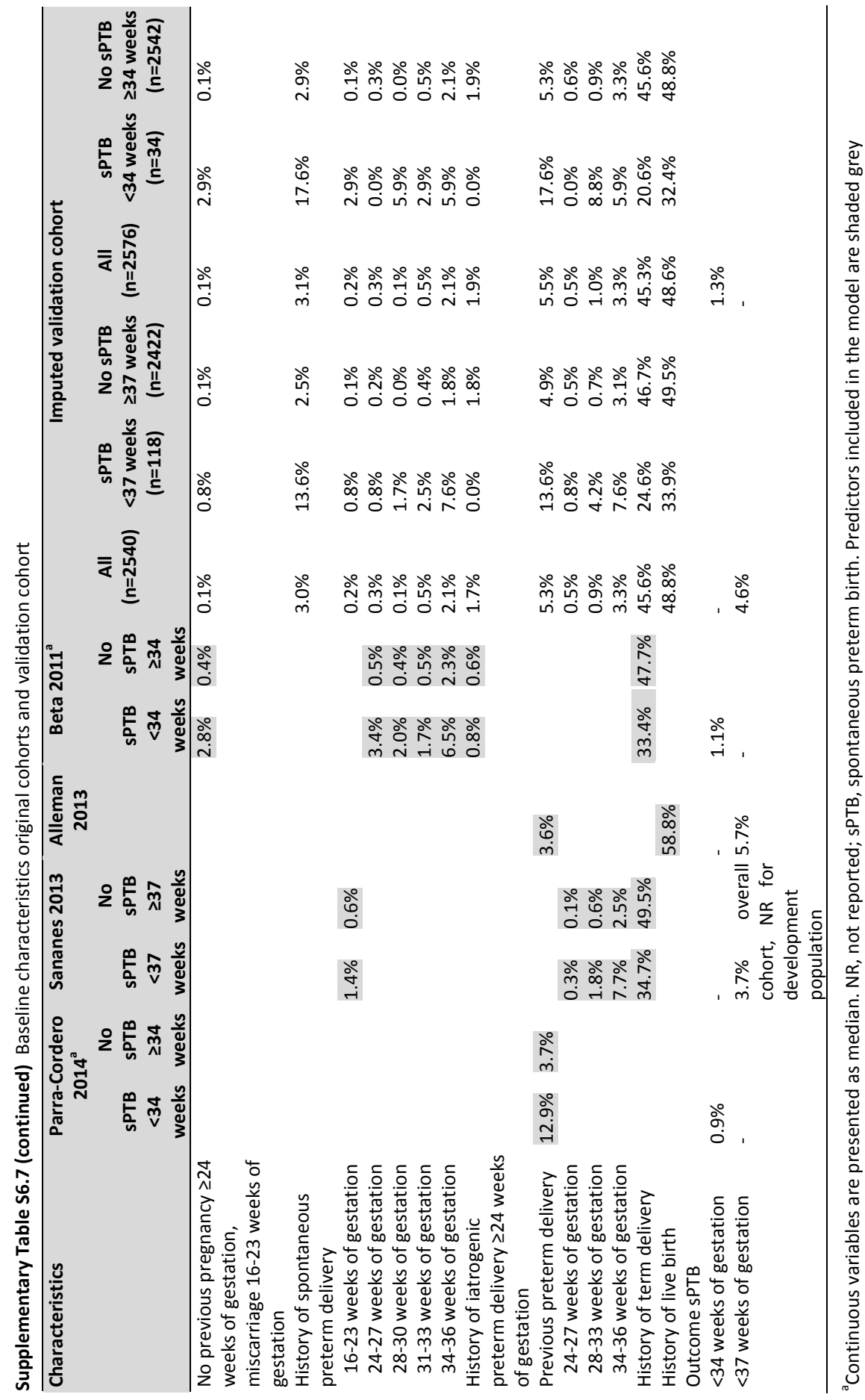



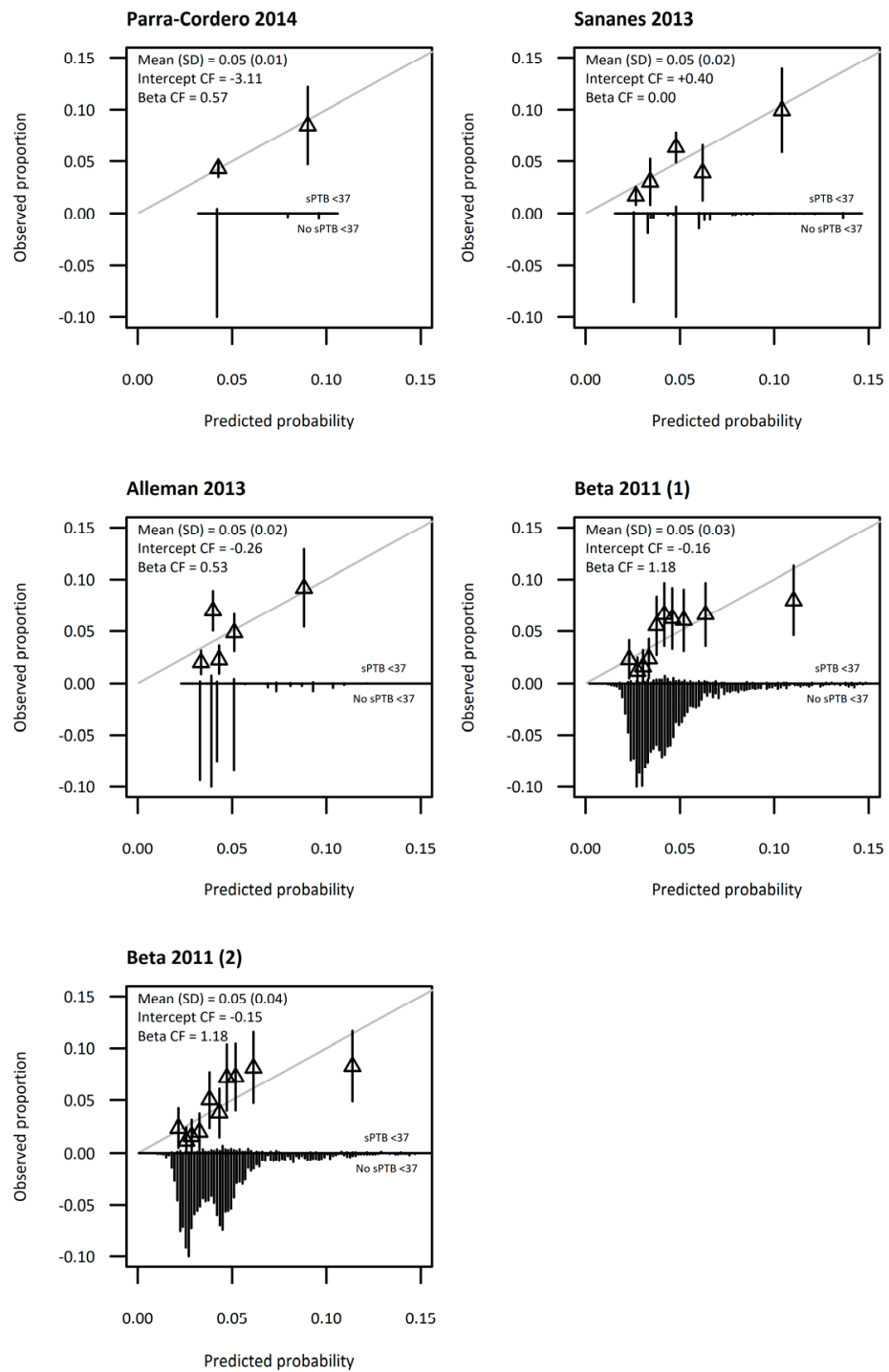

Supplementary Figure S6.2 Calibration plots of recalibrated first trimester prediction models for spontaneous preterm birth (sPTB) $<37$ weeks of gestation. The grey line is the reference line with intercept $=0$ and slope $=1$ (perfect calibration). Triangles correspond to grouped predicted risks with $95 \%$ confidence intervals (vertical lines). CF, correction factor 

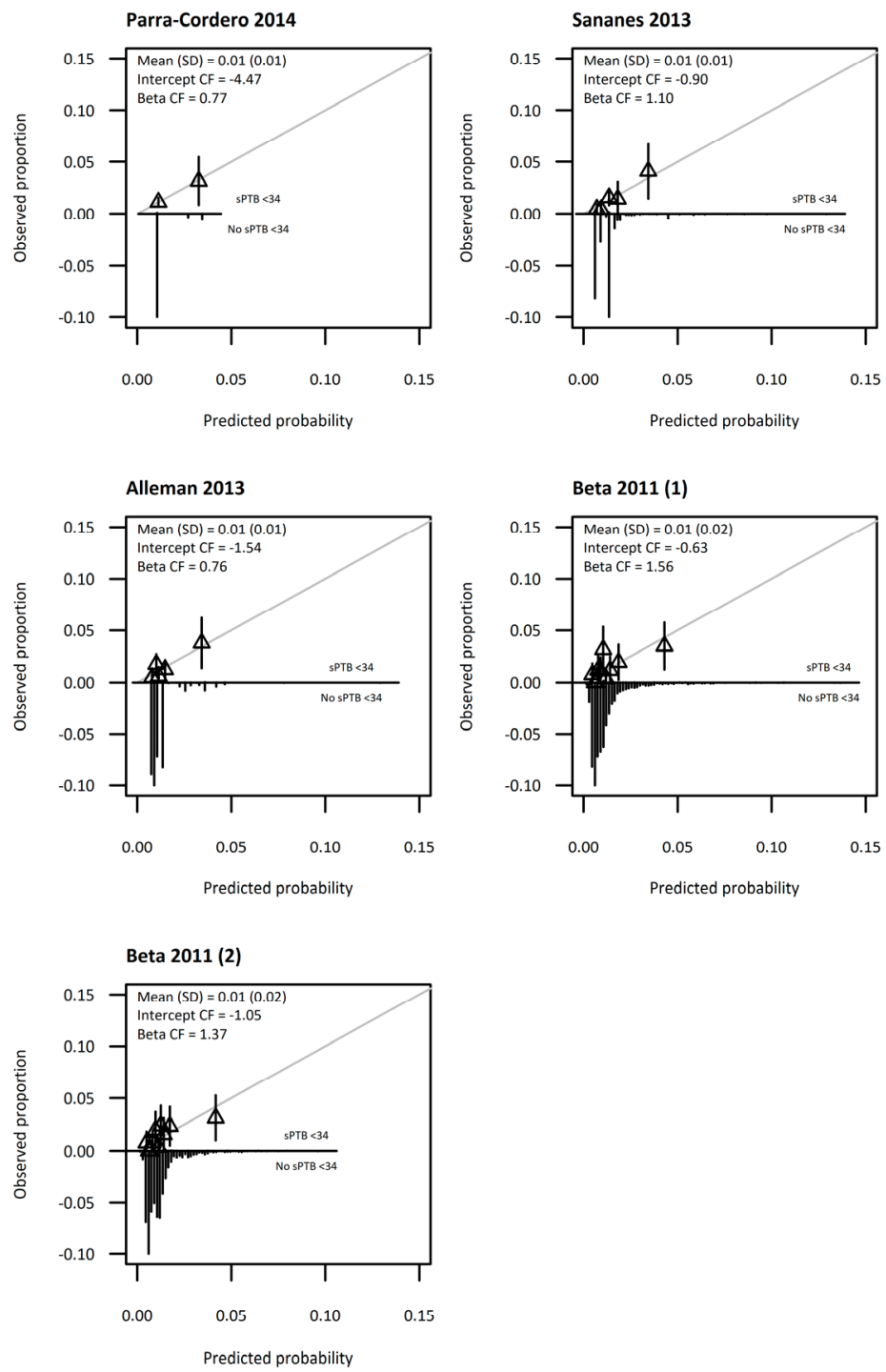

Supplementary Figure S6.3 Calibration plots of recalibrated first trimester prediction models for spontaneous preterm birth (sPTB) $<34$ weeks of gestation. The grey line is the reference line with intercept $=0$ and slope $=1$ (perfect calibration). Triangles correspond to grouped predicted risks with $95 \%$ confidence intervals (vertical lines). CF, correction factor 


\section{PAR T I I}

Calcium intake during pregnancy 


\section{CHAPTER 7}

Calcium intake from diet and supplement use during early pregnancy: the Expect Study I

Jessica P.M.M. Willemse, Linda J.E. Meertens, Hubertina C.J. Scheepers, Nina M.J. Achten, Simone J. Eussen, Martien C. van Dongen, and Luc J.M. Smits 


\begin{abstract}
Introduction

Adequate calcium intake during pregnancy is of major importance for the health of both mother and fetus. Up to date evidence on the prevalence of inadequate calcium intake among pregnant women is sparse for Western countries, and it is unknown to what extent inadequate dietary calcium intake is adequately balanced by supplement use. The objective of this study was to estimate calcium intake from both diet and supplement use during early pregnancy in the Netherlands.
\end{abstract}

\title{
Methods
}

As part of the Expect cohort study, 2477 pregnant women (8-16 weeks of gestation) completed an online questionnaire including questions on baseline characteristics, the use of calcium-containing supplements and a short Food Frequency Questionnaire. Intake data were used to calculate median calcium intakes from diet, supplements, and combined, and to compare these values with currently accepted requirement levels.

\section{Results}

Forty-two percent of the pregnant women had a total calcium intake below the estimated average requirement of $800 \mathrm{mg} / \mathrm{day}$, and $60 \%$ did not meet the adequate intake of $1000 \mathrm{mg} /$ day. Median (interquartile range) calcium intake was 886 (611-1213) mg/day. Calcium-containing supplements were used by $64.8 \%$ of the women at 8 weeks of gestation, with a median (interquartile range) calcium content of 120.0 (60.0-200.0) mg/day. Prenatal vitamins were the most often used calciumcontaining supplements (60.6\%).

\section{Discussion}

Sixty percent of Dutch pregnant women have an inadequate calcium intake. Supplements are frequently used, but most do not contain sufficient amounts to correct this inadequate intake. 


\section{Introduction}

Fetal growth places high demands on maternal calcium status ${ }^{1,2}$. Although part of the demand is met by means of increased intestinal calcium absorption ${ }^{3-5}$, adequate calcium intake by the mother remains important. Insufficient calcium intake poses risks to both fetus and mother. Fetal risks include restricted intrauterine growth, low birth weight, poor bone mineralization and preterm birth, whereas maternal risks include hypertension and pre-eclampsia ${ }^{6,7}$. Several trials have shown beneficial effects of calcium supplementation in the prevention of pre-eclampsia ${ }^{8-12}$.

Recommended calcium intake varies between countries from 900 to $1200 \mathrm{mg} / \mathrm{day}^{13,14}$. The World Health Organization (WHO) and the Food and Agriculture Organization (FAO) of the United Nations recommend a dietary calcium intake of $1200 \mathrm{mg} /$ day for pregnant women and $1000 \mathrm{mg} /$ day for non-pregnant adults (19-50 years old $)^{5,15}$. In the Netherlands, the recommended adequate intake (AI) is $1000 \mathrm{mg} /$ day for all adults, irrespective of pregnancy status ${ }^{16}$.

Diet is the main contributor to total calcium intake ${ }^{17}$. Large differences in calcium intakes between countries have been linked with diversity in food habits and access to food $^{18}$. A WHO survey showed dietary calcium intake to be inadequate $\quad<1000$ $\mathrm{mg} /$ day) among $89 \%$ of nulliparous pregnant women in developing countries ${ }^{18}$. In view of the good availability and affordability of dairy products in the Netherlands, calcium intake might be expected to be adequate, and likewise in other Western countries. Nevertheless, based on the Generation R study, mean dietary calcium intake of Dutch pregnant women was calculated to be just above $1100 \mathrm{mg} / \mathrm{day}$ with a standard deviation of $311^{19}$, indicating that one in every three women may have an intake below the adequate intake (Al) of $1000 \mathrm{mg} / \mathrm{day}^{20}$.

Dietary calcium intake can be complemented with the intake of calcium-containing food supplements. The WHO currently recommends calcium supplementation as part of antenatal care for women with an inadequate dietary calcium intake to lower the risk of developing pre-eclampsia ${ }^{5}$. To our knowledge, only few studies analysed total daily calcium intake from both food and supplement use ${ }^{21,22}$. Moreover, these studies did not evaluate a large cohort in a Western country. It is also unclear to what extent calcium is advised or prescribed in Dutch clinical practice or how much elementary calcium is ingested from both diet and supplements by Dutch pregnant women. In a small survey, we found that $89 \%$ of the gynaecologists $(n=18)$ and $10 \%$ of the midwives $(n=30)$ counsel their patients on calcium supplements. Most counselling (74\%) was directed, toward pregnant women at high risk for pre-eclampsia.

The main purpose of this study was to estimate total daily calcium intake from both food and supplement use among Dutch women during early pregnancy. To this end, we used data from a population-based pregnancy cohort. Our study's second purpose was to evaluate the calcium content of currently used supplements. 


\section{Methods}

\section{Study population}

Data were collected as part of the Expect Study I, a prospective cohort study performed in the south-eastern part of the Netherlands with the main purpose to validate published first-trimester obstetric prediction models ${ }^{23}$. Pregnant women were recruited in 36 midwifery practices and 6 hospitals between July 1, 2013 and January 1, 2015, with follow-up until December 31, 2015. Eligibility criteria for the Expect Study were: less than 16 weeks of gestation and a minimum age of 18 years. The Medical Ethical Committee of the Maastricht University Medical Centre evaluated the study protocol and declared that no ethical approval was necessary (MEC 13-4053). All participating women gave online informed consent.

Figure 7.1 shows the flowchart of the study population. For this study, we included only women that filled out the questionnaire at 8 weeks of gestation or later, allowing most pregnant women to have adapted their diet or started using supplements. On the basis of this restriction, 136 women had to be excluded. We also excluded one woman with missing values in all dietary questions. Finally, 2477 women were available for analysis.

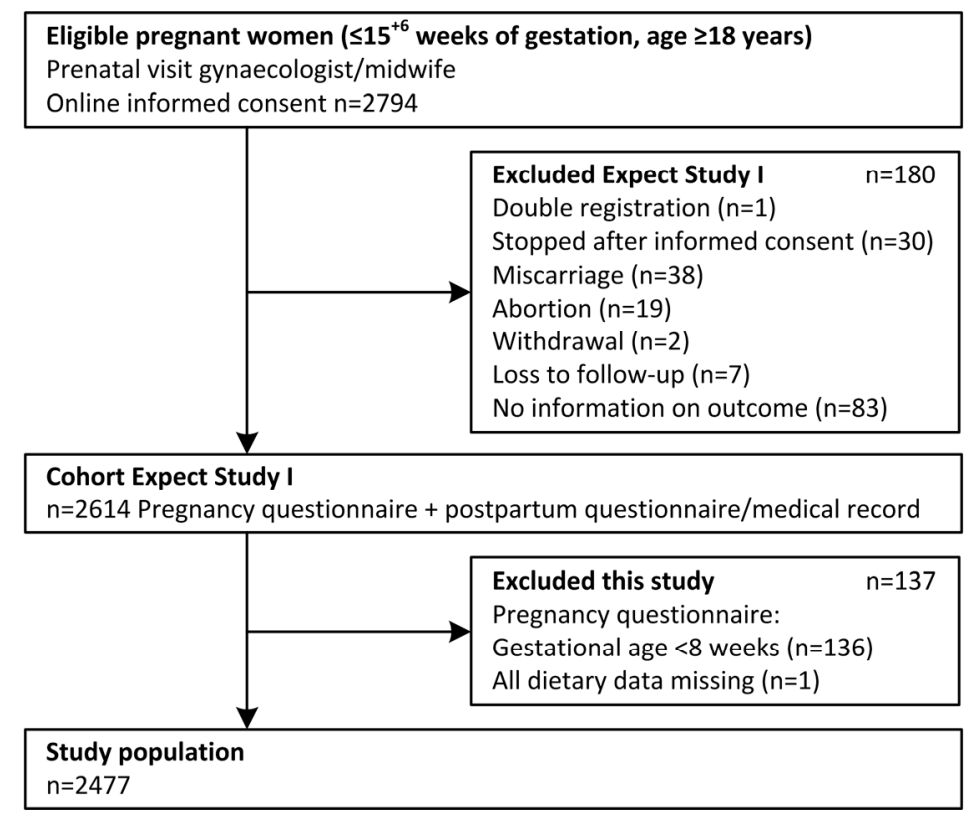

Figure 7.1 Inclusion flowchart 


\section{Data collection}

Women were asked to complete an online questionnaire before 16 weeks of gestation (a paper version was available upon request), containing questions about a range of variables including socio-demographic characteristics, lifestyle, obstetric history, medical conditions and family history. Supplement use before and during pregnancy was asked for, focusing on folic acid, vitamin D, prenatal vitamins, general multivitamins and calcium preparations, as well as dietary intake of calcium and vitamin D.

\section{Dietary intake}

The Dutch FFQ-TOOL ${ }^{\mathrm{TM}}$ (FFQ = Food Frequency Questionnaire) was used for the selection of food products contributing to calcium and vitamin D intake ${ }^{24}$. For the present study we only focused on calcium intake. Based on intake data for 20-45 years old (non-pregnant) women who participated in the Dutch National Food Consumption Survey 2007-2010 (DNFCS 2007-2010), we selected food products that cumulatively cover $>80 \%$ of the variance in calcium intake ${ }^{25}$. The selection procedure resulted in 18 food items, for which the frequency of use (reference period: last month) and the average amount (quantity) of use were asked: milk and buttermilk; yoghurt and fromage frais (with or without fruit); yoghurt drinks and other dairy beverages; chocolate milk; custard and pudding; Dutch cheese; non-Dutch cheese and cream cheese; cheese spread; bread spread (subtypes: margarine; low-fat margarine; and butter); cooking fat (bake and fry products); and fish (subtypes: fat fish such as salmon, mackerel, eel and white harring; lean fish such as codfish, tilapia, panga fish and trout; white fish fillet; smoked or steamed fish; herring; and fish fingers. Milk, dairy products and cheese were included in the questionnaire as major sources of calcium and bread spread, bake and fry products, and fish as major sources of vitamin D.

We included only questions on food products that cumulatively cover $>80 \%$ of the variance in dietary calcium intake and eliminated food products with small calcium contents in order to encourage participants to complete the full questionnaire of the Expect Study I. Covering the complete dietary calcium intake in this study was not feasible, as the FFQ was part of an intensive questionnaire containing several pregnancy related topics, with the main purpose to validate a number of published first-trimester obstetric prediction models. The food items in the questionnaire covered an estimated $62 \%$ of the total absolute dietary calcium intake. In case dietary calcium intakes were either $0 \mathrm{mg} /$ day or $>1750 \mathrm{mg} /$ day, women were contacted to check whether any unintended errors were made. Since intakes of zero calcium, in the mostly Caucasian study population, are quite unrealistic, we checked whether exclusion of these outliers (dietary calcium intake $0 \mathrm{mg} /$ day, $\mathrm{n}=7$ ) was of influence on median dietary calcium intake and the percentage of total inadequate intake in a sensitivity analysis. Exclusion of dietary calcium intakes $>1750 \mathrm{mg} /$ day was also 
analysed $(n=78)$, as well as the combination of excluding dietary calcium intakes of 0 and $>1750 \mathrm{mg} /$ day $(\mathrm{n}=85)$.

\section{Supplements}

Questions on potentially calcium-containing supplements such as prenatal vitamins, general multivitamins and calcium supplements, were included for this study. We requested start and period of use (start of usage before and during pregnancy, when potentially stopped, current use), brand and any subtype, frequency of use per week, and amount of tablets per day.

Calcium was standardized to the elemental form in milligrams, based on the labels. We contacted the manufacturers for clarification when the exact elementary amount of calcium in the supplement was unclear.

\section{Data analysis}

Baseline characteristics were analysed and presented as percentages. Missing values in the baseline characteristics of the Expect Study I cohort regarding education level $(n=3)$ and body mass index $(n=5)$, were imputed using stochastic regression imputation based on predictive mean matching ${ }^{26}$.

We calculated individual daily dietary calcium intake by multiplying frequency of consumption by consumed amounts of all assessed food products. The product intake (grams per day) were combined with the calcium content of each product according to the Dutch Food Composition Table of 2010 (NEVO-online $2010^{27}$ and DNFCS2007$2010^{25}$ ). Missing frequency and amount values were imputed with the modal value of all valid values for the specific variable. To account for the incomplete coverage of the FFQ, we adjusted the estimated calcium intake values (estimated intake*100/61.65). The adjusted total calcium intakes were used in the analyses and presented in the results.

We calculated percentages of women using the different calcium-containing supplements for each week of gestation. Daily calcium intake from supplement use was computed by combining frequency, amount of supplements and content of specific supplements among current users at 8 weeks of gestation. In case a participant used a supplement but did not know the exact (subtype) brand, the modal value was imputed. Median values of calcium supplement intake at 8 weeks of gestation were calculated.

Median values of total calcium intake, both dietary calcium intake and calcium intake from supplement use, were calculated and presented in milligrams per day, with interquartile range (IQR). Total calcium intake was compared to the Estimated Average Requirement (EAR) of $800 \mathrm{mg} /$ day and the Adequate Intake (AI) of $1000 \mathrm{mg} /$ day. An calcium intake level of $800 \mathrm{mg} /$ day is expected to satisfy the needs of $50 \%$ of all pregnant women ${ }^{28}$. The Al of $1000 \mathrm{mg}$ calcium per day is considered to be adequate for all pregnant women ${ }^{29}$.

Analyses were performed using IBM SPSS Statistics version 23. 


\section{Results}

\section{Study population}

The baseline characteristics of the study population $(n=2477)$ are shown in Table 7.1. Almost all women were of Caucasian origin, more than $80 \%$ of the women were aged 26 to 35 years, and $55 \%$ had a finished tertiary level of education. Half of the study population was nulliparous and $54 \%$ of the women had a normal pre-pregnancy body mass index (20.0-24.9).

Table 7.1 Baseline characteristics of the study population

\begin{tabular}{|c|c|}
\hline Characteristics & Study population $(n=2477)^{a}$ \\
\hline \multicolumn{2}{|l|}{ Age, years } \\
\hline $18-25$ & $11 \%$ \\
\hline $26-30$ & $43 \%$ \\
\hline $31-35$ & $38 \%$ \\
\hline$>35$ & $9 \%$ \\
\hline \multicolumn{2}{|c|}{ Body mass index before pregnancy, $\mathrm{kg} / \mathrm{m}^{2}$} \\
\hline$<20,0$ & $13 \%$ \\
\hline $20,0-24,9$ & $54 \%$ \\
\hline $25,0-29,9$ & $22 \%$ \\
\hline$>30,0$ & $11 \%$ \\
\hline \multicolumn{2}{|l|}{ Ethnicity } \\
\hline Caucasian & $97 \%$ \\
\hline Asian & $0.8 \%$ \\
\hline Afro-Caribbean & $0.1 \%$ \\
\hline Hispanic & $0.4 \%$ \\
\hline Mixed & $2 \%$ \\
\hline Nulliparous & $51 \%$ \\
\hline Tertiary level of education & $55 \%$ \\
\hline
\end{tabular}

${ }^{\text {a }}$ Percentages do not always add up to $100 \%$ due to rounding

\section{Total calcium intake}

Median (IQR) calcium intake was 886 (611-1213) mg/day. Forty-two percent of the women $(n=1045)$ had a total calcium intake below the EAR and 60\% $(n=1489)$ did not meet the Al of $1000 \mathrm{mg} /$ day (Figure 7.2).

\section{Dietary calcium intake}

Diet was the main contributor to total calcium intake (Figure 7.2). Almost all women (99.8\%) used at least one of the requested calcium-containing dietary products. Dietary calcium intake varied from a minimum of $0 \mathrm{mg} /$ day to a maximum of $4215.8 \mathrm{mg} /$ day. Median (IQR) dietary calcium intake was 798 (530-1113) mg/day. The products most contributing to dietary calcium intake were consumption of Dutch cheese (31\%) and milk (27\%).

Based on just food intake, $50 \%$ of the women had an intake below the EAR of $800 \mathrm{mg} /$ day. In this group, $16 \%$ added enough calcium from supplements to their diet to reach the EAR. Sixty-seven percent of the women did not achieve the Al through 
dietary intake. Eleven percent of these women added enough supplemental calcium to meet the Al.

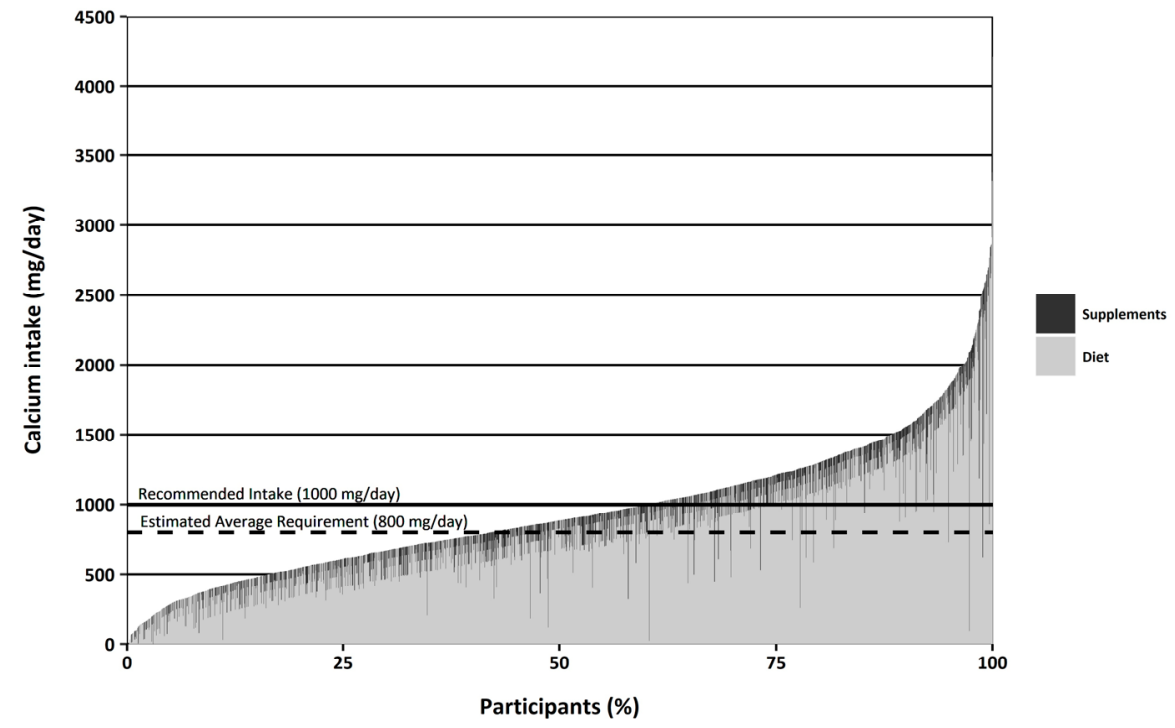

Figure 7.2 Calcium intake from diet and supplement use at 8 weeks of gestation

\section{Supplement use}

Supplement use per category varied before and during early pregnancy (Figure 7.3). Before pregnancy, $29 \%$ of the women started the use of prenatal vitamins and at 8 weeks of gestation this type of supplements was used by $61 \%$. On the other hand, the use of general multivitamins declined from $8 \%$ usage before pregnancy to $5 \%$ at 8 weeks of gestation. The use of specific calcium supplements did not show much variation. Supplements containing only calcium were used by just $1 \%$ of the women before pregnancy and $2 \%$ used them at 8 weeks of gestation.

\section{Calcium content of supplements}

Median (IQR) calcium intake from supplement use at 8 weeks of gestation was 120 (60-200) mg/day among supplement users.

The median (IQR) calcium intake from prenatal vitamins at 8 weeks of gestation (among 61\% users) was 120 (60-200) mg/day. The calcium content of various calciumcontaining prenatal vitamins ranged from 60 to $326 \mathrm{mg}$ calcium per tablet. Three of the 23 prenatal vitamins did not contain any calcium.

For general multivitamins, the median (IQR) calcium intake was 103 (5-162) mg/day at 8 weeks of gestation (among $5 \%$ users). The calcium content of 66 reported general 
multivitamins ranged from 10 to $500 \mathrm{mg}$ per tablet and eighteen reported general multivitamins did not contain any calcium.

The median (IQR) calcium intake from specific calcium supplements at 8 weeks of gestation (among 2\% users) was 337 (214-508) mg/day. The content of the reported specific calcium supplements ranged from 240 to $1000 \mathrm{mg}$ calcium per tablet.

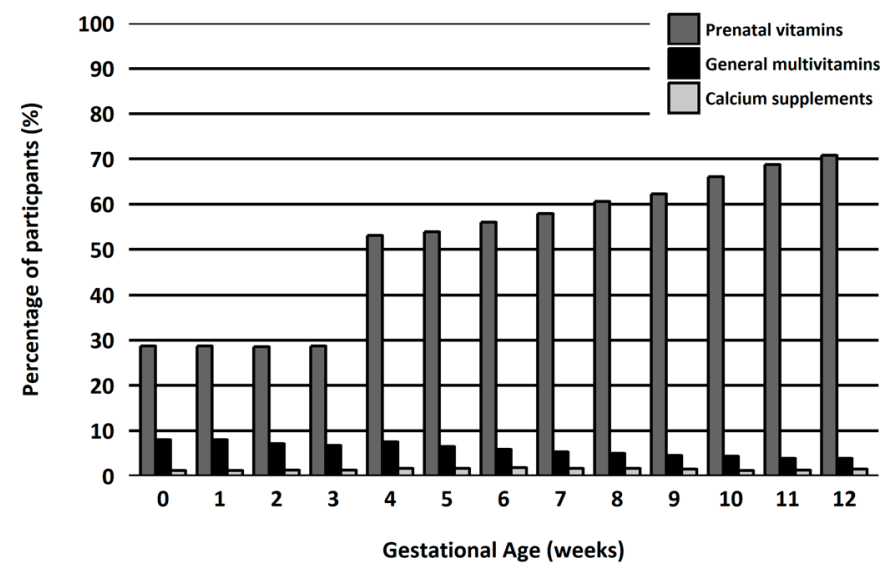

Figure 7.3 Calcium-containing supplement use per gestational age

\section{Sensitivity analyses}

Exclusion of participants with a dietary calcium intake of $0 \mathrm{mg} / \mathrm{day}(\mathrm{n}=6)$, $>1750 \mathrm{mg} /$ day $(\mathrm{n}=111)$ or both $(\mathrm{n}=117)$, resulted in a median (IQR) dietary calcium intake of 863 (532-1113) mg/day, 770 (518-1059) mg/day, and 771 (520-1059) $\mathrm{mg} /$ day, respectively. Total median (IQR) calcium intake was 887 (614-1214) mg/day $(n=2471), 860$ (596-1159) mg/day $(n=2366)$ and 861 (597-1160) mg/day $(n=2360)$ after exclusion of participants with a dietary calcium intake of either $0 \mathrm{mg} / \mathrm{day}$, $>1750 \mathrm{mg} /$ day, or both, respectively. The percentage of women with a total calcium intake $<E A R$ was $42 \%, 44 \%$, and $44 \%$ after exclusion of participants with a dietary calcium intake of $0 \mathrm{mg} / \mathrm{day},>1750 \mathrm{mg} / \mathrm{day}$, or both, respectively. Sixty percent, $63 \%$ and $63 \%$ had a total calcium intake $<\mathrm{Al}$ after exclusion of participants with a dietary calcium intake of $0 \mathrm{mg} /$ day, $>1750 \mathrm{mg} /$ day, or both, respectively.

\section{Discussion}

\section{Main findings}

We found that $42 \%$ of the population (48\%) had a total calcium intake below the EAR of $800 \mathrm{mg} /$ day. In addition, $60 \%$ of the women did not meet the Al of $1000 \mathrm{mg}$ calcium per day. 


\section{Previous findings on calcium intake}

The beneficial effects of an adequate calcium intake during pregnancy have been a topic of interest for quite a long time ${ }^{6,7,30-36}$. Dietary calcium intake during pregnancy has been mainly assessed among populations in developing countries, and lowest intakes were predominantly found in Asia and Africa ${ }^{18}$. A WHO systematic review from 2005 showed that the average dietary calcium intake in developed countries was below the $\mathrm{Al}$ in half of the included studies ${ }^{18}$. More recent studies showed even higher proportions of inadequate calcium intake in women of reproductive age in developed countries with calcium intakes below $\mathrm{Al}$ in more than half of the population ${ }^{32,33}$. In the Netherlands, mean dietary calcium level of Dutch women in the first trimester of pregnancy was calculated to be 1108 (standard deviation of 311) based on results of the Generation R study ${ }^{19}$. The Dutch National Food Consumption Survey 2007-2010 showed that half of the women in their reproductive age did not reach the Al of $1000 \mathrm{mg}$ calcium per day by diet alone, and that calcium supplements were used by only $4-8 \%{ }^{25}$.

To the best of our knowledge, the current study is the first that assessed calcium intake from both diet and supplement use in Dutch pregnant women. Results from the present study revealed that the proportion of calcium intake below the Al was even higher as compared to the Dutch National Food Consumption Survey, and findings reported in the Generation R study.

\section{Implications}

We showed that dietary sources alone are insufficient to meet an adequate calcium intake in $67 \%$ of the pregnant women. Ingestion of the amount of calcium necessary to reach the EAR or Al is not easily achieved via diet alone ${ }^{32}$. Although dairy products are the largest contributor to calcium intake, $100 \mathrm{~g}$ milk contains only 108 to $200 \mathrm{mg}$ calcium $^{27}$. Changing dietary habits is challenging for many women, despite a presumed higher awareness of health issues during pregnancy ${ }^{37,38}$.

Dietary intake can be complemented by supplements to achieve an adequate calcium intake. Supplement use is related to a higher prevalence of meeting the Al for calcium $^{33,39}$. Women appeared to be willing to use supplements during pregnancy as $74 \%$ of the women in our study used prenatal vitamins, general multivitamins or specific calcium supplements. Morisset et al. ${ }^{40}$ demonstrated that calcium-containing supplements were used by $73 \%$ of their study-population $(n=1186)$, which is comparable to our study population. However, the calcium content of the most frequently used supplements - prenatal vitamins - is insufficient for complementing the dietary calcium intake to a level that meets the EAR or the Al. Remarkably, three of the 23 used prenatal vitamins did not even contain any calcium. Moreover, the effectiveness of prenatal vitamins other than separate folic acid and vitamin $D$ has never been proven ${ }^{41}$. Because of the insufficient calcium content of most prenatal vitamins and multivitamins, it seems essential to advise the use of separate calcium supplements for pregnant women with an inadequate calcium intake. We recently 
showed that advising all pregnant women to use calcium supplements can be expected to cause substantial reductions in the incidence of pre-eclampsia as well as related health care costs ${ }^{42}$. No major side effects have been described, but the tolerable upper level of $2500 \mathrm{mg}$ calcium per day should be taken into account, since hypercalcemia could cause renal insufficiency, vascular and soft tissue calcification, hypercalciuria and kidney stones ${ }^{20,25}$.

\section{Strengths \& limitations}

Our study provides an overview of calcium intake levels by pregnant women based on both diet and supplement use. A major strength of our study is the large sample size of 2477 participants. In our population, women of Caucasian origin were somewhat overrepresented and more than half of the population had a high educational level, which corresponds to the composition of the population of Dutch women in their thirties $^{43}$. A previous Canadian study showed that calcium intake was lower in women with lowest educational levels ${ }^{40}$, so the overrepresentation of high-educated women in our study may have led to an underestimation of the total percentage of women with an inadequate intake.

A few limitations of our study should be addressed. Firstly, since there is no biochemical assay to display the nutritional calcium status, we had to depend on questionnaires. Repeated dietary recalls or records might have been considered as more accurate approaches for food intake assessment. However, this method would not be achievable in a large cohort. Nevertheless, the FFQ method is widely used for food product and nutrient intake assessment. The main strength of the FFQ is the ranking of individuals according to their intakes of frequently used foods and nutrients, although it is also considered a feasible tool to gain insight in the percentage of inadequate intake in a large population ${ }^{44}$. Secondly, our assessment of dietary calcium intake included only those products that explained most variance in calcium intake (cumulatively cover $>\mathbf{8 0} \%$ ) in order to minimize the load of the questionnaire. The selected products inquired in our questionnaire contributed to more than 60 percent of the total dietary calcium intake and we adjusted the dietary calcium intake to $100 \%{ }^{24}$. This selection procedure probably has resulted in an underestimation of total dietary calcium intake ${ }^{40}$. The 5 most contributing food products to dietary calcium intake that were not inquired in our study were bread (3.9\%), water $(3.7 \%)$, cooked or stir fried vegetables $(3.5 \%)$, coffee $(2.2 \%)$ and tea (1.6\%). Even though the contribution of these food products to total calcium intake is limited and already covered in the recalculation from $61.65 \%$ to $100 \%$, we compared our methods to the methods used in a more extensive FFQ. In order to ensure that our methods estimated the correct total calcium amount, we applied our methods to the data of pregnant women from an older birth cohort study $(n=2855)^{45}$. Thirty-nine of the 213 food items from the KOALA-FFQ were comparable to the food items inquired in our study. Total calcium intake based on the 39 food items was strongly correlated to calcium intake based on the complete KOALA-FFQ (Pearson's $r=0.95$ ). 
Women who did not consume food products inquired in our questionnaire have a recalculated total dietary calcium intake of $0 \mathrm{mg}$, while they may have consumed other calcium-containing products. However, sensitivity analysis did not show large differences in calcium intake after exclusion of women with a dietary calcium intake of $0 \mathrm{mg} /$ day. Thirdly, recall may not have been optimal as dietary intake was inquired for the month prior to filling in the questionnaire. Lastly, there may have been intraindividual variation in food intake, which was not covered by the applied measurement procedure. Food intake may vary over time and perhaps especially during pregnancy as women may experience sickness in early pregnancy. Previous evidence showed that calcium intake from supplement use does not differ much across trimesters ${ }^{46}$.

\section{Conclusion}

Our study provides insight in calcium intake from both diet and supplement use during early pregnancy. We found that $60 \%$ of the pregnant population had an inadequate total calcium intake. Calcium supplementation during pregnancy by daily use of separate calcium tablets is recommendable for all women with inadequate calcium intakes. 


\section{References}

1. Ward, K.A., Adams, J.E., and Mughal, M.Z., Bone status during adolescence, pregnancy and lactation. Curr Opin Obstet Gynecol, 2005. 17(4): p. 435-9.

2. Ritchie, L.D., Fung, E.B., Halloran, B.P., Turnlund, J.R., Van Loan, M.D., Cann, C.E., et al., A longitudinal study of calcium homeostasis during human pregnancy and lactation and after resumption of menses. Am J Clin Nutr, 1998. 67(4): p. 693-701.

3. Kalkwarf, H.J. and Specker, B.L., Bone mineral changes during pregnancy and lactation. Endocrine, 2002. 17(1): p. 49-53.

4. Cross, N.A., Hillman, L.S., Allen, S.H., Krause, G.F., and Vieira, N.E., Calcium homeostasis and bone metabolism during pregnancy, lactation, and postweaning: a longitudinal study. Am J Clin Nutr, 1995. 61(3): p. 514-23.

5. World Health Organization. Guideline Calcium Supplementation in pregnant women. 2013; Available from: http://apps.who.int/iris/bitstream/10665/85120/1/9789241505376_eng.pdf.

6. Crowther, C.A., Hiller, J.E., Pridmore, B., Bryce, R., Duggan, P., Hague, W.M., et al., Calcium supplementation in nulliparous women for the prevention of pregnancy-induced hypertension, preeclampsia and preterm birth: an Australian randomized trial. FRACOG and the ACT Study Group. Aust N Z J Obstet Gynaecol, 1999. 39(1): p. 12-8.

7. Bucher, H.C., Guyatt, G.H., Cook, R.J., Hatala, R., Cook, D.J., Lang, J.D., et al., Effect of calcium supplementation on pregnancy-induced hypertension and preeclampsia: a meta-analysis of randomized controlled trials. JAMA, 1996. 275(14): p. 1113-7.

8. Hofmeyr, G.J., Lawrie, T.A., Atallah, A.N., Duley, L., and Torloni, M.R., Calcium supplementation during pregnancy for preventing hypertensive disorders and related problems. Cochrane Database Syst Rev, 2014. 6: p. CD001059.

9. Patrelli, T.S., Dall'asta, A., Gizzo, S., Pedrazzi, G., Piantelli, G., Jasonni, V.M., et al., Calcium supplementation and prevention of preeclampsia: a meta-analysis. J Matern Fetal Neonatal Med, 2012. 25(12): p. 2570-4.

10. Villar, J., Belizan, J.M., and Fischer, P.J., Epidemiologic observations on the relationship between calcium intake and eclampsia. Int J Gynaecol Obstet, 1983. 21(4): p. 271-8.

11. Tang, R., Tang, I.C., Henry, A., and Welsh, A., Limited evidence for calcium supplementation in preeclampsia prevention: a meta-analysis and systematic review. Hypertens Pregnancy, 2015. 34(2): p. 181-203.

12. Villar, J., Merialdi, M., Gulmezoglu, A.M., Abalos, E., Carroli, G., Kulier, R., et al., Nutritional interventions during pregnancy for the prevention or treatment of maternal morbidity and preterm delivery: an overview of randomized controlled trials. J Nutr, 2003. 133(5 Suppl 2): p. 1606S-1625S.

13. Broekhuijsen, K., Aardnoudse, J.G., \& van Pampus, M.G,, De kennis van gezonde primigravidae over pre-eclampsie en HELLP-syndroom. NTOG (Nederlands Tijdschrift voor Obstetrie en Gynaecologie), 2011. 9: p. 406-412.

14. EFSA NDA Panel (EFSA Panel on Dietetic Products, Nutrition and Allergies), Scientific Opinion on Dietary Reference Values for calcium. EFSA Journal, 2015. 13(5): 4101: p. 82 pp.

15. Food and Agriculture Organisation, Human Vitamin and Mineral requirements. 2011; Available from http://www.fao.org/3/a-y2809e.pdf.

16. Hart, W., Aanbevelingen voor calcium en vitamine D in het rapport 'Voedingsnormen' van de gezondheidsraad. Ned. Tijdschrift Tandheelkunde, 2003(110): p. 78-81.

17. Flynn, A., Hirvonen, T., Mensink, G.B., Ocke, M.C., Serra-Majem, L., Stos, K., et al., Intake of selected nutrients from foods, from fortification and from supplements in various European countries. Food Nutr Res, 2009. 53.

18. Merialdi, M., Mathai, M., Ngoc, N.T.N., Purwar, M., Campodonico, L., Abdel-Aleem, H., Hofmeyr, G.J., Rojas, M.X., Perez-Cuevas, R., Joseph, G., Hieu, N.T., Radha, N.A., Motghare, V., Carroli, G., Cerro del, S., Giordano, D., Ahmed, A., Mangesi, L., Roodt, A., Mahmoud, F.A., Piaggio, G., \& Villar, J., World Health Organisation Systematic Review of the literature and multinational nutritional survey of calcium intake during pregnancy. Fetal Matern Med Rev, 2005. 16(02): p. 97-121.

19. Heppe, D.H., Medina-Gomez, C., Hofman, A., Franco, O.H., Rivadeneira, F., and Jaddoe, V.W., Maternal first-trimester diet and childhood bone mass: the Generation R Study. Am J Clin Nutr, 2013. 98(1): p. 224-32. 
20. Ross, A.C., The 2011 report on dietary reference intakes for calcium and vitamin D. Public Health Nutr, 2011. 14(5): p. 938-9.

21. Cormick, G., Zhang, N.N., Andrade, S.P., Quiroga, M.J., Di Marco, I., Porta, A., et al., Gaps between calcium recommendations to prevent pre-eclampsia and current intakes in one hospital in Argentina. BMC Res Notes, 2014. 7: p. 920.

22. Jia, H.X., Han, J.H., Li, H.Z., Liang, D., Deng, T.T., and Chang, S.Y., Mineral Intake in Urban Pregnant Women from Base Diet, Fortified Foods, and Food Supplements: Focus on Calcium, Iron, and Zinc. Biomed Environ Sci, 2016. 29(12): p. 898-901.

23. Meertens, L.J.E., Scheepers, H.C., De Vries, R.G., Dirksen, C.D., Korstjens, I., Mulder, A.L., et al., External Validation Study of First Trimester Obstetric Prediction Models (Expect Study I): Research Protocol and Population Characteristics. JMIR Res Protoc, 2017. 6(10): p. e203.

24. Molag, M.L., de Vries, J.H., Duif, N., Ocke, M.C., Dagnelie, P.C., Goldbohm, R.A., et al., Selecting informative food items for compiling food-frequency questionnaires: comparison of procedures. $\mathrm{Br} \mathrm{J}$ Nutr, 2010. 104(3): p. 446-56.

25. Van Rossum, C.T.M., Fransen, H.P., Verkaik-Kloosterman, J., Buurma-Rethans, E.J.M., \& Ocké, M.C. . Dutch National Food Consumption Survey 2007-2010. 2011; Available from: http://www.rivm.nl/bibliotheek/rapporten/350050006.pdf.

26. Van Buuren, S., Flexible imputation of missing data. 2012: CRC press.

27. Dutch National Institute for Public Health and the Environment (RIVM), NEVO-online 2010-2.0, 2010. Bilthoven: RIVM. Available from: https://nevo-online.rivm.nl/.

28. Ross, A.C., Manson, J.E., Abrams, S.A., Aloia, J.F., Brannon, P.M., Clinton, S.K., et al., The 2011 Dietary Reference Intakes for Calcium and Vitamin D: what dietetics practitioners need to know. J Am Diet Assoc, 2011. 111(4): p. 524-7.

29. Institute of Medicine, Dietary Reference Intakes for Calcium, Phosphorus, Magnesium, Vitamin D, and Fluoride. 1997, Washington DC: National Academy of Sciences.

30. Jarjou, L.M., Laskey, M.A., Sawo, Y., Goldberg, G.R., Cole, T.J., and Prentice, A., Effect of calcium supplementation in pregnancy on maternal bone outcomes in women with a low calcium intake. Am J Clin Nutr, 2010. 92(2): p. 450-7.

31. Sabour, H., Hossein-Nezhad, A., Maghbooli, Z., Madani, F., Mir, E., and Larijani, B., Relationship between pregnancy outcomes and maternal vitamin $D$ and calcium intake: A cross-sectional study. Gynecol Endocrinol, 2006. 22(10): p. 585-9.

32. Nicklas, T.A., O'Neil, C.E., and Fulgoni, V.L., 3rd, The role of dairy in meeting the recommendations for shortfall nutrients in the American diet. J Am Coll Nutr, 2009. 28 Suppl 1: p. 73s-81s.

33. Bailey, R.L., Dodd, K.W., Goldman, J.A., Gahche, J.J., Dwyer, J.T., Moshfegh, A.J., et al., Estimation of total usual calcium and vitamin D intakes in the United States. J Nutr, 2010. 140(4): p. 817-22.

34. Melnik, B.C., John, S.M., and Schmitz, G., Milk consumption during pregnancy increases birth weight, a risk factor for the development of diseases of civilization. J Transl Med, 2015. 13: p. 13.

35. Heppe, D.H., van Dam, R.M., Willemsen, S.P., den Breeijen, H., Raat, H., Hofman, A., et al., Maternal milk consumption, fetal growth, and the risks of neonatal complications: the Generation R Study. Am J Clin Nutr, 2011. 94(2): p. 501-9.

36. Olsen, S.F., Halldorsson, T.I., Willett, W.C., Knudsen, V.K., Gillman, M.W., Mikkelsen, T.B., et al., Milk consumption during pregnancy is associated with increased infant size at birth: prospective cohort study. Am J Clin Nutr, 2007. 86(4): p. 1104-10.

37. Wood, F., Robling, M., Prout, H., Kinnersley, P., Houston, H., and Butler, C., A question of balance: a qualitative study of mothers' interpretations of dietary recommendations. Ann Fam Med, 2010. 8(1): p. 51-7.

38. Raberg Kjollesdal, M.K., Telle Hjellset, V., Bjorge, B., Holmboe-Ottesen, G., and Wandel, M., Barriers to healthy eating among Norwegian-Pakistani women participating in a culturally adapted intervention. Scand J Public Health, 2010. 38(5 Suppl): p. 52-9.

39. Burnett-Hartman, A.N., Fitzpatrick, A.L., Gao, K., Jackson, S.A., and Schreiner, P.J., Supplement use contributes to meeting recommended dietary intakes for calcium, magnesium, and vitamin $\mathrm{C}$ in four ethnicities of middle-aged and older Americans: the Multi-Ethnic Study of Atherosclerosis. J Am Diet Assoc, 2009. 109(3): p. 422-9. 
40. Morisset, A.S., Weiler, H.A., Dubois, L., Ashley-Martin, J., Shapiro, G.D., Dodds, L., et al., Rankings of iron, vitamin $D$, and calcium intakes in relation to maternal characteristics of pregnant Canadian women. Appl Physiol Nutr Metab, 2016. 41(7): p. 749-57.

41. Wolf, H.T., Hegaard, H.K., Huusom, L.D., and Pinborg, A.B., Multivitamin use and adverse birth outcomes in high-income countries: a systematic review and meta-analysis. Am J Obstet Gynecol, 2017.

42. Meertens, L.J.E., Scheepers, H.C.J., Willemse, J., Spaanderman, M.E.A., and Smits, L.J.M., Should women be advised to use calcium supplements during pregnancy? A decision analysis. Matern Child Nutr, 2018. 14(1): e12479.

43. Centraal Bureau voor de Statistiek, Jonge vrouwen vaker hoogopgeleid dan jonge mannen (Young women more often highly educated than young men). 2016; Available from: https://www.cbs.nl/nl$\mathrm{nl} /$ nieuws/2016/10/jonge-vrouwen-vaker-hoogopgeleid-dan-jonge-mannen.

44. Hjartaker, A., Andersen, L.F., and Lund, E., Comparison of diet measures from a food-frequency questionnaire with measures from repeated 24-hour dietary recalls. The Norwegian Women and Cancer Study. Public Health Nutr, 2007. 10(10): p. 1094-103.

45. Kummeling, I., Thijs, C., Penders, J., Snijders, B.E., Stelma, F., Reimerink, J., et al., Etiology of atopy in infancy: the KOALA Birth Cohort Study. Pediatr Allergy Immunol, 2005. 16(8): p. 679-84.

46. Gomez, M.F., Field, C.J., Olstad, D.L., Loehr, S., Ramage, S., and McCargar, L.J., Use of micronutrient supplements among pregnant women in Alberta: results from the Alberta Pregnancy Outcomes and Nutrition (APrON) cohort. Matern Child Nutr, 2015. 11(4): p. 497-510. 


\section{CHAPTER 8}

Should women be advised to use calcium supplements during pregnancy? A decision analysis

Linda J.E. Meertens, Hubertina C.J. Scheepers, Jessica P.M.M. Willemse, Marc E.A. Spaanderman, and Luc J.M. Smits

Maternal and Child Nutrition, 2018 Jan; 14(1). 


\begin{abstract}
Introduction

Adequate calcium intake during pregnancy is important in the prevention of pre-eclampsia. A substantial proportion of pregnant women do not meet the recommended daily calcium intake, even in developed countries. Nonetheless, calcium supplementation is not routinely advised to pregnant women in most countries. We aimed to predict the impact of advising pregnant women to use calcium supplements (1000 mg/day) on the number of cases of pre-eclampsia prevented and related health care costs.
\end{abstract}

\title{
Methods
}

By use of a decision-analytic model, we assessed the expected impact of advising calcium supplementation to either (1) all pregnant women, (2) women at high risk of developing pre-eclampsia, or (3) women with a low dietary calcium intake compared with current care. Calculations were performed for a hypothetical cohort of 100,000 pregnant women living in a high-income country, although input parameters of the model can be adjusted so as to fit other settings.

\section{Results}

The incidence of pre-eclampsia could be reduced by $25 \%, 8 \%$, or $13 \%$ when advising calcium supplementation to all pregnant women, women at high risk of pre-eclampsia, or women with a low dietary calcium intake, respectively. Expected net financial benefits of the three scenarios were of $€ 4,621,465, € 2,059,165$, or $€ 2,822,115$ per 100,000 pregnant women, respectively.

\section{Discussion}

Advising pregnant women to use calcium supplements can be expected to cause substantial reductions in the incidence of pre-eclampsia as well as related health care costs. It appears most efficient to advise calcium supplementation to all pregnant women, not subgroups only. 


\section{Introduction}

Calcium supplementation is a promising intervention for the prevention of preeclampsia (PE). A meta-analysis of 13 randomized controlled trials (RCT) comprising 15,730 pregnant women, showed an overall reduction of $55 \%$ in the risk of PE among women receiving calcium supplements (>1000 $\mathrm{mg} /$ day) from the second half of pregnancy to delivery as compared to women receiving placebo supplements (risk ratio $(\mathrm{RR}), 0.45 ; 95 \%$ confidence interval $(95 \% \mathrm{Cl}), 0.31-0.65)^{1}$. The risk reduction was more pronounced among women with an increased risk of hypertensive disorders (RR 0.22 , $95 \% \mathrm{Cl} 0.12-0.42$, five trials) and among women with a low dietary calcium intake (mean intake $<900 \mathrm{mg} /$ day) (RR 0.36, 95\% Cl 0.20-0.65, eight trials).

Calcium supplementation of $1000 \mathrm{mg} /$ day (elemental) costs about 50 euros per pregnancy $^{2,3}$. Side effects are uncommon and usually mild ${ }^{1,4}$. Despite its documented protective effect, relative cheapness, and safety, calcium supplementation is still not part of standard antenatal care in most countries. The World Health Organization recommends calcium supplementation as part of antenatal care in populations where calcium intake is low ${ }^{5}$.

Recommended calcium intake for pregnant women varies between 900 and 1200 $\mathrm{mg} /$ day, depending on the country ${ }^{6,7}$. Actual intake among pregnant women often doesn't meet the recommendation, even in countries with sufficient availability and affordability of calcium-rich foods ${ }^{8}$. For instance, in a recent Dutch pregnancy cohort study, mean maternal dietary calcium intake was $1108 \mathrm{mg} /$ day with a standard deviation of $311 \mathrm{mg}$, indicating that more than one-third of the women had an intake below $1000 \mathrm{mg} / \mathrm{day}^{9}$. The contribution of calcium-containing supplement use to total daily calcium intake is low ${ }^{10,11}$.

Although adequate calcium intake through calcium-rich foods should be encouraged, available experimental evidence implies that calcium supplementation, either among all pregnant women or selected subgroups, could yield important health gains. Other factors, however, also contribute to the eventual success of implementing calcium supplementation in antenatal care. These include the size of the target population, the incidence of $P E$, the percentage of women already taking calcium supplements, and the uptake of the intervention.

As to financial impact, costs of calcium supplements and savings due to prevented cases of PE should be taken into account.

The aim of this study was to predict the impact of advising pregnant women to use calcium supplements ( $1000 \mathrm{mg} /$ day) on the number of cases of PE prevented and related health care costs.

\section{Methods}

\section{Analytical model}

We assessed the expected impact of advising calcium supplementation (1000 $\mathrm{mg} /$ day), from 20 weeks of pregnancy to delivery, to (1) all pregnant women, (2) 
women at high risk of developing $\mathrm{PE}$, or (3) women with a low dietary calcium intake ( $<900 \mathrm{mg} /$ day). We designed a simple decision-analytic model for the comparison of these three scenarios with current care (Figure 8.1) ${ }^{12}$. The patient population was a hypothetical cohort of 100,000 pregnant women living in a high-income country such as the Netherlands. Variables used in the model were the following: size of the target population, incidence of PE, efficacy of calcium supplementation during pregnancy, estimated number of women currently using calcium supplements, expected compliance with the advice, cost of one case of PE (in-hospital costs for both mother and baby from diagnosis of PE until discharge from hospital after delivery), and cost of calcium supplements per pregnancy.

The model was developed in Microsoft Excel and is available as supplementary material.

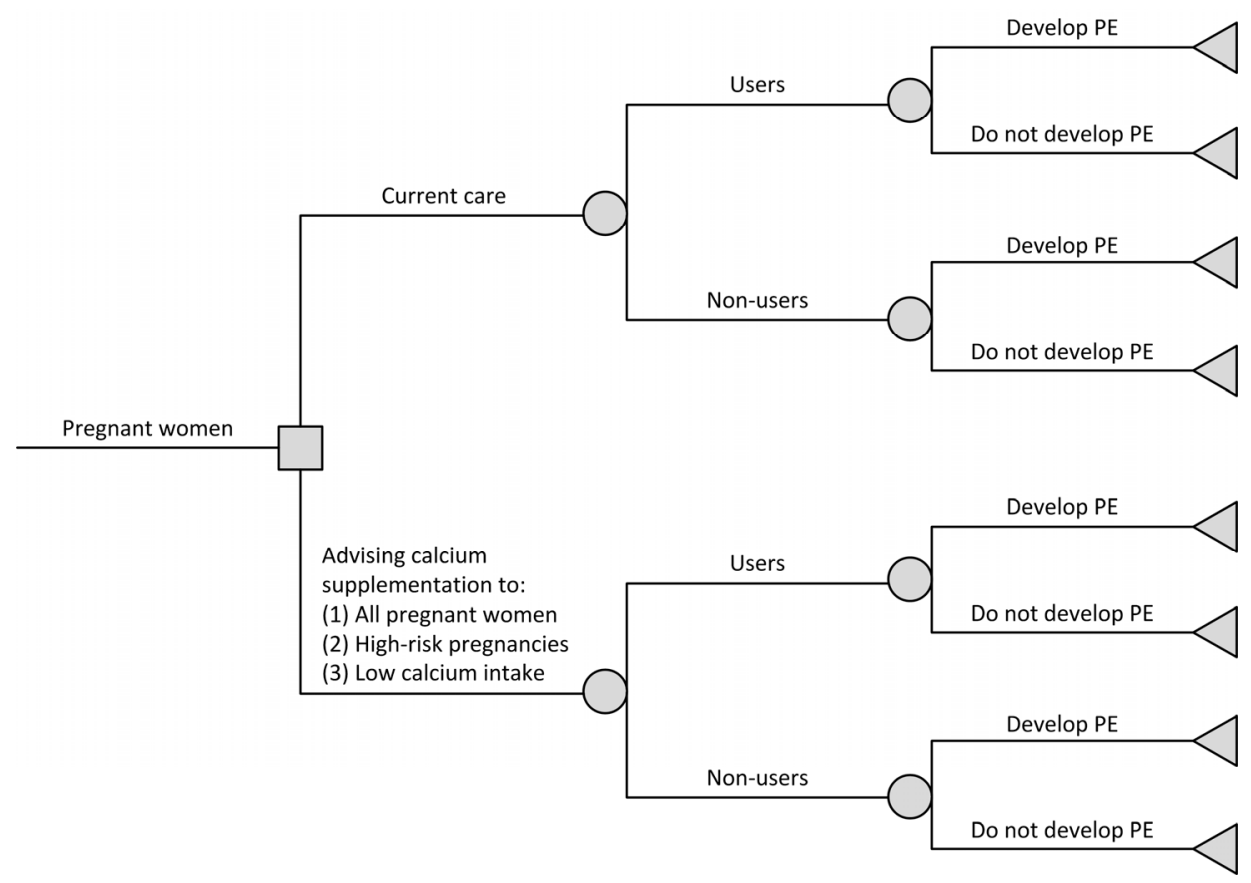

Figure 8.1 Decision tree comparing current care with advising calcium supplementation (1000 mg/day) to different scenarios in the prevention of pre-eclampsia. $\mathrm{PE}=$ pre-eclampsia. Legend: The decision tree illustrates the comparison of current care with advising calcium supplementation (1000 mg/day) to (1) all pregnant women, (2) women at high risk of developing pre-eclampsia, or (3) women with a low dietary intake ( $<900 \mathrm{mg} /$ day) in the prevention of pre-eclampsia 


\section{Data sources}

We obtained base-case values and reported ranges of the relevant input parameters from published literature and government reports.

Where no specific evidence was available, we employed conservative estimates based on related information from the literature or input from clinical experts.

The eligible population modeled reflects the Dutch pregnant population. No data source was available for the number of women at high risk of developing $\mathrm{PE}$, as this is also dependent on the definition of high risk. We made a conservative estimate based on interviews with Dutch obstetricians. The number of pregnant women with a low dietary calcium intake was estimated on data from a Dutch birth cohort study and data from the Dutch National Food Consumption Survey among women of reproductive age ${ }^{9,11}$. The incidence of PE was obtained from a nationwide Dutch cohort study, as the Dutch perinatal registry (Perined) has no reliable data about the exact incidence of $P E^{13}$. PE incidence data among women at high risk of developing $P E$ and women with low dietary calcium intake were acquired from international literature studies ${ }^{1,14,15}$. The effect sizes of calcium supplementation in the prevention of $\mathrm{PE}$ in the different target populations were obtained from the most recently published systematic review ${ }^{1}$. The number of pregnant women currently using calcium supplements during pregnancy was estimated on the basis of data from the Dutch National Food Consumption Survey among women of reproductive age, survey among pregnant women in Australia, and interviews with Dutch obstetricians ${ }^{11,16}$. No data source was available on the uptake of the advice to use calcium supplements during pregnancy as this is no recommendation yet in Dutch obstetric care. We made a conservative estimate based on Dutch data about the use of folic acid supplementation during pregnancy ${ }^{17,18}$ For calculating the financial impact outcomes, in-hospital cost of one case of PE was derived from a review containing an economic evaluation of tests and treatments on $\mathrm{PE}^{14}$. Cost of calcium supplements per pregnancy was obtained from Care Institute Netherlands which calculates drug costs based on the actual Pharmacy Purchase Price ${ }^{2}$.

The values and sources of all clinical and financial input parameters are summarized in Table 8.1.

\section{Outcome measures}

With the model, we calculated the changes in health outcomes between the new scenarios and current care in terms of absolute reduction, relative reduction, and number needed to advise. The absolute reduction was defined as the difference in the number of cases of PE between the new scenario and current care, and relative reduction as the percentage difference in incidence of $P E$ between the new scenario and current care. The number needed to advise was calculated as the average number of pregnant women that need to be advised to use calcium supplements in the new scenario to prevent one case of PE compared with current care. 


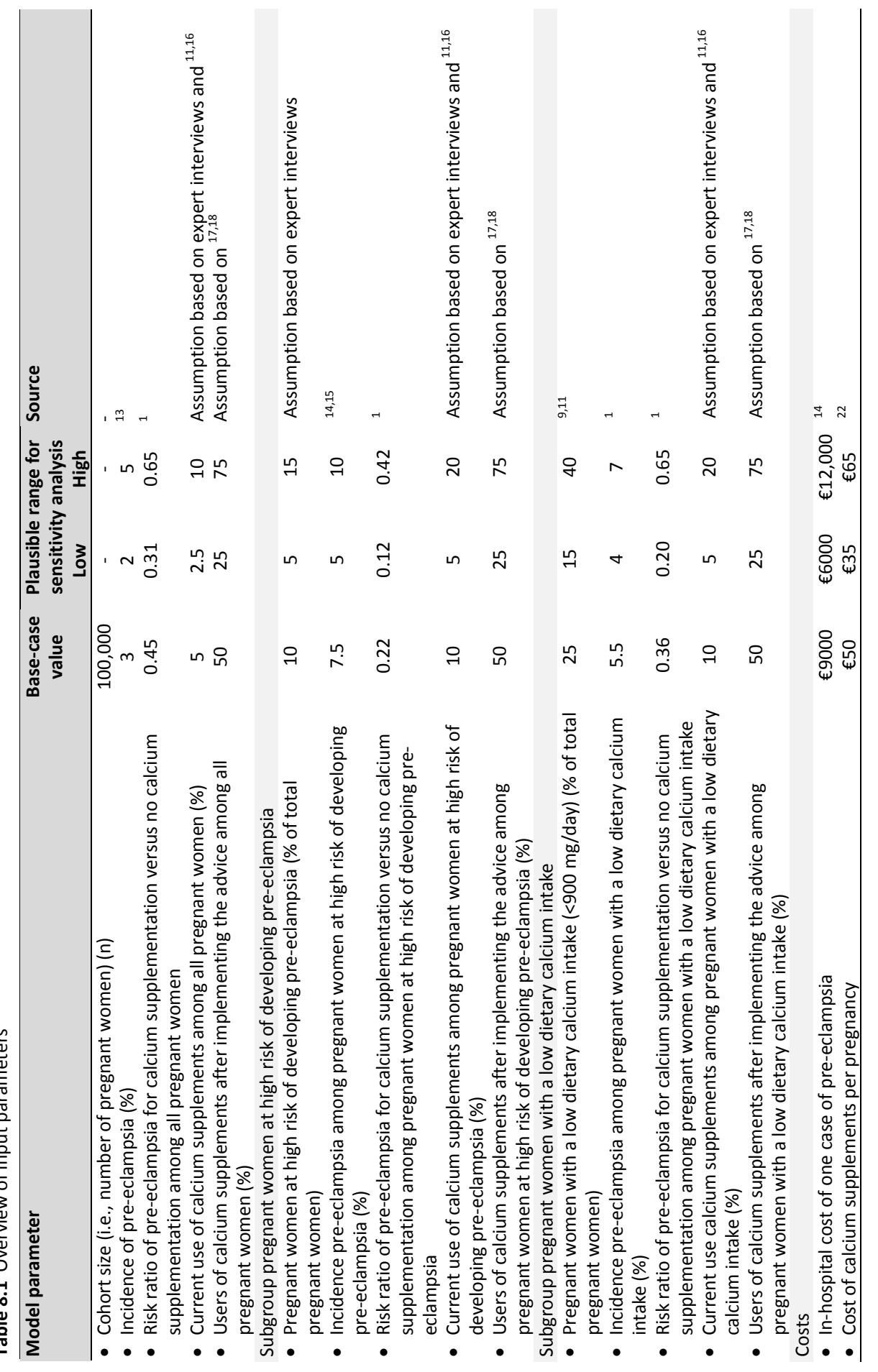


The financial impact of prevented cases of PE in the new scenario compared to current care was calculated by multiplying the absolute reduction by unit cost of one case of PE. The extra cost of calcium supplements was defined as the additional cost of calcium supplements in the new scenario compared to current care. The net financial impact was calculated from a public payer's perspective by subtracting extra cost of calcium supplements from the financial impact of prevented cases of PE. Financial quantities were expressed in euros $(€)$. No discounting was applied to either costs or clinical outcomes. Time horizon, in line with the timing used in the meta-analysis, spanned the $20^{\text {th }}$ weeks of pregnancy until discharge of mother or child from hospital after delivery ${ }^{1}$.

\section{Sensitivity analysis}

One-way sensitivity analyses were performed for each scenario to evaluate the impact of variations of values of model input parameters on the absolute reduction and net financial impact. Input parameters were varied one at a time within a plausible range around the base-case value based on literature review or realistic assumptions. Ranges used for the sensitivity analyses are presented in Table 8.1. The results of the sensitivity analyses were plotted in tornado diagrams using $\mathrm{R}$ version 3.2.3.

\section{Results}

\section{Base-case}

Table 8.2 presents the expected number of PE prevented and related health care costs for the three scenarios compared to current care in a hypothetical cohort of 100,000 pregnant women.

Table 8.2 The expected impact on prevented cases of pre-eclampsia and related health care costs of advising calcium supplementation during pregnancy - a comparison of three scenarios with current care

\begin{tabular}{|c|c|c|c|c|}
\hline & Current care & $\begin{array}{c}\text { Scenarios - A } \\
\text { (1) } \\
\text { All pregnant } \\
\text { women } \\
(n=100,000)\end{array}$ & $\begin{array}{l}\text { Idvising calcium sur } \\
\qquad(2) \\
\text { Pregnant women } \\
\text { at high risk of } \\
\text { pre-eclampsia } \\
\text { (n=10,000) }\end{array}$ & $\begin{array}{c}\text { pplementation to: } \\
\text { (3) } \\
\text { Pregnant women } \\
\text { with a low dietary } \\
\text { calcium intake } \\
(n=25,000) \\
\end{array}$ \\
\hline \multicolumn{5}{|l|}{ Cohort } \\
\hline Number of pregnant women (n) & 100,000 & 100,000 & 100,000 & 100,000 \\
\hline Users of calcium supplements ( $n$ ) & 5,000 & 50,000 & 9,500 & 16,250 \\
\hline Cases of pre-eclampsia (n) & 3,000 & 2,237 & 2,746 & 2,624 \\
\hline \multicolumn{5}{|l|}{ Clinical impact cases of pre-eclampsia } \\
\hline Absolute reduction $(\mathrm{n})$ & & 763 & 254 & 376 \\
\hline Relative reduction $(\%)$ & & 25 & 8 & 13 \\
\hline Number needed to advise ( $\mathrm{n}$ ) & & 131 & 39 & 66 \\
\hline \multicolumn{5}{|c|}{ Financial impact } \\
\hline \multicolumn{2}{|c|}{ Cost savings from prevented cases of pre-eclampsia } & $€ 6,871,465$ & $€ 2,284,165$ & $€ 3,384,615$ \\
\hline \multicolumn{2}{|c|}{ Extra cost of calcium supplements } & $€ 2,250,000$ & $€ 225,000$ & $€ 562,500$ \\
\hline \multicolumn{2}{|l|}{ Net financial impact } & $+€ 4,621,465$ & $+€ 2,059,165$ & $+€ 2,822,115$ \\
\hline
\end{tabular}


In current care, PE complicates $3 \%$ of all pregnancies $(3000 / 100,000)$. The base-case analysis indicated that if calcium supplementation is advised to all pregnant women $(n=100,000)$ (scenario 1), 763 cases of PE will be prevented (i.e. relative reduction of $25 \%$ ). The estimated net financial benefit (savings minus costs of calcium supplements) was $€ 4,621,465$ per 100,000 pregnant women. If calcium supplementation is advised to subpopulations of pregnant women at high risk of PE (scenario 2) or pregnant women with a low dietary calcium intake (scenario 3), an estimated 254 and 376 cases of PE will be prevented, respectively, and estimated net benefits amount to $€ 2,059,165$ and $€ 2,822,115$. The numbers needed to advise is lowest in scenario 2 and highest in scenario 1.

\section{Sensitivity analysis}

One-way sensitivity analyses performed for the different scenarios are illustrated in Figure 8.2. The results indicated that calcium supplementation during pregnancy is both clinically and financially beneficial within all plausible ranges. The strongest influence was found for the number of users of calcium supplements in the new scenarios and the efficacy of the use of calcium supplements. In scenario 2 and 3, results were additionally influenced by the size of the subpopulation, with larger impacts in case of larger target populations.

\section{Discussion}

\section{Main findings}

The results of our decision analysis indicate that advising calcium supplementation to all pregnant women, pregnant women at high risk of $\mathrm{PE}$, or pregnant women with a low dietary calcium intake can be expected to reduce the incidence of PE by $25 \%, 8 \%$, or $13 \%$, respectively. Expected net financial benefits are $€ 4,621,465, € 2,059,165$, or $€ 2,822,115$ per 100,000 pregnant women. Although clinical and financial benefits may vary with varying parameter estimates, it is implausible that effects will be reversed.

\section{Strengths and limitations}

Translation of efficacious preventive interventions to clinical practice remains a challenge ${ }^{19}$. Randomized controlled trials may not represent real-world conditions, and do not by themselves yield sufficient information for inference on the population impact of implementing an intervention. Decision analysis, combining evidence from efficacy studies with that of various other sources, is necessary in order to provide insight to caregivers, budget holders, policy makers, and health insurance companies as to whether an efficacious intervention is attractive for implementation. 
(1) All pregnant women
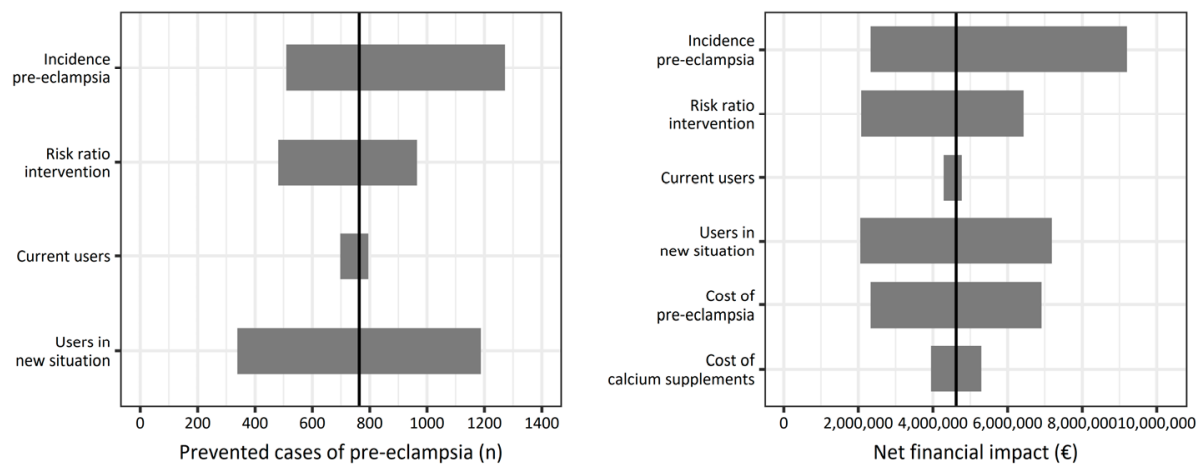

(2) Pregnant women at high risk of pre-eclampsia
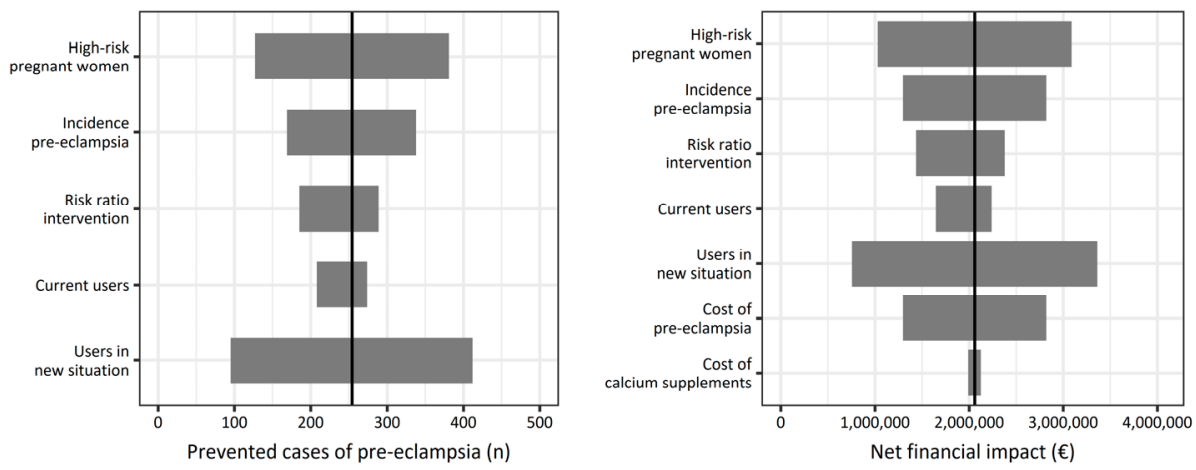

(3) Pregnant women with a low dietary calcium intake
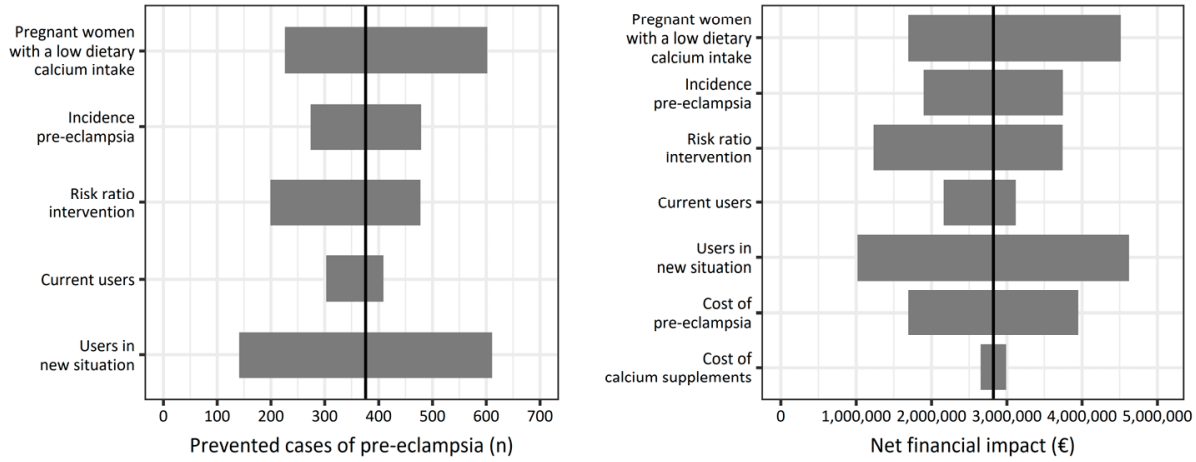

Figure 8.2 Tornado diagrams of one-way sensitivity analyses results for prevented cases of pre-eclampsia and net financial impact, per 100,000 pregnant women. Legend: The vertical line in the center of the chart represents the prevented cases of pre-eclampsia or net financial impact for the base-case values. The bars show the variation of input parameters within plausible ranges 
Other researchers have estimated the clinical and financial impact of diagnostic or preventive interventions to reduce pregnancy complications ${ }^{14,20-24}$. Meads et al. (2008) also considered the cost-effectiveness of calcium supplementation in the prevention of $\mathrm{PE}$, but under less realistic assumptions, namely that in current care no pregnant women use calcium supplements and that the uptake of the intervention would be $100 \%$.

We recognize that although we have used the best evidence for obtaining accurate input values, our analysis is limited by the availability and quality of existing evidence. We derived the effect estimate of calcium supplementation from a high GRADE systematic review ${ }^{1}$. As the authors of that review noted, overall effects may be overestimated due to stronger effects found in smaller studies (which predominantly included high-risk women), or publication bias. Also, different effects of calcium supplementation may be expected across populations with different baseline levels of calcium intake. However, as evidenced by our sensitivity analysis, even more modest effects can be expected to yield considerably favourable effects on population health as well as economic outcomes.

For the few parameters for which no evidence was available, we attempted to take account for the uncertainty by staying conservative when determining the base case values, so as not to obtain overoptimistic results. We also performed sensitivity analyses, the results of which did not reveal a dependency of the conclusions on variation of the input values within all plausible ranges.

We did not take into account investments for implementation of the intervention. Therefore, the expenditure is expected to be higher depending on the extent of the efforts, particularly in the first years of implementation. On the other hand, we also did not consider long-term costs for mother and child due to PE (i.e. costs related to neurodevelopmental impairment of children born preterm or to cardiovascular disease in the mother), as these are problematic to quantify ${ }^{25-27}$. Including these costs would have made the economic benefits of the intervention more favourable.

Our cost calculations were made from a public payer's perspective, implying that we assumed that women prepared to use calcium supplements would receive a prescription from their health care provider. Assuming that pregnant women would have to pay for calcium supplements themselves would, with equal uptake, lead to higher benefits from the perspective of the public payer. For the estimation of the expected uptake of the calcium advice, we made use of the rate of folic acid use in the periconceptional period in the Netherlands, which intervention is currently not financially reimbursed by health insurance companies. As prescription and reimbursement is expected to improve uptake rates, and higher uptake will lead to higher economic and health benefits (see Figure 8.2), our results probably give a conservative picture of expected effects. 


\section{Interpretation}

Our results provide support for the idea that advising the use of calcium supplements to pregnant women can bring about important health effects on population level. Besides, it can reduce health care costs.

We calculated the expected impact from a high-income perspective, using values specific for the Dutch situation. Comparable results can be expected for other highincome countries. In low-income countries, particularly those in which inadequate dietary calcium intake is more prevalent or baseline risk of PE is higher, health and economic effects may be more favourable $8,28,29$. Our model can be used for the calculation of country-specific effects by making use of local point estimates and plausible ranges.

Reaching an adequate calcium intake through calcium-rich foods should be primarily encouraged. However, women may not be prepared to consume the daily amount of foods necessary to reach an adequate intake. For example, to take in $1000 \mathrm{mg}$ of elementary calcium by milk only, at least four glasses $(200 \mathrm{ml}$ each) have to be consumed. Trials of behavioural interventions to increase maternal dietary calcium intake have shown mixed results ${ }^{30}$.

In view of our results, it seems efficient to advise using calcium supplements to all pregnant women. Women who are not part of defined subgroups then can also profit from the intervention, and no individual dietary calcium intake or risk of PE has to be estimated. Although the number needed to advise is higher in the overall pregnant population as compared to subgroups, this seems acceptable as calcium supplementation is a non-invasive, well tolerated, and - provided that it is used prudently - safe intervention. Recent studies among the elderly have raised concerns that high-dose calcium supplementation might increase the risk of cardiovascular disease ${ }^{31-33}$. Available evidence remains, however, inconclusive. Moreover, most pregnant women will stop using the supplements after delivery and therefore use it for only a short period of time.

The specific dose of supplemental calcium needed to reduce the risk of PE is unknown and probably dependent on the dietary intake of calcium. Low-dose calcium supplementation ( $<1 \mathrm{~g} /$ day) has shown a reduction in the risk of PE in some studies, but evidence is limited and more high-quality trials are needed ${ }^{1}$. Until more evidence is available, supplementation of $1000 \mathrm{mg} /$ day is recommendable, keeping an eye on the upper level of $2500 \mathrm{mg} / \mathrm{day}^{1,5-7}$. Effects of calcium supplementation could be further enhanced if combined with vitamin $D$, as calcium absorption occurs principally via an active transcellular vitamin D-dependent process ${ }^{34,35}$.

Although our results indicate that favourable economic and health effects can be obtained even with suboptimal uptake of the intervention, a challenge remains to effectively implement the intervention in health care practice ${ }^{36,37}$. Implementation efforts require that attention be paid to accessibility, affordability, acceptability, and adherence to the intervention from a patient's, care providers', and organizational point of view. Implementation strategies for low-income countries have major 
challenges compared to high-income countries, such as limited accessibility to antenatal care and economic issues ${ }^{38,39}$.

Facilitators for implementation of calcium supplementation are good tolerance, absence of adverse effects, and the expectation that it can be implemented by different health care providers with moderate levels of training and expertise ${ }^{1,4}$. Uncertain but important factors are the extent to which antenatal care providers are effective in changing pregnant women's behavior, and whether or not calcium supplements are covered by health insurers. Research is needed on facilitators and barriers in the implementation of calcium supplementation among pregnant women.

\section{Conclusion}

In conclusion, our results indicate that advising calcium supplements to pregnant women can be expected to cause substantial reductions in the incidence of PE as well as related health care costs. Largest impact is expected from calcium supplementation advice to all pregnant women, not subgroups only. 


\section{Supplementary materials}

Computing framework of the decision-analytic model (published online, Maternal and Child Nutrition, DOI 10.1111/mcn.12479) 


\section{References}

1. Hofmeyr, G.J., Lawrie, T.A., Atallah, A.N., Duley, L., and Torloni, M.R., Calcium supplementation during pregnancy for preventing hypertensive disorders and related problems. Cochrane Database Syst Rev, 2014. 6: p. CD001059.

2. Zorginstituut Nederland, Medicijnkosten. Calciumcarbonaat. Available at: http://www.medicijnkosten.nl (Accessed February 19, 2016). 2016.

3. British National Formulary. Calcium Carbonate. BMJ Group and the Royal Pharmaceutical Society of Great Britain. Available at: http://www.medicinescomplete.com/mc/bnf/current/PHP93602-calciumcarbonate.htm?q=calcichew\&t=search\&ss=text\&p=7 - _hit (Accessed February 19, 2016). 2016.

4. Heaney, R.P., Kopecky, S., Maki, K.C., Hathcock, J., Mackay, D., and Wallace, T.C., A review of calcium supplements and cardiovascular disease risk. Adv Nutr, 2012. 3(6): p. 763-71.

5. WHO, Guideline: Calcium supplementation in pregnant women. World Health Organization: Geneva. 2013.

6. IOM (Institute of Medicine), Dietary Reference Intakes for Calcium and Vitamin D. Washington, DC: The National Academies Press. 2011.

7. EFSA NDA Panel (EFSA Panel on Dietetic Products, Nutrition and Allergies), Scientific Opinion on Dietary Reference Values for calcium. EFSA Journal, 2015. 13(5): p. 4101, 82 pp.

8. Merialdi, M., Mathai, M., Ngoc, N., Purwar, M., Campodonico, L., Abdel-Aleem, H., et al., World Health Organization systematic review of the literature and multinational nutritional survey of calcium intake during pregnancy. Fetal and Maternal Medicine Review, 2005. 16(02): p. 97-121.

9. Heppe, D.H., Medina-Gomez, C., Hofman, A., Franco, O.H., Rivadeneira, F., and Jaddoe, V.W., Maternal first-trimester diet and childhood bone mass: the Generation R Study. Am J Clin Nutr, 2013. 98(1): p. 224-32.

10. Bailey, R.L., Dodd, K.W., Goldman, J.A., Gahche, J.J., Dwyer, J.T., Moshfegh, A.J., et al., Estimation of total usual calcium and vitamin D intakes in the United States. J Nutr, 2010. 140(4): p. 817-22.

11. Van Rossum, C., Fransen, H., Verkaik-Kloosterman, J., Buurma-Rethans, E., and Ocké, M., Dutch National Food Consumption Survey 2007-2010: Diet of children and adults aged 7 to 69 years. RIVM rapport 350050006, 2011. Dutch.

12. Petrou, S. and Gray, A., Economic evaluation using decision analytical modelling: design, conduct, analysis, and reporting. BMJ, 2011. 342: p. d1766.

13. Von Schmidt auf Altenstadt, J.F., Hukkelhoven, C.W., van Roosmalen, J., and Bloemenkamp, K.W., Preeclampsia increases the risk of postpartum haemorrhage: a nationwide cohort study in the Netherlands. PLoS One, 2013. 8(12): p. e81959.

14. Meads, C.A., Cnossen, J.S., Meher, S., Juarez-Garcia, A., ter Riet, G., Duley, L., et al., Methods of prediction and prevention of pre-eclampsia: systematic reviews of accuracy and effectiveness literature with economic modelling. Health Technol Assess, 2008. 12(6): p. iii-iv, 1-270.

15. Duley, L., Henderson-Smart, D.J., Meher, S., and King, J.F., Antiplatelet agents for preventing preeclampsia and its complications. Cochrane Database Syst Rev, 2007(2): p. Cd004659.

16. Forster, D.A., Wills, G., Denning, A., and Bolger, M., The use of folic acid and other vitamins before and during pregnancy in a group of women in Melbourne, Australia. Midwifery, 2009. 25(2): p. 13446.

17. Woude, P.A., Walle, H.E., and Berg, L.T., Periconceptional folic acid use: still room to improve. Birth Defects Res A Clin Mol Teratol, 2012. 94(2): p. 96-101.

18. Sikkens, J.J., van Eijsden, M., Bonsel, G.J., and Cornel, M.C., Validation of self-reported folic acid use in a multiethnic population: results of the Amsterdam Born Children and their Development study. Public Health Nutr, 2011. 14(11): p. 2022-8.

19. Glasgow, R.E., Lichtenstein, E., and Marcus, A.C., Why don't we see more translation of health promotion research to practice? Rethinking the efficacy-to-effectiveness transition. Am J Public Health, 2003. 93(8): p. 1261-7.

20. Hadker, N., Garg, S., Costanzo, C., Miller, J.D., Foster, T., van der Helm, W., et al., Financial impact of a novel pre-eclampsia diagnostic test versus standard practice: a decision-analytic modeling analysis from a UK healthcare payer perspective. J Med Econ, 2010. 13(4): p. 728-37. 
21. Hadker, N., Garg, S., Costanzo, C., van der Helm, W., and Creeden, J., Are there financial savings associated with supplementing current diagnostic practice for preeclampsia with a novel test? Learnings from a modeling analysis from a German payer perspective. Hypertens Pregnancy, 2013. 32(2): p. 105-19.

22. Darmstadt, G.L., Bhutta, Z.A., Cousens, S., Adam, T., Walker, N., and de Bernis, L., Evidence-based, cost-effective interventions: how many newborn babies can we save? Lancet, 2005. 365(9463): p. 977-88.

23. Zechmeister-Koss, I. and Piso, B., Affordability of programmes to prevent spontaneous preterm birth in Austria: a budget impact analysis. Eur J Public Health, 2014. 24(1): p. 145-50.

24. Bajaj, P.S. and Veenstra, D.L., A risk-benefit analysis of factor $V$ Leiden testing to improve pregnancy outcomes: a case study of the capabilities of decision modeling in genomics. Genet Med, 2013. 15(5): p. 374-81.

25. Mol, B.W., Roberts, C.T., Thangaratinam, S., Magee, L.A., de Groot, C.J., and Hofmeyr, G.J., Preeclampsia. Lancet, 2015.

26. Platt, M.J., Outcomes in preterm infants. Public Health, 2014. 128(5): p. 399-403.

27. Petrou, S., Eddama, O., and Mangham, L., A structured review of the recent literature on the economic consequences of preterm birth. Arch Dis Child Fetal Neonatal Ed, 2011. 96(3): p. F225-32.

28. Khan, K.S., Wojdyla, D., Say, L., Gulmezoglu, A.M., and Van Look, P.F., WHO analysis of causes of maternal death: a systematic review. Lancet, 2006. 367(9516): p. 1066-74.

29. Saleem, S., McClure, E.M., Goudar, S.S., Patel, A., Esamai, F., Garces, A., et al., A prospective study of maternal, fetal and neonatal deaths in low- and middle-income countries. Bull World Health Organ, 2014. 92(8): p. 605-12.

30. Jung, M.E., Stork, M.J., Stapleton, J., Bourne, J.E., and Martin Ginis, K.A., A systematic review of behavioural interventions to increase maternal calcium intake. Matern Child Nutr, 2014.

31. Lewis, J.R., Radavelli-Bagatini, S., Rejnmark, L., Chen, J.S., Simpson, J.M., Lappe, J.M., et al., The effects of calcium supplementation on verified coronary heart disease hospitalization and death in postmenopausal women: a collaborative meta-analysis of randomized controlled trials. J Bone Miner Res, 2015. 30(1): p. 165-75.

32. Bolland, M.J., Grey, A., Avenell, A., Gamble, G.D., and Reid, I.R., Calcium supplements with or without vitamin D and risk of cardiovascular events: reanalysis of the Women's Health Initiative limited access dataset and meta-analysis. BMJ, 2011. 342: p. d2040.

33. Bolland, M.J., Avenell, A., Baron, J.A., Grey, A., MacLennan, G.S., Gamble, G.D., et al., Effect of calcium supplements on risk of myocardial infarction and cardiovascular events: meta-analysis. BMJ, 2010. 341: p. c3691.

34. Heaney, R.P., Vitamin D and calcium interactions: functional outcomes. Am J Clin Nutr, 2008. 88(2): p. 541s-544s.

35. Fleet, J.C. and Schoch, R.D., Molecular mechanisms for regulation of intestinal calcium absorption by vitamin D and other factors. Crit Rev Clin Lab Sci, 2010. 47(4): p. 181-95.

36. Omotayo, M.O., Dickin, K.L., O'Brien, K.O., Neufeld, L.M., De Regil, L.M., and Stoltzfus, R.J., Calcium Supplementation to Prevent Preeclampsia: Translating Guidelines into Practice in Low-Income Countries. Adv Nutr, 2016. 7(2): p. 275-8.

37. Martin, S.L., Seim, G.L., Wawire, S., Chapleau, G.M., and Young, S.L., Translating formative research findings into a behaviour change strategy to promote antenatal calcium and iron and folic acid supplementation in western Kenya. Matern Child Nutr, 2017. 13(1).

38. Von Dadelszen, P., Firoz, T., Donnay, F., Gordon, R., Hofmeyr, G.J., Lalani, S., et al., Preeclampsia in low and middle income countries-health services lessons learned from the PRE-EMPT (PRE-EclampsiaEclampsia Monitoring, Prevention and Treatment) project. J Obstet Gynaecol Can, 2012. 34(10): p. 917-26.

39. Firoz, T., Sanghvi, H., Merialdi, M., and von Dadelszen, P., Pre-eclampsia in low and middle income countries. Best Pract Res Clin Obstet Gynaecol, 2011. 25(4): p. 537-48. 


\section{CHAPTER 9}

General discussion 
The studies described in this thesis focused on improving personalized obstetric care in both early risk assessment (part I) and intervention strategies (part II).

In the first part of this thesis, the predictive performance of all published first trimester prognostic prediction models containing exclusively non-invasive predictors for the risk of pre-eclampsia (PE), gestational diabetes mellitus (GDM), delivering an infant small-for-gestational-age (SGA) or large-for-gestational-age (LGA), and spontaneous preterm birth (PTB) were examined in a Dutch pregnant population ${ }^{1}$. Furthermore, the clinical potential of the best performing models was evaluated.

The clinical utility of prediction models is dependent on effective follow-up management. One of the available treatment strategies is adequate calcium intake in the prevention of PE. In the second part of this thesis, current calcium intake among Dutch pregnant women was assessed and the (cost)-effectiveness of different calcium supplementation strategies in the prevention of PE was evaluated.

This chapter provides an overview of the main findings and their clinical implications, methodological considerations, and recommendations for further research.

\section{External validation of first trimester obstetric prediction models}

Thirty-three published first trimester prediction models for the risk of PE $(n=10)$, GDM $(n=12)$, delivering an infant SGA $(n=6)$ or LGA $(n=6)$, and spontaneous PTB $(n=5)$ were selected for external validation in a large Dutch pregnant cohort. Most models showed a promising predictive performance in the development cohorts, with discriminative abilities up to $88 \%, 85 \%, 74 \%, 72 \%$, and $70 \%$ for GDM, PE, LGA, SGA, and spontaneous PTB, respectively. Discrimination is a measure of a model's ability to separate women who will develop the disease from those who will not. Calibration reflects the extent to which a model's predicted probabilities are in line with the actual outcome frequencies ${ }^{2}$.

\section{Pre-eclampsia}

External validation of the prediction models for PE showed a moderate discriminative performance for five models (area under the receiver operating characteristic curve, AUROC >0.70) (chapter 3). The model of Syngelaki et al. showed the best discriminative ability (AUROC 0.77$)^{3}$. Evaluation of the models' calibration indicated that most models consistently overestimated the risk of PE and were overfitted (low predictions too low and high predictions too high, calibration slope $<1$ ). Recalibration of the models led to closer fitting to the ideal calibration line.

\section{Gestational diabetes mellitus}

All 12 included prediction models for the risk of developing GDM showed a moderate predictive performance after external validation (AUROC 0.70) (chapter 4). The best discriminating models were those of Syngelaki et al. and Nanda et al. with an AUROC of $0.75^{3,4}$. Nearly all models overestimated the risk in our validation cohort. 
Recalibration considerably improved agreement between the actual risks and predicted probabilities for most models.

\section{Small- and large-for-gestational-age infants}

The validation of six prediction models for delivering an infant SGA below the $10^{\text {th }}$ percentile demonstrated poor discriminative performance for all models, with the highest AUROC (0.64) observed for the model of Boucoiran et al. (chapter 5$)^{5}$. The discriminative abilities of the models for delivering an infant LGA above the $90^{\text {th }}$ percentile were slightly better compared to the models predicting SGA (chapter 5). The model of Frick et al. showed the best discriminative performance (AUROC 0.69) ${ }^{6}$. All models showed better discriminative ability for predicting the more severe cases of SGA $\left(<5^{\text {th }}\right.$ percentile, AUROC up to 0.67$)$ and LGA ( $>95^{\text {th }}$ percentile, AUROC up to 0.74 ), which are also associated with a higher risk of adverse outcomes ${ }^{6,7}$. Initial calibration was poor for the prediction models for SGA. The models for LGA all overestimated the risk in our population. Recalibration yielded better agreement of the predicted risks with the actual risks for most models.

\section{Spontaneous preterm birth}

External validation of the prediction models for the risk of spontaneous PTB retrieved poor discriminative performance for spontaneous PTB $<37$ weeks of gestation and moderate for spontaneous PTB $<34$ weeks of gestation (chapter 6). The model of Beta et al. showed the best discriminative ability (AUROC 0.67 spontaneous PTB $<37$ weeks of gestation and AUROC 0.70 spontaneous PTB $<34$ weeks of gestation) ${ }^{8}$. Initial calibration was moderate and revealed closer fitting to the optimal calibration line after recalibration.

\section{Nulliparous women}

A subgroup analysis among nulliparous women was performed for all included models, as obstetric history (i.e. previous $P E$ ) is a strong determinant of recurrence. The discriminative performance of the models predicting GDM, SGA and LGA remained stable among nulliparous women (chapter 4 and 5). The discriminative ability of the models for PE considerably decreased among nulliparous women, with highest AUROC of 0.61 (model Syngelaki et al.) (chapter 3). Notably, even the models specifically developed for nulliparous women did not perform better than the other models $^{9-11}$. The models for spontaneous PTB discriminated poorly among nulliparous women (highest AUROC 0.56) (chapter 6).

Our results confirm the importance of externally validating prediction models. Upon external validation, we found that the discriminative performance decreased for nearly all included models. Although the necessity of performing external validation studies has been mentioned by others ${ }^{12,13}$, only a minority of the included models had been independently validated prior to our validation studies. Only two of the included 
models for PE, Poon et al. (Hypertension) and Plasencia et al., had been externally validated $^{14-16}$. Several studies have externally validated models for GDM, most of them addressing only up to five models ${ }^{17-21}$. In 2016, a first external validation study comparing the performance of all published non-invasive first trimester prediction models for the risk of GDM in an independent cohort was published ${ }^{22}$. The discriminative performance of the models was slightly higher compared to our results. We validated three additional models based on maternal characteristics. The comprehensive external validation study was performed among a Dutch population as well, but from another geographic area. This strengthens the generalizability of the models for GDM to the general Dutch population and even to comparable antenatal populations in other high-income countries. Multiple external validation of a prediction model adds to the robustness of model performance ${ }^{23}$. Two of the best performing models identified by our validation study, developed by Nanda et al. (AUROC 0.75) and Van Leeuwen et al. (AUROC 0.74), showed similar performances in several independent populations ${ }^{18-20,22}$. To our knowledge, no external validation studies of first trimester prognostic prediction models for SGA, LGA, and spontaneous PTB have been published so far.

\section{Clinical utility of externally validated obstetric prediction models}

Statistical performance measures are important aspects of a prediction model, but do not indicate the usefulness of a model in clinical practice ${ }^{13}$. Even if the statistical performance is not optimal, the model may be worth considering, and vice versa. Clinical utility depends on several inter-related factors apart from statistical performance, such as the severity of the outcome, the applicability of the model, and the effectiveness of the follow-up strategy.

\section{Pre-eclampsia}

Low-dose aspirin and calcium supplementation are well-documented interventions that reduce the risk of developing PE. Low-dose aspirin reduces the occurrence of PE by $10-43 \%$ among high-risk women, and also reduces related adverse outcomes (including PTB and SGA) ${ }^{24-28}$. A recent meta-analysis demonstrated that aspirin mainly reduces the risk of preterm $\mathrm{PE}$ (risk reduction $89 \%$ ), which is more related to adverse outcomes than term $\mathrm{PE}^{29}$. Calcium supplementation ( $\geq 1 \mathrm{~g} /$ day) lowers the risk of developing PE by $55-78 \%$, the effect being more pronounced among women with a low dietary calcium intake and women at increased risk of developing hypertensive pregnancy disorders ${ }^{30}$. Besides the efficiency of the intervention, low-dose aspirin and calcium supplementation are relatively cheap, generally not burdensome, safe, and have no major side effects ${ }^{25,30-33}$. The best performing prediction models for PE can help to guide decision-making of these efficacious non-invasive preventive interventions. Despite their moderate discriminative ability, particularly among nulliparous women, the models performed better or nearly the same compared with 
current risk assessment strategies based on single risk factors (the American College of Obstetricians and Gynecologists (ACOG) and National Institute for Health and Clinical Excellence (NICE), respectively) ${ }^{34-36}$. Moreover, compared to single risk factor strategies, using a prediction model has the advantage that a preferred trade-off between sensitivity and specificity can be selected.

\section{Gestational diabetes mellitus}

Early risk stratification for GDM may allow for targeted early screening and preventive interventions. Early screening of pregnant women for GDM by use of an oral glucose tolerance test (OGTT) is important as the disorder is mostly asymptomatic and the consequences, i.e. LGA, are often already present at the time of diagnosis. Clinical management of GDM improves pregnancy outcomes ${ }^{37-40}$. Internationally, however, there is no consensus whether to screen all women for GDM (universal screening) or only women with pre-specified risk factors (selective screening) ${ }^{41}$. Universal screening ensures highest detection rates, but (nearly) all women would have to undergo an OGTT, which would lead to unnecessary burden on low-risk women and health care resources. Although the best performing models do not provide more benefit at certain risk thresholds compared with current available screening strategies based on single risk factors (NICE and Dutch national guideline), an advantage is that a preferred trade-off between sensitivity and specificity can be selected ${ }^{42,43}$. Besides the potential of early diagnosis, most benefit would be obtained if GDM could be prevented. Despite emerging promising studies (i.e. lifestyle interventions, metformin), no evidence for primary prevention of GDM is available yet ${ }^{41,44-48}$. The limited available studies have methodological shortcomings such as heterogeneity and small sample size. For now, awareness and interventions towards a healthy lifestyle (i.e. diet and physical activity) are essential means in the prevention of GDM, which can be advised without causing harm.

\section{Small- and large-for-gestational-age infants}

The heterogeneous aetiology of fetal growth deviations complicates the prediction of SGA and LGA ${ }^{49,50}$. Infants who are constitutionally smaller or larger for gestational age are less related to adverse outcomes and also less likely to benefit from interventions ${ }^{50}$. Clinically relevant SGA and LGA frequently have a 'vascular' (i.e. hypertensive disorder) or 'metabolic' (i.e. high body mass index, GDM) origin, respectively. Although the included prediction models predict overall SGA and LGA, the predictors considerably overlap with those of models predicting hypertensive pregnancy disorders and GDM, respectively ${ }^{51,52}$. Recent meta-analyses demonstrated that low-dose aspirin modestly reduces the risk for delivering a SGA infant in women at high risk (risk ratio $0.56-0.76)^{25,26}$. However, high risk was primarily defined on the basis of an increased risk of developing a hypertensive pregnancy disorder rather than risk of delivering a SGA infant ${ }^{53}$. Expect for treatment of GDM, which indirectly lowers the risk of LGA, no effective intervention is currently available in the prevention of 
$\mathrm{LGA}^{49}$. Application of current available prediction models for SGA or LGA in settings where models for identification of 'vascular' (PE) and 'metabolic' (GDM) related pregnancy complications are applied, respectively, are not likely to result in additional clinical benefit regarding overlap of predictors and preventive interventions. Moreover, using the prediction models to select women for ultrasound fetal growth measurements in order to prevent labour-related complications will not be more beneficial compared to providing all women ultrasound follow-up.

\section{Spontaneous preterm birth}

Progesterone treatment has been reported to reduce the risk of spontaneous PTB in women at high risk (previous spontaneous PTB and midtrimester short cervix) ${ }^{54,55}$. Cervical cerclage and pessary have also been reported to prolong gestation in these high-risk women, but evidence on whether these interventions are either more or less effective than progesterone is limited ${ }^{56,57}$. The external validation of selected prediction models for the risk of spontaneous PTB demonstrated a poor performance among nulliparous women. Estimation of the risk in multiparous women relies mainly on the predictor 'previous history of spontaneous PTB'. The validated models do not add much value to current clinical care since caregivers are already aware that women with a prior spontaneous PTB are at high risk. Moreover, application of the best performing model for cervix length screening among nulliparous women will not be more beneficial than routine cervical length screening, resulting in a high number needed to screen in both situations ${ }^{58,59}$.

In conclusion, first trimester prognostic prediction models for PE and GDM can potentially improve early risk stratification in pregnancy towards more personalized obstetric care as effective follow-up management is available and models showed better performance compared to current risk strategies. The clinical relevance of prediction models for SGA and LGA might be questioned due to the underlying heterogeneous aetiology. Constitutionally smaller and larger infants are less related to adverse outcomes and also less likely to benefit from interventions. Clinically relevant fetal growth deviations are 'vascular' and 'metabolic' related. The validated prediction models for SGA and LGA are therefore not expected to provide additional clinical benefit in settings were models for PE and GDM are applied as predictors as well as primary preventive interventions overlap. The clinical utility of the validated models for spontaneous PTB is low due to poor performance among nulliparous women.

\section{Calcium in the prevention of pre-eclampsia}

Adequate calcium intake has a protective effect against development of hypertensive pregnancy disorders. Calcium supplementation is one of the interventions that can be used to prevent adverse pregnancy outcomes. Supplementation of at least $1000 \mathrm{mg}$ of calcium per day during pregnancy lowers the risk of developing a hypertensive 
pregnancy disorder (PE and gestational hypertension), particularly among women with a low dietary calcium intake or at increased risk of developing a hypertensive pregnancy disorder ${ }^{30}$. Besides, calcium supplementation is a safe and relatively cheap intervention $^{30,33}$. Whether advising calcium supplementation during pregnancy is (cost-)effective and which strategy provides most benefit depends, besides the efficacy of the intervention, on several other factors including current calcium intake, outcome incidence, uptake of the intervention, costs of intervention, and costs related to the outcome.

There is a scarcity of contemporary studies on the prevalence of inadequate calcium intake among pregnant women in Western countries, particularly regarding the use of calcium supplements. Therefore, we estimated calcium intake from both diet and supplement use in Dutch pregnant women during early pregnancy (chapter 7). Sixty percent of the pregnant women did not meet the recommended adequate intake of $1000 \mathrm{mg} /$ day. The median calcium intake was 886 (interquartile range 611-1213) $\mathrm{mg} /$ day. Supplements containing any calcium were used by $64.8 \%$ of the women at 8 weeks of gestation, but only $2 \%$ of the women specifically used calcium supplements. Although supplements were frequently used, the calcium content of the most used supplements, prenatal vitamins, was insufficient for complementing the dietary calcium intake to reach the recommended adequate intake.

Reaching an adequate intake through calcium-rich foods should be primarily encouraged. However, women may not be prepared to consume the daily amount of foods necessary to reach an adequate intake. Although dairy products are the largest contributor to calcium intake, $100 \mathrm{~g}$ semi-skimmed milk contains only $123 \mathrm{mg}$ calcium $^{60}$. Published trials of behavioural interventions to increase maternal dietary calcium intake have shown mixed results ${ }^{61}$. A decision analysis was performed to provide insight whether calcium supplementation is a potential (cost-)effective intervention for implementation in Dutch antenatal care (chapter 8 ). The results of the decision analysis indicated that advising calcium supplementation 1,000 mg/day to all pregnant women, pregnant women at high risk of $\mathrm{PE}$, or pregnant women with a low dietary calcium intake can be expected to reduce the incidence of PE by $25 \%, 8 \%$, or $13 \%$, respectively. Expected net financial benefits are $€ 4,621,465, € 2,059,165$, or $€ 2,822,115$ per 100,000 pregnant women, respectively. While the best evidence was used for obtaining accurate input values, the analysis is limited by the availability and quality of existing evidence. Clinical and financial benefits change with varying parameter estimates, however, it is implausible that effects will be reversed, as conservative input values were used. Although advising calcium supplementation to subgroups alone may be a more targeted approach, it might be more efficient to advise the use of calcium supplements to all pregnant women. In this way, women who are not part of defined subgroups also profit from the intervention and no individual dietary calcium intake or risk for developing PE has to be estimated. Although the number of women needed to advise calcium supplementation is higher in the overall pregnant population as compared to subgroups to obtain beneficial 
health effects, advising supplement intake in general is an acceptable approach as calcium supplementation is a non-invasive, well tolerated, and -provided that it is used prudently- safe intervention.

Although the results indicated that advising calcium supplementation during pregnancy can yield favourable economic and health effects, even with suboptimal uptake of the intervention, a challenge remains to effectively implement the intervention in health care practice ${ }^{62-64}$. Implementation efforts require that attention is paid to accessibility, affordability, acceptability, and adherence to the intervention from a patient's, care providers', and organizational point of view. Facilitators for the implementation of calcium supplementation are good tolerance, absence of adverse effects, and the expectation that it can be implemented by different health care providers with varying levels of training and expertise ${ }^{30,33}$. An uncertain but important factor that determines the adequate intake of calcium supplements is the extent to which antenatal care providers are able to influence pregnant women's behaviour.

\section{Methodological considerations}

This paragraph discusses the main methodological considerations of the research described in this thesis and how these may have influenced the results.

\section{Study design}

The studies described in this thesis included data of the Expect Study I, which is a multicentre prospective cohort study ${ }^{1}$. Because of broad eligibility criteria and multicentre recruitment (i.e. primary as secondary/tertiary care), an unselected sample of the Dutch obstetric population was included in this study. The use of web-based questionnaires, which is an efficient and user-friendly data collection tool in a population with high access to the Internet, provided high data quality and low numbers of missing data, which was mainly due to the incorporation of validation checks $^{65,66}$.

\section{Predictor and outcome assessment}

The prospective cohort design of the Expect Study I enabled optimal measurement of predictors and outcomes ${ }^{67}$. The dataset contained less than $1 \%$ missing data for almost all predictors and these were imputed using stochastic regression imputation in order to prevent biased results and a loss of statistical precision ${ }^{68}$. However, there was a substantial amount of missing data ( 10\%) regarding blood pressure measurements, which is most likely due to self-report of the measurements in the web-based questionnaire ${ }^{66}$. In addition, the variable blood pressure might have been subject to measurement error as the measurements were performed according to routine clinical practice ${ }^{69}$. Despite availability of standardized protocols for blood pressure measurement, this procedure is often not strictly followed in clinical 
practice. Mainly the included models predicting PE contained a predictor based on blood pressure measurement.

Outcomes were obtained from a combination of the medical record and a postpartum questionnaire. GDM and PE are, in contrast to gestational age at delivery and birth weight, no required registry outcomes in Dutch clinical care. Combination of both data sources ensured for most complete available information as possible in a large cohort. In case of discrepancies for the outcomes PE and GDM, health caregivers were contacted. A Dutch study showed that a web-based questionnaire might be considered as a valid complementary and alternative method to assess perinatal outcomes compared to obstetric records ${ }^{65}$. Moreover, outcomes may be defined and assessed differently across studies. External validation of multiple prediction models provides a fair comparison of the predictive performances in a particular population where specific diagnostic criteria for the outcome are used. Lastly, outcomes may be affected, especially among high-risk women, due to treatment bias, i.e. women received progesterone in order to prevent spontaneous PTB. Treatment bias may have resulted in an underestimation of model discrimination and calibration ${ }^{70,71}$.

\section{Sample size}

A specific methodological issue with respect to external validation studies is sample size. No golden rule is available for the required sample size of external validation studies. However, studies suggest that a minimum of 100 events, or preferably more, is needed for accurate and precise model performances ${ }^{72,73}$. The Expect Study I provided $>100$ cases for the primary outcomes SGA $<10^{\text {th }}$ percentile, LGA $>90^{\text {th }}$ percentile and spontaneous PTB $<37$ weeks of gestation. For the outcome GDM, we were able to add data from the PRIDE Study to obtain a sufficient number of cases $(n=127)$. The PRIDE Study is an on-going Dutch multicentre prospective cohort study among pregnant women, of which the study design and data collection are comparable to those of the Expect Study $\mathrm{I}^{74}$. Subgroup analyses showed that the models performed similar in the two cohorts, demonstrating consistency of the results in different Dutch populations. Only the outcome PE had less than 100 cases $(n=76)$. A study of Collins et al. showed that the precision of the AUROC and calibration slope did not differ much between studies with 75 to 100 events $^{72}$. Moreover, the external validation study of prediction models for GDM showed almost no difference between the predictive performance in the Expect Study I (76 cases) and overall validation cohort (127 cases). Although studies suggest that prediction of early onset PE may provide most benefit on health outcomes for both mother and child, it was not possible to validate these models due to its low incidence $(5 \text { cases })^{29,51,75,76}$.

\section{Calcium intake assessment}

A final methodological issue to be mentioned is the assessment of calcium intake in the Expect Study I. Since there are no reliable biomarkers of calcium intake, estimation of calcium intake is dependent on dietary assessment ${ }^{77}$. A food frequency 
questionnaire (FFQ) is a common method to assess dietary intake in large epidemiologic studies because of lower patient burden and costs compared to repeated dietary recalls and food records, which may be the most accurate approach for food intake assessment ${ }^{78,79}$. As assessment of dietary calcium intake was not the primary aim of the Expect Study I, using a comprehensive FFQ for calcium intake was not feasible. A selection of food products were included that cumulatively cover $>80 \%$ of the variance in calcium intake ${ }^{80}$. These food products contributed to $62 \%$ of total dietary calcium intake. As this selection procedure may have resulted in an underestimation of total dietary calcium intake, calcium intake was adjusted to $100 \%^{81-84}$. Besides, as suggested by our decision analysis, even in a situation with a lower proportion of women with an inadequate calcium intake, a general calcium advice can still be expected to yield considerably favourable effects on population health as well as economic outcomes.

\section{Clinical implications and future perspectives}

The studies in this thesis provide useful insights regarding prediction and prevention of adverse pregnancy outcomes, and raise perspectives for future research.

External validation is a first step towards clinical application of prediction models. Although there is room for further improvement of the models, in particular among nulliparous women, the predictive performance and clinical utility of the validated prediction models, which consisted of exclusively non-invasive predictors, appeared promising with regard to the outcomes GDM and PE. To considerably improve the existing prediction models, any new additional predictors need to have a strong relation with the outcome. Published studies showed that the predictive performance of a model, particularly predicting $\mathrm{PE}$, might improve by taking into account biomarkers or ultrasound imaging (i.e. uterine artery Doppler) ${ }^{51,52}$. However, these promising predictors are not always routinely performed or readily available in general antenatal care, and it is unknown whether models incorporating non-routine predictors are more (cost-)effective compared to non-invasive models ${ }^{51,85,86}$.

Besides evaluating the predictive performance of prediction models, it is also necessary that effective follow-up management is available. Prevention studies appear to disproportionally focus on secondary prevention rather than primary prevention. Moreover, although some promising primary preventive interventions are available (i.e. low-dose aspirin and calcium supplementation), these interventions are not integrated in standard antenatal care in most countries yet. Our decision analysis showed that recommendation of calcium supplementation during pregnancy might foster beneficial health effects on population level and reduces related health care costs, also in high-income countries. In conclusion, although further research towards improvement of prediction models and preventive measures is necessary, research should focus more on translation of currently available evidence into practice. 
In view of personalizing obstetric care, implementing the promising prediction models for GDM and PE might be an important step forward in the Dutch obstetric care system. Although implementation is a task facing challenge, the medical literature has paid relatively low attention to this important step $^{12,87,88}$. A prognostic prediction model provides objective estimates of developing a health outcome to guide health care providers and patients regarding decision-making towards follow-up management ${ }^{13}$. Estimated probabilities can be simply provided as an absolute value (scale $0-100 \%$ ) without providing follow-up management (assistive approach) or by explicitly recommending or prescribing specific follow-up management for estimated risk categories (decisive approach) ${ }^{88}$. The assistive approach leaves more room for judgment and intuition of women and caregivers, but a decisive approach may have greater clinical impact ${ }^{89-92}$. Determination of an acceptable risk threshold is a challenging aspect. Ideally, a screening test correctly identifies women who will develop the outcome while avoiding unnecessary follow-up management among women at low risk. However, in practice, a prognostic prediction model does not reach a $100 \%$ sensitivity and specificity and a certain rate of false positives or negatives are likely to occur. Decision curve analysis provides a first insight into the net benefit of a model over a range of risk thresholds compared to classifying all or no women at high risk for the outcome ${ }^{93}$. Decision curve analysis can also be used to evaluate the model with highest net benefit at a particular risk threshold. Nevertheless, choosing an acceptable cut-off is dependent on several factors such as efficiency, burden, and costs of the follow-up management, as well as incidence, burden, and related health care costs of the outcome. Even though only a small number of women may benefit from follow-up management, it can have a great positive impact on the population level ${ }^{94}$. Another important aspect is how to counsel women regarding early risk assessment of pregnancy complications to make informed decisions. This includes pre-risk assessment counselling (about how risk assessment would be beneficial) and post-risk assessment counselling (about possible consequences and management). Risk counselling has an important impact on risk perception of patients, which is an important determinant of patients' behaviour ${ }^{95}$. A recent Dutch study exploring pregnant women's perceptions, needs and preferences regarding the use of prediction models for PE showed that women had a positive attitude towards screening ${ }^{96}$. Although a high risk could cause (unnecessary) anxiety, self-monitoring together with increased alertness and professional counselling were considered benefits of using a prediction model ${ }^{96}$.

In the end, an empirical impact study is necessary for the evaluation of whether implementation of prediction model actually changes caregivers' and women's behaviour, which is necessary to obtain potential improvement of pregnancy outcomes and cost-effectiveness of care $^{87,88}$. 


\section{Translating evidence into clinical practice}

An impact study on the implementation of first trimester prediction models for PE and GDM combined with tailored care paths, and the recommendation to use calcium supplementation during pregnancy is currently performed in the south-eastern part of the Netherlands (Expect Study II) ${ }^{97}$. In April 2017, an early risk assessment tool (Expect Calculator, www.zwangerinlimburg.nl) was made available to primary as well as secondary/tertiary obstetric care in south-eastern part of the Netherlands. This tool contains the recalibrated prognostic models of Syngelaki et al. and Van Leeuwen et al. to predict the risk of PE and GDM, respectively ${ }^{3,98}$. Risk assessment of spontaneous PTB, SGA and LGA was also incorporated in the tool, but based on single risk factors according to current guidelines instead of a weighted combination of factors ${ }^{99}$. Besides early risk assessment, the tool provides personalized recommendations for antenatal care tailored to individual risks (Figure 9.1). The Limburg Obstetric Consortium (midwives, obstetricians, and deputies of maternity care centres in Limburg) developed tailored care paths and determined, partly based on women's opinions, acceptable risk threshold values ${ }^{99}$. Risks are displayed to pregnant women and health care professionals as absolute values on a visual scale including the determined threshold values to support shared-decision making regarding recommended follow-up management. Lastly, the tool provides patient information brochures relevant to the patient's risk profile.

The Expect Study II will evaluate the adherence and compliance to the risk-dependent care by caregivers and pregnant women, respectively. Moreover, satisfaction and health care costs will be evaluated and compared to data of Expect Study I (beforeafter study). This impact study will provide insight whether implementation of early risk assessment in combination with tailored care paths actually leads to behavioural changes of both caregivers and women, which is essential in order to achieve the intended health effects ${ }^{97}$. 


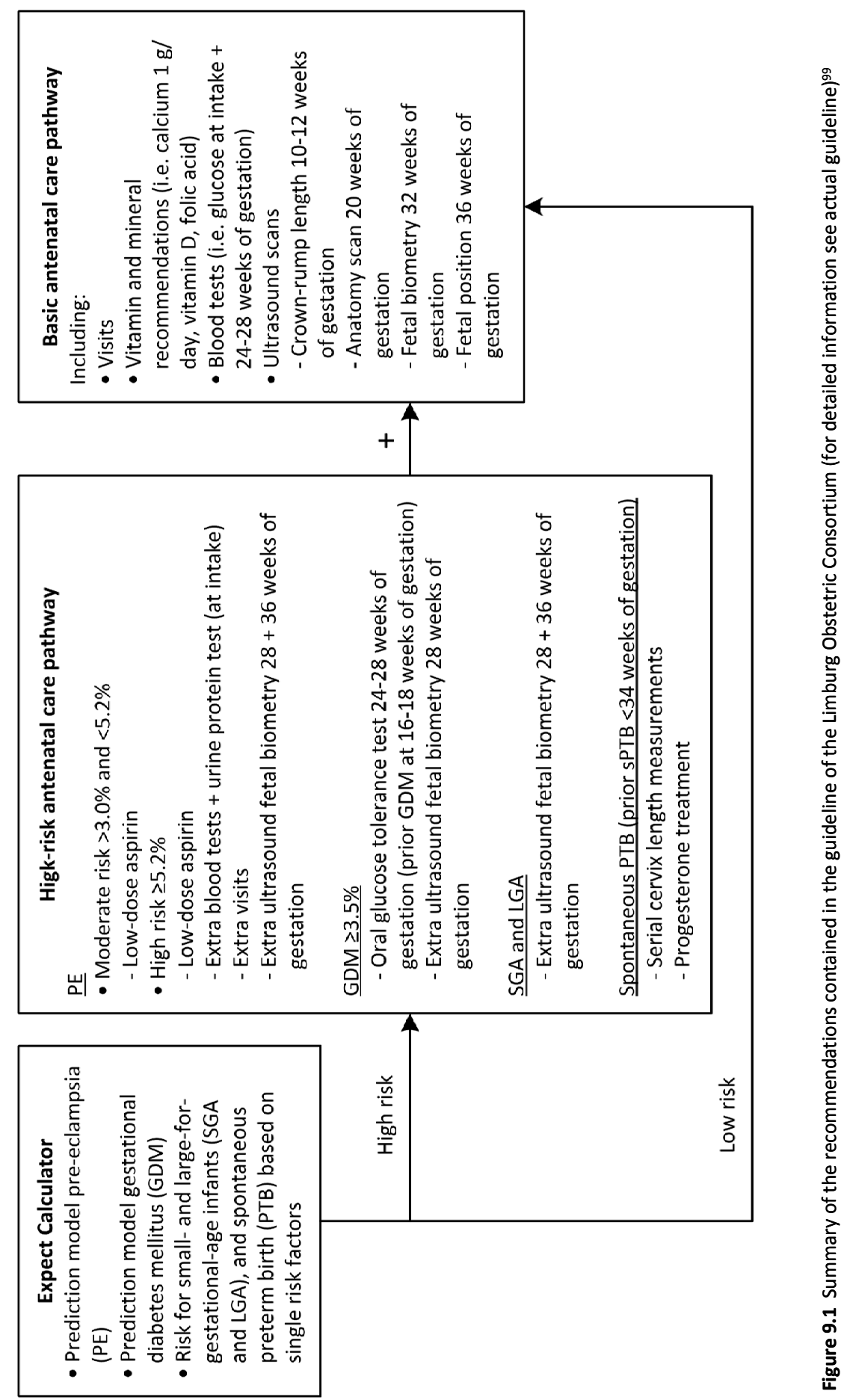




\section{Conclusion}

The studies in this thesis provide useful evidence for the establishment of personalized obstetric care with regard to both risk assessment and intervention strategies. Evaluation of the external validity and clinical utility of published first trimester models for the prediction of GDM, PE, spontaneous PTB, SGA and LGA revealed that there are prediction models for PE and GDM that are worth considering for application in clinical practice. Moreover, the results demonstrated that advising calcium supplementation during pregnancy, an efficacious intervention in the prevention of $\mathrm{PE}$, can bring about important health effects on population level and a substantial reduction in health care costs. A next step towards personalizing obstetric care is to investigate the impact of implementation of the best prediction models for PE and GDM combined with risk-dependent care paths in clinical practice on decisionmaking and behaviour of caregivers and pregnant women, which may ultimately lead to improved obstetric outcomes. 


\section{References}

1. Meertens, L.J.E., Scheepers, H.C., De Vries, R.G., Dirksen, C.D., Korstjens, I., Mulder, A.L., et al., External Validation Study of First Trimester Obstetric Prediction Models (Expect Study I): Research Protocol and Population Characteristics. JMIR Res Protoc, 2017. 6(10): p. e203.

2. Steyerberg, E.W., Vickers, A.J., Cook, N.R., Gerds, T., Gonen, M., Obuchowski, N., et al., Assessing the performance of prediction models: a framework for traditional and novel measures. Epidemiology, 2010. 21(1): p. 128-38.

3. Syngelaki, A., Bredaki, F.E., Vaikousi, E., Maiz, N., and Nicolaides, K.H., Body mass index at 11-13 weeks' gestation and pregnancy complications. Fetal Diagn Ther, 2011. 30(4): p. 250-65.

4. Nanda, S., Savvidou, M., Syngelaki, A., Akolekar, R., and Nicolaides, K.H., Prediction of gestational diabetes mellitus by maternal factors and biomarkers at 11 to 13 weeks. Prenat Diagn, 2011. 31(2): p. 135-41.

5. Boucoiran, I., Djemli, A., Taillefer, C., Rypens, F., Delvin, E., and Audibert, F., First-trimester prediction of birth weight. Am J Perinatol, 2013. 30(8): p. 665-72.

6. Frick, A.P., Syngelaki, A., Zheng, M., Poon, L.C., and Nicolaides, K.H., Prediction of large-forgestational-age neonates: screening by maternal factors and biomarkers in the three trimesters of pregnancy. Ultrasound Obstet Gynecol, 2016. 47(3): p. 332-9.

7. Mlynarczyk, M., Chauhan, S.P., Baydoun, H.A., Wilkes, C.M., Earhart, K.R., Zhao, Y., et al., The clinical significance of an estimated fetal weight below the 10th percentile: a comparison of outcomes of $<5$ th vs 5th-9th percentile. Am J Obstet Gynecol, 2017. 217(2): p. 198 e1-198 e11.

8. Beta, J., Akolekar, R., Ventura, W., Syngelaki, A., and Nicolaides, K.H., Prediction of spontaneous preterm delivery from maternal factors, obstetric history and placental perfusion and function at 1113 weeks. Prenat Diagn, 2011. 31(1): p. 75-83.

9. Audibert, F., Boucoiran, I., An, N., Aleksandrov, N., Delvin, E., Bujold, E., et al., Screening for preeclampsia using first-trimester serum markers and uterine artery Doppler in nulliparous women. Am J Obstet Gynecol, 2010. 203(4): p. 383.e1-8.

10. Kenny, L.C., Black, M.A., Poston, L., Taylor, R., Myers, J.E., Baker, P.N., et al., Early pregnancy prediction of preeclampsia in nulliparous women, combining clinical risk and biomarkers: the Screening for Pregnancy Endpoints (SCOPE) international cohort study. Hypertension, 2014. 64(3): p. 644-52.

11. North, R.A., McCowan, L.M., Dekker, G.A., Poston, L., Chan, E.H., Stewart, A.W., et al., Clinical risk prediction for pre-eclampsia in nulliparous women: development of model in international prospective cohort. BMJ, 2011. 342: p. d1875.

12. Kleinrouweler, C.E., Cheong-See, F.M., Collins, G.S., Kwee, A., Thangaratinam, S., Khan, K.S., et al., Prognostic models in obstetrics: available, but far from applicable. Am J Obstet Gynecol, 2016. 214(1): p. 79-90.e36.

13. Moons, K.G., Kengne, A.P., Grobbee, D.E., Royston, P., Vergouwe, Y., Altman, D.G., et al., Risk prediction models: II. External validation, model updating, and impact assessment. Heart, 2012. 98(9): p. 691-8.

14. Farina, A., Rapacchia, G., Freni Sterrantino, A., Pula, G., Morano, D., and Rizzo, N., Prospective evaluation of ultrasound and biochemical-based multivariable models for the prediction of late preeclampsia. Prenat Diagn, 2011. 31(12): p. 1147-52.

15. Herraiz, I., Arbues, J., Camano, I., Gomez-Montes, E., Graneras, A., and Galindo, A., Application of a first-trimester prediction model for pre-eclampsia based on uterine arteries and maternal history in high-risk pregnancies. Prenat Diagn, 2009. 29(12): p. 1123-9.

16. Allen, R.E., Zamora, J., Arroyo-Manzano, D., Velauthar, L., Allotey, J., Thangaratinam, S., et al., External validation of preexisting first trimester preeclampsia prediction models. Eur J Obstet Gynecol Reprod Biol, 2017. 217: p. 119-125.

17. Lovati, E., Beneventi, F., Simonetta, M., Laneri, M., Quarleri, L., Scudeller, L., et al., Gestational diabetes mellitus: including serum pregnancy-associated plasma protein-A testing in the clinical management of primiparous women? A case-control study. Diabetes Res Clin Pract, 2013. 100(3): p. 340-7. 
18. Sweeting, A.N., Appelblom, H., Ross, G.P., Wong, J., Kouru, H., Williams, P.F., et al., First trimester prediction of gestational diabetes mellitus: A clinical model based on maternal demographic parameters. Diabetes Res Clin Pract, 2017. 127: p. 44-50.

19. Syngelaki, A., Pastides, A., Kotecha, R., Wright, A., Akolekar, R., and Nicolaides, K.H., First-Trimester Screening for Gestational Diabetes Mellitus Based on Maternal Characteristics and History. Fetal Diagn Ther, 2015. 38(1): p. 14-21.

20. Theriault, S., Forest, J.C., Masse, J., and Giguere, Y., Validation of early risk-prediction models for gestational diabetes based on clinical characteristics. Diabetes Res Clin Pract, 2014. 103(3): p. 419-25.

21. van Leeuwen, M., Opmeer, B.C., Zweers, E.J., van Ballegooie, E., ter Brugge, H.G., de Valk, H.W., et al., External validation of a clinical scoring system for the risk of gestational diabetes mellitus. Diabetes Res Clin Pract, 2009. 85(1): p. 96-101.

22. Lamain-de Ruiter, M., Kwee, A., Naaktgeboren, C.A., de Groot, I., Evers, I.M., Groenendaal, F., et al., External validation of prognostic models to predict risk of gestational diabetes mellitus in one Dutch cohort: prospective multicentre cohort study. BMJ, 2016. 354: p. i4338.

23. Steyerberg, E., Clinical prediction models: a practical approach to development, validation, and updating. 2008: Springer Science \& Business Media.

24. Duley, L., Henderson-Smart, D.J., Meher, S., and King, J.F., Antiplatelet agents for preventing preeclampsia and its complications. Cochrane Database Syst Rev, 2007(2): p. Cd004659.

25. Meher, S., Duley, L., Hunter, K., and Askie, L., Antiplatelet therapy before or after 16 weeks' gestation for preventing preeclampsia: an individual participant data meta-analysis. Am J Obstet Gynecol, 2017. 216(2): p. 121-128 e2.

26. Roberge, S., Nicolaides, K., Demers, S., Hyett, J., Chaillet, N., and Bujold, E., The role of aspirin dose on the prevention of preeclampsia and fetal growth restriction: systematic review and meta-analysis. Am J Obstet Gynecol, 2017. 216(2): p. 110-120 e6.

27. Roberge, S., Nicolaides, K.H., Demers, S., Villa, P., and Bujold, E., Prevention of perinatal death and adverse perinatal outcome using low-dose aspirin: a meta-analysis. Ultrasound Obstet Gynecol, 2013. 41(5): p. 491-9.

28. Henderson, J.T., Whitlock, E.P., O'Connor, E., Senger, C.A., Thompson, J.H., and Rowland, M.G., Lowdose aspirin for prevention of morbidity and mortality from preeclampsia: a systematic evidence review for the U.S. Preventive Services Task Force. Ann Intern Med, 2014. 160(10): p. 695-703.

29. Roberge, S., Bujold, E., and Nicolaides, K.H., Aspirin for the prevention of preterm and term preeclampsia: systematic review and metaanalysis. Am J Obstet Gynecol, 2017.

30. Hofmeyr, G.J., Lawrie, T.A., Atallah, A.N., Duley, L., and Torloni, M.R., Calcium supplementation during pregnancy for preventing hypertensive disorders and related problems. Cochrane Database Syst Rev, 2014(6): p. CD001059.

31. Roberge, S., Bujold, E., and Nicolaides, K.H., Meta-analysis on the effect of aspirin use for prevention of preeclampsia on placental abruption and antepartum hemorrhage. Am J Obstet Gynecol, 2018.

32. Rolnik, D.L., Wright, D., Poon, L.C., O'Gorman, N., Syngelaki, A., de Paco Matallana, C., et al., Aspirin versus Placebo in Pregnancies at High Risk for Preterm Preeclampsia. N Engl J Med, 2017. 377(7): p. 613-622.

33. Heaney, R.P., Kopecky, S., Maki, K.C., Hathcock, J., Mackay, D., and Wallace, T.C., A review of calcium supplements and cardiovascular disease risk. Adv Nutr, 2012. 3(6): p. 763-71.

34. American College of Obstetricians and Gynecologists. Practice Advisory on Low-Dose Aspirin and Prevention of Preeclampsia: Updated Recommendations (July 2016). Available from: http://www.acog.org/About-ACOG/News-Room/Practice-Advisories/Practice-Advisory-Low-DoseAspirin-and-Prevention-of-Preeclampsia-Updated-Recommendations.

35. National Collaborating Centre for Women's and Children's Health, Hypertension in Pregnancy: The Management of Hypertensive Disorders During Pregnancy [CG107]. National Institute for Health and Clinical Excellence: Guidance. 2010.

36. LeFevre, M.L., Low-dose aspirin use for the prevention of morbidity and mortality from preeclampsia: U.S. Preventive Services Task Force recommendation statement. Ann Intern Med, 2014. 161(11): p. 819-26.

37. Alwan, N., Tuffnell, D.J., and West, J., Treatments for gestational diabetes. Cochrane Database Syst Rev, 2009(3): p. Cd003395. 
38. Hartling, L., Dryden, D.M., Guthrie, A., Muise, M., Vandermeer, B., and Donovan, L., Benefits and harms of treating gestational diabetes mellitus: a systematic review and meta-analysis for the U.S. Preventive Services Task Force and the National Institutes of Health Office of Medical Applications of Research. Ann Intern Med, 2013. 159(2): p. 123-9.

39. Horvath, K., Koch, K., Jeitler, K., Matyas, E., Bender, R., Bastian, H., et al., Effects of treatment in women with gestational diabetes mellitus: systematic review and meta-analysis. BMJ, 2010. 340: p. c1395.

40. Poolsup, N., Suksomboon, N., and Amin, M., Effect of treatment of gestational diabetes mellitus: a systematic review and meta-analysis. PLoS One, 2014. 9(3): p. e92485.

41. Chiefari, E., Arcidiacono, B., Foti, D., and Brunetti, A., Gestational diabetes mellitus: an updated overview. J Endocrinol Invest, 2017. 40 (9): p. 899-909.

42. National Institute for Health and Clinical Excellence. Diabetes in pregnancy: management from preconception to the postnatal period. Guideline NG3. 2015; Available from: http://nice.org.uk/guidance/ng3.

43. Nederlandse Vereniging voor Obstetrie en Gynaecologie. Richtlijn Diabetes mellitus en zwangerschap (2.0). 2010; Available from: http://www.nvog-documenten.nl/richtlijn/doc/index.php?type= save\&richtlijn_id=863.

44. Bain, E., Crane, M., Tieu, J., Han, S., Crowther, C.A., and Middleton, P., Diet and exercise interventions for preventing gestational diabetes mellitus. Cochrane Database Syst Rev, 2015(4): p. Cd010443.

45. Han, S., Middleton, P., and Crowther, C.A., Exercise for pregnant women for preventing gestational diabetes mellitus. Cochrane Database Syst Rev, 2012(7): p. Cd009021.

46. Kennelly, M.A. and McAuliffe, F.M., Prediction and prevention of Gestational Diabetes: an update of recent literature. Eur J Obstet Gynecol Reprod Biol, 2016. 202: p. 92-8.

47. Oostdam, N., van Poppel, M.N., Wouters, M.G., and van Mechelen, W., Interventions for preventing gestational diabetes mellitus: a systematic review and meta-analysis. J Womens Health (Larchmt), 2011. 20(10): p. 1551-63.

48. Tieu, J., Shepherd, E., Middleton, P., and Crowther, C.A., Dietary advice interventions in pregnancy for preventing gestational diabetes mellitus. Cochrane Database Syst Rev, 2017. 1: p. Cd006674.

49. Araujo Junior, E., Peixoto, A.B., Zamarian, A.C., Elito Junior, J., and Tonni, G., Macrosomia. Best Pract Res Clin Obstet Gynaecol, 2017. 38: p. 83-96.

50. Nardozza, L.M., Caetano, A.C., Zamarian, A.C., Mazzola, J.B., Silva, C.P., Marcal, V.M., et al., Fetal growth restriction: current knowledge. Arch Gynecol Obstet, 2017. 295(5): p. 1061-1077.

51. Al-Rubaie, Z., Askie, L.M., Ray, J.G., Hudson, H.M., and Lord, S.J., The performance of risk prediction models for pre-eclampsia using routinely collected maternal characteristics and comparison with models that include specialised tests and with clinical guideline decision rules: a systematic review. BJOG, 2016. 123(9): p. 1441-52.

52. Lamain - de Ruiter, M., Kwee, A., Naaktgeboren, C.A., Franx, A., Moons, K.G.M., and Koster, M.P.H., Prediction models for the risk of gestational diabetes: a systematic review. Diagnostic and Prognostic Research, 2017. 1(1): p. 3.

53. Groom, K.M. and David, A.L., The role of aspirin, heparin, and other interventions in the prevention and treatment of fetal growth restriction. Am J Obstet Gynecol, 2018. 218(2S): p. S829-S840.

54. Dodd, J.M., Jones, L., Flenady, V., Cincotta, R., and Crowther, C.A., Prenatal administration of progesterone for preventing preterm birth in women considered to be at risk of preterm birth. Cochrane Database Syst Rev, 2013(7): p. CD004947.

55. Romero, R., Conde-Agudelo, A., Da Fonseca, E., O'Brien, J.M., Cetingoz, E., Creasy, G.W., et al., Vaginal progesterone for preventing preterm birth and adverse perinatal outcomes in singleton gestations with a short cervix: a meta-analysis of individual patient data. Am J Obstet Gynecol, 2018. 218(2): p. 161-180.

56. Alfirevic, Z., Stampalija, T., and Medley, N., Cervical stitch (cerclage) for preventing preterm birth in singleton pregnancy. Cochrane Database Syst Rev, 2017. 6: p. CD008991.

57. Zheng, L., Dong, J., Dai, Y., Zhang, Y., Shi, L., Wei, M., et al., Cervical pessaries for the prevention of preterm birth: a systematic review and meta-analysis. J Matern Fetal Neonatal Med, 2017: p. 1-10.

58. Esplin, M.S., Elovitz, M.A., lams, J.D., Parker, C.B., Wapner, R.J., Grobman, W.A., et al., Predictive Accuracy of Serial Transvaginal Cervical Lengths and Quantitative Vaginal Fetal Fibronectin Levels for Spontaneous Preterm Birth Among Nulliparous Women. JAMA, 2017. 317(10): p. 1047-1056. 
59. Van der Ven, J., van Os, M.A., Kazemier, B.M., Kleinrouweler, E., Verhoeven, C.J., de Miranda, E., et al., The capacity of mid-pregnancy cervical length to predict preterm birth in low-risk women: a national cohort study. Acta Obstet Gynecol Scand, 2015. 94(11): p. 1223-34.

60. NEVO-online, versie 2016/5.0. RIVM, Bilthoven, 2016. Available from: http://nevoonline.rivm.nl/ProductenDetailsGetabt.aspx?tabid=9.

61. Jung, M.E., Stork, M.J., Stapleton, J., Bourne, J.E., and Martin Ginis, K.A., A systematic review of behavioural interventions to increase maternal calcium intake. Matern Child Nutr, 2016. 12(2): p. 193-204.

62. Martin, S.L., Seim, G.L., Wawire, S., Chapleau, G.M., and Young, S.L., Translating formative research findings into a behaviour change strategy to promote antenatal calcium and iron and folic acid supplementation in western Kenya. Matern Child Nutr, 2017. 13(1).

63. Omotayo, M.O., Dickin, K.L., O'Brien, K.O., Neufeld, L.M., De Regil, L.M., and Stoltzfus, R.J., Calcium Supplementation to Prevent Preeclampsia: Translating Guidelines into Practice in Low-Income Countries. Adv Nutr, 2016. 7(2): p. 275-8.

64. Grol, R. and Grimshaw, J., From best evidence to best practice: effective implementation of change in patients' care. Lancet, 2003. 362(9391): p. 1225-30.

65. Van Gelder, M., Vorstenbosch, S., Derks, L., Te Winkel, B., van Puijenbroek, E.P., and Roeleveld, N., Web-based questionnaires to assess perinatal outcome proved to be valid. J Clin Epidemiol, 2017. 90: p. 136-143.

66. Van Gelder, M.M., Schouten, N.P., Merkus, P.J., Verhaak, C.M., Roeleveld, N., and Roukema, J., Using Web-Based Questionnaires and Obstetric Records to Assess General Health Characteristics Among Pregnant Women: A Validation Study. J Med Internet Res, 2015. 17(6): p. e149.

67. Moons, K.G., Royston, P., Vergouwe, Y., Grobbee, D.E., and Altman, D.G., Prognosis and prognostic research: what, why, and how? BMJ, 2009. 338: p. b375.

68. Van Buuren, S., Flexible imputation of missing data. 2012: CRC press.

69. Poon, L.C., Zymeri, N.A., Zamprakou, A., Syngelaki, A., and Nicolaides, K.H., Protocol for measurement of mean arterial pressure at 11-13 weeks' gestation. Fetal Diagn Ther, 2012. 31(1): p. 42-8.

70. Cheong-See, F., Allotey, J., Marlin, N., Mol, B.W., Schuit, E., Ter Riet, G., et al., Prediction models in obstetrics: understanding the treatment paradox and potential solutions to the threat it poses. BJOG, 2016. 123(7): p. 1060-4

71. Pajouheshnia, R., Peelen, L.M., Moons, K.G.M., Reitsma, J.B., and Groenwold, R.H.H., Accounting for treatment use when validating a prognostic model: a simulation study. BMC Med Res Methodol, 2017. 17(1): p. 103.

72. Collins, G.S., Ogundimu, E.O., and Altman, D.G., Sample size considerations for the external validation of a multivariable prognostic model: a resampling study. Stat Med, 2016. 35(2): p. 214-26.

73. Vergouwe, Y., Steyerberg, E.W., Eijkemans, M.J., and Habbema, J.D., Substantial effective sample sizes were required for external validation studies of predictive logistic regression models. J Clin Epidemiol., 2005. 58(5): p. 475-83.

74. Van Gelder, M.M., Bretveld, R.W., Roukema, J., Steenhoek, M., van Drongelen, J., Spaanderman, M.E., et al., Rationale and design of the PRegnancy and Infant DEvelopment (PRIDE) Study. Paediatr Perinat Epidemiol, 2013. 27(1): p. 34-43.

75. Poon, L.C. and Nicolaides, K.H., Early prediction of preeclampsia. Obstet Gynecol Int, 2014. 2014: p. 297397.

76. Poon, L.C. and Nicolaides, K.H., First-trimester maternal factors and biomarker screening for preeclampsia. Prenat Diagn, 2014. 34(7): p. 618-27.

77. EFSA NDA Panel (EFSA Panel on Dietetic Products, Nutrition and Allergies), Scientific Opinion on Dietary Reference Values for calcium EFSA Journal, 2015. 13(5): p. 4101, 82 pp.

78. Nutrition epidemiology. New York: Oxford University Press; 1998.

79. Shim, J.S., Oh, K., and Kim, H.C., Dietary assessment methods in epidemiologic studies. Epidemiol Health, 2014. 36: p. e2014009.

80. Molag, M.L., de Vries, J.H., Duif, N., Ocke, M.C., Dagnelie, P.C., Goldbohm, R.A., et al., Selecting informative food items for compiling food-frequency questionnaires: comparison of procedures. $\mathrm{Br} \mathrm{J}$ Nutr, 2010. 104(3): p. 446-56.

81. Hacker-Thompson, A., Robertson, T.P., and Sellmeyer, D.E., Validation of two food frequency questionnaires for dietary calcium assessment. J Am Diet Assoc, 2009. 109(7): p. 1237-40. 
82. Macdonald, H.M., Garland, A., Burr, J., Strachan, A., Wood, A.D., Jamil, N.A., et al., Validation of a short questionnaire for estimating dietary calcium intakes. Osteoporos Int, 2014. 25(6): p. 1765-73.

83. Morisset, A.S., Weiler, H.A., Dubois, L., Ashley-Martin, J., Shapiro, G.D., Dodds, L., et al., Rankings of iron, vitamin $D$, and calcium intakes in relation to maternal characteristics of pregnant Canadian women. Appl Physiol Nutr Metab, 2016. 41(7): p. 749-57.

84. Sebring, N.G., Denkinger, B.I., Menzie, C.M., Yanoff, L.B., Parikh, S.J., and Yanovski, J.A., Validation of three food frequency questionnaires to assess dietary calcium intake in adults. J Am Diet Assoc, 2007. 107(5): p. 752-9.

85. Henderson, J.T., Thompson, J.H., Burda, B.U., and Cantor, A., Preeclampsia screening: Evidence report and systematic review for the us preventive services task force. JAMA, 2017. 317(16): p. 1668-1683.

86. Steyerberg, E.W., Moons, K.G., van der Windt, D.A., Hayden, J.A., Perel, P., Schroter, S., et al., Prognosis Research Strategy (PROGRESS) 3: prognostic model research. PLoS Med, 2013. 10(2): p. e1001381.

87. Moons, K.G., Altman, D.G., Vergouwe, Y., and Royston, P., Prognosis and prognostic research: application and impact of prognostic models in clinical practice. BMJ, 2009. 338: p. b606.

88. Reilly, B.M. and Evans, A.T., Translating clinical research into clinical practice: impact of using prediction rules to make decisions. Ann Intern Med, 2006. 144(3): p. 201-9.

89. Kappen, T.H., Vergouwe, Y., van Wolfswinkel, L., Kalkman, C.J., Moons, K.G., and van Klei, W.A., Impact of adding therapeutic recommendations to risk assessments from a prediction model for postoperative nausea and vomiting. Br J Anaesth, 2015. 114(2): p. 252-60.

90. Kawamoto, K., Houlihan, C.A., Balas, E.A., and Lobach, D.F., Improving clinical practice using clinical decision support systems: a systematic review of trials to identify features critical to success. BMJ, 2005. 330(7494): p. 765.

91. Michie, S. and Johnston, M., Changing clinical behaviour by making guidelines specific. BMJ, 2004. 328(7435): p. 343-5.

92. Kappen, T.H., van Loon, K., Kappen, M.A., van Wolfswinkel, L., Vergouwe, Y., van Klei, W.A., et al., Barriers and facilitators perceived by physicians when using prediction models in practice. J Clin Epidemiol, 2016. 70: p. 136-45.

93. Vickers, A.J. and Elkin, E.B., Decision curve analysis: a novel method for evaluating prediction models. Med Decis Making, 2006. 26(6): p. 565-74.

94. Jorgensen, J.M., Hedley, P.L., Gjerris, M., and Christiansen, M., Ethical issues related to screening for preeclampsia. Bioethics, 2014. 28(7): p. 360-7.

95. Gordon-Lubitz, R.J., MSJAMA. Risk communication: problems of presentation and understanding. JAMA, 2003. 289(1): p. 95.

96. Crombag, N.M., Lamain-de Ruiter, M., Kwee, A., Schielen, P.C., Bensing, J.M., Visser, G.H., et al., Perspectives, preferences and needs regarding early prediction of preeclampsia in Dutch pregnant women: a qualitative study. BMC Pregnancy Childbirth, 2017. 17(1): p. 12.

97. Van Montfort, P., Willemse, J.P., Dirksen, C.D., van Dooren, I.M., Meertens, L.J., Spaanderman, M.E., et al., Implementation and Effects of Risk-Dependent Obstetric Care in the Netherlands (Expect Study II): Protocol for an Impact Study. JMIR Res Protoc, 2018. 7(5): p. e10066.

98. Van Leeuwen, M., Opmeer, B.C., Zweers, E.J., van Ballegooie, E., ter Brugge, H.G., de Valk, H.W., et al., Estimating the risk of gestational diabetes mellitus: a clinical prediction model based on patient characteristics and medical history. BJOG, 2010. 117(1): p. 69-75.

99. Lemmens, S.M.P., Spaanderman, M.E.A., and Röselaers, Y.C.M. Verloskundig Consortium Limburg. Limburg Obstetric Quality System Zorgpaden (aanbevelingen). Versie 1.3, mei 2017. Available from: http://www.zwangerinlimburg.nl/sites/expectstudie/files/loqs_zorgpaden_aanbevelingen_0.pdf. 


\section{A D D E N U M}

Summary

Nederlandstalige samenvatting

Valorisation

Dankwoord

Curriculum Vitae

List of publications 


\section{Summary}

Risk selection is a continuous process during obstetric care. Current Dutch risk management typically involves reacting to maternal and fetal problems when they already exist or are imminent, and contributes little to early detection or prevention. Early estimation of patient-specific risks for the development of pregnancy complications might improve adverse pregnancy outcomes by shifting prenatal care from a series of routine visits to more personalized obstetric care tailored to women's specific needs. The current thesis focused on improving personalized obstetric care in both early risk assessment (part I) and intervention strategies (part II).

Prognostic prediction models can help identify women at increased risk of developing an adverse pregnancy outcome, combining multiple risk factors in an algorithm, and taking into account the weight of each risk factor and possible interrelations. Several prediction models addressing important obstetric outcomes have been published; however, external validation studies are scarce and impact studies even more so. External validation, i.e. the evaluation of the performance of the model in populations other than the one used for model development, is crucial before implementing a model in clinical practice. The first part of this thesis focused on the external validation of all published prediction models using routinely collected parameters and applicable in the first trimester of pregnancy, for the risk of pre-eclampsia (PE), gestational diabetes mellitus (GDM), delivering an infant small- or large-forgestational-age (SGA or LGA), and spontaneous preterm birth (PTB) in a Dutch pregnant population (Expect Study I). Furthermore, the clinical potential of the best performing models was evaluated.

A multicentre prospective cohort study was performed in the south-eastern part of the Netherlands between July 1, 2013 and December 31, 2015 (Expect Study I). Six hospitals and 36 midwifery practices recruited 2614 eligible pregnant women. Information on predictor variables was obtained by a web-based questionnaire completed before 16 weeks of gestation. Pregnancy outcomes were established using a web-based postpartum questionnaire and medical records. Chapter 2 describes the study design and population characteristics of the Expect Study I in more detail. The study population of the external validation studies contained 76, 203, 224, and 118 cases of PE $(2.9 \%)$, SGA $<10^{\text {th }}$ percentile $(7.9 \%), \mathrm{LGA}>90^{\text {th }}$ percentile $(8.7 \%)$, and spontaneous PTB $<37$ weeks of gestation (4.6\%), respectively. For the outcome GDM, the validation cohort was complemented with data from another Dutch pregnant prospective cohort (PRIDE Study), and included 5263 women. GDM was diagnosed in 127 women $(2.7 \%)$.

Thirty-three prediction models for the risk of PE ( $n=10)$, GDM $(n=12)$, SGA $(n=6)$, LGA $(n=6)$, and spontaneous PTB $(n=5)$ were systematically selected from the literature. Most models showed a promising predictive performance in the development cohorts, with discriminative abilities up to $88 \%, 85 \%, 74 \%, 72 \%$, and $70 \%$ for GDM, PE, 
LGA, SGA, and spontaneous PTB, respectively. The predictive performance of each model in the validation cohort was assessed by means of discrimination (area under the receiver operating characteristic curve, AUROC) and calibration. A subgroup analysis was performed among nulliparous women.

External validation of the prediction models for PE showed a moderate discriminative performance for five models (AUROC 0.73 to 0.77 ) (chapter 3). Calibration plots showed that most models consistently overestimated the risk of PE. Despite their moderate predictive performance, particularly among nulliparous women (highest AUROC 0.61), the models performed better or nearly the same compared with current risk assessment strategies (the American College of Obstetricians and Gynecologists (ACOG) and National Institute for Health and Clinical Excellence (NICE), respectively). The best-performing prediction models for PE can help to guide decision-making regarding low-dose aspirin and calcium supplementation, which are efficacious noninvasive interventions that reduce the risk of developing PE.

All selected prediction models for GDM showed a moderate discriminative performance after external validation (AUROC 0.68 to 0.75 ) (chapter 4). The discriminative performance remained stable among nulliparous women. Calibration plots indicated that nearly all models overestimated the risk of GDM. Although the best-performing models do not provide more benefit at certain risk thresholds compared with current available screening strategies (NICE and Dutch national guideline), the best models are easily applicable in clinical practice and enable personalized selective screening. Early screening of pregnant women for GDM by use of an oral glucose tolerance test is important as the disorder is mostly asymptomatic and clinical management improves GDM-related adverse outcomes.

The study reported on in chapter 5 demonstrated poor discriminative performance for all models predicting the risk of SGA $<10^{\text {th }}$ percentile (AUROC 0.52 to 0.64 ). Discrimination of the models for LGA $>90^{\text {th }}$ percentile ranged from 0.60 to 0.69 . The discriminative ability of all models remained stable among nulliparous women and improved for predicting the more severe cases of SGA $\left(<5^{\text {th }}\right.$ percentile, AUROC up to $0.67)$ and LGA $\left(>95^{\text {th }}\right.$ percentile, AUROC up to 0.74$)$. The models were poorly calibrated. The clinical relevance of the models is limited due their moderate predictive performance and because the definitions of SGA and LGA do not exclude constitutionally larger or smaller infants. As most clinically relevant fetal growth deviations are 'vascular' or 'metabolic' related, the models for SGA and LGA are not likely to provide additional benefit over models predicting hypertensive disorders and GDM, respectively, due overlap of predictors and available treatment strategies.

External validation of the prediction models for the risk of spontaneous PTB retrieved poor discriminative performance for spontaneous PTB $<37$ weeks of gestation (AUROC 0.54 to 0.67 ) and moderate for spontaneous PTB $<34$ weeks of gestation (AUROC 0.56 to 0.70 ) (chapter 6). The models discriminated poorly among nulliparous women (highest AUROC 0.56). Initial calibration was moderate. The validated models do not 
add much value to current clinical care since caregivers are already aware that women with a prior spontaneous PTB are at high risk.

As mentioned above, the clinical utility of prediction models is dependent on effective follow-up management. The second part of this thesis focused on adequate calcium intake in the prevention of PE. Published research demonstrated that calcium supplementation of at least $1000 \mathrm{mg} /$ day during pregnancy reduces the risk of developing a hypertensive pregnancy disorder, particularly in high-risk women or women with a low dietary calcium intake. Whether advising calcium supplementation during pregnancy is (cost-)effective and which strategy provides most benefit depends, besides the efficacy of the intervention, on several other factors including current calcium intake, outcome incidence, uptake of the intervention, costs of intervention, and costs related to the outcome.

In chapter 7, the calcium intake from both diet and supplement use in Dutch pregnant women during early pregnancy was estimated. Almost two thirds of the women in the Expect Study I cohort did not meet the recommended adequate intake of $1000 \mathrm{mg} /$ day. The median calcium intake was $819 \mathrm{mg} /$ day (interquartile range 543-1125 mg/day). Although supplements were frequently used, the calcium content of the most used supplements, prenatal vitamins, was insufficient for complementing the dietary calcium intake to reach the recommended adequate intake.

A decision analysis was performed to provide insight whether calcium supplementation is a potential (cost-)effective intervention for implementation in Dutch antenatal care (chapter 8). The results indicated that advising calcium supplementation $1000 \mathrm{mg} /$ day to all pregnant women, pregnant women at high risk of $\mathrm{PE}$, or pregnant women with a low dietary calcium intake can be expected to reduce the incidence of PE by $25 \%, 8 \%$, or $13 \%$, respectively. Expected net financial benefits are $€ 4,621,465$, $€ 2,059,165$, or $€ 2,822,115$ per 100,000 pregnant women, respectively. Although advising calcium supplementation to subgroups alone may be a more targeted approach, it might be more efficient to advise the use of calcium supplements to all pregnant women. In this way, women who are not part of defined subgroups also profit from the intervention and no individual dietary calcium intake or risk for developing PE has to be estimated.

In conclusion, this thesis demonstrates, as discussed in more detail in chapter 9, that prognostic prediction models for PE and GDM based on routinely collected parameters can potentially improve early risk stratification in pregnancy towards more personalized obstetric care. Moreover, advising calcium supplementation during pregnancy, an efficacious intervention in the prevention of $\mathrm{PE}$, can bring about important health effects on population level and a substantial reduction in health care costs. An impact study is currently being performed in the south-eastern part of the Netherlands to see whether implementation of the best prediction models for PE and GDM combined with tailored care paths, and the recommendation to use calcium supplementation during pregnancy actually changes caregivers' and women's 
Addendum

behaviour, which is necessary to obtain potential improvement of pregnancy outcomes (Expect Study II). 


\section{Nederlandstalige samenvatting}

Risicoselectie, ofwel het inschatten van de kans op het krijgen van een bepaalde uitkomst, is een continu proces gedurende de zwangerschap, bevalling en kraambed. De traditionele Nederlandse verloskundige zorg opereert met name reactief ten aanzien van maternale en/of foetale problemen en is minder gericht op vroege detectie of preventie van zwangerschapscomplicaties. Een vroege inschatting van de individuele kans op het ontwikkelen van een zwangerschapscomplicatie kan slechte zwangerschapsuitkomsten mogelijk verbeteren door de prenatale zorg te veranderen van routine afspraken naar meer zorg op maat, afgestemd op de behoeften van iedere zwangere vrouw (gepersonaliseerde zorg). Het huidige proefschrift richtte zich op het verbeteren van gepersonaliseerde verloskundige zorg, zowel op het gebied van vroege risico-inschatting (deel I) als interventiestrategieën (deel II).

Prognostische predictiemodellen, ofwel risicomodellen of voorspelmodellen, zouden kunnen helpen bij het selecteren van vrouwen met een verhoogde kans op het ontwikkelen van een ongunstige zwangerschapsuitkomst. Predictiemodellen zijn gebaseerd op meerdere risicofactoren (multivariabel), waarbij er rekening wordt gehouden met de bijdrage van elke risicofactor aan het wel of niet optreden van de uitkomstmaat en de onderlinge relaties tussen de risicofactoren. In de internationale medische literatuur is een aanzienlijk aantal predictiemodellen voor belangrijke obstetrische uitkomsten gepubliceerd. Externe validatiestudies zijn echter niet algemeen en studies van hun klinische impact zijn er nauwelijks. Externe validatie, i.e. het evalueren van de prestatie van het model in een andere populatie dan gebruikt voor de ontwikkeling van het model, is cruciaal voordat het model geïmplementeerd kan worden in de klinische praktijk. In het eerste deel van dit proefschrift werden gepubliceerde predictiemodellen, die de kans op pre-eclampsie (PE), diabetes gravidarum (DG), een te groot of te klein kind voor de zwangerschapsduur, of een spontane vroeggeboorte voorspellen, extern gevalideerd in een Nederlandse populatie. Alleen predictiemodellen gebaseerd op factoren die routinematig worden gemeten in de Nederlandse verloskundige zorg (bijv. maternale kenmerken of bloeddruk) én die toepasbaar zijn in het eerste trimester van de zwangerschap werden beschouwd. Tevens werd de potentiële klinische bruikbaarheid van de best presterende modellen geëvalueerd.

Een multicenter prospectief cohortonderzoek werd uitgevoerd in de provincie Limburg tussen 1 juli 2013 en 31 december 2015 (Expect Studie I). Zes ziekenhuizen en 36 verloskundigenpraktijken includeerden 2614 zwangere vrouwen. Gegevens over de risicofactoren werden verkregen via een online vragenlijst die vóór 16 weken zwangerschap werd ingevuld. Informatie over de zwangerschapsuitkomsten werd verkregen via een online postpartum vragenlijst en het medische dossier. In hoofdstuk 2 worden de onderzoeksopzet en de populatiekenmerken van de Expect Studie I in meer detail beschreven. De studiepopulatie van de verschillende externe validatiestudies bevatte 76 gevallen van PE (2,9\%), 203 en 223 kinderen met 
respectievelijk een geboortegewicht $<10$ e percentiel $(7,9 \%)$ en een geboortegewicht $>90$ e percentiel $(8,7 \%)$, en 118 vrouwen met een spontane vroeggeboorte $(4,6 \%)$. De studiepopulatie voor de uitkomst DG werd aangevuld met gegevens van een ander Nederlands cohortonderzoek onder zwangere vrouwen (PRIDE Studie) en bestond uit 5263 vrouwen. DG werd in 127 vrouwen gediagnosticeerd $(2,7 \%)$.

Drieëndertig predictiemodellen die de kans op PE $(n=10), D G(n=12)$, een te klein $(n=6)$ of te groot $(n=6)$ kind voor de zwangerschapsduur, of een spontane vroeggeboorte $(n=5)$ voorspellen, werden systematisch geselecteerd uit de medische literatuur. De meeste modellen hadden een veelbelovend voorspellend vermogen in de populaties waarin ze ontwikkeld waren, met onderscheidende vermogens tot wel $88 \%, 85 \%$, $74 \%, 72 \%$, en $70 \%$ voor respectievelijk DG, PE, een geboortegewicht $>90$ e percentiel, geboortegewicht $<10 \mathrm{e}$ percentiel en spontane vroeggeboorte. Het voorspellend vermogen van elk model in het validatiecohort werd beoordeeld door het bepalen van de discriminatie (de mate waarin een model onderscheid kan maken tussen vrouwen die wel en juist niet de complicatie zullen ontwikkelen; oppervlakte onder de ROCcurve, AUROC) en kalibratie (de mate van overeenkomst tussen de voorspelde kansen en geobserveerde uitkomsten). Er werd een subgroepanalyse uitgevoerd onder vrouwen die voor het eerst gingen bevallen (nulliparae).

Vijf predictiemodellen voor de kans op het ontwikkelen van PE hadden een matig discriminerend vermogen na externe validatie (AUROC 0,73 tot 0,77) (hoofdstuk 3). De kalibratiegrafieken toonden dat de meeste modellen de kans op PE stelselmatig overschatten. De modellen presteerden, ondanks hun matig onderscheidend vermogen met name in nulliparae (hoogste AUROC 0,61 ), beter of vrijwel hetzelfde dan de huidige richtlijnen voor risicoselectie (American College of Obstetricians and Gynecologists) en National Institute for Health and Clinical Excellence, NICE). De best presterende predictiemodellen voor PE kunnen hulp bieden bij het nemen van beslissingen met betrekking tot het gebruik van een lage dosis aspirine en calciumsupplementen tijdens de zwangerschap. Aspirine en calciumsupplementen zijn nietinvasieve interventies die de kans op het ontwikkelen van PE reduceren.

Alle geselecteerde predictiemodellen voor de kans op het ontwikkelen van DG hadden een matig discriminerend vermogen na externe validatie (range AUROC 0,68 tot 0,75 ) (hoofdstuk 4). Het discriminerend vermogen bleef stabiel in nulliparae. De kalibratiegrafieken toonden dat vrijwel alle modellen de kans op het ontwikkelen van DG overschatten. Hoewel de best presterende modellen bij bepaalde risicodrempels niet meer voordeel bieden ten opzichte van de huidige richtlijnen voor risicoselectie (NICE en de landelijke Nederlandse richtlijn), zijn de modellen eenvoudig te gebruiken in de klinische praktijk en maken ze gepersonaliseerde selectieve screening mogelijk. Vroegtijdige screening van zwangere vrouwen op DG met behulp van een orale glucose tolerantie test is belangrijk, aangezien de aandoening meestal asymptomatisch is en ongunstige uitkomsten verbetert kunnen worden door behandeling. 
In hoofdstuk 5 toonden alle geselecteerde predictiemodellen voor de kans op het krijgen van een kind met een geboortegewicht <10e percentiel een slecht discriminerend vermogen (AUROC 0,52 tot 0,64). De oppervlakte onder de ROC-curve van de modellen voor de kans op het krijgen van een kind met een geboortegewicht $>90$ e percentiel varieerden van 0,60 tot 0,69 . Het discriminerende vermogen van alle modellen bleef stabiel in nulliparae. Tevens konden alle modellen de kans op een kind met een extreem laag of hoog geboortegewicht voor de zwangerschapsduur beter voorspellen (hoogste AUROC 0,67 en 0,74 voor respectievelijk <5e percentiel en >95e percentiel). De modellen waren slecht gekalibreerd. De klinische relevantie van de modellen is beperkt door enerzijds de matige prestaties in het validatiecohort en anderzijds doordat constitutioneel kleine of grote kinderen niet worden uitgesloten in de definities van een te klein of te groot kind voor de zwangerschapsduur op basis van het geboortegewichtpercentiel. De meeste klinisch relevante foetale groeideviaties hebben een 'vasculaire' of 'metabole' oorzaak. De gevalideerde modellen voor een te klein of te groot kind voor de zwangerschapsduur bieden waarschijnlijk geen extra voordeel ten opzichte van modellen die respectievelijk hypertensieve zwangerschapsaandoeningen en DG voorspellen, aangezien de risicofactoren in de betreffende predictiemodellen overlappen alsmede de beschikbare behandelmogelijkheden.

De geselecteerde predictiemodellen voor de kans op een spontane vroeggeboorte hadden een slecht tot matig discriminerend vermogen voor respectievelijk een zwangerschapsduur $<37$ weken (AUROC 0,54 tot 0,67) en $<34$ weken (AUROC 0,56 tot 0,70 ) na externe validatie (hoofdstuk 6). De modellen toonden een slecht discriminerend vermogen in nulliparae (hoogste AUROC 0,56). De kalibratie van de modellen was matig. De gevalideerde modellen hebben vrijwel geen toegevoegde waarde in de klinische praktijk aangezien zorgverleners zich er al van bewust zijn dat vrouwen met een eerdere spontane vroeggeboorte een hoog risico hebben op herhaling.

Zoals hierboven vermeld, is de klinische bruikbaarheid van predictiemodellen afhankelijk van beschikbare effectieve interventiemogelijkheden. Het tweede deel van dit proefschrift richtte zich op een adequate calciuminname ter preventie van PE. Gepubliceerde studies hebben aangetoond dat het gebruik van calciumsupplementen tijdens de zwangerschap, ten minste $1000 \mathrm{mg} / \mathrm{dag}$, de kans op het ontwikkelen van een hypertensieve zwangerschapsaandoening vermindert, met name bij hoog-risico vrouwen of vrouwen met een lage inname van calcium uit voeding. Óf het adviseren van calciumsuppletie tijdens de zwangerschap (kosten-)effectief is en welke strategie het meeste voordeel biedt hangt, naast de werkzaamheid van de interventie, af van verschillende andere factoren, waaronder de huidige calciuminname, incidentie van de uitkomst, opvolging van het advies, kosten van de interventie en kosten gerelateerd aan de uitkomst.

In hoofdstuk 7 werd de calciuminname op basis van voeding als supplementgebruik bij Nederlandse zwangere vrouwen bepaald. Bijna twee derde van de vrouwen in het Expect I cohort behaalden niet de aanbevolen adequate inname van $1000 \mathrm{mg} / \mathrm{dag}$. De 
mediane inname van calcium was $819 \mathrm{mg} /$ dag (interkwartielafstand 543-1125 $\mathrm{mg} / \mathrm{dag}$ ). Hoewel supplementen vaak werden gebruikt, was het calciumgehalte van de meest gebruikte supplementen, zwangerschapsmultivitaminen, onvoldoende om de calciuminname uit de voeding te compenseren tot aan de aanbevolen adequate hoeveelheid.

Een theoretische impactanalyse werd uitgevoerd om inzicht te verschaffen of calciumsuppletie tijdens de zwangerschap een potentieel (kosten-)effectieve interventie is voor implementatie in de Nederlandse prenatale zorg (hoofdstuk 8). De resultaten toonden aan dat het adviseren van het gebruik van calciumsupplementen (1000 mg/dag) aan alle zwangere vrouwen, zwangere vrouwen met een hoog risico op $\mathrm{PE}$ of zwangere vrouwen met een lage calciuminname, de incidentie van PE met respectievelijk $25 \%, 8 \%$, of $13 \%$ kan reduceren. De verwachte netto financiële voordelen zijn respectievelijk €4.621.465, €2.059.165 of €2.822.115 per 100.000 zwangere vrouwen. Hoewel het adviseren van calciumsupplementen aan specifieke subgroepen een gerichtere aanpak zal zijn, is het waarschijnlijk efficiënter om het gebruik van calciumsupplementen aan alle zwangere vrouwen te adviseren. Op deze manier profiteren tevens vrouwen die geen deel uitmaken van gedefinieerde subgroepen van de interventie en hoeft er geen individuele calciuminname of kans op het ontwikkelen van PE te worden geschat.

Concluderend laat dit proefschrift zien, zoals bediscussieerd in hoofdstuk 9, dat prognostische predictiemodellen voor PE en DG, gebaseerd op routinematig gemeten factoren, de risicoselectie aan het begin van de zwangerschap kunnen verbeteren naar meer gepersonaliseerde verloskundige zorg. Tevens kan het adviseren van het gebruik van calciumsupplementen tijdens de zwangerschap, een effectieve interventie bij de preventie van PE, mogelijk belangrijke gezondheidseffecten op populatieniveau en een aanzienlijke verlaging van de kosten van de gezondheidszorg opleveren. Momenteel wordt een impactstudie uitgevoerd waarbij wordt geëvalueerd of de implementatie van de beste predictiemodellen voor PE en DG, in combinatie met zorgpaden afgestemd op het individuele risicoprofiel, en de aanbeveling om calciumsupplementen tijdens de zwangerschap te gebruiken daadwerkelijk het gedrag van zorgverleners en vrouwen verandert, hetgeen nodig is voor een potentiële verbetering van zwangerschapsuitkomsten (Expect Studie II). 


\section{Valorisation}

This chapter describes the (future) valorisation of the research described in this thesis. Valorisation can be defined as the process of value creation from knowledge, by making it applicable and available for economic or societal utilisation, and by translating it in the form of new business, products, services or processes ${ }^{1}$.

\section{Relevance}

In the Netherlands approximately 170,000 babies are born yearly ${ }^{2}$. Perinatal mortality, defined as stillbirths and deaths of infants within the first 28 days of life, is considered an important quality indicator of obstetric care ${ }^{3,4}$. By the turn of the last century, perinatal mortality, especially fetal mortality, was substantially higher in the Netherlands than in other European countries ${ }^{5,6}$. Five years later the situation had improved, but still the Netherlands, with its much-praised health care system, showed above-average perinatal mortality rates ${ }^{7}$. In 2008, a steering committee established by the Minister of Health Care published recommendations to optimize obstetric care, which resulted in a ZonMw research programme Pregnancy and Childbirth ${ }^{8}$. The four main priorities of the programme were aetiology of perinatal and maternal morbidity and mortality (1), health education and health promotion during the preconceptional period, pregnancy and postpartum period (2), risk selection and screening (3), and organization of obstetric care $(4)^{9}$. In the meantime, the perinatal mortality rate (per 1000 births) substantially declined from 12.3 in 2000 to 7.3 in 2016 (Figure 1) ${ }^{10}$, and the position in the European ranking improved ${ }^{11}$.

In the Netherlands, $85 \%$ of the perinatal deaths go together with asphyxia, preterm birth (PTB), congenital anomalies, and small-for-gestational-age (SGA), also called BIG 4. A BIG 4 condition occurs in $16,3 \%$ of all pregnancies ${ }^{12}$. Pre-eclampsia (PE), a hypertensive pregnancy disorder, is associated with SGA and PTB, while gestational diabetes mellitus (GDM) increases the risk for infants born large-for-gestational-age $(L G A)^{13,14}$. Infants born LGA are at increased risk for asphyxia and birth injuries ${ }^{15}$.

Early identification of women at increased risk of developing adverse outcomes during pregnancy is important considering the short- and, even more important, long-term health consequences for both mother and child. Early risk stratification provides opportunities for personalized medicine, the right intervention (treatment, prevention, diagnosis) for the right person at the right time and place from the right healthcare provider $^{16}$. Tailored care may, next to reducing maternal and child morbidity and mortality, improve health-related quality of life, satisfaction with care, and reduce healthcare and societal costs. This thesis focused on improving personalised obstetric care in both early risk assessment (part I) and intervention strategies (part II). 


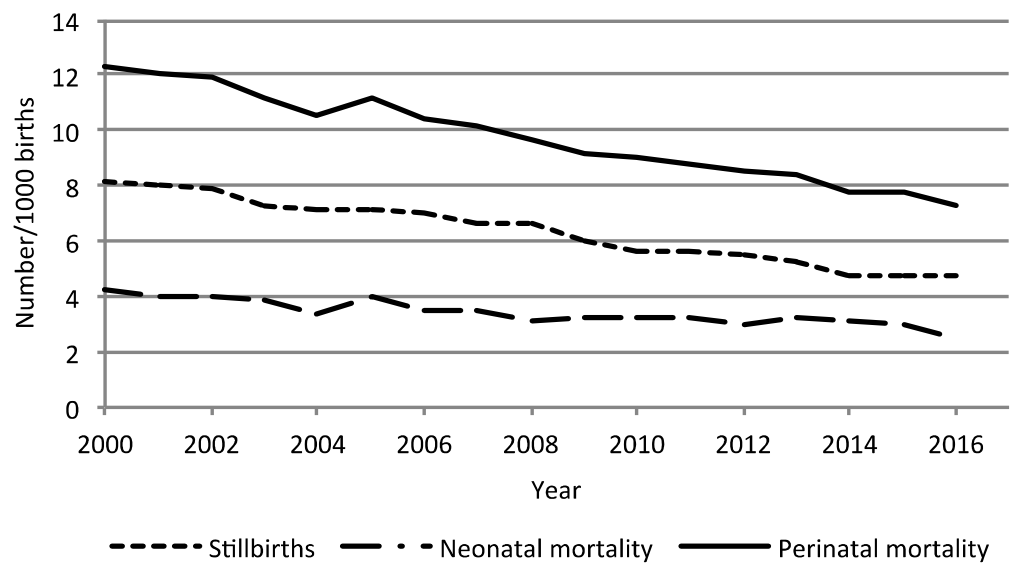

Figure 1 Trends in perinatal mortality ( $\geq 22$ weeks of gestation -28 days of life) in the Netherlands, 2000$2016^{10}$

\section{Early prediction of adverse pregnancy outcomes}

Obstetric care is based upon risk management, especially in the Netherlands, where the level of care is matched to the level of risk ${ }^{17}$. Dutch primary care midwives work autonomously and monitor the pregnancy of women who are considered to be at low risk to develop pregnancy complications. Pregnant women at risk are assigned to an obstetrician in second or tertiary care. This unique system emphasizes the importance for early identification of women with a high probability to develop pregnancy complications ${ }^{18}$. Around $85 \%$ of pregnant women start antenatal care with a primary midwife and $\sim 55 \%$ of these women are referred to secondary or tertiary care during pregnancy or labour ${ }^{2}$. The obstetric indication list (VIL) is an official national guideline to judge the risk and need for referral ${ }^{19}$. Although the guideline is evidence-based as much as possible, a drawback is that it is not an individual risk assessment tool, nor does it describe what the content of primary and secondary/tertiary care should be. Moreover, current risk management typically involves reaction to maternal and fetal problems when they already exist or are imminent, and contributes little to early detection or prevention.

Prognostic prediction models may be accurate tools to identify women at high risk for developing adverse pregnancy outcomes as multiple risk factors are combined in an algorithm, taking into account the risk dependent weight of each risk factor and possible interrelations ${ }^{20}$. Several first trimester prediction models addressing important obstetric outcomes have been published ${ }^{21}$. While the reported performance of numerous prediction models is promising, external validation studies are scarce and impact studies even more ${ }^{21}$. External validation, which is the evaluation of the performance of the model in populations other than used for model development, is crucial before implementing a model in clinical practice ${ }^{22,23}$. 
In this thesis, the predictive performance of first trimester prognostic prediction models for the risk of PE, GDM, spontaneous PTB, and delivering an infant SGA or LGA among Dutch pregnant women was evaluated. Only models consisting exclusively of routinely collected maternal predictors were included as more 'specialized' tests (i.e. uterine artery Doppler or biomarkers) provide additional costs, might be inconvenient for pregnant women, and are not routinely performed or readily available in general antenatal settings ${ }^{24-26}$. The latter is a particular important aspect when applying a prediction model in the unique Dutch obstetric setting. The studies in this thesis confirm the importance of an external validation study as nearly all models performed less well in our population. Moreover, as the currently published models have been developed in different countries among various types of populations and settings, evaluation of the predictive performance of all available prediction models in one independent Dutch cohort allowed for a fair comparison of the potential value in Dutch obstetric care ${ }^{27}$. Furthermore, the clinical potential of the best performing models was evaluated as a prediction model can only lead to improved outcomes for both mother and child of they can guide healthcare professionals and individuals in their decision making regarding further management that are tailored to individual risk profiles. Besides prevention of adverse outcomes, the use of prediction models can also lead to a more efficient use of re-sources and refraining from unnecessary testing and interventions in low-risk women.

This thesis revealed that the best performing prediction models for PE and GDM are worth considering for application in Dutch clinical practice as follow-up management is available and models showed better performance compared to current risk strategies. Low-dose aspirin and calcium supplementation are efficacious and noninvasive interventions in the prevention of $\mathrm{PE}$. In case of GDM, the prediction models can allow for targeted early screening by use of an oral glucose tolerance test.

\section{Prevention of adverse pregnancy outcomes}

A number of management strategies have shown to be effective in the prevention of adverse pregnancy outcomes. Calcium supplementation, one of the interventions that can be used, of at least $1000 \mathrm{mg}$ of calcium per day during pregnancy lowers the risk of developing a hypertensive pregnancy disorder (PE and gestational hypertension), particularly among women with a low dietary calcium intake or at increased risk of developing a hypertensive pregnancy disorder ${ }^{28}$. Despite its documented preventive effect, a minimal risk for side effects ${ }^{28,29}$, and relative low costs (about $€ 50$ per pregnancy) ${ }^{30,31}$, this approach is still not part of antenatal care in most countries. The World Health Organization recommends calcium supplementation as part of antenatal care in populations where calcium intake is low ${ }^{32}$. However, also in populations with sufficient availability and affordability of calcium-rich foods, calcium supplementation among pregnant women is expected to have major public health implications.

This thesis indicated that almost two thirds of the pregnant women did not meet an intake of $1000 \mathrm{mg} /$ day as recommended by the Dutch Health Council ${ }^{33}$. The 
contribution of calcium-containing supplements to total calcium intake was low. Although $64.8 \%$ of the women used supplements containing calcium, only $2 \%$ of the women used high-dose calcium supplements. Moreover, the calcium content of the most used supplements, prenatal vitamins, was insufficient for complementing the dietary calcium intake to reach the recommended adequate intake. The results of the decision analysis showed that advising calcium supplementation $1000 \mathrm{mg} / \mathrm{day}$ is a potential (cost-)effective intervention for implementation in Dutch antenatal care, with an expected reduction in the incidence of PE and net financial benefits up to $25 \%$ and $€ 4,621,465$, respectively. The economic benefits, i.e. health care and societal costs, may even be more favourable as long-term costs for both mother and child due to the burden of disease (i.e. cardiovascular disease or impaired neurodevelopment) were not considered ${ }^{14,34,35}$. Although advising calcium supplementation to subgroups alone may be a more targeted approach, it might be more efficient to advise the use of calcium supplements to all pregnant women. In this way, women who are not part of defined subgroups also profit from the intervention and no individual dietary calcium intake or risk for developing PE has to be estimated. The results of the decision analysis were published, in addition to scientific journal ${ }^{36}$, in the Dutch newspaper de Volkskrant (January 22, 2016) ${ }^{37}$ and subsequently by several other media sources (i.e. RTL news television ${ }^{38}$ ), even across the border (VTM news Belgium ${ }^{39}$ ). Recently, the Dutch Health Council recommends, also based on our decision analysis, that obstetric health caregivers should pay attention to an adequate calcium intake during pregnancy ${ }^{40}$.

\section{Translation of knowledge to personalized obstetric care}

The studies in this thesis provide useful insights regarding prediction and prevention of adverse pregnancy outcomes, as described in more detail in the general discussion. Although further research towards improvement of prediction models, in particular among nulliparous women, and preventive measures is necessary, a next step towards optimization of Dutch obstetric care is to implement the findings in clinical care. While implementation is a task facing challenge, the medical literature has paid relatively low attention to this important step ${ }^{21,41,42}$. Implementation efforts require that attention is paid to accessibility, affordability, acceptability, and adherence to the intervention strategies from a patient's, care providers', and organizational point of view. Changing caregivers' and women's behaviour is necessary to ultimately obtain the potential improvements of pregnancy outcomes and cost-effectiveness of care $^{41,42}$. A recent Dutch study exploring pregnant women's perceptions, needs, and preferences regarding the use of prediction models for PE showed that women had a positive attitude towards screening ${ }^{43}$. Although being confronted with an elevated risk could increase anxiety, self-monitoring together with better alertness and professional counselling were considered benefits of using a prediction model ${ }^{43}$. In the end, an impact study is needed to determine whether implementation of the prediction models for GDM and $\mathrm{PE}$ and the recommendation to use calcium 
supplements during pregnancy actually leads to the intended improvements ${ }^{41,42}$. An impact study on the implementation of first trimester prediction models for PE and GDM combined with tailored care paths, and the recommendation to use calcium supplementation during pregnancy is currently performed in the south-eastern part of the Netherlands (Expect Study II) ${ }^{44}$. In April 2017, an early risk assessment tool (Expect Calculator, www.zwangerinlimburg.nl) was made available to primary as well as secondary/tertiary ob-stetric care. The tool provides, besides early risk estimation, personalized recommendations for antenatal care tailored to individual risks, which were developed by the Limburg Obstetric Consortium (midwives, obstetricians, and deputies of maternity care centres in Limburg) ${ }^{45}$. Moreover, the tool provides patient information brochures relevant to the patient's risk profile. The Expect Study II will evaluate the adherence and compliance to the risk-dependent care by caregivers and pregnant women, respectively. Moreover, satisfaction and health care costs will be evaluated and compared to data of Expect Study I (before-after study). 


\section{References}

1. Interdepartementale Programmadirectie Kennis en Innovatie, Van voornemens naar voorsprong: kennis moet circuleren, 2009: Den Haag.

2. Perined, Perinatale Zorg in Nederland 2016. Utrecht: Perined, 2018.

3. Richardus, J.H., Graafmans, W.C., Verloove-Vanhorick, S.P., Mackenbach, J.P., EuroNatal International Audit, P., and EuroNatal Working, G., Differences in perinatal mortality and suboptimal care between 10 European regions: results of an international audit. BJOG, 2003. 110(2): p. 97-105.

4. Zeitlin, J., Wildman, K., Breart, G., Alexander, S., Barros, H., Blondel, B., et al., Selecting an indicator set for monitoring and evaluating perinatal health in Europe: criteria, methods and results from the PERISTAT project. Eur J Obstet Gynecol Reprod Biol, 2003. 111 Suppl 1: p. S5-S14.

5. Buitendijk, S., Zeitlin, J., Cuttini, M., Langhoff-Roos, J., and Bottu, J., Indicators of fetal and infant health outcomes. Eur J Obstet Gynecol Reprod Biol, 2003. 111 Suppl 1: p. S66-77.

6. Zeitlin, J., Wildman, K., Breart, G., Alexander, S., Barros, H., Blondel, B., et al., PERISTAT: indicators for monitoring and evaluating perinatal health in Europe. Eur J Public Health, 2003. 13(3 Suppl): p. 29-37.

7. EURO-PERISTAT project, with SCPE EUROCAT, EURONEOSTAT. European Perinatal Health Report 2008. Available from: http://www.europeristat.co.

8. Stuurgroep zwangerschap en geboorte. Een goed begin. Veilige zorg rond zwangerschap en geboorte. December 2009. Available from: http://www.rijksoverheid.nl/documenten/kamerstukken/ 2009/12/30/een-goed-begin-veilige-zorg-rond-zwangerschap-en-geboorte.

9. ZonMw. Programmatekst Zwangerschap en Geboorte. Den Haag: 2011. Available from: http://www.zonmw.nl/nl/onderzoek-resultaten/preventie/programmas/programmadetail/zwangerschap-en-geboorte/publicaties/.

10. Volksgezondheid en zorg. Trend in perinatale sterfte 2000-2016. Data Perined. 2018, RIVM: Bilthoven. Available from: http://www.volksgezondheidenzorg.info/onderwerp/sterfte-rond-de-geboorte/ cijfers-context/trends - !node-trend-perinatale-sterfte.

11. EUROSTAT. Fetal, peri- and neonatal mortality rates by country of occurrence. Last update: 28/02/2018. Available from: http://appsso.eurostat.ec.europa.eu/nui/submitViewTableAction.do.

12. Bonsel, G., Birnie, E., Denktas, S., Poeran, J., and Steegers, E., Lijnen in de perinatale sterfte, Signalementstudie Zwangerschap en Geboorte 2010. 2010, Rotterdam: Erasmus MC.

13. Koning, S.H., Hoogenberg, K., Lutgers, H.L., and Van den Berg, P.P., Gestational Diabetes Mellitus:current knowledge and unmet needs. 2016.

14. Mol, B.W., Roberts, C.T., Thangaratinam, S., Magee, L.A., de Groot, C.J., and Hofmeyr, G.J., Preeclampsia. Lancet, 2016. 387(10022): p. 999-1011.

15. Araujo Junior, E., Peixoto, A.B., Zamarian, A.C., Elito Junior, J., and Tonni, G., Macrosomia. Best Pract Res Clin Obstet Gynaecol, 2017. 38: p. 83-96.

16. Redekop, W.K. and Mladsi, D., The faces of personalized medicine: a framework for understanding its meaning and scope. Value Health, 2013. 16(6 Suppl): p. S4-9.

17. Bais, J.M.J. and Pel, M., The basis of the Dutch obstetric system: risk selection. Eur Clinics Obstet Gynaecol, 2006. 2(4): p. 209-212.

18. Visser, G.H.A., Obstetric care in the Netherlands: relic or example? J Obstet Gynaecol Can, 2012. 34(10): p. 971-975.

19. Commissie Verloskunde van het Collegevoorzorgverzekeringen. Verloskundig Vandemecum Verloskundige indicatielijst (VIL). 2003.

20. Steyerberg, E.W., Vickers, A.J., Cook, N.R., Gerds, T., Gonen, M., Obuchowski, N., et al., Assessing the performance of prediction models: a framework for traditional and novel measures. Epidemiology, 2010. 21(1): p. 128-38.

21. Kleinrouweler, C.E., Cheong-See, F.M., Collins, G.S., Kwee, A., Thangaratinam, S., Khan, K.S., et al., Prognostic models in obstetrics: available, but far from applicable. Am J Obstet Gynecol, 2016. 214(1): p. 79-90.e36.

22. Altman, D.G., Vergouwe, Y., Royston, P., and Moons, K.G., Prognosis and prognostic research: validating a prognostic model. BMJ, 2009. 338: p. b605.

23. Justice, A.C., Covinsky, K.E., and Berlin, J.A., Assessing the generalizability of prognostic information. Ann Intern Med, 1999. 130(6): p. 515-24. 
24. Al-Rubaie, Z., Askie, L.M., Ray, J.G., Hudson, H.M., and Lord, S.J., The performance of risk prediction models for pre-eclampsia using routinely collected maternal characteristics and comparison with models that include specialised tests and with clinical guideline decision rules: a systematic review. BJOG, 2016. 123(9): p. 1441-52.

25. Henderson, J.T., Thompson, J.H., Burda, B.U., and Cantor, A., Preeclampsia screening: Evidence report and systematic review for the us preventive services task force. JAMA, 2017. 317(16): p. 1668-1683.

26. Steyerberg, E.W., Moons, K.G., van der Windt, D.A., Hayden, J.A., Perel, P., Schroter, S., et al., Prognosis Research Strategy (PROGRESS) 3: prognostic model research. PLoS Med, 2013. 10(2): p. e1001381.

27. Collins, G.S. and Moons, K.G., Comparing risk prediction models. BMJ, 2012. 344: p. e3186.

28. Hofmeyr, G.J., Lawrie, T.A., Atallah, A.N., Duley, L., and Torloni, M.R., Calcium supplementation during pregnancy for preventing hypertensive disorders and related problems. Cochrane Database Syst Rev, 2014(6): p. CD001059.

29. Heaney, R.P., Kopecky, S., Maki, K.C., Hathcock, J., Mackay, D., and Wallace, T.C., A review of calcium supplements and cardiovascular disease risk. Adv Nutr, 2012. 3(6): p. 763-71.

30. BMJ Group and the Royal Pharmaceutical Society of Great Britain. British National Formulary. Calcium Carbonate. 2016 [cited February 19, 2016]; Available from:

http://www.medicinescomplete.com/mc/bnf/current/PHP93602-calcium-carbonate.htm?q= calcichew\&t=search\&ss=text\&p=7 - _hit.

31. Zorginstituut Nederland. Medicijnkosten. Calciumcarbonaat. 2016 [cited February 19, 2016]; Available from: http://www.medicijnkosten.nl.

32. WHO, Guideline: Calcium supplementation in pregnant women. World Health Organization: Geneva. 2013.

33. Health Council of the Netherlands. Dietary reference intakes: calcium, vitamin D, thiamin, riboflavin, niacin, pantothenic acid, and biotin. The Hague: Health Council of the Netherlands, 2000; publication no. 2000/12. ISBN 90-5549-323-6.

34. Petrou, S., Eddama, O., and Mangham, L., A structured review of the recent literature on the economic consequences of preterm birth. Arch Dis Child Fetal Neonatal Ed, 2011. 96(3): p. F225-32.

35. Platt, M.J., Outcomes in preterm infants. Public Health, 2014. 128(5): p. 399-403.

36. Meertens, L.J.E., Scheepers, H.C.J., Willemse, J., Spaanderman, M.E.A., and Smits, L.J.M., Should women be advised to use calcium supplements during pregnancy? A decision analysis. Matern Child Nutr, 2018. 14(1).

37. Jonker, A., Extra calcium kan zwangerschapsvergiftiging voorkomen, in de Volkskrant. January 22, 2016, Persgroep Nederland BV: Amsterdam.

38. RTL Nederland Interactief B.V., RTL nieuws Mediaoverzicht - Extra calcium kan zwangerschapsvergiftiging voorkomen (de Volkskrant), January 22, 2016.

39. VTM nieuws. Zwangere vrouw moet extra calcium nemen. January 23, 2016; Available from: https://nieuws.vtm.be/binnenland/175612-zwangere-vrouw-moet-extra-calciumnemen?post_id=955180054519351_955180041186019\#_=_.

40. Health Council of the Netherlands, Prenatal screening, The Hague: Health Council of the Netherlands, 2016; publication no. 2016/19.

41. Moons, K.G., Altman, D.G., Vergouwe, Y., and Royston, P., Prognosis and prognostic research: application and impact of prognostic models in clinical practice. BMJ, 2009. 338: p. b606.

42. Reilly, B.M. and Evans, A.T., Translating clinical research into clinical practice: impact of using prediction rules to make decisions. Ann Intern Med, 2006. 144(3): p. 201-9.

43. Crombag, N.M., Lamain-de Ruiter, M., Kwee, A., Schielen, P.C., Bensing, J.M., Visser, G.H., et al., Perspectives, preferences and needs regarding early prediction of preeclampsia in Dutch pregnant women: a qualitative study. BMC Pregnancy Childbirth, 2017. 17(1): p. 12.

44. Van Montfort, P., Willemse, J.P.P.M., Dirksen, C.D., Van Dooren, I.M.A., Meertens, L.J.E., Spaanderman, M.E., et al., Implementation and Effects of Risk-dependent Obstetric Care in the Netherlands: Research Protocol of an Impact Study (Expect Study II). JMIR Res Protoc, 2018. 7(5): $p$. e10066.

45. Lemmens, S.M.P., Spaanderman, M.E.A., and Röselaers, Y.C.M. Verloskundig Consortium Limburg. Limburg Obstetric Quality System Zorgpaden (aanbevelingen). Versie 1.3, mei 2017. Available from: http://www.zwangerinlimburg.nl/sites/expectstudie/files/loqs_zorgpaden_aanbevelingen_0.pdf. 


\section{Dankwoord}

Ik kijk met een trots gevoel terug op de leerzame en plezierige jaren van mijn promotieonderzoek. Promoveren doe je niet alleen. Een groot woord van dank aan alle mensen die mij daarbij geholpen hebben. Er zijn een aantal personen die ik in het bijzonder wil bedanken voor hun bijdrage, steun of vriendschap.

Allereerst een woord van dank aan mijn copromotores dr. L.J.M. Smits en dr. H.C.J. Scheepers en promotor prof. dr. M.H. Prins. Ik ben jullie zeer dankbaar dat jullie mij de mogelijkheid hebben gegeven om te promoveren.

Beste Liesbeth en Luc (ladies first), het is alweer 6 jaar geleden dat ik als stagiaire mocht beginnen op de toen nog 'papieren versie' van de Expect Study. Door jullie open en prettige manier van werken voelde ik mij al heel snel thuis op het project. Het opzetten en uitvoeren van de Expect Study was af en toe een gecompliceerde bevalling, maar wat een prachtkind is het geworden! We waren een team, L3, waarbij methodologie en kliniek goed in balans waren. De vele conversaties over het klinische nut van de predictiemodellen tot... waar waren we ook alweer? Ik mis het nu al!

Luc, je enthousiasme voor methodologie en met name predictiemodellen sloeg snel over. Als dagelijks begeleider was je er altijd voor het onderzoek, maar je had ook altijd interesse voor mij als persoon. Ik heb ontzettend veel geleerd van je kritische en 'taalkundige' kijk op wetenschappelijk schrijven. De kers op de taart tijdens het promotieonderzoek was toch wel de landelijke en internationale belangstelling voor het adviseren van calcium suppletie tijdens de zwangerschap. Wij kochten zo blij als een kind de Volkskrant op het station in Utrecht!

Liesbeth, ik waardeer je enthousiasme, realistische instelling en betrokkenheid. Ondanks je overvolle agenda in de kliniek was er altijd tijd voor het onderzoek, al was het soms een mail met losse woorden. Het klinische nut van de resultaten werd nooit uit het oog verloren. Dank ook voor je persoonlijke betrokkenheid en je steun om mijn eigen weg te volgen.

De leden van de beoordelingscommissie, prof. dr. S.P.J. Kremers, prof. dr. J.L.H. Evers, dr. H. Groen, prof. dr. S.G. Oei en dr. C.T.M.C.N. Thijs, wil ik bedanken voor de beoordeling van dit proefschrift.

Ik wil graag de leden van de Expect projectgroep bedanken: prof. dr. M.E.A. Spaanderman, prof. dr. R.G. de Vries, prof. dr. C.D. Dirksen, dr. I. Korstjens, prof. dr. A.L.M. Mulder, dr. M.J. Nieuwenhuijze, prof. dr. J.G. Nijhuis en prof. dr. O.C.P. van Schayck.

De Expect Study was niet tot stand gekomen zonder de medewerking van alle verloskundigenpraktijken en ziekenhuizen in de provincie Limburg. Dank voor jullie vertrouwen in de studie, jullie inzet om zwangere vrouwen te motiveren deel te nemen aan de studie en voor het opsturen van alle gegevens. Een groot woord van 
dank aan alle zwangere vrouwen die hebben deelgenomen aan de Expect Study. Jullie deelname aan het onderzoek tijdens een van de bijzonderste periodes van jullie leven was onmisbaar voor het tot stand komen van dit proefschrift.

Ik wil de LOQS projectgroep en alle leden van de werkgroepen bedanken. Wat is er een hoop bereikt de afgelopen jaren.

Marc Spaanderman en Yvonne Röselaers, de kartrekkers, in één woord chapeau! Stephanie, ondanks de werkafstand (Deb1 en Uns50) hadden wij al snel een klik. Onze lunch- en koffiepauzes duurden vaak net iets langer dan gepland. Ik ben ontzettend trots op jou! Wat een berg werk heb jij verzet, met als resultaat een prachtig aanbevelingendocument LOQS zorgpaden.

Co-auteurs, hartelijk dank voor het kritisch becommentariëren van mijn manuscripten.

Sander van Kuijk, een speciaal woord van dank voor je kritische blik en imput(aties) en de bevestiging als ik weer met de zoveelste 'maar als'... kwam.

Het onderzoeksteam van de PRIDE Study in Nijmegen, in het bijzonder Marleen van Gelder, wil ik bedanken voor het vertrouwen, de prettige samenwerking en het delen van onderzoeksgegevens.

Ik wil MEMIC centrum voor data en informatie management bedanken voor de fijne samenwerking, in het bijzonder Dirk en Donovan.

Tevens wil ik de stagiaires die de afgelopen jaren op de Expect Study zijn geweest hartelijk danken voor hun bijdrage.

$\mathrm{Er}$ is heel wat publiciteit geweest voor de Expect Study. In het bijzonder wil ik Monique Leclair, Monique Winthagen-Bertram, Ralph de Vos en Tom Janssen bedanken. Ralph maakte prachtige foto's van de destijds hoogzwangere Monique en Monique. Nu trotse mamma's van stoere kleuters! Tom, bedankt voor het beknopt, krachtig en begrijpelijk verwoorden van de tekst voor de patiëntfolders!

Monique Janssen, bedankt! Jij weet altijd een afspraak in te plannen in een overvolle agenda.

Ik wil alle collega's van de afdeling Epidemiologie bedanken voor de fijne werksfeer en de gezelligheid tijdens de teamuitjes. Het kajakken (oftewel slepen met een kajak over stenen) zal niet snel worden vergeten. Gelukkig was de afsluitende BBQ wel erg geslaagd. Eind goed, al goed $(-)$.

Conny, niets is jou teveel. Bedankt voor de fijne samenwerking, de secretariële ondersteuning en je inzet voor de Expect Study! 
Jos en Harry hartelijk dank voor de hulp bij ICT problemen. Harry, bedankt voor het maken van de Access file voor het invoeren van de ontvangen medische gegevens en je geduld.

De dames van het secretariaat (Yvonne, Mariëlle en Petra) wil ik bedanken voor de ondersteuning.

Nicole en Pieter, bedankt voor jullie bijdrage bij het selecteren van de voedingsvragen. Martien, hartelijk dank voor uw enorme bijdrage aan het verkrijgen van de voedingsdata.

Ik wil de (oud-)aiossen bedanken voor de gezellige lunches, etentjes, borrels en uitjes.

Huub, ik kon het 'even buurten' erg waarderen. Dank voor je hulp bij R troubles! De fast food fridays hebben we toch te laat ingevoerd.

Mijn kamergenoten, Louise, Karlijn, Pim en Jessica, wil ik in het bijzonder bedanken voor de fijne 'huiselijke' sfeer, wetenschappelijke discussies, het delen van bijzondere momenten, kletsen over van alles en nog wat, de zoetigheden en de foute uurtjes (al kan in niet werken met muziek).

Karlijn, onze eerste ontmoeting was op de overvolle stagiairekamer van Deb. Ondertussen ben je al een trotse mama van Mees en Lune. Ik waardeer je kritische blik. Daarnaast heb ik enorme bewondering voor je fantastische naaiwerken. Wellicht kom ik nog eens een beginnerscursus volgen.

Louise, vanaf mijn eerste werkdag als promovendus waren we kamergenoten en al snel werd het vriendschap. Ondanks onze totaal verschillende promotieonderwerpen konden we goed met elkaar sparren als we weer eens geniale ideeën hadden of vastliepen. Tevens ging dat ook vanzelf over niet-wetenschappelijke onderwerpen. We hebben lief en leed gedeeld op de kamer, met als hoogtepunt de geboorte van jullie stoere binken Lars en Noud. Onze vakantie in Curaçao was onvergetelijk. Danki Dushi!

Pim en Jessica, mijn oud-stagiaires, collega-onderzoekers op de Expect Study en paranimfen.

Pim, ondanks dat we qua karakter 360 graden van elkaar verschillen, konden we het al snel goed met elkaar vinden. We vulden elkaar goed aan en daardoor waren we een sterk team! Met een trots en gerust gevoel kon ik de Expect Study overdragen aan jou voor de $2^{\mathrm{e}}$ fase van het onderzoek. Wellicht moet je Facebook binnenkort eens op de hoogte stellen dat je toch echt niet zwanger bent.

Jessica, ik waardeer je aanstekelijke lach en enthousiasme! Ik ben trots dat ons calciumproject is uitgegroeid tot een apart promotieonderzoek. Knap hoe je dit combineert met een baan in de kliniek. Als iemand inspiratie nodig heeft voor een fantastische reis hoeft diegene jou maar te bellen of de prachtige foto's te bekijken, in één woord wow!

Ik wens jullie allebei veel succes met de afronding! 
Ik wil de mede-treinreizigers traject Klimmen/Ransdaal - Maastricht (Randwyck) bedanken. Op de vroege ochtend al lekker keuvelen over het (dorps)nieuws van de dag, dat maakte het treinritje toch net iets gezelliger.

Vriendinnen en vrienden, ik kan me altijd ontzettend verheugen op de momenten samen, of het nu een goed gesprek is of een knallend feestje. Dat we nog veel 'sjpass en plezeer' samen mogen maken!

Lieke en Dorien, het is alweer heel wat jaren geleden dat we op SMC uren achterstevoren zaten te kletsen tijdens de wiskundeles. Ik vind onze regelmatige bijpraatdates erg gezellig. Dorien, al is het nu 'op afstand', je bent snel weer in 't sjunne Limburg.

Sharona, vanaf het begin van de A-KO opleiding waren wij onafscheidelijk en al snel vriendinnen. Ook al zien we elkaar nu niet meer zo vaak, het voelt altijd weer als vanouds! Ik ben trots op jou!

Spammm girls, bikkels, vrouwluuj van Ranzel (en ondertussen omstreken) en aanhang. Kletsen, spelletjes, feestjes, uitjes, bbq'en, $3^{\mathrm{e}}$ kerstdag en ga maar door. Wat hebben wij het gezellig! Onze jaarlijkse weekendjes weg zijn altijd onvergetelijk.

Monique H., (bootcamp)buddy for life, bedankt voor de (sportieve) ontspanning! Oellies, naast een carnavalsgroep zijn we ook een hechte vriendengroep. Onze oud en nieuw weekendjes zijn altijd genieten, met als hoogtepunt de quiz waarbij iedereen altijd ultra fanatiek is.

Mijn (schoon en soort-van-)familie wil ik bedanken voor de fijne momenten en hun interesse in mijn onderzoek.

Siem, Pim en Koen, 'tantie' kijkt er naar uit dat jullie binnenkort weer met papa en mama in Ranzel komen wonen. Kunnen we vaker samen 'ravotten'!

Rianne, wat fijn om een goede vriendin als schoonzus te hebben.

Ik draag dit proefschrift op aan mijn schoonmoeder Anny en 'gruëtsje' oma Ranzel die de afronding van mijn promotieonderzoek helaas niet meer hebben kunnen meemaken.

Lieve mam, pap \& Angelique, Chris, Yourie en Veronique, bedankt voor alles wat zo vanzelfsprekend lijkt. Het meest waardeer ik dat er altijd een thuis is! Jullie zijn de beste! En tsja... de daltons zijn tegenwoordig niet meer op leeftijd gerangschikt.

Leeve Rob, wat hubbe veer 't fijn saame! Ondanks dat we op werkgebied totaal verschillende interesses hebben begrijp en steun je mij volledig. Ik kijk uit naar onze grote dag op 29 september 2018 en naar alles wat nog op ons pad mag komen. Jij bent de allerliefste!

\section{Linda}




\section{Curriculum Vitae}

Linda Meertens was born on February 18th, 1988 in Heerlen, the Netherlands. She completed secondary school at Sintermeertencollege in Heerlen in 2006. Linda obtained her BSc degree in Molecular Life Sciences at Maastricht University (Maastricht, the Netherlands) in 2009. Consecutively, she started the 4-year Physician-Clinical Investigator Research Master at Maastricht University. She was awarded the top 3\% student award in the academic years 2009/2010 and 2010/2011. In 2013, Linda obtained her MD and MSc in clinical research degree with

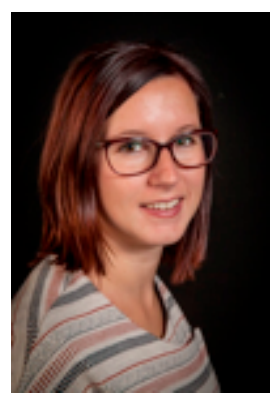
the distinction cum laude. After her graduation, she started her PhD research at the Department of Epidemiology at Maastricht University (Care and Public Health Research Institute, CAPHRI) under supervision of dr. Luc J.M. Smits, dr. Liesbeth (H) C.J. Scheepers, and prof. dr. Martin H. Prins. The research (Expect Study) was performed in collaboration with the Limburg Obstetric Quality System project. The scientific work, as presented in this thesis, was published in peer-reviewed journals and presented on several (international) conferences. 


\section{List of publications}

Meertens, L.J.E., Scheepers, H.C.J., van Kuijk, S.M.J., Aardenburg, R., van Dooren, I.M.A., Langenveld, J., van Wijck, A.M., Zwaan, I.M., Spaanderman, M.E.A., Smits, L.J.M., External validation and clinical usefulness of first trimester prediction models for the risk of pre-eclampsia: a prospective cohort study. Fetal Diagn Ther, 2018.

Van Montfort, P., Willemse, J.P.M.M., Dirksen, C.D., van Dooren, I.M.A., Meertens, L.J.E., Spaanderman, M.E.A., Zelis, M., Zwaan, I.M., Scheepers, H.C.J., Smits, L.J.M, Implementation and Effects of Risk-Dependent Obstetric Care in the Netherlands (Expect Study II): Protocol for an Impact Study. JMIR Res Protoc, 2018. 7(5): p. e10066.

Meertens, L.J.E.*, van Montfort, P.*, Scheepers, H.C.J., van Kuijk, S.M.J., Aardenburg, R., Langenveld, J., van Dooren, I.M.A., Zwaan, I.M., Spaanderman, M.E.A., Smits, L.J.M., Prediction models for the risk of spontaneous preterm birth based on maternal characteristics: a systematic review and independent external validation. Acta Obstet Gynecol Scand, 2018.

Meertens, L.J.E., Scheepers, H.C.J., Willemse, J.P.M.M., Spaanderman, M.E.A., and Smits, L.J.M., Should women be advised to use calcium supplements during pregnancy? A decision analysis. Matern Child Nutr, 2018. 14(1).

Meertens, L.J.E., Scheepers, H.C.J., De Vries, R.G., Dirksen, C.D., Korstjens, I., Mulder, A.L., Nieuwenhuijze, M.J., Nijhuis, J.G., Spaanderman, M.E.A., Smits, L.J.M., External Validation Study of First Trimester Obstetric Prediction Models (Expect Study I): Research Protocol and Population Characteristics. JMIR Res Protoc, 2017. 6(10): p. e203.

Notten, F., Meertens, L.J.E., Wissink, B., and Scheepers, H.C.J., Consecutive intraumbilical vein injection of misoprostol and intravenous sulprostone in the management of retained placenta. Arch Gynecol Obstet, 2014. 289(1): p. 35-40.

Bergenhenegouwen, L.A., Meertens, L.J.E., Schaaf, J., Nijhuis, J.G., Mol, B.W., Kok, M., Scheepers, H.C.J., Vaginal delivery versus caesarean section in preterm breech delivery: a systematic review. Eur J Obstet Gynecol Reprod Biol, 2014. 172: p. 1-6.

\section{Submitted:}

Meertens, L.J.E., Scheepers, H.C.J., van Kuijk, S.M.J., Roeleveld, N., Aardenburg, R., van Dooren, I.M.A., Langenveld, J., Zwaan, I.M., Spaanderman, M.E.A., van Gelder, M.M.H.J., Smits, L.J.M., External validation and clinical utility of first trimester prediction models for gestational diabetes mellitus: a prospective cohort study. 
Meertens, L.J.E., Smits, L.J.M., van Kuijk, S.M.J., Aardenburg, R., van Dooren, I.M.A., Langenveld, J., Zwaan, I.M., Spaanderman, M.E.A., Scheepers, H.C.J., First-trimester prediction models for small- and large-for-gestational-age infants: external validation and clinical usefulness.

Willemse, J.P.M.M., Meertens, L.J.E., Scheepers, H.C.J., Achten, N.M.J., Eussen, S.J., van Dongen, M.C., Smits, L.J.M., Calcium intake from diet and supplement use during early pregnancy: the Expect Study I.

*Equal contribution 